\title{
Towards the Development of Efficient and Economical Short Span Modular Bridges
}

Scott A. Morgan

West Virginia University

Follow this and additional works at: https://researchrepository.wvu.edu/etd

\section{Recommended Citation}

Morgan, Scott A., "Towards the Development of Efficient and Economical Short Span Modular Bridges" (2010). Graduate Theses, Dissertations, and Problem Reports. 4633.

https://researchrepository.wvu.edu/etd/4633

This Thesis is protected by copyright and/or related rights. It has been brought to you by the The Research Repository @ WVU with permission from the rights-holder(s). You are free to use this Thesis in any way that is permitted by the copyright and related rights legislation that applies to your use. For other uses you must obtain permission from the rights-holder(s) directly, unless additional rights are indicated by a Creative Commons license in the record and/ or on the work itself. This Thesis has been accepted for inclusion in WVU Graduate Theses, Dissertations, and Problem Reports collection by an authorized administrator of The Research Repository @ WVU. For more information, please contact researchrepository@mail.wvu.edu. 


\title{
Towards the Development of Efficient and Economical Short Span Modular Bridges
}

\author{
Scott A. Morgan \\ Thesis submitted to the \\ College of Engineering and Mineral Resources \\ at West Virginia University \\ in partial fulfillment of the requirements \\ for the degree of \\ Master of Science \\ in \\ Civil and Environmental Engineering
}

Karl E. Barth, Ph. D., Chair

John P. Zaniewski, Ph. D.,

Uduya B. Halabe, Ph. D.

Department of Civil and Environmental Engineering

Morgantown, West Virginia

2010

Keywords: $s$ teel b ridge, modular br idge, standardized br idge, bridge de sign preferences, bridge statistics 


\title{
Abstract \\ Towards the Development of Efficient and Economical Short Span Modular Bridges
}

\author{
Scott A. Morgan
}

The Federal Highway Administration's National Bridge Index consists of over 600,000 bridges. Of these bridges, over $25 \%$ are considered either structurally deficient or functionally obsolete. While several state bridge departments have standard designs for bridge components in order to speed up the design process in replacing these bridges, few have standard designs for the bridge superstructure.

This work investigates current practices and trends in the design of short span bridges through the use of a survey. The survey was presented to the bridge department of every state in the country and responses were collected from $86 \%$ of these states. Based on the responses to these surveys, two courses were pursued in this work: the research and grading of both existing and developing modular bridge technologies that have application in short span steel bridges and the development of standard short span steel bridge superstructures using conventional design approaches.

In collaboration with the American Iron and Steel Institute's Short Span Steel Bridge Alliance and other professionals in the bridge industry, a collection of modular bridge systems and elements were compiled and researched. Based on the Federal Highway Administration's Highways for LIFE initiative, which promotes the development of Long-lasting highway infrastructure using Innovations to accomplish Fast construction of Efficient and safe highways and bridges, a grading system was developed for professionals in the industry to grade the major modular bridge systems researched. Based on the grading of these systems, a system will be further developed into a set of standardized short span bridge designs.

Second, standard short span steel bridge designs were developed to create a design aid for bridge engineers. In these designs, bridges with spans ranging from 40 feet to 140 feet in 5 foot increments were developed for rolled steel sections, homogeneous steel plate girder sections and hybrid steel plate girder sections. The rolled sections were designed using two design approaches: the lightest weight possible and the lightest weight possible with a limited section depth. Based on these designs, a suite of rolled sections were selected to be efficient sections of larger span ranges. This limited suite provides the opportunity for stock piling common rolled steel girder sections. Without needing to order the fabrication of the rolled girder sections, a more efficient transition from design to construction can be achieved. The plate girder sections were designed with a limited depth and utilizing a set of limited plate sizes to allow for the stock piling of common steel plate sizes. These designs will also act as a framework for future design plans using a modular bridge system. 


\section{Acknowledgements}

I would like to thank my advisor, Dr. Karl Barth for giving me the opportunity to pursue my Master's Degree while providing his support and guidance throughout my graduate career. I would also like to thank the American Iron and Steel Institute's Short Span Steel Bridge Alliance for funding this research and providing assistance and guidance in the collection and analysis of my data.

Additionally, I would like to thank my fellow graduate students of B11 for their support specifically Gregory Michaelson and Jennifer Stains. Mr. Michaelson worked alongside me throughout the entirety of my graduate career. Without him there to "bounce ideas around with," I would not have made it this far. Ms. Stains was supportive near the end of my graduate career and always available to aid in the writing process of this document.

Lastly, I would like to thank my family. My parents, Steven and Judith Morgan, instilled in me an importance and persistence in the field of education. My brother, Andrew Morgan, provided his guidance and experience throughout my college career. My fiancée, Kathryn Ehrlich provided her support, patience and love that have been essential in my pursuit of my master's degree. 


\section{Table of Contents}

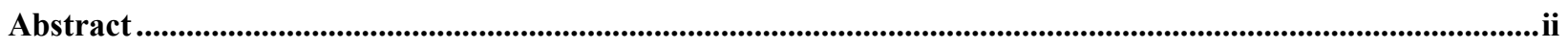

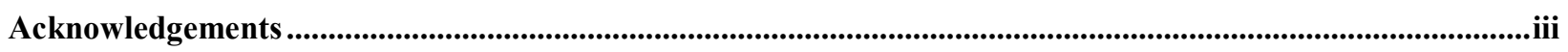

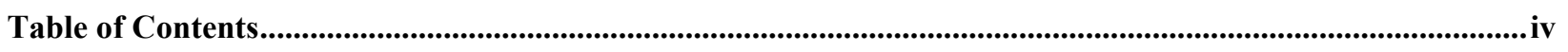

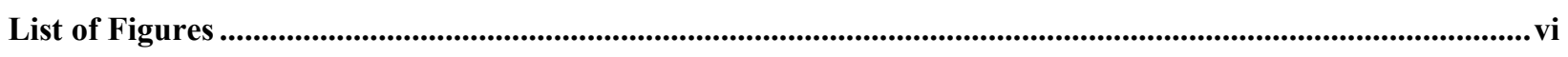

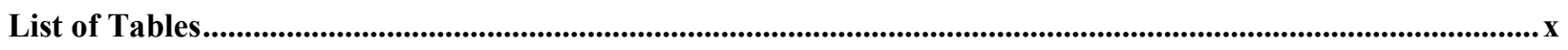

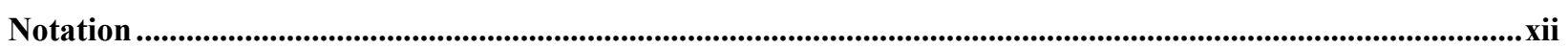

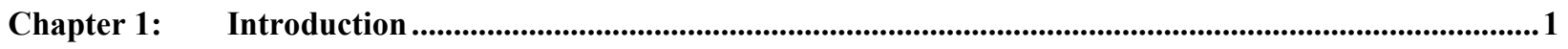

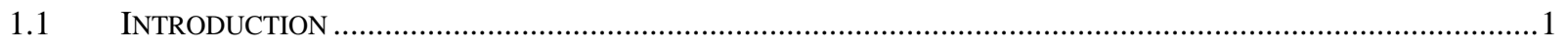

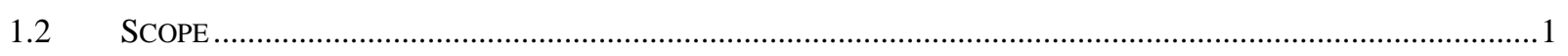

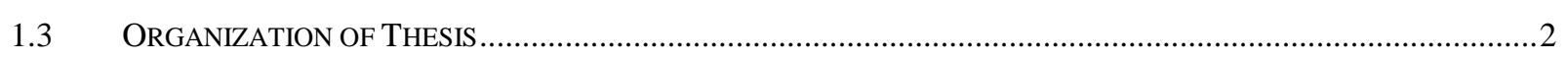

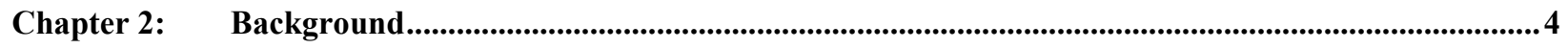

2.1 FEDERAL HighWAY AdMINISTRATION HigHWAYS FOR LIFE ......................................................

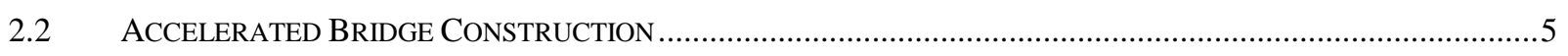

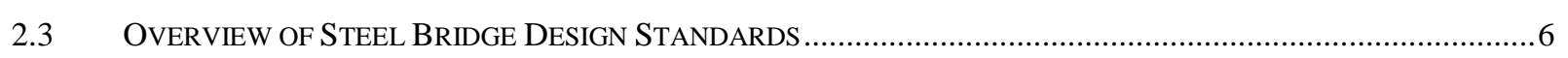

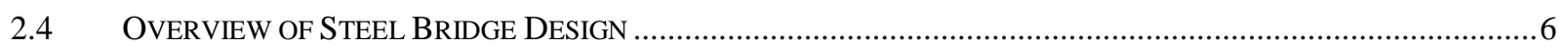

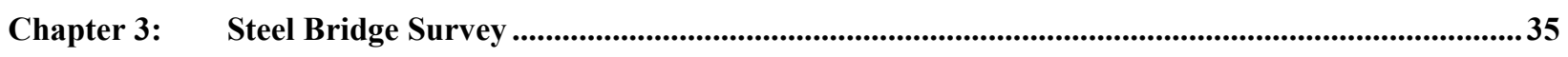

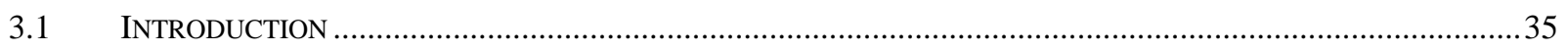

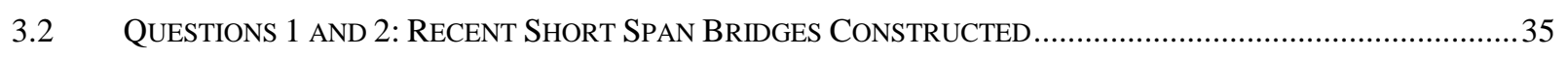

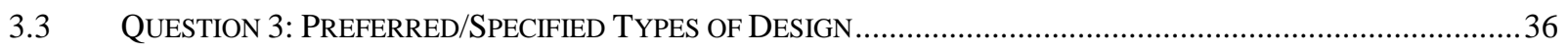

3.4 QUESTION 4: TYPICAL CROSS-SECTIONS AND GIRDER SPACINGS.....................................................38

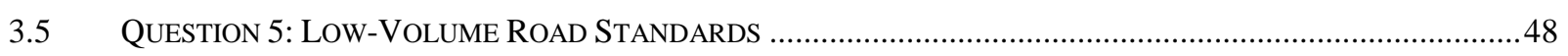

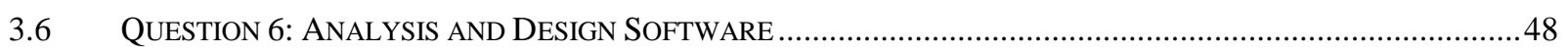

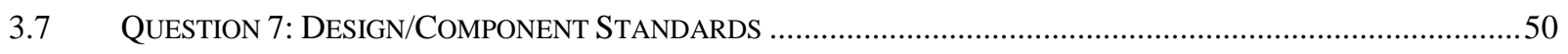

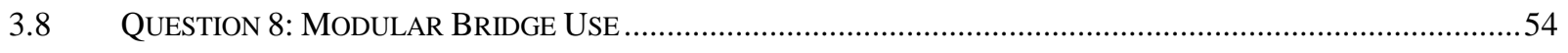

3.9 QUESTION 9: EXPECTATIONS OF A BEST PRACTICES MANUAL ................................................................55

3.10 QUESTION 10: AASHTO LRFD LOAD FACTORS/COMBINATIONS...........................................................55

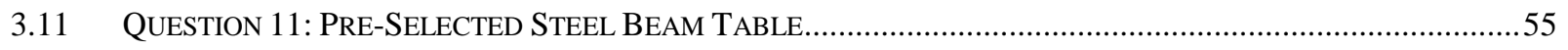

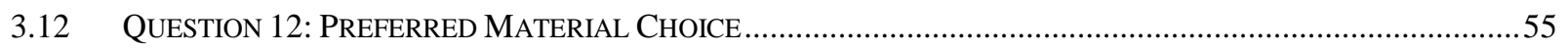

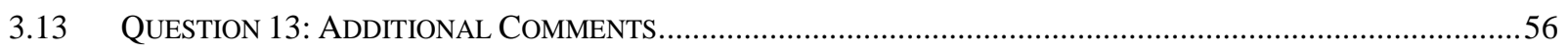

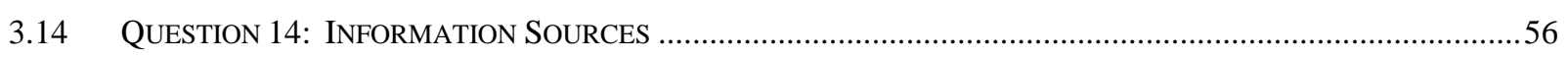

Chapter 4: $\quad$ Modular Bridge Components and Systems .........................................................................57 


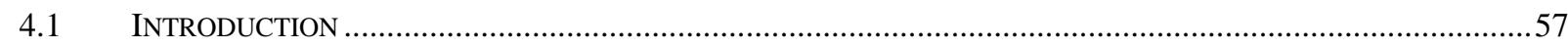

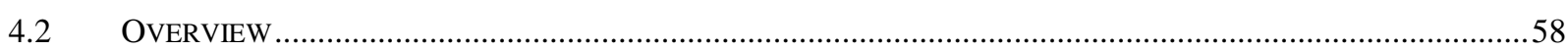

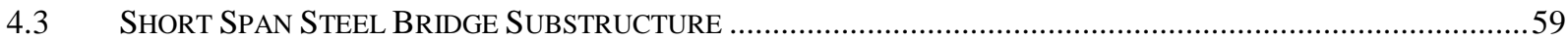

4.4 SHORT SPAN STEEL BRIDGE SUPERSTRUCTURES ................................................................................78

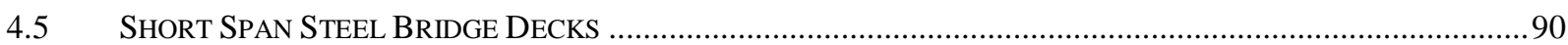

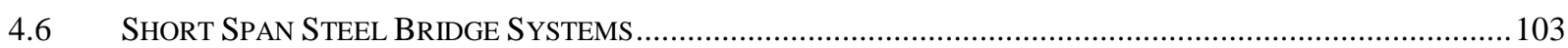

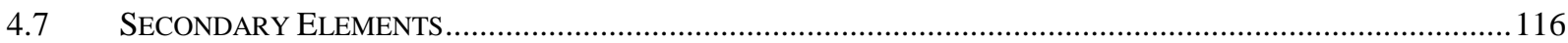

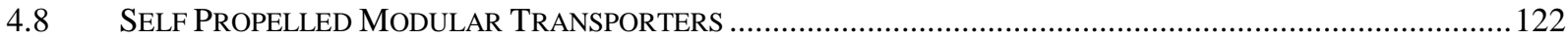

Chapter 5: Grading of Modular Systems ......................................................................................................125

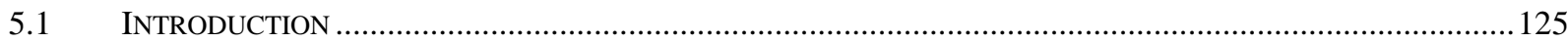

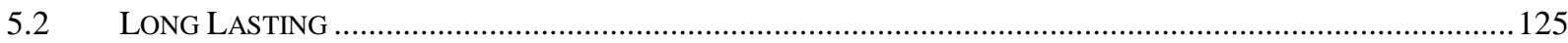

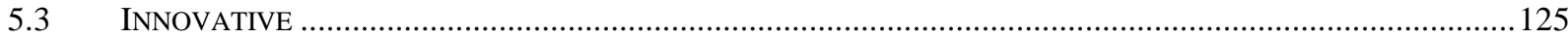

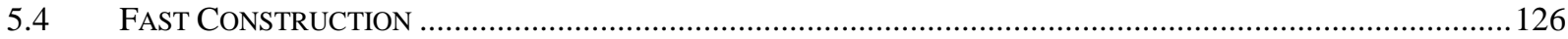

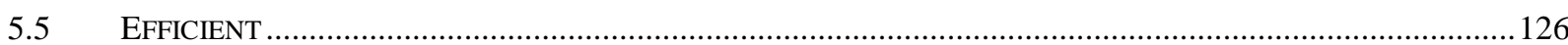

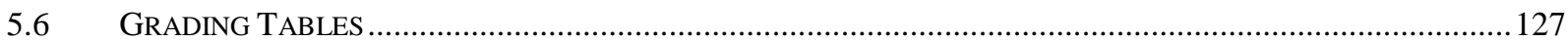

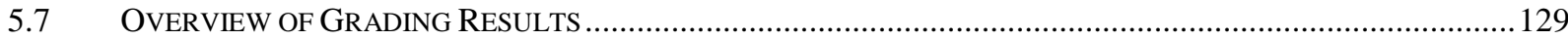

Chapter 6: Standardized Short Span Steel Bridge Designs ...................................................................................... 130

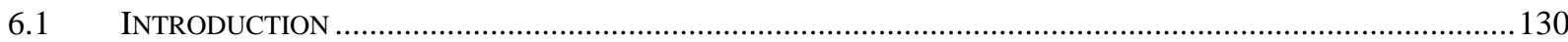

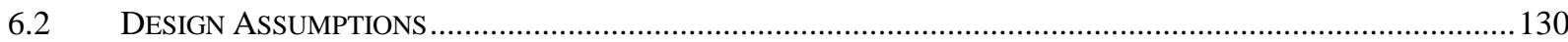

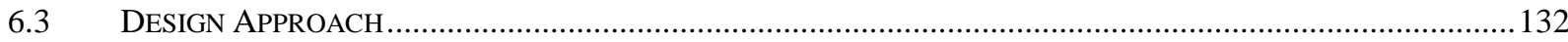

6.4 OptiMIZED STEEL BRIDGE Design RESULTS.....................................................................................134

6.5 REDUCED SUITE OF ROLLED STEEL GIRDERS ………...................................................................... 149

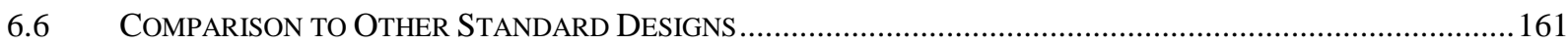

Chapter 7: Summary and Conclusions .................................................................................................................... 174

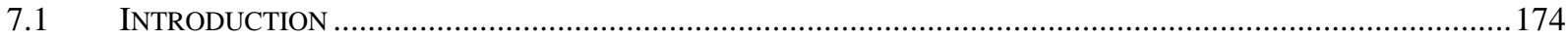

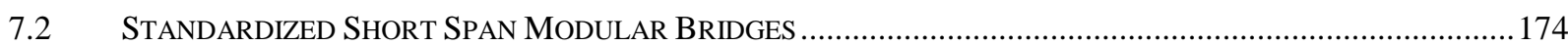

7.3 STANDARDIZED SHORT SPAN STEEL BRIDGE DESIGNS .......................................................................... 175

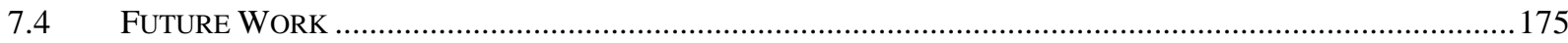

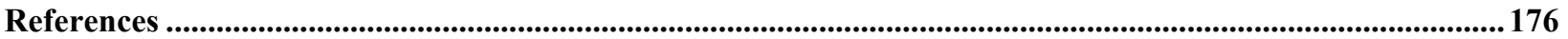

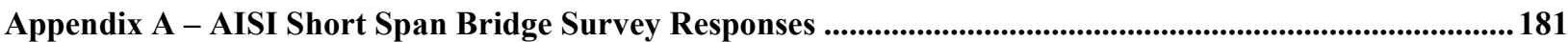




\section{List of Figures}

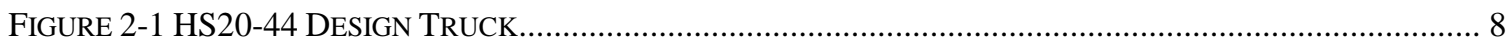

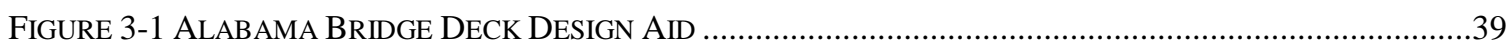

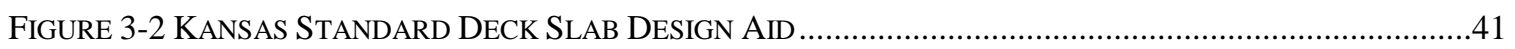

FIGURE 3-3 KANSAS DECK REINFORCEMENT DESIGN AID ............................................................................42

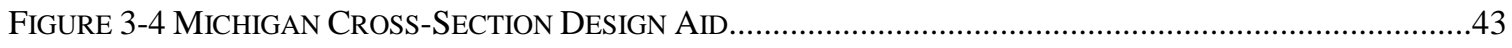

FIGURE 3-5 OKLAHOMA STANDARD BRIDGE CROSS-SECTION DESIGN AID .....................................................46

FiguRE 3-6 TEXAS TyPICAL TRANSVERSE SECTION EXAMPLE 24 FT WIDTH....................................................

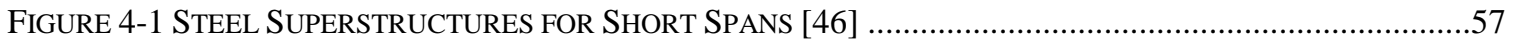

FiguRE 4-2 PRECAST REINFORCED CONCRETE BENT CAP [14] ...............................................................60

FiguRE 4-3 PRECAST Concrete AbUtMENT STEM [14] .....................................................................62

Figure 4-4 Diagram of Precast Concrete Abutment Stem With SteEl SuPERSTRucture [50].........62

Figure 4-5 MEChanically StabILIZEd EaRTH Wing WaLL [28] ...........................................................64

FigURE 4-6 INSTALLATION OF GEOSYNTHETICALLY CONFINED SOIL WALL [19] ..........................................65

FiguRE 4-7 GEOSYNTHETICALly ConfinEd SOIL BRIDGE ABUTMENT [18]...............................................66

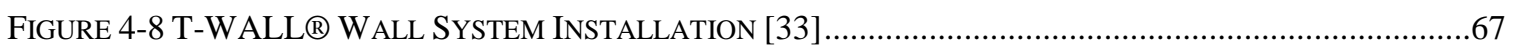

FigURE 4-9 SOUTHARD STREET BRIDGE, TRENTON, NJ [34]...................................................................68

FIGURE 4-10 DRAWING OF PRECAST FOOTING [14] ..............................................................................69

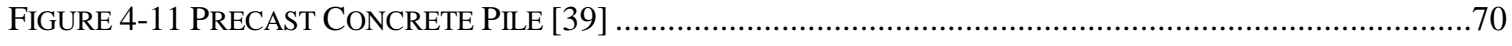

FiguRE 4-12 DRIVEN STEEL PILES FoR PIERS/ABUTMENTS [12] ....................................................................

FiguRE 4-13 DRIVEN STEEL PILES For PIERS/ABUTMENTS [12] .................................................................72

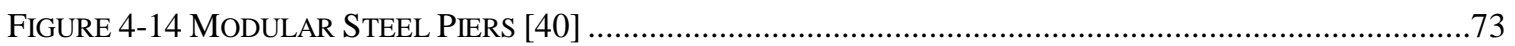

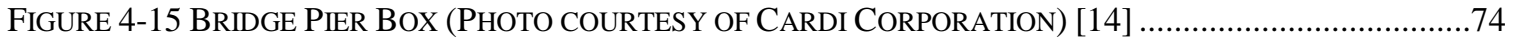

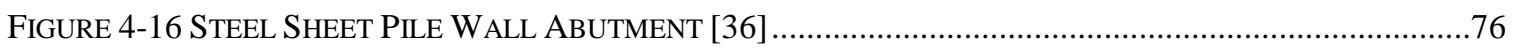

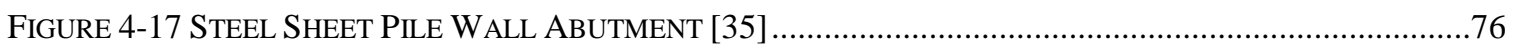

FiguRE 4-18 SUPERSILL ${ }^{\circledR}$ ABUTMENT AND BACK WALL By RosCOE BRIDGE [48] .......................................78

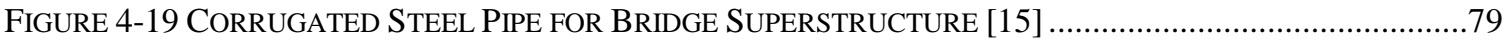

Figure 4-20 Corrugated Structural Plate as a Bridge SuPERSTRUCtURE [9] .................................81

FiguRE 4-21 DOUBLE SUPER-CoR $®$ BRIDGE BY BIG R BRIDGE [10] ...........................................................82

Figure 4-22 Wide Flange Rolled Steel Shapes as Bridge Superstructure (U.S. Bridge Tour) ....84

Figure 4-23 StEel Plate GIRDERS AS BRIDGE SuPERSTRUCTURE [11] .....................................................85

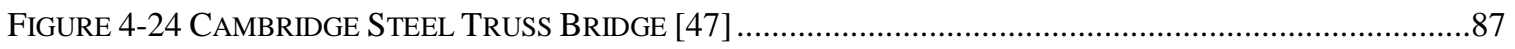

FiguRE 4-25 PLAN OF A WARREN TruSS BRIDGE [24] ..............................................................................8

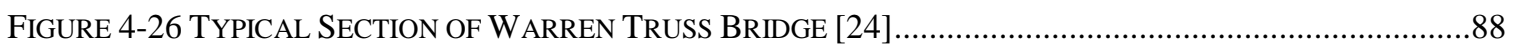

FigURE 4-27 ELEVATION VIEW OF SPACE TRUSS BRIDGE [24] .................................................................

FIGURE 4-28 TYPICAL SECTION OF SPACE TRUSS BRIDGE [24] .................................................................90 


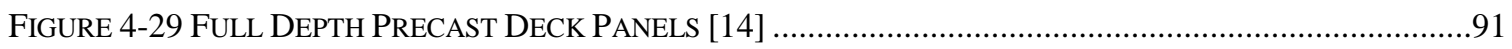

FIGURE 4-30 OpEN GRID DECKING BEING PLACED [37] ......................................................................92

Figure 4-31 EXodermic DeCK Details courtesy of the D.S. Brown CoMPANy [14] ...........................94

FIGURE 4-32 FRP DECK PANEL INSTALLATION [22] ............................................................................95

Figure 4-33 Diagram of Bridge Deck Employing Partial Depth Precast Concrete Deck Panel .96

FiguRE 4-34 INSTALLATION OF TRANSVERSE TIMBER DECK ONTO STEEL STRINGERS [52] ...........................98

FiguRE 4-35 UNDERSIDE OF STEEL ORTHOTROPIC DECK [25] .................................................................99

Figure 4-36 Sandwich Panel Modular Steel Bridge Deck System [58] ..........................................101

FIGURE 4-37 SAMPLE "SANDWICH" COMPOSITION [58] ..........................................................................101

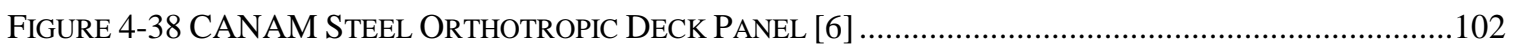

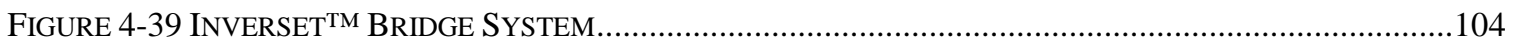

Figure 4-40 TyPICAL CRosS SECTION FOR Folded Plate BRIDGE SySTEM [8] .......................................105

Figure 4-41 Section of Folded Plate Girder BRidge REAdy to Be Stacked And SHipPEd [8].........105

FigURE 4-42 SIMPLE FOR DEAD LOAD AND CONTINUOUS FOR LIVE LOAD SYSTEM [44].............................107

Figure 4-43 AsSEmbly of PretopPed Girder Section BuILt By Big R BRidge [7] ..............................108

FigURE 4-44 UNLOADING PRETOPPED GIRDER SYSTEM FOR I-95 BRIDGE IN VIRGINIA [56]........................109

Figure 4-45 Precast Modular System DeVEloped by SDR ENGineERING Consultants [42] ...........109

Figure 4-46 Modular SteEl Girders With Stay-In-Place FormWork Plates [42] ...........................110

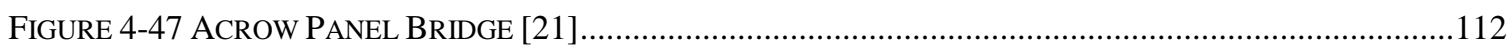

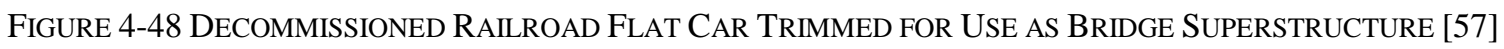
.113

FIGURE 4-49 SiDE VIEW OF RAILROAD FLATCAR BRIDGE [57] ............................................................113

FigURE 4-50 END VIEW OF RAILROAD FLATCAR BRIDGE [57].............................................................114

FIGURE 4-51 CON-STRUCT PREFABRICATED BRIDGE [53] ......................................................................115

FiguRE 4-52 EXAMPLE OF CON-STRUCT BRIDGE CROSS-SECTION [54] ...................................................115

FiguRE 4-53 STEEL BEAM RAIL BARRIER (U.S. BRIDGE TOUR) .............................................................116

Figure 4-54 STEEL BEAM RAIL ConNECTION (U.S. BRIDGE TOUR) .......................................................117

FIGURE 4-55 PRECAST CONCRETE BRIDGE BARRIER [49] ...................................................................118

Figure 4-56 Example of SteEL "X" Shaped Cross Frame [12] ........................................................120

FiguRE 4-57 CuRved SteEl BRIDGe Frame WITH K-Shaped Cross Frames [27] ..................................121

FIGURE 4-58 BRIDGE WITH STEEL DIAPHRAGMS [31] .........................................................................122

Figure 4-59 SeLf PropelLed Modular TRANSPORTER [38] ...............................................................123

Figure 4-60 Transportation of Bridge Segment Using Self Propelled Modular Transporter

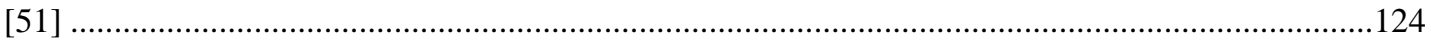

Figure 6-1 Typical EleVation of SteEl Plate GIRDER Sections...................................................131

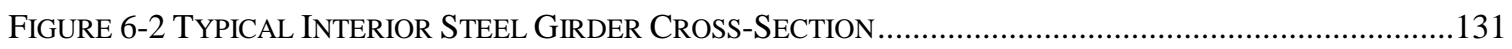

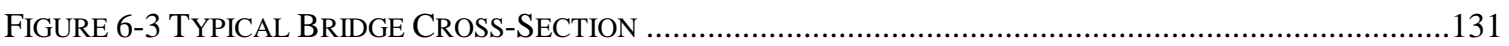


FiguRE 6-4 RolLEd STEEL GIRDER SECTIONS - 6 FoOT SPACING ......................................................139

FIGURE 6-5 RolLED STEEL GIRDER SECTIONS - 7 FOOT 6 INCH GIRDER SPACING........................................139

Figure 6-6 RolLEd STEEL GIRDER SECTIONS - 9 FoOT GIRDER SPACING …….....................................140

FiguRE 6-7 Rolled STEEL GiRder SECTIONS - 10 FoOt 6 INCH GIRDER SPACING.....................................140

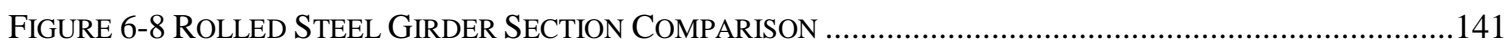

FiguRE 6-9 STEEL Plate GiRder SECTIONS - 6 FoOT GIRDER SPACING .......................................................146

Figure 6-10 SteEl Plate GiRder Sections - 7 Foot 6 InCH GIRder Spacing .......................................146

Figure 6-11 SteEl Plate GiRder Sections - 9 FoOt Girder SPACING ..................................................147

Figure 6-12 Steel Plate Girder Sections - 10 Foot 6 InCH GIRder Sections .....................................147

FiguRE 6-13 STEEL Plate GIRDER SECTION COMPARISONS .................................................................148

FiguRE 6-14 5 SELECTED SECTIONS - LiMITED DEPTH (40 FT - 60 FT) ..................................................151

FiguRE 6-15 5 SELECTED SECTIONS - LighteST WEIGHT (40 FT - 60 FT)...................................................151

FIGURE 6-16 5 SELECTED SECTIONS - LIMITED DEPTH (60 FT - 80 FT) .........................................................152

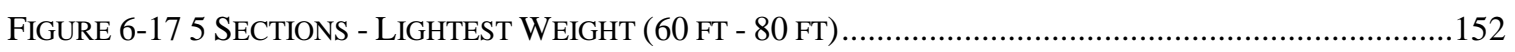

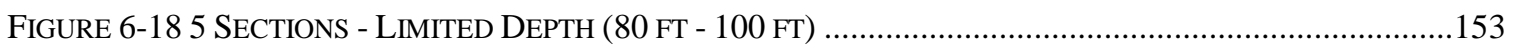

FigURE 6-19 5 SECTIONS - LIGHTEST WEIGHT (80 FT - 100 FT) ...............................................................153

FIGURE 6-20 5 SECTIONS - LIMITED DEPTH (100 FT - 110 FT) ……........................................................154

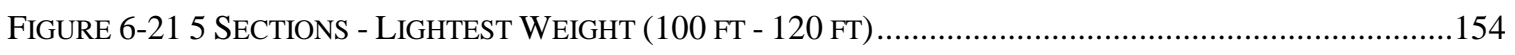

FigURE 6-22 5 SECTIONS - LiMITED DEPTH (120 FT - 140 FT) ...............................................................155

FIGURE 6-23 5 SECTIONS - LighTEST WEIGHT (120 FT - 140 FT) ................................................................155

FIGURE 6-24 7 SECTIONS - LIMITED DEPTH (100 FT - 120 FT) ..................................................................156

FigURE 6-25 7 SECTIONS - LIGHTEST WEIGHT (100 FT - 120 FT) ..............................................................156

FIGURE 6-26 7 SECTIONS - LIMITED DEPTH (120 FT - 140 FT) ...............................................................157

FIGURE 6-27 7 SECTIONS - LighTEST WEIGHT (120 FT - 140 FT) .................................................................157

FigURE 6-28 10 SECTIONS - LiMITED DEPTH (40 FT - 60 FT) ....................................................................158

FIGURE 6-29 10 SECTIONS - LIGHTEST WEIGHT (40 FT - 60 FT) ...............................................................158

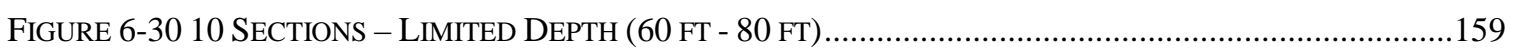

FigURE 6-31 10 SECTIONS - LightEST WEIGHT (60 FT - 80 FT) ...............................................................159

FIGURE 6-32 10 SECTIONS - LIMITED DEPTH (80 FT - 100 FT) .................................................................

FigURE 6-33 10 SECTIONS - LightEST WEIGHT (80 FT - 100 FT) .................................................................160

FiguRE 6-34 WVU 10 FT - 6 IN. / OKLAHOMA 11 FT - 10 IN. WEIGHT COMPARISON .....................................162

FIGURE 6-35 WVU 7 FT - 6 IN. / TEXAS 7 FT - 4 IN. WEIGHT COMPARISON .................................................163

FIGURE 6-36 WVU 9 FT / TEXAS 8 FT - 4 IN. WEIGHT COMPARISON ..........................................................164

FIGURE 6-37 WVU 6 FT AND 7 FT - 6 IN. / TEXAS 7 FT WEIGHT COMPARISON .............................................165

FIGURE 6-38 WVU 6 FT / VIRGINIA 6 FT - 6 IN. WEIGHT COMPARISON ................................................167

FIGURE 6-39 WVU 7 FT - 6 IN. / VIRGINIA 7 FT - 6 IN. WEIGHT COMPARISON............................................168

FIGURE 6-40 WVU 9 FT / VIRGINIA 9 FT WEIGHT COMPARISON .................................................................169 
FIGURE 6-41 WVU 9 FT / AISI 8 FT - 6 IN. WEIGHT COMPARISON......................................................170

FIGURE 6-42 WVU 9 FT / AISI 9 FT WEIGHT COMPARISON ....................................................................171

FIGURE 6-43 WVU 10 FT - 6 IN. / AISI 10 FT WEIGHT COMPARISON......................................................172 


\section{List of Tables}

TABLE 2-1 STRENGTH LIMIT STATE LOAD FACTORS ..............................................................................10

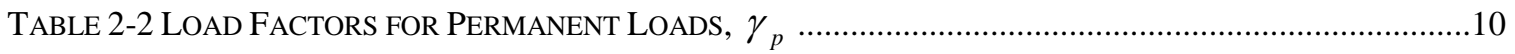

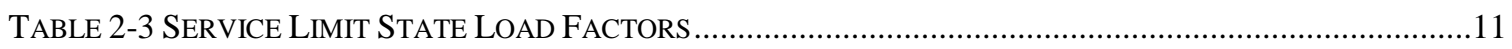

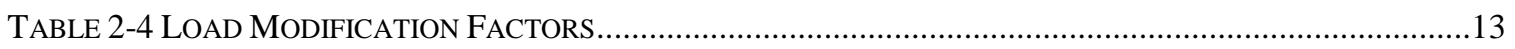

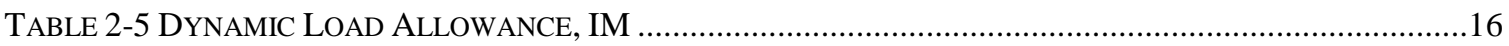

TABLE 2-6 MULIPLE PRESENCE FACTORS, M ………..............................................................................

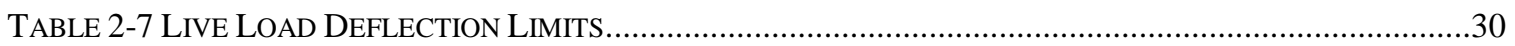

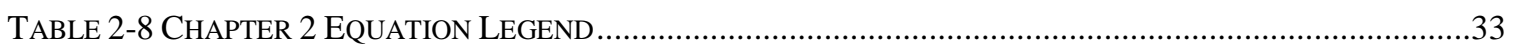

TABLE 3-1 BRIDGES ConSTRUCTED LAST YEAR (INCLUDING CALIFORNIA)...............................................35

TABLE 3-2 BRIDGES ConStRUCTED LAST YEAR (EXCLUdiNg CALIFORNIA) ...............................................36

Table 3-3 Minimum Width of Travelway for Specified Design Volume - North Dakota Design

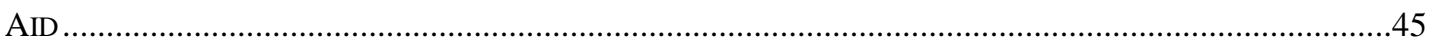

TABle 3-4 Minimum Clear RoadWay Width Based on DESIGN WidTH ...............................................45

TABLE 3-5 Wyoming CROSS-SECTION DESIGN AID ..................................................................................48

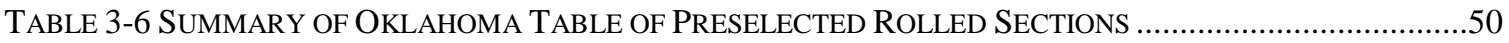

TABLE 3-7 SUMMARY OF SOUTH CAROLINA TABLE OF DECK OVERHANGS......................................................51

TABle 3-8 Summary TeXas Tables of Preselected Rolled SteEl Sections .......................................52

TABLE 5-1 GRADING SHEET FOR EACH ModULAR BRIDGE SYSTEMS .......................................................128

TABLE 5-2 WeIGHTEd GRAdES OF EACH ModulaR BRIDGE SySTEM ....................................................129

TABLE 6-1 RolLEd STEEL GIRDER SECTIONS - 6 FOOT GIRDER SPACING ..................................................135

TABLE 6-2 Rolled SteEl GIRDER SeCtIONS - 7 FoOT 6 INCH GIRDER SPACING ........................................136

TABLE 6-3 Rolled STEEL GIRDER SECTIONS - 9 FoOT GIRDER SPACING ................................................137

TABle 6-4 Rolled SteEl GIRDER SeCtions - 10 FoOt 6 INCH SPACING ..................................................138

TABLE 6-5 SteEl Plate GiRder SeCtions - 6 Foot GIRDER SPACING ...................................................142

TABle 6-6 Steel Plate Girder Sections - 7 Foot 6 Inch Girder SPACiNG...........................................143

TABLE 6-7 SteEl Plate GiRder SeCtions - 9 Foot GIRdER SPACING ......................................................144

TABle 6-8 Steel Plate GiRder Sections - 10 Foot 6 InCh Girder SPACiNG..........................................145

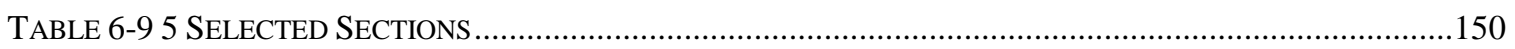

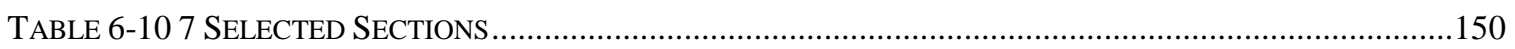

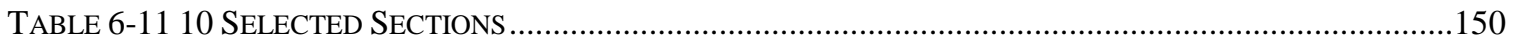

TABLE 6-12 WVU 10 FT - 6 IN. / OKLAHOMA 11 FT - 10 IN. SECTION COMPARISON......................................161

TABLE 6-13 WVU 7 FT - 6 IN. / TEXAS 7 FT - 4 IN. SECTION COMPARISON ...................................................163

TABLE 6-14 WVU 9 FT / TEXAS 8 FT - 8 IN. SECTION COMPARISON ..............................................................164

TABLE 6-15 WVU 6 FT AND 7 FT - 6 IN. / TEXAS 7 FT SECTION COMPARISON ...............................................165

TABLE 6-16 WVU 6 FT / VIRGINIA 6 FT - 6 IN. SECTION COMPARISON .........................................................166 
TABLE 6-17 WVU 7 FT - 6 IN. / VIRGINIA 7 FT - 6 IN. SECTION COMPARISON …….......................................167

TABLE 6-18 WVU 9 FT / VIRGINIA 9 FT SECTION COMPARISON..................................................................168

TABLE 6-19 WVU 9 FT / AISI 8 FT - 6 IN. SECTION COMPARISON ...............................................................170

TABLE 6-20 WVU 9 FT / AISI 9 FT SECTION COMPARISON .......................................................................171

TABLE 6-21 WVU 10 FT - 6 IN. / AISI 10 FT SECTION COMPARISON .........................................................172 


\section{Notation}

\begin{tabular}{|c|c|c|}
\hline A & $=$ & $\begin{array}{l}\text { detail category constant for fatigue resistance; total gross cross-sectional } \\
\text { area of the member }\left(\text { in. }^{2} \text { ) }\right.\end{array}$ \\
\hline ADTT & $=$ & average daily truck traffic over the design life \\
\hline $\mathrm{ADTT}_{\mathrm{SL}}$ & $=$ & single lane ADTT \\
\hline$A_{f t}$ & $=$ & $\begin{array}{l}\text { sum of the flange area and the area of any cover plates on the side of the } \\
\text { neutral axis corresponding to } D_{n}\left(\text { in }^{2}\right)\end{array}$ \\
\hline$a_{w c}$ & $=$ & $\begin{array}{l}\text { ratio of two times the web area in compression to the area of the } \\
\text { compression flange }\end{array}$ \\
\hline$b_{f}$ & $=$ & full width of the flange (in.) \\
\hline $\mathrm{b}_{\mathrm{fc}}$ & $=$ & full width of the compression flange (in.) \\
\hline$b_{\mathrm{ft}}$ & $=$ & full width of the tension flange (in.) \\
\hline$b_{s}$ & $=$ & effective width of concrete deck (in.) \\
\hline $\mathrm{C}$ & $=$ & ratio of the shear-buckling resistance to the shear yield strength \\
\hline $\mathrm{C}_{\mathrm{b}}$ & $=$ & moment gradient modifier \\
\hline $\mathrm{D}$ & $=$ & web depth (in.) \\
\hline $\mathrm{D}_{\mathrm{c}}$ & $=$ & depth of the web in compression in the elastic range (in.) \\
\hline $\mathrm{D}_{\mathrm{cp}}$ & $=$ & depth of the web in compression at the plastic moment (in.) \\
\hline $\mathrm{D}_{\mathrm{n}}$ & $=$ & $\begin{array}{l}\text { larger of the distances from the elastic neutral axis of the cross-section to } \\
\text { the inside face either flange (in.) }\end{array}$ \\
\hline $\mathrm{D}_{\mathrm{p}}$ & $=$ & $\begin{array}{l}\text { distance from the top of the concrete deck to the neutral axis of the } \\
\text { composite section at the plastic moment (in.) }\end{array}$ \\
\hline$D_{t}$ & $=$ & total depth of the composite section (in.) \\
\hline
\end{tabular}




\begin{tabular}{|c|c|c|}
\hline d & $=$ & total depth of the steel section (in.) \\
\hline$d_{e}$ & $=$ & $\begin{array}{l}\text { horizontal distance from the centerline of the exterior web of exterior } \\
\text { beam at deck level to the interior edge of curb or traffic barrier (ft) }\end{array}$ \\
\hline $\mathrm{d}_{0}$ & $=$ & transverse stiffener spacing (in.) \\
\hline $\mathrm{d}_{\mathrm{s}}$ & $=$ & $\begin{array}{l}\text { distance from the centerline of the closest plate longitudinal stiffener or } \\
\text { from the gage line of the closest angle longitudinal stiffener to the inner } \\
\text { surface or leg of the compression-flange element (in.) }\end{array}$ \\
\hline $\mathrm{E}$ & $=$ & modulus of elasticity of steel (ksi) \\
\hline $\mathrm{E}_{\mathrm{B}}$ & $=$ & modulus of elasticity of beam material (ksi) \\
\hline$E_{D}$ & $=$ & modulus of elasticity of deck material (ksi) \\
\hline $\mathrm{F}_{\mathrm{yc}}$ & $=$ & specified minimum yield strength of a compression flange (ksi) \\
\hline e & $=$ & $\begin{array}{l}\text { eccentricity of a design truck or a design lane load from the center of } \\
\text { gravity of the pattern of girders ( } \mathrm{ft} \text { ) }\end{array}$ \\
\hline$e_{g}$ & $=$ & distance between centers of gravity of the basic beam and deck (in.) \\
\hline $\mathrm{F}_{\mathrm{crw}}$ & $=$ & nominal bend-buckling resistance for webs (ksi) \\
\hline $\mathrm{F}_{\mathrm{nc}}$ & $=$ & nominal flexural resistance of the compression flange (ksi) \\
\hline $\mathrm{F}_{\mathrm{nt}}$ & $=$ & nominal flexural resistance of the tension flange (ksi) \\
\hline $\mathrm{F}_{\mathrm{yc}}$ & $=$ & specified minimum yield strength of a compression flange (ksi) \\
\hline $\mathrm{F}_{\mathrm{yf}}$ & $=$ & specified minimum yield strength of a flange (ksi) \\
\hline $\mathrm{F}_{\mathrm{yr}}$ & $=$ & $\begin{array}{l}\text { compression-flange stress at the onset of nominal yielding with the cross- } \\
\text { section, including residual stress effects, but not including compression- } \\
\text { flange lateral bending (ksi) }\end{array}$ \\
\hline $\mathrm{F}_{\mathrm{yt}}$ & $=$ & specified minimum yield strength of a tension flange (ksi) \\
\hline $\mathrm{F}_{\mathrm{yw}}$ & $=$ & specified minimum yield strength of a web (ksi) \\
\hline
\end{tabular}




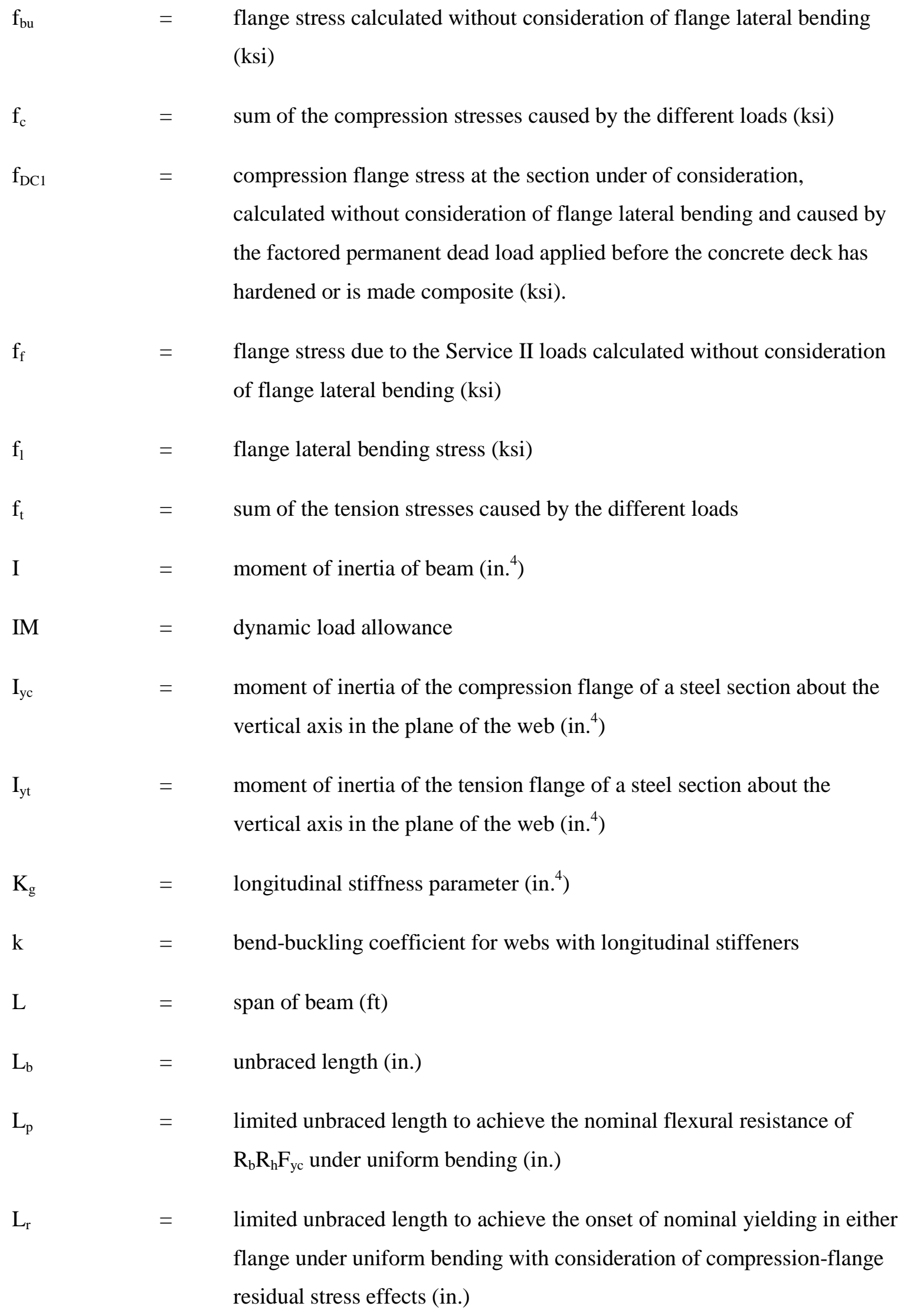




\begin{tabular}{|c|c|c|}
\hline $\mathrm{M}_{\mathrm{n}}$ & $=$ & nominal flexural resistance of the section (kip-in.) \\
\hline $\mathrm{M}_{\mathrm{p}}$ & $=$ & plastic moment of the composite section (kip-in.) \\
\hline $\mathrm{M}_{\mathrm{u}}$ & $=$ & bending moment about the major-axis of the cross-section (kip-in.) \\
\hline $\mathrm{M}_{\mathrm{y}}$ & $=$ & yield moment (kip-in.) \\
\hline $\mathrm{m}$ & $=$ & multiple presence factor \\
\hline $\mathrm{N}_{\mathrm{B}}$ & $=$ & number of beams, stringers or girders \\
\hline $\mathrm{N}_{\mathrm{L}}$ & $=$ & number of design lands as specified in Article 3.6.1.1.1 \\
\hline $\mathrm{n}$ & $=$ & number of stress range cycles per truck passage \\
\hline $\mathrm{Q}_{\mathrm{i}}$ & $=$ & force effect \\
\hline $\mathrm{R}_{\mathrm{b}}$ & $=$ & web load-shedding factor as specified in Article 6.10.1.10.2 \\
\hline $\mathrm{R}_{\mathrm{h}}$ & $=$ & hybrid factor determined as specified in Article 6.10.1.10.1 \\
\hline $\mathrm{R}_{\mathrm{n}}$ & $=$ & nominal resistance \\
\hline $\mathrm{R}_{\mathrm{r}}$ & $=$ & factored resistance: $\Phi \mathrm{R}_{\mathrm{m}}$ \\
\hline$r_{t}$ & $=$ & effective radius of gyration for lateral torsional buckling (in.) \\
\hline S & $=$ & spacing of beams or webs (ft) \\
\hline $\mathrm{S}_{\mathrm{xt}}$ & $=$ & $\begin{array}{l}\text { elastic section modulus about the major axis of the section to the tension } \\
\text { flange (in. }{ }^{3} \text { ) }\end{array}$ \\
\hline$t_{f}$ & $=$ & flange thickness (in.) \\
\hline $\mathrm{t}_{\mathrm{fc}}$ & $=$ & thickness of the compression flange (in.) \\
\hline$t_{\mathrm{ft}}$ & $=$ & thickness of the tension flange (in.) \\
\hline$t_{s}$ & $=$ & depth of concrete slab (in.) \\
\hline$t_{w}$ & $=$ & web thickness (in.) \\
\hline $\mathrm{V}_{\mathrm{cr}}$ & $=$ & shear-buckling resistance (kip) \\
\hline
\end{tabular}




\begin{tabular}{|c|c|c|}
\hline $\mathrm{V}_{\mathrm{n}}$ & $=$ & nominal shear resistance (kip) \\
\hline $\mathrm{V}_{\mathrm{p}}$ & $=$ & plastic shear force (kip) \\
\hline $\mathrm{V}_{\mathrm{u}}$ & $=$ & $\begin{array}{l}\text { shear in the web at the section under consideration due to the factored } \\
\text { loads (kip) }\end{array}$ \\
\hline $\mathrm{X}_{\mathrm{ext}}$ & $=$ & $\begin{array}{l}\text { horizontal distance from the center of gravity of the pattern of girders to } \\
\text { the exterior girder (ft) }\end{array}$ \\
\hline $\mathrm{x}$ & $=$ & $\begin{array}{l}\text { horizontal distance from the center of gravity of the pattern of girders to } \\
\text { each girder ( } \mathrm{ft} \text { ) }\end{array}$ \\
\hline$\eta_{\mathrm{i}}$ & $=$ & $\begin{array}{l}\text { load modifier: a factor relating to ductility, redundancy and operational } \\
\text { classification }\end{array}$ \\
\hline$\eta_{\mathrm{D}}$ & $=$ & a factor relating to ductility, as specified in Article 1.3.3 \\
\hline$\eta_{\mathrm{I}}$ & $=$ & a factor relating to operational classification, as specified in Article 1.3.5 \\
\hline$\eta_{\mathrm{R}}$ & $=$ & a factor relating to redundancy, as specified in Article 1.3.4 \\
\hline$\gamma_{\mathrm{i}}$ & $=$ & load factor: a statistically based multiplier applied to force effects \\
\hline$\gamma_{\mathrm{p}}$ & $=$ & load factor for permanent loading \\
\hline$(\Delta \mathrm{F})_{\mathrm{n}}$ & $=$ & nominal fatigue resistance (ksi) \\
\hline$(\Delta \mathrm{f})$ & $=$ & $\begin{array}{l}\text { force effect, live load stress range due to the passage of the fatigue load } \\
\text { (ksi) }\end{array}$ \\
\hline$\lambda_{\mathrm{f}}$ & $=$ & slenderness ratio for the compression flange \\
\hline$\lambda_{\mathrm{pf}}$ & $=$ & limiting slenderness ratio for a compact flange \\
\hline$\lambda_{\mathrm{rf}}$ & $=$ & limiting slenderness ratio for a noncompact flange \\
\hline$\lambda_{\mathrm{rw}}$ & $=$ & limiting slenderness ratio for a noncompact web \\
\hline
\end{tabular}


$\Phi$

$\Phi_{\mathrm{f}}$

$\Phi_{\mathrm{v}}$

$=$

resistance factor: a statistically based multiplier applied to nominal resistance

$=\quad$ resistance factor for flexure

resistance factor for shear 


\section{Chapter 1: Introduction}

\subsection{Introduction}

There are a large number of bridges in the United States that are considered structurally deficient or functionally obsolete. The Federal Highway Association (FHWA) has introduced an initiative titled Highways for LIFE in an effort to help in reducing these issues. This FHWA focus area promotes the development of bridge design and construction that leads to Long lasting bridges that are Innovative, have Fast construction times and are economically Efficient. This thesis takes these principles and looks into possible bridge alternatives that have not been fully embraced by the bridge community, specifically modular steel bridges, which may provide a solution for some of the short span bridges that need replaced.

\subsection{Scope}

The focus of this research is to find a steel-based alternative for short span bridge design that can meet the expectations of the Federal Highway Association's Highways for LIFE initiative. In order to see the current practices and preferences for the design of short span bridges in the United States, a survey was developed and distributed to each state's department of transportation.

Based on the principles of the Highways for LIFE initiative and the low use of steel for short span bridges, the Short Span Steel Bridge Alliance was looking for a way to find a marketable steel product that can be used in the short span bridge range. Modular bridges were researched to see what opportunities exist in making a quickly constructible short span steel bridge. Once a large collection of modular bridge technologies were found and analyzed, a grading system was developed to allow professionals in the bridge community to determine which modular bridge options can be efficiently integrated with current bridge design practices.

The second approach pursued to create a more efficient bridge design process was the development of a collection of standardized steel bridge superstructures using conventional steel girder systems. Girder sections were developed using rolled steel girder sections and steel plate girder sections. The steel plate girder systems were designed using a series of limited plate sizes to take advantage of the benefits of stock piling plates of common sizes. The number of rolled steel girder sections was narrowed to develop a suite of girder sections that were found to be adequate over a large variety of bridge scenarios. 


\subsection{Organization of Thesis}

This research is separated into seven chapters and one appendix. Chapter Two discusses the background that led to the work in this thesis. It provides information for the Federal Highways Association's initiative titled Highways for LIFE, the development of Accelerated Bridge Construction practices and an overview of the steel bridge design process as specified in the $5^{\text {th }}$ Edition (2010) of the AASHTO LRFD Bridge Design Specifications (AASHTO Specifications).

Chapter Three presents the Short Span Bridge Survey developed in association with the Short Span Steel Bridge Alliance. This chapter presents the survey as it was sent to each state's department of transportation and then provides explanation for each question and the results as found from responses.

Chapter Four presents an overview of modular bridge technology that is being developed or already in use. The chapter is split into the modular substructures, superstructures, deck systems and overall modular systems. Also, provided in this chapter is an overview of secondary bridge elements such as traffic barriers and cross-frames for bridges and an overview of a specific modular construction process that involves the use of Self-Propelled Modular Transporters.

Chapter Five discusses the grading system used to evaluate which modular bridge system is the most beneficial to pursue as a short span bridge alternative at this time. The grading system was developed to follow the principles of the Highways for Life initiative presented in Chapter Two. This chapter explains the grading system and categories as well as describing the category weights. Lastly, it provides an example of the grading tables presented to the engineers who took part in the survey and an overview of the results to the grading survey.

Chapter Six presents a set of predesigned steel girder sections that have been developed as a design aid for engineers in designing short span steel bridges. This chapter explains the methods and assumptions made in the design process and presents the tables of sections that were designed. The tables of this chapter provide steel girder designs that were developed for four different girder spacing arrangements and with span lengths ranging from 40 to 140 feet in 5 foot increments. These tables are intended to begin establishing a framework for how the modular bridge design aid can be organized in order to provide an efficient design tool for bridge engineers. 
Chapter Seven presents an overview of the results of this research. It provides concluding remarks and recommendations for future research projects. 


\section{Chapter 2: Background}

\subsection{Federal Highway Administration Highways for LIFE}

In response to the deteriorating infrastructure of the United States, the Federal Highway Administration began an initiative that they have named Highways for LIFE. The purpose of this initiative is "to advance Long-lasting highway infrastructure using Innovations to accomplish Fast construction of Efficient and safe highways and bridges.” [17] The following three objectives are also listed for this initiative:

- Improve safety during and after construction,

- $\quad$ Reduce congestion caused by construction and

- Improve the quality of the highway infrastructure.

For the initiative to make the required change in the highway community's attitude, a combination of research, education and encouragement are to be applied. By finding the best, innovative highway technologies and publicizing them, educating those involved in the application of these innovations and convincing the bridge community through rewards to apply them, the organization intends to change the attitudes of bridge engineers towards application of innovative bridge systems. [17]

The organization has partnered with several technologies in order to refine and accelerate the adoption of promising highway innovations. Examples of technologies that have been aided by the Highways for LIFE initiative include: an All-Weather Pavement Marking System, Fully Precast Bridge Bents for Use in Seismic Regions and Full Depth Ultra High Performance Concrete Waffle Bridge Panels. [17]

Highways for LIFE has also developed a collection of informational material that promotes the use of innovative highway practices and publicizes the bridges that have applied these innovations. Through the articles published and the seminars presented by the organization, innovative highway practices are receiving more overall publicity. These materials and seminars also educate engineers in the proper application of innovative highway technologies. [17]

There are also a number of demonstration projects from twenty different states that display different highway innovations in use. These projects have been developed into videos 
and presentations to provide visual displays of innovative highway projects that are currently in progress or have been completed. These presentations provide the engineer with evidence that innovative bridge technologies can be applied to actual designs and can be beneficial to the design and construction processes. [17]

\subsection{Accelerated Bridge Construction}

Rapid bridge construction concepts have been used in the railroad industry for several years in order to avoid service interruptions. In the highway bridge system, these innovations have been limited. The main cause for this trend is that as the country's infrastructure system was developed, new bridges and roads were constructed with no pressure due to construction time. With several bridges nearing the end of their design lives and traffic volumes ever increasing, urgency has developed to find ways to replace bridges without greatly disrupting traffic. Several states have developed standard bridge elements, but little effort has been devoted to standardized, modular bridge systems. The three major applications of modular steel bridge systems can be classified as Temporary Bridges, Emergency Bridges and Permanent Bridges. [42]

Temporary bridges are used as a method to divert traffic during bridge repair, rehabilitation, construction or replacement. These bridges can be installed for short periods of time and later disassembled and stored until needed again. This provides an alternative to costly detours, traffic maintenance and increased traffic volumes. [42]

Emergency bridges are a form of temporary bridge that is intended to take the place of a bridge that may become unusable due to incidents, natural disasters or pre-meditated attacks. Installation of a bridge that needs replaced without notice can be very difficult using traditional methods, but a bridge that is already constructed and stored can quickly restore passage to the travel-way. [42]

Permanent bridges are required by the AASHTO Specifications to have a design service life of 75 years. Through the use of mass production and an inherent reduction in on-site construction time, benefits can be found in the bridge construction process when using prefabricated bridge elements. Different designers around the world have been developing modular bridge concepts which include prefabricated sections of the bridge with elements already assembled off-site. These sections assembled off-site can either be fabricated in a controlled manufacturing location or adjacent to the bridge site to be later installed. [42] 
The first modular prefabricated steel bridge systems were developed in the 1930's to meet the needs of the British military in remote environments. These systems were composed of prefabricated panels that could be bolted together on-site to create truss sections for a bridge. A combination of floor beams and steel decking could then be connected to create the deck of the bridge. The second type of prefabricated steel bridge systems developed were first used in the 1950's as a way to replace timber bridges that were deteriorating. This system was comprised of either prefabricated steel plate girders or full-length truss members with a steel decking system placed on top of the prefabricated structural members. [42]

Several variations of each of these two early modular bridge systems have been developed and researched since their first applications. Some of the more successful variations are discussed later in Chapter Four.

\subsection{Overview of Steel Bridge Design Standards}

Several states have standards and recommendations for bridge design. These design aids range from pre-designed bridge elements to recommended bridge dimensions. Chapter Three has a section that summarizes the design aids provided in state survey responses and the additional design aids found through further review of the state bridge department websites.

\subsection{Overview of Steel Bridge Design}

\subsubsection{Introduction}

This section presents an overview of the specifications for steel bridge design as presented in the $5^{\text {th }}$ Edition (2010) of the AASHTO LRFD Bridge Design Specifications.

\subsubsection{Effective Width - Article 4.6.2.6}

The term effective width refers to the width of the concrete slab, assumed to have a uniform stress distribution, which contributes to the section properties of the girder being analyzed. For an interior girder, the effective deck width is to be taken as one-half the distance to the adjacent girder on each side. For an exterior girder, the effective deck width is to be taken as one-half the distance to the adjacent girder plus the full overhang width. [2]

\subsubsection{Loads - Section 3}

There are two major classifications for bridge design loads: permanent and transient. The permanent (or dead) loads are assumed to be either constant after the completion of construction or varying only over a long period of time; these loads are made up of the bridge elements 
themselves and thus are generally present throughout the life of the bridge. The transient (or live) loads can vary over a short period of time with respect to the overall lifetime of the bridge. Descriptions of both types of loads are presented below. [2]

\subsubsection{Dead Loads - Article 3.5.1}

Generally, dead loads are broken into the two categories of non-composite dead loads $\left(D_{1}\right)$ and composite dead loads ( $\mathrm{DC}_{2}$ and $\left.\mathrm{DW}\right)$. DC 1 represents the loads that are present on the bridge girders before composite action has taken place between the girders and the deck; this is generally due to the concrete deck not fully hardening. For a typical I-girder bridge with a concrete deck, these loads will include the weight of the steel girders, the concrete deck, the stayin-place formwork, the concrete haunches, the concrete overhang tapers and the steel diaphragms. It is assumed that these loads are only acting on the steel girders before the deck has been able to reach 75 percent of its compressive strength. $\mathrm{DC}_{2}$ represents the loads that act on the composite girder section including the hardened concrete deck; these loads include the weights of the curbs, the traffic barriers, the sidewalks, the bridge railings, etc. DW represents the weight of future wearing surfaces that may be applied to the bridge over its lifetime. [2]

\subsubsection{Live Loads - Article 3.6}

The design vehicular live load applied to the bridge is designated as the HL-93 by Article 3.6.1.2.1 of the AASHTO Design Specifications. The definition of the load is described as a combination of the design truck, or tandem, and the design lane load. Article 3.6.1.2.2 presents the design truck as consisting of a 72-kip truck with an 8-kip front axle and two 32-kip rear axles. The distance between the front axle and the first rear axle is fixed at $14 \mathrm{ft}$, but the distance between the two rear axles can vary between 14 and 30 feet. Transversely, the wheels of the design truck are spaced $6 \mathrm{ft}$ apart. Article 3.6.1.2.3 describes the design tandem as a pair of 25kip axles spaced $4 \mathrm{ft}$ apart with a transverse distance of $6 \mathrm{ft}$. Article 3.6.1.2.4 describes the design lane load as a $0.64 \mathrm{klf}$ uniformly distributed load with a transverse width of $10 \mathrm{ft}$. [2] 


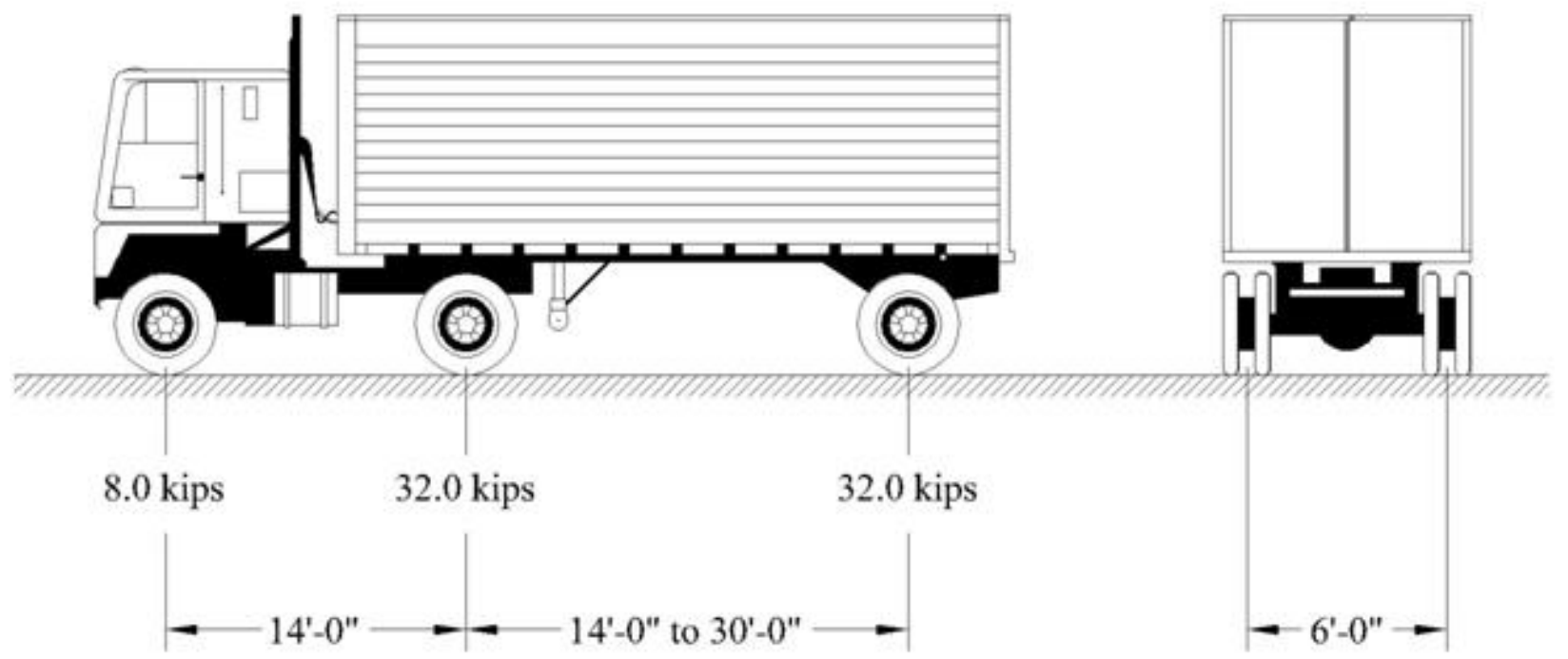

\section{Figure 2-1 HS20-44 Design Truck}

\subsubsection{Construction Loads - Article 2.5.3}

Construction loads are modeled for the bridge in order to check the bridge's resistance to stresses caused by the construction process. The loads generally checked as contributing to the lateral stresses of the girders include the overhang deck forms, the concrete deck overhangs, the screed rails, the railings, the walkways and the finishing machine. Typical weight of the deck overhang is assumed to be partially supported by the exterior girder. The bridge deck is cast in a sequence, to minimize cracking, where generally the positive bending regions are cast first and allowed to harden before the negative bending regions are cast. [2]

\subsubsection{Load Combinations - Article 3.4.1}

In order to account for the statistic probability of different loads occurring simultaneously, the AASHTO LRFD Bridge Specifications provides different load combinations to apply to the bridge being analyzed. The equation provided in the specifications showing limit states is as shown:

$$
\sum \eta_{i} \gamma_{i} Q_{i} \leq \phi R_{n}=R_{r}
$$

The factors used in this equation are provided in Tables 3.4.1-1 and 3.4.1-2 of the AASHTO Specifications. The following sections will describe each load combination. [2] 


\subsubsection{Strength Load Combinations}

The strength limit state is to be checked in order to ensure that strength and stability are provided to resist the specified load combinations. The design live load, described in Section 2.4.3.2 of this thesis, is applied to the bridge during the strength limit state. [2]

The Strength I load combination is used as a basic load combination relating to the normal vehicular use of the bridge. This load combination neglects the effects of wind on the bridge. The load factors of 1.25 for the non composite dead load $\left(\mathrm{DC}_{1}\right), 1.5$ for the composite dead load $\left(\mathrm{DC}_{2}\right)$ and 1.75 for the live loads (LL) are applied for this load combination. [2]

The Strength II load combination is related to the use of the bridge by Owner-specified special design vehicles, evaluation permit vehicles or both vehicles with no wind load. The load factors of Strength I are applied to Strength II except that the LL factor is reduced to 1.35. [2]

The Strength III load combination is related to the bridge being exposed to wind velocities exceeding $55 \mathrm{mph}$. The load factors used for Strength I for the dead loads remain the same. The live load is neglected for this load combination and the wind load has a load factor of 1.4 for this load combination. [2]

The Strength IV load combination relates to structures with a very high dead load to live load force effects ratio. For this load combination all permanent loads are factored by 1.5. This combination neglects the effects of live and wind loads on the structure. This load combination can control during certain stages of construction. [2]

The Strength V load combination is related to the bridge being subjected to $55 \mathrm{mph}$ winds and normal vehicular use. This load combination used the same load factors as the Strength II load combination except that the wind load is reduced to 0.40. [2]

The strength load factors described in this section can be seen in Table 2-1, and the load factors applied to the different dead loads can be seen in Table 2-2, below: 
Table 2-1 Strength Limit State Load Factors

\begin{tabular}{|c|c|c|c|c|c|c|c|c|c|}
\hline $\begin{array}{c}\text { Load } \\
\text { Combination } \\
\text { Limit State } \\
\end{array}$ & $\begin{array}{l}\mathrm{DC} \\
\mathrm{DD} \\
\mathrm{DW} \\
\mathrm{EH} \\
\mathrm{EV} \\
\mathrm{ES} \\
\mathrm{EL} \\
\mathrm{PS} \\
\mathrm{CR} \\
\mathrm{SH} \\
\end{array}$ & $\begin{array}{l}\text { LL } \\
\text { IM } \\
\text { CE } \\
\text { BR } \\
\text { PL } \\
\text { LS }\end{array}$ & WA & WS & WL & FR & TU & TG & SE \\
\hline $\begin{array}{l}\text { STRENGTH I } \\
\text { (unless noted) }\end{array}$ & $\gamma_{p}$ & 1.35 & 1.00 & - & - & 1.00 & $0.50 / 1.20$ & $\gamma_{T G}$ & $\gamma_{S E}$ \\
\hline STRENGTH II & $\gamma_{p}$ & 1.35 & 1.00 & - & - & 1.00 & $0.50 / 1.20$ & $\gamma_{T G}$ & $\gamma_{S E}$ \\
\hline STRENGTH III & $\gamma_{p}$ & - & 1.00 & 1.40 & - & 1.00 & $0.50 / 1.20$ & $\gamma_{T G}$ & $\gamma_{S E}$ \\
\hline STRENGTH IV & $\gamma_{p}$ & - & 1.00 & - & - & 1.00 & $0.50 / 1.20$ & - & - \\
\hline STRENGTH V & $\gamma_{p}$ & 1.35 & 1.00 & 0.40 & 1.00 & 1.00 & $0.50 / 1.20$ & $\gamma_{T G}$ & $\gamma_{S E}$ \\
\hline
\end{tabular}

Table 2-2 Load Factors for Permanent Loads, $\gamma_{p}$

\begin{tabular}{|l|r|c||}
\hline \multicolumn{1}{|c|}{$\begin{array}{c}\text { Type of Load, Foundation Type, and } \\
\text { Method Used to Calculate Downdrag }\end{array}$} & \multicolumn{2}{c|}{ Load Factor } \\
\cline { 2 - 3 } & Maximum & Minimum \\
\hline \hline DC: Component and Attachments & 1.25 & 0.90 \\
DC: Strength IV only & 1.50 & 0.90 \\
\hline DD: Downdrag $\quad$ Piles, $\alpha$ Tomlinson Method & 1.40 & 0.25 \\
& 1.05 & 0.30 \\
\hline DW: : Wearilled shafts, O'Neill and Reese (1999) Method & 1.25 & 0.35 \\
\hline EH: Horizontal Earth Pressure & 1.50 & 0.65 \\
- Active & & \\
- At-Rest & 1.50 & 0.90 \\
- AEP for anchored walls & 1.35 & 0.90 \\
\hline EL: Locked-in Construction Stresses & 1.35 & $\mathrm{~N} / \mathrm{A}$ \\
\hline EV: Vertical Earth Pressure & 1.00 & 1.00 \\
- Overall Stability & & \\
- Retaining Walls and Abutments & 1.00 & $\mathrm{~N} / \mathrm{A}$ \\
- Rigid Buried Structure & 1.35 & 1.00 \\
- Rigid Frames & 1.30 & 0.90 \\
- Flexible Buried Structures other than Metal Box Culverts & 1.35 & 0.90 \\
- Flexible Metal Box Culverts and Structural Plate Culverts with Deep & 1.95 & 0.90 \\
\hline Corrugations & & \\
\hline ES: Earth Surcharge & 1.50 & 0.90 \\
\hline \hline
\end{tabular}




\subsubsection{Service Load Combinations}

The Service Limit state is used to reduce the amount of cracking in the concrete portions of the bridge due to service level stresses and deflections. The stresses being analyzed are generally caused by large permanent and/or elastic deformations. [2]

The Service I load combination is related to the normal operational use of the bridge with an applied wind velocity of $55 \mathrm{mph}$ and all loads taken at their normal values. This load combination uses a load factor of 1.0 for all loads except for the applied wind load, which has a factor of 0.3. In this load combination, the owner has the option to enforce the optional live load deflection criteria specified in Article 2.5.2.6.2. This article provides a maximum deflection to be compared with the larger deflection due to the two loading scenarios provided in Article 3.6.1.3.2: the design truck alone or 25 percent of the design truck plus one full design lane load. [2]

The Service II load combination is used to control yielding of steel structures. The load factors are 1.0 for all dead loads and 1.3 for all live loads. The Service III and Service IV load combinations are only applicable to prestressed concrete members so they are not analyzed in this thesis. Table 2-3 below presents the load factors for the service limit states. [2]

Table 2-3 Service Limit State Load Factors

\begin{tabular}{|c|c|c|c|c|c|c|c|c|c||}
\hline & DC & & & & & & & & \\
& DD & & & & & & & & \\
& DW & & & & & & & & \\
& EH & & & & & & & & \\
& EV & LL & & & & & & & \\
& ES & IM & & & & & & & \\
EL & CE & & & & & & & \\
Load & PS & BR & & & & & & & \\
Combination & CR & PL & & & & & & & \\
Limit State & SH & LS & WA & WS & WL & FR & TU & TG & SE \\
\hline \hline Service I & 1 & 1.00 & 1.00 & 0.3 & 1.0 & 1.00 & $1.00 / 1.20$ & VTG & VSE \\
\hline Service II & 1 & 1.30 & 1.00 & - & - & 1.00 & $1.00 / 1.20$ & - & - \\
\hline
\end{tabular}

\subsubsection{Fatigue Load Combination}

The fatigue limit state is used to limit the growth of cracks caused by repetitive loadings over the life of the bridge. These cracks could eventually lead to fracture and failure of a specific part of the bridge. The Fatigue I load combination is meant to represent the infinite load-induced fatigue life of the bridge, while the Fatigue II load combination represents the finite load-induced 
fatigue life. The live load vehicle used for both of these load combinations is similar to the design truck described in Section 2.4.3.2 of this thesis except that the distance between the rear axles is fixed at $30 \mathrm{ft}$. The dynamic load allowance is specified as $15 \%$ for the fatigue limit state as opposed to $33 \%$ as specified for all other limit states. The live load is the only load applied to the bridge in fatigue analysis and the factors applied to the loads are 1.50 and 0.75 for Fatigue I and Fatigue II, respectively. [2]

\subsubsection{Load Modifiers}

Load modifiers are factors that account for ductility, redundancy and the operational classification of the bridge and make up the $\eta_{i}$ portion of equation 2.1. The three values are multiplied by one another to make up one load modification factor, $\eta_{i}$. [2]

\subsubsection{Ductility}

Article 1.3.3 specifies the load modification factor applied to loadings to account for the ductility of the bridge. This requirement is important in ensuring that visible inelastic deformations occur before failure at the strength and extreme event limit states. The values for this modification factor are provided in Table 2-4. [2]

\subsubsection{Redundancy}

Article 1.3.4 specifies the load modification factor applied to loads to account for the redundancy of the structure. This requirement is important in ensuring that the failure of one element of the bridge does not lead to catastrophic failure of the whole system. The values of this modification factor are provided in Table 2-4. [2]

\subsubsection{Operational Importance}

Article 1.3.5 specifies the load modification factor applied to loads to account for the operational importance of the bridge. This requirement provides higher resistance to bridges that have higher operational importance (emergency roadways, national security impact, etc.). The values of this modification factor are provided in Table 2-4. [2] 
Table 2-4 Load Modification Factors

\begin{tabular}{|l|l|}
\hline \multicolumn{2}{|l|}{ Ductility Factors } \\
\hline Nonductile components and connections & $\eta_{D} \geq 1.05$ \\
\hline Conventional designs and details & $\eta_{D}=1.00$ \\
\hline Components with more ductility & $\eta_{D} \geq 0.95$ \\
\hline Redundancy Factors & $\eta_{R} \geq 1.05$ \\
\hline Nonredundant members & $\eta_{R}=1.00$ \\
\hline Conventional levels of redundancy & $\eta_{R} \geq 0.95$ \\
\hline Exceptional levels of redundancy & $\eta_{I} \geq 1.05$ \\
\hline Operational Importance Factors & $\eta_{I}=1.00$ \\
\hline Critical or essential bridges & $\eta_{I} \geq 0.95$ \\
\hline Typical bridges
\end{tabular}

The modification factors provided in Table 2-4 apply to the strength limit state only, all other limit states use a factor of 1.0. [2]

\subsubsection{Distribution Factors}

Article 4.6.2.2 of the AASHTO Specification provides the means to reduce threedimensional analysis down to two-dimensional analysis by the means of distribution factors. The equations used to calculate these distribution factors are provided in the following sections. [2]

\subsubsection{Interior Girder Distribution Factors}

The equations for the distribution factors for the moment of an interior girder are provided in Table 4.6.2.2.2b-1 of the AASHTO Specifications and are presented below:

For one lane loaded:

$$
\begin{aligned}
& D F_{\text {OneLane }}=0.06+\left(\frac{S}{14}\right)^{0.4}\left(\frac{S}{L}\right)^{0.3}\left(\frac{K_{g}}{12.0 L t_{s}^{3}}\right)^{0.1} \\
& \text { where: } \quad K_{g}=n\left(I+A e_{g}^{2}\right)
\end{aligned}
$$




$$
n=\frac{E_{B}}{E_{D}}
$$

For two or more lanes loaded:

$$
D F_{\text {MultiLane }}=0.075+\left(\frac{S}{9.5}\right)^{0.6}\left(\frac{S}{L}\right)^{0.2}\left(\frac{K_{g}}{12.0 L t_{s}^{3}}\right)^{0.1}
$$

The equations for the distribution factors for the shear of an interior girder are provided in Table 4.6.2.2.3a-1 of the AASHTO Specifications and are presented below:

For one lane loaded:

$$
D F_{\text {OneLane }}=0.36+\frac{S}{25.0}
$$

For two or more lanes loaded:

$$
D F_{\text {MultiLane }}=0.2+\frac{S}{12}-\left(\frac{S}{35}\right)^{2.0}
$$

These equations are applicable when the following are within range:

$$
\begin{array}{ll}
\text { o } & 3.5 \leq S \leq 16.0 \text { (ft) } \\
\text { o } & 4.5 \leq t_{s} \leq 12.0 \text { (in) } \\
\text { o } & 20 \leq L \leq 240 \text { (ft) } \\
\text { o } & N_{b} \geq 4 \\
\text { o } & 10,000 \leq K_{g} \leq 7,000,000 \text { (moment distribution factors only) }
\end{array}
$$

In the equations for interior girders, multiple presence factors have already been applied; therefore need not be applied again. However, it is still necessary to divide by the multiple presence factors for the fatigue limit state. [2] 


\subsubsection{Exterior Girder Distribution Factors}

The equations for the distribution factors for the moment and shear of an exterior girder are provided in Table 4.6.2.2.2d-1 and Table 4.6.2.2.3b-1 of the AASHTO Specifications, respectively. For one design lane loaded, the distribution factors are to be determined by the use of the Lever Rule. To perform the Lever Rule, it is assumed that the deck is simply-supported between adjacent girders, and the distribution factor is determined by summing the moments about the interior girder directly adjacent to the exterior girder being investigated. The distribution factors for two or more lanes loaded are found by multiplying a correction factor to the corresponding interior girder factors. The equations for the correction factors are shown below:

$$
\begin{aligned}
& e_{\text {moment }}=0.77+\frac{d_{e}}{9.1} \\
& e_{\text {shear }}=0.6+\frac{d_{e}}{10}
\end{aligned}
$$

The commentary for Article 4.6.2.2.2d provides an additional investigation that must be checked since cross-frames and diaphragms are not considered in the distribution factor equations above. The equation is considered interim for now as research is being performed to develop a more representative factor. The equation is given as follows:

$$
R=\frac{N_{L}}{N_{b}}+\frac{X_{e x t} \sum^{N_{L}} e}{\sum_{b}^{N_{b}} x^{2}}
$$

To find the correct distribution factors using this equation, multiple presence factors must be applied to the result. [2]

\subsubsection{Fatigue Distribution Factors}

Article 3.6.1.4.3b of the AASHTO Specifications states that the distribution factors for the fatigue limit state must only consider one design truck. To achieve this, the distribution factors for one lane loaded situations only, calculated earlier for the interior and exterior girders must be divided by the appropriate multiple presence factors. [2] 


\subsubsection{Live Load Deflection Distribution Factor}

Article 2.5.2.6.2 of the AASTHTO Specifications describes the criteria to be followed when investigating the optional live load deflection check. The maximum deflection is determined by loading all of the design lanes of the bridge and assuming that all components will deflect equally. The distribution factor used for this test is as shown below:

$$
D F=m \frac{N_{L}}{N_{b}}
$$

\subsubsection{Other Factors}

To account for the movement of the design vehicle and the variability of how the vehicle can react to the driving surface and the effects that that can have on the bridge structure, dynamic load allowances, also called impact factors, are applied to the live load on the bridge. The dynamic load allowances vary based on the limit state being checked as can be seen in Table 2-5. [2]

Table 2-5 Dynamic Load Allowance, IM

\begin{tabular}{|l|c|}
\hline Component & IM \\
\hline \hline Deck Joints - All Limit States & $75 \%$ \\
\hline All Other Components & \\
$\bullet \quad$ Fatigue and Fracture Limit State & $15 \%$ \\
$\bullet \quad$ All Other Limit States & $33 \%$ \\
\hline
\end{tabular}

The other factors, mentioned several times in the sections on distribution factors, are called multiple presence factors. These factors account for the probability of multiple design lanes being loaded at the same time. The values of the different multiple presence factors are presented in Table 2-6 below: 
Table 2-6 Muliple Presence Factors, m

\begin{tabular}{|c|c|}
\hline Number of Loaded Lanes & $\begin{array}{c}\text { Multiple Presence } \\
\text { Factors, } \mathrm{m}\end{array}$ \\
\hline 1 & 1.20 \\
\hline 2 & 1.00 \\
\hline 3 & 0.85 \\
\hline$>3$ & 0.65 \\
\hline
\end{tabular}

\subsubsection{Summary of Article 6.10 of the $5^{\text {th }}$ Edition AASHTO LRFD Specifications}

\subsubsection{Cross Section Proportion Limits}

After years of construction and fabrication experience, cross section proportional limits have been developed as seen in Article 6.10.2 of the AASHTO Specifications. These limits were developed to restrict pre-service damage to components and as precautionary measures to protect against damage during handling, distortion caused by welding and other adverse structural behavior. [2]

\subsection{Web Proportions}

During construction, it is difficult to handle girders with large profiles and thin webs, therefore, Articles 6.10.2.1.1 and 6.10.2.1.2 limit the ratio of girder depth to thickness to:

Webs without Longitudinal Stiffeners

$$
\frac{D}{t_{w}} \leq 150
$$

Webs with Longitudinal Stiffeners

$$
\frac{D}{t_{w}} \leq 300
$$

\subsection{Flange Proportions}

Article 6.10.2.2 of the AASTHO Specifications states that compression and tension flanges shall be proportioned such that: 
$\frac{b_{f}}{2 t_{f}} \leq 12.0$

Eq. 2.6

which provides a practical upper limit to ensure that the flange will not distort excessively when welded to the web,

$b_{f} \geq D / 6$

Eq. 2.7

which ensures that post-buckling shear resistance can be developed due to tension-field action,

$t_{f} \geq 1.1 t_{w}$

Eq. 2.8

which ensures that some restraint will be provided by the flanges against web shear buckling and that the juncture between web bend-buckling and compression flange local buckling correspond with the equations provided in the AASHTO Specifications, and

$0.1 \leq \frac{I_{y c}}{I_{y t}} \leq 10$

which ensures more efficient flange proportions and prevents the use of sections that may be difficult to handle during construction.

\subsubsection{Strength Limit State - Section 6.10.6}

The strength limit state ensures that the bridge can provide adequate resistance to applied moments and shears that may occur over the design life of the bridge. The following sections will present the equations and processes as shown in the AASHTO Specifications. [2]

\subsection{Positive Flexural Capacity}

Article 6.10.6.2.2 of the AASHTO Specifications provides the requirements for the section in positive flexure to be considered compact. The article specifies the following limits:

- $\quad$ Minimum yield strength of the flanges less than $70.0 \mathrm{ksi}$

- Web satisfies proportion limit of: $\quad \frac{D}{t_{w}} \leq 150$ 
- Section satisfies the web slenderness limit of: $\quad \frac{2 D_{c p}}{t_{w}} \leq 3.76 \sqrt{\frac{E}{F_{y c}}}$

Article 6.10.7.3 of the AASHTO Specifications provides the Ductility Requirement that both compact and non-compact sections must meet. The requirement is specified as being:

$$
D_{p} \leq 0.42 D_{t}
$$

\subsection{Compact Sections}

The equations of Article 6.10.7.1 provide the checks required for flexural resistance of compact sections in positive flexure. The defining equation of this section is as follows:

$$
M_{u}+\frac{1}{3} f_{l} S_{x t} \leq \phi_{f} M_{n}
$$

At the strength limit state, the effects of the lateral flange bending are effectively neglected because it is assumed that the deck will resist all lateral forces. The ultimate moment of the equation is found through structural analysis of the bridge, while the nominal flexural resistance is found using the equations of Article 6.10.7.1.2. [2]

To protect the concrete deck from prematurely crushing, the following check is performed comparing the depth of the plastic neutral axis and the total depth of the girder from the top of the deck. If this check is satisfied the nominal flexural resistance is simply the plastic moment of the section as shown:

$$
\begin{gathered}
\text { If } D_{p} \leq 0.1 D_{t} \\
M_{n}=M_{p}
\end{gathered}
$$

If the above check is not satisfied, the following equation is used to calculate the nominal flexural resistance:

$$
M_{n}=M_{p}\left(1.07-0.7 \frac{D_{p}}{D_{t}}\right)
$$


The nominal flexural resistance of girders for continuous spans must also satisfy the following equation except when all sections satisfy the section proportion that will be described in a later section. [2]

$$
M_{n} \leq 1.3 R_{h} M_{y}
$$

\subsection{Noncompact Sections}

The nominal flexural resistance for composite noncompact sections is provided by the following equation:

Compression Flange:

$$
f_{b u} \leq \phi_{f} F_{n c}
$$

Tension Flange:

$$
f_{b u}+\frac{1}{3} f_{l} \leq \phi_{f} F_{n t}
$$

The equations for the nominal flexural resistance of the compression and tension flanges are calculated as follows:

$$
\begin{aligned}
& F_{n c}=R_{b} R_{h} F_{y c} \\
& F_{n t}=R_{h} F_{y t}
\end{aligned}
$$

The web load-shedding factor, $\mathrm{R}_{\mathrm{b}}$, used in the equation for nominal flexural resistance of the compression flange can be found as:

$$
R_{b}=1.0
$$

when the section is composite and is in positive flexure and the web of the section satisfies:

$$
\frac{D}{t_{w}} \leq 150
$$

or when one or more longitudinal stiffeners are provided and the section satisfies: 
$\frac{D}{t_{w}} \leq 0.95 \sqrt{\frac{E k}{F_{y c}}}$

Eq. 2.21

or the web satisfies:

$\frac{2 D_{c}}{t_{w}} \leq \lambda_{r w}$

Eq. 2.22

When none of the previously stated criteria are met, the following equation is used for $\mathrm{R}_{\mathrm{b}}$ :

$R_{b}=1-\left(\frac{a_{w c}}{1200+300 a_{w c}}\right)\left(\frac{2 D_{c}}{t_{w}}-\lambda_{r w}\right) \leq 1.0$

in which

$\lambda_{r w}=5.7 \sqrt{\frac{E}{F_{y c}}}$

where:

$a_{w c}=\frac{2 D_{c} t_{w}}{b_{f c} t_{f c}}$

for all sections except composite longitudinally-stiffened sections in positive flexure, where:

$a_{w c}=\frac{2 D_{c} t_{w}}{b_{f c} t_{f c}+b_{s} t_{s}\left(1-f_{D C 1} / F_{y c}\right) / 3 n}$

and if:

$\frac{d_{s}}{D_{c}} \geq 0.4$

then:

$k=\frac{5.17}{\left(d_{s} / D\right)^{2}} \geq \frac{9}{\left(D_{c} / D\right)^{2}}$

Eq. 2.27 
otherwise:

$$
k=\frac{11.64}{\left(\frac{D_{c}-d_{s}}{D}\right)^{2}}
$$

Article D6.3.1 of the AASHTO Specifications provides the equation for $\mathrm{D}_{\mathrm{c}}$ of composite sections, as shown:

$$
D_{c}=\left(\frac{-f_{c}}{\left|f_{c}\right|+f_{t}}\right) d-t_{f c} \geq 0
$$

For homogeneous cross-sections, the hybrid factor, $\mathrm{R}_{\mathrm{h}}$, can be taken to equal 1.0. For all hybrid girders the following equation from Article 6.10.1.10.1 applies:

$$
R_{h}=\frac{12+\beta\left(3 \rho-\rho^{3}\right)}{12+2 \beta}
$$

in which:

$$
\beta=\frac{2 D_{n} t_{w}}{A_{f n}}
$$

where: $\quad \rho=$ the smaller of $\mathrm{F}_{\mathrm{yw}} / \mathrm{f}_{\mathrm{n}}$ and $1.0[2]$

\subsection{Negative Flexural Capacity}

Article 6.10.6.2.3 of the AASHTO Specifications provides the proportional limits that determine whether the section is considered compact or not compact. If the following requirements are met, the section is considered compact:

- Specified minimum yield strengths of the flanges do not exceed $70.0 \mathrm{ksi}$

- $\quad$ The web satisfies the noncompact slenderness limit:

$$
\frac{2 D_{c}}{t_{w}}<5.7 \sqrt{\frac{E}{F_{y c}}}
$$

- $\quad$ The flanges satisfy the following ratio: 


$$
\frac{I_{y c}}{I_{y t}} \geq 0.3
$$

The negative flexural capacity can be calculated using Article 6.10.8 or Appendix A of Chapter 6. For this description, the design process of Article 6.10 .8 will be presented. Discretely braced flanges at the strength limit state must satisfy the following inequalities:

Compression Flange

$$
f_{b u}+\frac{1}{3} f_{l} \leq \phi_{f} F_{n c}
$$

Tension Flange

$$
f_{b u}+\frac{1}{3} f_{l} \leq \phi_{f} F_{n t}
$$

Continuously braced flanges at the strength limit state must satisfy the following inequality:

$$
f_{b u} \leq \phi_{f} R_{h} F_{y f}
$$

To determine the flexural resistance of the compression flange, the minimum is taken of the flange local buckling (FLB) strength and the lateral-torsional buckling (LTB) strengths that are calculated using Articles 6.10.8.2.2 and 6.10.8.2.3. [2]

\subsection{Flange Local Buckling}

Article 6.10.8.2.2 of the AASHTO Specifications provides the equation for the flange local buckling resistance of the compression flange. [2]

If: $\lambda_{f} \leq \lambda_{p f}$

$$
F_{n c(F L B)}=R_{b} R_{h} F_{y c}
$$

Otherwise:

$$
F_{n c(F L B)}=\left[1-\left(1-\frac{F_{y r}}{R_{h} F_{y c}}\right)\left(\frac{\lambda_{f}-\lambda_{p f}}{\lambda_{r f}-\lambda_{p f}}\right)\right] R_{b} R_{h} F_{y c}
$$

In which: 


$$
\begin{aligned}
& \lambda_{f}=\frac{b_{f c}}{2 t_{f c}} \\
& \lambda_{p f}=0.38 \sqrt{\frac{E}{F_{y c}}} \\
& \lambda_{r f}=0.56 \sqrt{\frac{E}{F_{y r}}}
\end{aligned}
$$

\subsection{Lateral-Torsional Buckling}

The equations for lateral torsional buckling resistance are provided in Article 6.10.8.2.3 of the AASHTO Specifications and are provided below:

$$
\begin{aligned}
& \text { If } L_{b} \leq L_{p} \\
& \qquad F_{n c(L T B)}=R_{b} R_{h} F_{y c} \\
& \text { If } L_{p}<L_{b} \leq L_{r} \\
& \qquad F_{n c(L T B)}=C_{b}\left[1-\left(1-\frac{F_{y r}}{R_{h} F_{y c}}\right)\left(\frac{L_{b}-L_{p}}{L_{r}-L_{p}}\right)\right] R_{b} R_{h} F_{y c} \leq R_{b} R_{h} F_{y c}
\end{aligned}
$$

If $L_{b}>L_{r}$

$$
F_{n c(L T B)}=F_{c r} \leq R_{b} R_{h} F_{y c}
$$

In which:

$$
\begin{aligned}
& L_{p}=1.0 r_{t} \sqrt{\frac{E}{F_{y c}}} \\
& L_{r}=\pi r_{t} \sqrt{\frac{E}{F_{y r}}}
\end{aligned}
$$

The value of the moment gradient modifier, $\mathrm{C}_{\mathrm{b}}$, is calculated according to the following equations: 
For unbraced cantilevers and for members where $f_{\text {mid }} / f_{2}>1$ or $f_{2}=0$

$$
C_{b}=1.0
$$

For all other cases:

$$
C_{b}=1.75-1.05\left(\frac{f_{1}}{f_{2}}\right)+0.3\left(\frac{f_{1}}{f_{2}}\right)^{2} \leq 2.3
$$

The value of the elastic lateral-torsional buckling stress is found using:

$$
F_{c r}=\frac{C_{b} R_{b} \pi^{2} E}{\left(\frac{L_{b}}{r_{t}}\right)^{2}}
$$

And the value for the effective radius of gyration for lateral-torsional buckling is found using:

$$
r_{t}=\frac{b_{f c}}{\sqrt{12\left(1+\frac{1}{3} \frac{D_{c} t_{w}}{b_{f c} t_{f c}}\right)}}
$$

\subsection{Flexural Resistance of Tension Flange}

The flexural resistance of the tension flange is found using Article 6.10.8.3 of the AASHTO Specifications. The equation is as follows

$$
F_{n t}=R_{h} F_{y t}
$$

\subsection{Shear}

For the strength limit state, Article 6.10.9.1 provides the equation that defines the necessary check for the shear resistance of the bridge girder. The limit is presented below:

$$
V_{u} \leq \phi_{v} V_{n}
$$

Eq. 2.52 
To determine the nominal resistance of the web panels to shear, the web must be classified as either stiffened or unstiffened. Article 6.10.9.1 defines the web as being considered stiffened if the web is:

- Without a longitudinal stiffener and with a transverse stiffener spacing not exceeding 3D, or

- With one or more longitudinal stiffeners and with a transverse stiffener spacing not exceeding $1.5 \mathrm{D}$

For sections that are not considered stiffened, Article 6.10.9.2 of the AASHTO Specifications provides the following equation for the nominal shear resistance:

$$
V_{n}=V_{c r}=C V_{p}
$$

Where:

$$
V_{p}=0.58 F_{y w} D t_{w}
$$

To calculate the value for $\mathrm{C}$, a ratio between shear buckling resistance and shear yield strength, Article 6.10.9.3.2 provides three possible equations that are used as follows:

$$
\begin{aligned}
& \text { If: } \frac{D}{t_{w}} \leq 1.12 \sqrt{\frac{E k}{F_{y w}}} \\
& C=1.0 \\
& \text { If: } 1.12 \sqrt{\frac{E k}{F_{y w}}}<\frac{D}{t_{w}} \leq 1.40 \sqrt{\frac{E k}{F_{y w}}} \\
& C=\frac{1.12}{\frac{D}{t_{w}}} \sqrt{\frac{E k}{F_{y w}}} \\
& \text { If: } \frac{D}{t_{w}}>1.40 \sqrt{\frac{E k}{F_{y w}}}
\end{aligned}
$$




$$
C=\frac{1.57}{\left(\frac{D}{t_{w}}\right)^{2}}\left(\frac{E k}{F_{y w}}\right)
$$

In which:

$$
k=5+\frac{5}{\left(\frac{d_{0}}{D}\right)^{2}}
$$

For webs that are considered stiffened, Article 6.10.9.3.2 provides the equations for the shear resistance of the section. For an interior panel, the following requirements must be met:

$$
\begin{gathered}
\frac{2 D t_{w}}{\left(b_{f c} t_{f c}+b_{f t} t_{f t}\right)} \leq 2.5 \\
V_{n}=V_{p}\left[C+\frac{0.87(1-C)}{\sqrt{1+\left(\frac{d_{0}}{D}\right)^{2}}}\right]
\end{gathered}
$$

In which:

$$
V_{p}=0.58 F_{y w} D t_{w}
$$

For the nominal shear resistance of an end web panel, the same equations that were presented earlier for an unstiffened web panel are followed. [2]

\subsubsection{Constructability}

Article 6.10 .3 of the AASHTO Specifications provides the limiting equations used to determine if adequate resistance is provided for to the girders during the construction process of the bridge. The proper load factors for construction are specified by Article 3.4.2 and are applied to the construction loads while checking the three constructability checks specified. This section will provide the equations to check for flange nominal yielding, flexural resistance and web-bend buckling. For discreetly braced compression flanges must meet the following limits: 
Flange Nominal Yielding

$f_{b u}+f_{l} \leq \phi_{f} R_{h} F_{y c}$

Eq. 2.62

Flexural Resistance

$f_{b u}+\frac{1}{3} f_{l} \leq \phi_{f} F_{n c}$

Eq. 2.63

and Web Bend-Buckling

$f_{b u} \leq \phi_{f} F_{c r w}$

Eq. 2.64

$f_{l} \leq 0.6 F_{y c}$

Eq. 2.65

Tension flanges that are discreetly or continuously braced must also satisfy the following limits provided in Articles 6.10.3.2.2 and 6.10.3.2.3:

Discretely Braced Tension Flange Article 6.10.3.2.2

$f_{b u}+f_{l} \leq \phi_{f} R_{h} F_{y t}$

Eq. 2.66

Continuously Braced Tension Flange Article 6.10.3.2.3

$f_{b u} \leq \phi_{f} R_{h} F_{y t}$

Eq. 2.67

\subsubsection{Service Limit State}

The service limit state is used to preserve the concrete bridge deck so that acceptable levels of rideability for the user and minimal deck deterioration over the service life of the bridge are provided. In situations that decks are subjected to permanent deformations and/or cracks, the service life of the bridge will be reduced and rapid deterioration of the bridge can occur. Web yielding and bend-buckling capacities are checked in order to protect the deck from premature failure. Elastic deformations of the bridge can also be checked at the owner's decision. [2]

\subsection{Permanent Deformations}

Lateral flange bending effects are applied to both the top and bottom flanges of the girder at the Service II limit state. Assuming that the concrete bridge deck is fully effective for both positive and negative flexure, the Service II load combination is applied to both the short-term 
and long-term composite sections as appropriate. Stresses are then found based on the composite section properties and the load factors that were described earlier. In order to prevent web yielding and bend-buckling from occurring prior to flange strength development, the flanges must satisfy the following equations provided in Article 6.10.4.2.2. [2]

Top Steel Flange of Composite Sections:

$$
f_{f} \leq 0.95 R_{h} F_{y f}
$$

Bottom Steel Flange of Composite Sections:

$$
f_{f}+\frac{f_{l}}{2} \leq 0.95 R_{h} F_{y f}
$$

Both flanges of Composite Sections:

$$
f_{f}+\frac{f_{l}}{2} \leq 0.80 R_{h} F_{y f}
$$

\subsection{Elastic Deformations Article 6.10.4.1}

As of the $5^{\text {th }}$ edition of the AASHTO Specifications, the limit for live load deflection is an option that the owner has the choice to have checked as a part of the bridge design. The suggested limits are presented in Article 2.5.2.6 of the AASHTO Specifications. For checking the live load deflection, the larger deflection will be used as caused by:

- the design truck plus impact or

- $\quad 25 \%$ of the design truck with impact plus the design lane load.

In performing this check, it is assumed that all of the components of the bridge deflect equally and that all design lanes are to be loaded equally. Along with any structurally continuous parts of the bridge, the short-term composite section is used as the stiffness of the structure when analyzing deflection. The suggested elastic deformation limits from Article 2.5.2.6 are provided below in Table 2-7. [2] 
Table 2-7 Live Load Deflection Limits

\begin{tabular}{|l|c|}
\hline Vehicular loads only & Span/800 \\
\hline Vehicular and/or pedestrian load & Span/1000 \\
\hline Vehicular loads on cantilever arm & Span/300 \\
\hline Vehicular and/or pedestrian loads on cantilever arms & Span/375 \\
\hline
\end{tabular}

\subsection{Web Requirements}

One cause for accelerated deck deterioration and possible rupture due to plastic deformations is web bend-buckling. To check if the girder webs meet the required resistance to web bend-buckling, the following equation is to be satisfied for the Service II load combination. [2]

$$
f_{c} \leq F_{c r w}
$$

where:

$$
F_{c r w}=\frac{0.9 E k}{\left(\frac{D}{t_{w}}\right)^{2}}
$$

\subsubsection{Fatigue and Fracture Limit State}

Articles 6.6.1.2 and 6.6.1.3 of the AASHTO Specifications outline load-induced and distortion-induced fatigue. Connection details are to be checked in these regards as described and illustrated in Table 6.6.1.2.3-1, Table 6.6.1.2.3-2 and Figure 6.6.1.2.3-1. The limit state for fatigue is based on the design life of the bridge and limits the live load stress ranges of each detail to prevent the growth of cracks. [2]

\subsection{Load Induced Fatigue}

The stress range caused by live loads can be computed for flexural members by using the short-term composite section, if shear connectors are provided throughout the length of the flexural member, assuming that the concrete deck is effective in both the positive and negative bending regions of the bridge. When determining stress ranges, residual stresses are not considered, and these provisions will be applied to only the details of the girder subjected to a net applied stress. Fatigue will only be considered in regions where permanent loads produce 
compression if the compression stresses are less than twice the maximum tensile stresses caused by the live loads of the fatigue limit state. Article 6.6.1.2.2 of the AASHTO Specifications provides the equation that each detail must follow for load-induced fatigue:

$$
\gamma(\Delta f) \leq(\Delta F)_{n}
$$

Fatigue II Load and finite life:

$$
(\Delta F)_{n}=\left(\frac{A}{N}\right)^{\frac{1}{3}}
$$

In which:

$$
N=(365)(75) n(A D T T)_{S L}
$$

\subsection{Distortion Induced Fatigue}

To satisfy distortion induced fatigue requirements, Article 6.6.1.3 of the AASHTO Specifications provides the guidelines that must be met. The details for connections are established so that sufficient load paths exist to properly transmit all intended and unintended forces through transverse, lateral and longitudinal members. These load paths are established through the use of welding or bolting of the compression and tension flanges of the girder crosssections where:

- connecting diaphragms or cross-frames,

- internal or external diaphragms or cross-frames,

- $\quad$ or floorbeams or strengers

are attached to transverse connection plates or to transverse stiffeners acting as connection plates. When better information is not available, the welded or bolted connections of straight, nonskewed bridges should be designed to resist a lateral load of at least 20.0 kips. Article 6.10.5.3 of the AASHTO Specifications provides the following limit in order to control buckling and elastic flexing of the web. [2]

$$
V_{u} \leq V_{c r}
$$




\subsection{Fracture}

Article 6.6.2 of the AASHTO Specifications states that primary longitudinal members that are subjected to tension forces under the strength limit state must meet the Charpy V-notch toughness requirements. The Charpy V-notch toughness requirements must also be applied to structural members that are considered fracture critical. Table 6.6.2-1 provides minimum service temperatures for different temperature zones, and Table 6.6.2-2 provides the Charpy V-notch requirements for each service temperature. [2] 
Table 2-8 Chapter 2 Equation Legend

\begin{tabular}{|c|c|}
\hline Chapter 2 Equation & AASHTO $5^{\text {th }}$ Edition Equation \\
\hline Eq. 2.1 & 1.3.2.1-1 \\
\hline Eq. 2.2 & C4.6.2.2.2d-1 \\
\hline Eq. 2.3 & 2.5.2.6.2 \\
\hline Eq. 2.4 & 6.10.2.1.1-1 \\
\hline Eq. 2.5 & 6.10.2.1.2-1 \\
\hline Eq. 2.6 & $6.10 .2 .2-1$ \\
\hline Eq. 2.7 & 6.10.2.2-2 \\
\hline Eq. 2.8 & $6.10 .2 .2-3$ \\
\hline Eq. 2.9 & $6.10 .2 .2-4$ \\
\hline Eq. 2.10 & 6.10.6.2.2-1 \\
\hline Eq. 2.11 & 6.10.7.3-1 \\
\hline Eq. 2.12 & 6.10.7.1.1-1 \\
\hline Eq. 2.13 & 6.10.7.1.2-1 \\
\hline Eq. 2.14 & 6.10.7.1.2-2 \\
\hline Eq. 2.15 & 6.10.7.1.2-3 \\
\hline Eq. 2.16 & 6.10.7.2.1-1 \\
\hline Eq. 2.17 & 6.10.7.2.1-2 \\
\hline Eq. 2.18 & 6.10.7.2.2-1 \\
\hline Eq. 2.19 & 6.10.7.2.2-2 \\
\hline Eq. 2.20 & 6.10.2.1.1-1 \\
\hline Eq. 2.21 & 6.10.1.10.2-1 \\
\hline Eq. 2.22 & 6.10.1.10.2-2 \\
\hline Eq. 2.23 & 6.10.1.10.2-3 \\
\hline Eq. 2.24 & 6.10.1.10.2-4 \\
\hline Eq. 2.25 & 6.10.1.10.2-5 \\
\hline Eq. 2.26 & 6.10.1.10.2-6 \\
\hline Eq. 2.27 & 6.10.1.9.2-1 \\
\hline Eq. 2.28 & 6.10.1.9.2-2 \\
\hline Eq. 2.29 & D6.3.1-1 \\
\hline Eq. 2.30 & 6.10.1.10.1-1 \\
\hline Eq. 2.31 & 6.10.1.10.1-2 \\
\hline Eq. 2.32 & 6.10.6.2.3-1 \\
\hline Eq. 2.33 & 6.10.6.2.3-2 \\
\hline Eq. 2.34 & 6.10.8.1.1-1 \\
\hline Eq. 2.35 & 6.10.8.1.2-1 \\
\hline Eq. 2.36 & 6.10.8.1.3-1 \\
\hline Eq. 2.37 & 6.10.8.2.2-1 \\
\hline Eq. 2.38 & 6.10.8.2.2-2 \\
\hline Eq. 2.39 & 6.10.8.2.2-3 \\
\hline
\end{tabular}




\begin{tabular}{|c|c|}
\hline Chapter 2 Equation & AASHTO $5^{\text {th }}$ Edition Equation \\
\hline Eq. 2.40 & $6.10 .8 .2 .2-4$ \\
\hline Eq. 2.41 & 6.10.8.2.2-5 \\
\hline Eq. 2.42 & 6.10.8.2.3-1 \\
\hline Eq. 2.43 & $6.10 .8 .2 .3-2$ \\
\hline Eq. 2.44 & $6.10 .8 .2 .3-3$ \\
\hline Eq. 2.45 & $6.10 .8 .2 .3-4$ \\
\hline Eq. 2.46 & $6.10 .8 .2 .3-5$ \\
\hline Eq. 2.47 & 6.10.8.2.3-6 \\
\hline Eq. 2.48 & 6.10.8.2.3-7 \\
\hline Eq. 2.49 & $6.10 .8 .2 .3-8$ \\
\hline Eq. 2.50 & 6.10.8.2.3-9 \\
\hline Eq. 2.51 & 6.10.8.3-1 \\
\hline Eq. 2.52 & 6.10.9.1-1 \\
\hline Eq. 2.53 & 6.10.9.2-1 \\
\hline Eq. 2.54 & 6.10.9.2-2 \\
\hline Eq. 2.55 & 6.10.9.3.2-4 \\
\hline Eq. 2.56 & 6.10.9.3.2-5 \\
\hline Eq. 2.57 & 6.10.9.3.2-6 \\
\hline Eq. 2.58 & 6.10.9.3.2-7 \\
\hline Eq. 2.59 & 6.10.9.3.2-1 \\
\hline Eq. 2.60 & 6.10.9.3.2-2 \\
\hline Eq. 2.61 & $6.10 .9 .3 .2-3$ \\
\hline Eq. 2.62 & $6.10 .3 \cdot 2 \cdot 1-1$ \\
\hline Eq. 2.63 & $6.10 .3 \cdot 2 \cdot 1-2$ \\
\hline Eq. 2.64 & 6.10.3.2.1-3 \\
\hline Eq. 2.65 & 6.10.1.6-1 \\
\hline Eq. 2.66 & 6.10.3.2.2-1 \\
\hline Eq. 2.67 & 6.10.3.2.3-1 \\
\hline Eq. 2.68 & $6.10 .4 .2 .2-1$ \\
\hline Eq. 2.69 & $6.10 .4 .2 .2-2$ \\
\hline Eq. 2.70 & $6.10 .4 .2 .2-3$ \\
\hline Eq. 2.71 & 6.10.4.2.2-4 \\
\hline Eq. 2.72 & 6.10.1.9.1-1 \\
\hline Eq. 2.73 & 6.6.1.2.2-1 \\
\hline Eq. 2.74 & 6.6.1.2.5-2 \\
\hline Eq. 2.75 & 6.6.1.2.5-3 \\
\hline Eq. 2.76 & 6.10.5.3-1 \\
\hline
\end{tabular}




\section{Chapter 3: Steel Bridge Survey}

\subsection{Introduction}

A survey was developed at West Virginia University in association with the Short Span Steel Bridge Alliance in order to obtain information about the practices and trends of state transportation departments with respect to the design and construction of short span bridges. Of the fifty states queried, survey responses were received from 43 different states providing an overall response rate of 86 .

The questions of the survey ranged from the material used for bridge superstructures in the last year to the use of bridge design standards and recommendations for bridge design. Appendix A provides a copy of the survey and copies of all received survey responses. The following sections present an overview of the questions and responses.

\subsection{Questions 1 and 2: Recent Short Span Bridges Constructed}

The first two questions of the survey focused on recent short span bridge projects constructed in each state. Of the states that responded to the survey, several provided either direct values or a collection of data that would yield trends in short span bridges built in the last year. The data was separated into categories of superstructure material and span length. Table 3-1 and Table 3-2 below provide a summary of the construction trends of the United States in the area of short span bridges. Due to the large amount of skew caused by the state of California, the percentages are provided for all states that responded and for all states that responded excluding California.

Table 3-1 Bridges Constructed Last Year (Including California)

\begin{tabular}{|c|c|c|}
\hline $\begin{array}{c}\text { Length } \\
\text { Category }\end{array}$ & $\begin{array}{c}\text { Number of } \\
\text { Bridges }\end{array}$ & Percentage Steel \\
\hline$<40 \mathrm{ft}$ & 1418 & $7 \%$ \\
\hline $40-60 \mathrm{ft}$ & 723 & $5 \%$ \\
\hline $60-80 \mathrm{ft}$ & 788 & $4 \%$ \\
\hline $80-100 \mathrm{ft}$ & 872 & $5 \%$ \\
\hline $100-120 \mathrm{ft}$ & 935 & $5 \%$ \\
\hline $120-140 \mathrm{ft}$ & 1146 & $6 \%$ \\
\hline Total & 5882 & $4 \%$ \\
\hline
\end{tabular}


Table 3-2 Bridges Constructed Last Year (Excluding California)

\begin{tabular}{|c|c|c|}
\hline $\begin{array}{c}\text { Length } \\
\text { Category }\end{array}$ & $\begin{array}{c}\text { Number of } \\
\text { Bridges }\end{array}$ & Percentage Steel \\
\hline$<40 \mathrm{ft}$ & 300 & $9 \%$ \\
\hline $40-60 \mathrm{ft}$ & 180 & $14 \%$ \\
\hline $60-80 \mathrm{ft}$ & 168 & $11 \%$ \\
\hline $80-100 \mathrm{ft}$ & 139 & $17 \%$ \\
\hline $100-120 \mathrm{ft}$ & 157 & $15 \%$ \\
\hline $120-140 \mathrm{ft}$ & 150 & $21 \%$ \\
\hline Total & 1094 & $14 \%$ \\
\hline
\end{tabular}

\subsection{Question 3: Preferred/Specified Types of Design}

The third question of the survey related to each state's bridge design practices. Where the first questions asked for the trends of superstructure material use in different spans of bridges, this question focuses on design choices that each state makes when designing various components. For the first element of the question, options were given to help the engineer understand the types of answers expected. This section provides an overview of responses for each bridge component queried in the question.

\subsubsection{Decking Systems}

The first design preference questioned was the decking systems used on bridges. The question specifically asked about the preferences in regards to cast-in-place concrete, precast concrete panels and steel stay-in-place formwork where the engineer could list all of the systems that they apply. In response to which systems the states use: over $90 \%$ of states responded castin-place concrete, 50\% stated stay-in-place formwork and approximately $26 \%$ responded with precast concrete panels. Approximately one-third of the states that responded, stated not using steel stay-in-place formwork, approximately $19 \%$ stated that they do not use at one form of precast concrete deck panels (full-depth or partial-depth are both discussed in Chapter Four) and approximately $5 \%$ of states mentioned that they do not utilize timber decks on short span bridges.

\subsubsection{Railing/Guardrail Systems}

The second design preference that was questioned was the railing and guardrail systems used for bridges. Over $77 \%$ of states that responded to this question listed concrete traffic barriers, primarily New Jersey and F-Shape barriers (explained in Chapter Four). Approximately $10 \%$ specifically mentioned steel railings as being used by their state. Very few states specified railing systems that their state disapproved the use of. 


\subsubsection{Topping and Wearing Surface}

The topping and wearing surfaces that were queried in the third part of the question referred to the preference of each state on what method they chose to apply to the top surface of the bridge deck to account for damages caused by vehicular traffic. Approximately 68\% replied that concrete was the only decking material used in their bridge design. Another 24\% refer to the use of either latex or epoxy as being used as part of the wearing surface (sometimes in combination with either cast-in-place concrete or hot mix asphalt). Few states referred to the use of hot mix asphalt or an additional concrete overlay as the wearing surface. Approximately 19\% of states responded that they do not allow the use of hot-mix-asphalt (either with or without latex membrane) on their bridge decks.

\subsubsection{Bridge Superstructures}

This part of the question asked the engineer performing the survey to specify what type of bridge superstructures that their state preferred to use in their bridge designs. Approximately $68 \%$ of states mentioned at least one form of prestressed and/or precast concrete girder system for the superstructure preference. Also, approximately 38\% of states referred to steel girders as one of their preferred superstructure options for short span bridges. Few states mentioned superstructure systems that their state disapproved of, but the systems that were mentioned include: fracture critical steel sections, conventional reinforced concrete and timber superstructures.

\subsubsection{Abutments}

The next section of the question asked the engineer for their state's preferences in bridge abutments. Approximately $81 \%$ of states responded with a concrete abutment system, most of which referred to either integral or semi-integral abutment systems (described in Chapter Four). Most of the other states referred to either a stub abutment, sheet pile wall system or mechanically stabilized earth systems. Only one state responded that they disapprove of mechanically stabilized earth wall systems when there is pile cap on piles to support the bridge.

\subsubsection{Pier Systems}

The last section of Question Three asks the engineer to describe their state's preferences in regards to pier systems for bridges. Approximately 58\% of states mentioned reinforced concrete as making up all or at least part of their pier systems. Specific designs that were mentioned include pile bent, or multi-column, systems (48\%) and hammerhead, or T-Pier, systems (12\%). 
Few states provided pier systems that their state disapproved of, but the systems that were mentioned include timber piles and concrete pier systems.

\title{
3.4 Question 4: Typical Cross-Sections and Girder Spacings
}

This question of the survey focused on state's bridge design aids that they employ in practice. The question was looking for pre-designed bridge cross-sections or details used to make a standard cross- section (girder spacing, lane width, etc). This section describes the answers received for this question and provides examples where applicable.

\begin{abstract}
Alabama
Mr. John Black, State Bridge Engineer at the Alabama Department of Transportation, responded in the survey that the state of Alabama uses standard gutter to gutter dimensions with corresponding girder spacings depending on the intended number of lanes on the bridge. His response stated:

- For 2 lane bridges, 40’ gutter to gutter, 7 foot girder spacing

- For 4 lane bridges, 44’ gutter to gutter, 8 foot girder spacing

Reviewing the Alabama Department of Transportation Bridge Bureau Structures Design and Detail Manual, a design aid for designing the deck was provided. This design aid gives a minimum deck thickness and a steel reinforcing design based on the girder spacing. This design aid can be seen in Figure 3-1.
\end{abstract}




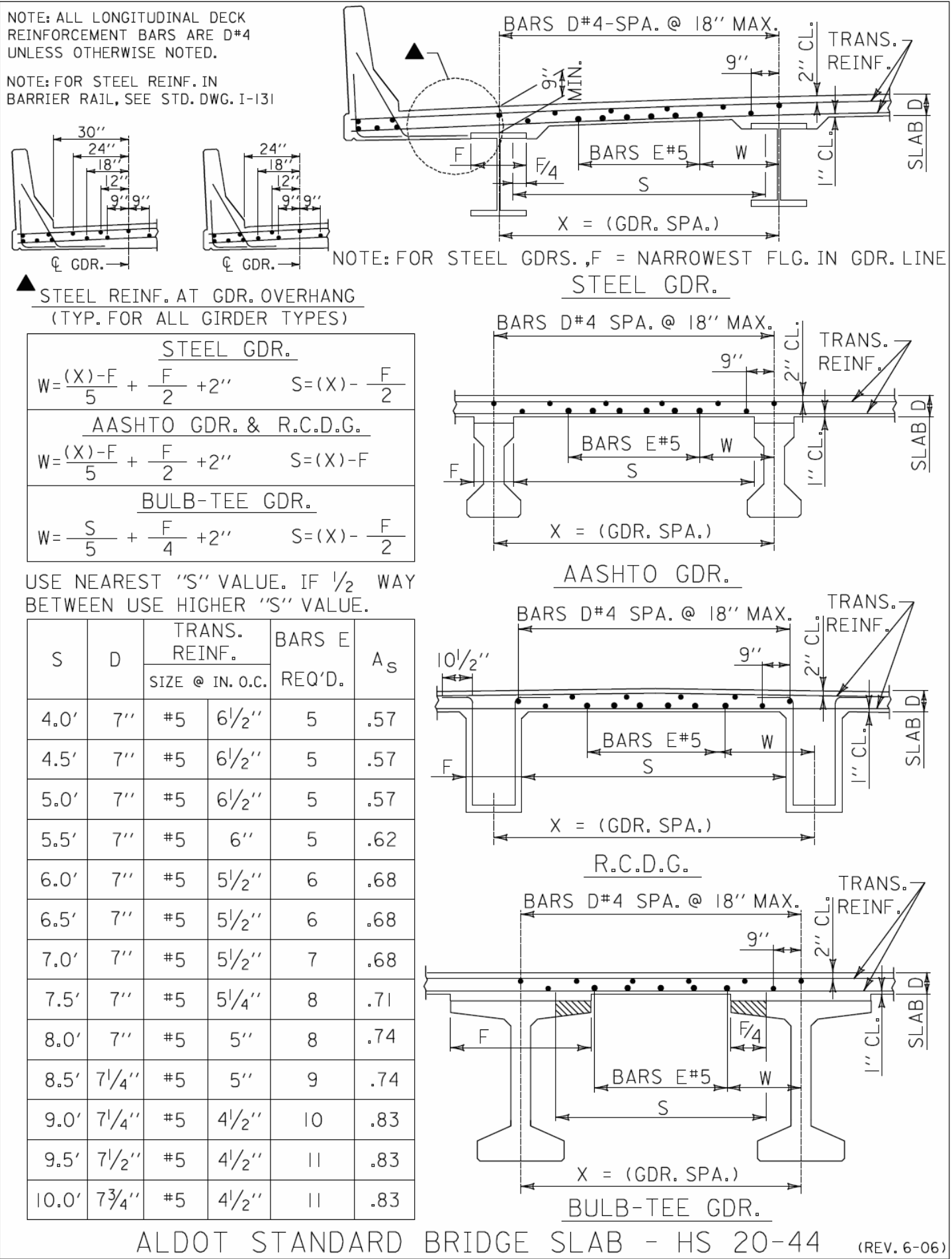

Figure 3-1 Alabama Bridge Deck Design Aid 


\section{Delaware}

Mr. Jiten Soneji, a Bridge Design Engineer at the Delaware Department of Transportation, responded in the survey that the Delaware "Bridge Design Manual gives ranges for what is acceptable” when it comes to cross-section dimensions. Reviewing the Delaware Department of Transportation Bridge Design Manual, recommended girder spacing ranges were found. The Manual suggested:

- Minimum Steel Beam Spacing: 8'-0”

- Desirable Steel Beam Spacing: 9'-0”

- Maximum Steel Beam Spacing: 10’-0”

The Manual includes an exception that in cases "where vertical clearance is not a problem, a wider maximum spacing (up to $12^{\prime}-6$ ”) may be justified with the approval of the Bridge Design Engineer on a case-by-case basis.”

\section{Kansas}

Mr. John Jones, a Manuals, Modeling and Policy Engineer at the Kansas Department of Transportation, referenced the Kansas Department of Transportation Design Manual as his response for this question. Reviewing Volume III of the Design Manual (Bridge Section), figures providing standard deck slabs for steel girder bridges were provided. These figures provide railing-to-railing (barrier-to-barrier) dimensions, girder spacings, overhang dimensions and typical decking designs. Another design aid was found that provides the designer with a figure that helps in determining the amount of reinforcing steel required for a bridge deck design. These design aids are provided in Figure 3-2 and Figure 3-3. 


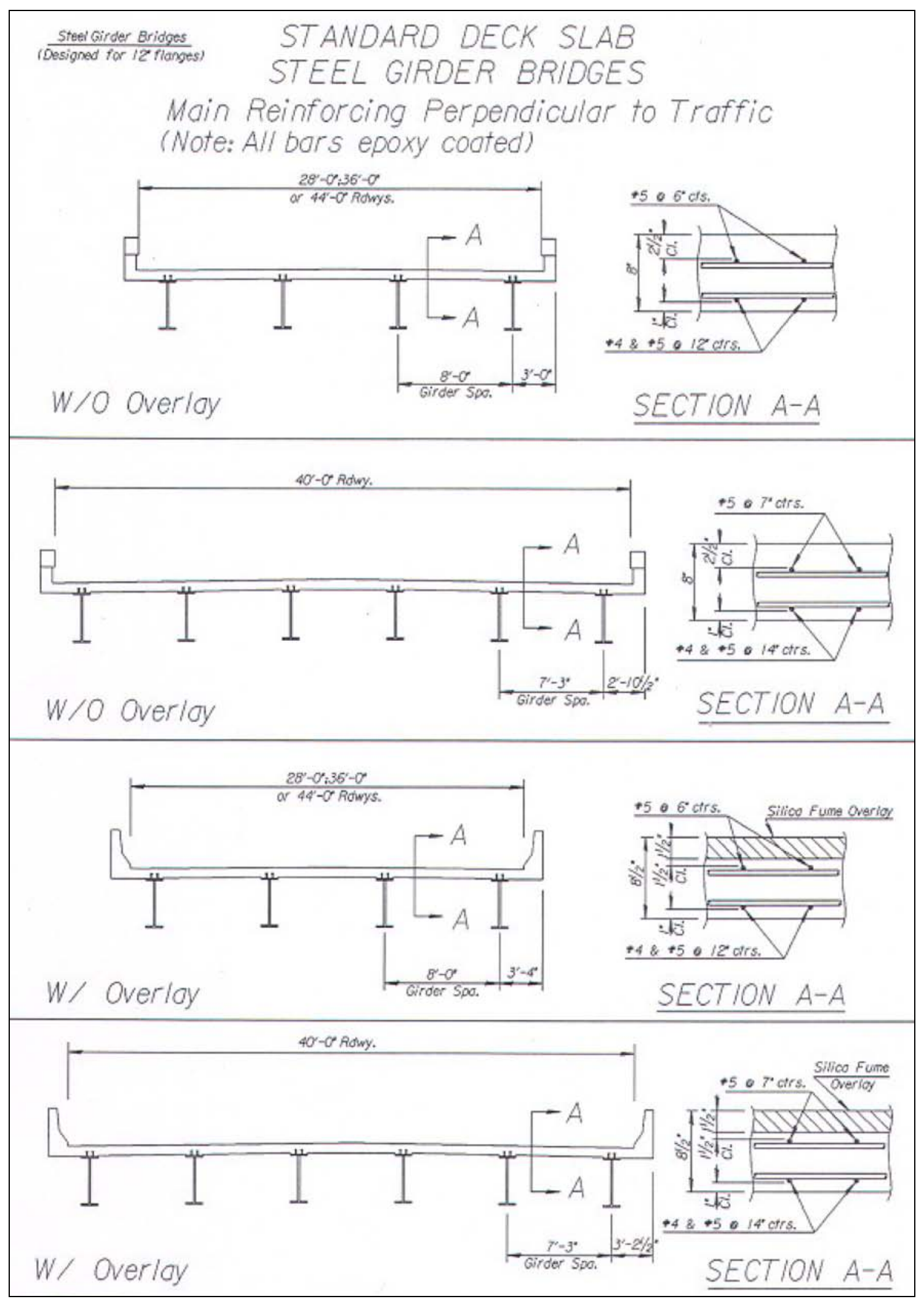

Figure 3-2 Kansas Standard Deck Slab Design Aid 


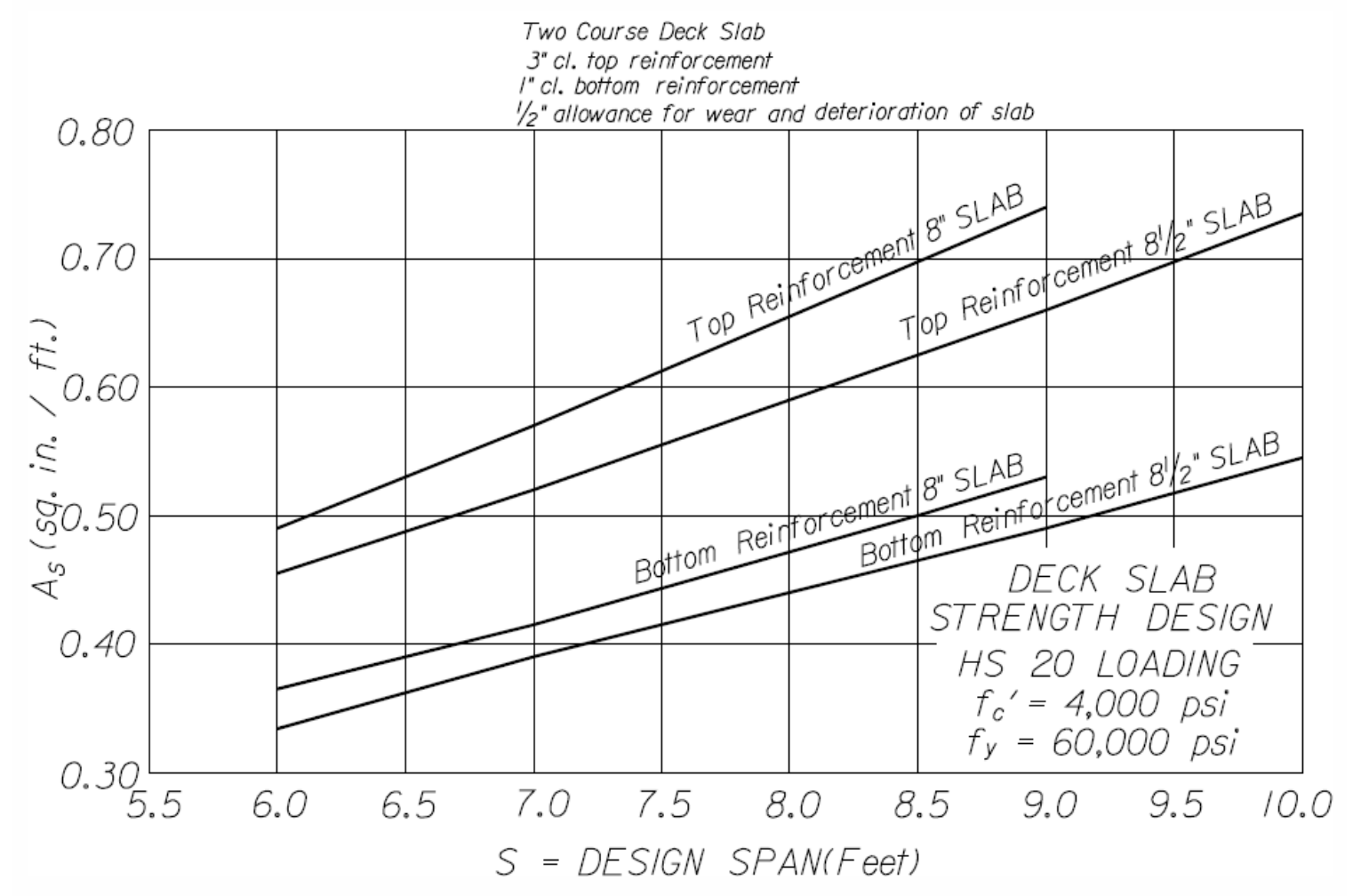

Figure 3-3 Kansas Deck Reinforcement Design Aid

\section{Michigan}

Mr. Steven Beck, a Bridge Design Supervising Engineer at the Michigan Department of Transportation, provided a link to a design aid used for designing the cross-section of bridges. Reviewing this design aid, it provides the designer with the means to determine the barrier-tobarrier distance of the bridge deck. This includes providing for lanes, shoulders and auxiliary lanes. An example of this design aid is provided in Figure 3-4. 


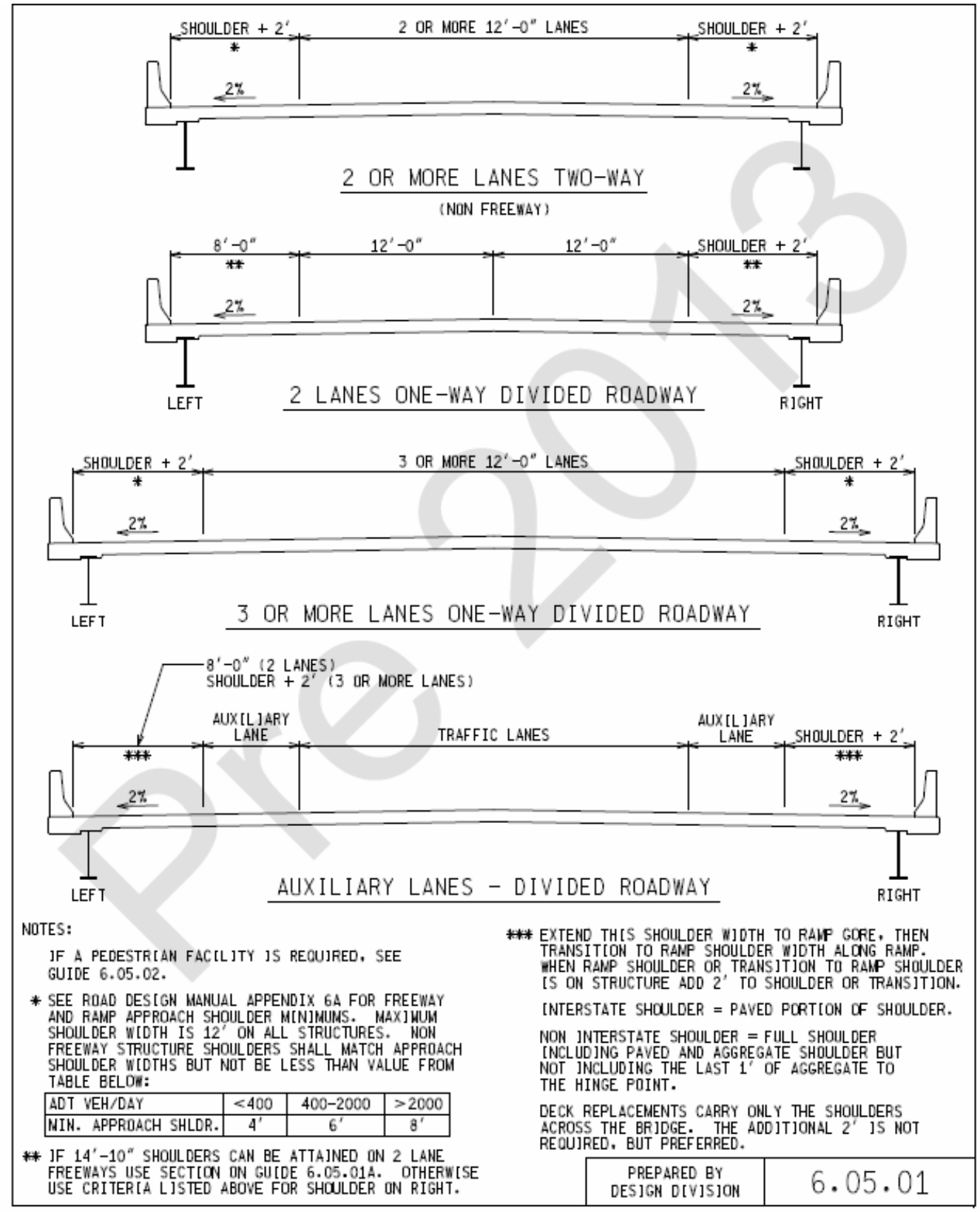

Figure 3-4 Michigan Cross-Section Design Aid

\section{Montana}

Mr. Kent Barnes, a Bridge Engineer at the Montana Department of Transportation, responded to the survey stating that the state of Montana has standard roadway widths for bridge design. Reviewing the Bridge Design Standards for the National Highway System (Interstate) posted on the Montana Department of Transportation web site; it provides a preferred roadway width of 38 feet for new bridges; this is comprised of: 
- $\quad$ One $4.0 \mathrm{ft}$ inside shoulder

- Two $12.0 \mathrm{ft}$ lanes, and

- $\quad$ One $10.0 \mathrm{ft}$ outside shoulder.

In Chapter 18 (Structural Steel Superstructures) of the Montana Structures Manual, it provides a recommended range for steel girder spacing. It states that the Montana Department of Transportation "uses girder spacings between $1.5 \mathrm{~m}(\sim 4.92 \mathrm{ft})$ and $4.5 \mathrm{~m}(\sim 14.76 \mathrm{ft})$ for most typical muli-girder steel bridges.”

\section{Nevada}

Mr. Todd Stefonowicz of the Structures Division of the Nevada Department of Transportation responded to the survey stating that Nevada uses standard girder spacings when designing bridges. The table that Mr. Stefonowicz referenced from the Nevada Structures Manual Chapter 11 (Preliminary Design) provided the following girder spacing ranges:

- Composite Steel Plate I-Girders: 8' - 14’

- Composite Steel Rolled Beams: 6’ - 10’

- Composite Steel Tub Girders Web-to-Web spacing: 8' - 12'

\section{North Dakota}

Mr. Terrence Underland, State Bridge Engineer at the North Dakota Department of Transportation, stated in his survey response that North Dakota's practice is to consider ADT and Roadway Classification when determining the roadway width. Further research into North Dakota's LRFD Bridge Design Manual provided the specific standards used for roadway widths. They specifically reference Exhibit 6-5 and Exhibit 6-6 from AASHTO's “A Policy on Geometric Design of Highways and Streets” with the exception of having a minimum road width of 40' for mainline interstate and railroad overheads. This 40' roadway provides for two 12' lanes, a 6' left shoulder, and a 12' right shoulder. A summary of the two referenced tables are provided in Table 3-3 and Table 3-4. 
Table 3-3 Minimum Width of Travelway for Specified Design Volume - North Dakota Design Aid

\begin{tabular}{|c|c|c|c|c|}
\hline & \multicolumn{4}{|c|}{ Minimum width of travelway (ft) for specified design volume (veh/day) } \\
\hline Design Speed (mph) & Under 400 & 400 to 1500 & 1500 to 2000 & Over 2000 \\
\hline 20 & $20^{\mathrm{b}}$ & 20 & 22 & 24 \\
\hline 25 & $20^{\mathrm{b}}$ & 20 & 22 & 24 \\
\hline 30 & $20^{\mathrm{b}}$ & 20 & 22 & 24 \\
\hline 35 & $20^{\mathrm{b}}$ & 22 & 22 & 24 \\
\hline 40 & $20^{\mathrm{b}}$ & 22 & 22 & 24 \\
\hline 45 & 20 & 22 & 22 & 24 \\
\hline 50 & 20 & 22 & 22 & 24 \\
\hline 55 & 22 & 22 & 24 & 24 \\
\hline 60 & 22 & 22 & 24 & 24 \\
\hline & 2.0 & $5.0^{\mathrm{c}}$ & 6.0 & 8.0 \\
\hline
\end{tabular}

a On roadways to be reconstructed, a 22-ft traveled way may be retained where the alignment and safety records are satisfactory.

b A 18-ft minimum width may be used for roadways with design volumes under 250 veh/day.

c Shoulder width may be reduced for design speeds greater than $30 \mathrm{mph}$ as long as a minimum roadway width of $30 \mathrm{ft}$ is maintained.

Table 3-4 Minimum Clear Roadway Width Based on Design Width

\begin{tabular}{|c|c|c|}
\hline $\begin{array}{c}\text { Design Volume } \\
\text { (veh/day) }\end{array}$ & $\begin{array}{c}\text { Minimum clear roadway width for } \\
\text { bridges }^{\text {a }}\end{array}$ & $\begin{array}{c}\text { Design loading structural } \\
\text { capacity }\end{array}$ \\
\hline 400 and under & Traveled way $+2 \mathrm{ft}$ (each side) & HS 20 \\
\hline 400 to 1500 & Traveled way $+3 \mathrm{ft}$ (each side) & HS 20 \\
\hline 1500 to 2000 & Traveled way $+4 \mathrm{ft}($ each side) & H \\
\hline Over 2000 & Approach roadway $(\text { width })^{\mathrm{b}}$ & HS 20 \\
\hline
\end{tabular}

a Where the approach roadway width (traveled way plus shoulders) is surfaced, that surface width should be carried across the structures.

b For bridges in excess of $100 \mathrm{ft}$ in length, the minimum width of traveled way plus $3 \mathrm{ft}$ on each side is acceptable. 


\section{Oklahoma}

Mr. Jack Schmeidel, Acting Assistant Division Engineer at the Oklahoma Department of Transportation, responded to the survey stating that the state of Oklahoma has a standard crosssection and a design aid that provides a specific rolled W-section for different span lengths. The standard cross-section is provided in Figure 3-5.

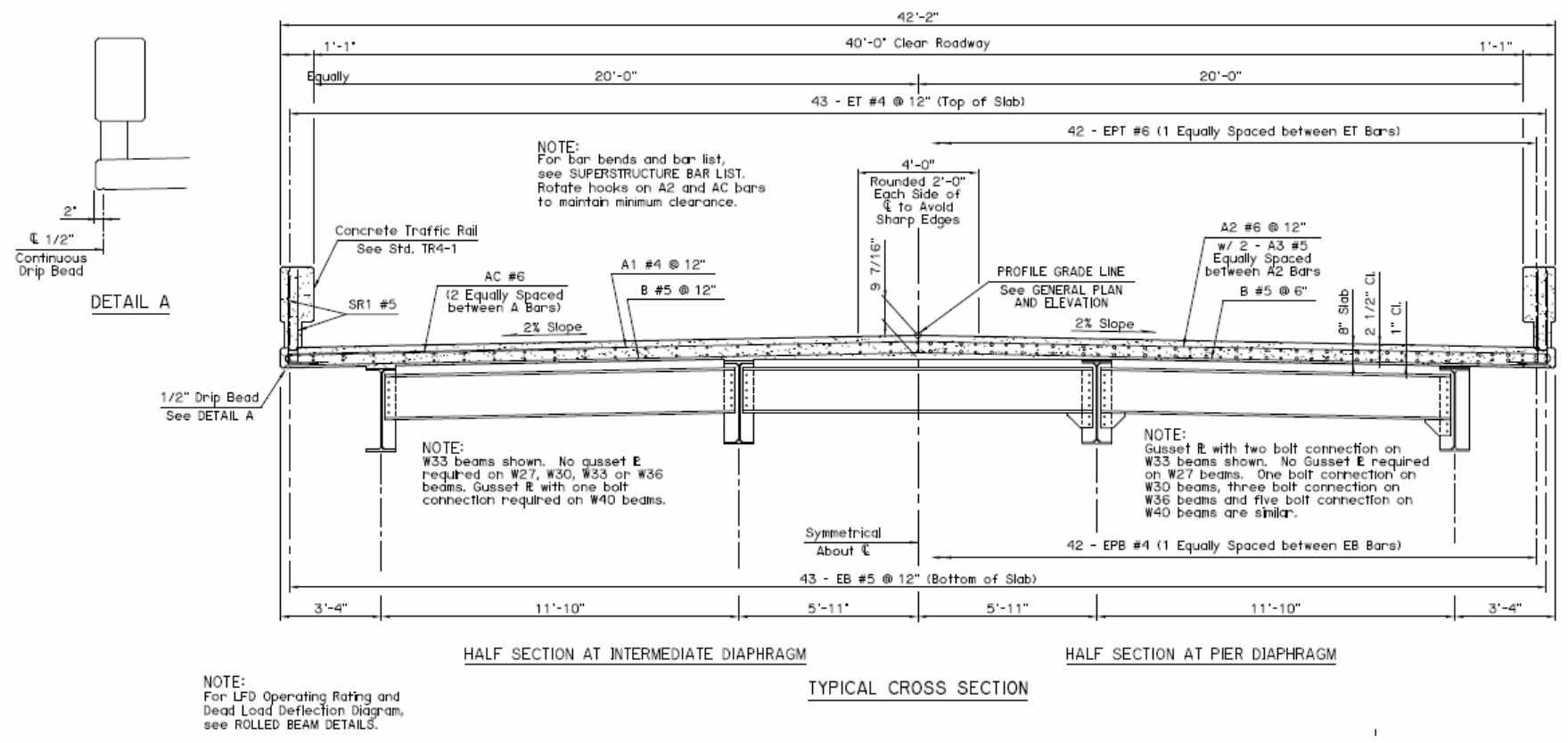

Figure 3-5 Oklahoma Standard Bridge Cross-Section Design Aid

\section{Oregon}

Mr. Bruce Johnson, State Bridge Engineer at the Oregon Department of Transportation, stated in the survey that the state of Oregon uses the recommendations of:

- Girder spacing for bridge spans less than 140': 10' - 12'

- Girder spacing for bridge spans larger than 140’: 11' - 14’

\section{Pennsylvania}

Mr. Tom Macioce, Chief Bridge Engineer at the Pennsylvania Department of Transportation, responded to the survey saying that Pennsylvania does not have any standard designs for bridge cross-section. He did continue by stating that typically, the range of girder spacings used by the state of Pennsylvania is between 10' and 14'. 


\section{South Carolina}

Mr. Barry Bowers, a Structural Design Support Engineer at the South Carolina Department of Transportation, provided a reference to the South Carolina Department of Transportation Bridge Design Manual in his survey response. Reviewing the referenced section, it states that "the typical girder spacing for SCDOT bridges is $7 \frac{1 / 2}{\mathrm{ft}}$ to $10 \mathrm{ft}$. The maximum spacing shall not exceed 10 1/2 ft.”

\section{Texas}

Mr. David Hohmann, Director of the Bridge Division at the Texas Department of Transportation, provided in his survey response links to standard cross-sections and design aids for superstructure selection that the state of Texas uses for bridge design. An example of one of their standard cross-sections is provided in Figure 3-6.

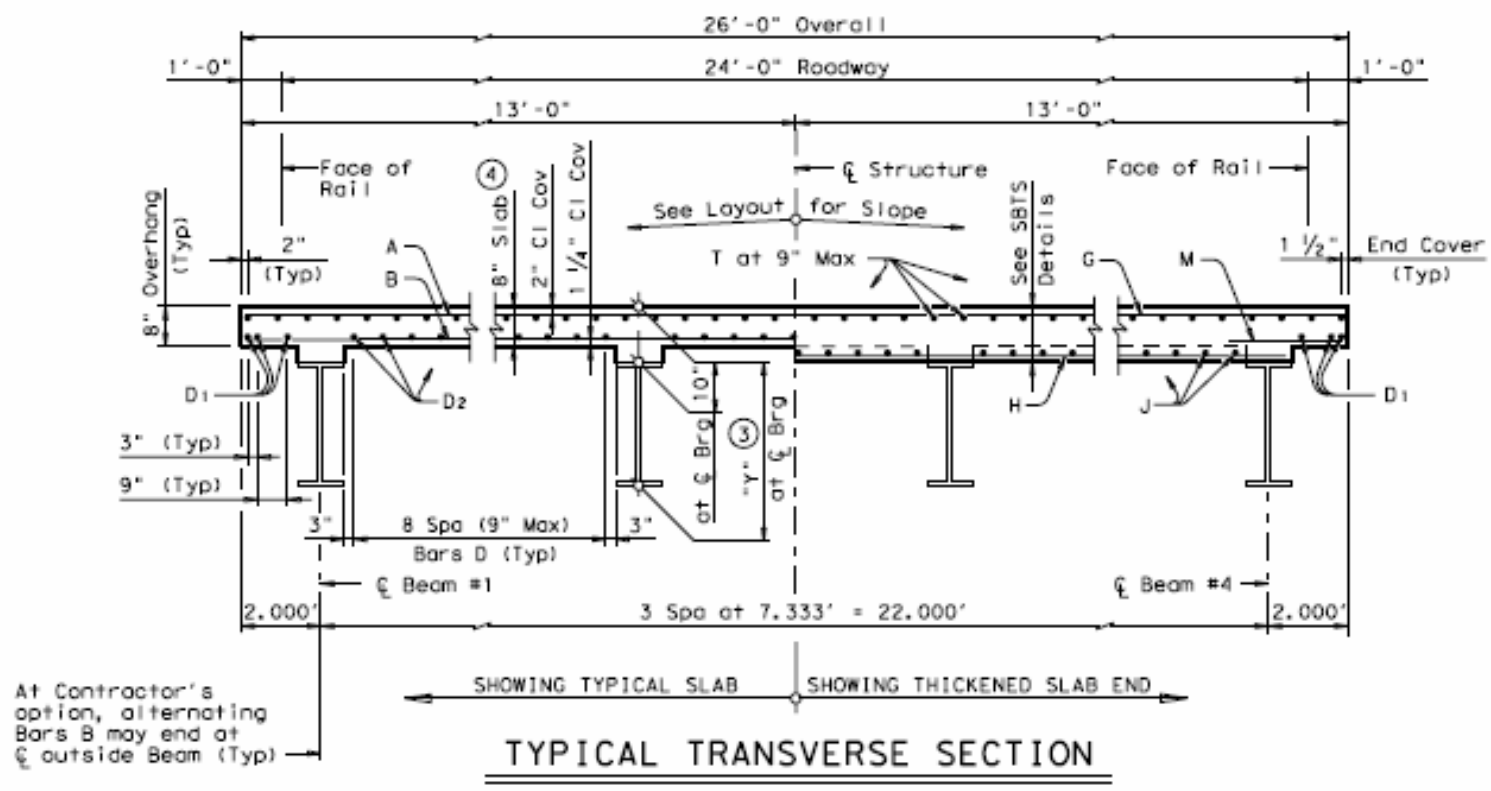

\section{Figure 3-6 Texas Typical Transverse Section Example $24 \mathrm{ft}$ Width}

\section{Wyoming}

Mr. Gregg Fredrick, State Bridge Engineer at the Wyoming Department of Transportation, provided a table in his survey response that provides several dimensions of the bridge cross-section based on the roadway width. A summary of this table is provided in Table 3-5. 
Table 3-5 Wyoming Cross-Section Design Aid

\begin{tabular}{|c|c|c|c|c|c|c|c|}
\hline \multicolumn{9}{|c|}{ Table of Girder Spacing } \\
\hline $\begin{array}{c}\text { Clear } \\
\text { Roadway } \\
\text { Width }\end{array}$ & $\begin{array}{c}\text { Out-Out } \\
\text { Width }\end{array}$ & $\begin{array}{c}\text { Number of Girders } \\
\text { Fide }\end{array}$ & $\begin{array}{c}\text { Welded } \\
\text { Flange }\end{array}$ & $\begin{array}{c}\text { Wider } \\
\text { Flange }\end{array}$ & $\begin{array}{c}\text { Welded } \\
\text { Plate }\end{array}$ & $\begin{array}{c}\text { Wide } \\
\text { Flange }\end{array}$ & $\begin{array}{c}\text { Welded } \\
\text { Plate }\end{array}$ \\
\hline $26.00 \mathrm{ft}$ & $29.33 \mathrm{ft}$ & 4 & 4 & $8.00 \mathrm{ft}$ & $7.50 \mathrm{ft}$ & $2.67 \mathrm{ft}$ & $3.42 \mathrm{ft}$ \\
\hline $28.00 \mathrm{ft}$ & $31.33 \mathrm{ft}$ & 4 & 4 & $8.50 \mathrm{ft}$ & $8.00 \mathrm{ft}$ & $2.92 \mathrm{ft}$ & $3.67 \mathrm{ft}$ \\
\hline $30.00 \mathrm{ft}$ & $33.33 \mathrm{ft}$ & 4 & 4 & $9.25 \mathrm{ft}$ & $8.50 \mathrm{ft}$ & $2.79 \mathrm{ft}$ & $3.92 \mathrm{ft}$ \\
\hline $32.00 \mathrm{ft}$ & $35.33 \mathrm{ft}$ & 5 & 4 & $7.50 \mathrm{ft}$ & $9.50 \mathrm{ft}$ & $2.67 \mathrm{ft}$ & $3.42 \mathrm{ft}$ \\
\hline $34.00 \mathrm{ft}$ & $37.33 \mathrm{ft}$ & 5 & 5 & $8.00 \mathrm{ft}$ & $7.50 \mathrm{ft}$ & $2.67 \mathrm{ft}$ & $3.67 \mathrm{ft}$ \\
\hline $36.00 \mathrm{ft}$ & $39.33 \mathrm{ft}$ & 5 & 5 & $8.50 \mathrm{ft}$ & $8.00 \mathrm{ft}$ & $2.67 \mathrm{ft}$ & $3.67 \mathrm{ft}$ \\
\hline $38.00 \mathrm{ft}$ & $41.33 \mathrm{ft}$ & 5 & 5 & $9.00 \mathrm{ft}$ & $8.50 \mathrm{ft}$ & $2.67 \mathrm{ft}$ & $3.67 \mathrm{ft}$ \\
\hline $40.00 \mathrm{ft}$ & $43.33 \mathrm{ft}$ & 5 & 5 & $9.50 \mathrm{ft}$ & $9.00 \mathrm{ft}$ & $2.67 \mathrm{ft}$ & $3.67 \mathrm{ft}$ \\
\hline $42.00 \mathrm{ft}$ & $45.33 \mathrm{ft}$ & 6 & 5 & $8.00 \mathrm{ft}$ & $9.50 \mathrm{ft}$ & $2.67 \mathrm{ft}$ & $3.67 \mathrm{ft}$ \\
\hline
\end{tabular}

\subsection{Question 5: Low-Volume Road Standards}

Continuing the questioning on bridge design practices, the fifth question of the survey asked the engineer if their state has standards or design methods specifically for bridges built on low-volume roads. Of the states that responded to this question, over 52\% said that they did not have any standards or design methods specifically for low-volume road bridges. Of the states that said that there were differences in how they design these types of bridges, $60 \%$ specifically mention that there are differences in the geometry of the bridge and roadway. Another 20\% specifically mention differences in traffic barriers or wearing surfaces used on these bridges. The rest of the responses either refer to specific types of bridges, the use of the AASHTO design guide or variations in the design process of these bridges (importance factor, do not employ overload vehicle, etc.)

\subsection{Question 6: Analysis and Design Software}

Question 6 of the survey asks the engineer what analysis and design software they employ in their bridge design process. Each state provided a list of programs that they use. Provided below are the top five most commonly used software packages with descriptions of each program.

The most common software company listed was Bentley with over $51 \%$ of responding states listing at least one Bentley program utilized for bridge designs. The comprehensive software package of LEAP Bridge is composed of several component design programs including: CONSPAN, CONBOX, RC-PIER and CONSYS. Each of these software packages provide analysis and design aids for different specific components of a bridge. CONSPAN aids in 
analyzing and designing simple-span and multiple-span prestressed beams for bridges; CONBOX aids in analyzing and designing post-tensioned and cast-in-place reinforced concrete box girder and slab bridges; RC-PIER aids in the analysis and design of reinforced concrete substructures; and CONSYS aids in LRFD live load and static load analysis of a bridge.

The next two most common software aids listed in survey responses had an equal number of references in survey results. The first software aid listed was in-house programs with over $38 \%$ of responding states answering with this response. These analysis and design tools are composed of programs developed for the specific bridge office using tools such as Microsoft Excel, MathCAD, Visual Basic, etc. With these programming tools, several calculation sets can be performed efficiently and are fully customizable for the needs and preferences of a specific office.

Merlin-Dash had an equal number of responses as in-house programs. Merlin-Dash is an overall design/analysis software program which has the ability to aid in dead load and live load analysis, determination of structural member size, check of AASHTO codes for all members, inventory and operating rating of all beam components and a total dead load pouring sequence stage analysis.

The next most common software mentioned in survey responses was the MDX Software package. This tool is able to aid the engineer in analyzing and/or designing straight or curved steel girder bridges according to ASD, LFD or LRFD specifications. It allows the engineer to specify hand-calculated loads or input parameters to allow the program to determine loads for the analysis of the bridge. The program selects steel member sizes based on user specifications and provides a rating of the girder selected. It can be used to analyze either a single girder or the entire girder system of a bridge.

The fifth most common software package mentioned in the survey results was the AASHTOWare programs of Virtis and/or Opis with over 25\% of responding states listing these as design aids. The two programs provide the engineer the ability to analyze reinforced concrete (both prestressed and non-prestressed) and steel girder bridges. Virtis provides the engineer with a means to analyze and rate these bridges using LFD and ASD ratings. Opis, using similar technologies, aids the engineer in the design of these bridges by providing AASHTO LRFD ratings and several other design tools. 


\subsection{Question 7: Design/Component Standards}

Several states have predesigned bridge components that are regularly used in the overall bridge design process including: substructure elements, superstructure elements, traffic barriers, etc. This section focuses on the superstructure design aids found for each state.

\section{Oklahoma}

Mr. Jack Schmeidel, Acting Assistant Division Engineer at the Oklahoma Department of Transportation, responded to the survey stating that the state of Oklahoma has a standard crosssection and a design aid that provides a specific rolled W-section for different span lengths. The standard cross-section is shown in Figure 3-5, page 46, and a summary of the design table is provided in Table 3-6 below:

Table 3-6 Summary of Oklahoma Table of Preselected Rolled Sections

\begin{tabular}{|c|c|}
\hline \multicolumn{2}{|c|}{ Rolled Sections } \\
\hline Span Length & Rolled Section \\
\hline $30 \mathrm{ft}$ & W27x84 \\
\hline $35 \mathrm{ft}$ & W30x90 \\
\hline $40 \mathrm{ft}$ & W30x99 \\
\hline $45 \mathrm{ft}$ & W30x116 \\
\hline $50 \mathrm{ft}$ & W33x130 \\
\hline $55 \mathrm{ft}$ & W36x135 \\
\hline $60 \mathrm{ft}$ & W36x150 \\
\hline $65 \mathrm{ft}$ & W40x167 \\
\hline $70 \mathrm{ft}$ & W40x183 \\
\hline $75 \mathrm{ft}$ & W40x199 \\
\hline $80 \mathrm{ft}$ & W40x215 \\
\hline $85 \mathrm{ft}$ & W40x249 \\
\hline $90 \mathrm{ft}$ & W40x277 \\
\hline $95 \mathrm{ft}$ & W40x297 \\
\hline $100 \mathrm{ft}$ & W40x324 \\
\hline
\end{tabular}

\section{South Carolina}

Mr. Barry Bowers, a Structural Design Support Engineer at the South Carolina Department of Transportation, provided a reference to the South Carolina Department of Transportation Bridge Design Manual in his survey response. Reviewing the referenced section of the manual, a table is provided relating the depth of the beam to the maximum deck overhang of the bridge deck. A summary of the table is provided in Table 3-7. 
Table 3-7 Summary of South Carolina Table of Deck Overhangs

\begin{tabular}{|c|c|}
\hline Depth of Beam $^{1}$ & Maximum Deck Overhang \\
\hline$<36$ in & Depth of Beam \\
\hline 36 in -48 in & 42 in \\
\hline$>48$ in & 45 in \\
\hline
\end{tabular}

${ }^{1}$ For structural steel plate girders, the web depth shall be used as the depth of beam.

\section{Texas}

Mr. David Hohmann, Director of the Bridge Division at the Texas Department of Transportation, provided in his survey response links to standard cross-sections and design aids for superstructure selection that the state of Texas uses for bridge design. An example of their standard cross-sections was provided in Figure 3-6, page 47, and a summary of the superstructure selection design aid for the pre-designed cross-sections is provided in Table 3-8. 
Table 3-8 Summary Texas Tables of Preselected Rolled Steel Sections

\begin{tabular}{|c|c|c|c|}
\hline \multicolumn{4}{|c|}{ Rolled Section } \\
\hline Span Length & $24 \mathrm{ft}$ Cross-Section & $28 \mathrm{ft}$ Cross-Section & $30 \mathrm{ft}$ Cross-Section \\
\hline \multirow{8}{*}{$30 \mathrm{ft}$} & W18x130 & W18x130 & W18x130 \\
\hline & W21x122 & W21x132 & W21x111 \\
\hline & W24x104 & W24x117 & W24x104 \\
\hline & W27x146 & W27x146 & W27x146 \\
\hline & W30x173 & W30x173 & W30x173 \\
\hline & W33x118 & W33x118 & W33x118 \\
\hline & W36x135 & W36x135 & W36x135 \\
\hline & W40x149 & W40x149 & W40x149 \\
\hline \multirow{8}{*}{$35 \mathrm{ft}$} & W18x130 & W18x130 & W18x130 \\
\hline & W21x122 & W21x132 & W21x111 \\
\hline & W24x104 & W24x117 & W24x104 \\
\hline & W27x146 & W27x146 & W27x146 \\
\hline & W30x173 & W30x173 & W30x173 \\
\hline & W33x118 & W33x118 & W33x118 \\
\hline & W36x135 & W36x135 & W36x135 \\
\hline & W40x149 & W40x149 & W40x149 \\
\hline \multirow{8}{*}{$40 \mathrm{ft}$} & W18x130 & W18x130 & W18x130 \\
\hline & W21x122 & W21x132 & W21x111 \\
\hline & W24x104 & W24x117 & W24x104 \\
\hline & W27x146 & W27x146 & W27x146 \\
\hline & W30x173 & W30x173 & W30x173 \\
\hline & W33x118 & W33x118 & W33x118 \\
\hline & W36x135 & W36x135 & W36x135 \\
\hline & W40x149 & W40x149 & W40x149 \\
\hline \multirow{8}{*}{$45 \mathrm{ft}$} & W18x130 & W18x130 & W18x130 \\
\hline & W21x122 & W21x132 & W21x111 \\
\hline & W24x104 & W24x117 & W24x104 \\
\hline & W27x146 & W27x146 & W27x146 \\
\hline & W30x173 & W30x173 & W30x173 \\
\hline & W33x118 & W33x118 & W33x118 \\
\hline & W36x135 & W36x135 & W36x135 \\
\hline & W40x149 & W40x149 & W40x149 \\
\hline \multirow{8}{*}{$50 \mathrm{ft}$} & W18x130 & W18x130 & W18x130 \\
\hline & W21x122 & W21x132 & W21x111 \\
\hline & W24x104 & W24x117 & W24x104 \\
\hline & W27x146 & W27x146 & W27x146 \\
\hline & W30x173 & W30x173 & W30x173 \\
\hline & W33x118 & W33x118 & W33x118 \\
\hline & W36x135 & W36x135 & W36x135 \\
\hline & W40x149 & W40x149 & W40x149 \\
\hline
\end{tabular}




\begin{tabular}{|c|c|c|c|}
\hline Span Length & $24 \mathrm{ft}$ Cross-Section & $28 \mathrm{ft}$ Cross-Section & $30 \mathrm{ft}$ Cross-Section \\
\hline \multirow{7}{*}{$55 \mathrm{ft}$} & W21x147 & W21x132 & W21x111 \\
\hline & W24x117 & W24x117 & W24x104 \\
\hline & W27x146 & W27x146 & W27x146 \\
\hline & W30x173 & W30x173 & W30x173 \\
\hline & W33x118 & W33x118 & W33x118 \\
\hline & W36x135 & W36x135 & W36x135 \\
\hline & W40x149 & W40x149 & W40x149 \\
\hline \multirow{7}{*}{$60 \mathrm{ft}$} & W21x166 & W21x166 & W21x132 \\
\hline & W24x146 & W24x131 & W24x117 \\
\hline & W27x146 & W27x146 & W27x146 \\
\hline & W30x173 & W30x173 & W30x173 \\
\hline & W33x118 & W33x118 & W33x118 \\
\hline & W36x135 & W36x135 & W36x135 \\
\hline & W40x149 & W40x149 & W40x149 \\
\hline \multirow{7}{*}{$65 \mathrm{ft}$} & & & W21x166 \\
\hline & W24x176 & W24x162 & W24x131 \\
\hline & W27x146 & W27x146 & W27x146 \\
\hline & W30x173 & W30x173 & W30x173 \\
\hline & W33x118 & W33x130 & W33x118 \\
\hline & W36x135 & W36x135 & W36x135 \\
\hline & W40x149 & W40x149 & W40x149 \\
\hline \multirow{6}{*}{$70 \mathrm{ft}$} & W24x207 & W24x207 & W24x162 \\
\hline & W27x178 & W27x178 & W27x146 \\
\hline & W30x173 & W30x173 & W30x173 \\
\hline & W33x130 & W33x141 & W33x118 \\
\hline & W36x135 & W36x135 & W36x135 \\
\hline & W40x149 & W40x149 & W40x149 \\
\hline \multirow{6}{*}{$75 \mathrm{ft}$} & & & W24x192 \\
\hline & W27x194 & W27x217 & W27x161 \\
\hline & W30x173 & W30x191 & W30x173 \\
\hline & W33x141 & W33x169 & W33x118 \\
\hline & W36x150 & W36x160 & W36x135 \\
\hline & W40x149 & W40x149 & W40x149 \\
\hline \multirow{6}{*}{$80 \mathrm{ft}$} & & & W24x229 \\
\hline & W27x235 & W27x235 & W27x194 \\
\hline & W30x211 & W30x191 & W30x173 \\
\hline & W33x169 & W33x201 & W33x152 \\
\hline & W36x150 & W36x170 & W36x150 \\
\hline & W40x149 & W40x167 & W40x149 \\
\hline \multirow{5}{*}{$85 \mathrm{ft}$} & & & W27x235 \\
\hline & W30x235 & W30x235 & W30x191 \\
\hline & W33x201 & W33x221 & W33x169 \\
\hline & W36x170 & W36x194 & W36x160 \\
\hline & W40x183 & W40x183 & W40x167 \\
\hline
\end{tabular}




\begin{tabular}{|c|c|c|c|}
\hline Span Length & $24 \mathrm{ft}$ Cross-Section & $28 \mathrm{ft}$ Cross-Section & $30 \mathrm{ft}$ Cross-Section \\
\hline \multirow{5}{*}{$90 \mathrm{ft}$} & & & W27x258 \\
\hline & W30x261 & W30x261 & W30x211 \\
\hline & W33x221 & W33x241 & W33x201 \\
\hline & W36x231 & W36x231 & W36x231 \\
\hline & W40x199 & W40x199 & W40x199 \\
\hline \multirow{3}{*}{$95 \mathrm{ft}$} & & & \\
\hline & W36x231 & W36x231 & W36x231 \\
\hline & W40x215 & W40x215 & W40x199 \\
\hline \multirow{3}{*}{$100 \mathrm{ft}$} & W33x291 & W33x291 & W33x241 \\
\hline & W36x262 & W36x231 & W36x231 \\
\hline & W40x215 & W40x2115 & W40x199 \\
\hline \multirow{3}{*}{$105 \mathrm{ft}$} & & & W33x263 \\
\hline & W36x302 & W36x247 & W36x231 \\
\hline & W40x249 & W40x249 & W40x215 \\
\hline \multirow{3}{*}{$110 \mathrm{ft}$} & & & W33x291 \\
\hline & & & W36x262 \\
\hline & W40x277 & W40x277 & W40x249 \\
\hline \multirow{2}{*}{$115 \mathrm{ft}$} & & & W36x302 \\
\hline & W40x324 & W40x297 & W40x249 \\
\hline $120 \mathrm{ft}$ & W40x362 & W40x324 & W40x277 \\
\hline
\end{tabular}

\section{Virginia}

Mr. Julius Volgyi, Assistant State Structure and Bridge Engineer at the Virginia Department of Transportation, referenced a design aid in his survey response that the state of Virginia uses for the design of bridge superstructures with timber decks. Mr. Volgyi also made mention of an outdated design aid for steel beam bridges with concrete decks. This second design aid helps the engineer determine several parameters of the bridge including: cross-section dimensions, girder dimensions, estimated quantities, etc.

\subsection{Question 8: Modular Bridge Use}

Question 8 of the survey asks the engineer if their state employs modular bridge systems. This refers to the use of modular bridge technology for temporary and/or permanent bridges. Of the states that responded to this question of the survey, over $47 \%$ stated that there state has not yet used modular bridges. Of the remaining states, about $41 \%$ referred to using modular bridges for emergencies, detours or other temporary bridge replacement situations. Another $9 \%$ specified only using modular bridges for research purposes at this time. 


\subsection{Question 9: Expectations of a Best Practices Manual}

Question 9 is the first of two questions that specifically refer to a Best Practices Manual that was the anticipated result of this research. The question introduces the manual that the Short Span Steel Bridge Alliance intended to develop and asks each engineer to describe any and all

components that they feel would be beneficial to include in the manual. Most of the states provided varying responses of what they would like to see in the manual. Common responses for the manual included: pre-selected steel beam shapes, connection details and interaction between the substructure and superstructure of the bridge. Other less common requests included: substructure units, details for simple for dead/continuous for live load design and plans for emergency bridge replacement using modular bridges.

\subsection{Question 10: AASHTO LRFD Load Factors/Combinations}

Question 10 of the survey asked the engineer what design loads and combinations their state uses in the bridge design process. This question asked if the loads and load combinations specified in the AASHTO Specifications are the only ones used in bridge design or if the state has any specific changes that they make. Of the states that responded to the question, one state mentioned that they have not fully implemented Load and Resistance Factor Design into their regular bridge design practices. About $79 \%$ of the states that responded stated that they use LRFD design with no variation. Another 16\% utilize LRFD but have made alterations specific for their state. These changes typically involved either increasing the design truck or live load factors. Also, some states have specific design vehicles and load cases that they also apply to the bridge in designing bridges.

\subsection{Question 11: Pre-Selected Steel Beam Table}

One of the recommendations mentioned in Question 9 for the Best Practices Manual was tables of pre-selected steel girders. Question 11 of the survey asks the engineer specifically if they believe that these tables being available could be useful for the bridge design process. Of the states that responded to this question, approximately $61 \%$ responded that they foresaw these tables being useful in aiding in the design of short span bridges. Of the states that said that they saw these tables as being useful, several mentioned that it would be useful in selecting a preliminary section to begin the analysis of the bridge.

\subsection{Question 12: Preferred Material Choice}

This question asks the bridge engineer if their state preferred certain superstructure material over alternatives and the reasoning behind this preference. Trends can be found based 
on the answers to earlier questions of the survey, but this question specifically asks for an explanation for this preference. The responses to this question did show a similar trend to the first two questions of the survey in that approximately $81 \%$ of states responded that they prefer concrete superstructures for bridges in the span ranges being studied. Only 5\% of states actually specified their material preference to be steel. The remaining $14 \%$ stated that their states do not have a preference on material and generally use whichever is most cost efficient for the situation. A majority of the states referred to cost when describing the reason for their preference in material; another important reasoning for the state's preference was directly related to the availability of specific materials.

\subsection{Question 13: Additional Comments}

This question provides the engineer an opportunity to provide any additional opinions they would like to mention. Responses to this question varied greatly between topics such as general comments about the bridge industry, recommended research topics and comments about previous responses to the survey.

\subsection{Question 14: Information Sources}

The final question of the survey asked the engineer to provide the sources where they receive bridge design and construction technical information and industry news. A collection of example publications, newsletters and websites were provided to allow the engineer to select sources from the lists. The opportunity for the engineer to write in responses was also provided for each type of source. For publications as information sources, 58\% of states responded Roads and Bridges Magazine, 52\% responded Engineering News-Record Magazine, 42\% responded Better Roads Magazine and 10\% responded Civil Engineering Magazine. For conferences as information sources, $30 \%$ of states responded that they attend AASHTO conferences, 21\% responded with National Steel Bridge Alliance conferences and 18\% responded with Precast/Prestressed Concrete Institute conferences. Few states responded that organization newsletters are important information sources. The two most common sources of this medium were $15 \%$ of states responding that the National Steel Bridge Alliance newsletter is an important information source and 9\% responded that the Precast/Prestressed Concrete Institute newsletter is an important information source for their department. In the area of websites as an important source of information, 52\% of states responded the Federal Highway Administration's website, 30\% responded the American Iron and Steel Institute's website and 27\% responded the National Steel Bridge Alliance's website. Based on these responses, it can be seen which news sources the country’s bridge departments are using to stay current with design and construction practices. 


\section{Chapter 4: Modular Bridge Components and Systems}

\subsection{Introduction}

The Short Span Steel Bridge Alliance is a group comprised of manufacturers, fabricators and representatives of related government organizations and associations who are stake holders in short span steel bridges. The main focus of the group is to increase awareness of the unique benefits, cost-competitiveness and safety facts involved with the use of short span steel bridges for spans of up to 140 feet. [5]

The Short Span Steel Bridge Alliance promotes short span steel bridges that can be built quickly, using local crews and often can be designed with prefabricated elements which provide a simpler installation and cost savings. A figure from a Short Span Steel Bridge Alliance brochure, provided in Figure 4-1, presents a summary of the types of steel superstructures that can be applied to various bridge spans within the short span range. [5]

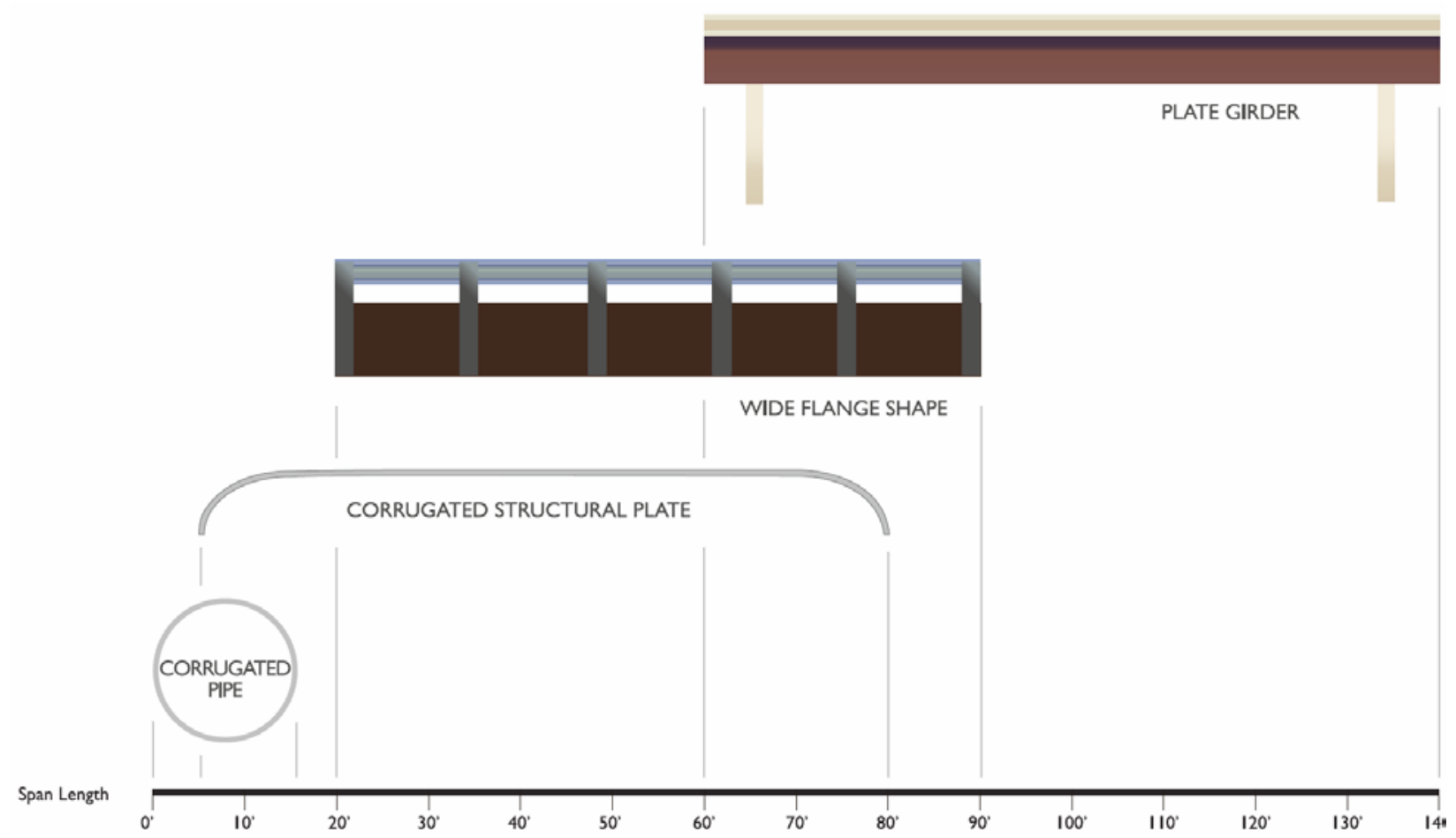

Figure 4-1 Steel Superstructures for Short Spans [46] 
The Federal Highway Administration (FHWA) has recently developed a program that they have titled Highways for LIFE with the word "LIFE" being an acronym for:

\section{Long Lasting \\ Innovative \\ Fast Construction \\ Efficient}

The Highways for Life program has the motto of "Get In, Get Out, and Stay Out”. This motto reinforces the idea of quickly constructing quality bridges that are sound enough to not need extensive attention throughout the remainder of its life span. Modular Bridge Technology is one solution that can aid in reaching these goals of overall better bridge design and construction. [14]

Several methods of Modular Bridge Technology are currently in use to build better quality bridges faster. The use of these different methods applies to all of the different sectors of bridge design and construction. Modular Bridge Technology has been applied to the substructure, superstructure and deck systems of constructed bridges with positive results. Some may not know all of the applications that have been used and tested. [14]

The use of Modular Bridge Technology is more than just a way to improve the efficiency of bridge design and construction. There are also the added benefits of: improving bridge site safety, lessening the disruption of traffic during construction, improving the quality of construction and reducing environmental impacts and life cycle costs. [14]

At the suggestion of the Federal Highway Administration, a technical working group was established to review the various options available for short span modular steel bridge construction. The Technical Working Group consists of representatives from industry associations (including the Short Span Steel Bridge Alliance), steel bridge fabricators, university faculty members, steel manufacturers, state departments of transportation representatives and government organizations (FHWA).

\subsection{Overview}

The approach of Modular Bridge Technology has been applied in multiple ways to increase the efficiency of the design and construction of different bridge elements. These applications have been used for the different parts of bridges including: substructure, superstructure and decking. There are also Modular Bridge Systems in use that combine multiple bridge elements (ex. superstructure and decking). This type of system may include a section of 
bridge that can be installed that provides normally separate parts of a bridge already assembled. An example of this would be an element that is transported to the bridge site and makes up both the superstructure and decking surface of the bridge. In constructing modular bridges, equipment has been developed specifically to transport and install prefabricated bridge sections.

This chapter covers several different Modular Bridge applications that are being used in bridge design and construction today, specifically in the field of short span steel bridges. The report will provide description, illustration, and evaluation of each of these methods, allowing the reader to become more aware of the overall benefit of using Modular Bridge Technology.

\subsection{Short Span Steel Bridge Substructure}

The substructure of the bridge consists of the portion of the bridge that supports the entire structure on the given soil and/or bedrock of the bridge-site. The design of the substructure can be varying especially due to the different soil conditions for each bridge-site and the weights of the structures differing for each project. Despite the great variance possibilities, some applications of Modular Bridge Technology have been developed. This section describes some of these applications, provide illustrations and evaluate the application to short span modular steel bridges.

\subsubsection{Precast Concrete Cap Beam}

\subsubsection{Description}

Precast concrete cap beams are the most common prefabricated elements in bridge substructures. These are generally the most difficult elements to construct on site using cast-inplace concrete, where shoring and forming can be extensive. Precast concrete cap beams have the benefits of the element being prefabricated off-site and only needing to be transported and installed on-site. An example of a precast concrete cap beam is shown in Figure 4-2. [14] 


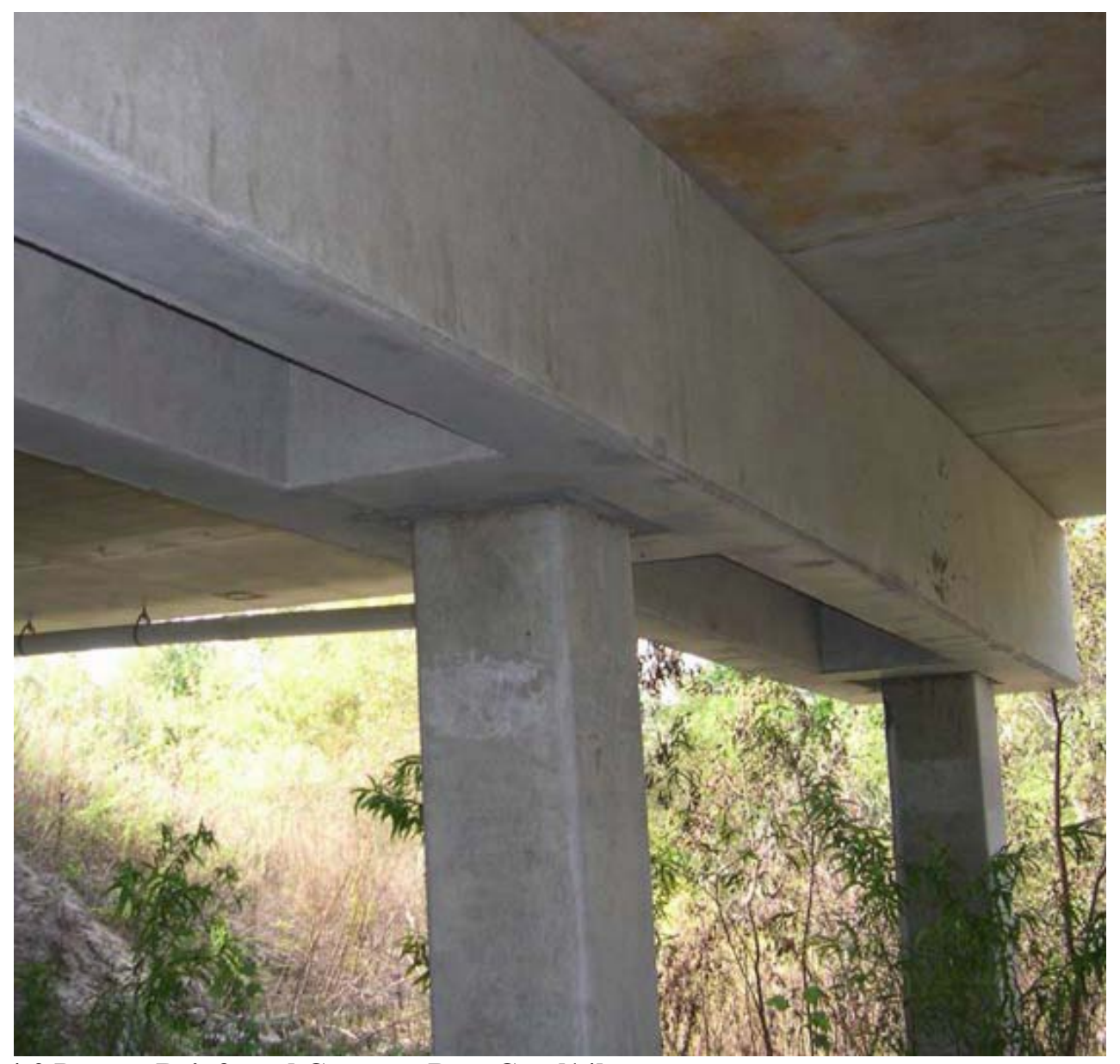

Figure 4-2 Precast Reinforced Concrete Bent Cap [14]

\subsubsection{Application}

Precast concrete cap beams connect to the tops of the piles/columns of the bridge substructure and support the bridge deck. [14]

\subsubsection{Constructability}

Due to the tolerance of cast-in-place columns and piers, large blockouts in the pier caps have been used successfully. Another type of connection used for this situation is large grouted pockets to develop semi-moment connections. Simple bolted connections can be used as well as a pinned connection. [14]

\subsubsection{Evaluation}

Due to the time and difficulty involved in the placement of a cast-in-place concrete cap beam, a prefabricated element is an efficient alternative worth considering; it is easier and faster to transport and connect the element than it is to cast the element on-site. 


\subsubsection{Research Needed}

There is still research that is required in the area of connection details.

\subsubsection{Precast Concrete Integral Abutments}

\subsubsection{Description}

Standard abutment construction can be a long process; therefore prefabrication can provide an excellent opportunity to reduce the overall construction time of a bridge project. With integral abutments, the structure of the abutment is made integral with the elements of the superstructure. The advantages of the integral abutment include: a reduction in bridge deck joints (a common area of deterioration in bridges) and the forces of the soil are transferred into the bridge superstructure, reducing the need for spread footings or multiple rows of piles. These types of abutments can be separated into two categories: fully-integral abutments and semiintegral abutments. Fully-integral abutments are more common and involve the connection between the abutment and the superstructure being a full moment connection. The connection between the semi-integral abutment structure and the bridge superstructure are pinned connections that allow for rotation at the ends of the superstructure. An example of a precast concrete abutment is shown in Figure 4-3 and a diagram of this modular bridge element working with a steel superstructure is shown in Figure 4-4. [14] 


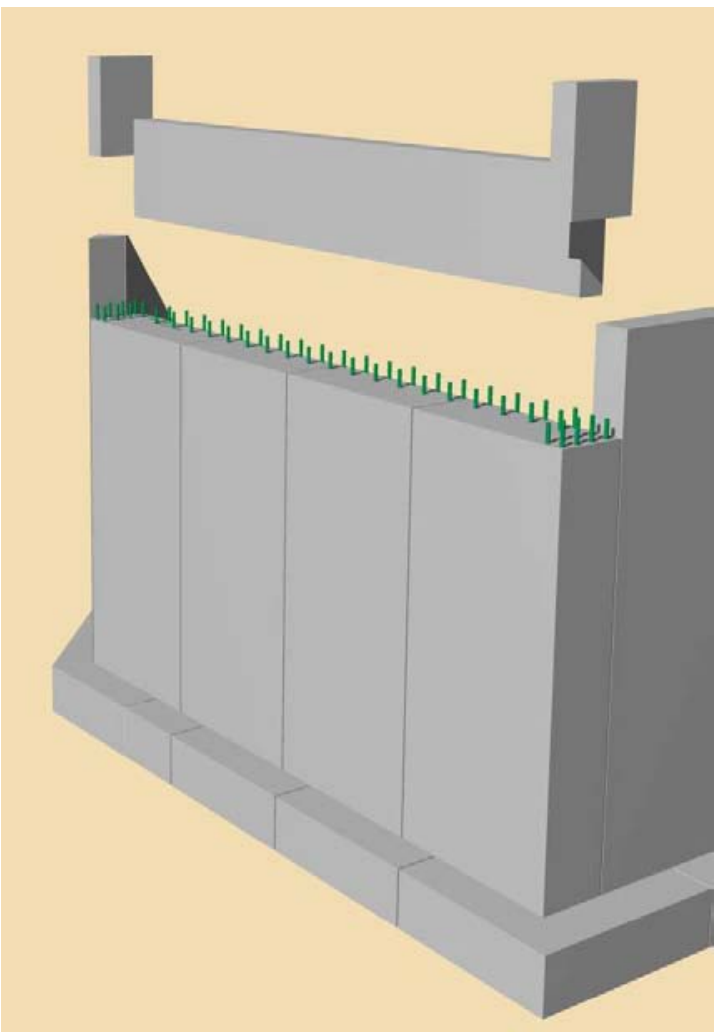

Figure 4-3 Precast Concrete Abutment Stem [14]

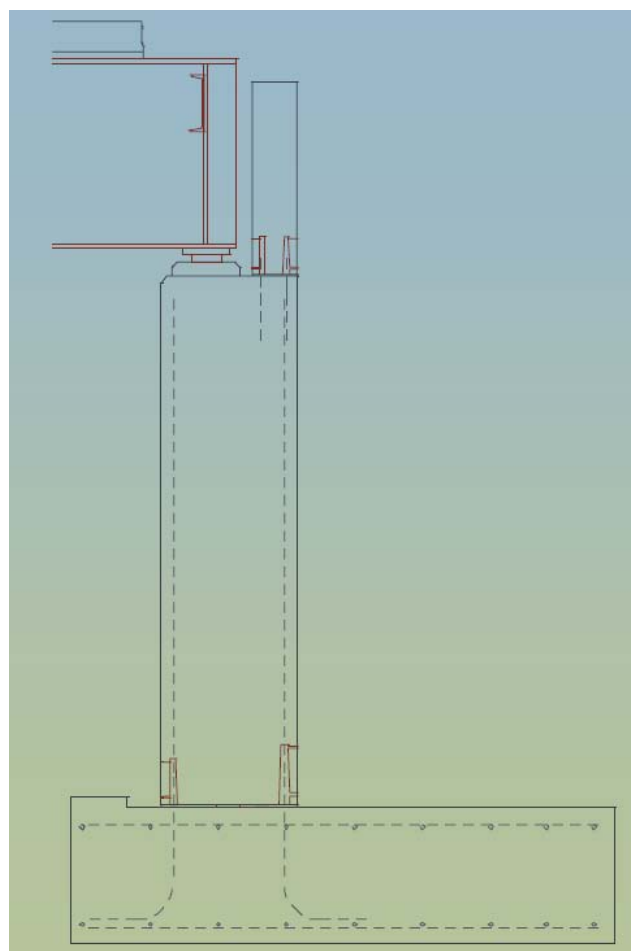

Figure 4-4 Diagram of Precast Concrete Abutment Stem with Steel Superstructure [50] 


\subsubsection{Application}

This system is installed to the top of the piles of the bridge substructure to support the ends of the bridge while also laterally supporting the adjacent soil from movement. [14]

\subsubsection{Constructability}

The connection between the abutment stem and steel piles can be accomplished using anchored steel plates that can be field welded or embedding the piles in large pockets to later be grouted or sealed with concrete. To connect the abutment to the concrete piles, grouted tube couplers can be used with reinforcing bars of the two elements. Similar to the steel piles, pockets and grouting can be used to connect the stems with concrete piles. To connect the adjacent stems, post-tensioning or small closure pours can be used. [14]

\subsubsection{Evaluation}

Prefabricating an integral abutment can save time in a bridge construction. Using these integral abutments, deck joints can be eliminated preventing problem areas for deterioration. This system can also reduce the need for a spread footing or multiple rows of piles.

\subsubsection{Research Needed}

Connections between the piling and footing and the connections between the adjacent stem elements are still the subject of ongoing research.

\subsubsection{Modular Precast Wall Systems}

\subsubsection{Description}

Prefabricated wall panels can be assembled and connected on-site to create modular precast wall systems. The two common forms of this modular bridge technology include mechanically stabilized earth wall systems and modular block systems. In the first form, mechanically stabilized earth systems, thin wall panels are placed and anchored to the adjacent soil. The devices used to anchor the wall panels engage the soil mass behind the wall panels to create a soil mass gravity wall. The process of installing this type of wall abutment can progress rapidly because the system is built while the soil is still being filled in behind the wall. In the latter system, modular block system, modular reinforced concrete modules are interconnected to build a soil gravity wall. An example of a mechanically stabilized earth wing wall is shown in Figure 4-5. [14] 


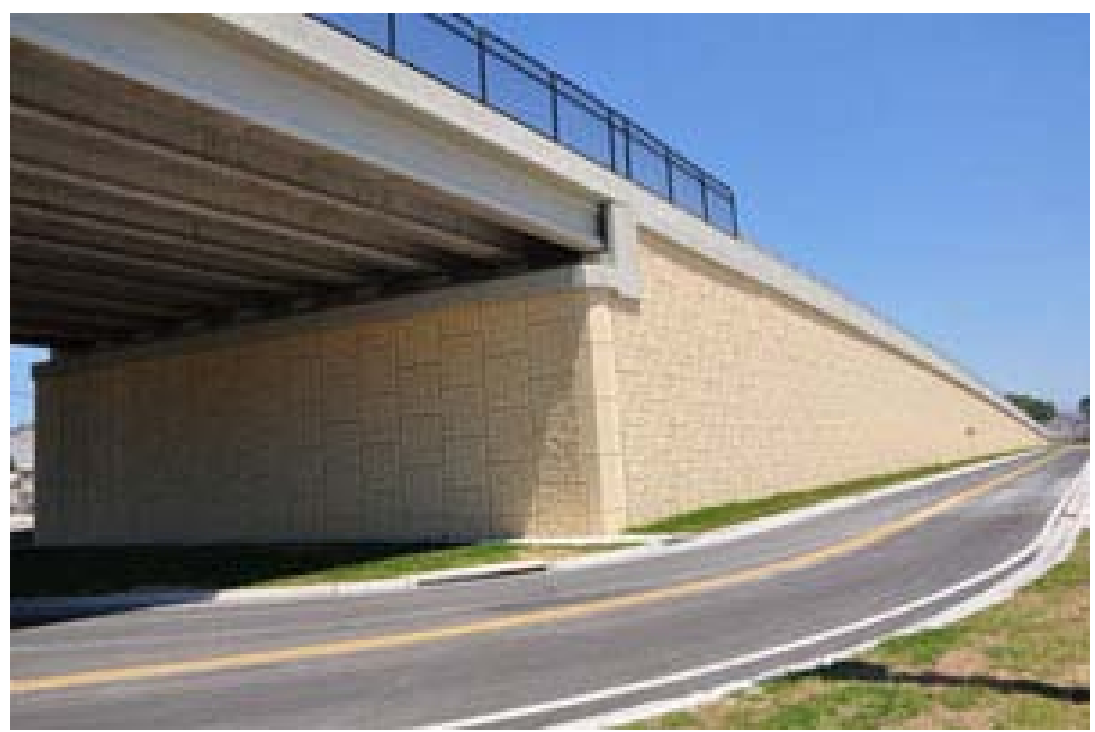

Figure 4-5 Mechanically Stabilized Earth Wing Wall [28]

\subsubsection{Application}

Mechanically stabilized earth systems are anchored to the soil to help support the soil and support the bridge superstructure. Similarly, modular block systems are gravity walls, in that their weight prevents soil movement, placed against the soil to meet the same objectives. [14]

\subsubsection{Constructability}

Modular block systems interlock with each other as they are constructed into a wall. The mechanically-stabilized earth system panels are anchored to the adjacent soil during the construction of the wall. [14]

\subsubsection{Evaluation}

These wall systems provide an efficient construction process. While the fill soil is being placed, either, the wall and its anchorages are placed within the adjacent fill soil, or the wall is built using reinforced concrete modules. This system can be constructed faster than geosynthetically confined soil wall abutments. Mechanically stabilized earth walls do have the downside of a failure rate of approximately 2-10\%. [19]

\subsubsection{Research Needed}

Research is needed for reducing the failure rate of this type of bridge abutment. 


\subsubsection{Geosynthetically Confined Soil Wall Abutment}

\subsubsection{Description}

Geosynthetically confined soil wall abutments are systems that connect the wall and the soil to create a composite structure. To keep the structure internally stable, fabric sheets are used to connect the wall with the soil behind it in the form of a friction connection. Similar to the mechanically stabilized earth systems, these walls are assembled with fabrics being placed within the soil while the backfill material is placed in layers. An example of a geosynthetically confined soil wall being installed is shown in Figure 4-6 and an example of a geosynthetically confined soil abutment is shown in Figure 4-7. [19]

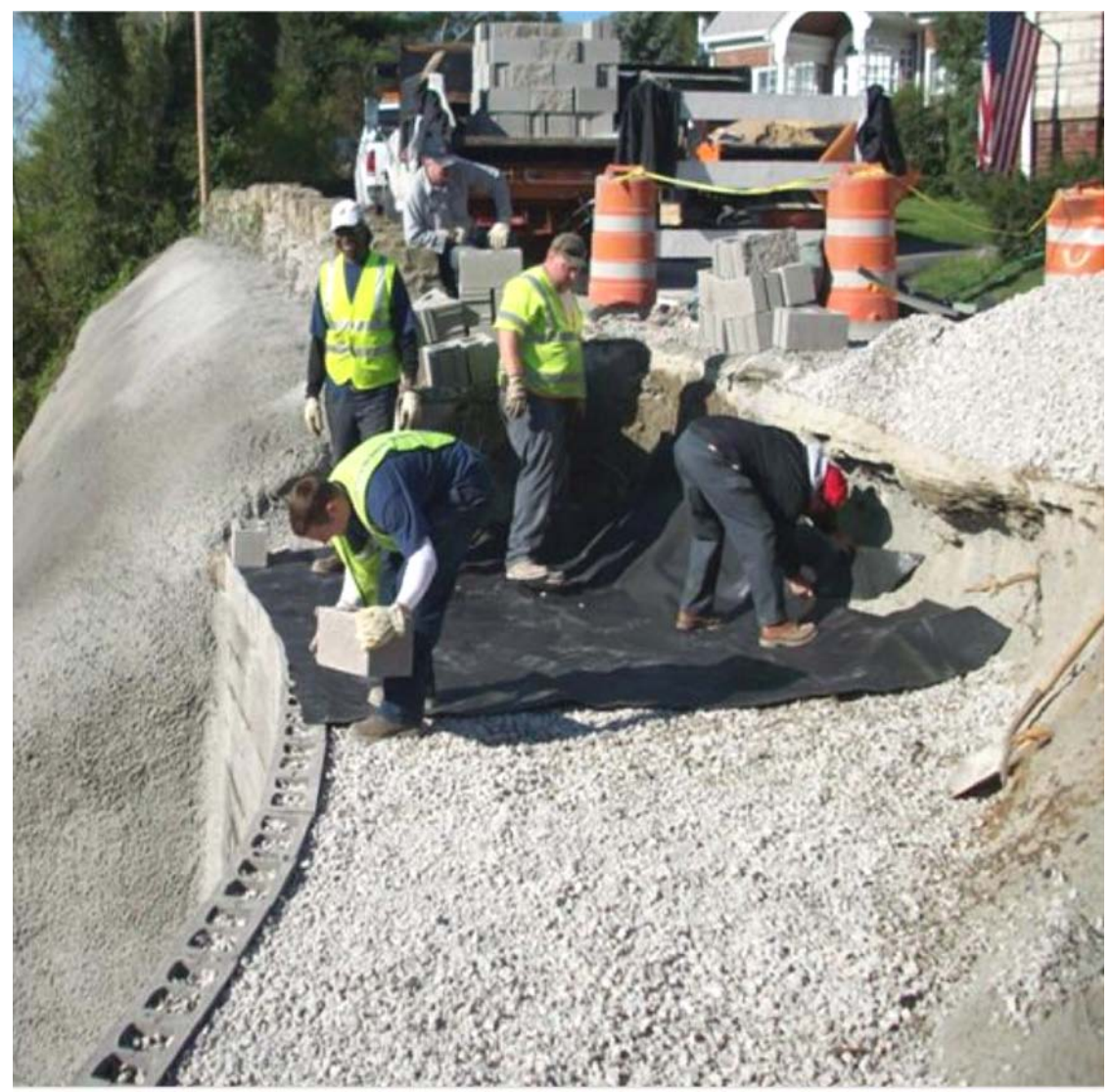

Figure 4-6 Installation of Geosynthetically Confined Soil Wall [19] 


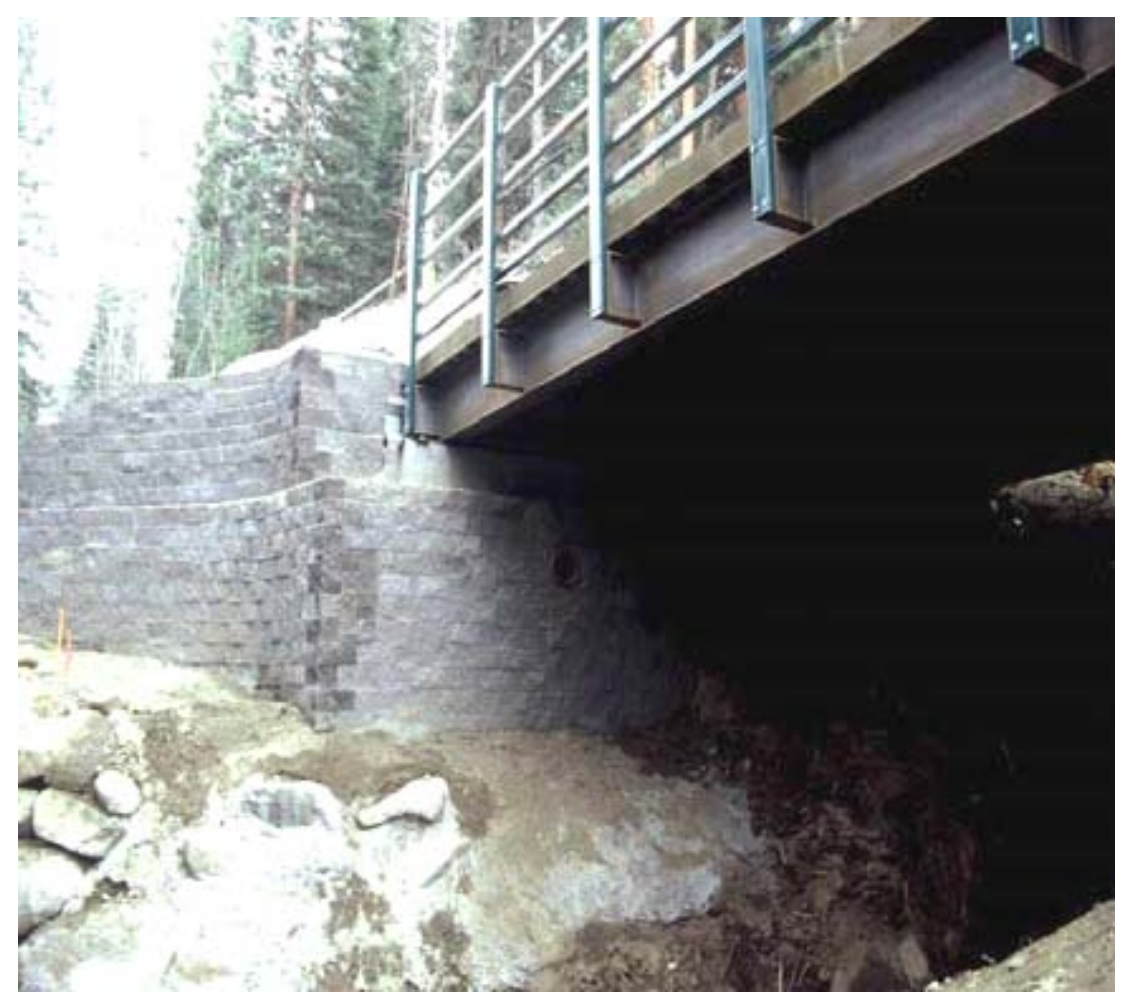

Figure 4-7 Geosynthetically Confined Soil Bridge Abutment [18]

\subsubsection{Application}

Geosynthetically confined soil bridge abutments attach to the adjacent soil to prevent soil movement and to support the bridge superstructure. [19]

\subsubsection{Constructability}

The blocks of the geosynthetically confined soil abutments are installed in rows while the fabric is applied between the blocks and the soil. This binding to the soil helps connect and stabilize the wall as a whole. [19]

\subsubsection{Evaluation}

This system is more stable and has a higher safety factor than mechanically stabilized earth systems. The fabric inclusions are lightweight and the installation process is not difficult.

\subsubsection{Research Needed}

No research needs were found for this modular element. 


\subsubsection{T-WALL ${ }^{\circledR}$ Retaining Wall System}

\subsubsection{Description}

The T-WALL® retaining wall system, provided by the Neel Company, combines the design principles of precast concrete modular walls with the gravity wall. The precast concrete, T-shaped wall segments that make up the retaining wall are designed to stack and interlock to create the wall surface. The stems of the "T's" have a friction interaction with the soil backfill placed behind the wall. This method causes the system to act as a stable gravity wall. An image showing the installation of the T-WALL ${ }^{\circledR}$ system is provided in Figure 4-8 and an image of a bridge where these elements have been installed is provided in Figure 4-9. [33]

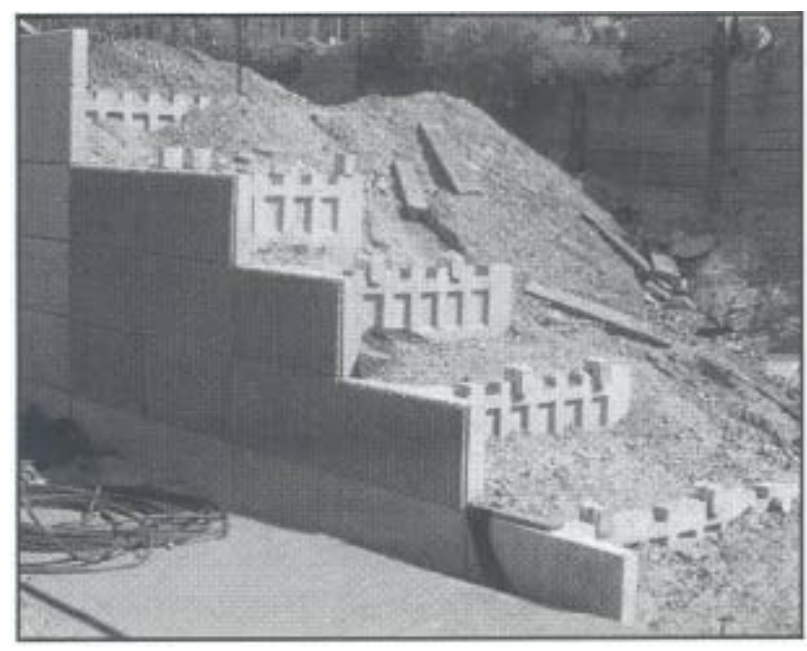

Figure 4-8 T-WALL® Wall System Installation [33]

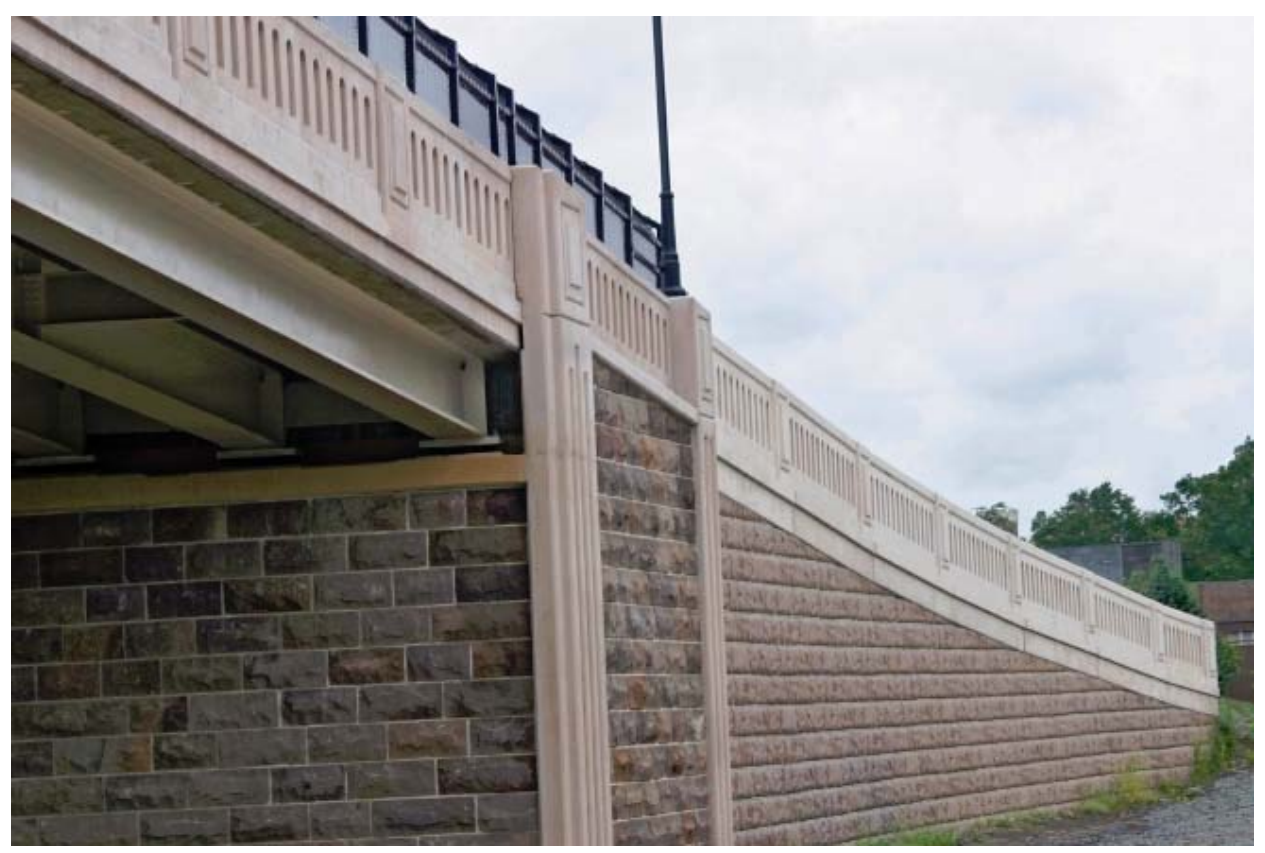


Figure 4-9 Southard Street Bridge, Trenton, NJ [34]

\subsubsection{Application}

The T-WALL ${ }^{\circledR}$ modules are stacked and arranged to create an earth retaining wall for the substructure of the bridge. [33]

\subsubsection{Constructability}

The modules are stacked and connected using locking elements. The weight of the modules and the friction between the wall stems and the soil hold them in place. [33]

\subsubsection{Evaluation}

This system combines the ideas behind the modular precast wall and the geosynthetically confined soil wall. Construction of this system is simplified in that only the modules and the backfill need placed sequentially.

\subsubsection{Research Needed}

No research needs were found for this modular element.

\subsubsection{Precast Concrete Footing}

\subsubsection{Description}

Few states have worked with precast footings in bridge projects. The difficulty in effectively using this application of modular bridge technology is insuring adequate seating on the subgrade. If the seating is inadequate, rocking of the footings and settlement of the foundation are possible results. In consideration of this issue, one can apply flowable concrete or grout under the footing. The grout can either be a flowable fill or a low grade concrete. The strength of the flowable material is not of great importance since the material is simply being used as a filler material. An example of a plan for a precast footing is provided in Figure 4-10. [14] 


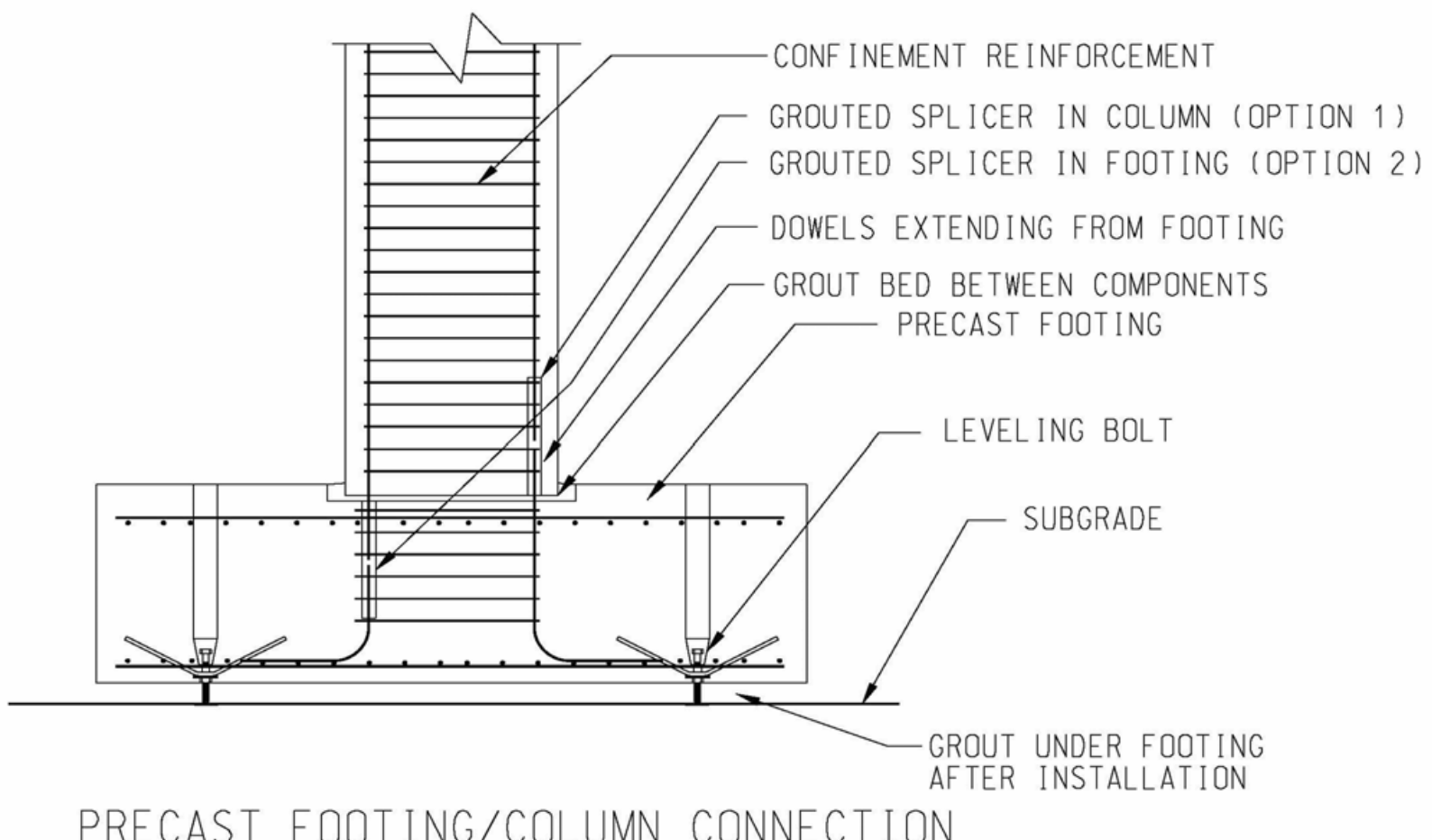

Figure 4-10 Drawing of Precast Footing [14]

\subsubsection{Application}

Precast footings are installed on the soil to support the substructure and superstructure of the bridge. These are used when soil conditions are adequate to not require piles. [14]

\subsubsection{Constructability}

For the connection between the precast footing and the subgrade, flowable concrete or grout is used to create adequate seating. One state has used grouted shear key connections to connect adjacent precast footings. A small closure pour can be used as well to connect the footing sections. Due to continuing research, connection between the footing and the piles is specific to the situation. [14]

\subsubsection{Evaluation}

This system is appropriate when the engineer has confidence in the soil subgrade's ability to support the precast footing. While a filler material can be used, the possibilities of settlement or rocking can be an important issue. This system can work well, but it should only be used when it is safe for the structure. 


\subsubsection{Research Needed}

This prefabricated element is still being researched. Very few states actually have experimented with this technique. More research will take place before precast footings are used more frequently. [14]

\subsubsection{Precast Concrete Pile}

\subsubsection{Description}

Precast piles are used more commonly than precast footings. Normally, these piles have a square, round or octagonal cross-sectional shape. Precast concrete pile companies have developed standard details for their product. An example of a precast pile is shown in Figure 4-11. [14]

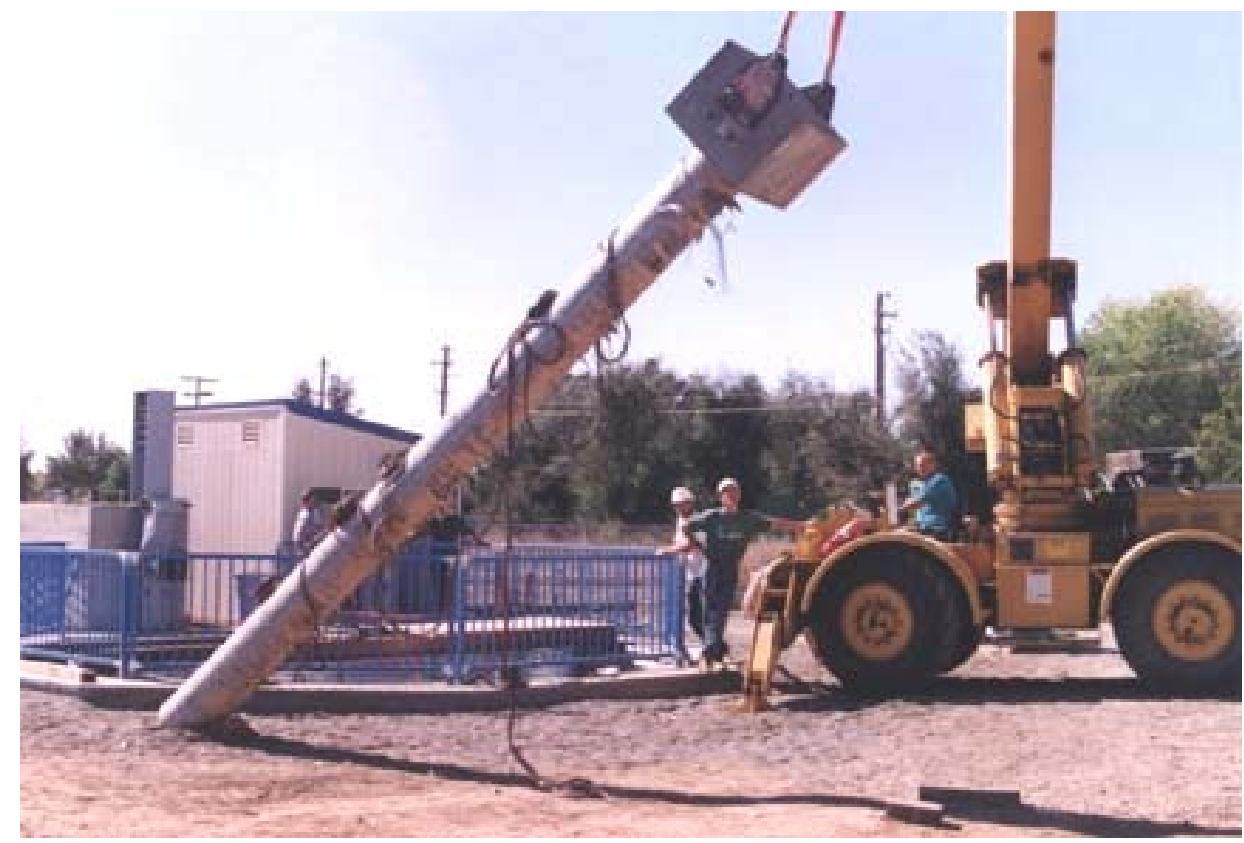

Figure 4-11 Precast Concrete Pile [39]

\subsubsection{Application}

Precast concrete piles are used when soil conditions are not adequate for spread footings. The piles are used to support the bridge structure on the soil and/or bedrock. [14]

\subsubsection{Constructability}

The PCI manual "Precast Prestressed Concrete Piles" (BM-20-04) gives details for splicing precast concrete piles. One state has developed a detail for splicing hollow square piles using a reinforced concrete closure pour. [14] 


\subsubsection{Evaluation}

This system provides a driven pile instead of a cast-in-place concrete pile. Cast-in-place piles require more time and preparation.

\subsubsection{Research Needed}

Research may be needed to investigate the ductility of precast piles with integral abutments.

\subsubsection{Driven Steel Piles}

\subsubsection{Description}

Similar to precast concrete piles, driven steel piles have been used to make up the abutments and/or piers of short span modular steel bridges. These piles are driven to the required depth in order to provide support the required loads and a pile bent is installed along the top of the piles to support the bridge superstructure. Examples of these types of piers are provided in Figure 4-12 and Figure 4-13. [14]

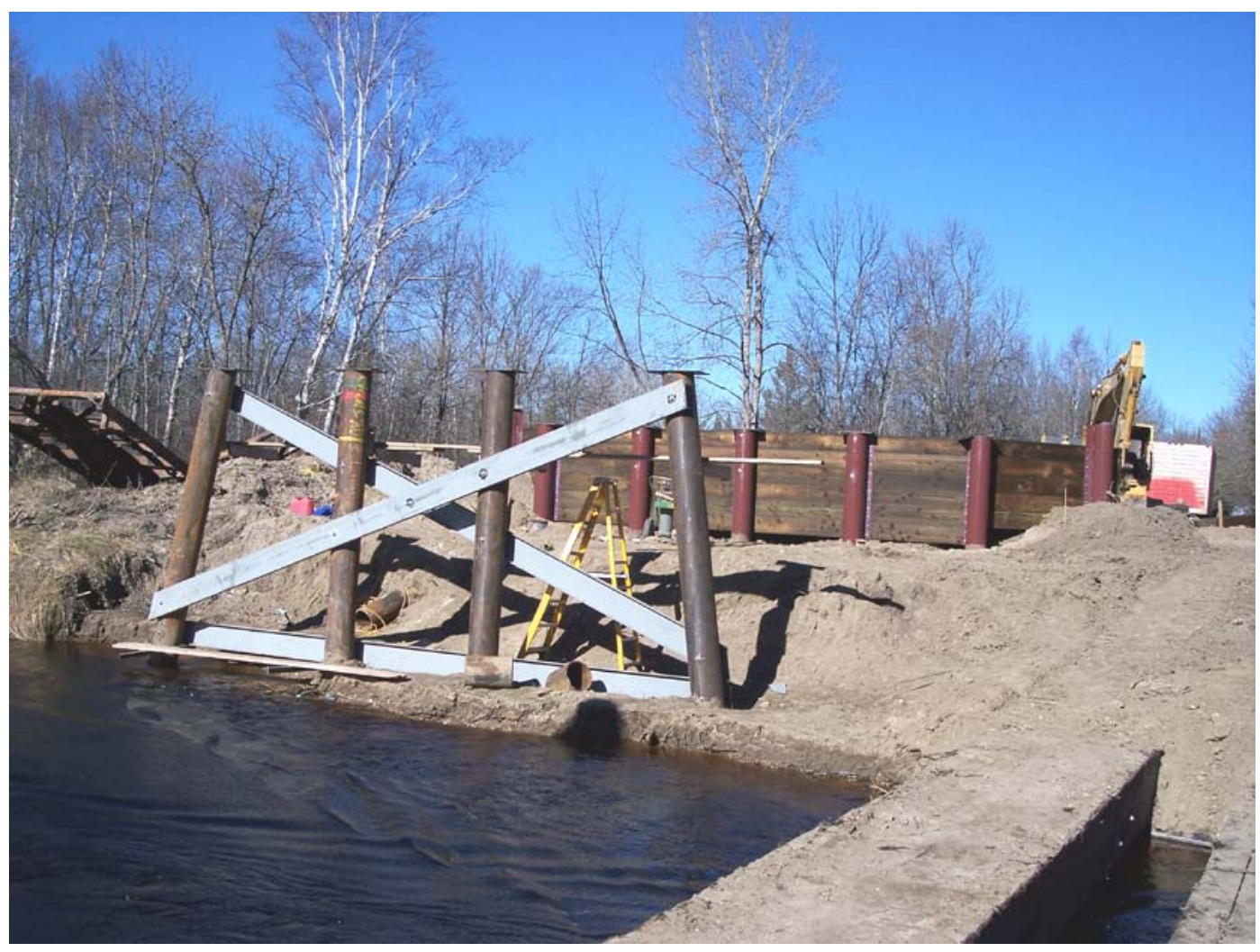

Figure 4-12 Driven Steel Piles for Piers/Abutments [12] 


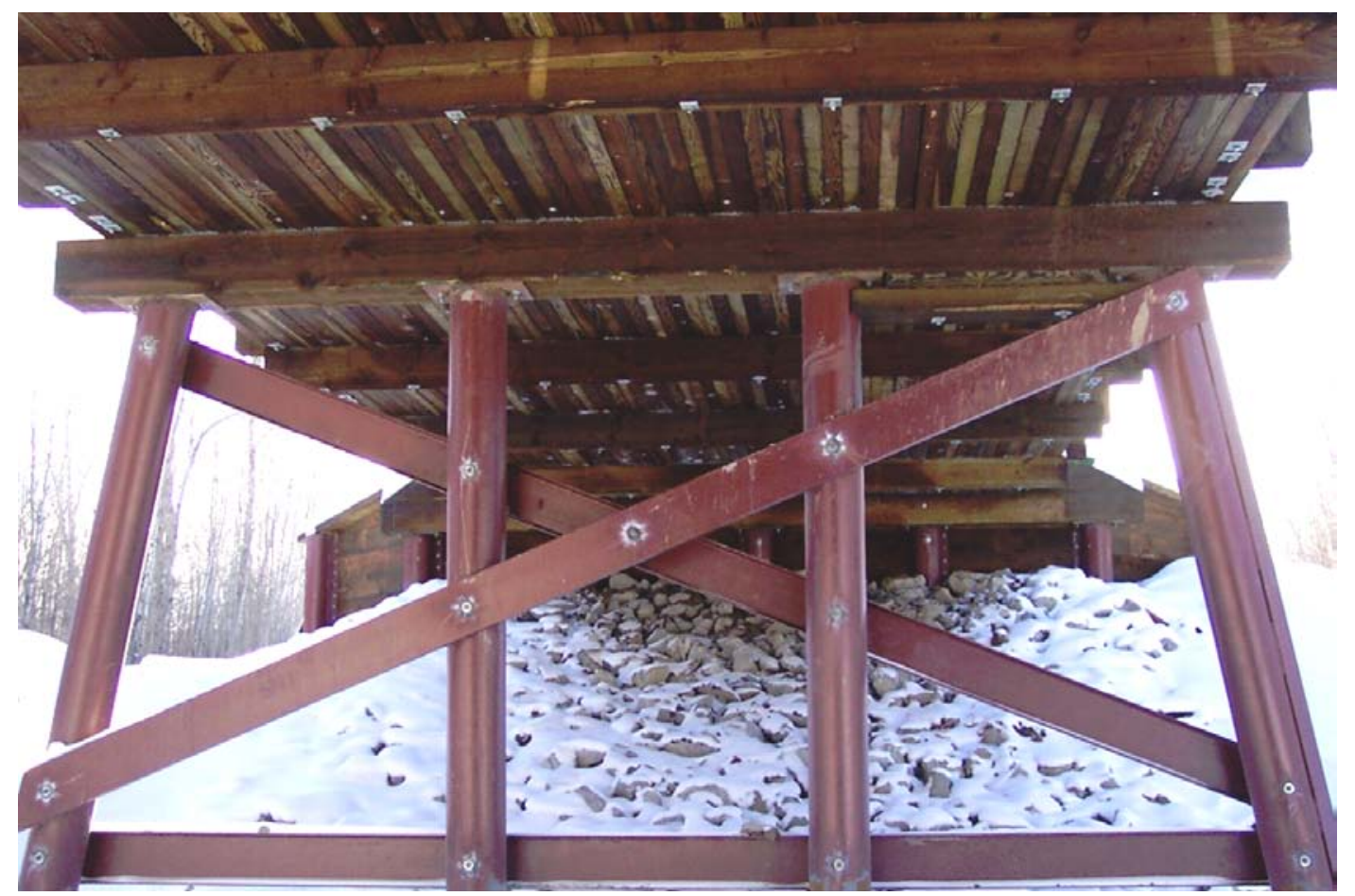

Figure 4-13 Driven Steel Piles for Piers/Abutments [12]

\subsubsection{Application}

Steel piles are driven to the required depth to support the structure. The portion above ground is braced and topped with a pier cap to create a pile bent that supports the superstructure on. [14]

\subsubsection{Constructability}

Some states connect the steel piles to the pier cap by welding the tops of the piles to steel plates. Other states have used piles that are hollow with precast pier caps; an anchor system is established between the cap and piles with a closure pour used to finalize the connection. [14]

\subsubsection{Evaluation}

This system employs a driven pile instead of a cast-in-place concrete pile. Cast-in-place piles require more time and preparation.

\subsubsection{Research Needed}

No research needs were found for this modular element. 


\subsubsection{Modular Steel Piers}

\subsubsection{Description}

Modular steel piers are prefabricated braced frame structures based on systems developed initially for offshore platforms. These piers resist lateral forces more efficiently that concrete piers. Installation of this type of pier can be performed in days instead of months required for cast-in-place concrete piers. An example of modular steel piers used in a bridge structure is provided in Figure 4-14. [40]

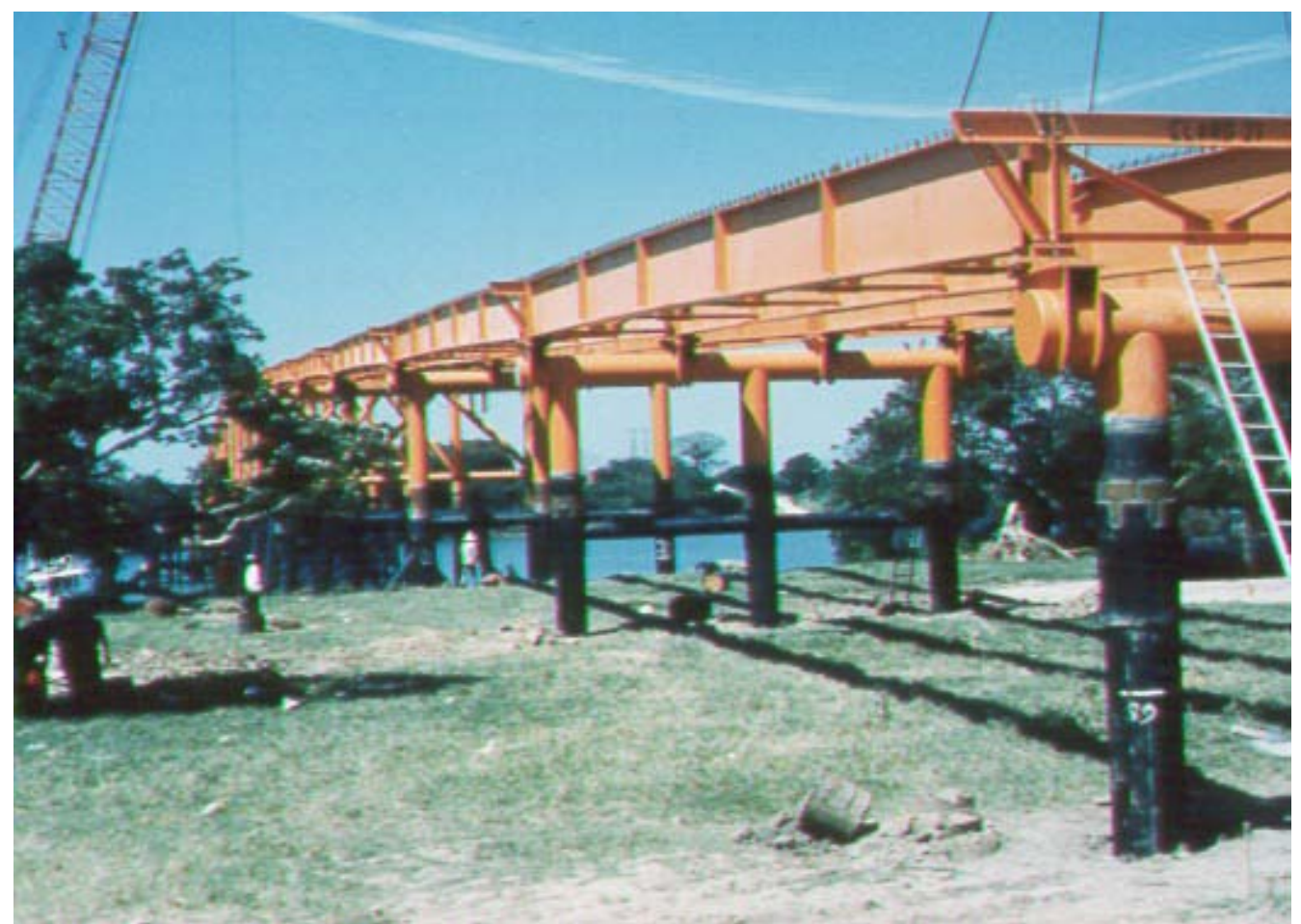

\section{Figure 4-14 Modular Steel Piers [40]}

\subsubsection{Application}

Modular steel piers are used to support the bridge superstructure at intermediate support points along the bridge. [40]

\subsubsection{Constructability}

No information of constructability of this modular element was found.

\subsubsection{Evaluation}

This system is more structurally efficient than concrete piers in that it resists lateral forces. Elements being prefabricated, installation can be completed at a faster schedule helping reduce the time of traffic impact, costs and the impact to the environment. 


\subsubsection{Research Needed}

No research needs were found for this modular element.

\subsubsection{Precast Pier Box Cofferdam}

\subsubsection{Description}

Constructing pier footings on piles is one of the more difficult processes in the construction of piers in water. Complicated sheeting systems and cofferdams can be involved in this type of construction. Precast concrete pier boxes have been used to dewater areas where drilled shafts connect to bridge footings. These can be used to reduce the need for complicated dewatering systems and deep cofferdams. An example of a bridge pier box is shown in Figure 4-15. [14]

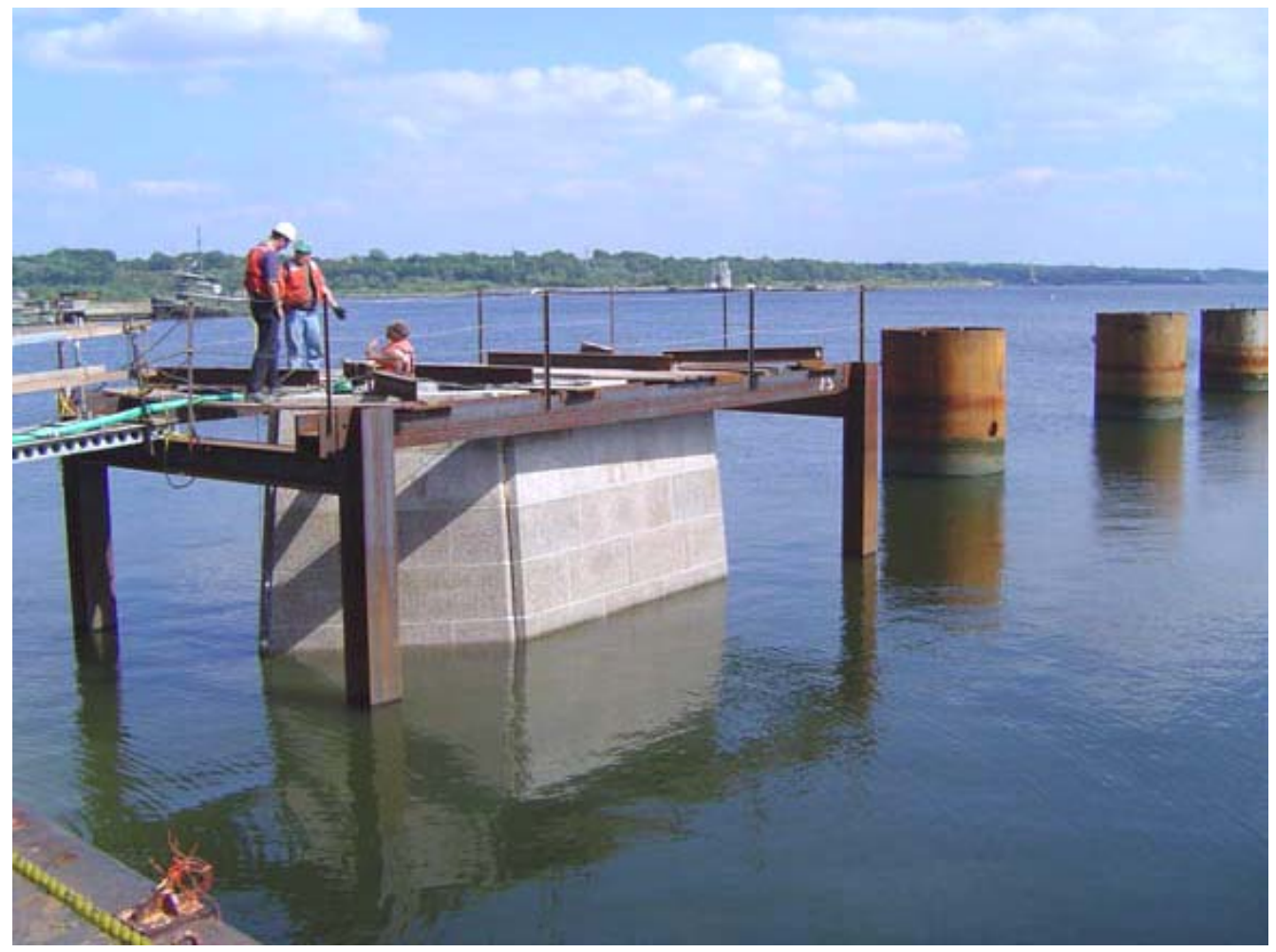

Figure 4-15 Bridge Pier Box (Photo courtesy of Cardi Corporation) [14]

\subsubsection{Application}

Precast pier box cofferdams are used as an alternative to sheeting systems and cofferdams that are normally used to dewater areas for the connection of pier footings to piles installed into underwater drilled shafts. [14] 


\subsubsection{Constructability}

In cases, the precast cofferdam has been placed over the pile and sealed with a small tremie pour around the shaft. [14]

\subsubsection{Evaluation}

In preparation for bridge footings in water, a precast pier box can greatly ease the process of dewatering and connection.

\subsubsection{Research Needed}

No research needs were found for this modular element.

\subsubsection{Sheet Pile Wall Abutments}

\subsubsection{Description}

Sheet pile wall abutments are constructed from hot-rolled structural shapes with interlocks on the flange tips. These interlocks permit individual sections to be connected to form a continuous steel wall. Steel sheet piles are characterized by their profile which includes Zprofiles, U-profiles, and straight-profiles. The majority of design involved in using a sheet pile wall abutment comes in determining what type of sheet, vertical and horizontal forces are taken by the sheet piling in this structure, how deep to drive it and determine if and where anchorage devices are needed. Examples of sheet pile wall abutments are shown in Figure 4-16 and Figure 4-17. [16] [43] 


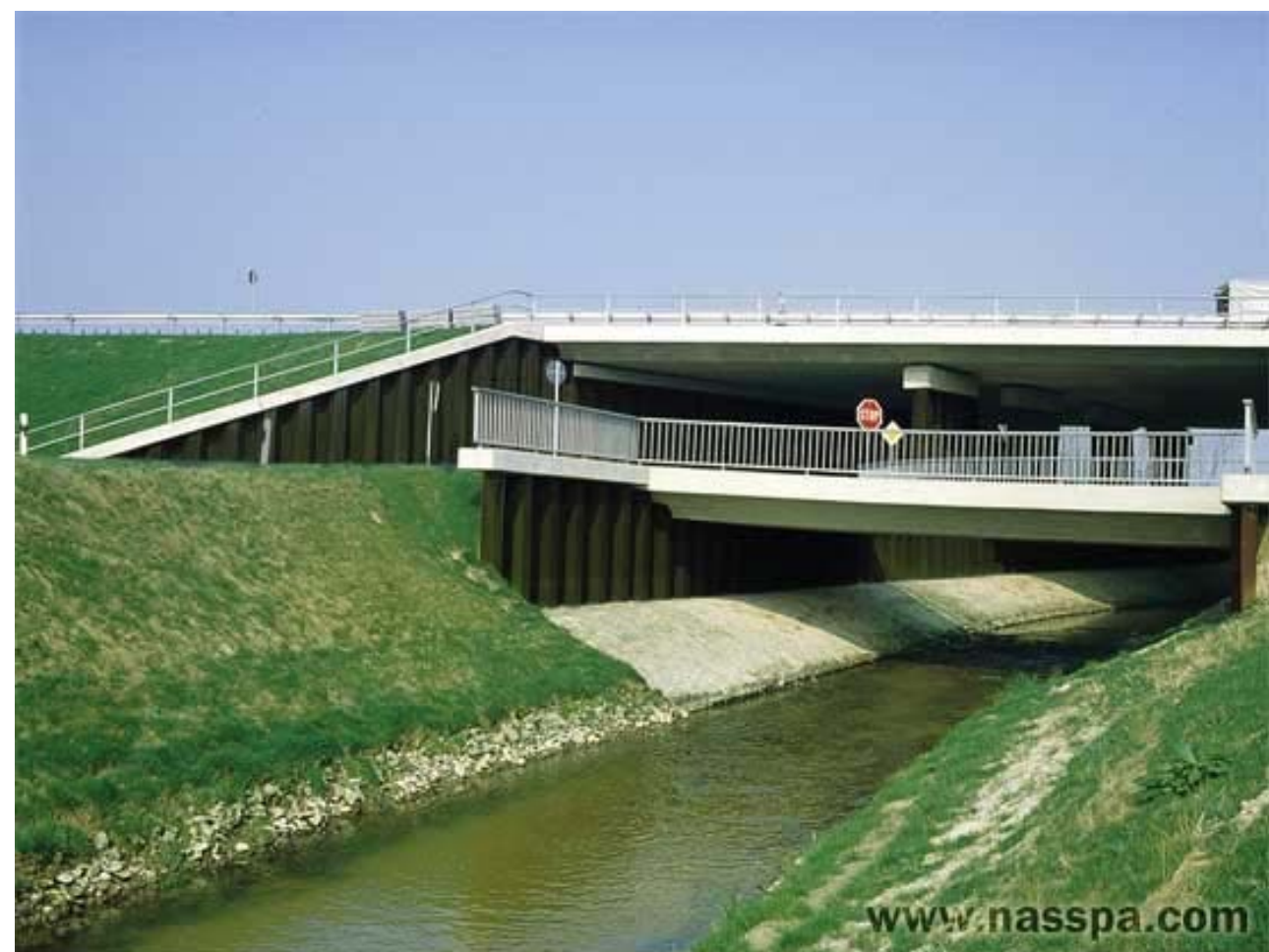

Figure 4-16 Steel Sheet Pile Wall Abutment [36]

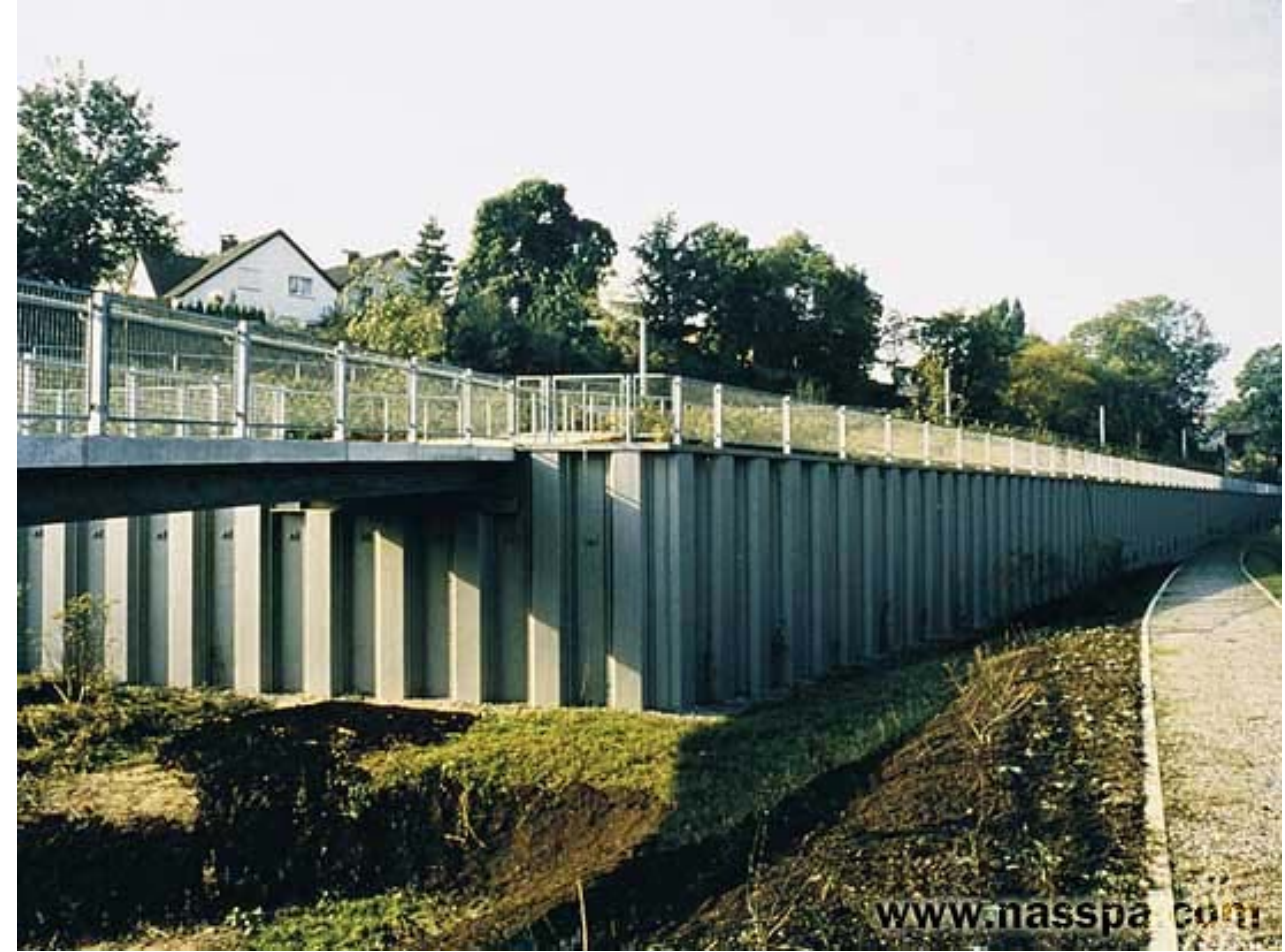

Figure 4-17 Steel Sheet Pile Wall Abutment [35] 


\subsubsection{Application}

Sheet pile walls are used as a bridge abutment alternative. This system supports the soil adjacent to the bridge approach. [16]

\subsubsection{Constructability}

The plates of the steel sheet piles walls are designed to interlock along the edges while the sheets are being driven into place. [16]

\subsubsection{Evaluation}

Hot-rolled steel sheet piles are cost effective solution for a piled foundation is required to support a bridge or where speed of construction is critical. Abutments formed from sheet piling are able to act as both foundation and abutment and can be driven in a single operation, requiring a minimum of space and time for construction. The material is lighter and easier to transport than precast concrete panels and sheet piling is produced to meet one of several applicable ASTM specifications. The interlocking steel sheet piling provides a water tight structure and the site does not need to be dewatered before installation is performed. [20]

Abutment structures have their own unique set of exposure conditions, design requirements, service life, aesthetic goals and economic requirements. While some projects benefit from some supplemental corrosion protection i.e., coatings, sacrificial steel, alternate materials, cathodic protection, in many applications steel sheet piling does not require any additional protection. When supplemental corrosion protection is required, there is a wide variety of protection alternatives to ensure the steel sheet piling meets the project requirements. The need for corrosion protection is a function of both the exposure, which determines the projected loss of steel due to corrosion, and the design life of the structure. Local experience with corrosion in similar structures can be a valuable guide in this decision. [20]

\subsubsection{Research Needed}

No research needs were found for this modular element.

\subsubsection{SuperSill@ Abutments and Back Walls}

\subsubsection{Description}

Developed and implemented by Roscoe Bridge, Supersill ${ }^{\circledR}$ Abutments and Back Walls are another application of modular bridge technology. This system uses a steel spread footing casing that is filled with cast-in-place concrete and a steel soil retaining wall. The system is designed so the bridge assembly can continue even if the concrete truck has not yet arrived to fill 
the footing casing. The empty casing is lightweight and easier to unload and install than precast concrete footings. An example of the SuperSill ${ }^{\circledR}$ Abutment are shown in Figure 4-18. [48]

Figure 4-18 SuperSill ${ }^{\circledR}$ Abutment and Back Wall by Roscoe Bridge [48]

\subsubsection{Application}

The SuperSill ${ }^{\circledR}$ Abutments and Back Walls are applied specifically to the ends of Roscoe modular bridges. This system supports the bridge superstructure while also supporting the adjacent soil. [48]

\subsubsection{Constructability}

The Supersill ${ }^{\circledR}$ Abutment box is placed on top of the piles. Inside of the box is a support system that connects with the piles. The concrete poured into the box, solidifies the system. [48]

\subsubsection{Evaluation}

This system is easy to transport and install. It considers the variation of cast-in-place concrete arrival. This system also provides the bridge with a modular steel back wall.

\subsubsection{Research Needed}

No research needs were found for this modular element.

\subsection{Short Span Steel Bridge Superstructures}

The superstructure of a bridge is made up of the portion of the bridge built on top of the substructure and supports the bridge deck. Several materials and structural configurations can be used to make up the superstructure of a bridge, but this report will focus more on short span steel 
bridges. A publication from the Short Span Steel Bridge Alliance provides different short span bridge superstructures using different steel configurations depending on spans that the bridge must support. This section will describe several different steel superstructures, illustrate the different structure types and evaluate the different systems for short span modular steel bridges.

\subsubsection{Corrugated Steel Pipe}

\subsubsection{Description}

Corrugated steel piping is a form of prefabricated steel superstructure that can be installed rapidly. Due to newly developed steel grades with many beneficial properties, a steel superstructure like this can be lightweight, strong and cost efficient. The Short Span Steel Bridge Alliance brochure recommends this type of superstructure for spans under approximately 15 feet. An example of Corrugated Steel Pipe is shown in Figure 4-19. [46]

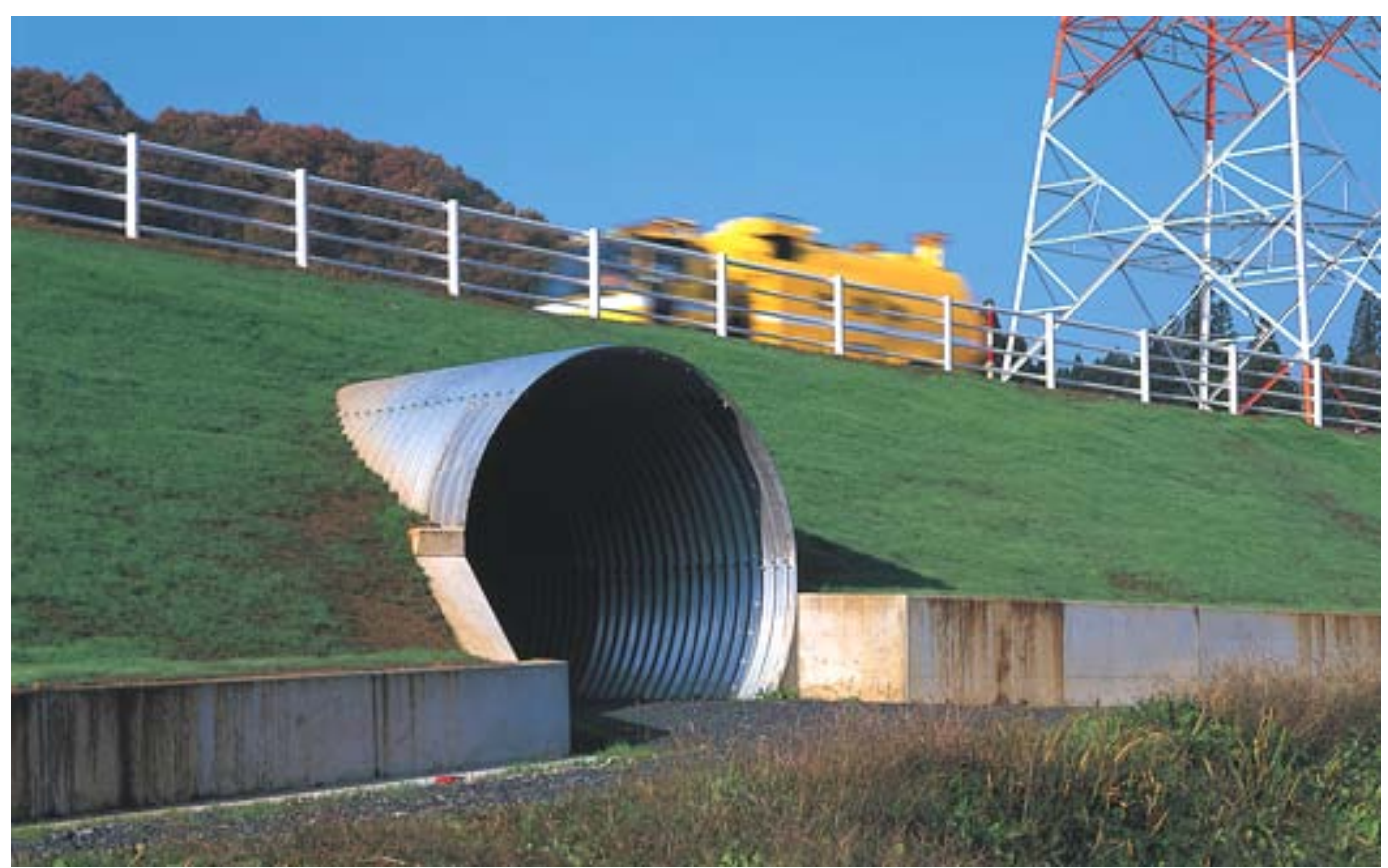

Figure 4-19 Corrugated Steel Pipe for Bridge Superstructure [15]

\subsubsection{Application}

The Short Span Steel Bridge Alliance brochure implies that this alternative can be applied to spans under approximately 15 feet to support the bridge deck and applied live loads. [46] 


\subsubsection{Constructability}

The corrugated steel pipe is secured to the adjacent soil through the use of anchor bolts. The sections that make up the pipe are also bolted together. Couplings are used to prohibit soil and water from getting through the sides of the corrugated steel pipe. Reinforcement may be applied to the pipe to provided extra strength. Backfill and an earth retention system is used to make up the rest of the structure that supports the roadway. [32]

\subsubsection{Evaluation}

Corrugated pipes are available with different levels of coating that can provide service lives of up to 100 years. These pipes also come in a variety of sizes providing a variety of lowerend spans to which they can be applied.

\subsubsection{Research Needed}

No research needs were found for this modular element.

\subsubsection{Corrugated Structural Plates}

\subsubsection{Description}

Corrugated structural plates are another prefabricated steel option for a superstructure. These structural plates are formed in such a way to support the rest of the bridge structure and still allow for the traversed travel way to be usable. The Short Span Steel Bridge Alliance brochure recommends this form of steel superstructure for spans between approximately 5 and 60 feet. An example of a bridge using this type of steel superstructure can be seen in Figure 4-20. [46] 


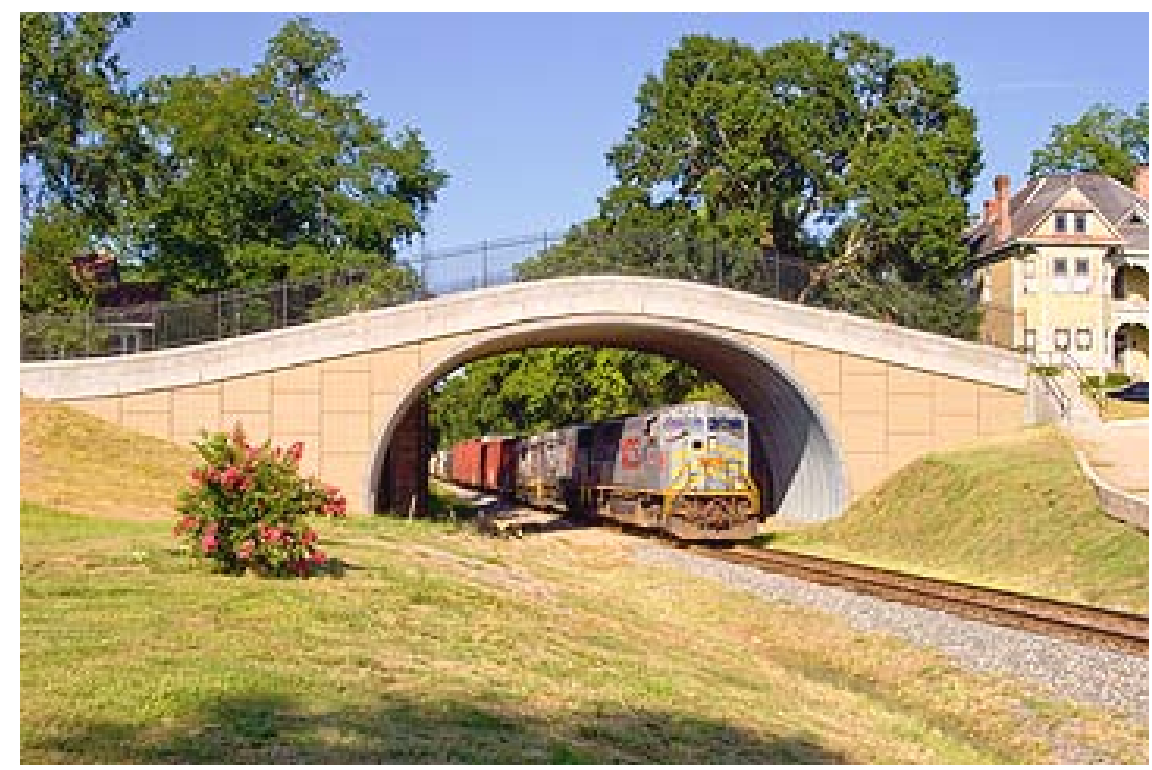

Figure 4-20 Corrugated Structural Plate as a Bridge Superstructure [9]

\subsubsection{Application}

The Short Span Steel Bridge Alliance brochure implies that this alternative can be applied to spans between approximately 5 and 60 feet. [46]

\subsubsection{Constructability}

The plate ends are bolted or anchored to the bridge footing to support the plate. Bolts are also used to connect the sections of the corrugated steel plate and connect the section to the end treatments. Reinforcement is generally added to the plates in order to provide extra strength to the structure. Earth retaining structures and backfill make up the rest of the structure to support the roadway. [32]

\subsubsection{Evaluation}

These superstructure systems are cost effective and quick to install. There are a wide range of designs that allow for these to be used on a variety of spans.

\subsubsection{Research Needed}

Of the several different reinforcing ribs being used to stiffen structural plate culverts, only a select few have published composite properties. There is a need for research in the area of the degree of composite action of ribs with structural plate culverts. This research can lead to a more efficient use of the combined strength of the materials and aid in developing more cost efficient designs. [28] 


\subsubsection{Big R Bridge (Super-Cor $\Re)$}

\subsubsection{Description}

The Modular Bridge Company Big R Bridge has developed a unique alternate version of the corrugated structural plate bridge. In the Super-Cor ${ }^{\circledR}$ Bridge, the corrugated plate is replaced by large annular corrugations. These lightweight panels provide more stiffness than a conventional structural plate bridge. The panels are easy to transport and required significantly less bolts than the conventional steel plate. The panels are light enough that they can be assembled next to job-site and then moved into place by relatively light equipment. This system also has the advantage of being adaptable; it can be widened easily by adding more panels and adapting the rest of the structure. An example of one of a Super-Cor ${ }^{\circledR}$ Bridge is shown in Figure 4-21. [10]

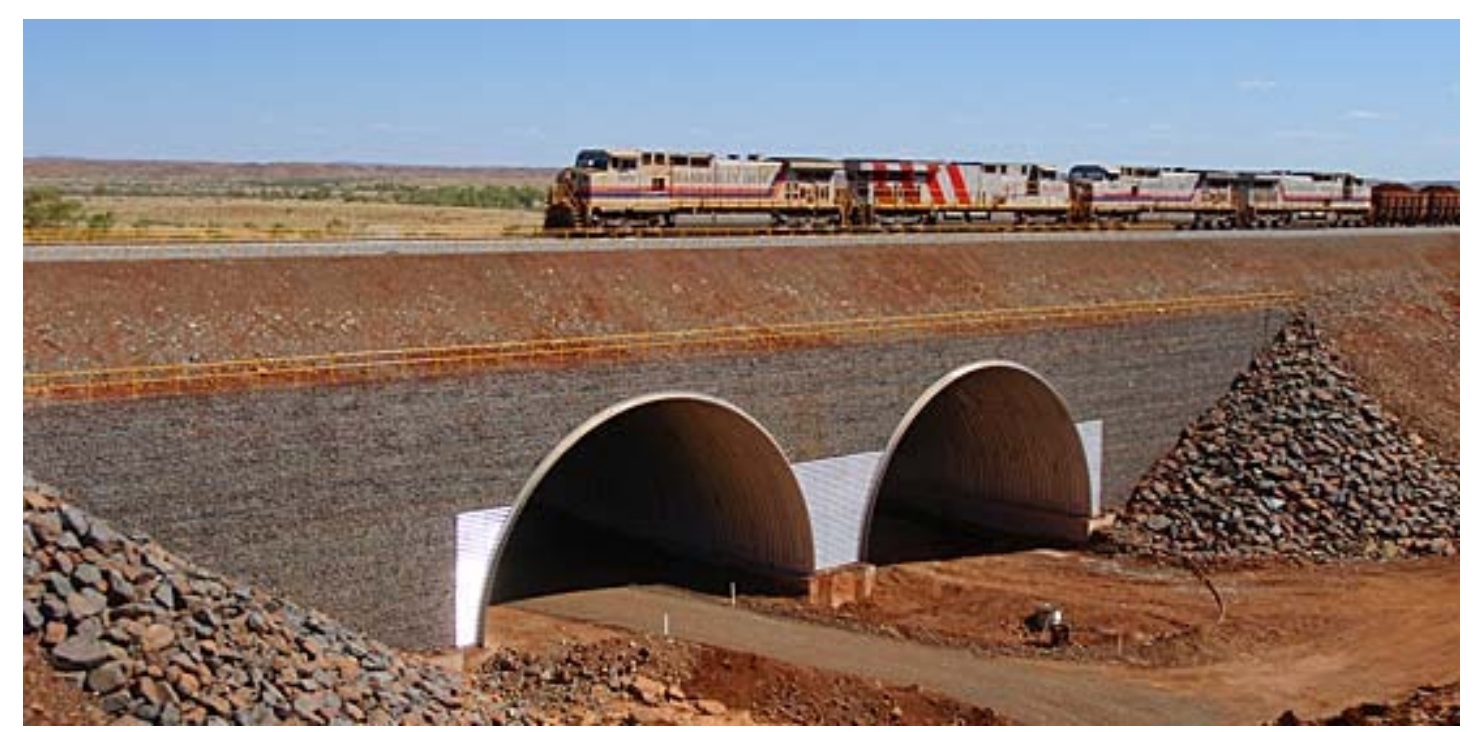

Figure 4-21 Double Super-Cor® Bridge by Big R Bridge [10]

\subsubsection{Application}

Big R Bridge states that the Super-Cor ${ }^{\circledR}$ bridge superstructure can be used for spans exceeding 82 feet. The superstructure supports the deck and applied live loads while allowing for traversing traffic underneath the bridge. [10]

\subsubsection{Constructability}

The Super-Cor ${ }^{\circledR}$ panels are bolted together and are connected to the footing through either bolts or anchors depending on the footer material. Earth retaining structures and backfill make up the rest of the bridge structure that supports the roadway. [10] 


\subsubsection{Evaluation}

This system can be built quickly and has all of the same benefits as the Corrugated Structural Plates. This system has the added benefit of being easily widened by adding more of the angular plates used to make the initial structure. Also, with the light weight, being able to construct the clearing and then move it to the required location can be beneficial in lessening the time for traffic impact.

\subsubsection{Research Needed}

No research needs were found for this modular element.

\subsubsection{Wide Flange Shapes}

\subsubsection{Description}

Wide flange shapes are used as a common superstructure element for bridges between approximately 20 and 90 feet. These elements are aligned parallel to traffic flow under the bridge deck to support the loads of the bridge. Generally the deck is attached to the girders in such a way to make the deck and girders behave cooperatively as composite members. While in longer spans the unit weight of steel used for the bridge can be higher than that of steel plate girders, the unit cost of steel is much lower for rolled members. Transverse stiffeners are not normally required for rolled sections and simple diaphragm details aid in making rolled sections an affordable superstructure. An example of a wide flange rolled steel bridge is provided in Figure 4-22. [11] 


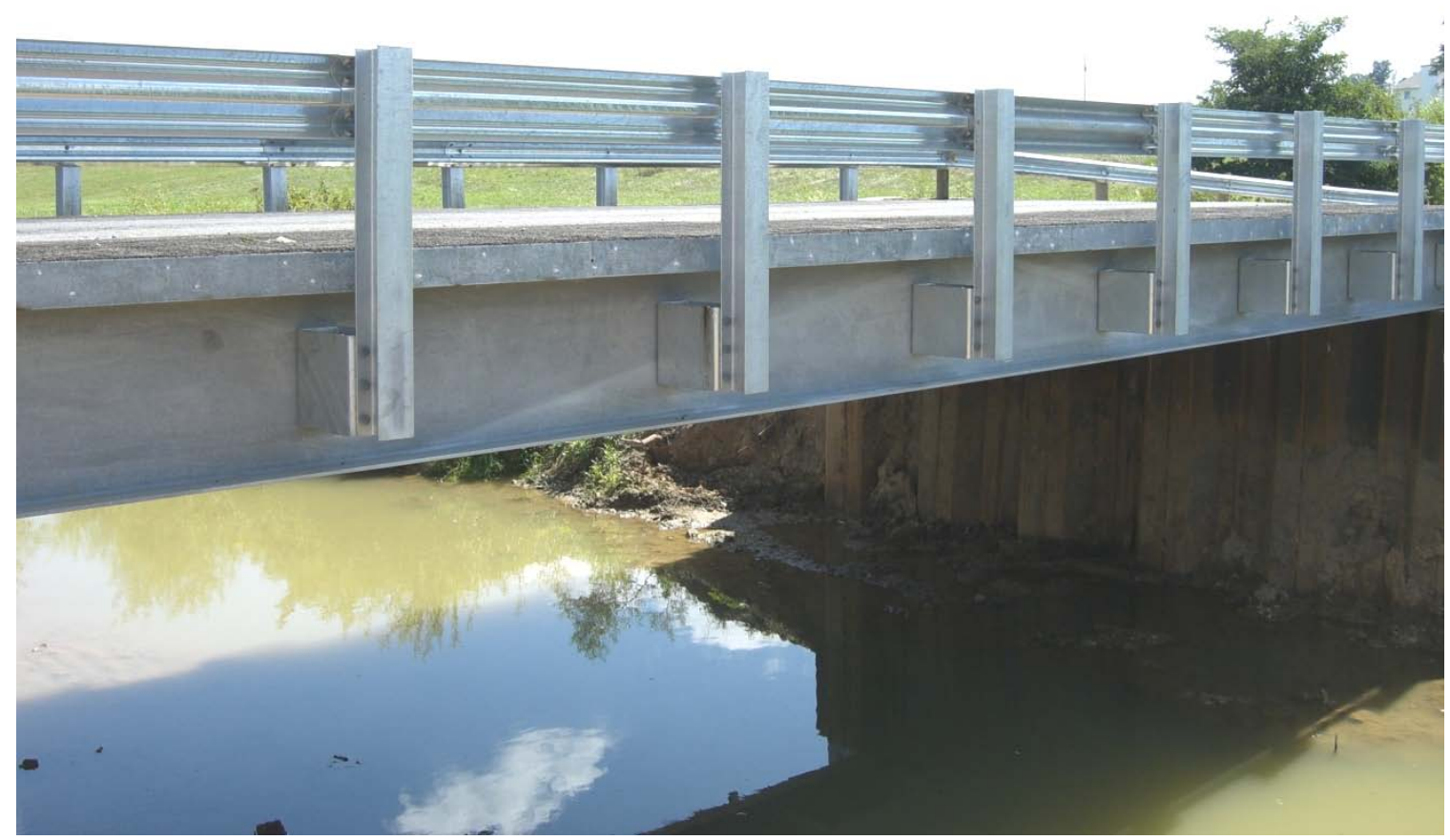

Figure 4-22 Wide Flange Rolled Steel Shapes as Bridge Superstructure (U.S. Bridge Tour)

\subsubsection{Application}

The Short Span Steel Bridge Alliance brochure implies that this alternative can be applied to spans between approximately 20 and 90 feet. The superstructure supports the deck and applied live loads and provides clearance for traverse beneath the bridge. [11]

\subsubsection{Constructability}

Generally, for span lengths less than 200 feet (all bridges considered in this report), girders can be erected with little to no falsework. During erection, pier brackets are often used to provide stability to negative moment sections of the bridge until the positive moment sections are erected. [11]

\subsubsection{Evaluation}

Rolled steel wide flange sections used as the superstructure of short span bridges can be more cost effective due to not required transverse stiffeners and simple diaphragm assembly. The unit weight of steel for the bridge is higher than that of plate girder bridges, though. 


\subsubsection{Research Needed}

No research needs were found for this modular element.

\subsubsection{Plate Girders}

\subsubsection{Description}

Steel plate girders are one of the most common steel superstructure elements. When used in a bridge structure, the plate girders are installed parallel with the direction of traffic. Floorbeams are placed transversely under the deck to distribute the bridge loads. Similar to rolled steel wide flange members, the deck is placed causing the deck and girders to act as composite members. The shape of steel plate girders differ from rolled sections in that rolled sections are doubly-symmetric "I-shaped” sections and steel plate girders can be detailed to be more efficient and are generally only singularly-symettric. These customizing options cause steel plate girders to have a lighter unit weight. The more difficult diaphragm details and the need for transverse stiffeners lead to this choice not always being as cost-efficient as rolled sections for a wide range of short span situations. An example of a bridge using steel plate girders is provided in Figure 4-23. [11]

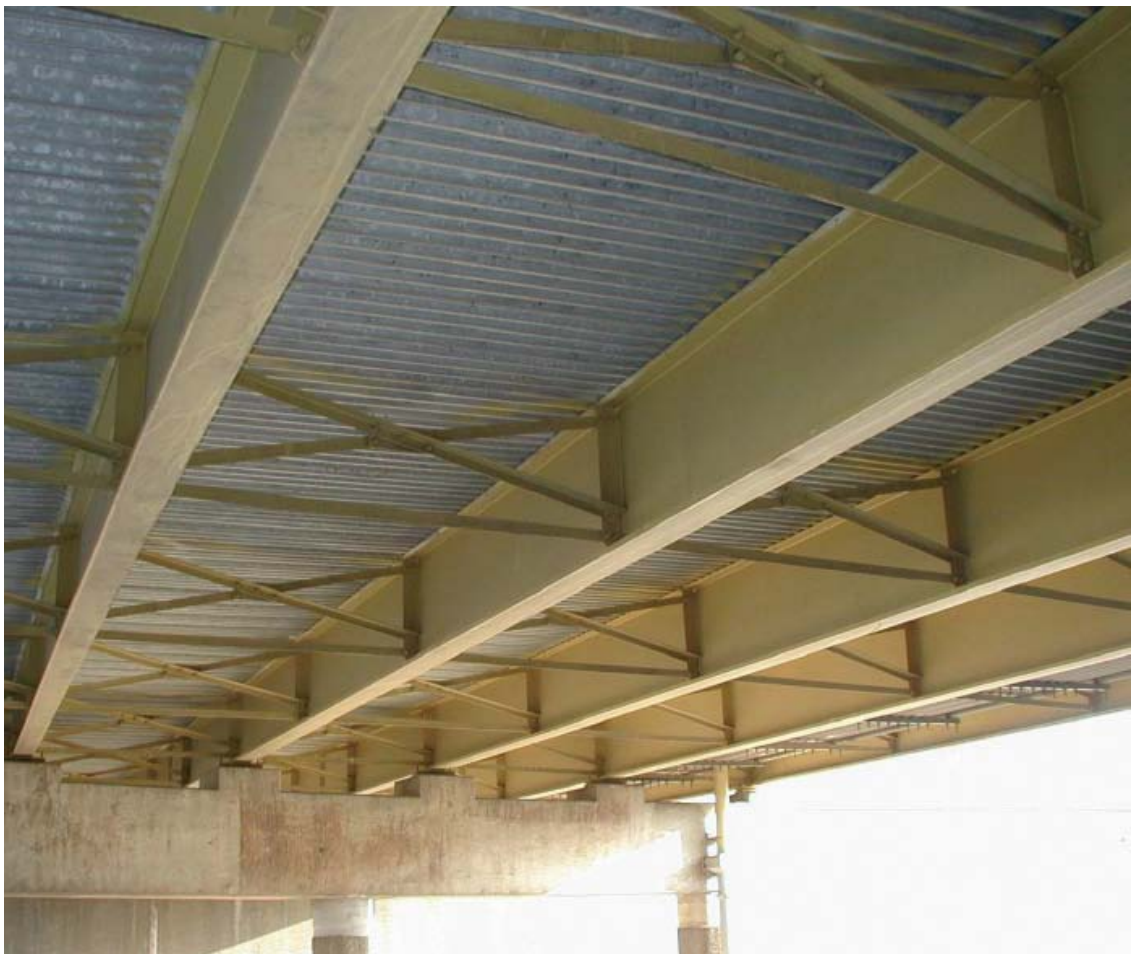

Figure 4-23 Steel Plate Girders as Bridge Superstructure [11] 


\subsubsection{Application}

The Short Span Steel Bridge Alliance brochure implies that this alternative can only be applied to spans between approximately 60 and 140 feet. The superstructure supports the deck and applied live loads and provides clearance for traverse beneath the bridge. [11]

\subsubsection{Constructability}

Generally, for span lengths less than 200 feet (all bridges considered in this report), girders can be erected with little to no falsework. During erection, pier brackets are often used to provide stability to negative moment sections of the bridge until the positive moment sections are erected. [11]

\subsubsection{Evaluation}

This system is more efficient in steel weight per unit length than a rolled steel girder system but is not always as cost effective. Similar to rolled steel sections, this system acts as a composite section with the deck.

\subsubsection{Research Needed}

No research needs were found for this modular element.

\subsubsection{Steel Truss Bridge}

\subsubsection{Cambridge Steel Truss Bridge}

\subsection{Description}

The superstructure of a Cambridge Steel Truss Bridges is made up of the two truss structures on the sides of the bridge. Despite the trusses being composed of discrete members (arranged to form triangles) that are subjected primarily to axial loads, the two trusses generally react like two large support beams. Floorbeams are attached to the truss and run perpendicular to the flow of traffic to support the bridge loads that are distributed by stringers that run parallel with the flow of traffic. The top and bottom members of the truss system, chords, are often attached laterally to provide stiffness and resistance to wind loads. For the Cambridge Steel Truss Bridge, the top chords are generally arched. An example of a Cambridge Steel Truss Bridge is provided in Figure 4-24. [11] 


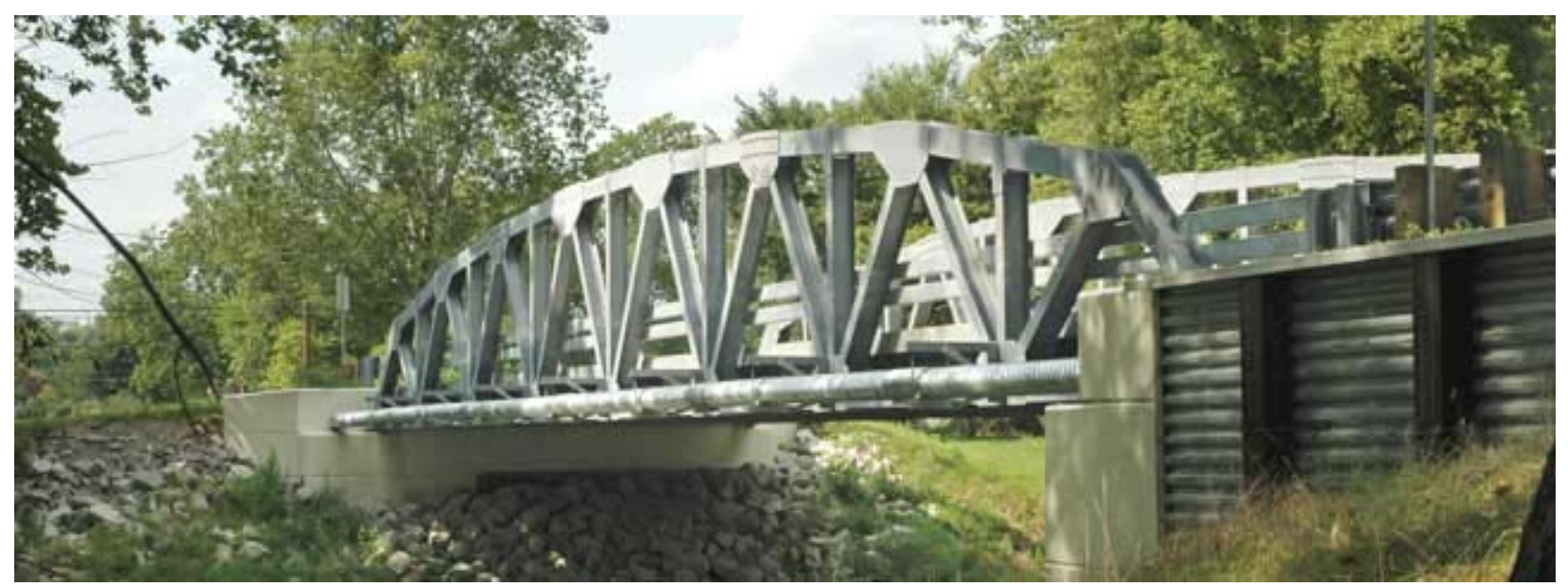

Figure 4-24 Cambridge Steel Truss Bridge [47]

\subsection{Application}

This type of Truss System is installed along the sides of the bridge deck with floorbeams connecting the bottom chords to support the deck. This type of superstructure can support bridges of varying spans. [11]

\subsection{Constructability}

The members to be assembled are lighter for a truss system than those used for rolled steel girders and plate steel girders. There are of course several more members to be assembled in a truss system than in other superstructure methods. Because of the lighter member size, smaller cranes can be used in the construction process. The elements are connected to one another using bolted connections. For simple span trusses, falsework towers are usually required to facilitate erection. For continuous trusses, a cantilever erection can be used using falsework towers near the interior piers. [11]

\subsection{Evaluation}

Cambridge Steel Truss Bridges are considered highly aesthetically pleasing. The erection process can be much more complicated than that of steel plate girder bridges. Some companies are transporting the trusses as prefabricated elements to the bridge site, quickening the bridge construction process.

\subsection{Research Needed}

No research needs were found for this modular element. 


\subsubsection{Warren Steel Truss Bridge}

\subsection{Description}

This superstructure system is similar to the Cambridge Steel Truss Bridge system in that it consists of two trusses acting continuously between the abutments of the bridge. Again, the trusses are made up of top and bottom chords with axially loaded discrete members between them. This truss system differs from the Cambridge system in that the top and bottom chords are parallel and all of the discrete sections are arranged in a way to create inverted alternating equilateral triangles. An example of a Warren Truss Bridge is provided in Figure 4-25 and a view of a typical section of a Warren Truss Bridge is provided in Figure 4-26. [24]

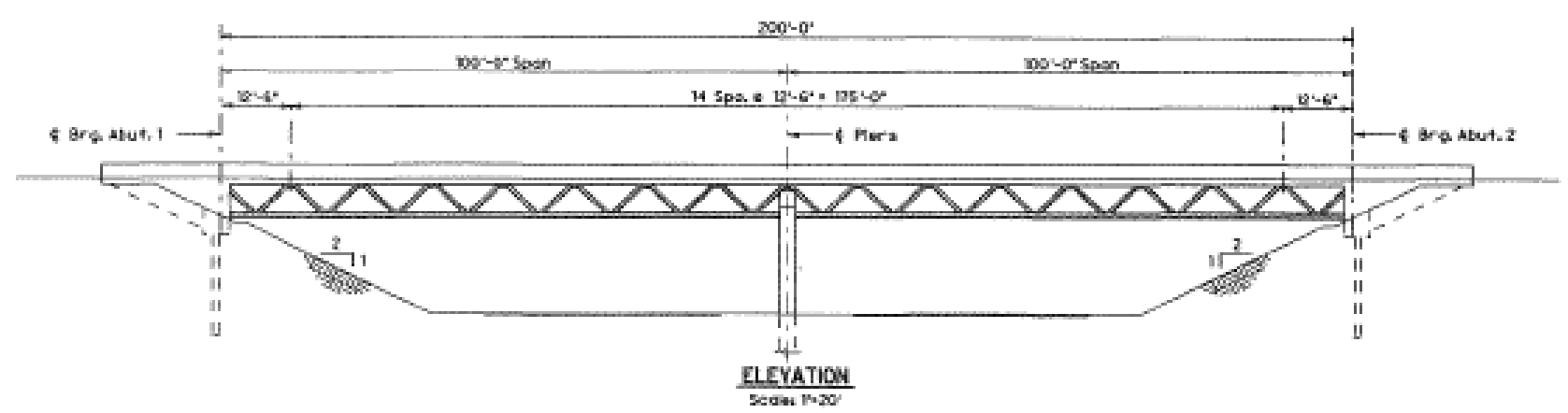

Figure 4-25 Plan of a Warren Truss Bridge [24]

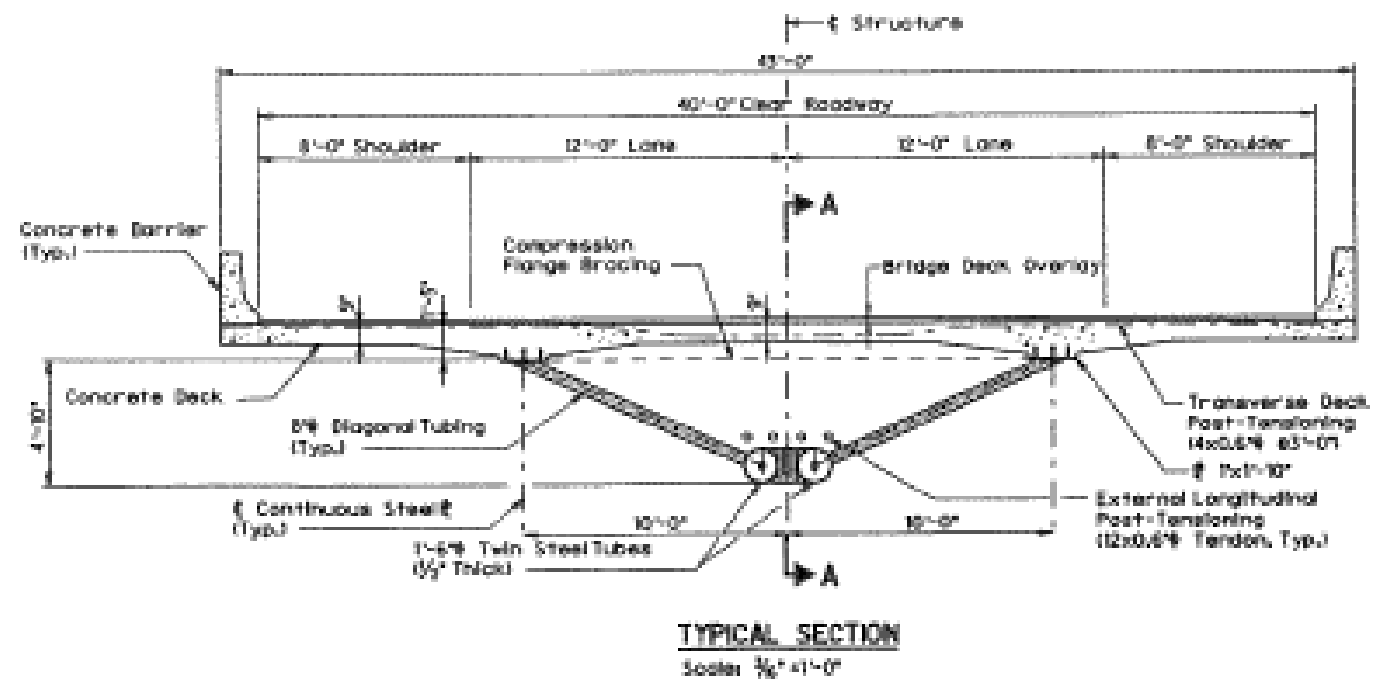

Figure 4-26 Typical Section of Warren Truss Bridge [24]

\subsection{Application}

This type of truss system can be applied to the sides (similar to the Cambridge Truss) or underneath (as shown in Figure 4-26). [24] 


\subsection{Constructability}

For the Warren Truss Bridge shown in Figure 4-26, the truss members are prefabricated in sections. The diagonals are welded to the top and bottom chords. The truss sections are delivered to the job-site by truck to be assembled. During erection the sections are supported by permanent pier or temporary support. The trusses will be used to support the falsework to be used for the deck placement. [24]

\subsection{Evaluation}

Similar to the Cambridge Steel Truss Bridges, Warren Steel Truss Bridges are considered aesthetically pleasing. Also these bridges can be more complex to construct unless set as a modular system.

\subsection{Research Needed}

No research needs were found for this modular element.

\subsubsection{Steel Space Truss Bridge}

\subsection{Description}

Where the last two truss systems involved planar trusses, steel space trusses are constructed to be three-dimensional. For this truss scenario, the truss is composed of one chords connected in three planes by the axial members to form a triangular shape. These superstructure elements can be difficult to use for bridge construction unless they are installed as modular sections. An example of a steel space truss bridge is provided in Figure 4-27 and a view of a typical section of a steel space truss bridge is provided in Figure 4-28. [24]

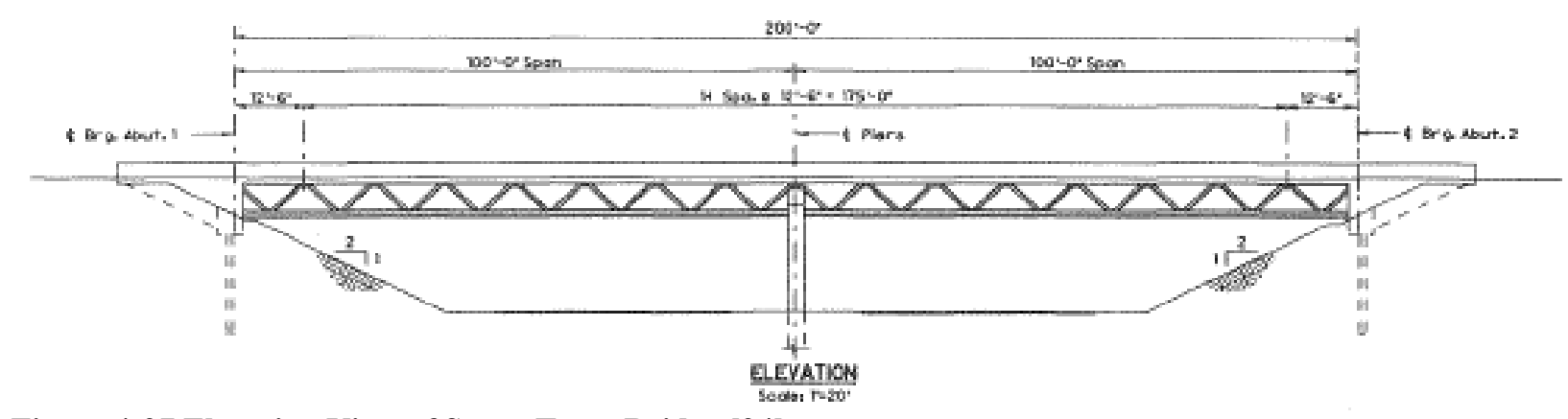

Figure 4-27 Elevation View of Space Truss Bridge [24] 


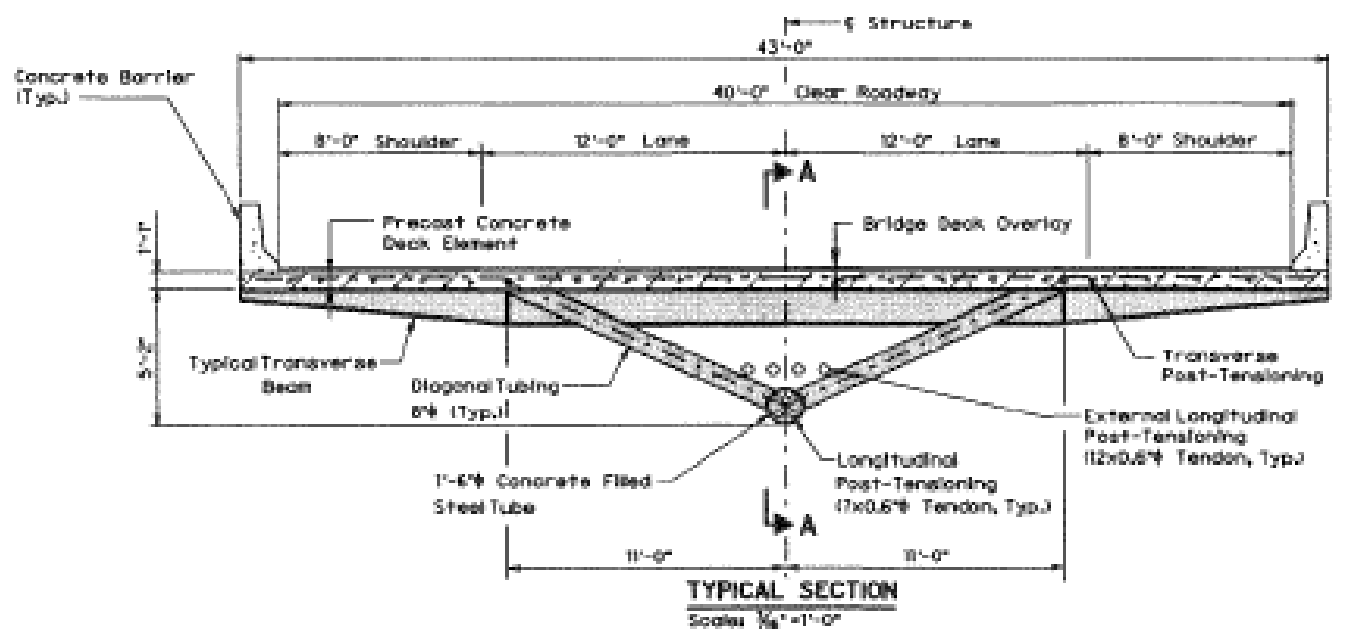

Figure 4-28 Typical Section of Space Truss Bridge [24]

\subsection{Application}

The space truss system is applied to the bottom side of the bridge deck (as shown in Figure 4-28). [24]

\subsection{Constructability}

For the space truss bridge shown in Figure 4-28, the truss is prefabricated in the form of modular units. These sections are transported to the bridge site by truck. The modulated units are installed using erection beams or temporary falsework. Erection beams would be installed between abutments and piers to support the modular sections and lessening traffic disruption. The deck can then be installed atop the superstructure. [24]

\subsection{Evaluation}

As other steel bridge truss systems, they are considered aesthetically pleasing. Due to the three-dimensional truss system, these can be difficult to construct on site unless the elements are installed as modular sections.

\subsection{Research Needed}

No research needs were found for this modular element.

\subsection{Short Span Steel Bridge Decks}

The decking system of a bridge can be defined as the surface which the traversing traffic drives upon. This is the surface which is used as a continuation of the driving surface on either side of the bridge. Commonly, cast-in-place concrete is used as the method of placing a deck on a short span bridge, but due to the time of preparing formwork this can be a very time consuming process. Prefabricated deck systems are some of the most commonly used applications of 
modular bridge technology. This section will go into greater detail of describing, illustrating and evaluating different methods of prefabricated deck systems for short span modular steel bridges.

\subsubsection{Full Depth Precast Deck Slabs}

\subsubsection{Description}

Full depth precast deck slabs are one of the most common prefabricated deck systems. With this decking system, the deck is poured and cast in section before being delivered and installed at the bridge site. The reinforcing in the concrete deck is generally either mild reinforcement or prestressing. An example of a full depth precast deck slab can be seen in Figure 4-29. [14]

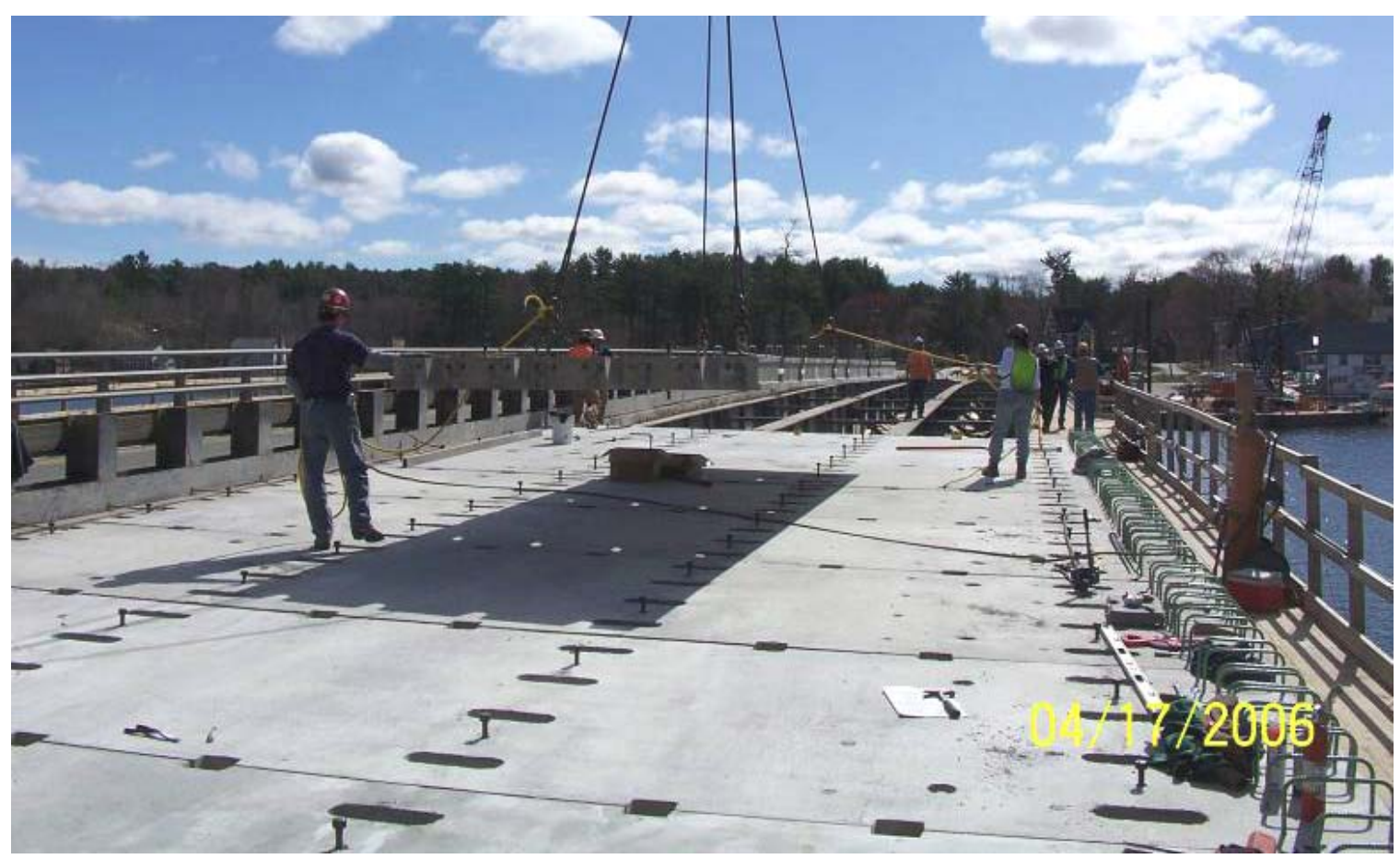

Figure 4-29 Full Depth Precast Deck Panels [14]

\subsubsection{Application}

Full depth precast deck panels are used as an alternative to cast-in-place concrete decks. They provide a driving surface for traffic. [14]

\subsubsection{Constructability}

In the strength direction of the panels, the panels will be connected progressively and small reinforced closure pours can be used. In the distribution direction of the panels, grouted shear key connections are used. [14] 


\subsubsection{Evaluation}

This system has been used by a number of states already and significant research has been performed to improve the technology. A PCI Bridge Technical committee has published design and detailing standards for full depth precast deck slabs making design easier for the engineer.

\subsubsection{Research Needed}

No research needs were found for this modular element.

\subsubsection{Open Grid Decks}

\subsubsection{Description}

Open grid decks can be described as small-scale steel framing systems used as a bridge deck. They are made up of transverse sections to distribute the load across main rail members providing strength to the decking system. An example of an open grid deck is provided in Figure 4-30. [14]

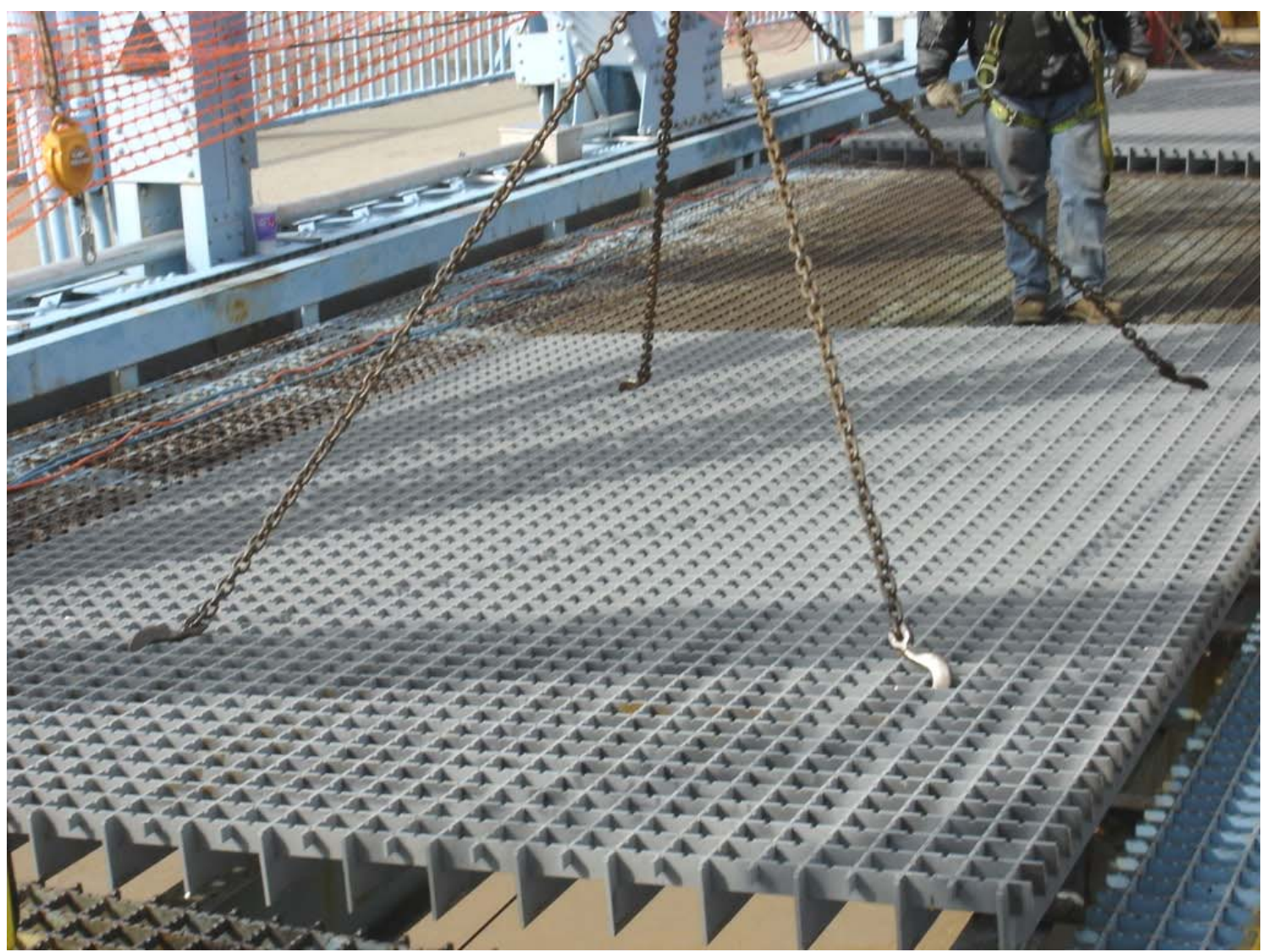

Figure 4-30 Open Grid Decking Being Placed [37] 


\subsubsection{Application}

Open grid deck panels are used as an alternative to cast-in-place concrete decks. They provide a driving surface for traffic. [14]

\subsubsection{Constructability}

The connection between grid panels is made up of bolted or welded connections. Due to the possibility of fatigue issues, bolted connections are preferred. Bolted or weld connections can be used to connect the deck panels to the steel frame. Grouted shear connector pockets are another option for this connection detail. Generally, when steel guard rails are to be mounted on the deck panels, bolted connections are used. [14]

\subsubsection{Evaluation}

These decks are beneficial for situations where lightweight decks are required, such as movable bridges and suspension bridges.

\subsubsection{Research Needed}

No research needs were found for this modular element.

\subsubsection{Concrete/Steel Hybrid Decks}

\subsubsection{Description}

Concrete/steel hybrid decks consist of a combination of the open grid deck and the full depth precast deck panel systems. There are two common forms of this decking system: partially filled grid decks and exodermic decks. The partially filled grid decks involve casting concrete for the lower section of the deck and including the open grid. Later the rest of the deck will be poured on site. The exodermic decks involve the same process as the partially filled grid decks except that a majority of the concrete is placed above the steel grid. These systems act as composite members. An example of an exodermic deck is provided in Figure 4-31. [14] 


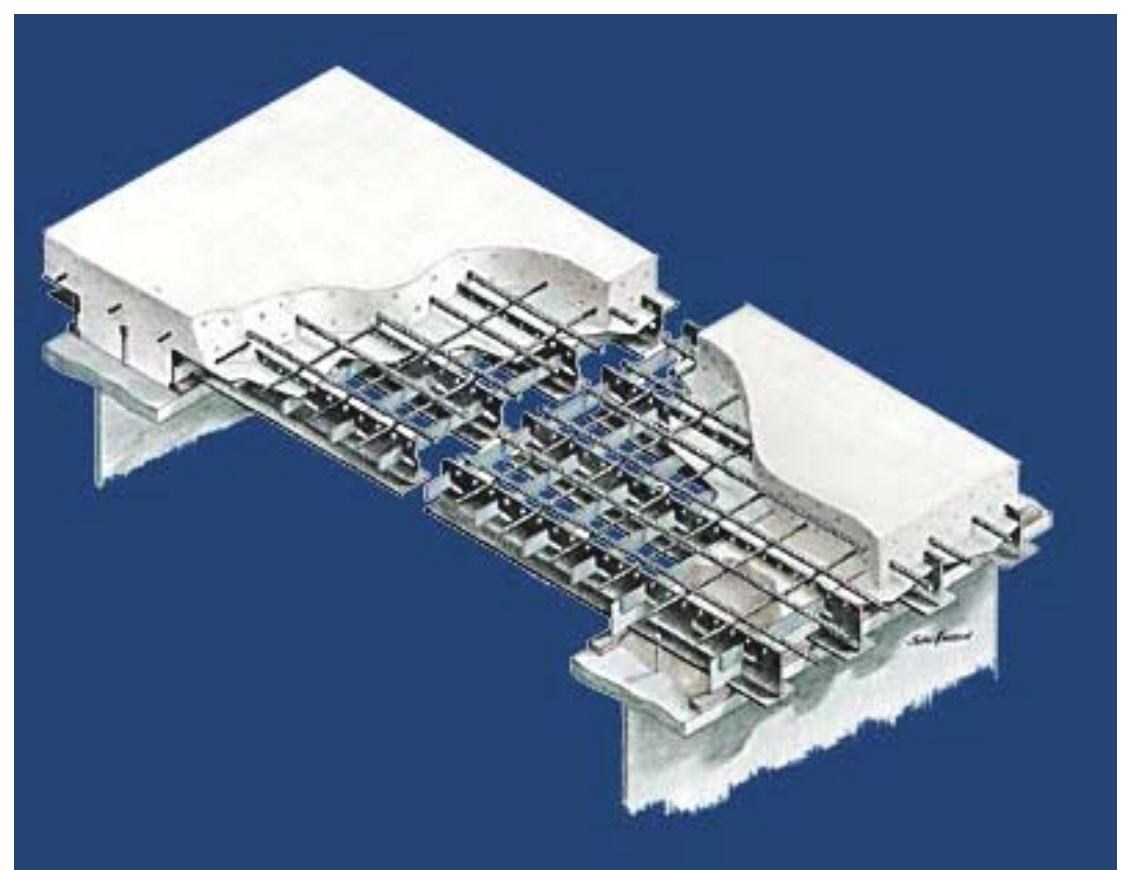

Figure 4-31 Exodermic Deck Details courtesy of the D.S. Brown Company [14]

\subsubsection{Application}

Concrete/steel hybrid deck panels are used as an alternative to cast-in-place concrete decks. They provide a driving surface for traffic. [14]

\subsubsection{Constructability}

To connect the separate panels to one another, bolted or welded connections are used. Since the deck is very similar to a full depth precast concrete depth, welded stud shear connectors are used to connect the deck panels to the steel framing. [14]

\subsubsection{Evaluation}

With the partially filled grid decks, the deck can be placed without on-site formwork, which is a time-consuming process in bridge construction. With the exodermic deck, the benefit of not having to prepare formwork is again prevalent. This case also has the benefit of the composite action in the deck increasing the efficiency of the system.

\subsubsection{Research Needed}

No research needs were found for this modular element. 


\subsubsection{Fiber Reinforced Polymer Decks}

\subsubsection{Description}

Fiber reinforced polymers (FRP), primarily used in the aerospace industry, have started being applied to the design of bridges. FRP composites are primarily made up of fibers aligned within a resin material in such a way to make a very strong and very customizable material. The most common fiber choices are glass and carbon fibers. In the use of bridge decking, FRP have been molded into cellular panels that can be installed as full-depth deck panels. An example of an FRP deck panel is provided in Figure 4-32. [14]

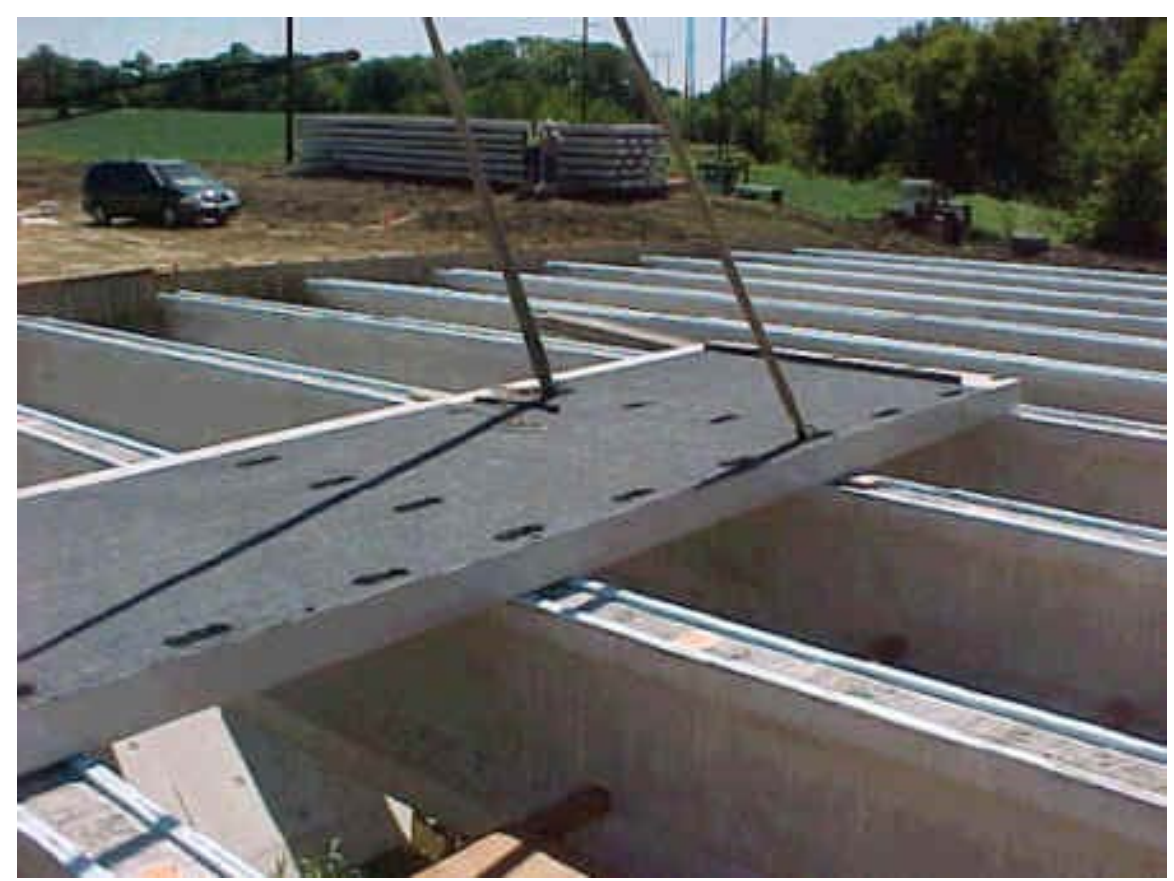

Figure 4-32 FRP Deck Panel Installation [22]

\subsubsection{Application}

FRP deck panels are used as an alternative to cast-in-place concrete decks. They provide a driving surface for traffic. [14]

\subsubsection{Constructability}

To connect the panels to one another, the panels are design to interlock with male-female shear keys. Another option for connecting the panels is the use of high quality epoxy adhesives. To connect the panels to the steel framing, pockets are formed over the beams to allow for welded stud shear connectors and non-shrink grout. Bolts can also be used to connect the panels to the steel framing. [14] 


\subsubsection{Evaluation}

FRP products have the benefits of having high strength, low weight, high stiffness to weight ratio, and corrosion resistance. The deck being prepared in panels, transporting the deck to the jobsite and placing the deck panels is efficient.

\subsubsection{Research Needed}

Research is needed for the durability of the wearing surface of this type of modular bridge element.

\subsubsection{Partial Depth Precast Concrete Deck Panels}

\subsubsection{Description}

The partial depth precast concrete deck panels system involves first placing a layer of deck panels on the steel superstructure and then pouring the remainder of the reinforced concrete deck at a later time. This method prevents the need for as much formwork (normally, the most time consuming part of concrete deck placement) as a cast-in-place concrete deck. An example of a partial depth precast concrete deck panel is shown in Figure 4-33. [14]

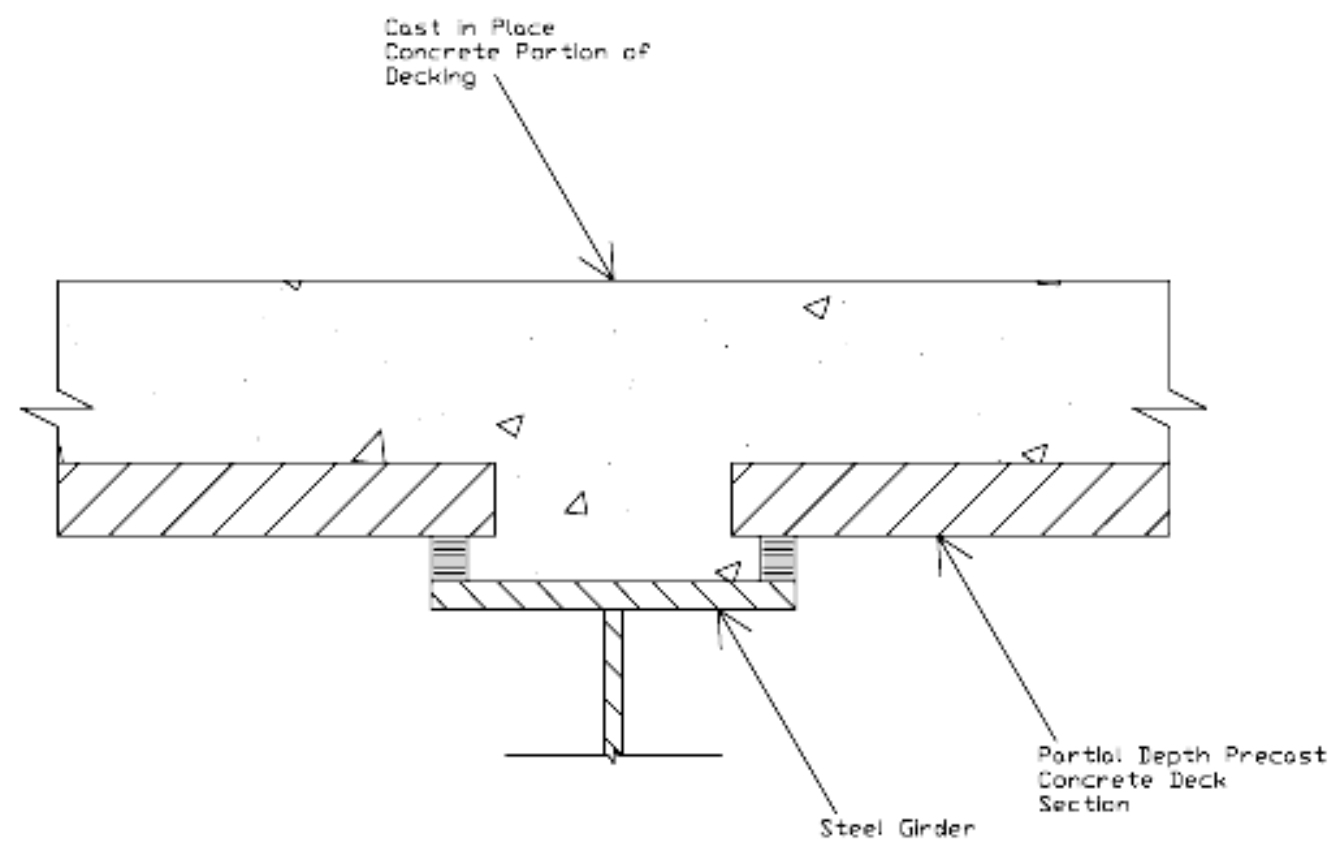

Figure 4-33 Diagram of Bridge Deck Employing Partial Depth Precast Concrete Deck Panel 


\subsubsection{Application}

Partial depth precast deck panels are used as an alternative to cast-in-place concrete decks. They provide a driving surface for traffic. [14]

\subsubsection{Constructability}

The panels will be connected to one another when the rest of the deck panel depth is being poured. To connect the panels to the steel framing, welded stud shear connectors are used in the gap between adjacent panels. [14]

\subsubsection{Evaluation}

With the lower portion of the deck being precast, forming is not required in setting up for the deck system. This system is similar to the partially filled grid deck.

\subsubsection{Research Needed}

Research on the effectiveness of the composite action between the deck and the girders may be necessary.

\subsubsection{Timber Deck Panels}

\subsubsection{Description}

Due to a great amount of study by the United States Department of Agriculture Forests Products Laboratory (USDA FPL), there is a significant amount of information about timber panels and beams as well as standard details for timber bridges. Currently, timber bridges are primarily used on low-volume travel-ways, but the same design idea can be applied to larger volume roads as well. Timber deck panels can be applied to superstructures besides timber. Standard details are available for attaching transverse timber panels to longitudinal stringers. The bridges often incorporate crash-tested railings attached directly to the timber deck panels. Generally, an asphalt wear surface is applied to protect the panels. An example of timber deck panels being applied to a steel bridge is provided in Figure 4-34. [14] 


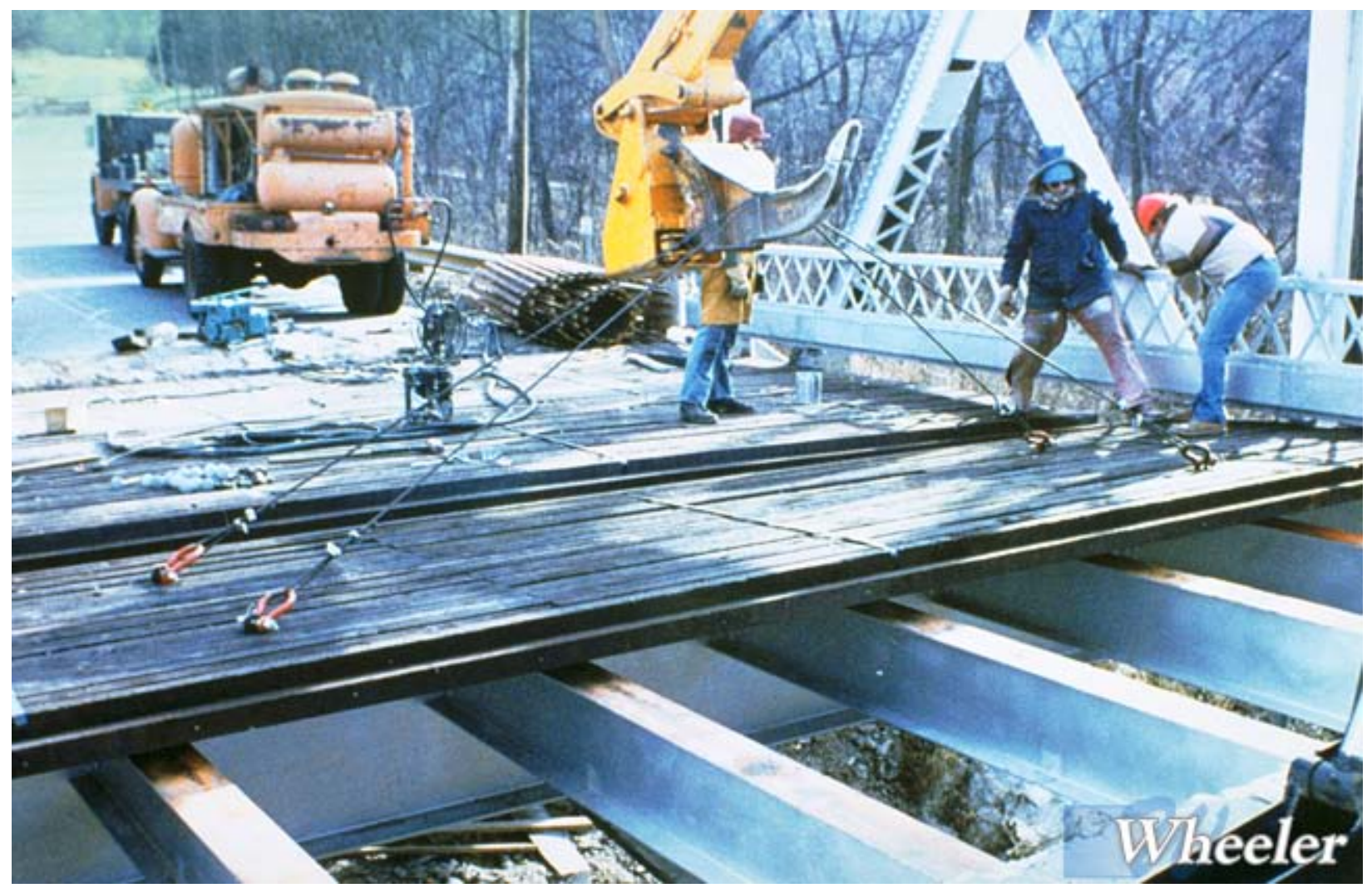

Figure 4-34 Installation of Transverse Timber Deck onto Steel Stringers [52]

\subsubsection{Application}

Timber deck panels are used as an alternative to cast-in-place concrete decks. They provide a driving surface for traffic. [14]

\subsubsection{Constructability}

These deck panels have been connected to one another using steel dowels placed in the depth of the panels. Currently, load transfer beams are placed mid-bay between the stringers to transfer the shear more effectively. To connect the deck panels to the steel framing, bolts and brackets are used. It should be remembered that this does not cause composite action. [14]

\subsubsection{Evaluation}

Timber decks are generally used for low-volume roads. When attached to beams, composite action does not take place.

\subsubsection{Research Needed}

Currently, research is being performed on new waterproofing products to be applied to the top of the deck panels to protect the steel from moisture moving through the timber deck panels. 


\subsubsection{Steel Orthotropic Decks}

\subsubsection{Description}

Steel orthotropic decks consist of steel elements assembled through welding off-site to create a prefabricated system of decking and floor beams to be installed on-site. Several bridges in the world with long spans have utilized orthotropic steel deck systems in their superstructures. Even though these types of decks have been used extensively in Europe, Asia and South America; the concept has not yet fully been accepted in the United States. With the growing trend towards quicker construction with an overall longer bridge life, the steel orthotropic deck may be an economic solution. If the decks are designed integral, with the girders as a common flange, cost savings on designing these components can be realized. This method can lead to a completely steel superstructure which has the potential to provide a long service life. The other leading benefits of this bridge decking system are the minimization of dead load on the bridge and the rapid construction that will lessen the impact on traffic. An example of a steel orthotropic deck is shown in Figure 4-35. [25]

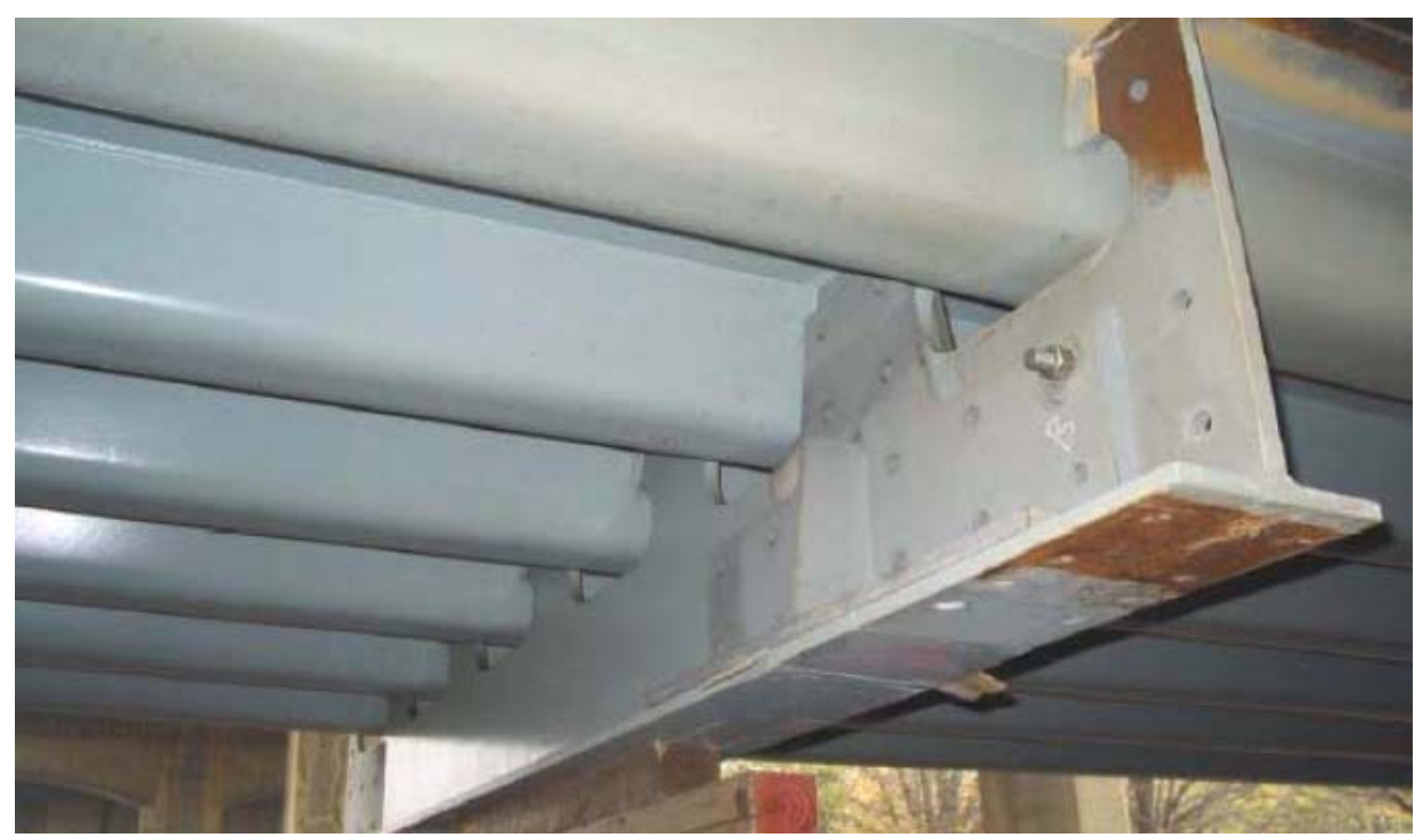

Figure 4-35 Underside of Steel Orthotropic Deck [25]

There have been past problems with steel orthotropic decks especially in the area of fatigue cracking in the weld connections. Welding details are being developed to minimize this type of cracking. By their nature, steel orthotropic decks are inherently redundant in their design causing many of these fatigue cracks to arrest themselves. [25] 


\subsubsection{Application}

Steel orthotropic decks can either be used as a decking system to the steel superstructure frame on site or can be prefabricated with steel girders and installed on site as part of a modular bridge system. [25]

\subsubsection{Constructability}

The multiple elements that make up steel orthotropic deck systems are fabricated off-site to make bridge deck modules that will be assembled and field welded at the bridge site. The sections are generally light enough to place safely with a single crane. [25]

\subsubsection{Evaluation}

Steel orthotropic decks have the potential to be a great solution for modular steel bridges. Their rapid construction, minimization of dead load and long service life are great benefits that could really help the infrastructure of the United States. Once research provides more efficient means of fatigue crack control in these deck systems and more success stories of this system in U.S. bridge applications accumulate, a trend in the use of this system is likely to develop.

\subsubsection{Research Needed}

Research on fatigue cracking in steel orthotropic decks is being performed at the ATLSS Engineering Research Center at Lehigh University. [41]

\subsubsection{Sandwich Panel Modular Steel Bridge Deck}

\subsubsection{Description}

This bridge decking system is composed of two layers of steel plates attached by welds to an inner layer of HSS steel members. The deck is transported to the bridge-site in 8 foot wide panel sections. The top plate of the "sandwich" is generally a 5/8" steel plate to resist wheel loads and ensure the performance of the wearing surface; the bottom plate of the "sandwich" is generally a 3/16" plate to accommodate for the weld of the sandwich materials. The panels are field welded on-site to remove the bridge joints on the top of the deck and powder actuated fasteners are used to attach panels on the bottom plates. Precast Jersey barriers can then be bolted onto the deck and finally the wearing surface is applied. A diagram of the sandwich panel modular steel bridge deck assembly is provided in Figure 4-36 and an example of the panel assembly is provided in Figure 4-37. [58] 


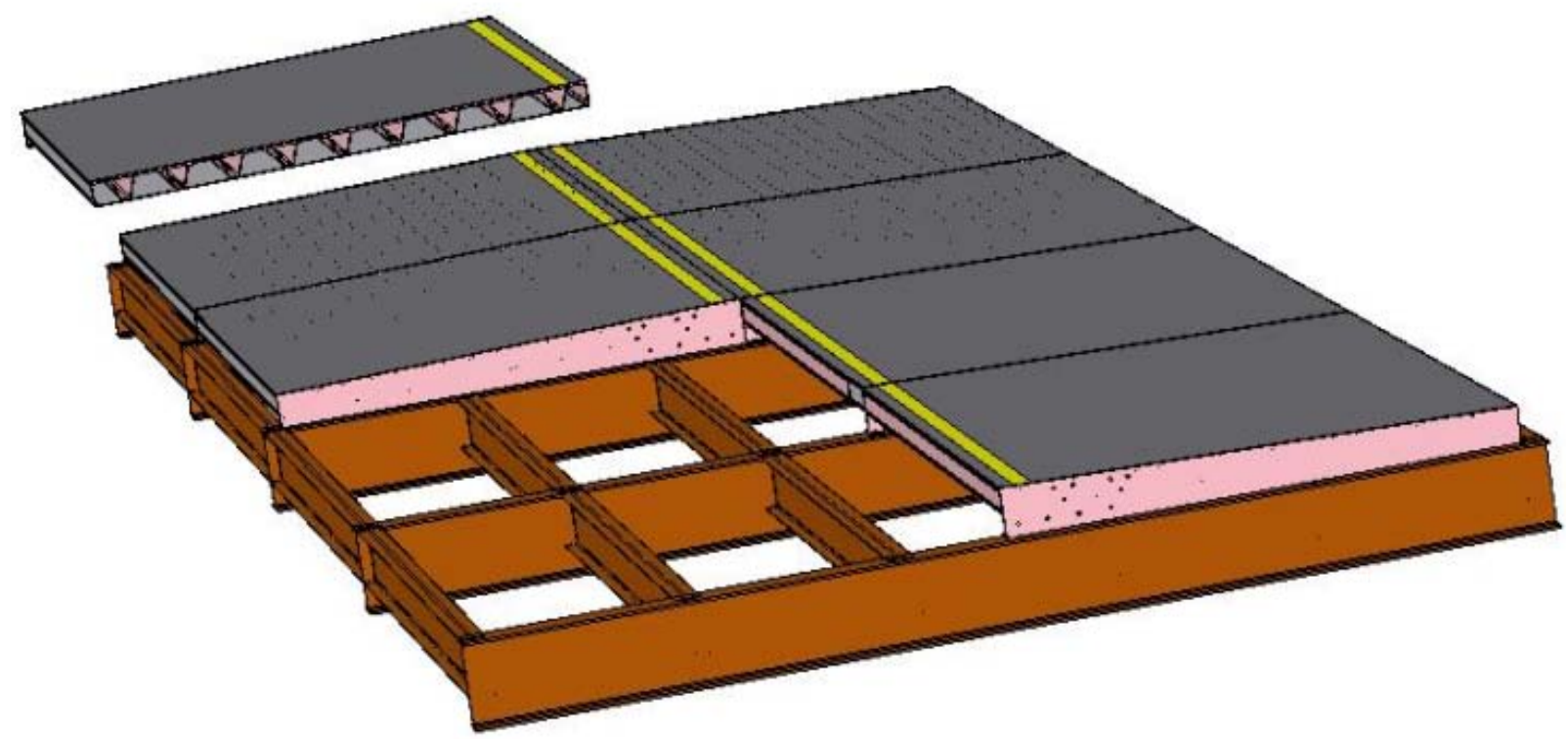

Figure 4-36 Sandwich Panel Modular Steel Bridge Deck System [58]

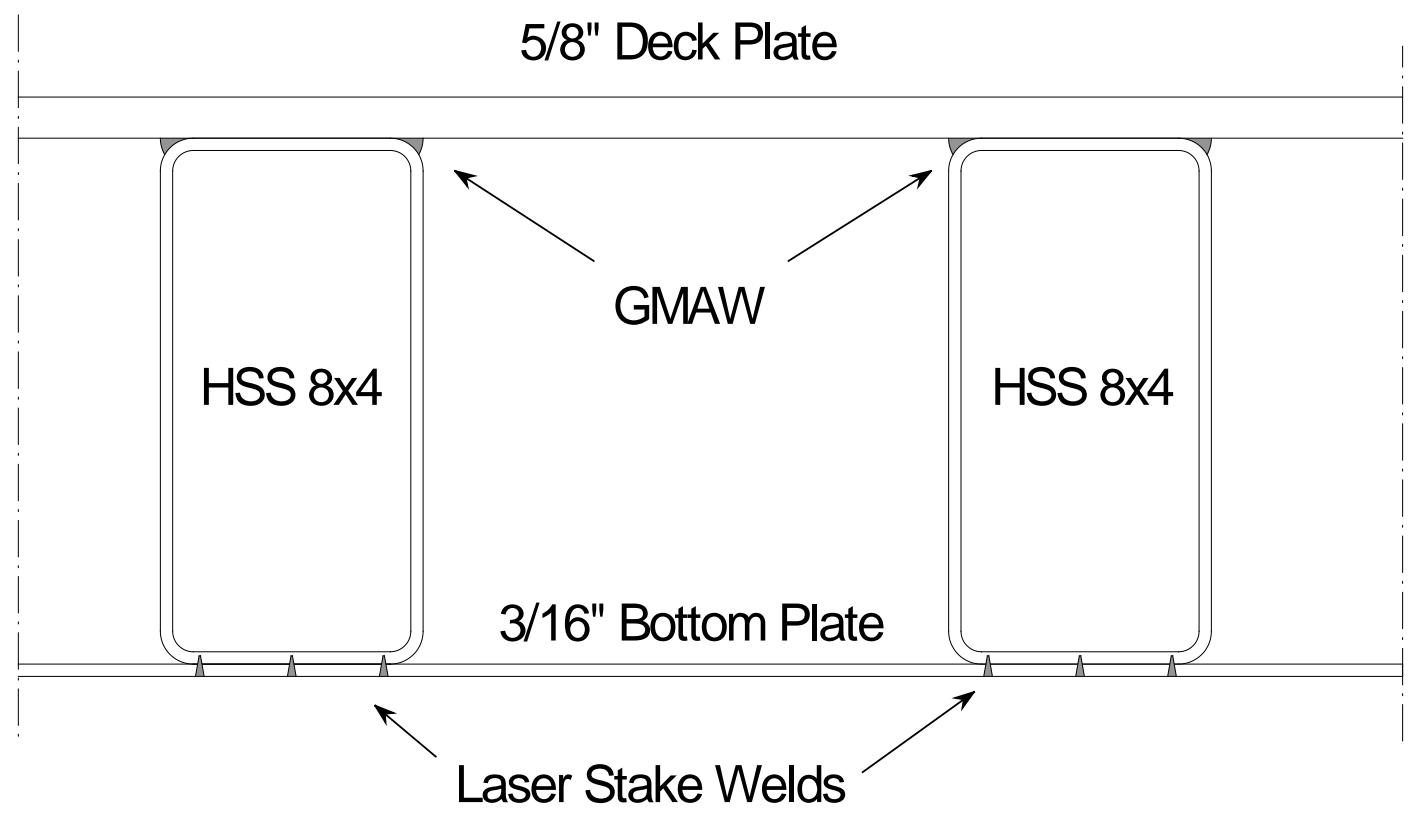

Figure 4-37 Sample "Sandwich" Composition [58]

\subsubsection{Application}

Steel "Sandwich" Panels are used as an alternative to cast-in-place concrete decks. They provide a driving surface for traffic. [58] 


\subsubsection{Constructability}

The panels are field welded on-site to remove the bridge joints on the top of the deck and powder actuated fasteners are used on the bottom plates to attach the panels to one another. The panels can be attached to the steel framing using bolting or grouting. [58]

\subsubsection{Evaluation}

This system is approximately half the weight of a concrete deck. It is suitable for automated mass production. The deck provides the structure flange bracing eliminating the need for cross frames. The construction time of this type of deck is approximately two weeks.

\subsubsection{Research Needed}

No research needs were found for this modular element.

\subsubsection{CANAM (Steel Orthotropic Deck Product)}

\subsubsection{Description}

Orthotropic decks were initially used as a cost-effective and rapid system in the replacement of bridges destroyed in Germany during the Second World War. The technology has grown over the years, especially in Europe and Asia, and has been applied to bridges in North America. The steel orthotropic deck product recently developed by CANAM is fabricated into long panels that facilitate efficient transportation and field assembly with a minimum amount of field welding. An example of their steel orthotropic decking panels is provided in Figure 4-38. [6]

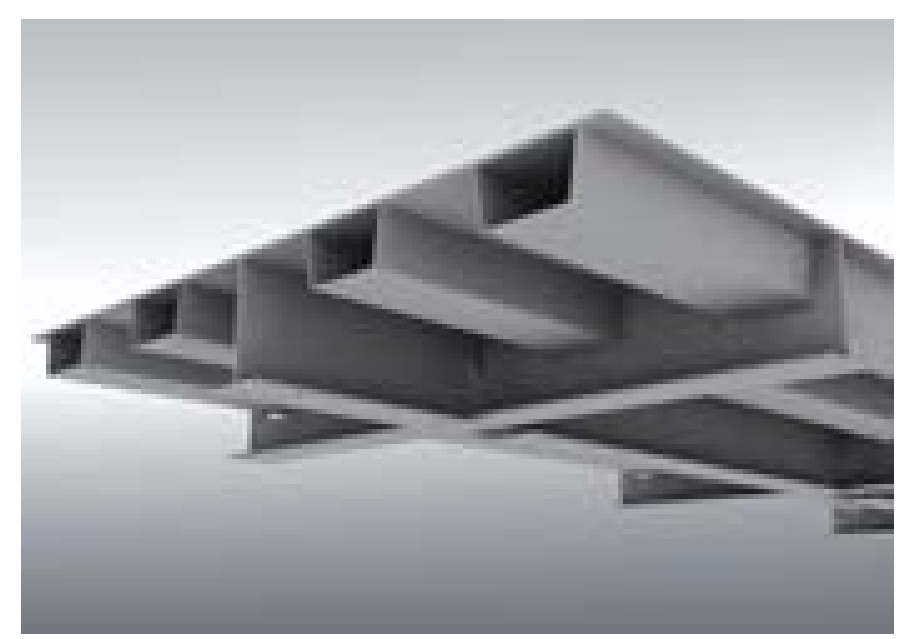

Figure 4-38 CANAM Steel Orthotropic Deck Panel [6] 


\subsubsection{Application}

CANAM Steel Orthotropic Deck Panels are used as an alternative to cast-in-place concrete decks. They provide a driving surface for traffic. [6]

\subsubsection{Constructability}

Inverted Ts (as seen in Figure 4-38) are installed along the longitudinal axis of the bridge to transfer shear and generate composite action between the steel framing and the orthotropic decks. [6]

\subsubsection{Evaluation}

This type of decking has a service life of up to 75 years. Being fabricated in long panels, transportation and assembly is efficient.

\subsubsection{Research Needed}

No research needs were found for this modular element.

\subsection{Short Span Steel Bridge Systems}

Some agencies involved with the application of modular bridge technology in the design and construction of short span steel bridges have developed entire bridge systems for rapid and efficient bridge construction. This section presents some of these specialized bridge systems for short span modular steel bridges, provide illustrations that display these systems and provide an evaluation.

\subsubsection{Amcrete (Inverset ${ }^{\mathrm{TM}}$ )}

\subsubsection{Description}

The Inverset ${ }^{\mathrm{TM}}$ system, produced by Amcrete Products, Inc., is a bridge system consisting of sections of the superstructure and the decking surface prefabricated together. The decks of these elements are cast upside-down and suspended from wide flange steel girders to create the bridge modules. This method causes a prestressing effect in the steel girders, and when the section is turned upright for placement, the deck is in a compression state. An example of an Inverset ${ }^{\mathrm{TM}}$ Bridge system is provided in Figure 4-39. [23] 


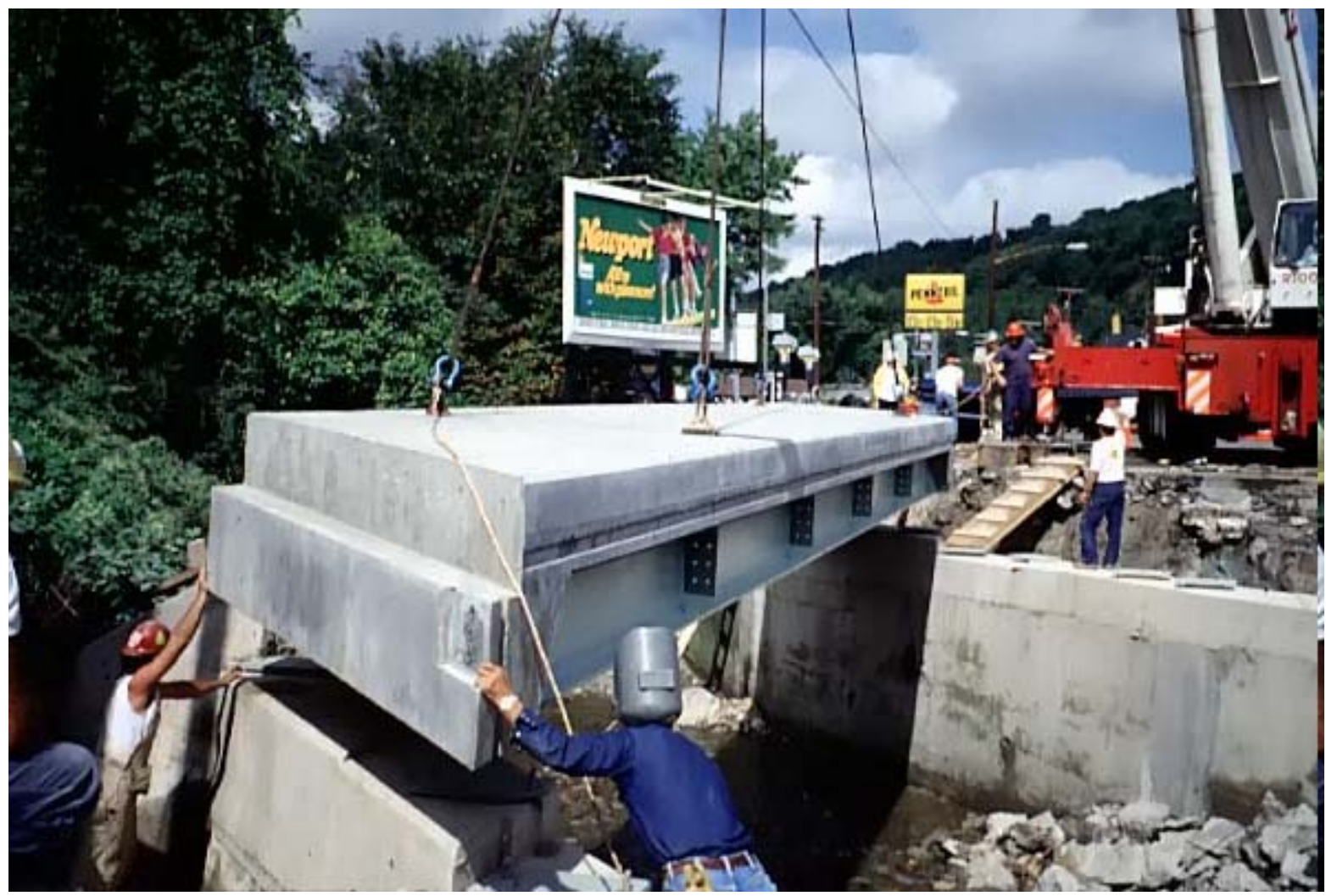

Figure 4-39 Inverset ${ }^{\mathrm{TM}}$ Bridge System

\subsubsection{Application}

Inverset ${ }^{\mathrm{TM}}$ Bridge Systems are used as a combination of the superstructure and decking system of the bridge. It is connected to the bridge substructure on-site. [23]

\subsubsection{Constructability}

The bridge modules are transported to the site completely fabricated. Once on site, the sections are installed onto the substructure. [23]

\subsubsection{Evaluation}

This system allows for a quick and complete installation of the bridge with less on-site connection required during construction. The system acts as a prestressed system due to being cast in the inverted manner. Transportation and installation of these systems is made easier by fewer amount of pieces to assemble on site.

\subsubsection{Research Needed}

No research needs were found for this modular bridge system. 


\subsubsection{Folded Plate Bridge System}

\subsubsection{Description}

The superstructure of this type of bridge is composed of standard shapes built from bending flat steel plates into inverted tub sections using a break press. This type of standard shape has many advantages for bridge owners and steel fabricators. Given the size of the largest press breaks in use today, this system can be used for a bridge with a maximum span of about 60 feet. The folds in the plates are uniform while the thickness and the dimensions vary depending on the required span. In designing these girders, the main variables are the thickness of the plate and where to bend them. An example of the cross-section of a folded plate girder is provided in Figure 4-40 and an example of the modular section is provided in Figure 4-41. [8]

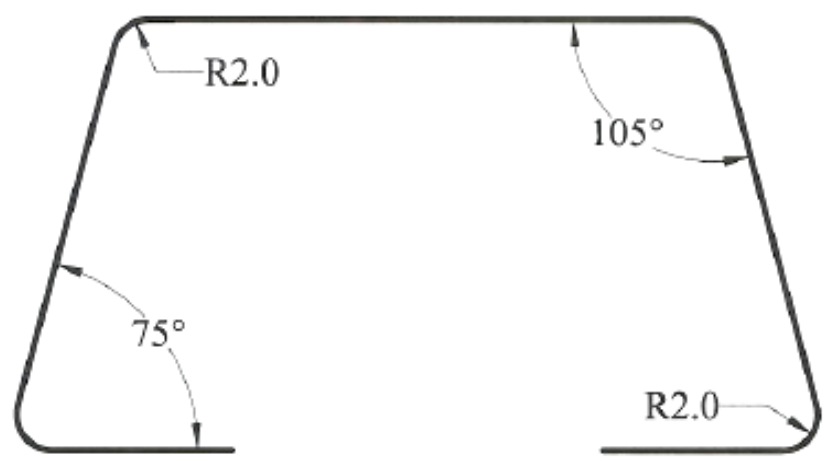

Figure 4-40 Typical Cross Section for Folded Plate Bridge System [8]

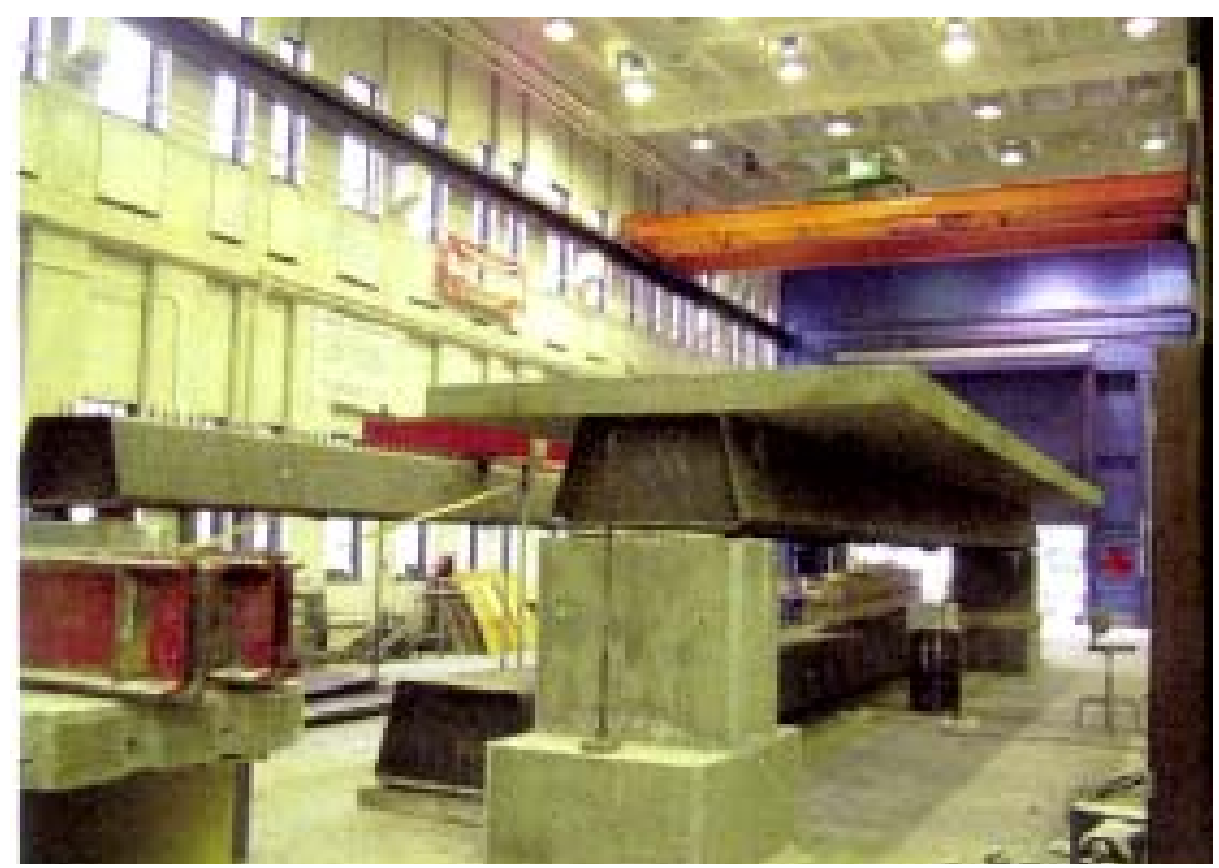

Figure 4-41 Section of Folded Plate Girder Bridge Ready to be Stacked and Shipped [8] 


\subsubsection{Application}

Folded plate girders can be already attached to deck panels in order to be used as a combination of the superstructure and decking systems. This system is installed as the bridge substructure on-site. [8]

\subsubsection{Constructability}

The system can be constructed using accelerated bridge construction methods or traditional bridge construction methods. [8]

\subsubsection{Evaluation}

The inverted tub shape used in this bridge system eliminates the need of cross frames for either global or local stability. Eliminating the need for this extra steel can noticeably reduce the cost of the bridge project. The shape is also designer-friendly as it will accommodate the standard types of formwork used for casting concrete. The width of the top flange (normally between 25 and 35 inches) provides a safer walking surface than that of the traditional wide flange section. Due to the opening of the tub shape being on the bottom of the element, inspection is easier than for standard box or tub girder bridges.

\subsubsection{Research Needed}

Research on folded plate girder sections is being performed at the University of Nebraska-Lincoln. The effect of cold bending is a research topic to that could be perused for this modular bridge system. [8]

\subsubsection{Simple for Dead Load and Continuous for Live Load}

\subsubsection{Description}

This system involves placing simple span steel members across the piers initially but adding the required concrete diaphragm later in construction to create a continuous structural system. This system was developed to keep the ease of assembling simple spans but also have the benefits of a continuous structure for the live loads of traffic use. This system eliminates field splices and simplifies the design details for the connection of the piers to the superstructure (which normally consist of various combinations of anchor bolts, sole plate and often expensive bearing types). An example of the simple for dead load and continuous for live load system is provided in Figure 4-42. [26] 


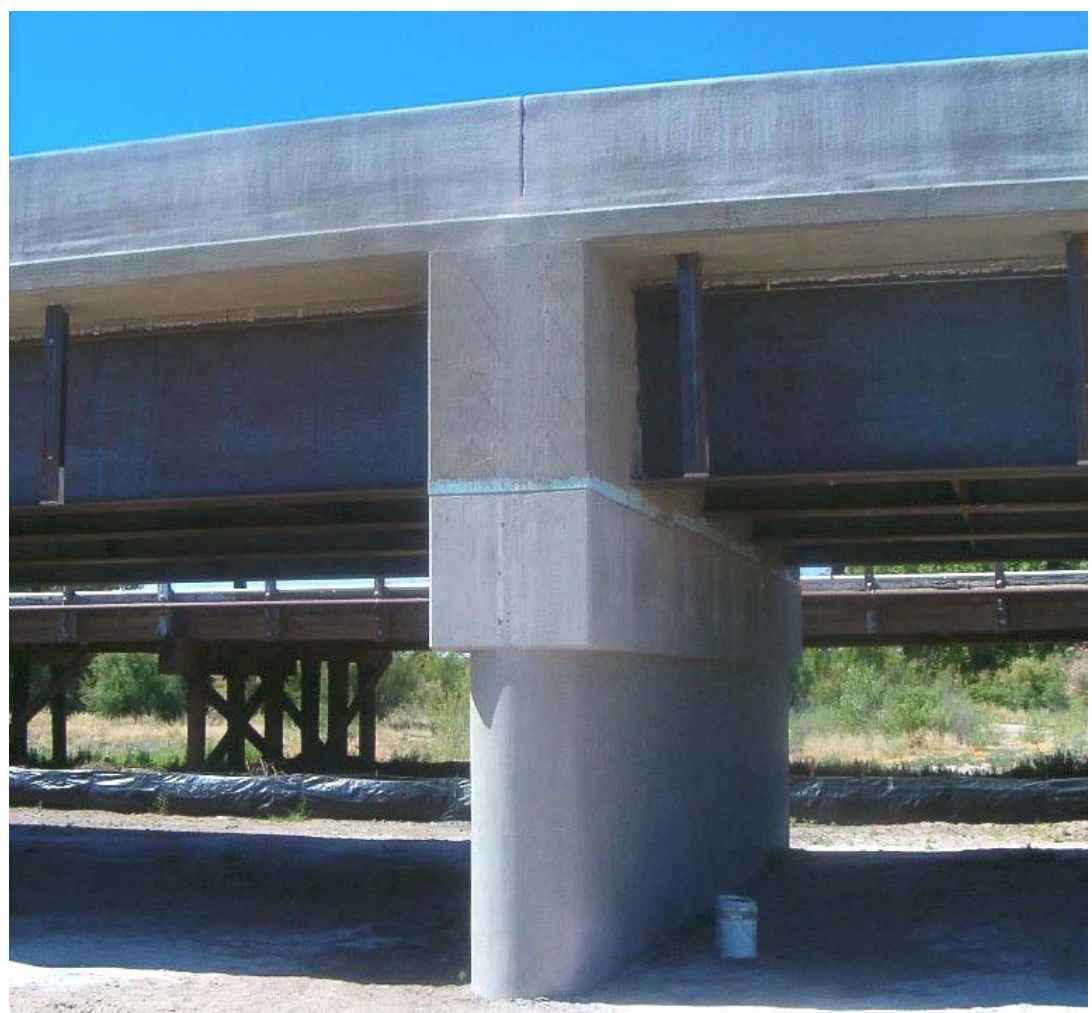

Figure 4-42 Simple for Dead Load and Continuous for Live Load System [44]

\subsubsection{Application}

The simple for dead load and continuous for live load system is a special bridge construction process rather than an application of special bridge elements as is for other systems in this section. This system can be applied to any situation where it is beneficial to have simple spans during initial construction and needing the strength of a continuous span during service. [26]

\subsubsection{Constructability}

To convert the two simple spans to one continuous span, a concrete diaphragm is constructed at the pier. The bottom flanges of the two girders are connected by a partial penetration weld applied before the pouring of wet concrete. The concrete is poured over the pier creating a reinforced concrete diaphragm including small steel reinforcing bars to prevent longitudinal movement. Before the placement of the diaphragm, a thin layer of foam is applied to the pier to separate the diaphragm from the pier cap. [26] 


\subsubsection{Evaluation}

This system has the benefits of assembling a simple span bridge but also has the benefits of carrying live loads with a continuous system. The assembly process is easier and more cost effective than performing field splices and traditional connections over the piers.

\subsubsection{Research Needed}

The topic of system design and behavior is a possible research area.

\subsubsection{Pretopped Girder Section}

\subsubsection{Description}

This prefabricated bridge system includes combinations of superstructure elements and decks fabricated together before transporting them to the job-site. This system is beneficial for the reduced time of construction it provides; this is due to the bolt connections on-site and the lack of field welding. Some have the negative perception that these bridges are only useful for temporary bridges or that the span must be right for the prefabricated sections available. Pretopped girder sections can be designed to be permanently installed and are specifically designed for the required span. Different groups have developed different methods of pretopped girder bridges. An example of a Big R Bridge is provided in Figure 4-43, a bridge installed in Virginia is presented in Figure 4-44and the bridge designed by SDR Engineering Consults is shown in Figure 4-45. [45]

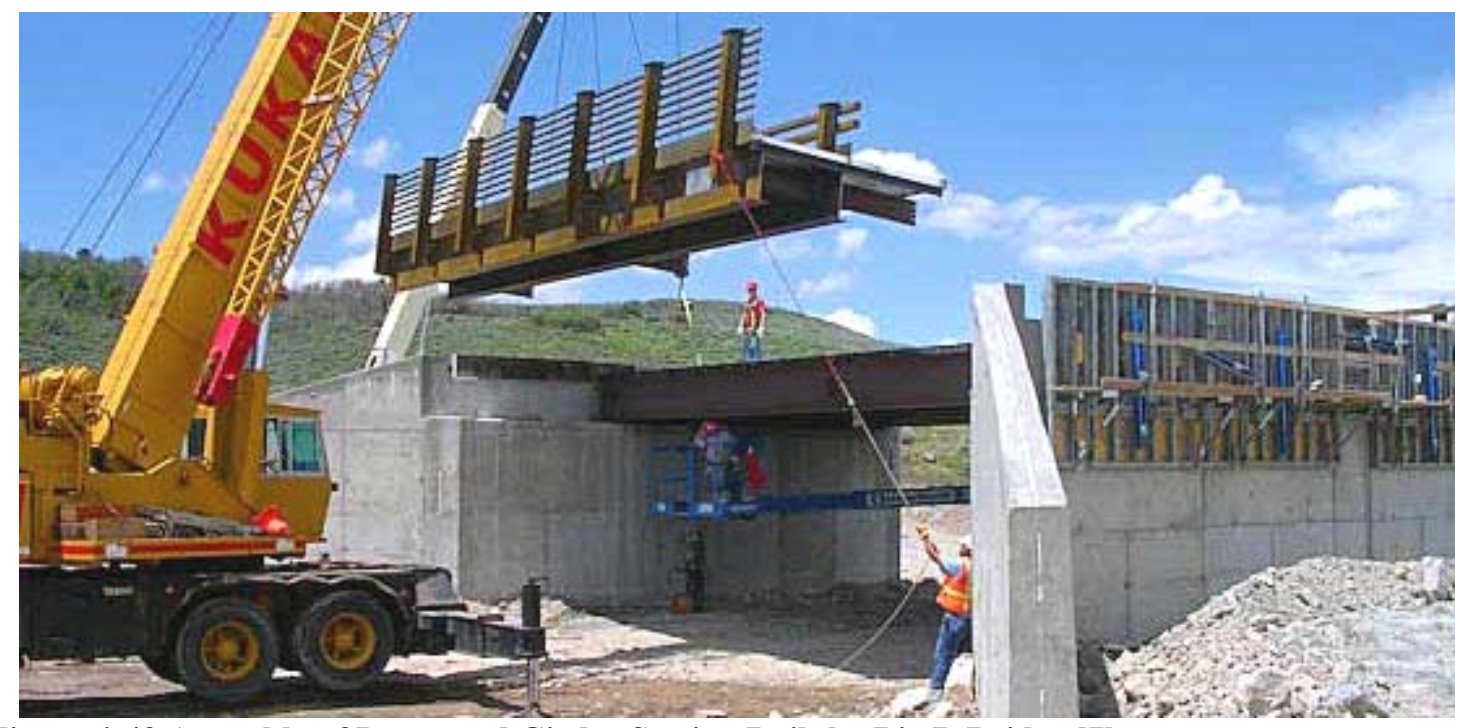

Figure 4-43 Assembly of Pretopped Girder Section Built by Big R Bridge [7] 


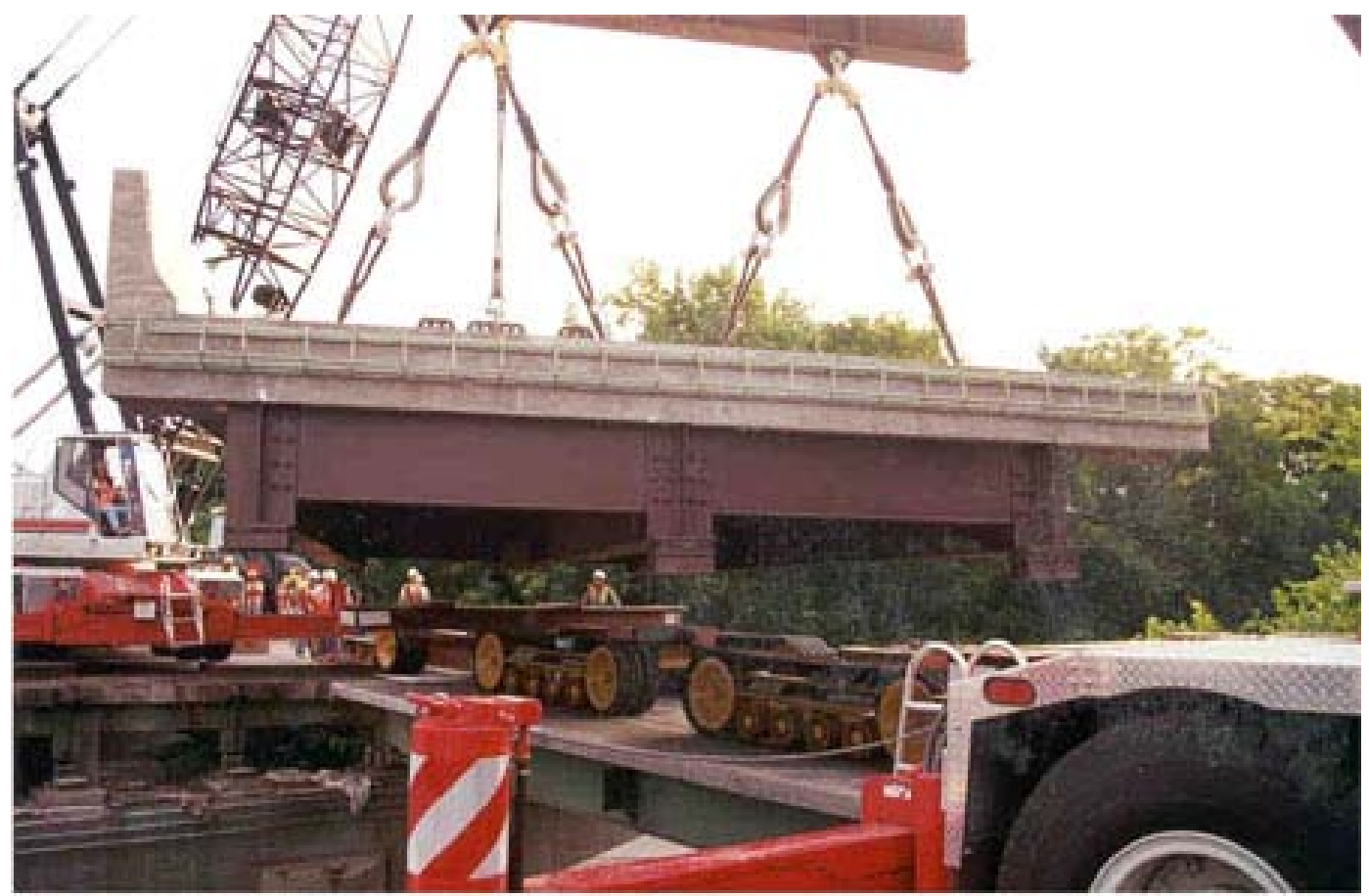

Figure 4-44 Unloading Pretopped Girder System for I-95 Bridge in Virginia [56]

Interior Modular Unit

Exterior Modular Unit

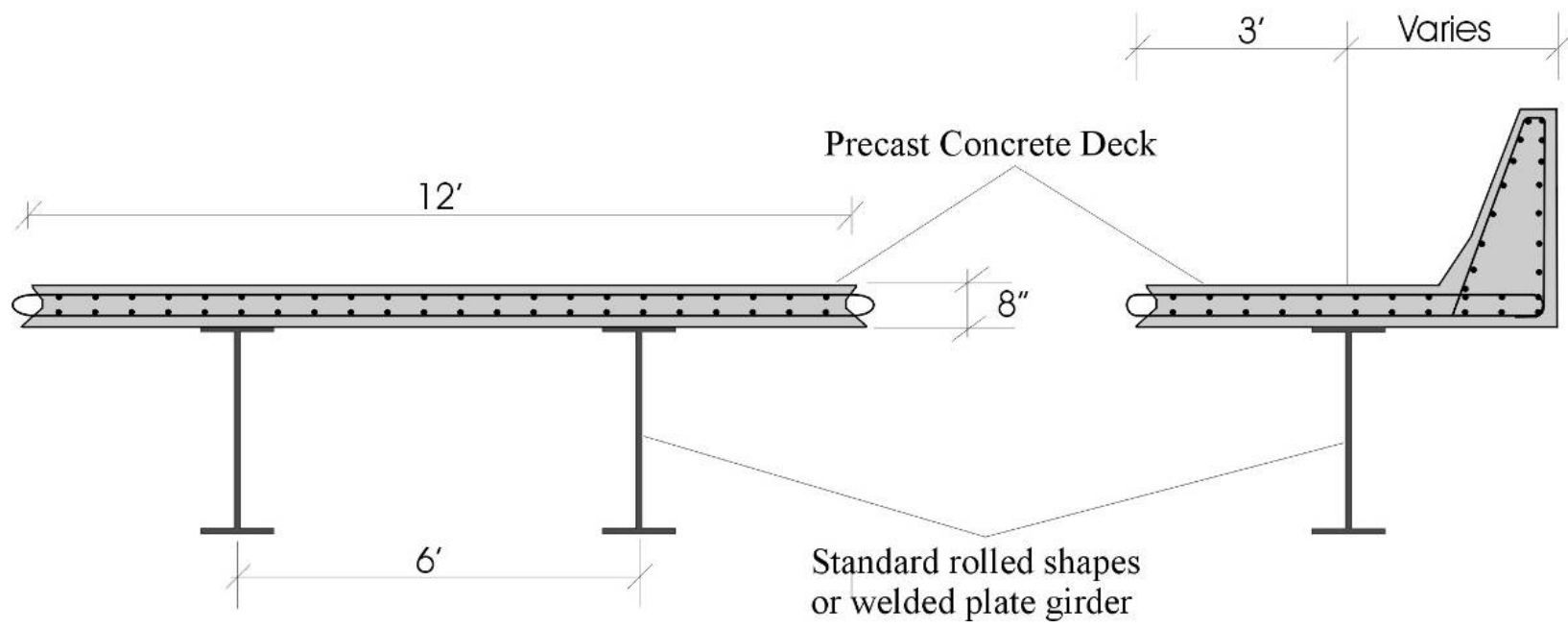

Figure 4-45 Precast Modular System Developed by SDR Engineering Consultants [42]

\subsubsection{Application}

Pretopped girder sections as sections of preconstructed steel framework with bridge decking already installed can be used on the bridge as both the superstructure and bridge deck. This system can be installed to the bridge substructure on-site. [45] 


\subsubsection{Constructability}

All bridge welds are performed during fabrication and not at the bridge site. Bolted connections are used on site to connect the bridge segments. These bolted connections allow for easy and quick construction with small crews and light equipment. [45]

\subsubsection{Evaluation}

This system provides quality bridges that are constructed quickly. Despite the negative perception of this type of short span steel bridge, they can be designed for permanent use and are normally designed specifically for the bridge site.

\subsubsection{Research Needed}

Ongoing research on the longitudinal and transverse joints between the sections is being performed.

\subsubsection{Modular Steel Girder/Cast-in-Place Deck System}

\subsubsection{Description}

The modular steel girder/cast-in-place deck system was presented in a report developed by SDR Engineering Consultants. This system is similar to the pretopped girder system described before except that the deck is not cast before delivering bridge sections to the bridge site. Cold formed steel plates are attached to the steel girders to act as the formwork for the bridge deck. Wire mesh is welded to the cold formed plates to provide reinforcement for the concrete deck that is poured on site. As the bridge sections are brought to the bridge site and placed adjacently, they are bolted to one another. A diagram displaying the bridge sections is provided in Figure 4-46. [42]

Interior Modular Unit

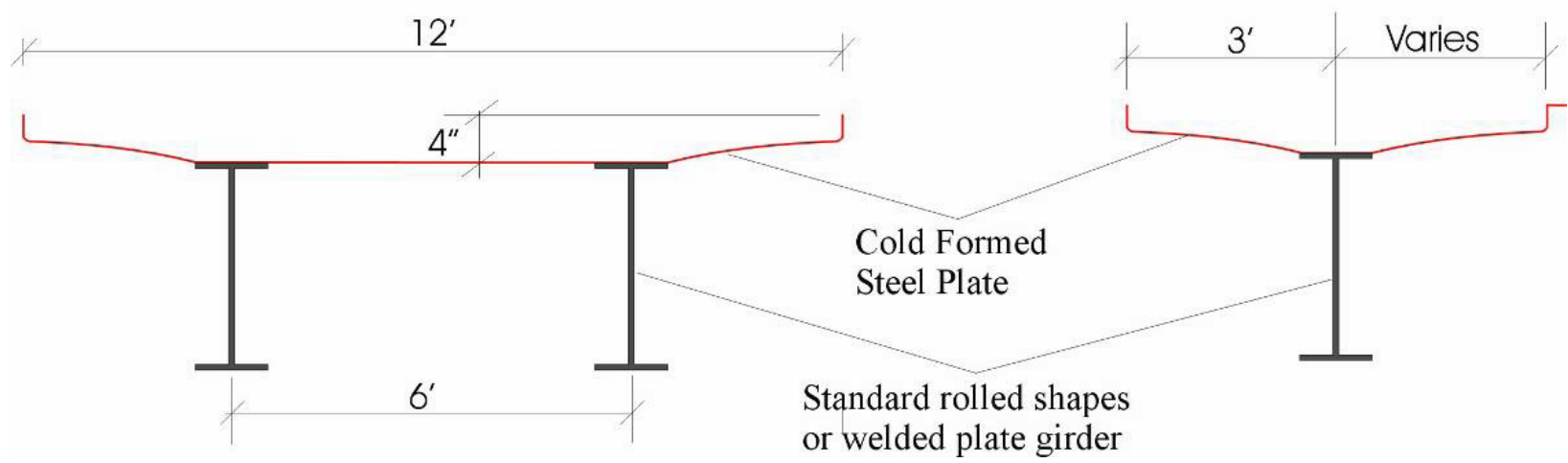

Figure 4-46 Modular Steel Girders with Stay-In-Place Formwork Plates [42]

\section{Exterior Modular Unit}




\subsubsection{Application}

The modular steel girder/cast-in-place deck sections are used as the superstructure of the bridge and provide a means of easily pouring the deck without requiring additional formwork. [42]

\subsubsection{Constructability}

The modular sections are attached to one another through bolted connections. The reinforcing wire mesh is welded to the steel plates. [42]

\subsubsection{Evaluation}

While this system does not provide the benefit of saving contruction time with a prefabricated deck, it does provide formwork to easily pour the deck soon after the sections have been installed. Connection of steel sections is easy with on-site bolting.

\subsubsection{Research Needed}

No research needs were found for this modular bridge system.

\subsubsection{Acrow Panel Bridging System (700XS® System)}

\subsubsection{Description}

The Acrow Panel Bridging System, also known as the 700XS® System, is a light bridge composed of large orthotropic deck units and tall truss systems. The trusses of this type of bridge are $50 \%$ taller than alternate panel bridges which provide the bridge with $50 \%$ greater bending strength and 20\% greater shear strength. The orthotropic deck units can handle heavy wheel loads such as those in the AASHTO LRFD Bridge Design Specifications. These bridges can be easily transported to the bridge site using standard trucks or standard dry ocean containers. These bridges can be erected quickly and easily. An example of an Acrow Panel Bridge is provided in Figure 4-47. [4] 


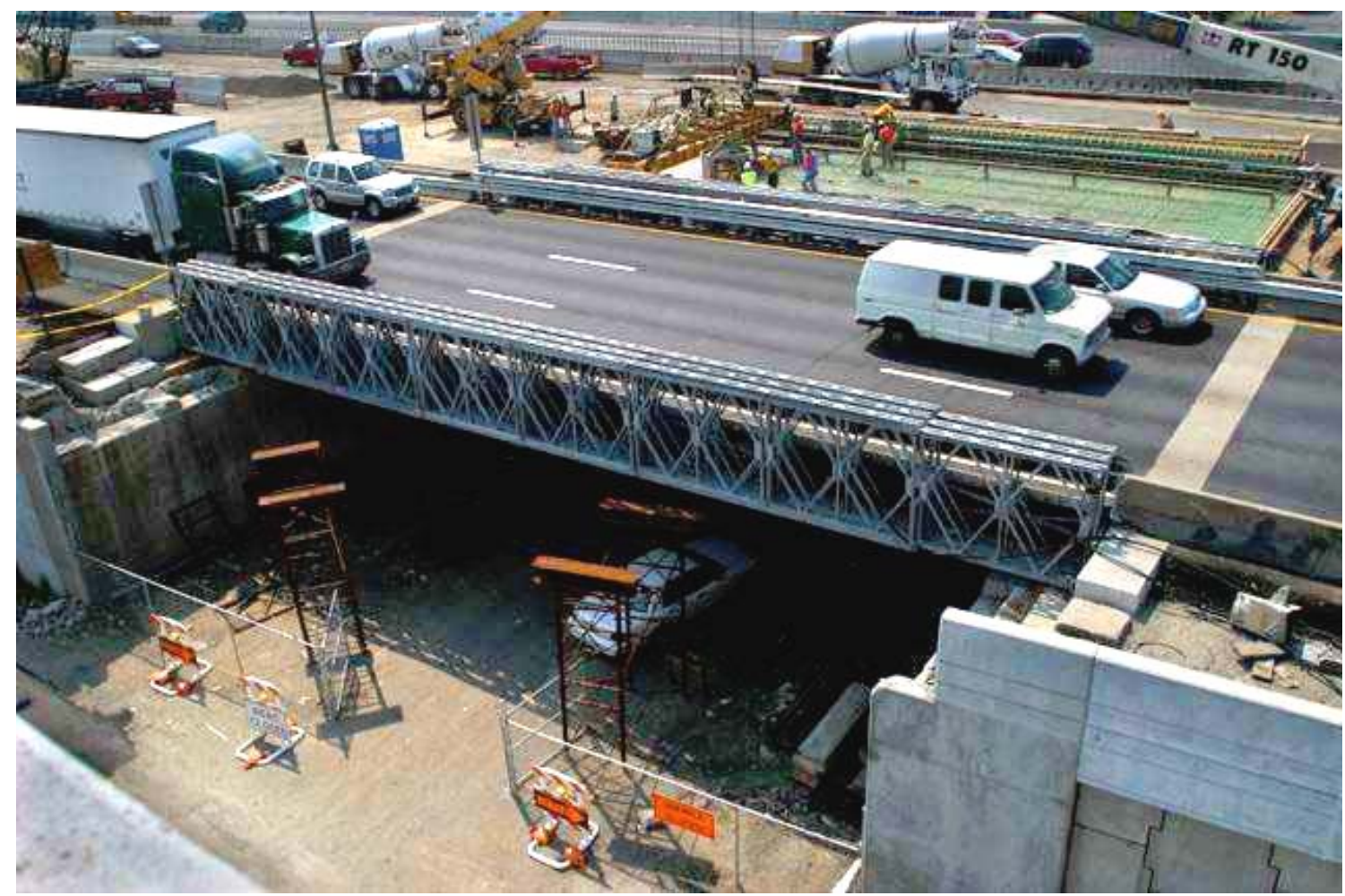

Figure 4-47 Acrow Panel Bridge [21]

\subsubsection{Application}

Acrow Panel Bridges are composed of both the truss systems and deck panels. This system acts as both the superstructure and decking system of the bridge. This can be brought to the job-site and installed on the bridge substructure. [4]

\subsubsection{Constructability}

There are several methods to install the Acrow $700 \mathrm{XS}{ }^{\circledR}$ Bridge. The most common method is to slide the bridge into place as a cantilever system from the home bank to the end bank. For this method, a launching nose must be constructed at the front of the bridge with rollers. Counterweights are added to the back end of the structure in order to keep the center of gravity from the being past the launch nose. The other common method of installation is lifting the bridge into place with the use of a crane. This option can be more difficult, but if an adequate sized crane is available, it is a plausible installation method. [4]

\subsubsection{Evaluation}

This bridge system can be transported and installed quickly and easily. Due to the design of the superstructure, this type of bridge is stronger than alternate panel bridges. 


\subsubsection{Research Needed}

No research needs were found for this modular bridge system.

\subsubsection{Railroad Flatcar System}

\subsubsection{Description}

One economical bridge superstructure option that has been experimented with is the use of decommissioned railroad flatcars as the superstructure of the bridge. This idea has been applied primarily to short span, low volume county roads. For a single lane road one flatcar can provide the entire superstructure, where multiple flatcars can be placed adjacently for wider bridges. An example of a railroad flatcar trimmed to be used as a bridge superstructure is presented in Figure 4-48. Pictures of the bridge made from the flat car are presented in Figure 4-49 and Figure 4-50. [57]

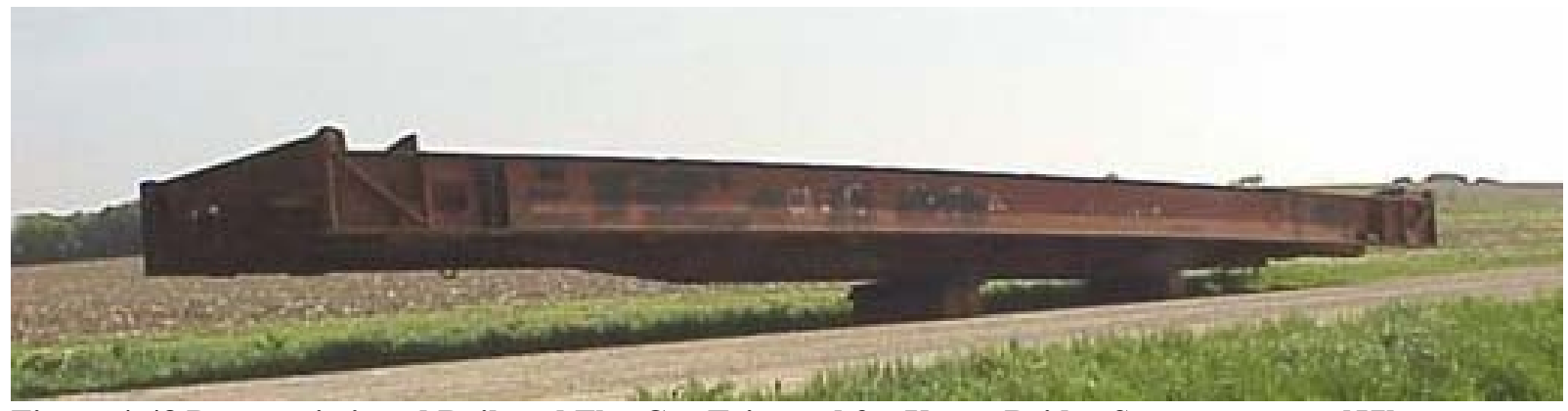

Figure 4-48 Decommissioned Railroad Flat Car Trimmed for Use as Bridge Superstructure [57]

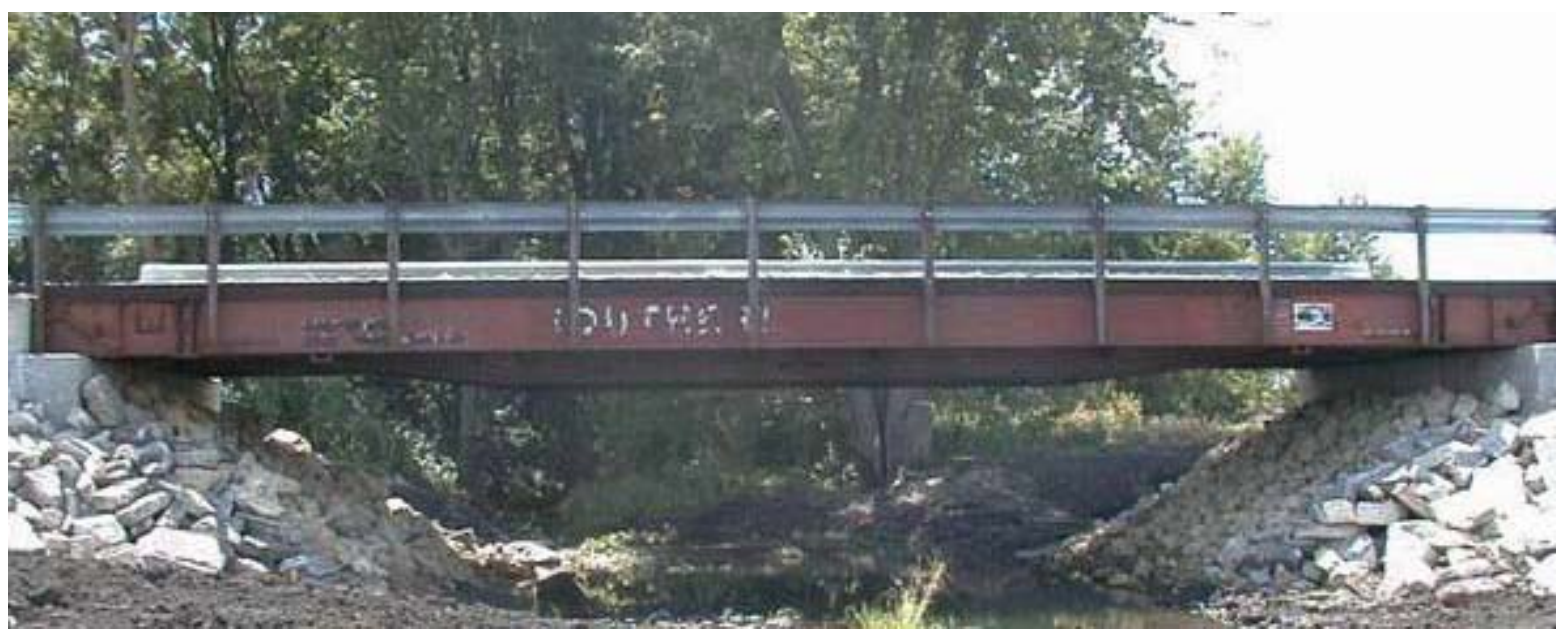

Figure 4-49 Side View of Railroad Flatcar Bridge [57] 


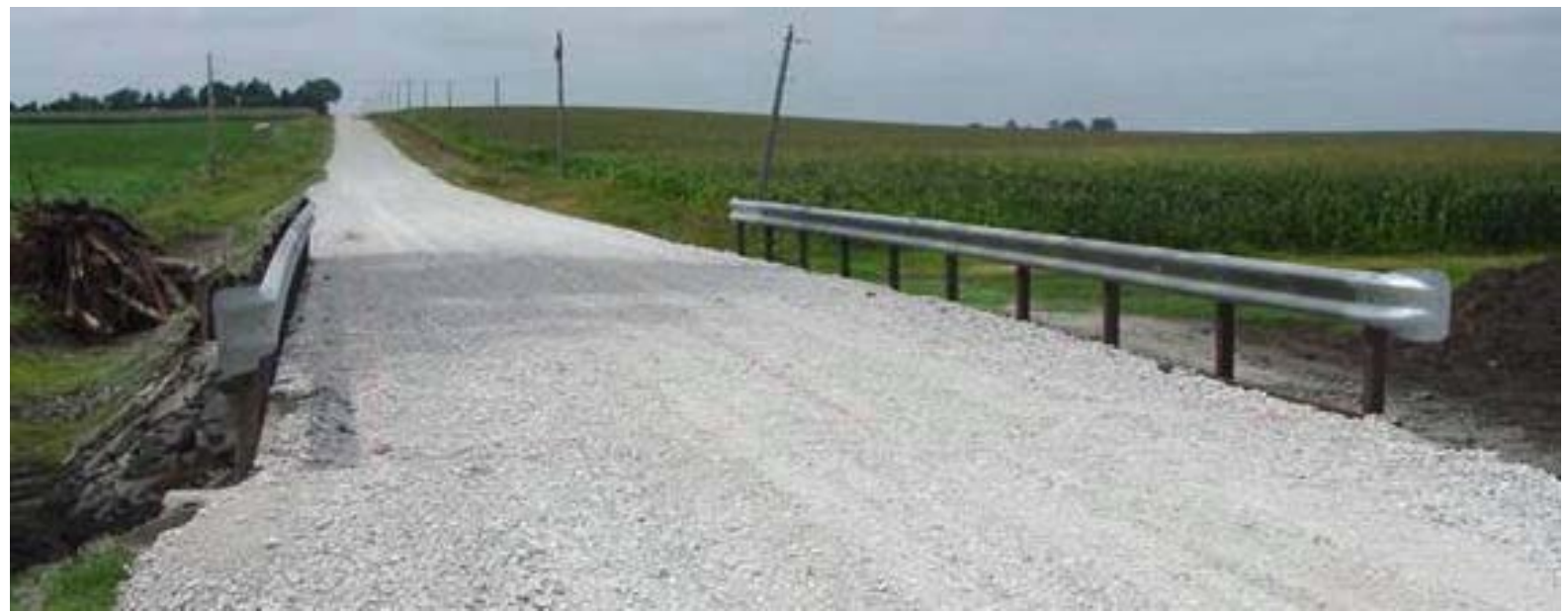

Figure 4-50 End View of Railroad Flatcar Bridge [57]

\subsubsection{Application}

Railroad flatcars are installed onto the bridge substructure. Concrete is then used to create a flat deck. Guardrails can then be attached to the flatcar to provide more safety to the roadway. [57]

\subsubsection{Constructability}

The flatcar is attached to the abutment through the use of bolting or welding. On a two lane bridge, the flatcars can be attached using threaded rods through the channel between. Concrete is used to fill the channel while pouring the deck. [57]

\subsubsection{Evaluation}

This system provides an economical option for short span bridges. The superstructure utilizes recycled materials.

\subsubsection{Research Needed}

No research needs were found for this modular bridge system.

\subsubsection{Con-Struct ${ }^{\mathrm{TM}}$ Prefabricated Bridge System}

\subsubsection{Description}

The Con-Struct ${ }^{\mathrm{TM}}$ prefabricated bridge system is a system developed by Tricon Precast, Ltd. This system consists of galvanized steel box girders that are attached compositely to a precast concrete deck system. Bridges of up to 100 foot spans can be built using this bridge system. The modules of this bridge can be trucked to the bridge site and installed to the bridge substructure by use of a crane. This system provides the entire superstructure of the bridge and can be modified for different bridge widths through installing modules adjacently. An example 
of a bridge made with the Con-Struct ${ }^{\mathrm{TM}}$ system can be seen in Figure 4-51, and a diagram of a standard cross-section of a module can be seen in Figure 4-52. [53]

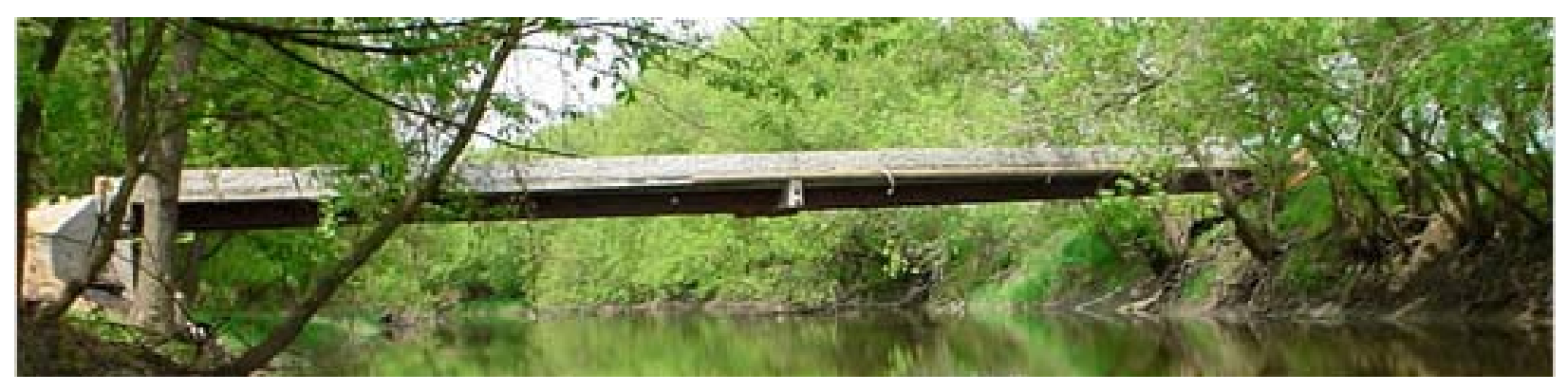

Figure 4-51 Con-Struct Prefabricated Bridge [53]

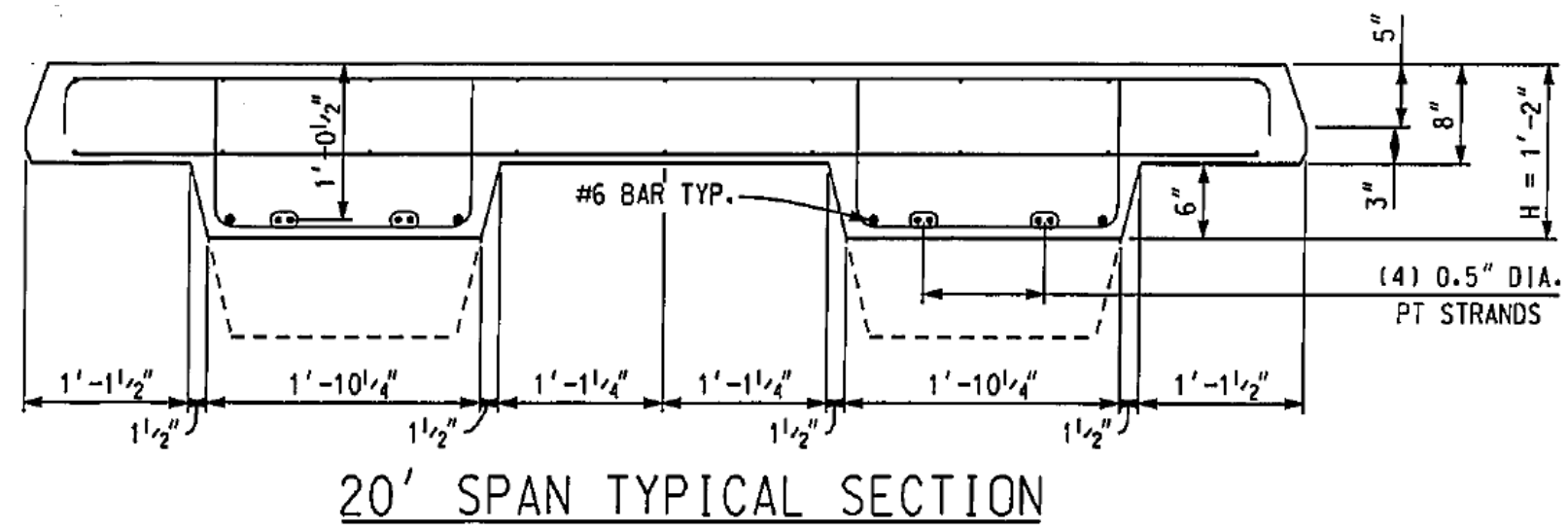

Figure 4-52 Example of Con-Struct Bridge Cross-Section [54]

\subsubsection{Application}

Con-Struct bridge sections are installed onto the bridge substructure. To create the desired bridge width, modules are placed adjacently to widen the bridge width. [53]

\subsubsection{Constructability}

The steel box girders and the bridge deck are already assembled when the bridge modules arrive at the bridge site. The system has abutment sections that attach directly to the bridge abutments constructed at the bridge site. [54]

\subsubsection{Evaluation}

This system provides the entire superstructure of the bridge. The system was developed to be easy-to-install and provide customization in the bridge designs. 


\subsubsection{Research Needed}

No research needs were found for this modular bridge system.

\subsection{Secondary Elements}

\subsubsection{Railing Systems}

Railing systems are required to help safely keep vehicles on the bridge structure. Barriers and railing systems are rigidly attached to the bridge and designed to handle impact loads from errant vehicles and redirect the vehicle away from edge of the bridge. This section will specifically look at steel beam rails and precast concrete barriers that are designed to provide safe railing systems to short span modular steel bridges.

\subsubsection{Steel Beam Rail}

\subsection{Description}

This railing system includes a combination of strong posts and steel beams used to guide errant vehicles back onto the roadway. A common steel section for this type of barrier is a Wbeam. Versions of these barriers have proven to be at least a Test Level 3 or better according to the testing system established by NCHRP 350. An example of a bridge using this type of railing can be seen if Figure 4-53 and a closer look at the connection is provided in Figure 4-54. [55]

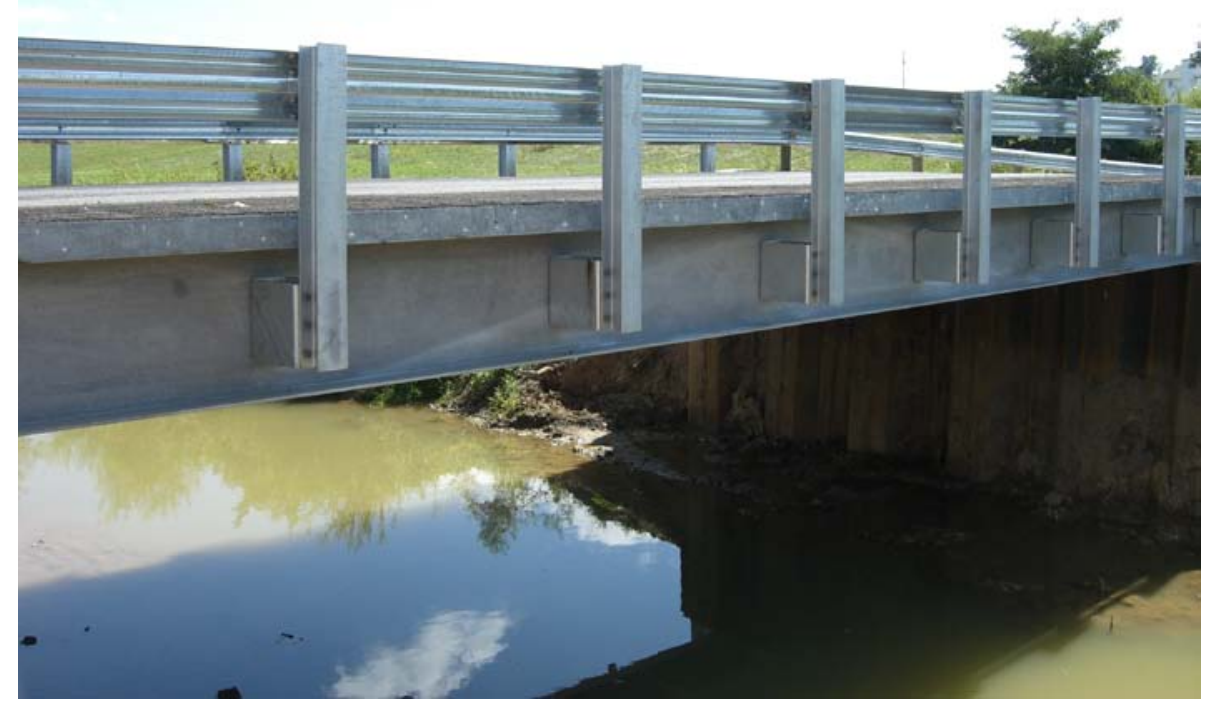

Figure 4-53 Steel Beam Rail Barrier (U.S. Bridge Tour) 


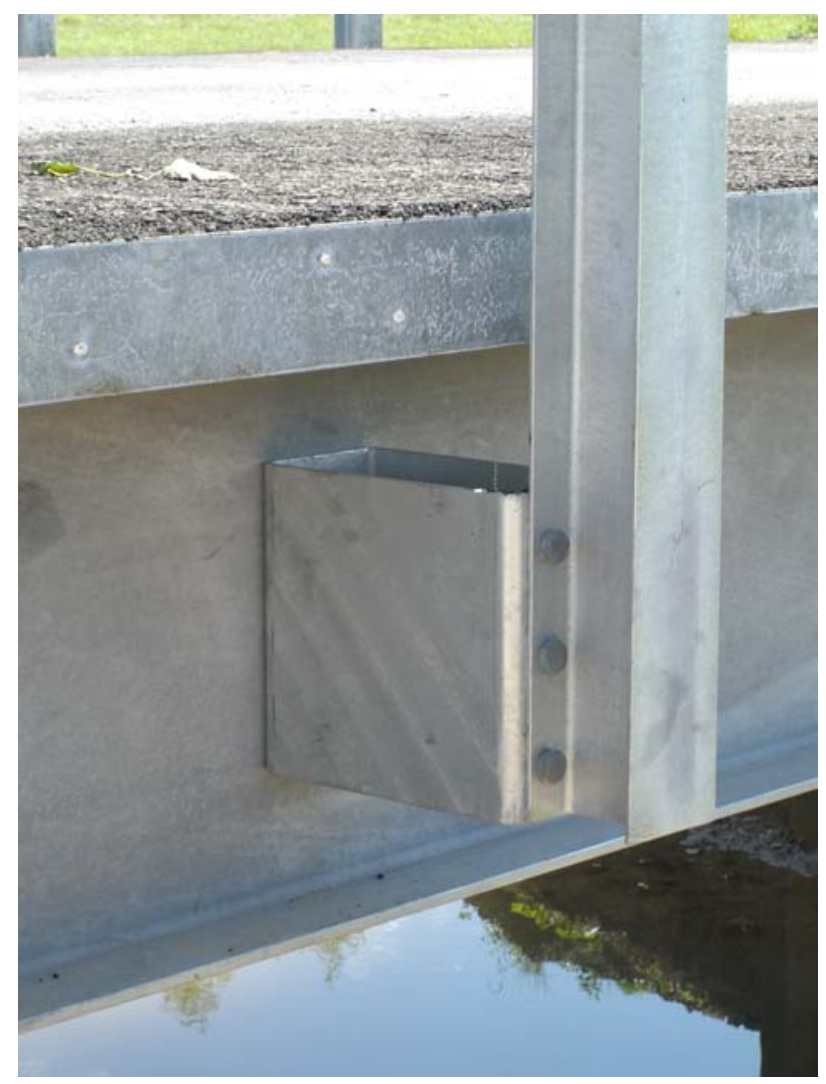

Figure 4-54 Steel Beam Rail Connection (U.S. Bridge Tour)

\subsection{Application}

Steel beam rails are installed on the bridge in order to provide a protection to the users so as not to allow them to leave the travel way. [55]

\subsection{Constructability}

One method of connecting steel beam rails can be seen in Figure 4-54, a portion of the railing system is welded to the exterior girders of the bridge. Another method of attaching the railing system is by mounting the posts directly on top of the bridge deck. For either situation, the connection must provide enough strength to resist the force of an errant vehicle collision.

\subsection{Evaluation}

Steel beam rails are lighter than concrete barriers and they impose on the roadway less allowing for a narrower bridge deck. As opposed to concrete barriers, steel beam rails do not have the issue of holding water on the bridge roadway. Connection for this type of railing system may involve on-site welding. 


\subsection{Research Needed}

No research needs were found for this secondary element.

\subsubsection{Precast Concrete Barrier}

\subsection{Description}

Precast concrete barriers are a common method used to keep errant vehicles from leaving the travel way. There are different shapes of this type of barrier, but the most common two are the New Jersey and F-Shape barriers. Precast concrete barriers are designed to be placed and connected to adjacent sections and provide enough resistance to prevent vehicles from leaving the road. An example of a precast concrete barrier is provided in Figure 4-55. [49]

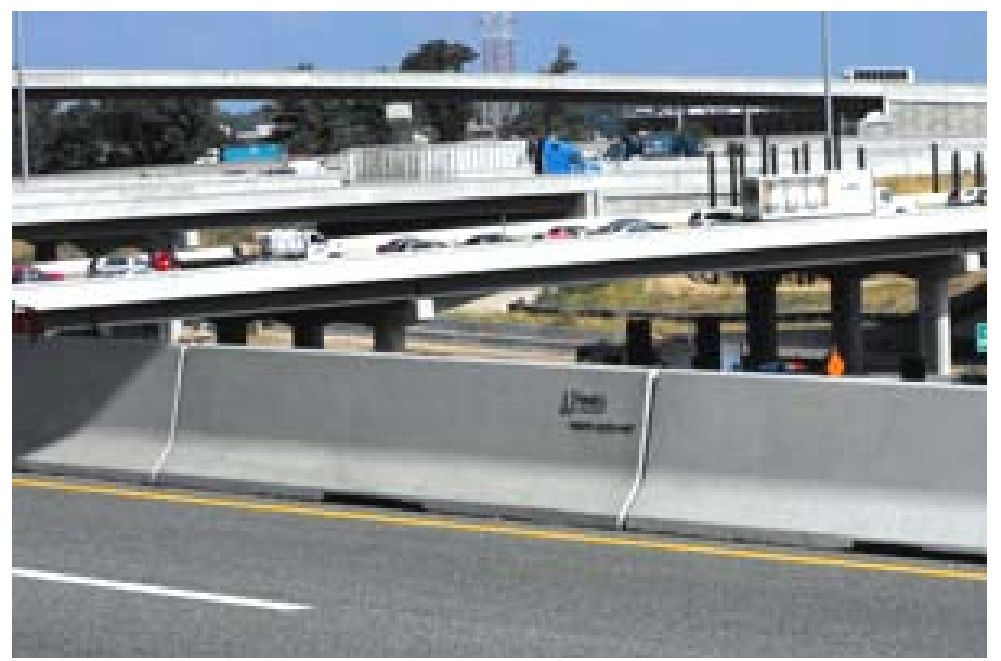

Figure 4-55 Precast Concrete Bridge Barrier [49]

\subsection{Application}

Precast concrete barriers are installed on the edges of a bridge in order to keep errant vehicles from leaving the travelway. [49]

\subsection{Constructability}

These barriers can be connected to one another using an interlocking system. The barrier as a whole can be attached to the bridge deck using a mechanical keyway and a grouting material. Other such systems may utilize vertical reinforcement or other anchorage systems to hold the barriers in place on the bridge. [49]

\subsection{Evaluation}

Precast concrete barriers are attached to the top of the bridge deck instead of being attached to the exterior girders of the bridge possibly causing the need for a wider bridge deck 
than that needed when steel beam rails are used. This type of barrier does have the potential to cause water retention on the deck which can cause safety issues. With the weight of this type of barrier, the bridge has a larger composite dead load than that of a steel beam railing system.

\subsection{Research Needed}

No research needs were found for this secondary element.

\subsubsection{Cross-Frames and Diaphragms}

In the design and construction of steel plate girder bridges, several configurations of cross-frames and diaphragms have been used to provide lateral support to the bridge frame. This section will specifically look at the use of " $X$ " shaped cross-frames, " $K$ " shaped cross-frames and folded plate diaphragms.

\subsubsection{1 "X" Shape Cross-Frame}

\subsection{Description}

There are three primary configurations of the " $X$ " shaped cross-frame: simple " $X$ " configuration, " $\mathrm{X}$ " shape with a bottom strut and " $\mathrm{X}$ " shape with bottom and top struts. [30]

The simple " $\mathrm{X}$ " configuration while being the most economical to fabricate, may not provide the most cost-effective bridge overall. For certain bridges it is possible that this type of cross-frame can provide proper support for both lateral loads and cantilever concrete casting loads; but in cases where the braces cannot handle the weight of wet concrete on the overhangs properly, additional bracing will be required. [30]

The addition of a bottom strut to the simple " $X$ " configuration provides a more rigid path connecting the bottom flanges of all the girders. This connection can provide the needed extra support for the overhang loads during construction. This system is assuming that the stresses due to lateral wind loads on the bridge are migrating to the bottom strut. [30]

The " $X$ " configuration with both top and bottom struts ensures the designer that the top and bottom flanges of the girders are braced to resist the lateral wind loads and cantilever overhang loads acting on the bridge. Generally, this system is only needed for deep girders or large diaphragm spacings. [30] 


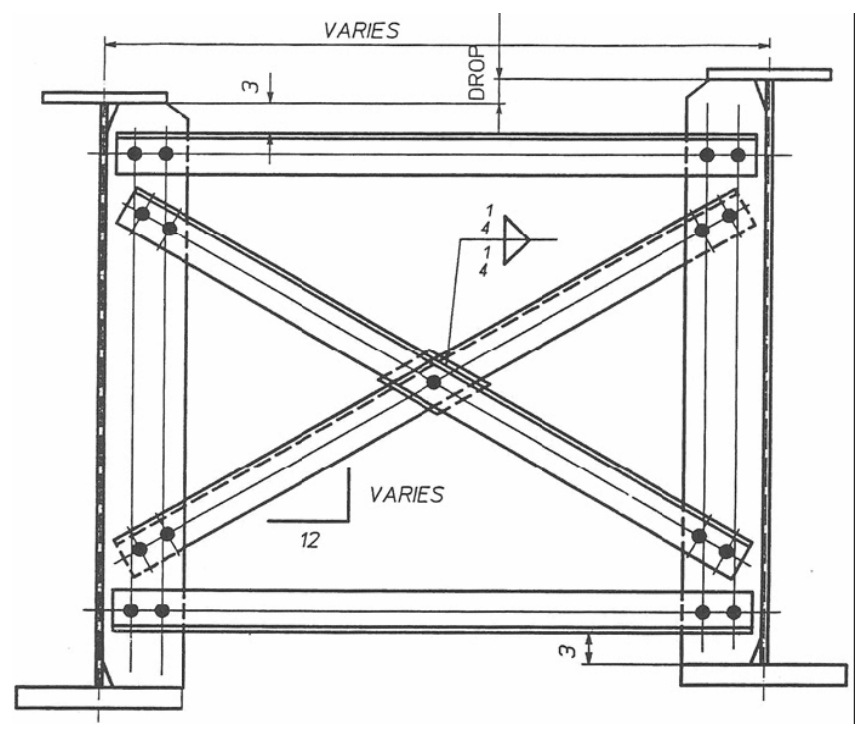

Figure 4-56 Example of Steel "X" Shaped Cross Frame [12]

\subsection{Application}

" $\mathrm{X}$ " shape cross-frames are installed into the gaps between bridge girders in order to provide lateral support to the bridge superstructure. [30]

\subsection{Constructability}

The cross-frame elements are generally bolted to stiffeners that are welded to the webs of the bridge girders. [30]

\subsection{Evaluation}

With the different configurations of " $\mathrm{X}$ " shaped cross-frames, the engineer can use this system to provide lateral bracing to nearly any steel plate girder bridge. Generally, " $X$ " shape cross-frames are more economical than "K” shape cross-frames.

\subsection{Research Needed}

No research needs were found for this secondary element.

\subsubsection{2 "K" Shape Cross-Frame}

\subsection{Description}

" $\mathrm{K}$ " shaped cross-frames are similar to " $\mathrm{X}$ " shaped cross-frames in that they are composed of multiple steel members to provide lateral strength to the superstructure. Where " $X$ " shaped cross-frames are more efficient when the ratio of girder spacing to girder depth is approximately 1 , " $K$ ” shaped cross-frames are better when this ratio is greater than 1.5. An example of a bridge using “ $K$ ” shaped cross-frames is provided in Figure 4-57. [12] 


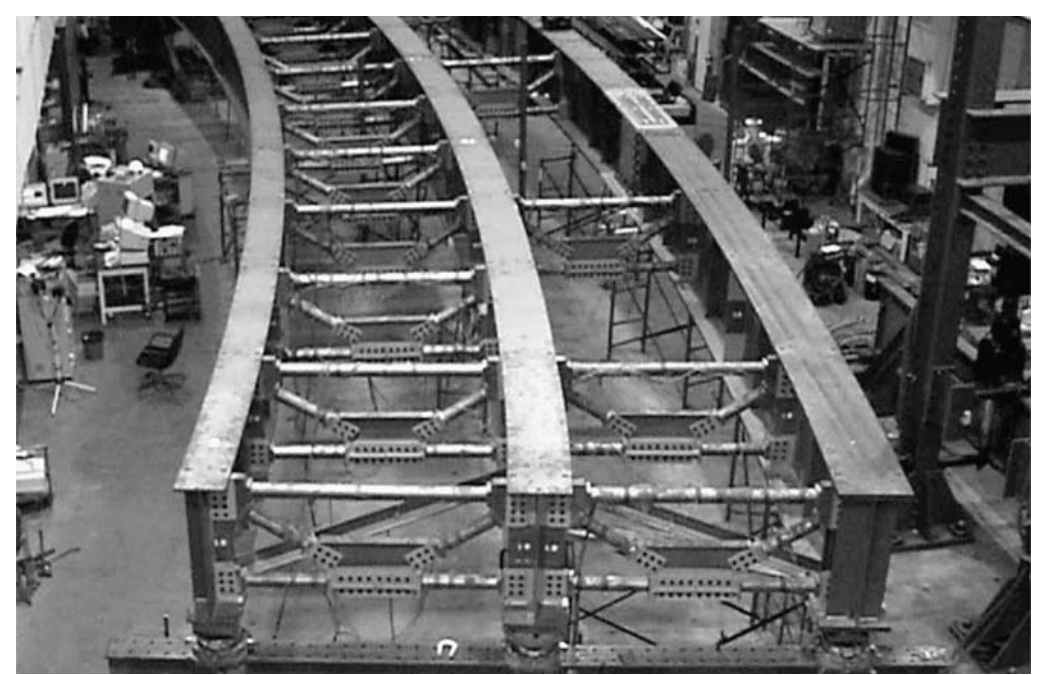

Figure 4-57 Curved Steel Bridge Frame with K-Shaped Cross Frames [27]

\subsection{Application}

"K" shape cross-frames are installed into the gaps between bridge girders in order to provide lateral support to the bridge superstructure. [12]

\subsection{Constructability}

The cross-frame elements are generally bolted to stiffeners that are welded to the webs of the bridge girders. [12]

\subsection{Evaluation}

"K" shaped cross-frames are not always the most cost effective option for lateral support to a bridge superstructure. As mentioned, for cases where the ratio of girder spacing to girder depth is over 1.5, " $\mathrm{K}$ ” shaped cross-frames are considered to be the efficient choice.

\subsection{Research Needed}

No research needs were found for this secondary element.

\subsubsection{Diaphragms}

\subsection{Description}

Diaphragms, like other cross-frame systems, are included in the steel framework of a bridge to help the bridge resist lateral loads. As opposed to the " $\mathrm{X}$ " shaped and " $\mathrm{K}$ " shaped cross-frame systems, diaphragms consist of single members performing the lateral bracing. Diaphragms are normally "I”, “C” or “T” shaped steel members. An example of a bridge using steel diaphragms is presented in Figure 4-58. [12] 


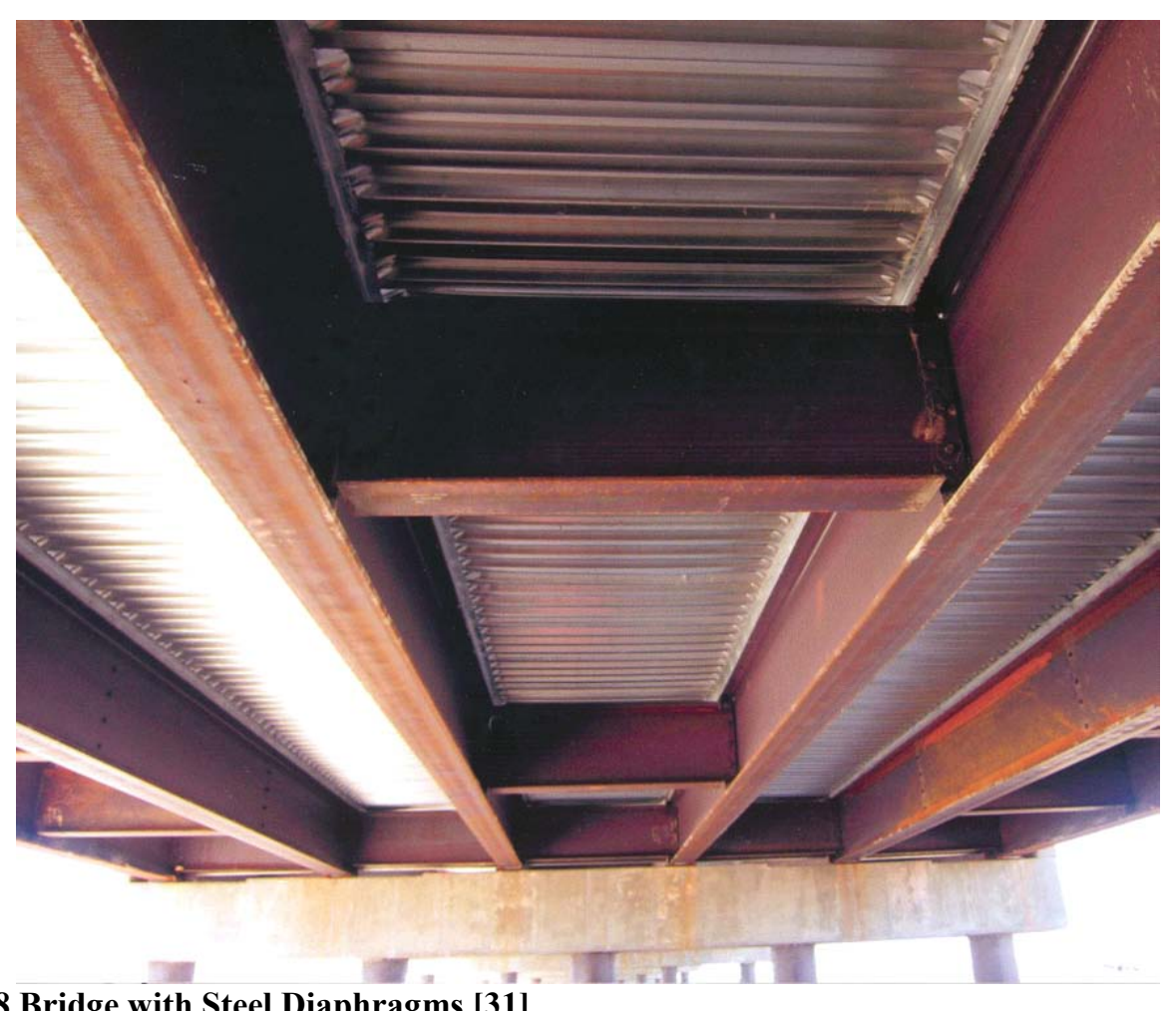

Figure 4-58 Bridge with Steel Diaphragms [31]

\subsection{Application}

Diaphragms are installed into the gaps between bridge girders in order to provide lateral support to the bridge superstructure. [12]

\subsection{Constructability}

The ends of the diaphragms are either welded or bolted to stiffener plates attached to the webs of the bridge girders. [12]

\subsection{Evaluation}

A downside to this type of lateral bracing is that inspection becomes difficult unless proper precautions are taken (ex: manholes).

\subsection{Research Needed}

No research needs were found for this secondary element.

\subsection{Self Propelled Modular Transporters}

\subsubsection{Description}

The Federal Highway Administration's Highways for LIFE program's major objectives is lessening the time of construction. One method to shorten the time of bridge construction is self 
propelled modular transporters. This system is a transportation method used to move the new bridge structure to the job-site and/or remove the old bridge structure from the job-site. Self propelled modular transporters are made up of a combination of multi-axle platforms that are operated through state-of-the-art computer systems. They are designed to lift, carry and set very large loads precisely into the final position then quickly leave the job-site to re-open the area to traffic. These transporters are able to move the bridge structures (prefabricated bridge systems) in or out of place in minutes or hours. Besides the savings of reducing the construction cost, the use of this system has the added benefits of: Reducing traffic disruption, Improving work-zone safety, and Minimizing impact to the environment. Examples of bridge sections being transported and installed by self propelled modular transporters are shown in Figure 4-59 and Figure 4-60. [1] [3]

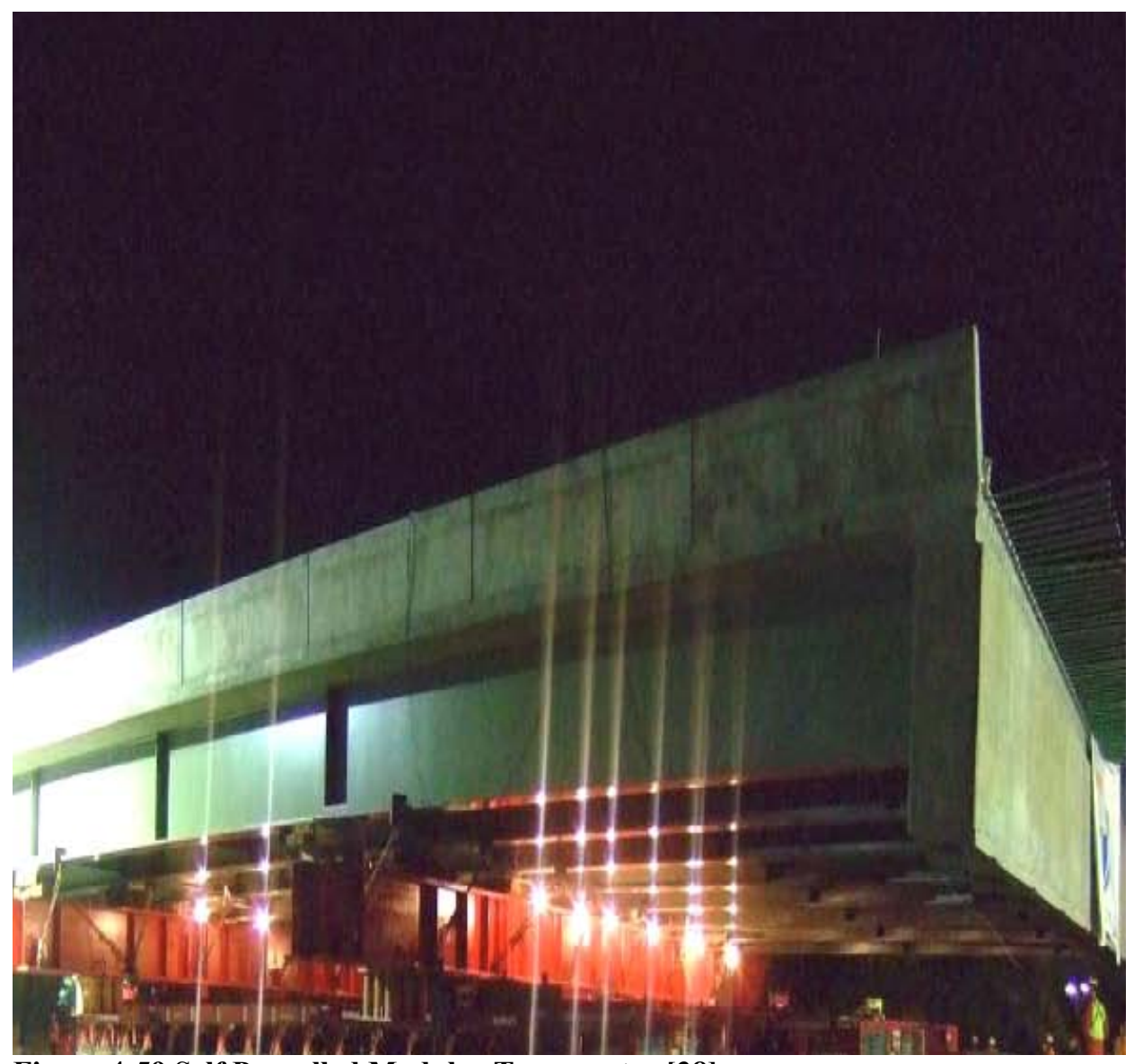

Figure 4-59 Self Propelled Modular Transporter [38] 


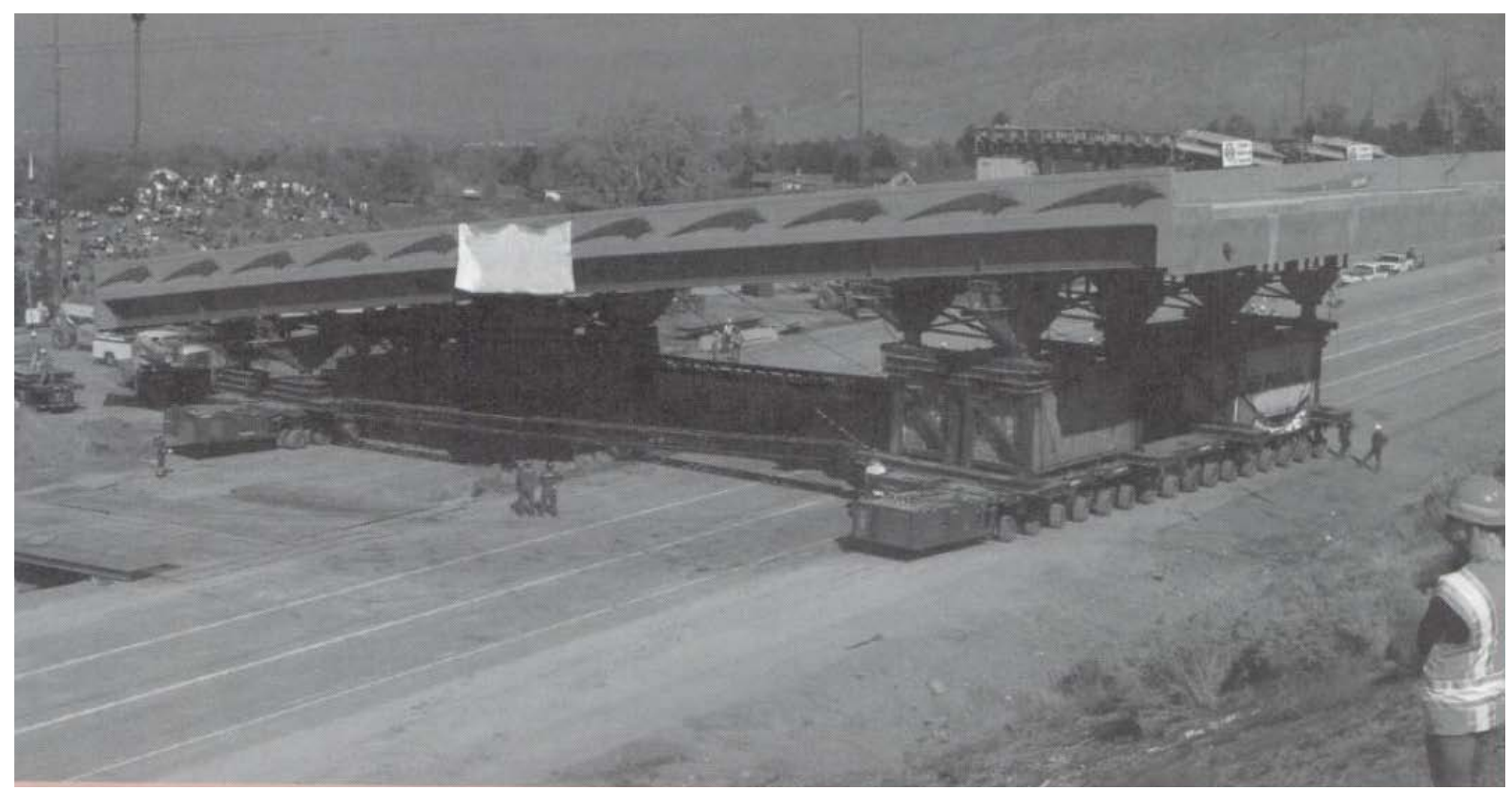

Figure 4-60 Transportation of Bridge Segment Using Self Propelled Modular Transporter [51]

\subsubsection{Application}

Self propelled modular transporters are used to transport, lift and maneuver bridges/bridge sections either on to or off of the bridge site. [3]

\subsubsection{Constructability}

For this construction method, the entire bridge is essentially constructed in the staging area and transported to the bridge site. Most of the construction is actually performed in the controlled conditions of the staging area. [3]

\subsubsection{Evaluation}

This bridge technology is beneficial when a fully-prefabricated bridge superstructure/decking is used for a bridge that is on a road that has a large value on traffic interruption. It can quickly remove and replace a section of bridge with the travel way only being out of commission for hours instead of days or months.

\subsubsection{Research Needed}

No research needs were found for this installation equipment. 


\section{Chapter 5: Grading of Modular Systems}

\subsection{Introduction}

Once a comprehensive collection of modular bridge systems and elements were collected, the input of bridge professionals was sought by the Short Span Steel Bridge Alliance in order to develop modular bridge standards. To gather the opinions and understandings of the bridge professionals, a system was developed to allow for grading of each modular system in several categories and sub-categories. The four major categories used in grading the bridge systems follow the idea of the Highways for LIFE program, in that they grade the bridge systems for properly meeting the goals of being Long Lasting, Innovative, Fast Construction and Efficient. The following sections describe the four major grading categories, their sub-categories and development of category weighting. Finally, examples of the grading tables and a summary of the results is presented.

\subsection{Long Lasting}

The first category in the rating system, Long Lasting, represents the expected longevity of the bridge system. There are two sub-categories within this major category: future maintenance and connection durability. The future maintenance grading is on a scale of 1 to 15 and represents the expected needs for upkeep to help the system remain in operational order; the higher the grade, the less maintenance required. The connection durability grading is on a scale of 1 to 10 and represents the ability of the connection to provide proper strength in holding the bridge elements together over the life of the bridge; the more reliable the connection the higher the grading. The grading of these two sub-categories provides the first quarter of the overall bridge system grade with a higher emphasis on the overall future maintenance of the system or element due to the costs that can incur from several future repairs.

\subsection{Innovative}

The second category in the rating system, Innovative, represents the bridge system being new and creative while still being practical and designable. The four sub-categories of this major category are: Aesthetics, Research Needed, Comprehensive Design and Designer Comfort. The aesthetics grading is on a scale of 1 to 5 and represents the system providing an aesthetically pleasing bridge; the higher the aesthetic value, the higher the grade. The research needed grading is on a scale of 1 to 5 and represents the research still required in order for this bridge system to be adequately applied to the public highway system; the less research still required on the topic, 
the higher the grading. The comprehensive design grading is on a scale of 1 to 5 and represents the amount of simplification provided to the bridge construction process through providing prefabricated elements; the more simplification provided, the higher the grade. The designer comfort grading is on a scale of 1 to 10 and represents how difficult it will be to educate practicing engineers how to design with the given bridge system; the easier the adaptation, the higher the grading. These four sub-categories provide the second quarter of the overall grading.

\subsection{Fast Construction}

The third category in the rating system, Fast Construction, represents the time saved by selecting this modular bridge system over the use of conventional bridge construction practices. The two sub-categories of this major category are: Time of Construction and Time of Fabrication. The time of construction grading is on a scale of 1 to 15 and represents the time saved in installing this bridge system on the bridge site in comparison to a conventional bridge construction; the less time the road is closed for construction, the higher the grade. The time of fabrication grading is on a scale of 1 to 10 and represents the time required to fabricate and deliver the given bridge system in comparison to other prefabricated bridge elements; the less time required to fabricate and deliver the system, the higher the grade. These two sub-categories make up the third quarter of the overall grading of the bridge system with the highest emphasis being on the time of construction. This weighting was selected because the reduction of road closure time is a high benefit of modular bridge technology and full advantage of this quality should be taken.

\subsection{Efficient}

The final category in rating the system, Efficient, represents the opportunity for economical savings that can be realized through the use of the modular bridge system. The two sub-categories of this major category are: Material Costs and Man Hours. The material costs grading is on a scale of 1 to 15 and represents the total costs incurred from materials by the use of this bridge system; the lower the material costs, the higher the grading. The man hours grading is on a scale of 1 to 10 and represents the labor force required to fabricate and install the given modular bridge system; the less laborer required to fabricate and install the system, the higher the grade. These two sub-categories represent the final quarter of the overall grading of the modular bridge system. 


\subsection{Grading Tables}

The grading tables sent to the professionals in the bridge community for grading were simplified to a web survey format that asked the engineer to scale each category on a scale of 1 to 10. Final scaling will be conducted when the survey results are completed, however, the subsequent section will present an evaluation of the scores received by the time of this publication. Each page of the web survey provided an entire grading table for each modular system in question. The categorires of modular bridge systems to be graded by the professionals included:

- Beam and Precast Deck Panels,

- Predecked Beam Systems,

- $\quad$ Truss-Type Systems,

- Modular Space-Truss Systems,

- Metal Deck Systems and

- Railroad Flatcar Systems

The web survey provides an identical table for grading each modular bridge system. An example of one of the grading sheets provided in the web survey is presented below in Table 5-1. 


\section{Table 5-1 Grading Sheet for Each Modular Bridge Systems}

\begin{tabular}{|c|c|c|c|c|c|c|c|c|c|c|}
\hline \multirow{2}{*}{$\begin{array}{l}\text { Grading } \\
\text { Criteria }\end{array}$} & \multicolumn{10}{|c|}{ Grade } \\
\hline & 1 & 2 & 3 & 4 & 5 & 6 & 7 & 8 & 9 & 10 \\
\hline $\begin{array}{l}\text { Long-Lasting: Future Maintenance }(10=\text { a small amount of future upkeep is needed to keep bridge system } \\
\text { functional in comparison to a conventional bridge, } 1=a \text { lot of future upkeep is needed })\end{array}$ & & & & & & & & & & \\
\hline $\begin{array}{l}\text { Long-Lasting: Connection Durability }(10=\text { high durability in terms of durability of the connections between } \\
\text { parts of the bridge system or between bridge systems themselves, } 1=\text { not durable) }\end{array}$ & & & & & & & & & & \\
\hline $\begin{array}{l}\text { Innovative: Aesthetics }(10=\text { physical appearance of the bridge is very aesthetically pleasing, } 1=\text { bridge } \\
\text { appearance is not pleasing) }\end{array}$ & & & & & & & & & & \\
\hline $\begin{array}{l}\text { Innovative: Research Needed (10 = no research is required for bridge to be applied nationally, } 1=\text { a lot of } \\
\text { research is still required) }\end{array}$ & & & & & & & & & & \\
\hline $\begin{array}{l}\text { Innovative: Comprehensive Design }(10=\text { all bridge elements included in the design, } 1=\text { no bridge } \\
\text { elements included in the design) }\end{array}$ & & & & & & & & & & \\
\hline $\begin{array}{l}\text { Innovative: Designer Comfort }(10=\text { design process very familiar to the average engineer, } 1=\text { design is not } \\
\text { familiar) }\end{array}$ & & & & & & & & & & \\
\hline $\begin{array}{l}\text { Fast Construction: Time of Construction }(10=\text { very little time needed to construct the bridge, } 1=\text { a lot of } \\
\text { time required) }\end{array}$ & & & & & & & & & & \\
\hline $\begin{array}{l}\text { Fast Construction: Time of Fabrication }(10=\text { little time needed for the fabrication } \& \text { delivery of the bridge, } 1 \\
=\text { a lot of time needed) }\end{array}$ & & & & & & & & & & \\
\hline $\begin{array}{l}\text { Efficient: Material Cost (10 = cost of material is low compared to that of conventional bridges, } 1=\text { cost is } \\
\text { very high) }\end{array}$ & & & & & & & & & & \\
\hline $\begin{array}{l}\text { Efficient: Man Hours (10 = very low cost of work hours required to fabricate and install bridge, } 1=\text { cost is } \\
\text { high) }\end{array}$ & & & & & & & & & & \\
\hline
\end{tabular}




\subsection{Overview of Grading Results}

Survey results were collected from ten bridge professionals from various companies in the bridge industry. Their grading of each modular bridge system rated each category on a scale of 1 to 10 . The average of these ratings was taken and then weighted according to the weighting scale presented earlier in this chapter. The weighted grades of the survey responses are presented below in Table 5-2.

\section{Table 5-2 Weighted Grades of Each Modular Bridge System}

\begin{tabular}{|c|c|c|c|c|c|c|}
\hline \multirow[b]{2}{*}{ Grading Criteria } & \multicolumn{6}{|c|}{ Modular Bridge System } \\
\hline & 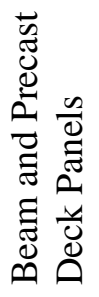 & 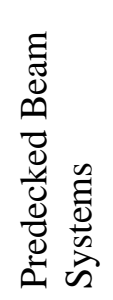 & 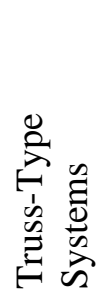 & 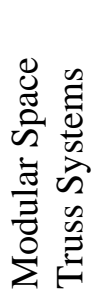 & 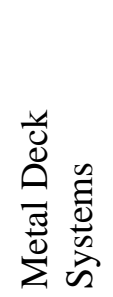 & 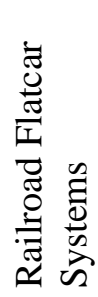 \\
\hline Future Maintenance (10\%) & 8.7 & 8.7 & 6.0 & 8.7 & 5.0 & 5.7 \\
\hline Connection Durability (10\%) & 5.2 & 5.9 & 4.1 & 5.7 & 3.1 & 3.4 \\
\hline Aesthetics (5\%) & 3.0 & 3.0 & 2.3 & 3.5 & 2.6 & 1.7 \\
\hline Research Needed (5\%) & 3.2 & 3.3 & 3.2 & 1.8 & 2.1 & 2.7 \\
\hline Comprehensive Design (5\%) & 3.5 & 3.5 & 3.4 & 2.2 & 2.2 & 2.7 \\
\hline Designer Comfort (10\%) & 6.6 & 6.9 & 5.8 & 3.0 & 3.4 & 4.1 \\
\hline Time of Construction (15\%) & 11.3 & 9.3 & 9.8 & 7.3 & 9.8 & 10.0 \\
\hline Time of Fabrication (10\%) & 6.8 & 6.2 & 6.1 & 4.3 & 4.4 & 6.9 \\
\hline Material Costs (15\%) & 8.5 & 7.8 & 8.8 & 8.2 & 8.0 & 10.8 \\
\hline Man Hours Required (10\%) & 6.1 & 5.6 & 5.3 & 3.2 & 4.2 & 6.3 \\
\hline Total Grade & 62.9 & 60.2 & 54.8 & 47.9 & 44.8 & 54.3 \\
\hline
\end{tabular}

As can be seen from Table 5-2, the Beam and Precast Deck Panels and Predecked Beam Systems were the two modular bridge systems that scored the highest overall in the survey. Based on these grades, these two systems are considered the best modular bridge systems to be further developed into standard designs. 


\section{Chapter 6: Standardized Short Span Steel Bridge Designs}

\subsection{Introduction}

This design study was performed to create design aids to increase the efficiency of the bridge design process and to develop a framework for the future design of standardized short span modular bridges. To create these design aids, optimized designs were developed for a variety of short span steel bridges. To create a design aid that is applicable to the wide variety of bridge sites and bridge design standards used around the country, bridges of multiple span lengths, cross-sections and girder types were considered in the optimized designs. The span lengths considered in the bridge designs range from 40 feet to 140 feet in length in 5 foot increments. To create multiple bridge cross-sections, four different girder spacings were used: 6 feet, 7 feet -6 inches, 9 feet and 10 feet -6 inches. Both wide-flanged, rolled steel girder sections and steel plate girder I-sections were developed in the optimized designs of this study. Version 6.5 of the MDX Line Girder Rating Software, which employs the $4^{\text {th }}$ Edition of the AASHTO LRFD Bridge Design Specifications, was used to evaluate the limit states of each girder design. Bridge designs were performed for a typical interior girder.

\subsection{Design Assumptions}

The short span steel girder sections were designed in accordance with the $4^{\text {th }}$ Edition of the AASHTO LRFD Bridge Design Specifications. A typical girder elevation is shown in Figure 6-1, where $\mathrm{L}$ is the span length, $\mathrm{C}$ represents the cross-brace spacing and the lengths of the bottom flange transitions are presented. Interior girders were designed for the girder spacing arrangements of 6 feet, 7 feet -6 inches, 9 feet and 10 feet -6 inches. In the designs, it was assumed that there were 5 girders in the bridge system and that the bridge deck consisted of 3 lanes. The typical interior girder cross-section layout is shown in Figure 6-2, and the typical bridge cross-section layout is shown in Figure 6-3. Full composite action between the designed steel girder sections and the concrete slab was assumed to be created through the use of headed shear studs.

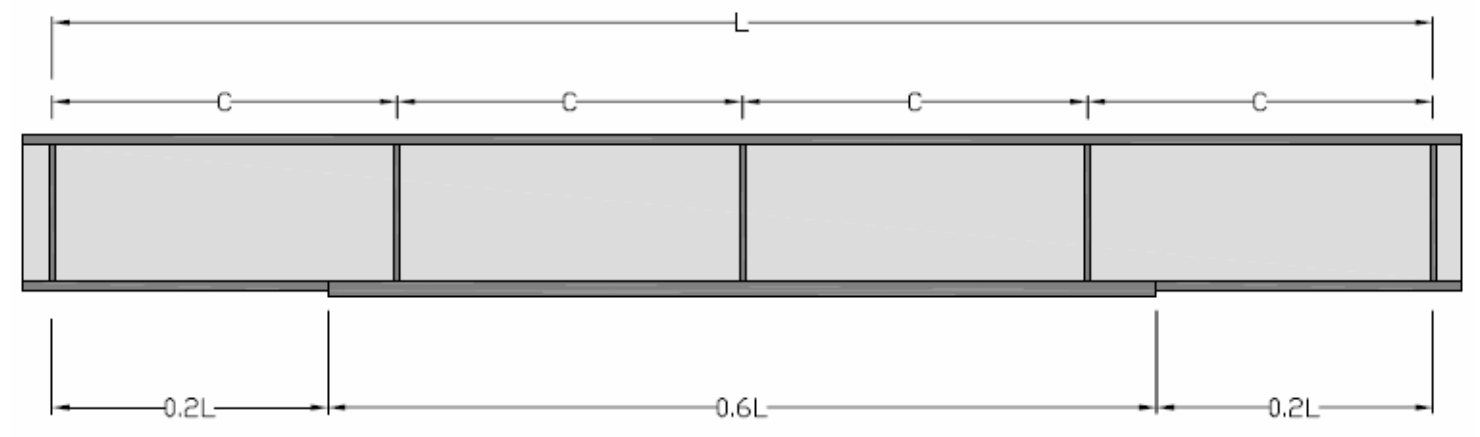


Figure 6-1 Typical Elevation of Steel Plate Girder Sections

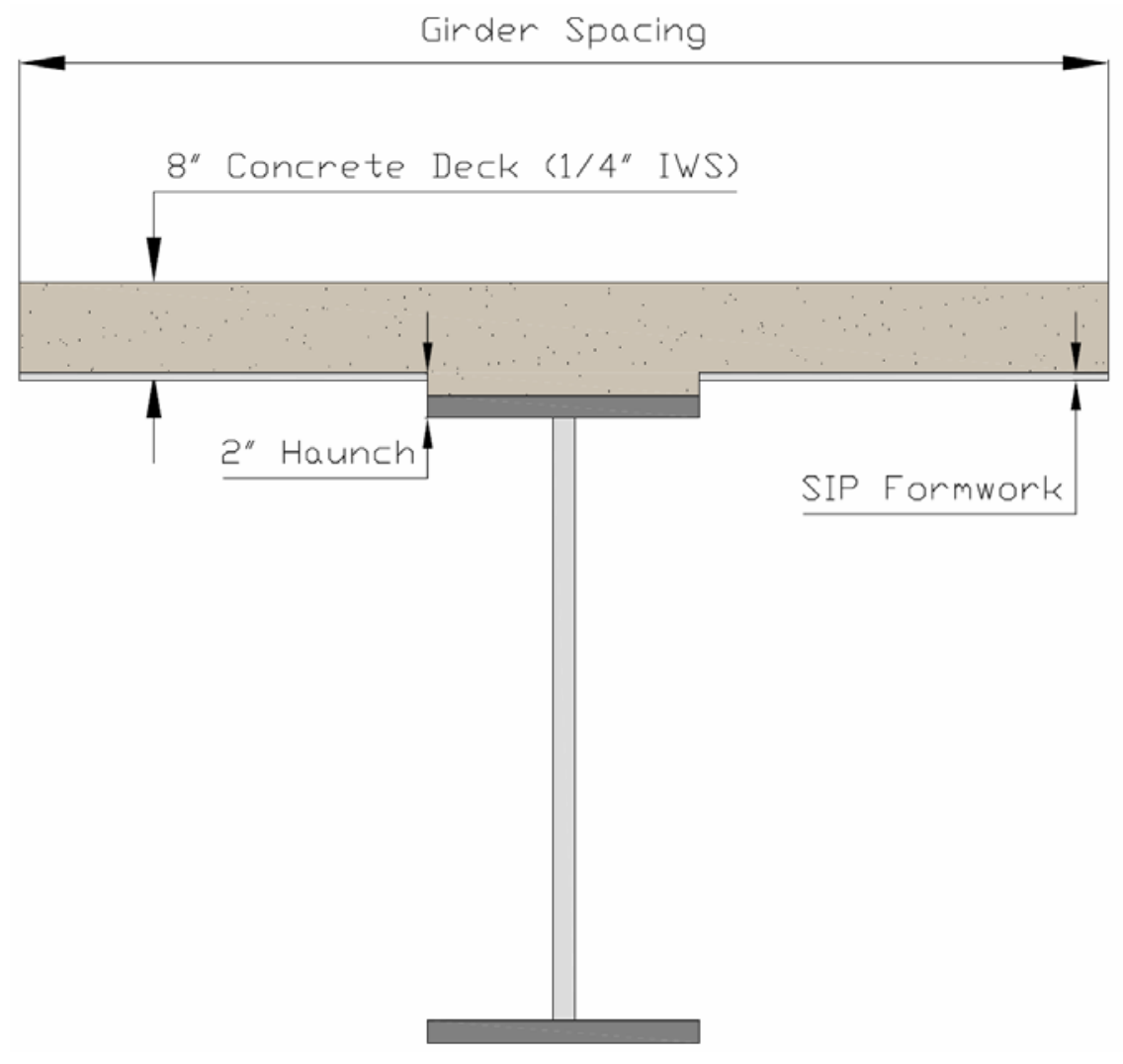

Figure 6-2 Typical Interior Steel Girder Cross-Section

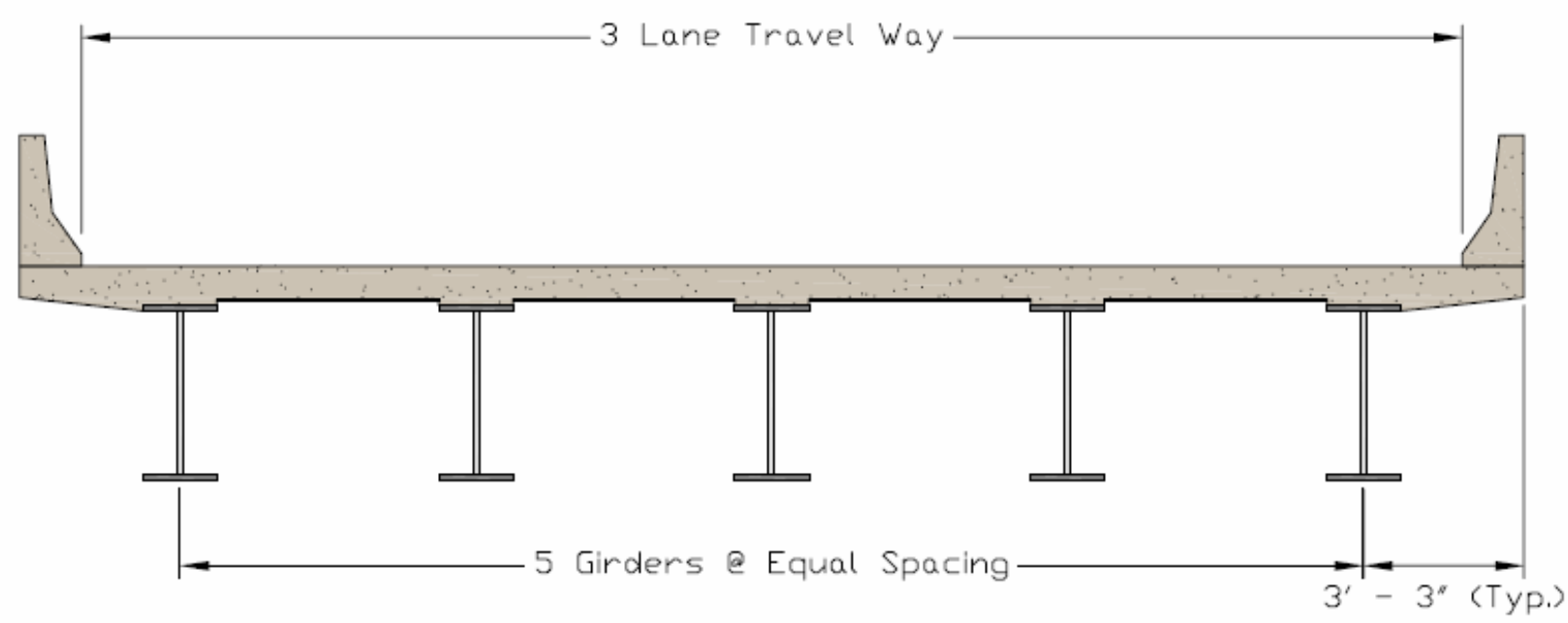

Figure 6-3 Typical Bridge Cross-Section

The rolled steel girder sections and the homogeneous steel plate girder sections in these designs employ $50 \mathrm{ksi}$ steel. The hybrid steel plate girder sections have $50 \mathrm{ksi}$ steel in the compression flange and 
web plates and $70 \mathrm{ksi}$ steel in the tension flange plate. For all girder sections, excluding the rolled steel girder sections of the Lightest Weight Design Approach, a length to depth ratio of 25 was assumed. The depth in this ratio includes the entire depth of the bridge superstructure $=$ i.e. bridge deck depth plus the concrete haunch thickness plus the girder depth. The concrete haunch is defined as the distance from the bottom of the compression flange to the bottom of the concrete deck.

The following parameters were assumed for each bridge girder design:

- Steel stay-in-place (SIP) formwork unit weight: 15 psf

- Future wearing surface: 25 psf

- Concrete barriers: $305 \mathrm{lbs} / \mathrm{ft}$

- Miscellaneous steel weight increase: 5\%

- Compressive strength of concrete: 4,000 psi

- $\quad$ Concrete unit weight: 150 pcf

- $\quad$ Steel unit weight: 490 pcf

- Concrete haunch thickness: 2 in

- Constant flange width

- Constant web height

\subsection{Design Approach}

The goal of this work is to develop a set of standardized designs that increase the efficiency of short span steel bridge design. The standardized designs of this study were developed based on optimized girder designs, which employ different bridge parameters and design approaches. There are four major sets of bridge designs in this work: Limited Depth rolled girder sections, Lightest Weight rolled girder sections, Homogeneous steel plate girder sections and Hybrid steel plate girder sections.

The girder designs were evaluated using Version 6.5 of the MDX Line Girder Rating Software which was referred to by several states in the bridge survey, presented in Chapter 3. Given the parameters of the design approach and girder type, a trial section was selected. Based on this trial section and the tributary area of the cross-section, a design evaluation was performed. The limit states evaluated for each design and their respective AASHTO Specification reference are provided below. 
- Strength Limit State

o $\quad$ Factored Bending Stress - Strength I Loading (Article 6.10.6.2)

o Factored Shear (Article 6.10.6.3)

- Service Limit State

o Elastic Deformations (Article 6.10.4.1)

o Permanent Deformations (Article 6.10.4.2)

- Constructability Limit State

o Web Bend-Buckling Resistance (Article 6.10.1.9)

o Flexure (Article 6.10.3.2)

- Fatigue Limit State

o $\quad$ Load-Induced Fatigue (Article 6.6.1.2)

If the section was found to violate any of the evaluated limit states or found to not be economical, appropriate increases or decreases of the section size were made and the section re-evaluated. This process was followed for all four sets of girder designs with appropriate modifications made for the different types of girders evaluated

The rolled girder sections were designed following two different design approaches: limited depth and lightest weight. The limited depth rolled girder sections were developed employing the Length/Depth ratio of 25. Using this ratio, a girder depth could be selected and a trial section could be evaluated. Wide flange sections of the given depth were evaluated until the most economic section for the given bridge situation was found. The lightest weight rolled girder sections were developed in the same method without the restriction of the Length/Depth ratio.

The steel plate girder sections were designed using two different material configurations: homogeneous and hybrid. For both material configurations the Length/Depth ratio was used to determine the dimensions of the web plate. The compression and tension flanges were selected to create the trial section to begin the evaluation process. Based on the evaluation of the section, dimensions of the flange plates were modified to find a girder section that was both adequate and economic. 
In designing the steel plate girder sections, a limited selection of common steel plate dimensions were used to take advantage of stock piling materials. The following dimensions were employed for the steel plates:

- Web plates

o Depth: 24 in, 32 in, 40 in, 48 in and 56 in

o Thickness: $1 / 2$ in and $3 / 4$ in

- Flange plates

o Width: 12 in, 14 in, 16 in, 18 in and 20 in

o Thickness: $3 / 4$ in, 1 in, $1 \frac{1 / 2}{2}$ in and 2 in

\subsection{Optimized Steel Bridge Design Results}

The following tables display the results of the optimized steel bridge designs developed in this study. Table 6-1 through Table 6-4 present the rolled steel girder sections designed in this research for each span length and girder spacing combination. Figure 6-4 through Figure 6-7 present the weights of the rolled steel girder sections for each span length and girder spacing. The use of these figures will be presented in the next section of this thesis as a starting point for the development of the limited suites of rolled steel girder sections. Table 6-5 through Table 6-8 present the steel plate girder sections designed in this research for each span length and girder spacing combination. Figure 6-9 through Figure 6-12 present the weights of the steel plate girder sections for each span length and girder spacing. These figures present the design capabilities of using limited steel plate sizes in short span bridge designs. Lastly, Figure 6-8 and Figure 6-13 provide comparisons of all the steel girder designs developed for their respective girder type. 
Table 6-1 Rolled Steel Girder Sections - 6 Foot Girder Spacing

\begin{tabular}{|c|c|c|c|c|c|}
\hline & $\begin{array}{c}\text { Span } \\
\text { Length (ft.) }\end{array}$ & $\mathrm{L} / \mathrm{D}$ & $\begin{array}{l}\text { Rolled } \\
\text { Section }\end{array}$ & $\begin{array}{l}\text { Cross Frame } \\
\text { Spacing (ft.) }\end{array}$ & $\begin{array}{l}\text { Weight } \\
\text { (tons) }\end{array}$ \\
\hline \multirow{21}{*}{ 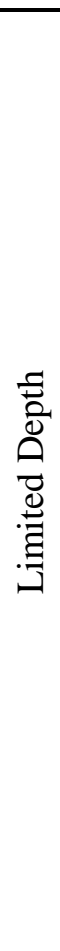 } & 40 & 15.80 & W21x62 & 20 & 1.24 \\
\hline & 45 & 17.67 & W21x83 & 22.5 & 1.87 \\
\hline & 50 & 19.59 & W21x111 & 25 & 2.78 \\
\hline & 55 & 19.73 & W24x117 & 27.5 & 3.22 \\
\hline & 60 & 21.31 & W24x162 & 20 & 4.86 \\
\hline & 65 & 22.91 & W24x192 & 21.67 & 6.24 \\
\hline & 70 & 22.85 & W27x194 & 23.33 & 6.79 \\
\hline & 75 & 24.39 & W27x217 & 25 & 8.14 \\
\hline & 80 & 24.25 & W30x211 & 20 & 8.44 \\
\hline & 85 & 23.93 & W33x221 & 21.25 & 9.39 \\
\hline & 90 & 25.23 & W33x241 & 22.5 & 10.85 \\
\hline & 95 & 25.14 & W36x247 & 23.75 & 11.73 \\
\hline & 100 & 26.36 & W36x282 & 25 & 14.10 \\
\hline & 105 & 24.38 & W44x230 & 26.25 & 12.08 \\
\hline & 110 & 25.44 & W44x262 & 27.5 & 14.41 \\
\hline & 115 & 26.53 & W44x290 & 28.75 & 16.68 \\
\hline & 120 & 27.57 & W44x335 & 30 & 20.10 \\
\hline & 125 & 30.65 & W40x431 & 31.25 & 26.94 \\
\hline & 130 & 31.62 & W40x503 & 32.5 & 32.70 \\
\hline & 135 & 32.55 & W40x593 & 33.75 & 40.03 \\
\hline & 140 & 33.76 & W40x593 & 35 & 41.51 \\
\hline \multirow{21}{*}{ 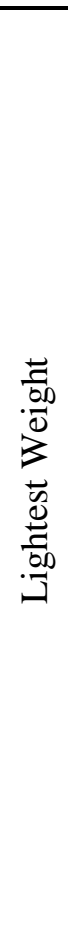 } & 40 & 15.80 & W21x62 & 20 & 1.24 \\
\hline & 45 & 16.31 & W24x68 & 22.5 & 1.53 \\
\hline & 50 & 16.64 & W27x84 & 25 & 2.10 \\
\hline & 55 & 16.97 & W30x90 & 27.5 & 2.48 \\
\hline & 60 & 18.44 & W30x108 & 20 & 3.24 \\
\hline & 65 & 18.50 & W33x118 & 21.67 & 3.84 \\
\hline & 70 & 19.88 & W33x130 & 23.33 & 4.55 \\
\hline & 75 & 20.08 & W36x135 & 25 & 5.06 \\
\hline & 80 & 20.27 & W40x149 & 20 & 5.96 \\
\hline & 85 & 21.44 & W40x167 & 21.25 & 7.10 \\
\hline & 90 & 22.59 & W40x183 & 22.5 & 8.24 \\
\hline & 95 & 23.76 & W40x211 & 23.75 & 10.02 \\
\hline & 100 & 23.22 & W44x230 & 25 & 11.50 \\
\hline & 105 & 24.38 & W44x230 & 26.25 & 12.08 \\
\hline & 110 & 25.44 & W44x262 & 27.5 & 14.41 \\
\hline & 115 & 26.53 & W44x290 & 28.75 & 16.68 \\
\hline & 120 & 27.57 & W44x335 & 30 & 20.10 \\
\hline & 125 & 30.65 & W40x431 & 31.25 & 26.94 \\
\hline & 130 & 31.62 & W40x503 & 32.5 & 32.70 \\
\hline & 135 & 32.55 & W40x593 & 33.75 & 40.03 \\
\hline & 140 & 33.76 & W40x593 & 35 & 41.51 \\
\hline
\end{tabular}


Table 6-2 Rolled Steel Girder Sections - 7 Foot 6 Inch Girder Spacing

\begin{tabular}{|c|c|c|c|c|c|}
\hline & $\begin{array}{l}\text { Span } \\
\text { Length } \\
\text { (ft.) }\end{array}$ & $\mathrm{L} / \mathrm{D}$ & $\begin{array}{l}\text { Rolled } \\
\text { Section }\end{array}$ & $\begin{array}{l}\text { Cross Frame } \\
\text { Spacing (ft.) }\end{array}$ & $\begin{array}{c}\text { Weight } \\
\text { (tons) }\end{array}$ \\
\hline \multirow{21}{*}{ 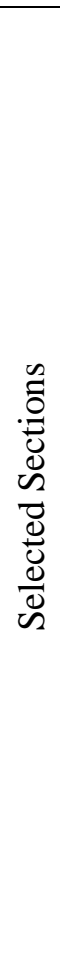 } & 40 & 15.76 & W21x73 & 20 & 1.46 \\
\hline & 45 & 17.65 & W21x101 & 22.5 & 2.27 \\
\hline & 50 & 19.59 & W21x111 & 25 & 2.78 \\
\hline & 55 & 19.73 & W24x117 & 27.5 & 3.22 \\
\hline & 60 & 19.73 & W27x129 & 20 & 3.87 \\
\hline & 65 & 19.85 & W30x132 & 21.67 & 4.29 \\
\hline & 70 & 21.26 & W30x148 & 23.33 & 5.18 \\
\hline & 75 & 20.02 & W36x150 & 25 & 5.63 \\
\hline & 80 & 21.34 & W36x160 & 20 & 6.40 \\
\hline & 85 & 22.61 & W36x182 & 21.25 & 7.74 \\
\hline & 90 & 22.59 & W40x183 & 22.5 & 8.24 \\
\hline & 95 & 23.93 & W40x199 & 23.75 & 9.45 \\
\hline & 100 & 25.01 & W40x211 & 25 & 10.55 \\
\hline & 105 & 24.29 & W44x262 & 26.25 & 13.76 \\
\hline & 110 & 25.44 & W44x262 & 27.5 & 14.41 \\
\hline & 115 & 28.66 & W40x297 & 28.75 & 17.08 \\
\hline & 120 & 29.76 & W40x324 & 30 & 19.44 \\
\hline & 125 & 28.72 & W44x335 & 31.25 & 20.94 \\
\hline & 130 & 29.87 & W44x335 & 32.5 & 21.78 \\
\hline & 135 & 32.83 & W40x503 & 33.75 & 33.95 \\
\hline & 140 & 34.05 & W40x503 & 35 & 35.21 \\
\hline
\end{tabular}


Table 6-3 Rolled Steel Girder Sections - 9 Foot Girder Spacing

\begin{tabular}{|c|c|c|c|c|c|}
\hline & $\begin{array}{c}\text { Span } \\
\text { Length }\end{array}$ & $\mathrm{L} / \mathrm{D}$ & $\begin{array}{l}\text { Rolled } \\
\text { Section }\end{array}$ & $\begin{array}{l}\text { Cross Frame } \\
\text { Spacing (ft.) }\end{array}$ & $\begin{array}{l}\text { Weight } \\
\text { (tons) }\end{array}$ \\
\hline \multirow{21}{*}{ 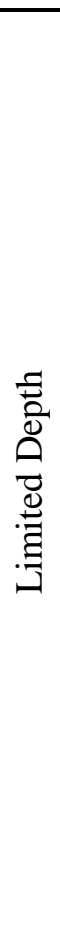 } & 40 & 15.70 & W21x83 & 20 & 1.66 \\
\hline & 45 & 17.65 & W21x101 & 22.5 & 2.27 \\
\hline & 50 & 19.52 & W21x122 & 25 & 3.05 \\
\hline & 55 & 19.68 & W24x131 & 27.5 & 3.60 \\
\hline & 60 & 21.42 & W24x146 & 20 & 4.38 \\
\hline & 65 & 23.04 & W24x176 & 21.67 & 5.72 \\
\hline & 70 & 22.94 & W27x178 & 23.33 & 6.23 \\
\hline & 75 & 24.48 & W27x194 & 25 & 7.28 \\
\hline & 80 & 24.25 & W30x211 & 20 & 8.44 \\
\hline & 85 & 23.93 & W33x221 & 21.25 & 9.39 \\
\hline & 90 & 25.23 & W33x241 & 22.5 & 10.85 \\
\hline & 95 & 25.14 & W36x247 & 23.75 & 11.73 \\
\hline & 100 & 26.40 & W36x262 & 25 & 13.10 \\
\hline & 105 & 26.18 & W40x277 & 26.25 & 14.54 \\
\hline & 110 & 27.41 & W40x297 & 27.5 & 16.34 \\
\hline & 115 & 26.42 & W44x335 & 28.75 & 19.26 \\
\hline & 120 & 29.63 & W40x362 & 30 & 21.72 \\
\hline & 125 & 30.74 & W40x397 & 31.25 & 24.81 \\
\hline & 130 & 31.88 & W40x431 & 32.5 & 28.02 \\
\hline & 135 & 32.83 & W40x503 & 33.75 & 33.95 \\
\hline & 140 & 33.76 & W40x593 & 35 & 41.51 \\
\hline \multirow{21}{*}{ 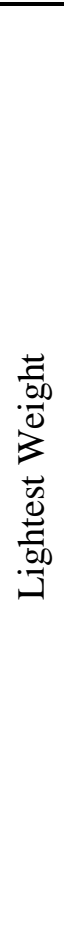 } & 40 & 14.45 & W24x76 & 20 & 1.52 \\
\hline & 45 & 14.98 & W27x84 & 22.5 & 1.89 \\
\hline & 50 & 15.37 & W30x99 & 25 & 2.48 \\
\hline & 55 & 16.86 & W30x116 & 27.5 & 3.19 \\
\hline & 60 & 17.08 & W33x118 & 20 & 3.54 \\
\hline & 65 & 17.41 & W36x135 & 21.67 & 4.39 \\
\hline & 70 & 17.73 & W40x149 & 23.33 & 5.22 \\
\hline & 75 & 18.92 & W40x167 & 25 & 6.26 \\
\hline & 80 & 21.28 & W36x182 & 20 & 7.28 \\
\hline & 85 & 22.50 & W36x210 & 21.25 & 8.93 \\
\hline & 90 & 22.51 & W40x211 & 22.5 & 9.50 \\
\hline & 95 & 23.69 & W40x235 & 23.75 & 11.16 \\
\hline & 100 & 25.01 & W40x249 & 25 & 12.45 \\
\hline & 105 & 24.29 & W44x262 & 26.25 & 13.76 \\
\hline & 110 & 27.41 & W40x297 & 27.5 & 16.34 \\
\hline & 115 & 28.52 & W40x324 & 28.75 & 18.63 \\
\hline & 120 & 29.64 & W40x362 & 30 & 21.72 \\
\hline & 125 & 30.74 & W40x397 & 31.25 & 24.81 \\
\hline & 130 & 31.88 & W40x431 & 32.5 & 28.02 \\
\hline & 135 & 32.83 & W40x503 & 33.75 & 33.95 \\
\hline & 140 & 33.76 & W40x593 & 35 & 41.51 \\
\hline
\end{tabular}


Table 6-4 Rolled Steel Girder Sections - 10 Foot 6 Inch Spacing

\begin{tabular}{|c|c|c|c|c|c|}
\hline & $\begin{array}{c}\text { Span } \\
\text { Length }\end{array}$ & $\mathrm{L} / \mathrm{D}$ & $\begin{array}{l}\text { Rolled } \\
\text { Section }\end{array}$ & $\begin{array}{l}\text { Cross Frame } \\
\text { Spacing (ft.) }\end{array}$ & $\begin{array}{l}\text { Weight } \\
\text { (tons) }\end{array}$ \\
\hline \multirow{21}{*}{ 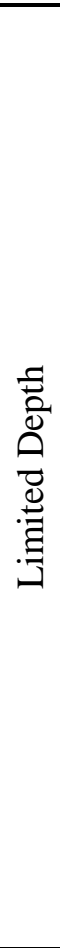 } & 40 & 15.65 & W21x93 & 20 & 1.86 \\
\hline & 45 & 17.63 & W21x111 & 22.5 & 2.50 \\
\hline & 50 & 19.51 & W21x132 & 25 & 3.30 \\
\hline & 55 & 19.64 & W24x146 & 27.5 & 4.02 \\
\hline & 60 & 21.31 & W24x162 & 20 & 4.86 \\
\hline & 65 & 22.91 & W24x192 & 21.67 & 6.24 \\
\hline & 70 & 22.85 & W27x194 & 23.33 & 6.79 \\
\hline & 75 & 24.39 & W27x217 & 25 & 8.14 \\
\hline & 80 & 24.12 & W30x235 & 20 & 9.40 \\
\hline & 85 & 23.83 & W33x241 & 21.25 & 10.24 \\
\hline & 90 & 25.08 & W33x291 & 22.5 & 13.10 \\
\hline & 95 & 25.04 & W36x282 & 23.75 & 13.40 \\
\hline & 100 & 26.30 & W36x302 & 25 & 15.10 \\
\hline & 105 & 26.04 & W40x324 & 26.25 & 17.01 \\
\hline & 110 & 27.17 & W40x362 & 27.5 & 19.91 \\
\hline & 115 & 28.28 & W40x397 & 28.75 & 22.83 \\
\hline & 120 & 29.51 & W40x397 & 30 & 23.82 \\
\hline & 125 & 31.41 & W40x431 & 31.25 & 26.94 \\
\hline & 130 & 31.62 & W40x503 & 32.5 & 32.70 \\
\hline & 135 & 32.55 & W40x593 & 33.75 & 40.03 \\
\hline & 140 & 33.76 & W40x593 & 35 & 41.51 \\
\hline \multirow{21}{*}{ 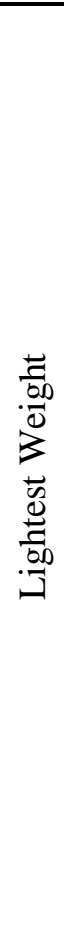 } & 40 & 14.15 & W24x84 & 20 & 1.68 \\
\hline & 45 & 13.89 & W30x90 & 22.5 & 2.03 \\
\hline & 50 & 15.37 & W30x108 & 25 & 2.70 \\
\hline & 55 & 15.65 & W33x118 & 27.5 & 3.25 \\
\hline & 60 & 16.07 & W36x135 & 20 & 4.05 \\
\hline & 65 & 16.47 & W40x149 & 21.67 & 4.84 \\
\hline & 70 & 17.66 & W40x167 & 23.33 & 5.85 \\
\hline & 75 & 19.95 & W36x182 & 25 & 6.83 \\
\hline & 80 & 21.17 & W36x210 & 20 & 8.40 \\
\hline & 85 & 22.55 & W36x231 & 21.25 & 9.82 \\
\hline & 90 & 23.81 & W36x247 & 22.5 & 11.12 \\
\hline & 95 & 23.76 & W40x249 & 23.75 & 11.83 \\
\hline & 100 & 23.48 & W44x262 & 25 & 13.10 \\
\hline & 105 & 26.04 & W40x324 & 26.25 & 17.01 \\
\hline & 110 & 28.70 & W36x361 & 27.5 & 19.86 \\
\hline & 115 & 29.87 & W36x395 & 28.75 & 22.71 \\
\hline & 120 & 29.51 & W40x397 & 30 & 23.82 \\
\hline & 125 & 30.65 & W40x431 & 31.25 & 26.94 \\
\hline & 130 & 31.62 & W40x503 & 32.5 & 32.70 \\
\hline & 135 & 32.55 & W40x593 & 33.75 & 40.03 \\
\hline & 140 & 33.76 & W40x593 & 35 & 41.51 \\
\hline
\end{tabular}




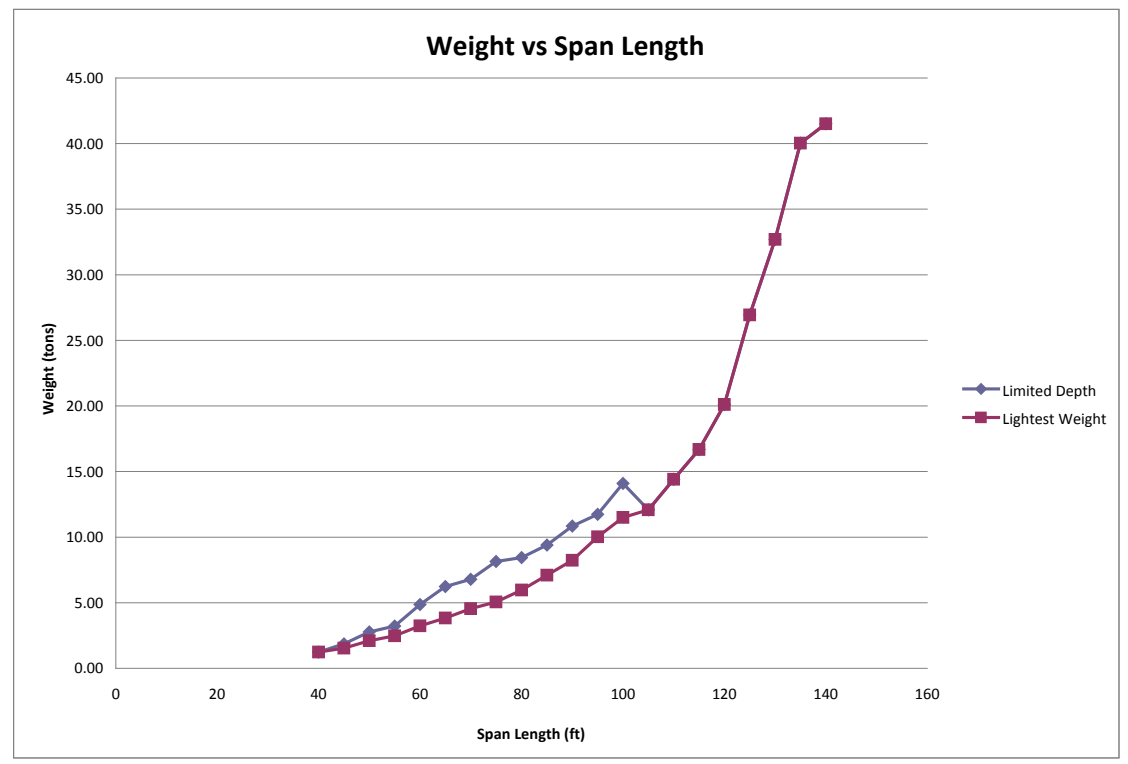

Figure 6-4 Rolled Steel Girder Sections - 6 Foot Spacing

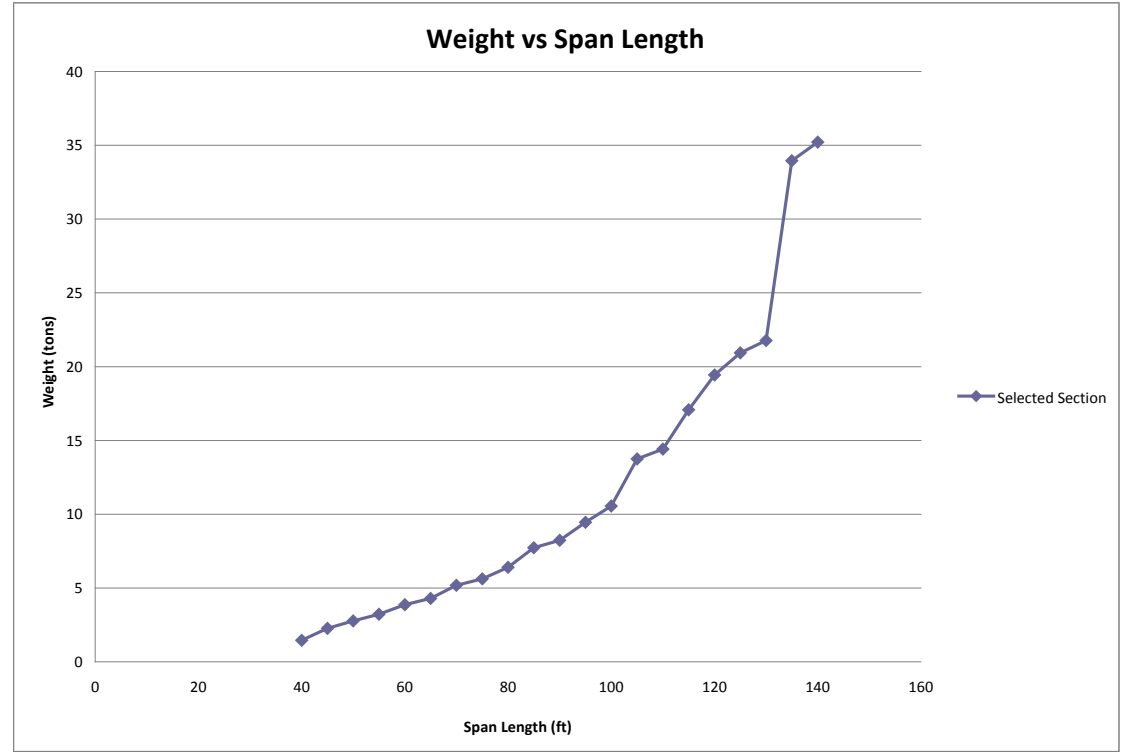

Figure 6-5 Rolled Steel Girder Sections - 7 Foot 6 Inch Girder Spacing 


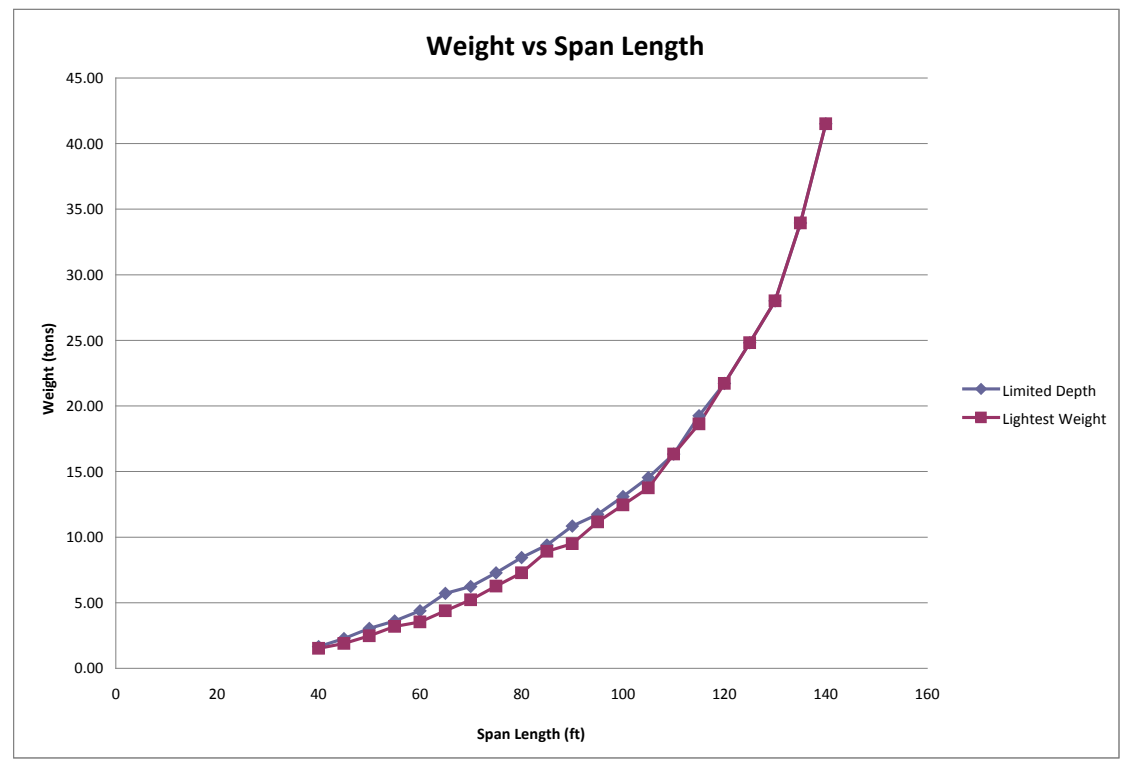

Figure 6-6 Rolled Steel Girder Sections - 9 Foot Girder Spacing

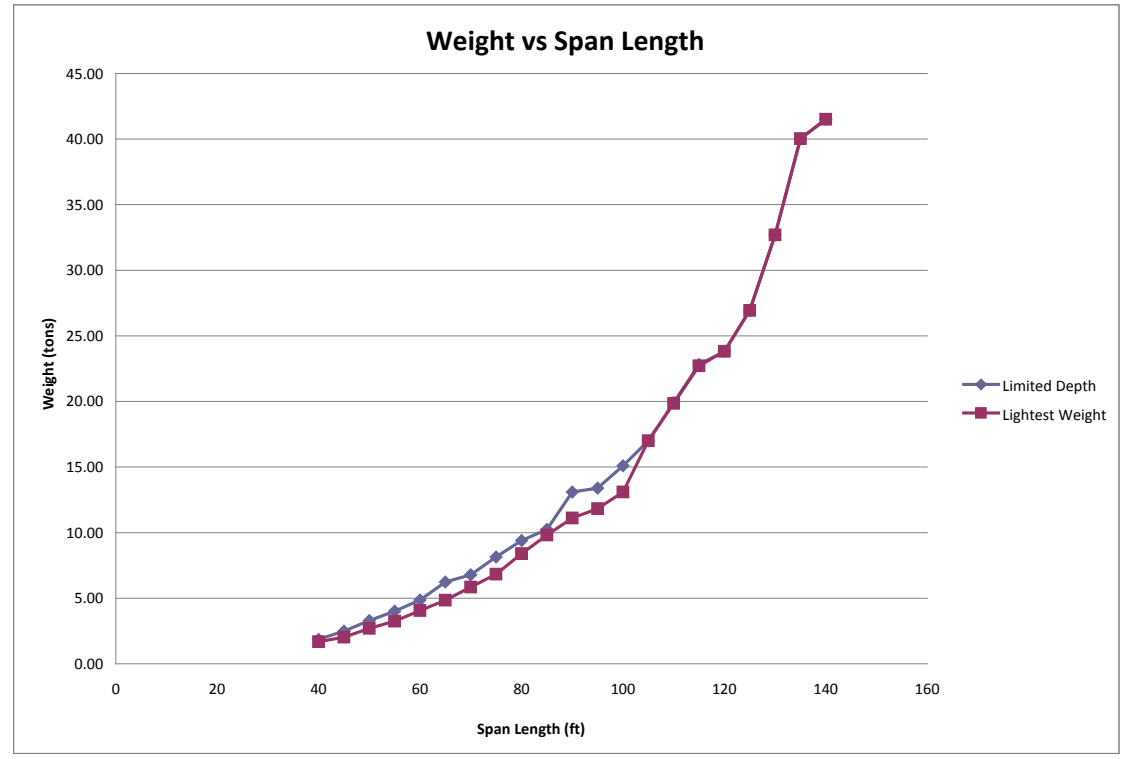

Figure 6-7 Rolled Steel Girder Sections - 10 Foot 6 Inch Girder Spacing 


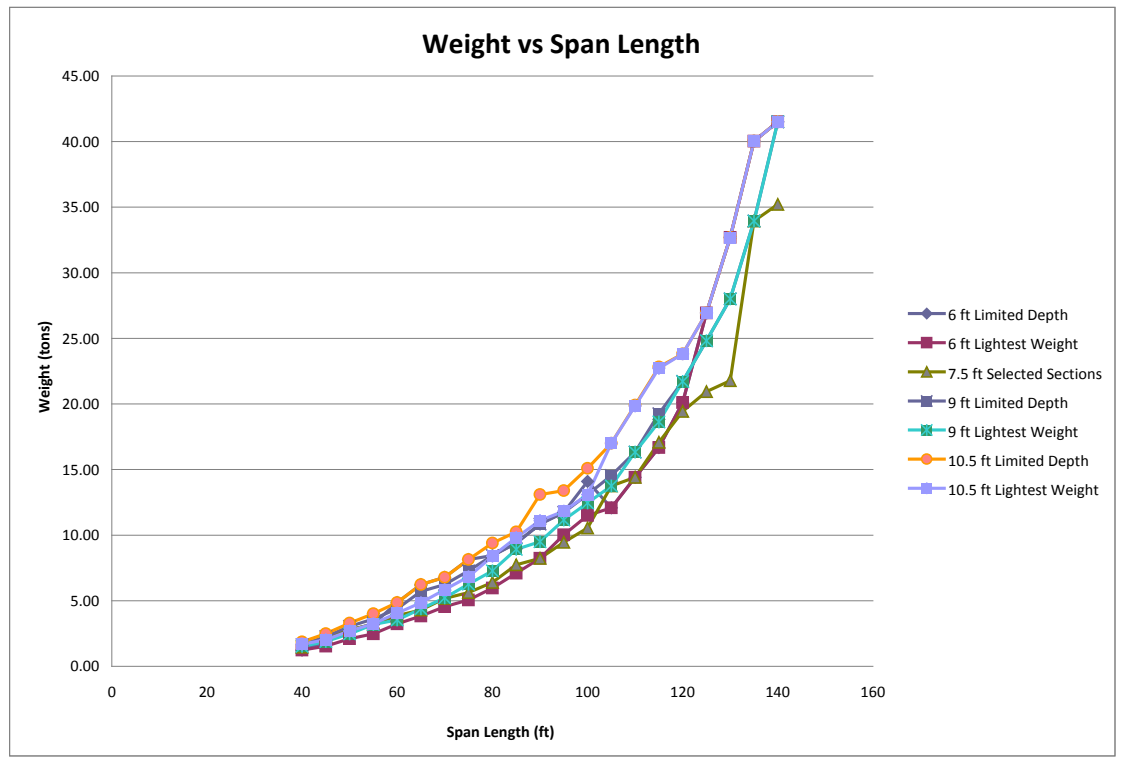

Figure 6-8 Rolled Steel Girder Section Comparison 
Table 6-5 Steel Plate Girder Sections - 6 Foot Girder Spacing

\begin{tabular}{|c|c|c|c|c|c|c|c|c|c|c|c|}
\hline & $\begin{array}{l}\text { Span } \\
\text { Length }\end{array}$ & $\mathrm{L} / \mathrm{D}$ & $\begin{array}{l}\mathrm{b}_{\mathrm{tf}} \\
\text { (in.) }\end{array}$ & $\begin{array}{c}\mathrm{t}_{\mathrm{tf}} \\
\text { (in.) }\end{array}$ & $\begin{array}{c}\text { D } \\
\text { (in.) }\end{array}$ & $\begin{array}{c}\mathrm{t}_{\mathrm{w}} \\
\text { (in.) }\end{array}$ & $\begin{array}{l}\mathrm{b}_{\mathrm{bf}} \\
\text { (in.) }\end{array}$ & $\begin{array}{c}t_{\mathrm{bf1} 1} \\
\text { (in.) }\end{array}$ & $\begin{array}{c}t_{b f 2} \\
\text { (in.) } \\
\end{array}$ & $\begin{array}{l}\text { Cross Frame } \\
\text { Spacing (ft.) }\end{array}$ & $\begin{array}{c}\text { Weight } \\
\text { (tons) }\end{array}$ \\
\hline \multirow{21}{*}{$\begin{array}{l}\vec{y} \\
\frac{1}{1} \\
0 \\
\text { b }\end{array}$} & 40 & 13.81 & 12 & 0.75 & 24 & 0.50 & 12 & 0.75 & 0.75 & 20 & 2.04 \\
\hline & 45 & 15.54 & 12 & 0.75 & 24 & 0.50 & 12 & 0.75 & 0.75 & 22.5 & 2.30 \\
\hline & 50 & 17.27 & 12 & 0.75 & 24 & 0.50 & 12 & 0.75 & 0.75 & 25 & 2.55 \\
\hline & 55 & 18.99 & 12 & 0.75 & 24 & 0.50 & 12 & 0.75 & 0.75 & 27.5 & 2.81 \\
\hline & 60 & 20.57 & 12 & 0.75 & 24 & 0.50 & 14 & 0.75 & 1.00 & 20 & 3.43 \\
\hline & 65 & 22.29 & 12 & 0.75 & 24 & 0.50 & 18 & 0.75 & 1.00 & 21.67 & 4.11 \\
\hline & 70 & 23.66 & 12 & 0.75 & 24 & 0.50 & 16 & 1.00 & 1.50 & 23.33 & 4.98 \\
\hline & 75 & 25.00 & 14 & 0.75 & 24 & 0.50 & 14 & 1.50 & 2.00 & 25 & 6.09 \\
\hline & 80 & 22.33 & 12 & 0.75 & 32 & 0.50 & 18 & 0.75 & 1.00 & 20 & 5.61 \\
\hline & 85 & 23.45 & 12 & 0.75 & 32 & 0.50 & 14 & 1.00 & 1.50 & 21.25 & 6.25 \\
\hline & 90 & 24.83 & 12 & 0.75 & 32 & 0.50 & 18 & 1.00 & 1.50 & 22.5 & 7.41 \\
\hline & 95 & 22.35 & 12 & 0.75 & 40 & 0.50 & 16 & 0.75 & 1.00 & 23.75 & 7.01 \\
\hline & 100 & 23.53 & 14 & 0.75 & 40 & 0.50 & 18 & 0.75 & 1.00 & 25 & 7.95 \\
\hline & 105 & 24.47 & 14 & 0.75 & 40 & 0.50 & 16 & 1.00 & 1.50 & 26.25 & 9.16 \\
\hline & 110 & 25.63 & 16 & 0.75 & 40 & 0.50 & 18 & 1.00 & 1.50 & 27.5 & 10.37 \\
\hline & 115 & 23.39 & 16 & 0.75 & 48 & 0.50 & 18 & 0.75 & 1.00 & 28.75 & 10.21 \\
\hline & 120 & 24.20 & 16 & 0.75 & 48 & 0.50 & 14 & 1.00 & 1.50 & 30 & 11.07 \\
\hline & 125 & 25.21 & 18 & 0.75 & 48 & 0.50 & 16 & 1.00 & 1.50 & 31.25 & 12.40 \\
\hline & 130 & 26.22 & 18 & 0.75 & 48 & 0.50 & 18 & 1.00 & 1.50 & 32.5 & 13.47 \\
\hline & 135 & 24.18 & 18 & 0.75 & 56 & 0.50 & 18 & 0.75 & 1.00 & 33.75 & 13.25 \\
\hline & 140 & 24.89 & 18 & 1.00 & 56 & 0.50 & 14 & 1.00 & 1.50 & 35 & 15.29 \\
\hline \multirow{21}{*}{ 胥 } & 40 & 13.81 & 12 & 0.75 & 24 & 0.50 & 12 & 0.75 & 0.75 & 20 & 2.04 \\
\hline & 45 & 15.54 & 12 & 0.75 & 24 & 0.50 & 12 & 0.75 & 0.75 & 22.5 & 2.30 \\
\hline & 50 & 17.27 & 12 & 0.75 & 24 & 0.50 & 12 & 0.75 & 0.75 & 25 & 2.55 \\
\hline & 55 & 18.99 & 12 & 0.75 & 24 & 0.50 & 12 & 0.75 & 0.75 & 27.5 & 2.81 \\
\hline & 60 & 20.57 & 12 & 0.75 & 24 & 0.50 & 14 & 0.75 & 1.00 & 20 & 3.43 \\
\hline & 65 & 22.29 & 12 & 0.75 & 24 & 0.50 & 18 & 0.75 & 1.00 & 21.67 & 4.11 \\
\hline & 70 & 23.66 & 12 & 0.75 & 24 & 0.50 & 16 & 1.00 & 1.50 & 23.33 & 4.98 \\
\hline & 75 & 25.00 & 14 & 0.75 & 24 & 0.50 & 14 & 1.50 & 2.00 & 25 & 6.09 \\
\hline & 80 & 22.33 & 12 & 0.75 & 32 & 0.50 & 18 & 0.75 & 1.00 & 20 & 5.61 \\
\hline & 85 & 23.45 & 12 & 0.75 & 32 & 0.50 & 14 & 1.00 & 1.50 & 21.25 & 6.25 \\
\hline & 90 & 24.83 & 12 & 0.75 & 32 & 0.50 & 18 & 1.00 & 1.50 & 22.5 & 7.41 \\
\hline & 95 & 22.35 & 12 & 0.75 & 40 & 0.50 & 16 & 0.75 & 1.00 & 23.75 & 7.01 \\
\hline & 100 & 23.53 & 14 & 0.75 & 40 & 0.50 & 18 & 0.75 & 1.00 & 25 & 7.95 \\
\hline & 105 & 24.47 & 14 & 0.75 & 40 & 0.50 & 16 & 1.00 & 1.50 & 26.25 & 9.16 \\
\hline & 110 & 25.63 & 16 & 0.75 & 40 & 0.50 & 18 & 1.00 & 1.50 & 27.5 & 10.37 \\
\hline & 115 & 23.39 & 16 & 0.75 & 48 & 0.50 & 18 & 0.75 & 1.00 & 28.75 & 10.21 \\
\hline & 120 & 24.20 & 16 & 0.75 & 48 & 0.50 & 14 & 1.00 & 1.50 & 30 & 11.07 \\
\hline & 125 & 25.21 & 18 & 0.75 & 48 & 0.50 & 16 & 1.00 & 1.50 & 31.25 & 12.40 \\
\hline & 130 & 26.22 & 18 & 0.75 & 48 & 0.50 & 18 & 1.00 & 1.50 & 32.5 & 13.47 \\
\hline & 135 & 24.18 & 18 & 0.75 & 56 & 0.50 & 18 & 0.75 & 1.00 & 33.75 & 13.25 \\
\hline & 140 & 24.89 & 18 & 1.00 & 56 & 0.50 & 14 & 1.00 & 1.50 & 35 & 15.29 \\
\hline
\end{tabular}


Table 6-6 Steel Plate Girder Sections - 7 Foot 6 Inch Girder Spacing

\begin{tabular}{|c|c|c|c|c|c|c|c|c|c|c|c|}
\hline & $\begin{array}{c}\text { Span } \\
\text { Length }\end{array}$ & $\mathrm{L} / \mathrm{D}$ & $\begin{array}{l}\mathrm{b}_{\mathrm{tf}} \\
\text { (in.) }\end{array}$ & $\begin{array}{l}\mathrm{t}_{\mathrm{tf}} \\
\text { (in.) }\end{array}$ & $\begin{array}{c}\mathrm{D} \\
\text { (in.) }\end{array}$ & $\begin{array}{l}t_{\mathrm{w}} \\
\text { (in.) }\end{array}$ & $\begin{array}{l}\mathrm{b}_{\mathrm{bf}} \\
\text { (in.) }\end{array}$ & $\begin{array}{c}\mathrm{t}_{\mathrm{bf1}} \\
\text { (in.) }\end{array}$ & $\begin{array}{c}\mathrm{t}_{\mathrm{bf2}} \\
\text { (in.) }\end{array}$ & $\begin{array}{l}\text { Cross Frame } \\
\text { Spacing (ft.) }\end{array}$ & $\begin{array}{l}\text { Weight } \\
\text { (tons) }\end{array}$ \\
\hline \multirow{21}{*}{$\begin{array}{l}\frac{\vec{n}}{y} \\
\frac{1}{1}\end{array}$} & 40 & 13.81 & 12 & 0.75 & 24 & 0.50 & 12 & 0.75 & 0.75 & 20 & 2.04 \\
\hline & 45 & 15.54 & 12 & 0.75 & 24 & 0.50 & 12 & 0.75 & 0.75 & 22.5 & 2.30 \\
\hline & 50 & 17.27 & 12 & 0.75 & 24 & 0.50 & 12 & 0.75 & 0.75 & 25 & 2.55 \\
\hline & 55 & 18.99 & 12 & 0.75 & 24 & 0.50 & 12 & 0.75 & 0.75 & 27.5 & 2.81 \\
\hline & 60 & 20.72 & 12 & 0.75 & 24 & 0.50 & 16 & 0.75 & 0.75 & 20 & 3.37 \\
\hline & 65 & 22.29 & 12 & 0.75 & 24 & 0.50 & 16 & 1.00 & 1.00 & 21.67 & 4.09 \\
\hline & 70 & 23.66 & 14 & 0.75 & 24 & 0.50 & 14 & 1.00 & 1.50 & 23.33 & 4.85 \\
\hline & 75 & 25.35 & 16 & 0.75 & 24 & 0.50 & 18 & 1.00 & 1.50 & 25 & 6.05 \\
\hline & 80 & 26.67 & 14 & 0.75 & 24 & 0.50 & 16 & 1.50 & 2.00 & 20 & 6.98 \\
\hline & 85 & 23.45 & 12 & 0.75 & 32 & 0.50 & 14 & 1.00 & 1.50 & 21.25 & 6.25 \\
\hline & 90 & 24.83 & 14 & 0.75 & 32 & 0.50 & 16 & 1.00 & 1.50 & 22.5 & 7.24 \\
\hline & 95 & 26.21 & 16 & 0.75 & 32 & 0.50 & 18 & 1.00 & 1.50 & 23.75 & 8.31 \\
\hline & 100 & 23.53 & 14 & 0.75 & 40 & 0.50 & 18 & 0.75 & 1.00 & 25 & 7.95 \\
\hline & 105 & 24.47 & 16 & 0.75 & 40 & 0.50 & 14 & 1.00 & 1.50 & 26.25 & 8.97 \\
\hline & 110 & 25.63 & 18 & 0.75 & 40 & 0.50 & 16 & 1.00 & 1.50 & 27.5 & 10.16 \\
\hline & 115 & 23.39 & 14 & 0.75 & 48 & 0.50 & 18 & 0.75 & 1.00 & 28.75 & 9.92 \\
\hline & 120 & 24.20 & 18 & 0.75 & 48 & 0.50 & 14 & 1.00 & 1.50 & 30 & 11.37 \\
\hline & 125 & 25.21 & 16 & 1.00 & 48 & 0.50 & 16 & 1.00 & 1.50 & 31.25 & 12.93 \\
\hline & 130 & 26.22 & 18 & 1.00 & 48 & 0.50 & 18 & 1.00 & 1.50 & 32.5 & 14.47 \\
\hline & 135 & 24.00 & 18 & 1.00 & 56 & 0.75 & 14 & 1.00 & 1.50 & 33.75 & 17.96 \\
\hline & 140 & 24.89 & 20 & 1.00 & 56 & 0.75 & 14 & 1.00 & 1.50 & 35 & 19.10 \\
\hline \multirow{21}{*}{$\begin{array}{l}\text { 莺 } \\
\text { 疍 }\end{array}$} & 40 & 13.81 & 12 & 0.75 & 24 & 0.50 & 12 & 0.75 & 0.75 & 20 & 2.04 \\
\hline & 45 & 15.54 & 12 & 0.75 & 24 & 0.50 & 12 & 0.75 & 0.75 & 22.5 & 2.30 \\
\hline & 50 & 17.27 & 12 & 0.75 & 24 & 0.50 & 12 & 0.75 & 0.75 & 25 & 2.55 \\
\hline & 55 & 18.99 & 12 & 0.75 & 24 & 0.50 & 12 & 0.75 & 0.75 & 27.5 & 2.81 \\
\hline & 60 & 20.72 & 12 & 0.75 & 24 & 0.50 & 16 & 0.75 & 0.75 & 20 & 3.37 \\
\hline & 65 & 22.29 & 12 & 0.75 & 24 & 0.50 & 16 & 1.00 & 1.00 & 21.67 & 4.09 \\
\hline & 70 & 23.66 & 14 & 0.75 & 24 & 0.50 & 14 & 1.00 & 1.50 & 23.33 & 4.85 \\
\hline & 75 & 25.35 & 16 & 0.75 & 24 & 0.50 & 18 & 1.00 & 1.50 & 25 & 6.05 \\
\hline & 80 & 26.67 & 14 & 0.75 & 24 & 0.50 & 16 & 1.50 & 2.00 & 20 & 6.98 \\
\hline & 85 & 23.45 & 12 & 0.75 & 32 & 0.50 & 14 & 1.00 & 1.50 & 21.25 & 6.25 \\
\hline & 90 & 24.83 & 14 & 0.75 & 32 & 0.50 & 16 & 1.00 & 1.50 & 22.5 & 7.24 \\
\hline & 95 & 26.21 & 16 & 0.75 & 32 & 0.50 & 18 & 1.00 & 1.50 & 23.75 & 8.31 \\
\hline & 100 & 23.30 & 14 & 0.75 & 40 & 0.50 & 12 & 1.00 & 1.50 & 25 & 7.84 \\
\hline & 105 & 24.47 & 16 & 0.75 & 40 & 0.50 & 14 & 1.00 & 1.50 & 26.25 & 8.97 \\
\hline & 110 & 25.63 & 18 & 0.75 & 40 & 0.50 & 16 & 1.00 & 1.50 & 27.5 & 10.16 \\
\hline & 115 & 23.39 & 16 & 0.75 & 48 & 0.50 & 16 & 0.75 & 1.00 & 28.75 & 9.86 \\
\hline & 120 & 24.41 & 18 & 0.75 & 48 & 0.50 & 18 & 0.75 & 1.00 & 30 & 10.96 \\
\hline & 125 & 25.21 & 16 & 1.00 & 48 & 0.50 & 14 & 1.00 & 1.50 & 31.25 & 12.38 \\
\hline & 130 & 26.22 & 18 & 1.00 & 48 & 0.50 & 16 & 1.00 & 1.50 & 32.5 & 13.89 \\
\hline & 135 & 24.18 & 18 & 1.00 & 56 & 0.75 & 12 & 1.00 & 1.00 & 33.75 & 16.54 \\
\hline & 140 & 25.07 & 20 & 1.00 & 56 & 0.75 & 14 & 1.00 & 1.00 & 35 & 18.10 \\
\hline
\end{tabular}


Table 6-7 Steel Plate Girder Sections - 9 Foot Girder Spacing

\begin{tabular}{|c|c|c|c|c|c|c|c|c|c|c|c|}
\hline & $\begin{array}{c}\text { Span } \\
\text { Length }\end{array}$ & $\mathrm{L} / \mathrm{D}$ & $\begin{array}{l}\mathrm{b}_{\mathrm{tf}} \\
\text { (in.) }\end{array}$ & $\begin{array}{l}\mathrm{t}_{\mathrm{tf}} \\
\text { (in.) }\end{array}$ & $\begin{array}{l}\mathrm{D} \\
\text { (in.) }\end{array}$ & $\begin{array}{l}t_{\mathrm{w}} \\
\text { (in.) }\end{array}$ & $\begin{array}{l}\mathrm{b}_{\mathrm{bf}} \\
\text { (in.) }\end{array}$ & $\begin{array}{l}\mathrm{t}_{\mathrm{bf1}} \\
\text { (in.) }\end{array}$ & $\begin{array}{l}\mathrm{t}_{\mathrm{bf} 2} \\
\text { (in.) }\end{array}$ & $\begin{array}{l}\text { Cross Frame } \\
\text { Spacing (ft.) }\end{array}$ & $\begin{array}{l}\text { Weight } \\
\text { (tons) }\end{array}$ \\
\hline \multirow{21}{*}{ 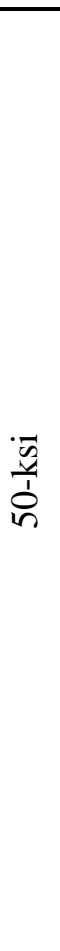 } & 40 & 13.81 & 12 & 0.75 & 24 & 0.50 & 12 & 0.75 & 0.75 & 20 & 2.04 \\
\hline & 45 & 15.54 & 12 & 0.75 & 24 & 0.50 & 12 & 0.75 & 0.75 & 22.5 & 2.30 \\
\hline & 50 & 17.27 & 12 & 0.75 & 24 & 0.50 & 12 & 0.75 & 0.75 & 25 & 2.55 \\
\hline & 55 & 18.86 & 12 & 0.75 & 24 & 0.50 & 12 & 0.75 & 1.00 & 27.5 & 2.98 \\
\hline & 60 & 20.57 & 12 & 0.75 & 24 & 0.50 & 14 & 0.75 & 1.00 & 20 & 3.43 \\
\hline & 65 & 22.29 & 14 & 0.75 & 24 & 0.50 & 18 & 0.75 & 1.00 & 21.67 & 4.28 \\
\hline & 70 & 23.66 & 14 & 0.75 & 24 & 0.50 & 14 & 1.00 & 1.50 & 23.33 & 4.85 \\
\hline & 75 & 25.35 & 18 & 0.75 & 24 & 0.50 & 18 & 1.00 & 1.50 & 25 & 6.24 \\
\hline & 80 & 26.67 & 16 & 0.75 & 24 & 0.50 & 18 & 1.50 & 2.00 & 20 & 7.68 \\
\hline & 85 & 23.45 & 14 & 0.75 & 32 & 0.50 & 14 & 1.00 & 1.50 & 21.25 & 6.46 \\
\hline & 90 & 24.83 & 16 & 0.75 & 32 & 0.50 & 16 & 1.00 & 1.50 & 22.5 & 7.47 \\
\hline & 95 & 26.21 & 18 & 0.75 & 32 & 0.50 & 18 & 1.00 & 1.50 & 23.75 & 8.55 \\
\hline & 100 & 23.30 & 16 & 0.75 & 40 & 0.50 & 16 & 1.00 & 1.50 & 25 & 8.98 \\
\hline & 105 & 24.47 & 18 & 0.75 & 40 & 0.50 & 18 & 1.00 & 1.50 & 26.25 & 10.16 \\
\hline & 110 & 25.38 & 16 & 1.00 & 40 & 0.50 & 14 & 1.50 & 2.00 & 27.5 & 11.45 \\
\hline & 115 & 23.19 & 18 & 0.75 & 48 & 0.50 & 16 & 1.00 & 1.50 & 28.75 & 11.41 \\
\hline & 120 & 24.20 & 18 & 1.00 & 48 & 0.50 & 18 & 1.00 & 1.50 & 30 & 13.35 \\
\hline & 125 & 25.00 & 18 & 1.00 & 48 & 0.50 & 14 & 1.50 & 2.00 & 31.25 & 14.29 \\
\hline & 130 & 26.00 & 20 & 1.00 & 48 & 0.50 & 16 & 1.50 & 2.00 & 32.5 & 16.10 \\
\hline & 135 & 24.00 & 18 & 1.00 & 56 & 0.75 & 16 & 1.00 & 1.50 & 33.75 & 18.56 \\
\hline & 140 & 24.89 & 20 & 1.00 & 56 & 0.75 & 18 & 1.00 & 1.50 & 35 & 20.34 \\
\hline \multirow{21}{*}{$\begin{array}{l}\text { 를 } \\
\text { 全 }\end{array}$} & 40 & 13.81 & 12 & 0.75 & 24 & 0.50 & 12 & 0.75 & 0.75 & 20 & 2.04 \\
\hline & 45 & 15.54 & 12 & 0.75 & 24 & 0.50 & 12 & 0.75 & 0.75 & 22.5 & 2.30 \\
\hline & 50 & 17.27 & 12 & 0.75 & 24 & 0.50 & 12 & 0.75 & 0.75 & 25 & 2.55 \\
\hline & 55 & 18.99 & 12 & 0.75 & 24 & 0.50 & 12 & 0.75 & 0.75 & 27.5 & 2.81 \\
\hline & 60 & 20.72 & 12 & 0.75 & 24 & 0.50 & 16 & 0.75 & 0.75 & 20 & 3.37 \\
\hline & 65 & 22.29 & 14 & 0.75 & 24 & 0.50 & 16 & 0.75 & 1.00 & 21.67 & 4.08 \\
\hline & 70 & 23.66 & 14 & 0.75 & 24 & 0.50 & 14 & 1.00 & 1.50 & 23.33 & 4.85 \\
\hline & 75 & 25.35 & 18 & 0.75 & 24 & 0.50 & 18 & 1.00 & 1.50 & 25 & 6.24 \\
\hline & 80 & 27.04 & 18 & 0.75 & 24 & 0.50 & 20 & 1.00 & 1.50 & 20 & 7.01 \\
\hline & 85 & 23.45 & 14 & 0.75 & 32 & 0.50 & 12 & 1.00 & 1.50 & 21.25 & 6.09 \\
\hline & 90 & 24.83 & 16 & 0.75 & 32 & 0.50 & 14 & 1.00 & 1.50 & 22.5 & 7.07 \\
\hline & 95 & 26.21 & 18 & 0.75 & 32 & 0.50 & 18 & 1.00 & 1.50 & 23.75 & 8.55 \\
\hline & 100 & 23.53 & 16 & 0.75 & 40 & 0.50 & 16 & 0.75 & 1.00 & 25 & 7.89 \\
\hline & 105 & 24.71 & 18 & 0.75 & 40 & 0.50 & 18 & 0.75 & 1.00 & 26.25 & 8.88 \\
\hline & 110 & 25.63 & 16 & 1.00 & 40 & 0.50 & 16 & 1.00 & 1.50 & 27.5 & 10.63 \\
\hline & 115 & 23.39 & 18 & 0.75 & 48 & 0.50 & 14 & 0.75 & 1.00 & 28.75 & 9.80 \\
\hline & 120 & 24.41 & 18 & 1.00 & 48 & 0.50 & 16 & 0.75 & 1.00 & 30 & 11.52 \\
\hline & 125 & 25.21 & 18 & 1.00 & 48 & 0.50 & 14 & 1.00 & 1.50 & 31.25 & 12.80 \\
\hline & 130 & 26.22 & 20 & 1.00 & 48 & 0.50 & 14 & 1.00 & 1.50 & 32.5 & 13.76 \\
\hline & 135 & 24.18 & 20 & 1.00 & 56 & 0.75 & 14 & 1.00 & 1.00 & 33.75 & 17.46 \\
\hline & 140 & 25.07 & 20 & 1.00 & 56 & 0.75 & 14 & 1.00 & 1.00 & 35 & 18.10 \\
\hline
\end{tabular}


Table 6-8 Steel Plate Girder Sections - 10 Foot 6 Inch Girder Spacing

\begin{tabular}{|c|c|c|c|c|c|c|c|c|c|c|c|}
\hline & $\begin{array}{c}\text { Span } \\
\text { Length }\end{array}$ & $\mathrm{L} / \mathrm{D}$ & $\begin{array}{l}\mathrm{b}_{\mathrm{tf}} \\
\text { (in.) }\end{array}$ & $\begin{array}{l}\mathrm{t}_{\mathrm{tf}} \\
\text { (in.) }\end{array}$ & $\begin{array}{c}\mathrm{D} \\
\text { (in.) }\end{array}$ & $\begin{array}{l}t_{\mathrm{w}} \\
\text { (in.) }\end{array}$ & $\begin{array}{l}\mathrm{b}_{\mathrm{bf}} \\
\text { (in.) }\end{array}$ & $\begin{array}{l}\mathrm{t}_{\mathrm{bf} 1} \\
\text { (in.) }\end{array}$ & $\begin{array}{l}t_{\mathrm{bf} 2} \\
\text { (in.) }\end{array}$ & $\begin{array}{l}\text { Cross Frame } \\
\text { Spacing (ft.) }\end{array}$ & $\begin{array}{l}\text { Weight } \\
\text { (tons) }\end{array}$ \\
\hline \multirow{21}{*}{$\begin{array}{l}\frac{\vec{n}}{y} \\
\frac{1}{1}\end{array}$} & 40 & 13.81 & 12 & 0.75 & 24 & 0.50 & 12 & 0.75 & 0.75 & 20 & 2.04 \\
\hline & 45 & 15.54 & 12 & 0.75 & 24 & 0.50 & 12 & 0.75 & 0.75 & 22.5 & 2.30 \\
\hline & 50 & 17.14 & 12 & 0.75 & 24 & 0.50 & 12 & 0.75 & 1.00 & 25 & 2.71 \\
\hline & 55 & 18.86 & 12 & 0.75 & 24 & 0.50 & 14 & 0.75 & 1.00 & 27.5 & 3.14 \\
\hline & 60 & 20.57 & 12 & 0.75 & 24 & 0.50 & 16 & 0.75 & 1.00 & 20 & 3.61 \\
\hline & 65 & 21.97 & 14 & 0.75 & 24 & 0.50 & 14 & 1.00 & 1.50 & 21.67 & 4.50 \\
\hline & 70 & 23.66 & 16 & 0.75 & 24 & 0.50 & 16 & 1.00 & 1.50 & 23.33 & 5.34 \\
\hline & 75 & 25.35 & 16 & 1.00 & 24 & 0.50 & 18 & 1.00 & 1.50 & 25 & 6.56 \\
\hline & 80 & 27.04 & 16 & 1.00 & 24 & 0.50 & 20 & 1.00 & 1.50 & 20 & 7.35 \\
\hline & 85 & 23.45 & 16 & 0.75 & 32 & 0.50 & 16 & 1.00 & 1.50 & 21.25 & 7.06 \\
\hline & 90 & 24.83 & 18 & 0.75 & 32 & 0.50 & 18 & 1.00 & 1.50 & 22.5 & 8.10 \\
\hline & 95 & 26.21 & 16 & 1.00 & 32 & 0.50 & 20 & 1.00 & 1.50 & 23.75 & 9.37 \\
\hline & 100 & 23.30 & 18 & 0.75 & 40 & 0.50 & 18 & 1.00 & 1.50 & 25 & 9.68 \\
\hline & 105 & 24.47 & 18 & 1.00 & 40 & 0.50 & 20 & 1.00 & 1.50 & 26.25 & 11.43 \\
\hline & 110 & 25.38 & 18 & 1.00 & 40 & 0.50 & 16 & 1.50 & 2.00 & 27.5 & 12.50 \\
\hline & 115 & 23.19 & 18 & 1.00 & 48 & 0.75 & 16 & 1.00 & 1.50 & 28.75 & 14.64 \\
\hline & 120 & 24.20 & 18 & 1.00 & 48 & 0.75 & 18 & 1.00 & 1.50 & 30 & 15.80 \\
\hline & 125 & 25.00 & 20 & 1.00 & 48 & 0.75 & 16 & 1.50 & 2.00 & 31.25 & 18.03 \\
\hline & 130 & 26.00 & 18 & 1.50 & 48 & 0.75 & 18 & 1.50 & 2.00 & 32.5 & 21.10 \\
\hline & 135 & 24.00 & 20 & 1.00 & 56 & 0.75 & 20 & 1.00 & 1.50 & 33.75 & 20.21 \\
\hline & 140 & 24.71 & 20 & 1.50 & 56 & 0.75 & 16 & 1.50 & 2.00 & 35 & 24.01 \\
\hline \multirow{21}{*}{$\begin{array}{l}\text { 莺 } \\
\text { 疍 }\end{array}$} & 40 & 13.81 & 12 & 0.75 & 24 & 0.50 & 12 & 0.75 & 0.75 & 20 & 2.04 \\
\hline & 45 & 15.54 & 12 & 0.75 & 24 & 0.50 & 12 & 0.75 & 0.75 & 22.5 & 2.30 \\
\hline & 50 & 17.27 & 12 & 0.75 & 24 & 0.50 & 12 & 0.75 & 0.75 & 25 & 2.55 \\
\hline & 55 & 18.99 & 12 & 0.75 & 24 & 0.50 & 12 & 0.75 & 0.75 & 27.5 & 2.81 \\
\hline & 60 & 20.57 & 12 & 0.75 & 24 & 0.50 & 12 & 0.75 & 1.00 & 20 & 3.25 \\
\hline & 65 & 22.29 & 14 & 0.75 & 24 & 0.50 & 16 & 0.75 & 1.00 & 21.67 & 4.08 \\
\hline & 70 & 23.66 & 16 & 0.75 & 24 & 0.50 & 14 & 1.00 & 1.50 & 23.33 & 5.03 \\
\hline & 75 & 25.35 & 16 & 1.00 & 24 & 0.50 & 18 & 1.00 & 1.50 & 25 & 6.56 \\
\hline & 80 & 26.67 & 16 & 1.00 & 24 & 0.50 & 14 & 1.50 & 2.00 & 20 & 7.24 \\
\hline & 85 & 23.45 & 16 & 0.75 & 32 & 0.50 & 12 & 1.00 & 1.50 & 21.25 & 6.31 \\
\hline & 90 & 24.83 & 18 & 0.75 & 32 & 0.50 & 14 & 1.00 & 1.50 & 22.5 & 7.30 \\
\hline & 95 & 26.21 & 18 & 1.00 & 32 & 0.50 & 16 & 1.00 & 1.50 & 23.75 & 8.86 \\
\hline & 100 & 23.30 & 18 & 0.75 & 40 & 0.50 & 12 & 1.00 & 1.50 & 25 & 8.35 \\
\hline & 105 & 24.71 & 18 & 1.00 & 40 & 0.50 & 18 & 0.75 & 1.00 & 26.25 & 9.68 \\
\hline & 110 & 25.63 & 18 & 1.00 & 40 & 0.50 & 14 & 1.00 & 1.50 & 27.5 & 10.52 \\
\hline & 115 & 23.39 & 18 & 1.00 & 48 & 0.75 & 14 & 1.00 & 1.00 & 28.75 & 13.30 \\
\hline & 120 & 24.41 & 18 & 1.00 & 48 & 0.75 & 16 & 1.00 & 1.00 & 30 & 14.29 \\
\hline & 125 & 25.42 & 20 & 1.00 & 48 & 0.75 & 18 & 1.00 & 1.00 & 31.25 & 15.74 \\
\hline & 130 & 26.22 & 18 & 1.50 & 48 & 0.75 & 14 & 1.00 & 1.50 & 32.5 & 17.96 \\
\hline & 135 & 24.00 & 20 & 1.00 & 56 & 0.75 & 12 & 1.00 & 1.50 & 33.75 & 17.82 \\
\hline & 140 & 24.89 & 18 & 1.50 & 56 & 0.75 & 12 & 1.00 & 1.50 & 35 & 20.15 \\
\hline
\end{tabular}




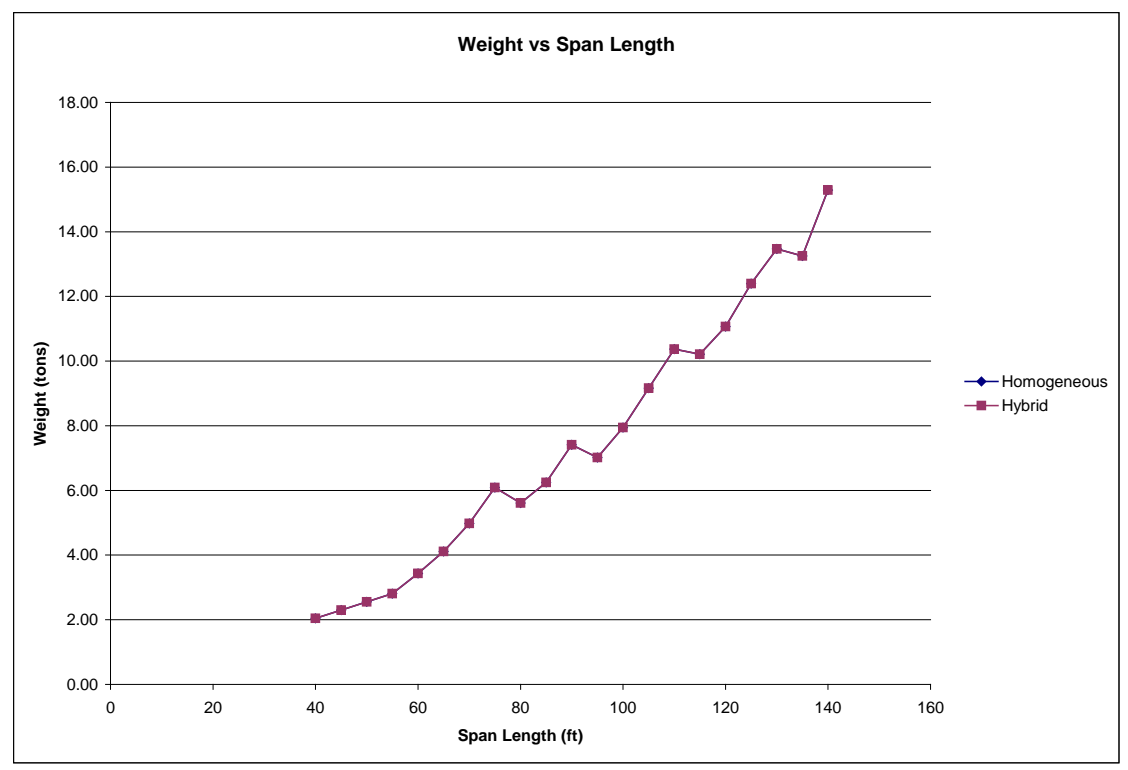

Figure 6-9 Steel Plate Girder Sections - 6 Foot Girder Spacing

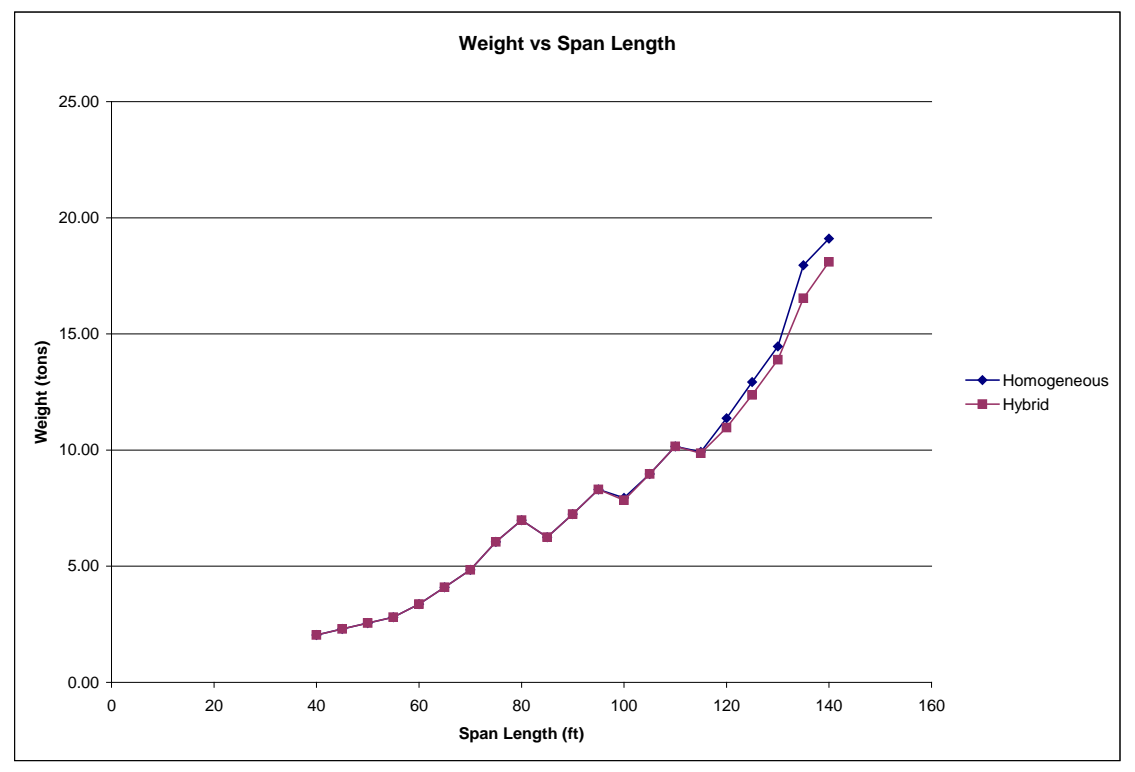

Figure 6-10 Steel Plate Girder Sections - 7 Foot 6 Inch Girder Spacing 


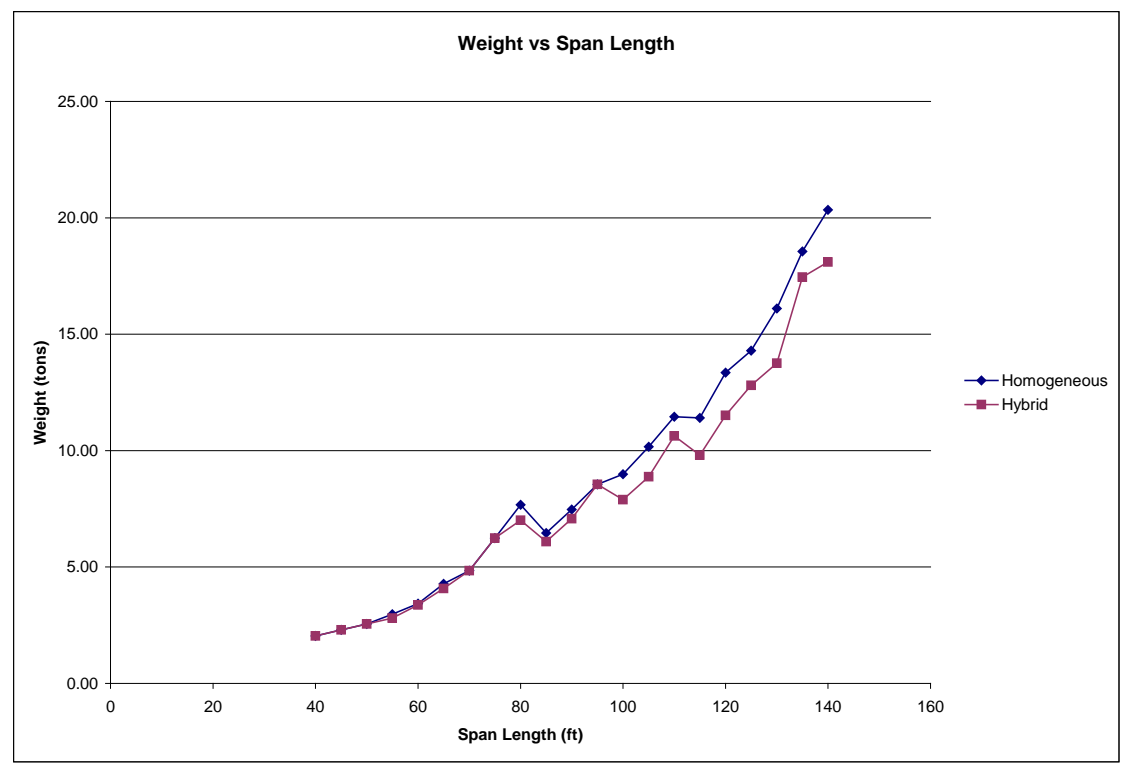

Figure 6-11 Steel Plate Girder Sections - 9 Foot Girder Spacing

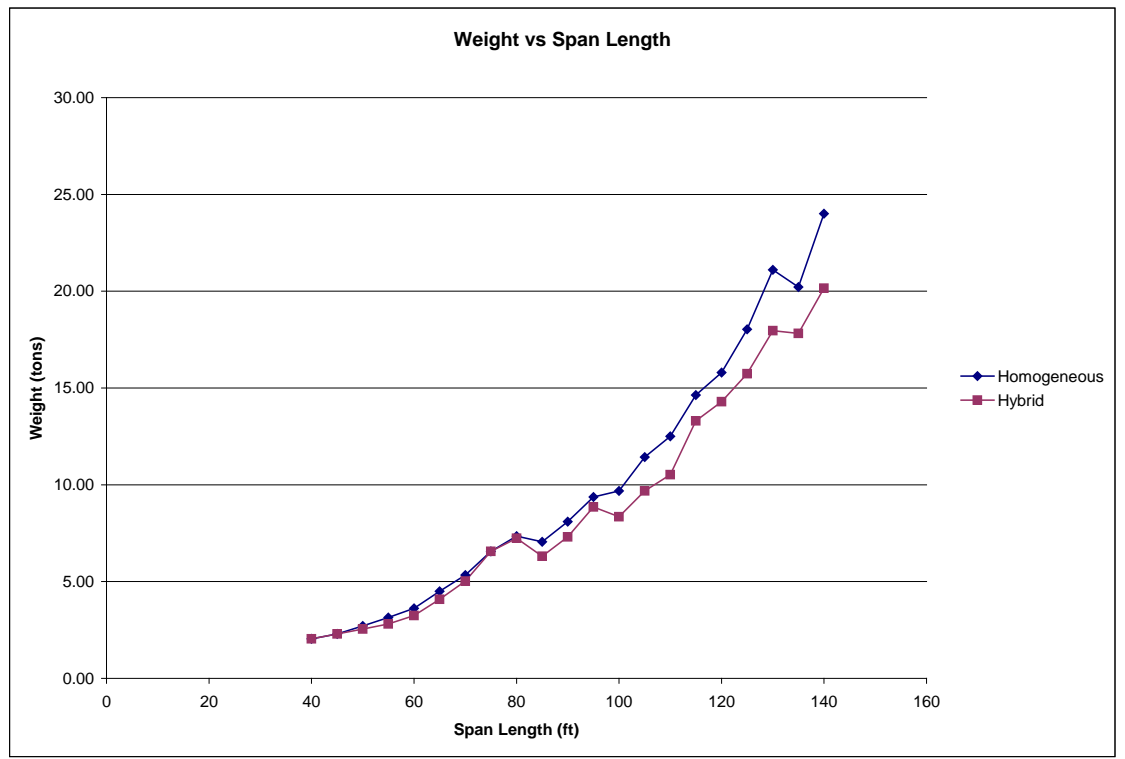

Figure 6-12 Steel Plate Girder Sections - 10 Foot 6 Inch Girder Sections 


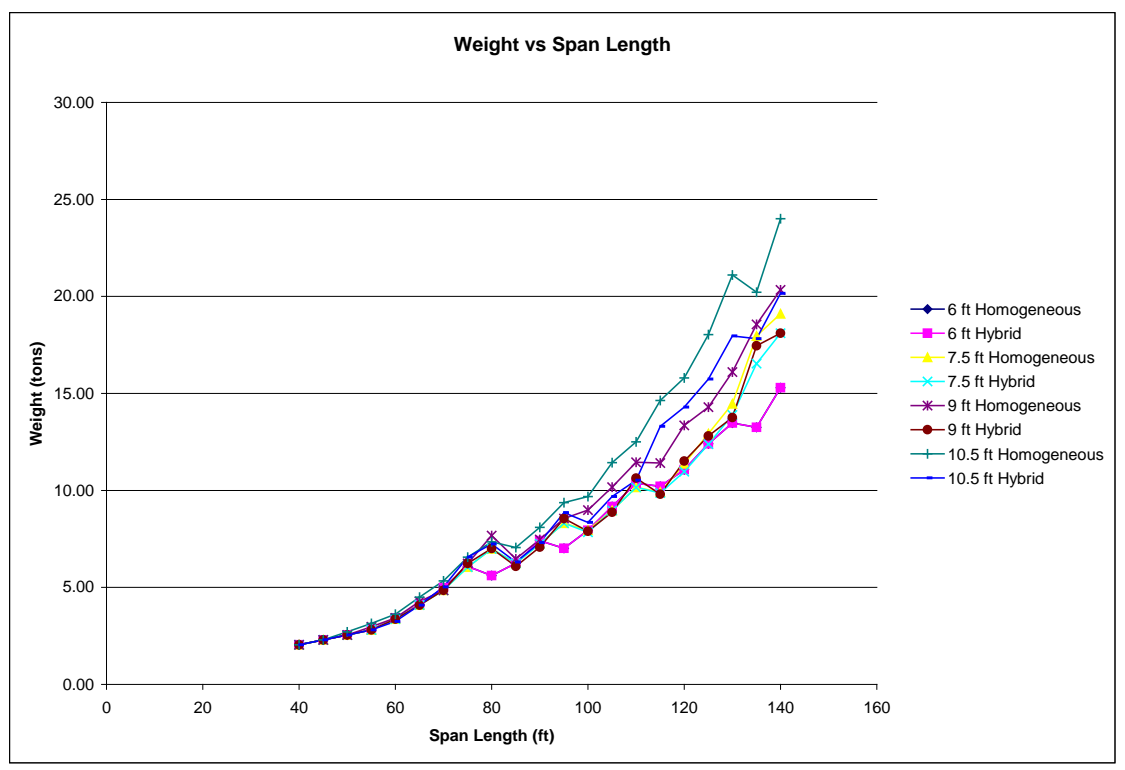

Figure 6-13 Steel Plate Girder Section Comparisons 


\subsection{Reduced Suite of Rolled Steel Girders}

After developing the optimized rolled steel girder section for each bridge span and girder spacing arrangement, a limited suite of rolled steel girders were selected as adequate sections for any of the evaluated girder spacing arrangements and over the range of bridge spans evaluated. To determine which girder sections would be included, all of the rolled girder sections were analyzed for a given span range and the largest girder section from that range was selected. The span ranges were separated for three different sets of girders: 5 selected sections, 7 selected sections and 10 selected sections. Each set of girder selections added to the number of girder sections in the limited suite but also provided more efficient designs for the bridges. In this sense, the 5 selected sections suite benefits the steel manufacturers in that they can stock pile these 5 rolled girder sections to be sold as needed. The 10 selected section suite benefits the designer in that they have a more efficient bridge design.

The ranges for the initial set of 5 sections were selected by dividing the total span length range of 40 feet to 140 feet into divisions of 20 feet. The ranges for the set of 7 sections were selected by keeping the first three ranges from the 5 selected sections and dividing the remaining ranges into 10 foot ranges. The last suite of selected sections was developed by dividing the total range into 10 foot increments. Table 6-9 through Table 6-11 present the results of these rolled steel girder selections. Figure 6-14 through Figure 6-23 present graphs showing the weights of the 5 selected sections compared to the optimized designs. Figure 6-24 through Figure 6-27 present the additional selected sections that are added to the suites between the 5 selected sections and the 7 selected sections. Figure 6-28 through Figure 6-33 present the additional selected sections that are added to the suites between the 7 selected sections and the 10 selected sections. 
Table 6-9 5 Selected Sections

\begin{tabular}{|c|c|c|}
\hline Span Range & Limited Depth & Lightest Weight \\
\hline $40 \mathrm{ft}-60 \mathrm{ft}$ & W24x162 & W36x135 \\
\hline $60 \mathrm{ft}-80 \mathrm{ft}$ & W30x235 & W36x210 \\
\hline $80 \mathrm{ft}-100 \mathrm{ft}$ & W36x302 & W44x262 \\
\hline $100 \mathrm{ft}-120 \mathrm{ft}$ & W40x397 & W40x397 \\
\hline $120 \mathrm{ft}-140 \mathrm{ft}$ & W40x593 & W40x593 \\
\hline
\end{tabular}

Table 6-10 7 Selected Sections

\begin{tabular}{|c|c|c|}
\hline Span Range & Limited Depth & Lightest Weight \\
\hline $40 \mathrm{ft}-60 \mathrm{ft}$ & W24x162 & W36x135 \\
\hline $60 \mathrm{ft}-80 \mathrm{ft}$ & W30x235 & W36x210 \\
\hline $80 \mathrm{ft}-100 \mathrm{ft}$ & W36x302 & W44x262 \\
\hline $100 \mathrm{ft}-110 \mathrm{ft}$ & W40x362 & W36x361 \\
\hline $110 \mathrm{ft}-120 \mathrm{ft}$ & W40x397 & W40x397 \\
\hline $120 \mathrm{ft}-130 \mathrm{ft}$ & W40x503 & W40x503 \\
\hline $130 \mathrm{ft}-140 \mathrm{ft}$ & W40x593 & W40x593 \\
\hline
\end{tabular}

Table 6-11 10 Selected Sections

\begin{tabular}{|c|c|c|}
\hline Span Range & Limited Depth & Lightest Weight \\
\hline $40 \mathrm{ft}-50 \mathrm{ft}$ & W21x132 & W21x111 \\
\hline $50 \mathrm{ft}-60 \mathrm{ft}$ & W24x162 & W36x135 \\
\hline $60 \mathrm{ft}-70 \mathrm{ft}$ & W27x194 & W40x167 \\
\hline $70 \mathrm{ft}-80 \mathrm{ft}$ & W30x235 & W36x210 \\
\hline $80 \mathrm{ft}-90 \mathrm{ft}$ & W33x291 & W36x247 \\
\hline $90 \mathrm{ft}-100 \mathrm{ft}$ & W36x302 & W44x262 \\
\hline $100 \mathrm{ft}-110 \mathrm{ft}$ & W40x362 & W36x361 \\
\hline $110 \mathrm{ft}-120 \mathrm{ft}$ & $\mathrm{W} 40 \times 397$ & W40x397 \\
\hline $120 \mathrm{ft}-130 \mathrm{ft}$ & $\mathrm{W} 40 \times 503$ & W40x503 \\
\hline $130 \mathrm{ft}-140 \mathrm{ft}$ & W40x593 & W40x593 \\
\hline
\end{tabular}




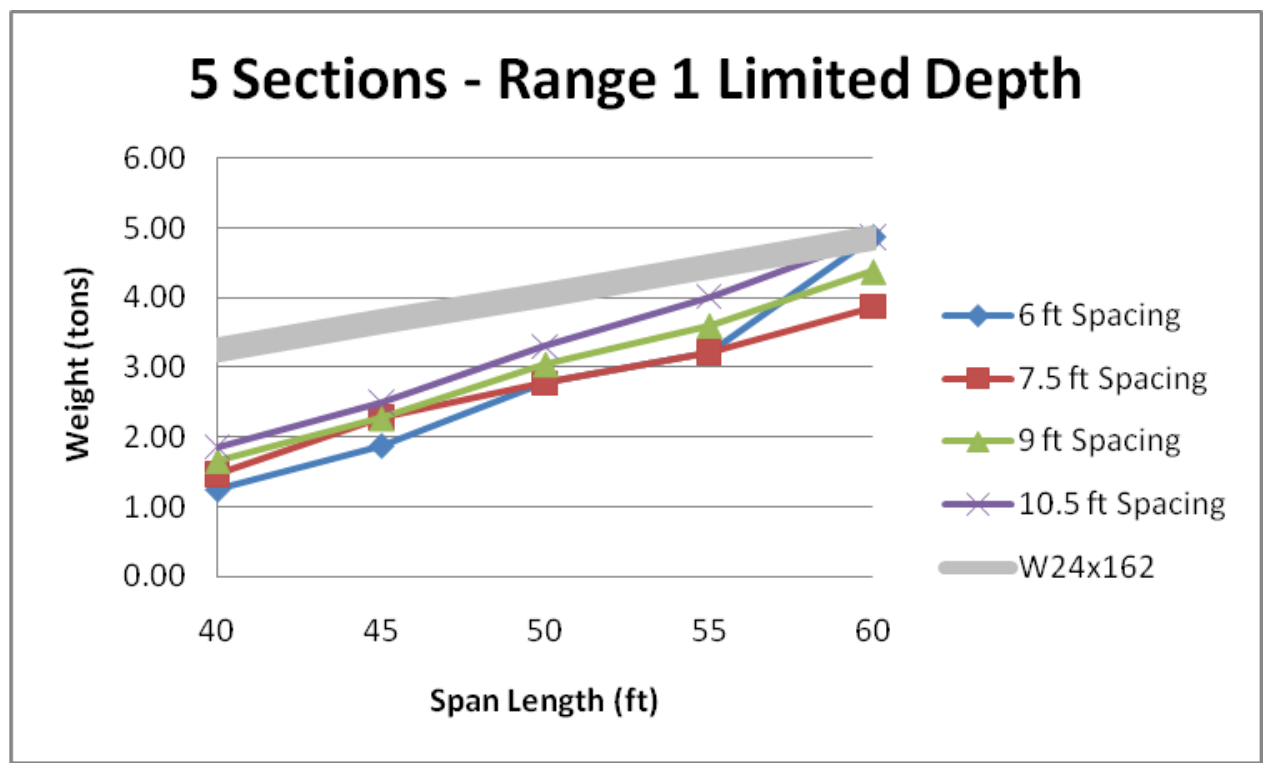

Figure 6-14 5 Selected Sections - Limited Depth (40 ft - $60 \mathrm{ft}$ )

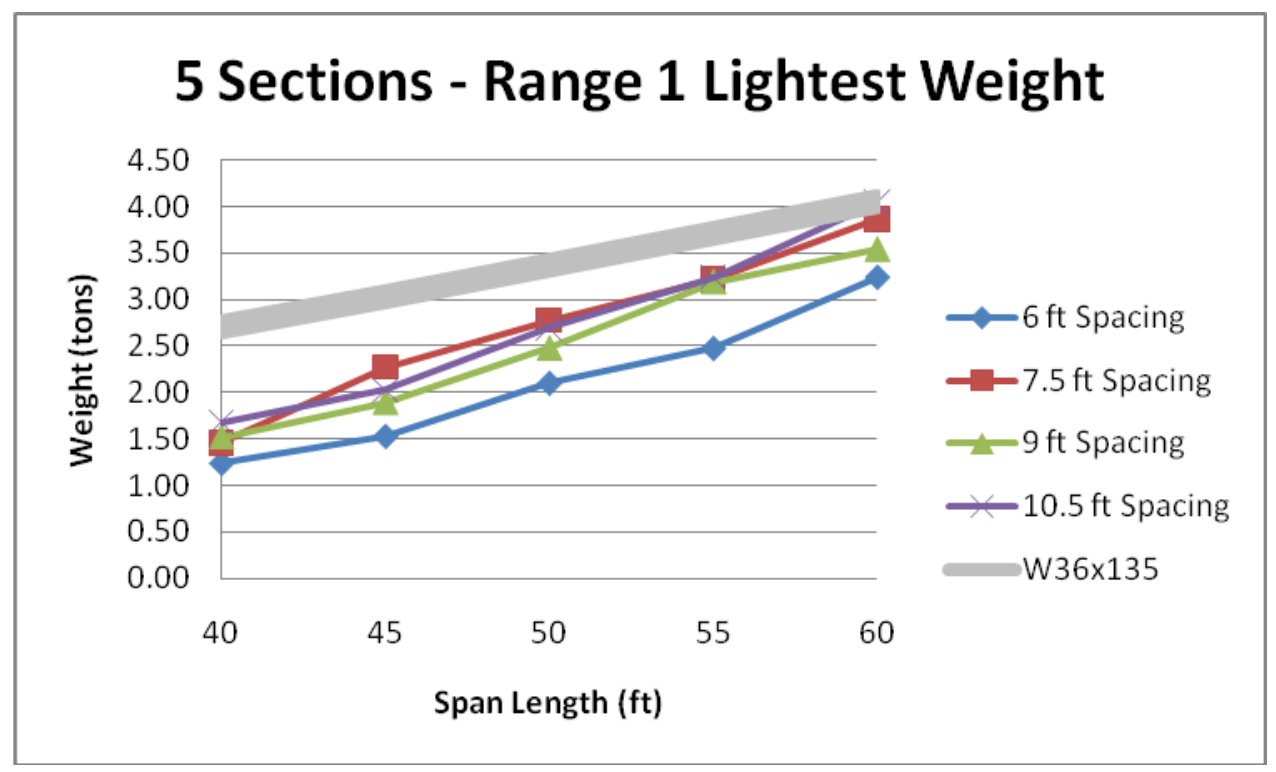

Figure 6-15 5 Selected Sections - Lightest Weight (40 ft - 60 ft) 


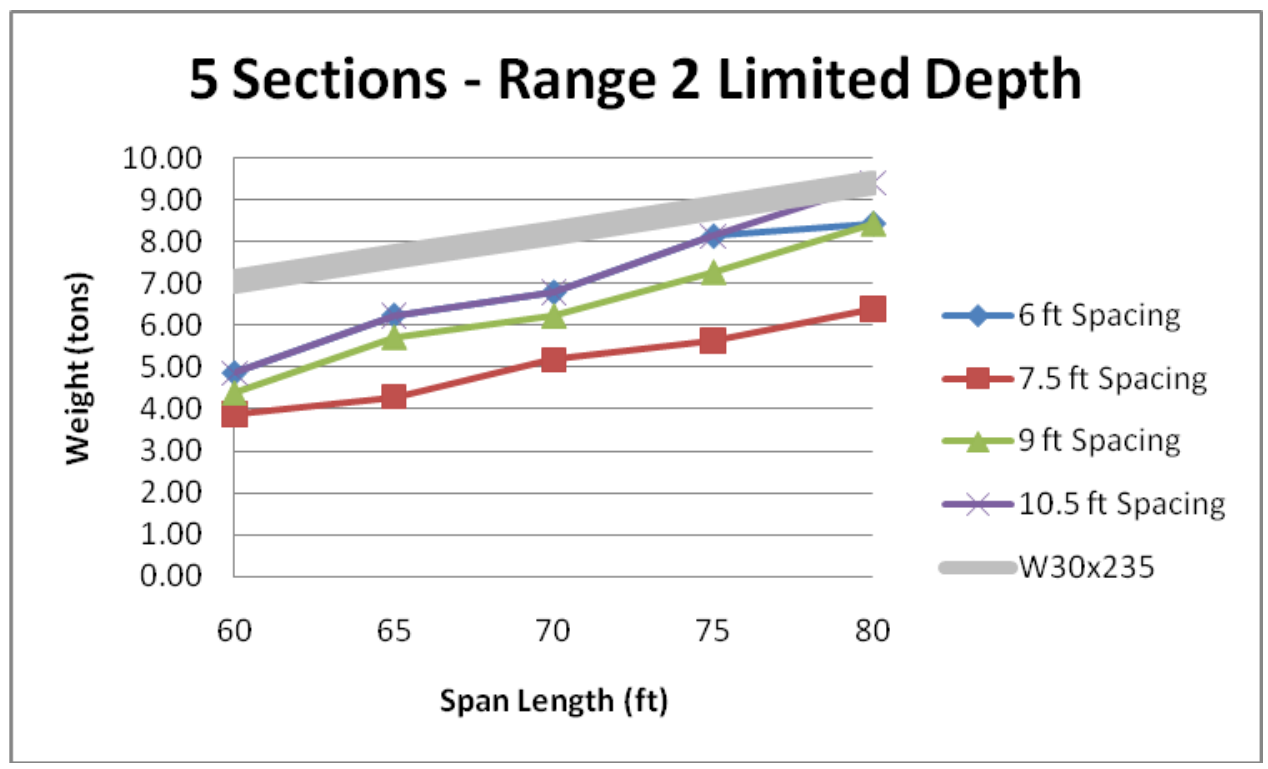

Figure 6-16 5 Selected Sections - Limited Depth (60 ft - $80 \mathrm{ft})$

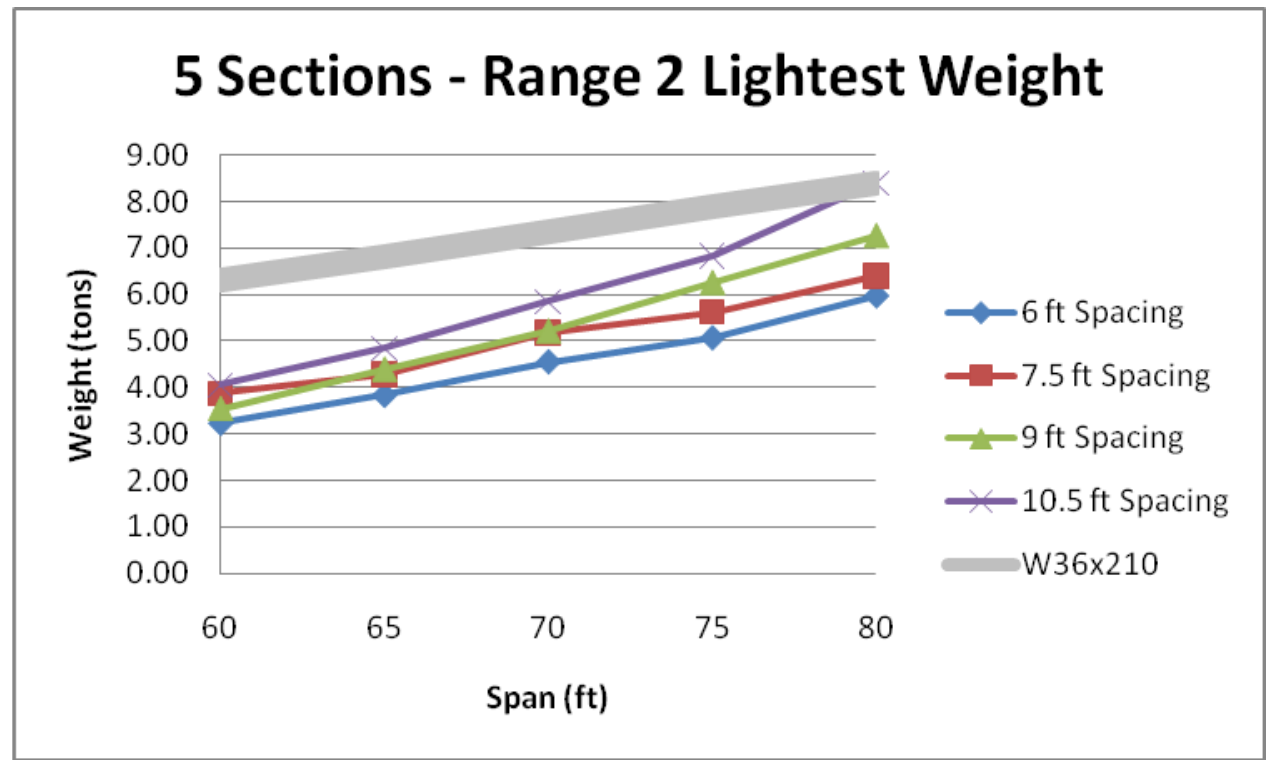

Figure 6-17 5 Sections - Lightest Weight (60 ft - 80 ft) 


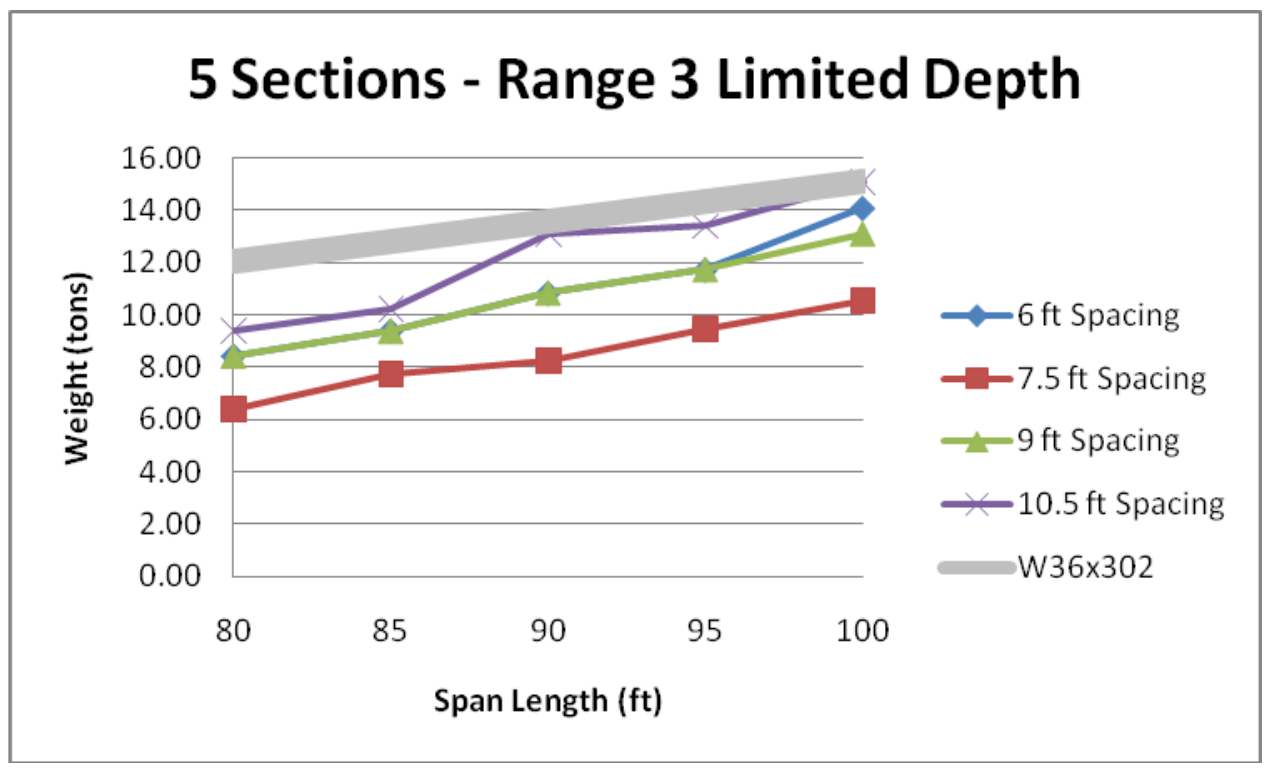

Figure 6-18 5 Sections - Limited Depth (80 ft - $100 \mathrm{ft})$

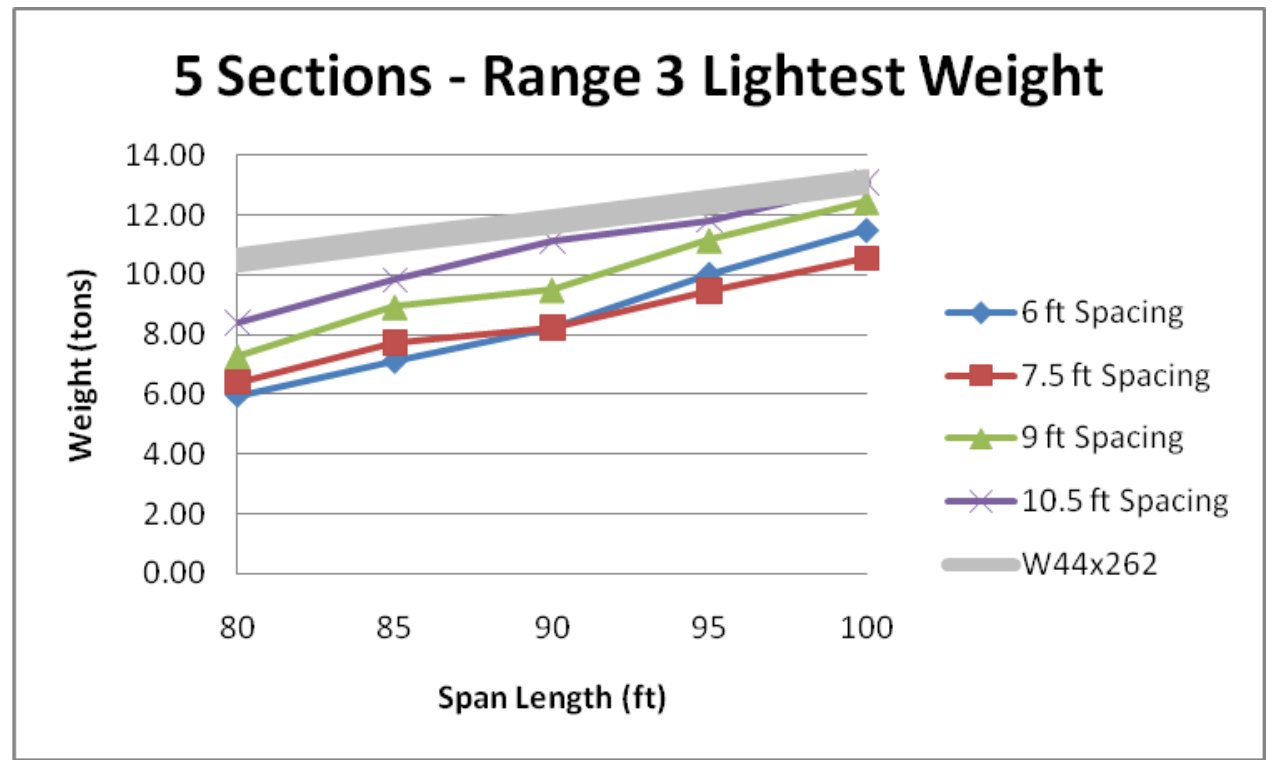

Figure 6-19 5 Sections - Lightest Weight (80 ft - 100 ft) 


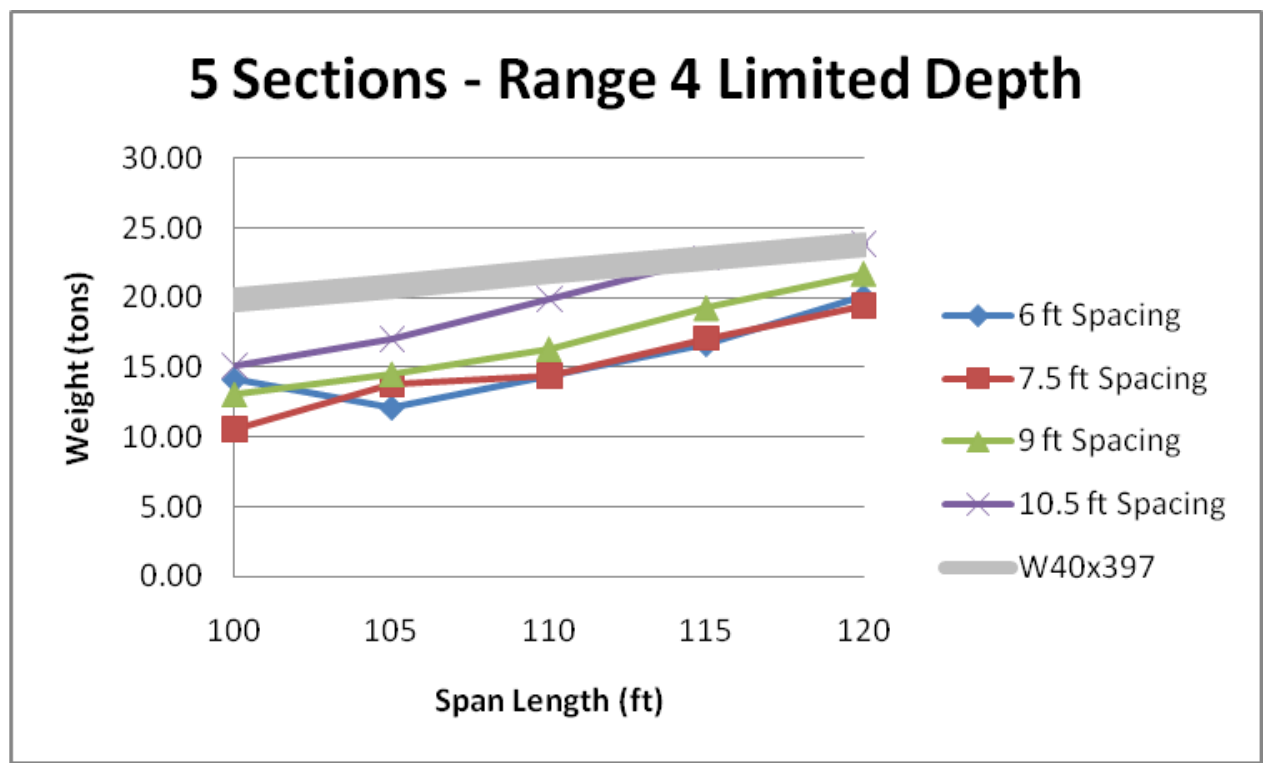

Figure 6-20 5 Sections - Limited Depth (100 ft - $110 \mathrm{ft})$

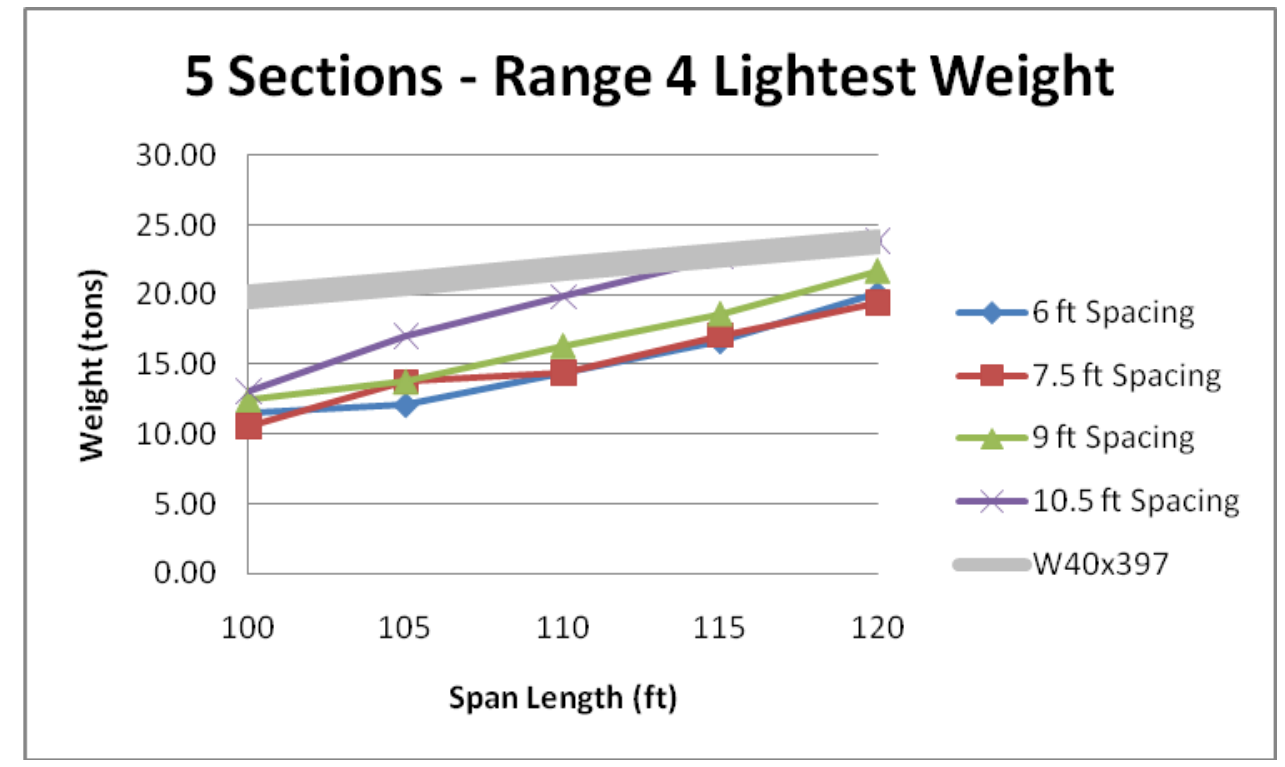

Figure 6-21 5 Sections - Lightest Weight (100 ft - $120 \mathrm{ft})$ 


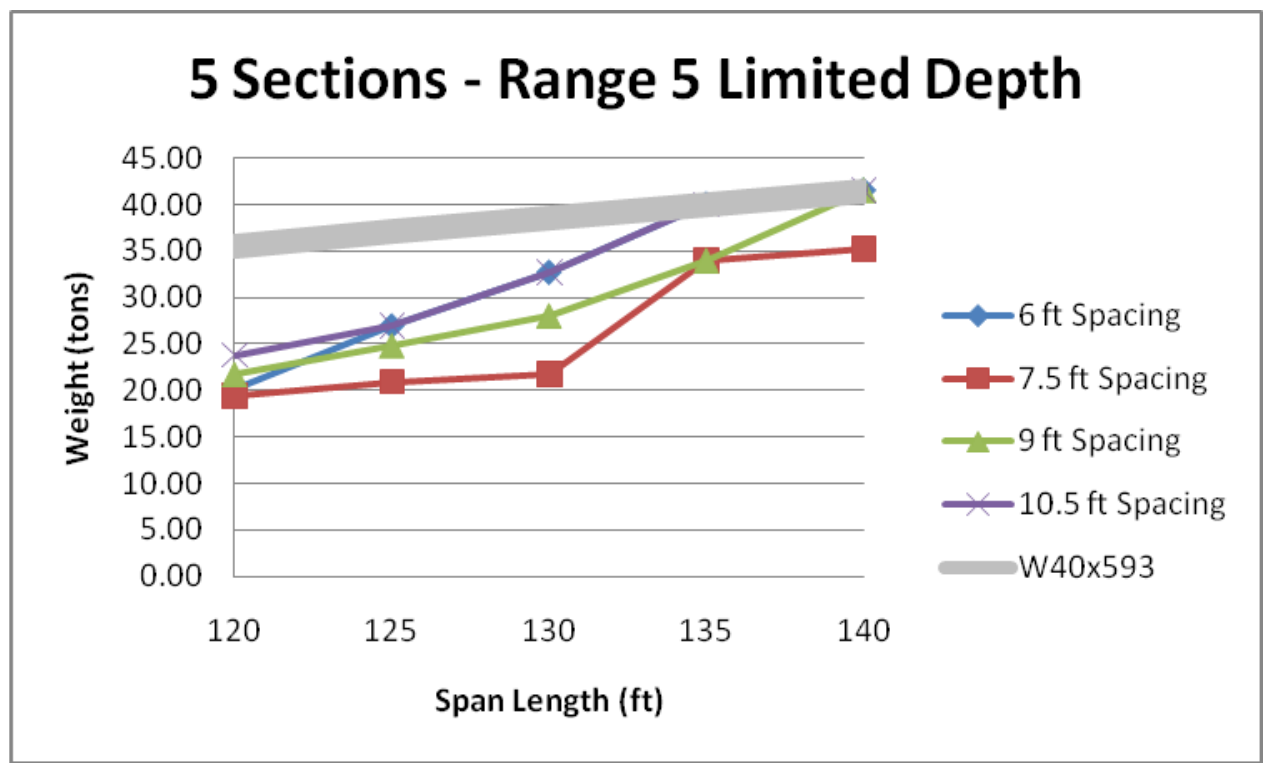

Figure 6-22 5 Sections - Limited Depth (120 ft - $140 \mathrm{ft})$

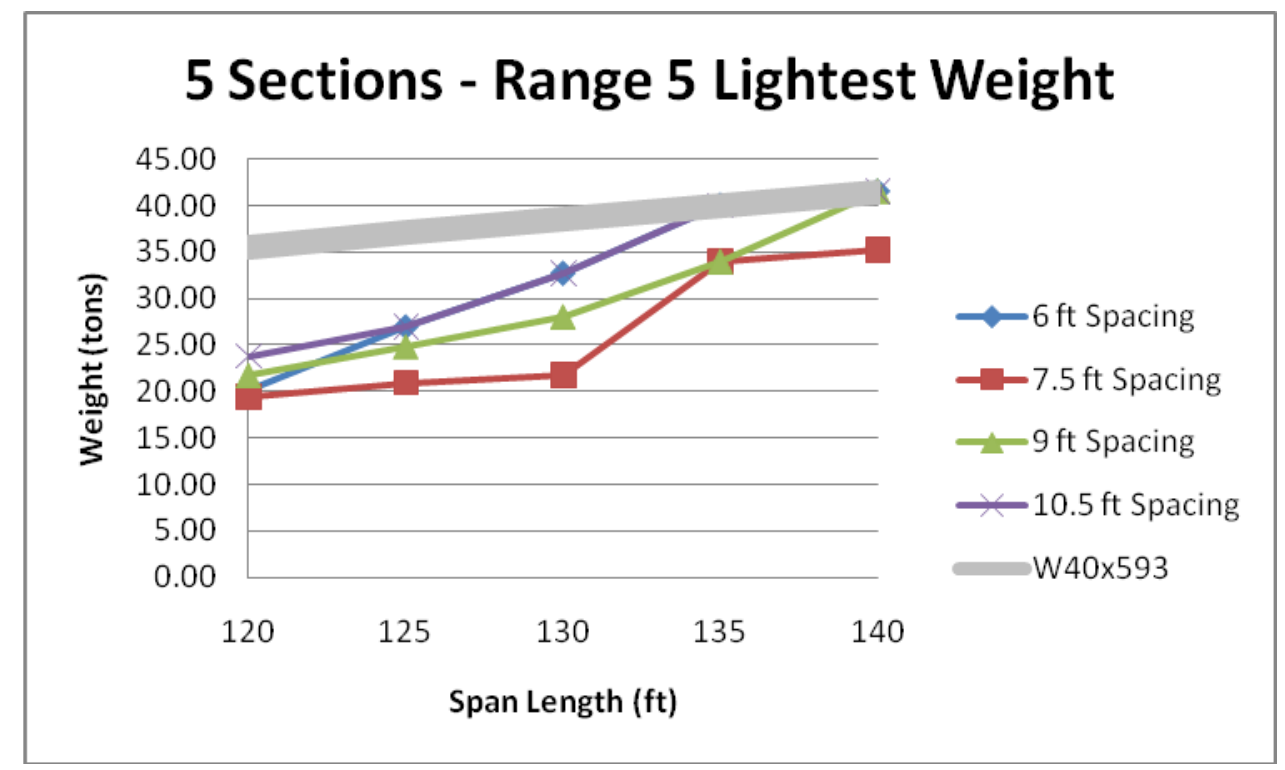

Figure 6-23 5 Sections - Lightest Weight (120 ft - $140 \mathrm{ft})$ 


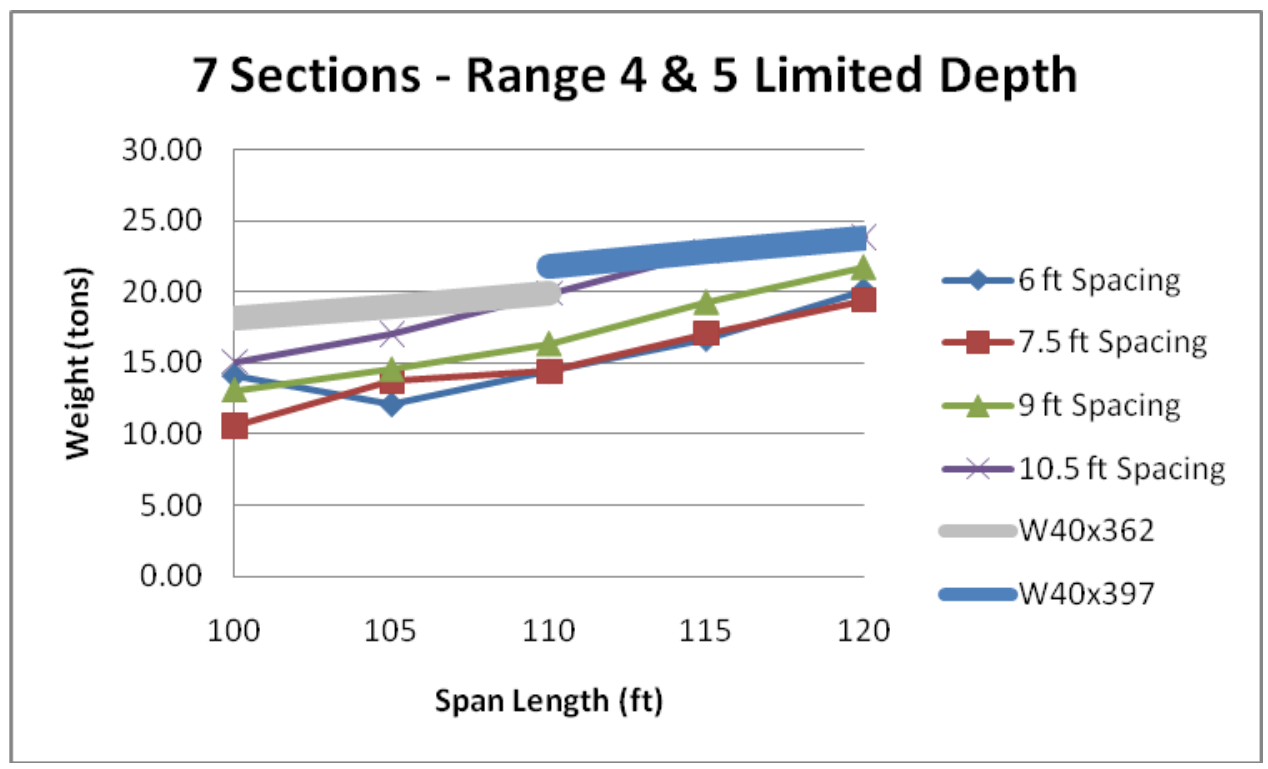

Figure 6-24 7 Sections - Limited Depth (100 ft - $120 \mathrm{ft})$

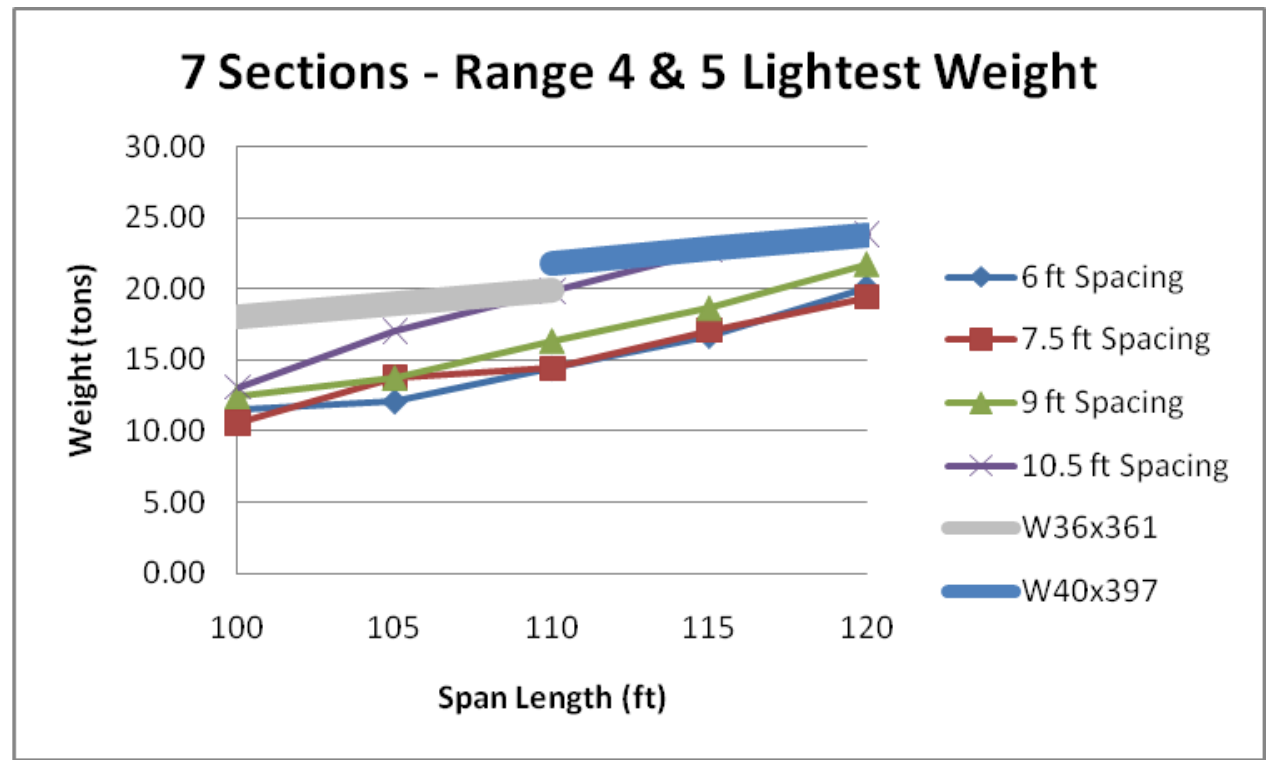

Figure 6-25 7 Sections - Lightest Weight (100 ft - $120 \mathrm{ft})$ 


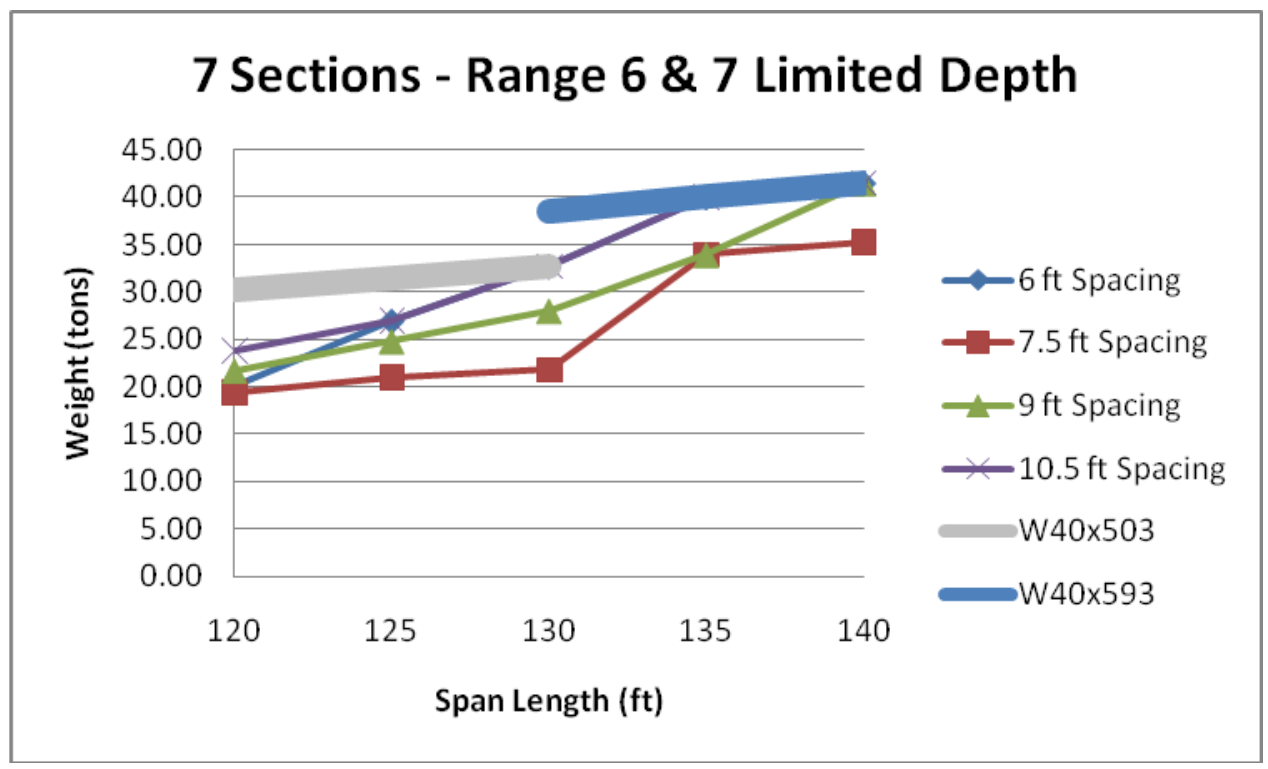

Figure 6-26 7 Sections - Limited Depth (120 ft - $140 \mathrm{ft})$

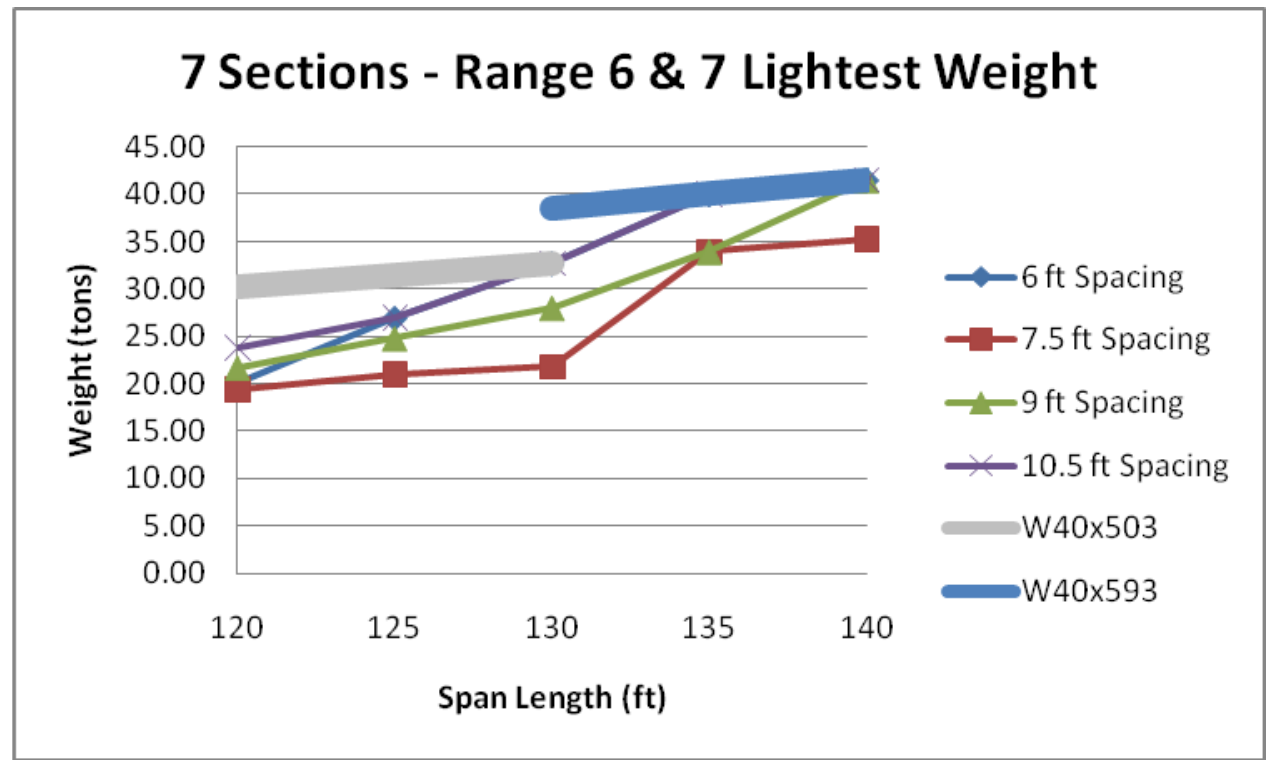

Figure 6-27 7 Sections - Lightest Weight (120 ft - $140 \mathrm{ft})$ 


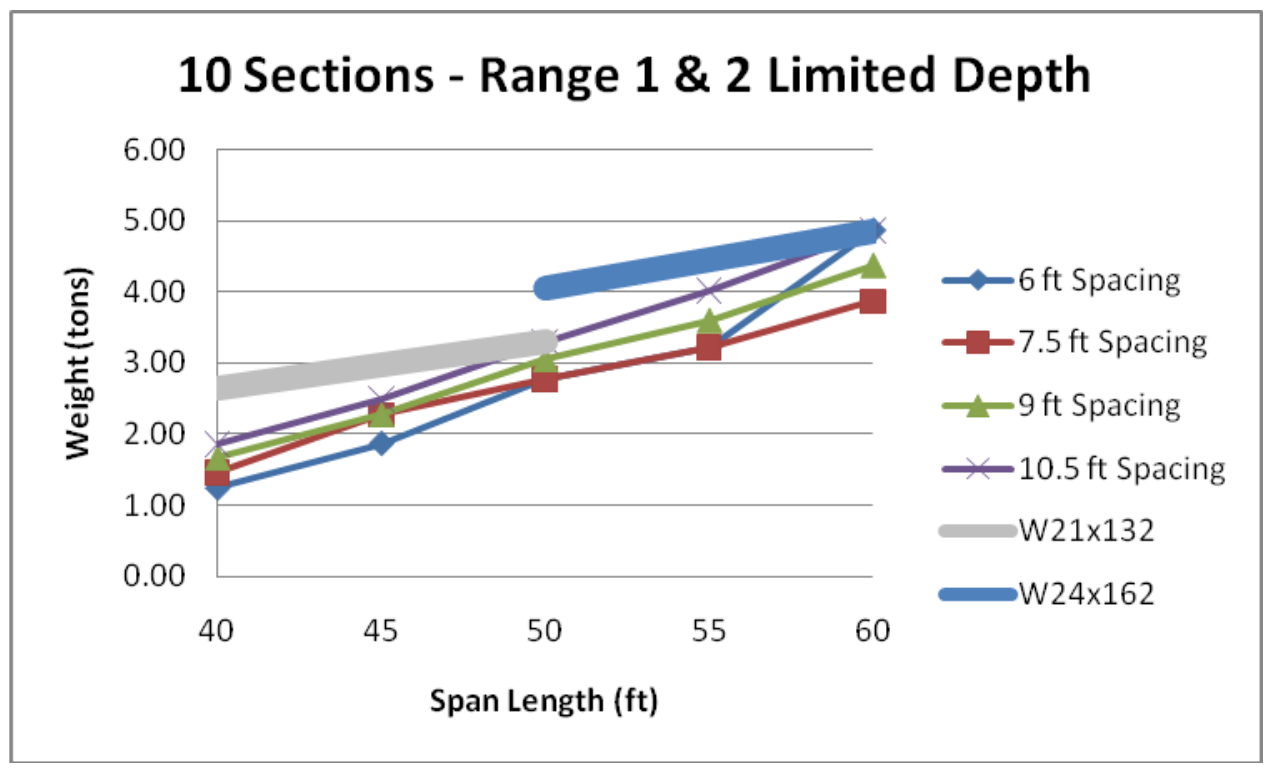

Figure 6-28 10 Sections - Limited Depth (40 ft - $60 \mathrm{ft})$

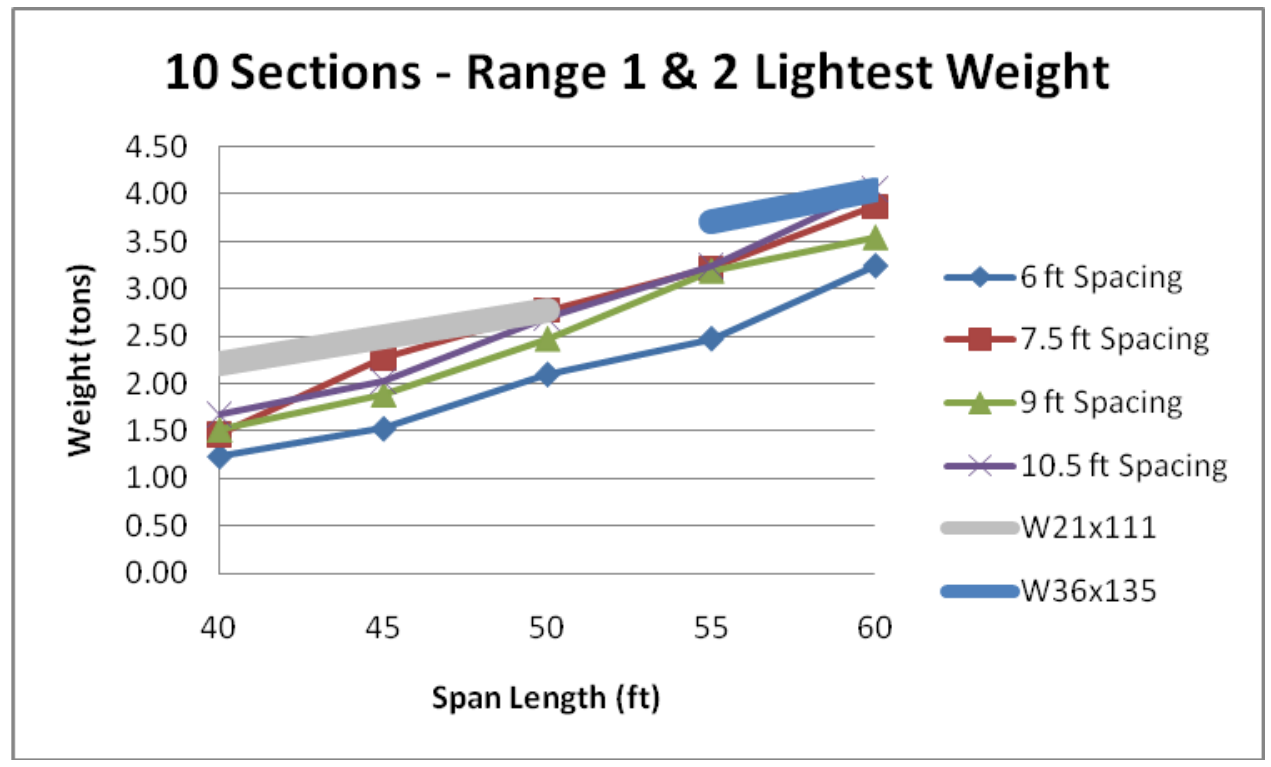

Figure 6-29 10 Sections - Lightest Weight (40 ft - $60 \mathrm{ft}$ ) 


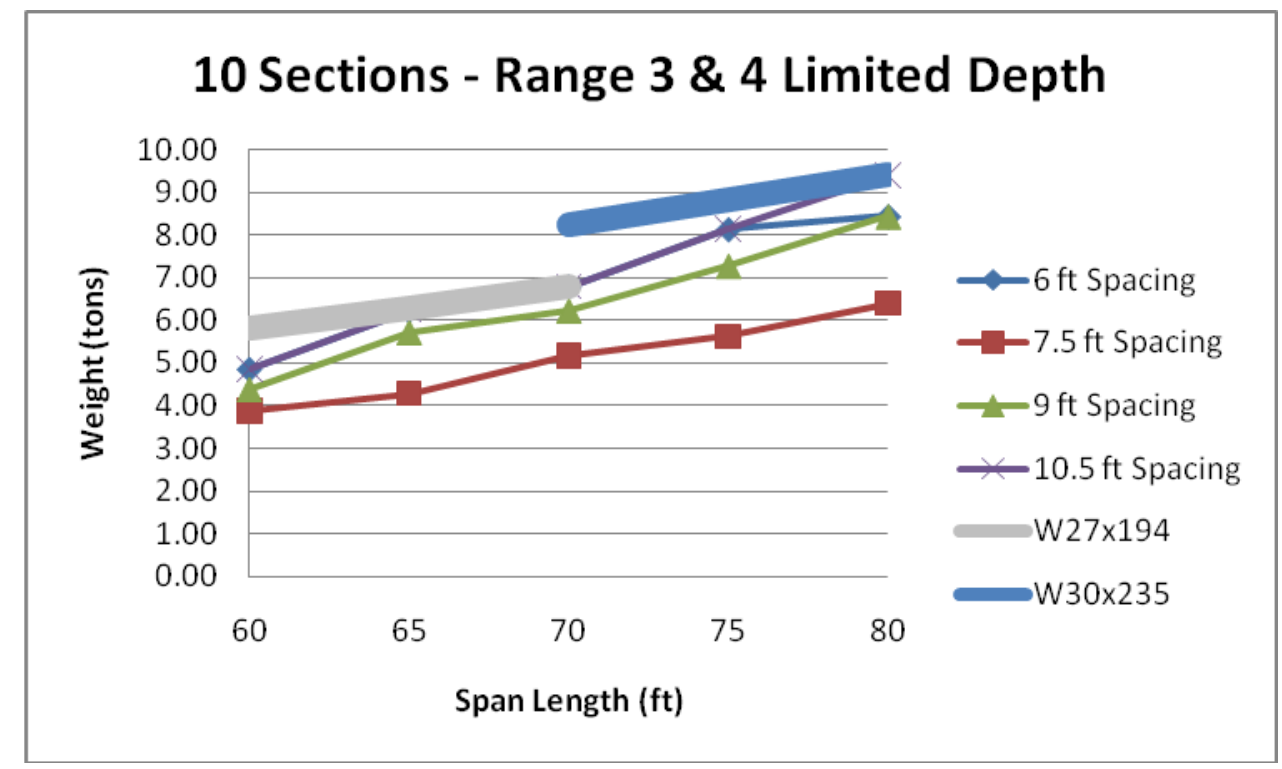

Figure 6-30 10 Sections - Limited Depth (60 ft - $80 \mathrm{ft})$

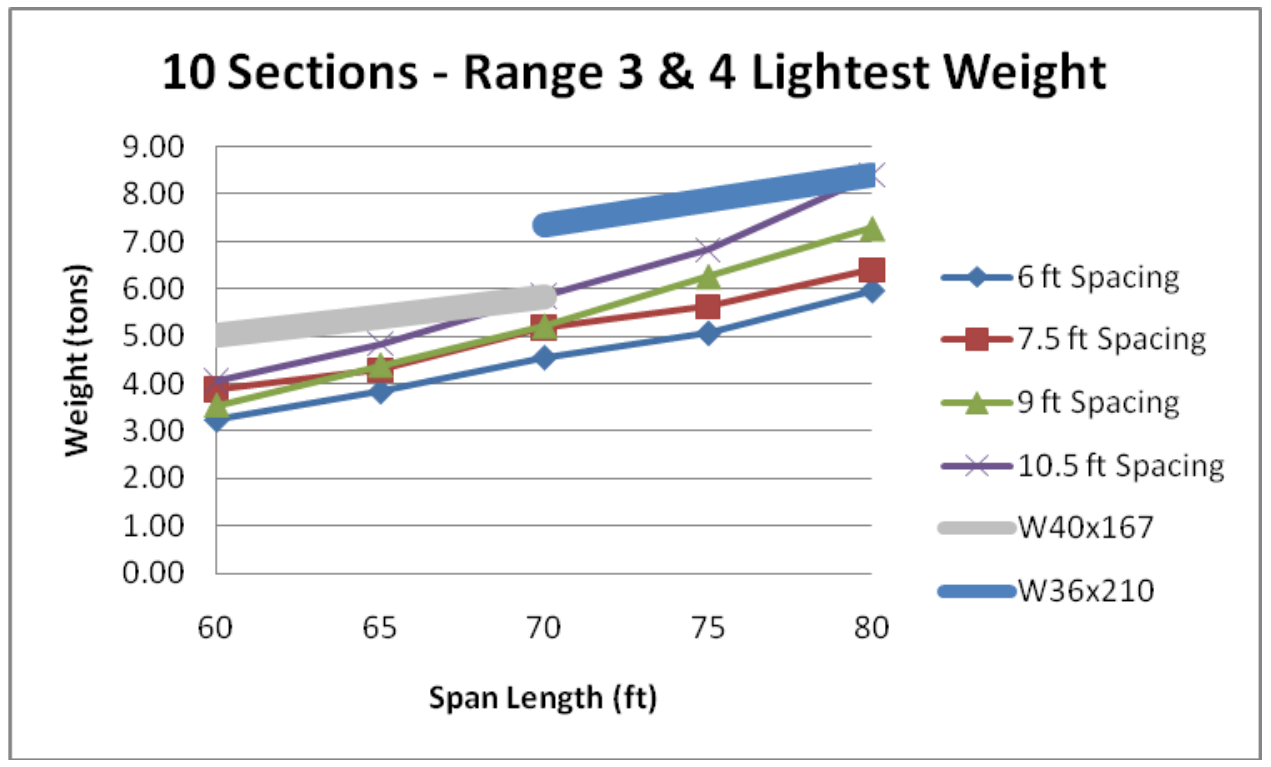

Figure 6-31 10 Sections - Lightest Weight (60 ft - $80 \mathrm{ft}$ ) 


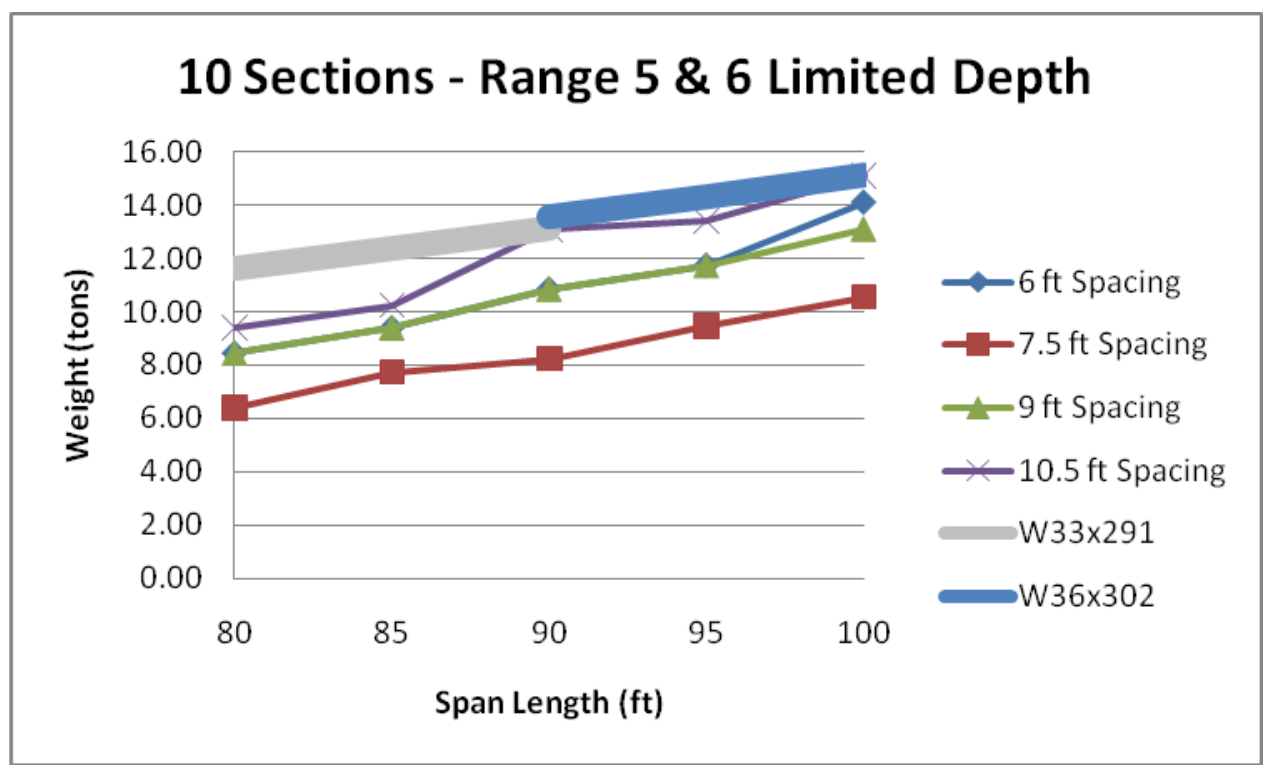

Figure 6-32 10 Sections - Limited Depth (80 ft - $100 \mathrm{ft})$

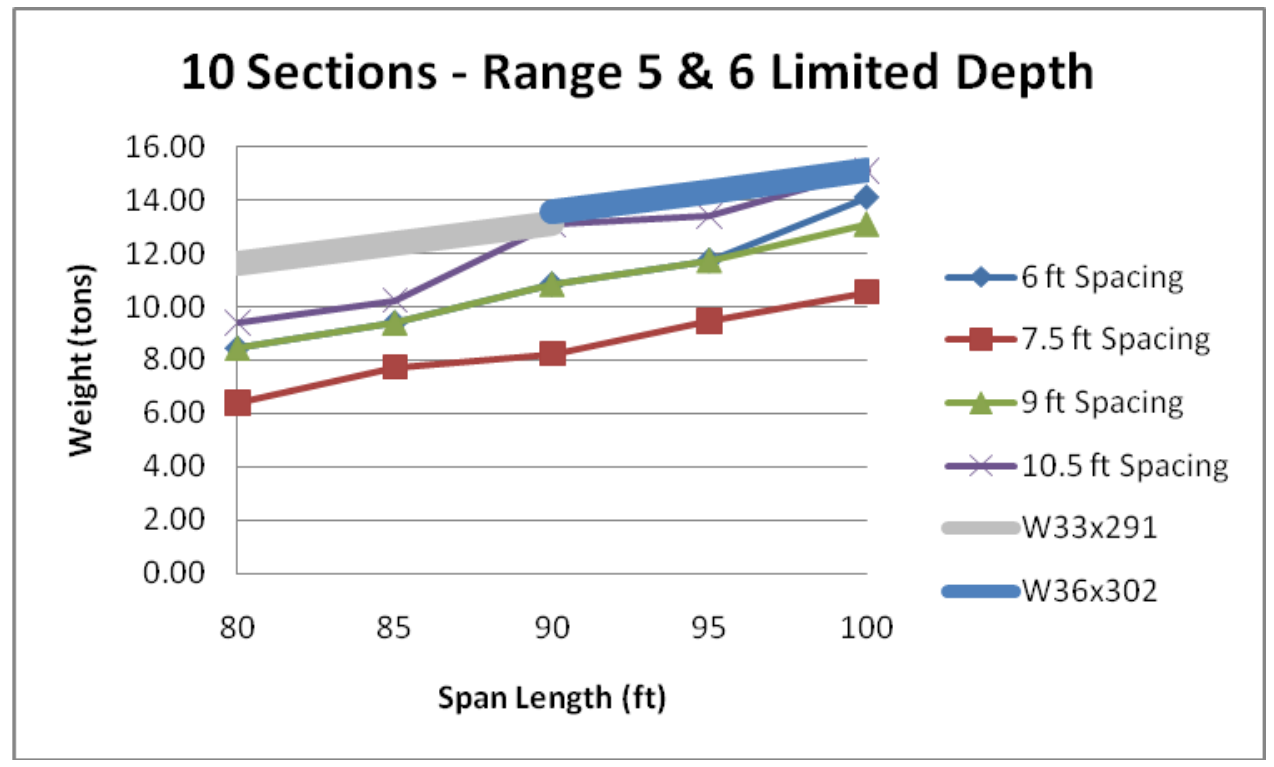

Figure 6-33 10 Sections - Lightest Weight (80 ft - $100 \mathrm{ft}$ ) 


\subsection{Comparison to Other Standard Designs}

In order to validate the designs developed in this research, comparisons were made between the steel girder sections from this work and other available state standard designs. The standards used in these comparisons include those of Texas, Oklahoma and Virginia as well as a set of pre-designed sections developed by the American Iron and Steel Institute. The following sections present similarities and differences between the bridge design parameters for each set of standard designs in comparison to the girders designed in this study. Tables comparing the sections selected in the standard designs and the designs of this research and figures comparing the weights of the standard designs and the designs of this research are presented in each section.

\subsubsection{Oklahoma Standards}

The state of Oklahoma has one set of pre-designed rolled steel girders for a typical bridge crosssection. Similar to the bridges in this research, Oklahoma's standard bridges have a deck thickness of 8 inches, but no integral wearing surface is specified. The bridge overhang for the Oklahoma bridges is $3 \mathrm{ft}$ $-4 \mathrm{in}$. which is similar to the $3 \mathrm{ft}-3 \mathrm{in}$. which was used for this work. The haunch of the Oklahoma bridges is 1 in not including the thickness of the top flange while the haunch thickness of this work is 2 in. including the top flange thickness. The major difference between the Oklahoma bridges and the designed bridges of this work is in the girder spacing; Oklahoma uses $11 \mathrm{ft}-10 \mathrm{in}$. while the maximum girder spacing of this work was $10 \mathrm{ft}-6$ in. A table of the two sets of selected sections in this comparison is presented in Table 6-12 and a graph comparing the selected section weights is shown in Figure 6-34.

Table 6-12 WVU $10 \mathrm{ft}$ - 6 in. / Oklahoma $11 \mathrm{ft}$ - 10 in. Section Comparison

\begin{tabular}{|c|c|c|}
\hline Span (ft) & WVU 10 ft- 6 in. & OK 11 ft -10 in. \\
\hline 40 & W24x84 & W30x99 \\
\hline 45 & W30x90 & W30x116 \\
\hline 50 & W30x108 & W33x130 \\
\hline 55 & W33x118 & W36x135 \\
\hline 60 & W36x135 & W36x150 \\
\hline 65 & W40x149 & W40x167 \\
\hline 70 & W40x167 & W40x183 \\
\hline 75 & W36x182 & W40x199 \\
\hline 80 & W36x210 & W40x215 \\
\hline 85 & W36x231 & W40x249 \\
\hline 90 & W36x247 & W40x277 \\
\hline 95 & W40x249 & W40x297 \\
\hline 100 & W44x262 & W40x324 \\
\hline
\end{tabular}


WVU $10 \mathrm{ft}$ - 6 in. I Oklahoma $11 \mathrm{ft} \mathrm{-} 10$ in. Comparison

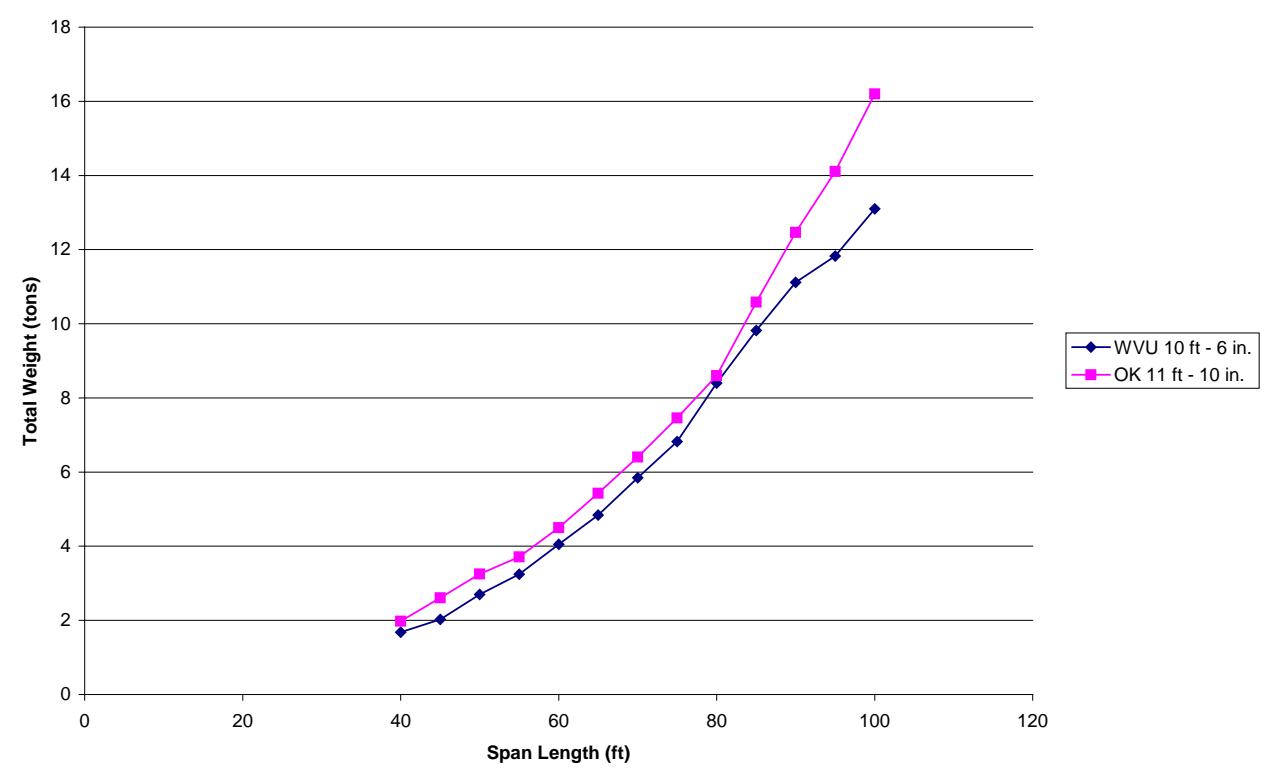

Figure 6-34 WVU $10 \mathrm{ft}$ - 6 in. / Oklahoma $11 \mathrm{ft} \mathrm{-} 10 \mathrm{in}$. Weight Comparison

\subsubsection{Texas Standards}

The state of Texas had three sets of standard bridge designs for three different bridge crosssections. All three bridge cross-section designs include 8 in. thick decks similar to the designs of this work but do not specify an integral wearing surface. All three cross-sections include a $2 \mathrm{ft}$ bridge overhang compared to the $3 \mathrm{ft}-3$ in. overhang of this work. The three Texas standard bridges have 2 in. haunches that do not include the thickness of the top flange of the steel section, while the haunches of this work are $2 \mathrm{in}$. including the top flange thickness. The set of girders from this work with $7 \mathrm{ft}-6 \mathrm{in}$. girder spacing is compared to the Texas bridges with a girder spacing of $7 \mathrm{ft}-4$ in. in Table 6-13 and Figure 6-35. The set of girders from this work with $9 \mathrm{ft}$ girder spacing is compared to the Texas bridges with a girder spacing of $8 \mathrm{ft}-8 \mathrm{in}$. in. Table 6-14 and Figure 6-36. The sets of girders from this work with $6 \mathrm{ft}$ and $7 \mathrm{ft}-6$ in. are compared to the Texas bridges with a girder spacing of $7 \mathrm{ft}$ in Table 6-15 and Figure 6-37. 
Table 6-13 WVU $7 \mathrm{ft}$ - 6 in. / Texas $7 \mathrm{ft}$ - 4 in. Section Comparison

\begin{tabular}{|c|c|c|}
\hline Span (ft) & WVU 7 ft -6 in. & TX 7 ft -4 in. \\
\hline 40 & W21x73 & W24x104 \\
\hline 45 & W21x101 & W24x104 \\
\hline 50 & W21x111 & W24x104 \\
\hline 55 & W24x117 & W24x117 \\
\hline 60 & W27x129 & W33x118 \\
\hline 65 & W30x132 & W33x118 \\
\hline 70 & W30x148 & W33x130 \\
\hline 75 & W36x150 & W33x141 \\
\hline 80 & W36x160 & W40x149 \\
\hline 85 & W36x182 & W36x170 \\
\hline 90 & W40x183 & W40x199 \\
\hline 95 & W40x199 & W40x215 \\
\hline 100 & W40x211 & W40x215 \\
\hline 105 & W44x262 & W40x249 \\
\hline 110 & W44x262 & W40x277 \\
\hline 115 & W40x297 & W40x324 \\
\hline 120 & W40x324 & W40x362 \\
\hline
\end{tabular}

WVU $7 \mathrm{ft}$ - 6 in. I Texas $7 \mathrm{ft}$ - 4 in. Comparison

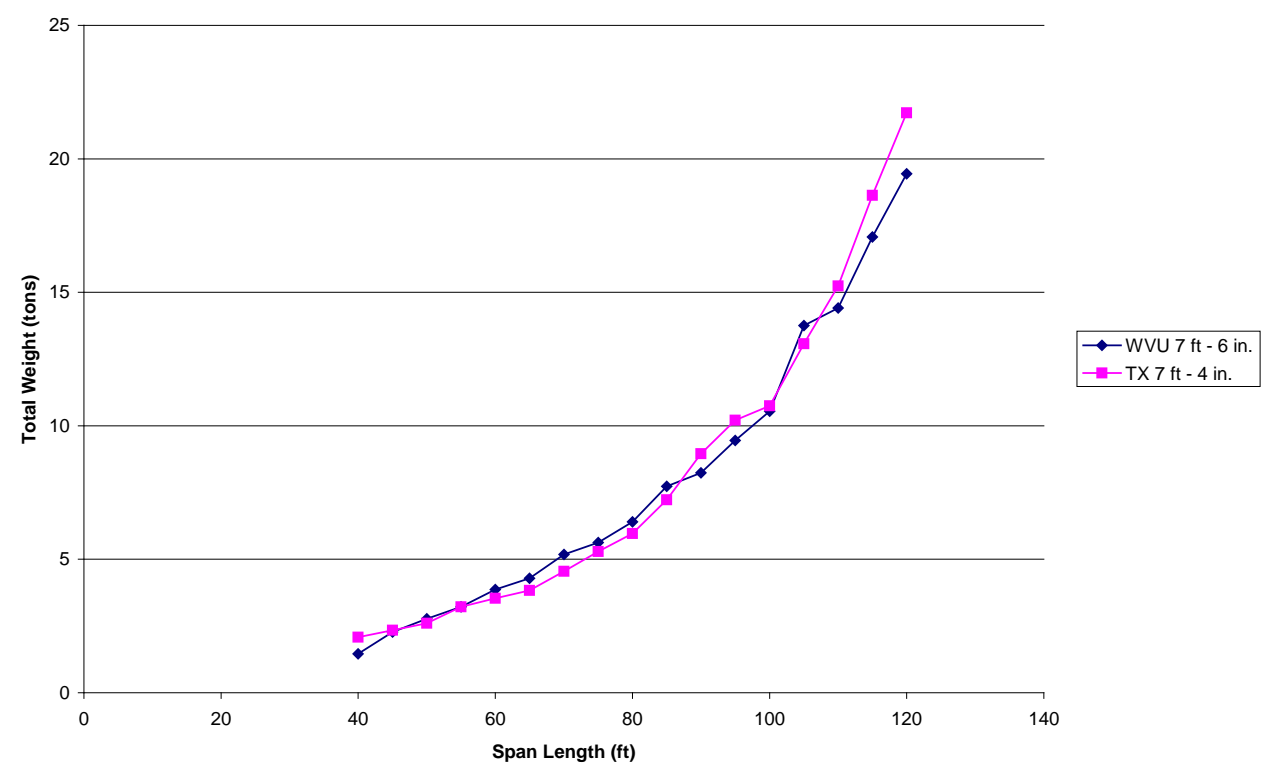

Figure 6-35 WVU $7 \mathrm{ft}$ - 6 in. / Texas $7 \mathrm{ft} \mathrm{-} 4$ in. Weight Comparison 
Table 6-14 WVU 9 ft / Texas 8 ft - 8 in. Section Comparison

\begin{tabular}{|c|c|c|}
\hline Span (ft) & WVU 9 ft & TX 8 ft -8 in. \\
\hline 40 & W24x76 & W24x117 \\
\hline 45 & W27x84 & W24x117 \\
\hline 50 & W30x99 & W24x117 \\
\hline 55 & W30x116 & W24x117 \\
\hline 60 & W33x118 & W33x118 \\
\hline 65 & W36x135 & W33x130 \\
\hline 70 & W40x149 & W36x135 \\
\hline 75 & W40x167 & W40x149 \\
\hline 80 & W36x182 & W40x167 \\
\hline 85 & W36x210 & W40x183 \\
\hline 90 & W40x211 & W40x199 \\
\hline 95 & W40x235 & W40x215 \\
\hline 100 & W40x249 & W36x247 \\
\hline 105 & W44x262 & W40x277 \\
\hline 110 & W40x297 & W40x277 \\
\hline 115 & W40x324 & W40x297 \\
\hline 120 & W40x362 & W40x324 \\
\hline
\end{tabular}

WVU $9 \mathrm{ft} /$ Texas $8 \mathrm{ft}$ - 8 in. Comparison

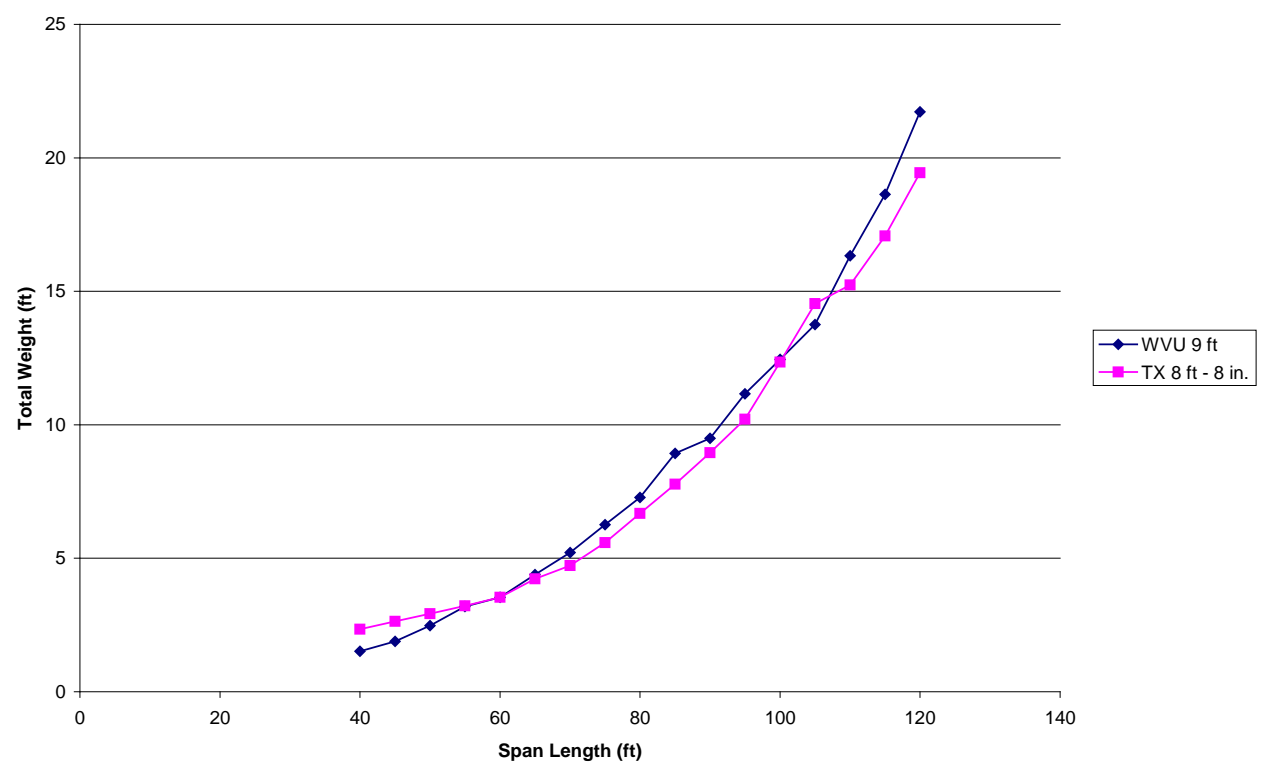

Figure 6-36 WVU $9 \mathrm{ft}$ / Texas $8 \mathrm{ft}$ - 4 in. Weight Comparison 
Table 6-15 WVU $6 \mathrm{ft}$ and $7 \mathrm{ft}-6 \mathrm{in}$. / Texas $7 \mathrm{ft}$ Section Comparison

\begin{tabular}{|c|c|c|c|}
\hline \multirow{2}{*}{ Span (ft) } & \multicolumn{2}{|c|}{ WVU } & TX \\
\cline { 2 - 4 } & $6 \mathrm{ft}$ & $7 \mathrm{ft}-6$ in. & $7 \mathrm{ft}$ \\
\hline 40 & W21x62 & W21x73 & W24x104 \\
\hline 45 & W24x68 & W21x101 & W24x104 \\
\hline 50 & W27x84 & W21x111 & W24x104 \\
\hline 55 & W30x90 & W24x117 & W24x104 \\
\hline 60 & W30x108 & W27x129 & W24x117 \\
\hline 65 & W33x118 & W30x132 & W33x118 \\
\hline 70 & W33x130 & W30x148 & W33x118 \\
\hline 75 & W36x135 & W36x150 & W33x118 \\
\hline 80 & W40x149 & W36x160 & W40x149 \\
\hline 85 & W40x167 & W36x182 & W36x160 \\
\hline 90 & W40x183 & W40x183 & W40x199 \\
\hline 95 & W40x211 & W40x199 & W40x199 \\
\hline 100 & W44x230 & W40x211 & W40x199 \\
\hline 105 & W44x230 & W44x262 & W40x215 \\
\hline 110 & W44x262 & W44x262 & W40x249 \\
\hline 115 & W44x290 & W40x297 & W40x249 \\
\hline 120 & W44x335 & W40x324 & W40x277 \\
\hline
\end{tabular}

WVU $6 \mathrm{ft}$ and $7 \mathrm{ft}-6$ in. I Texas $7 \mathrm{ft}$ Comparison

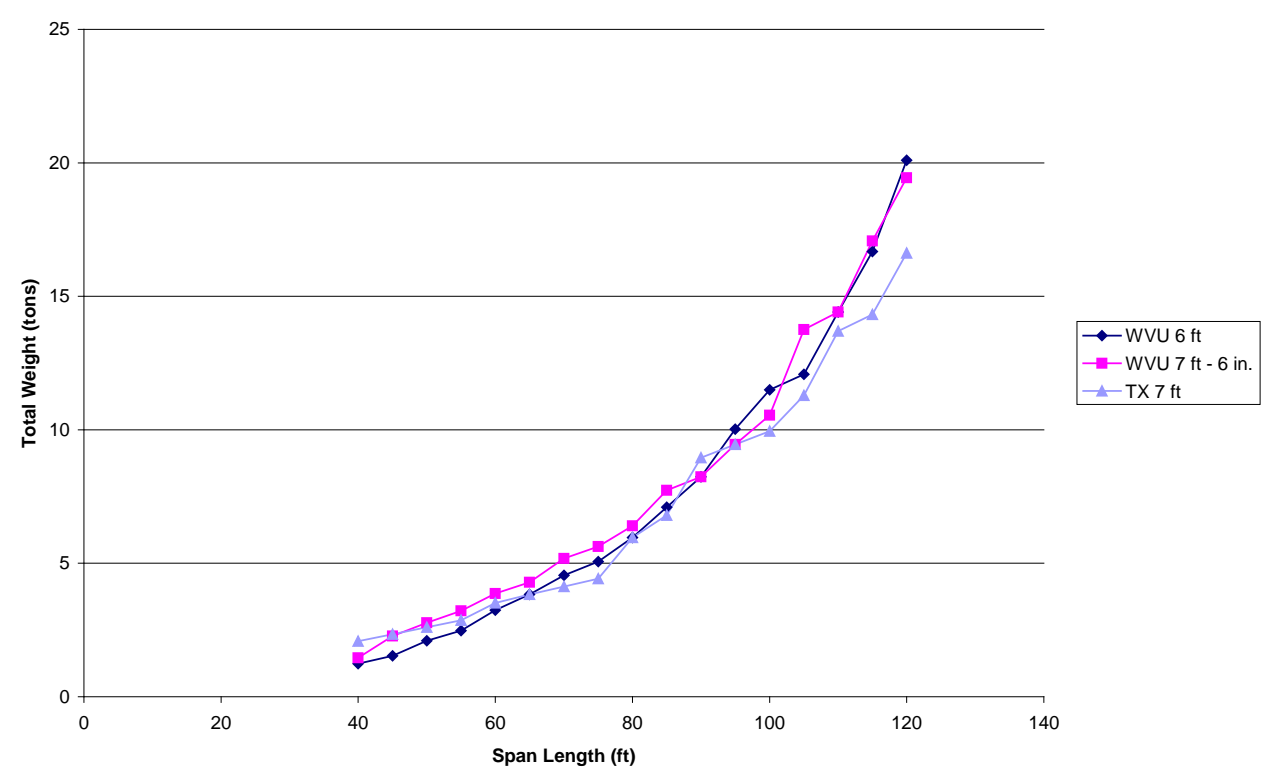

Figure 6-37 WVU $6 \mathrm{ft}$ and $7 \mathrm{ft}-6$ in. / Texas $7 \mathrm{ft}$ Weight Comparison 


\subsubsection{Virginia Standards}

The state of Virginia has a full package of standard bridge designs that do not meet current design specifications. Comparisons were made with three sets of their pre-designed bridges. All three bridge cross-section designs include 8 in. thick decks similar to the designs of this work but do not specify an integral wearing surface. All three cross-sections include a $2 \mathrm{ft}-11$ in. bridge overhang compared to the $3 \mathrm{ft}-3$ in. overhang of this work. The Virginia standard bridges do not specify a concrete haunch thickness, while the haunches of this work are 2 in. including the top flange thickness. The set of girders from this work with $6 \mathrm{ft}$ girder spacing is compared to the Virginia bridges with a girder spacing of $6 \mathrm{ft}-$ 6 in. in Table 6-16 and Figure 6-38. The set of girders from this work with $7 \mathrm{ft}-6$ in. girder spacing is compared to the Virginia bridges with a girder spacing of $7 \mathrm{ft}-6$ in. in Table 6-17 and Figure 6-39. The sets of girders from this work with $9 \mathrm{ft}$ girder spacing is compared to the Virginia bridges with a girder spacing of $9 \mathrm{ft}$ in Table 6-18 and Figure 6-40.

Table 6-16 WVU $6 \mathrm{ft}$ / Virginia $6 \mathrm{ft}-6$ in. Section Comparison

\begin{tabular}{|c|c|c|}
\hline Span (ft) & WVU 6 ft & VA 6 ft - 6 in. \\
\hline 40 & W21x62 & W24x76 \\
\hline 45 & W24x68 & W27x94 \\
\hline 50 & W27x84 & W30x99 \\
\hline 55 & W30x90 & W30x116 \\
\hline 60 & W30x108 & W33x118 \\
\hline 65 & W33x118 & W33x118 \\
\hline 70 & W33x130 & W33x118 \\
\hline 75 & W36x135 & W33x118 \\
\hline 80 & W40x149 & W36x135 \\
\hline
\end{tabular}


WVU 6 ft / Virginia $6 \mathrm{ft} \mathrm{-} 6$ in. Comparison

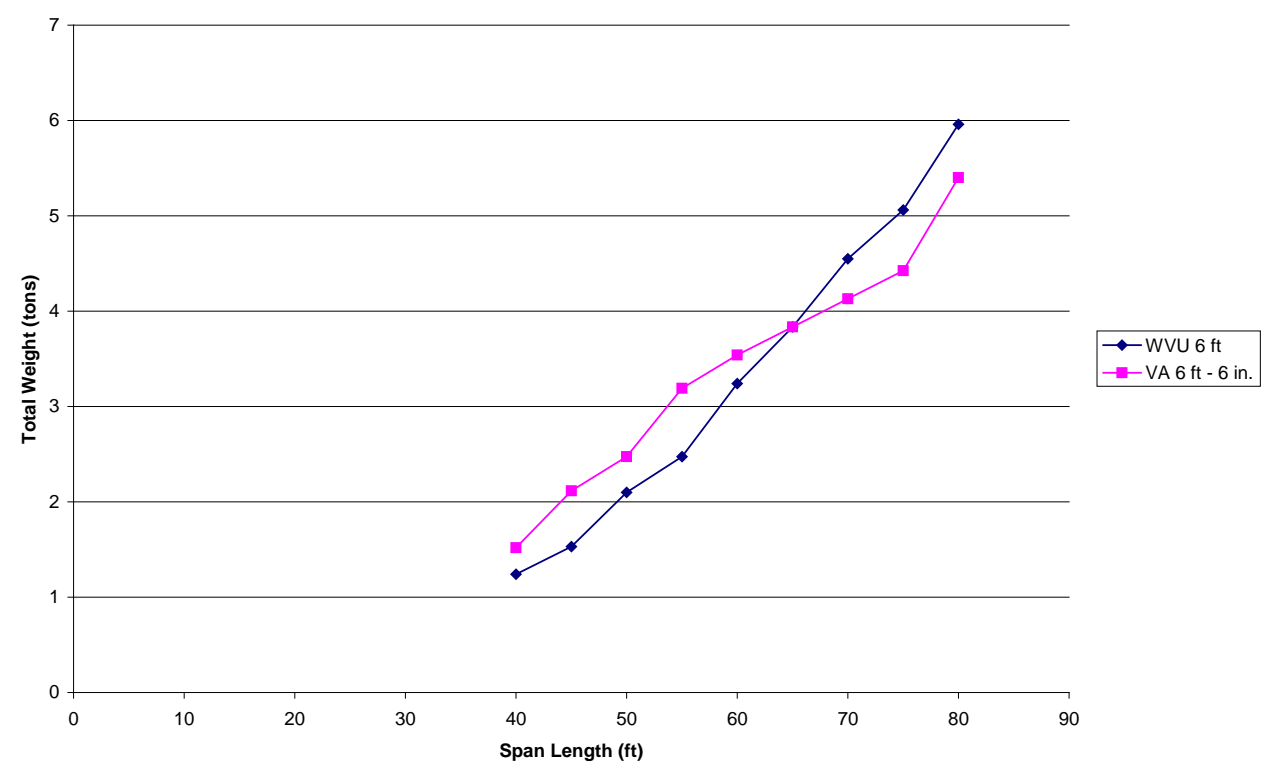

Figure 6-38 WVU $6 \mathrm{ft}$ / Virginia $6 \mathrm{ft}-6$ in. Weight Comparison

Table 6-17 WVU $7 \mathrm{ft}-6$ in. / Virginia $7 \mathrm{ft}-6$ in. Section Comparison

\begin{tabular}{|c|c|c|}
\hline Span (ft) & WVU 7 ft - 6 in. & VA 7 ft - 6 in. \\
\hline 40 & W21x73 & W27x84 \\
\hline 45 & W21x101 & W30x99 \\
\hline 50 & W21x111 & W30x116 \\
\hline 55 & W24x117 & W33x130 \\
\hline 60 & W27x129 & W33x118 \\
\hline 65 & W30x132 & W33x118 \\
\hline 70 & W30x148 & W33x118 \\
\hline 75 & W36x150 & W36x135 \\
\hline 80 & W36x160 & W36x135 \\
\hline
\end{tabular}


WVU $7 \mathrm{ft}-6$ in. I Virginia $7 \mathrm{ft}-6$ in. Comparison

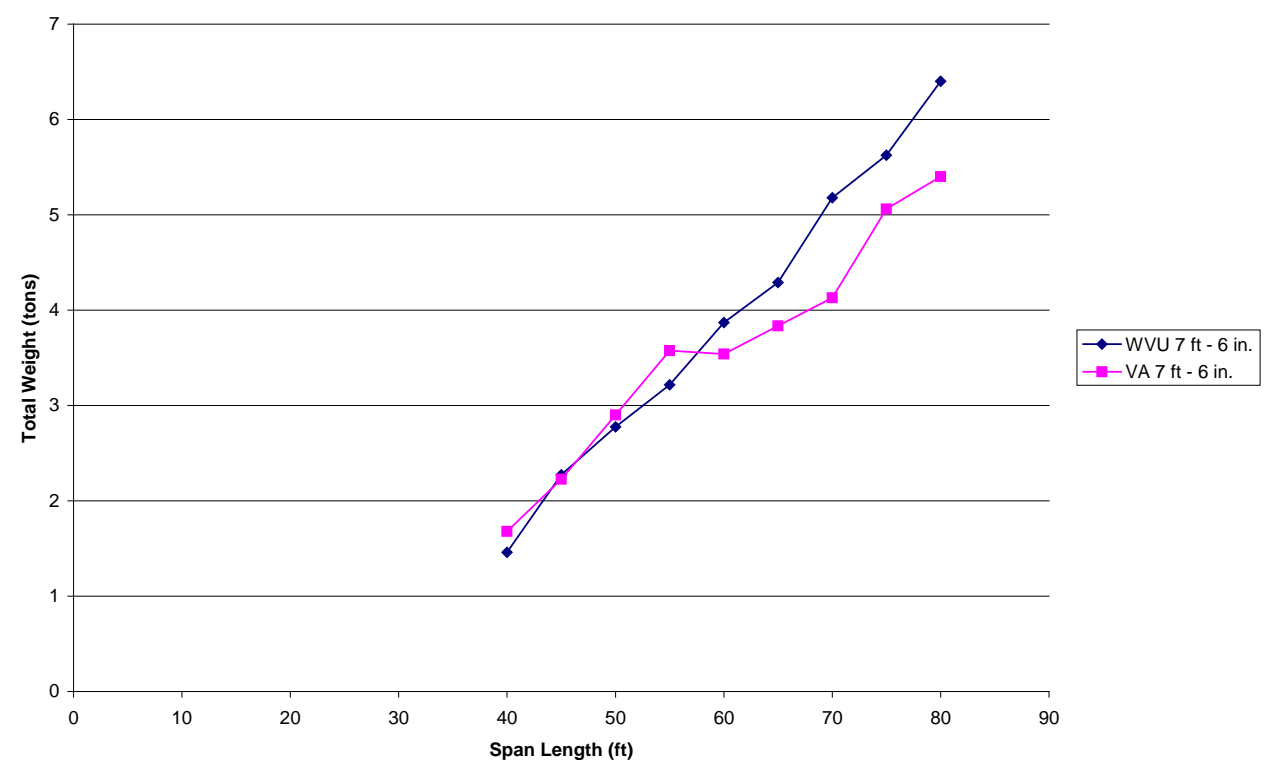

Figure 6-39 WVU $7 \mathrm{ft}-6$ in. / Virginia $7 \mathrm{ft}-6$ in. Weight Comparison

Table 6-18 WVU 9 ft / Virginia 9 ft Section Comparison

\begin{tabular}{|c|c|c|}
\hline Span (ft) & WVU 9 ft & VA 9 ft \\
\hline 40 & W21x73 & W27x84 \\
\hline 45 & W21x101 & W30x99 \\
\hline 50 & W21x111 & W30x116 \\
\hline 55 & W24x117 & W33x130 \\
\hline 60 & W27x129 & W33x118 \\
\hline 65 & W30x132 & W33x118 \\
\hline 70 & W30x148 & W33x118 \\
\hline 75 & W36x150 & W36x135 \\
\hline 80 & W36x160 & W36x135 \\
\hline
\end{tabular}




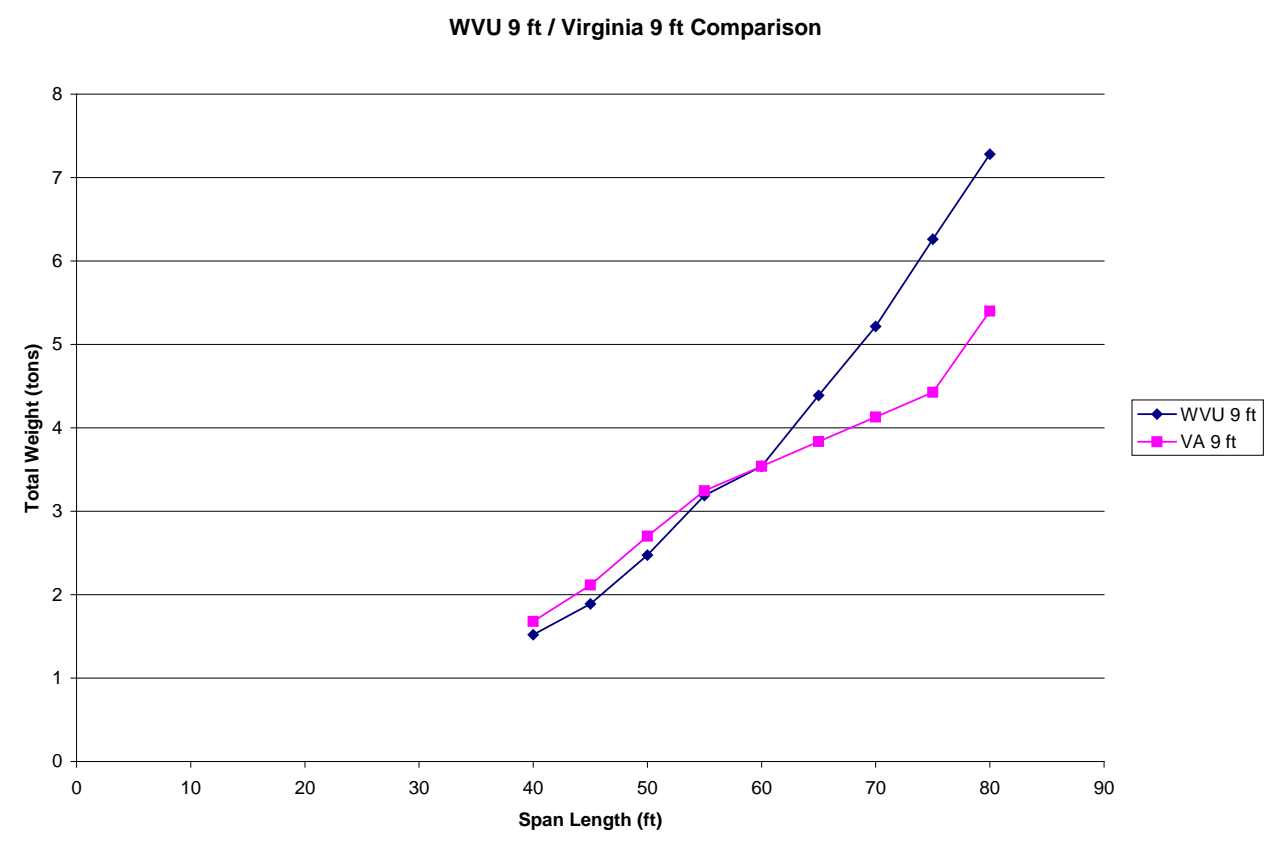

Figure 6-40 WVU 9 ft / Virginia $9 \mathrm{ft}$ Weight Comparison

\subsubsection{American Iron and Steel Institute Standards}

In 1995, the American Iron and Steel Institute published a set of pre-designed steel girder bridges. These designs were developed using Load Factor Design as opposed to the Load and Resistance Factor Design used in the designs of this research. Comparisons were made with three sets of their pre-designed bridges. All three bridge cross-section designs include 9 in. thick concrete decks with a $1 \frac{1}{2}$ in. integral wearing surface compared to the designs of this work which has 8 in. thick concrete decks with a 1/4 in. integral wearing surface. All three cross-sections include a 2 in. concrete haunch including the top flange similar to the bridges designed in this research. The first set of designs have a girder spacing of $8 \mathrm{ft}-6$ in. and an overhang of $3 \mathrm{ft}-6 \frac{1}{4} \mathrm{in}$. which were compared to the set of designs with a girder spacing of 9 $\mathrm{ft}$ and an overhang of $3 \mathrm{ft}-3 \mathrm{in}$. shown in Table 6-19 and Figure 6-41. The second set designs have a girder spacing of $9 \mathrm{ft}$ and an overhang of $3 \mathrm{ft}-3 \mathrm{in}$. which were compared to the set of designs with a girder spacing of $9 \mathrm{ft}$ and an overhang of $3 \mathrm{ft}-3$ in. shown in Table 6-20 and Figure 6-42. The third set of designs have a girder spacing of $10 \mathrm{ft}$ and an overhang of $3 \mathrm{ft}-3 \frac{1}{4} \mathrm{in}$. which were compared to the set of designs with a girder spacing of $10 \mathrm{ft}-6 \mathrm{in}$. and an overhang of $3 \mathrm{ft}-3$ in. shown in Table 6-21 and Figure 6-43. 
Table 6-19 WVU 9 ft / AISI $8 \mathrm{ft}$ - 6 in. Section Comparison

\begin{tabular}{|c|c|c|}
\hline Span (ft) & WVU 9 ft & AISI 8 ft -6 in. \\
\hline 40 & W24x76 & W27x84 \\
\hline 45 & W27x84 & W30x99 \\
\hline 50 & W30x99 & W30x116 \\
\hline 55 & W30x116 & W33x130 \\
\hline 60 & W33x118 & W40x149 \\
\hline 65 & W36x135 & W40x149 \\
\hline 70 & W40x149 & W40x167 \\
\hline 75 & W40x167 & W40x183 \\
\hline 80 & W36x182 & W40x211 \\
\hline 85 & W36x210 & W40x235 \\
\hline 90 & W40x211 & W36x260 \\
\hline 95 & W40x235 & W36x300 \\
\hline 100 & W40x249 & W36x328 \\
\hline 105 & W44x262 & W36x359 \\
\hline 110 & W40x297 & W36x393 \\
\hline
\end{tabular}

WVU $9 \mathrm{ft} /$ AISI $8 \mathrm{ft}-6$ in. Comparison

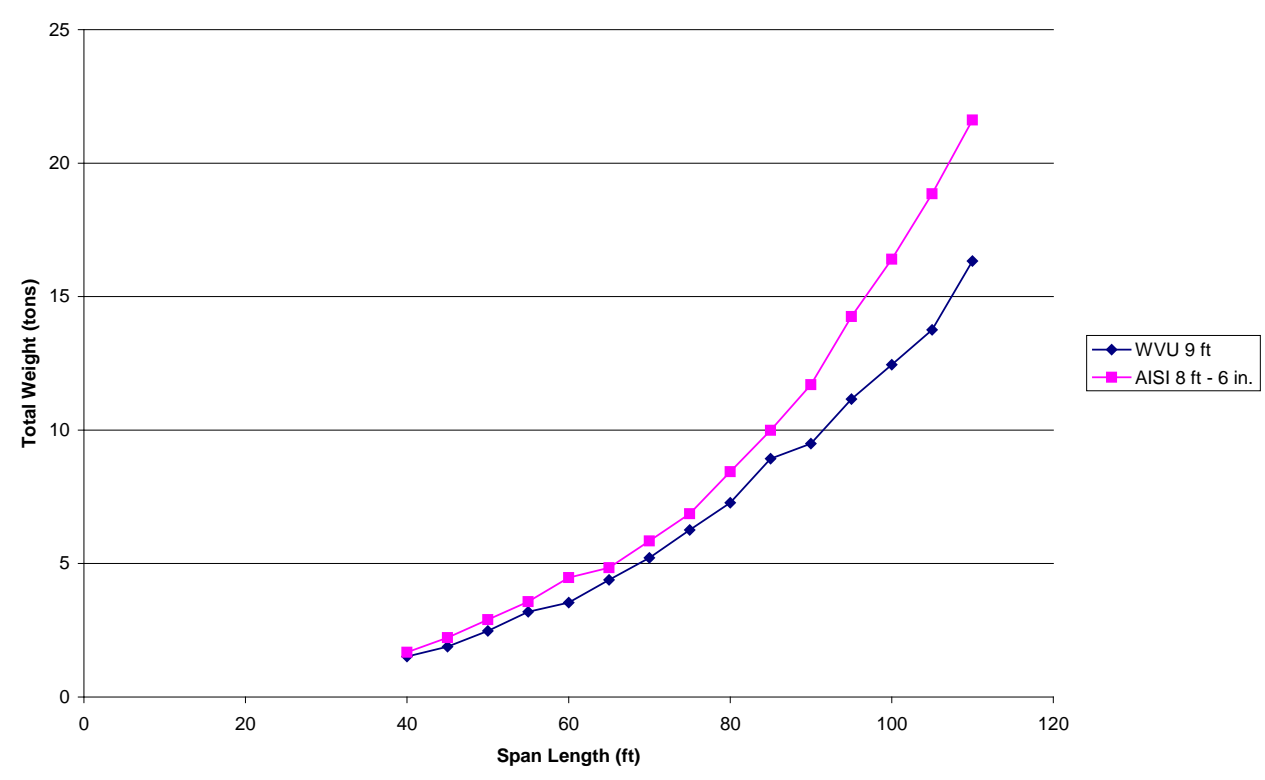

Figure 6-41 WVU 9 ft / AISI 8 ft - 6 in. Weight Comparison 
Table 6-20 WVU 9 ft / AISI 9 ft Section Comparison

\begin{tabular}{|c|c|l|}
\hline Span (ft) & WVU 9 ft & AISI 9 ft \\
\hline 40 & W24x76 & W30x90 \\
\hline 45 & W27x84 & W30x108 \\
\hline 50 & W30x99 & W33x118 \\
\hline 55 & W30x116 & W36x135 \\
\hline 60 & W33x118 & W40x149 \\
\hline 65 & W36x135 & W40x167 \\
\hline 70 & W40x149 & W36x182 \\
\hline 75 & W40x167 & W36x210 \\
\hline 80 & W36x182 & W36x230 \\
\hline 85 & W36x210 & W36x256 \\
\hline 90 & W40x211 & W36x280 \\
\hline 95 & W40x235 & W36x300 \\
\hline 100 & W40x249 & W36x328 \\
\hline 105 & W44x262 & W36x359 \\
\hline 110 & W40x297 & W36x393 \\
\hline
\end{tabular}

WVU $9 \mathrm{ft} /$ AISI $9 \mathrm{ft}$ Comparison

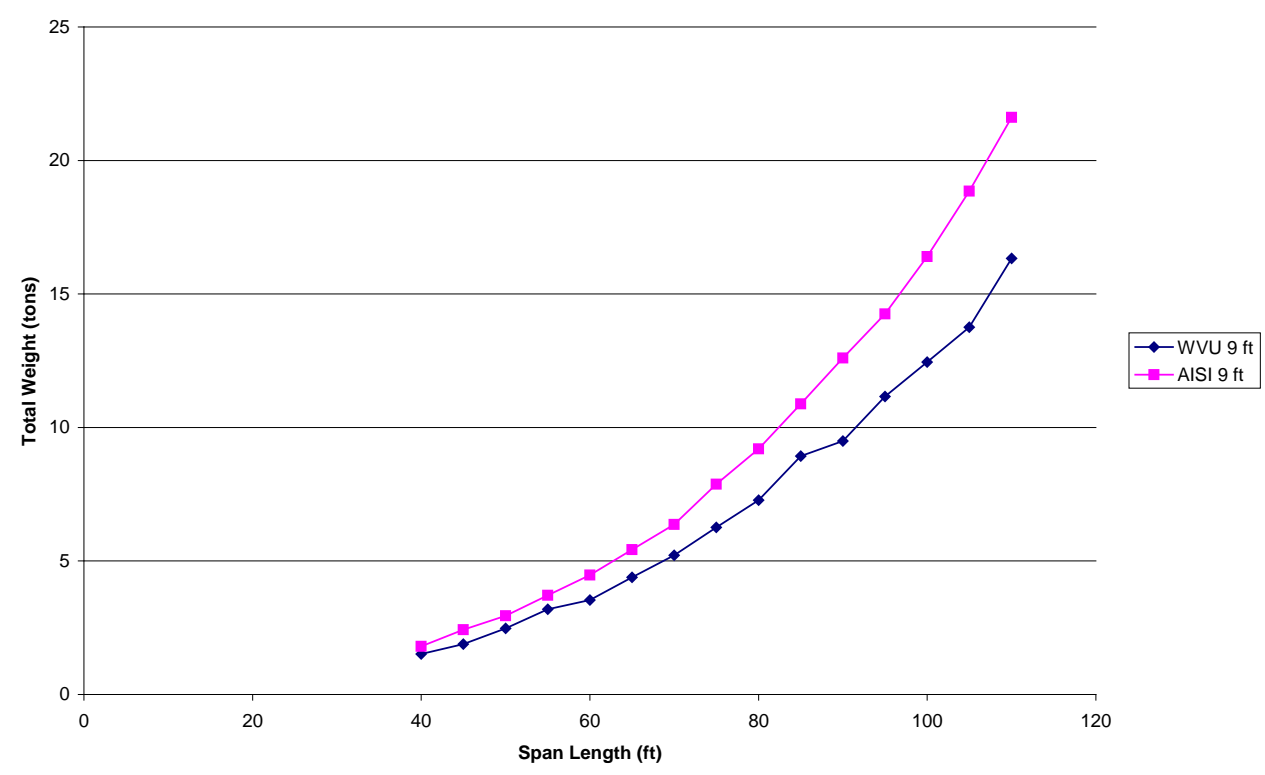

Figure 6-42 WVU 9 ft / AISI 9 ft Weight Comparison 
Table 6-21 WVU $10 \mathrm{ft}$ - 6 in. / AISI $10 \mathrm{ft}$ Section Comparison

\begin{tabular}{|c|c|c|}
\hline Span (ft) & WVU $10 \mathrm{ft}-6$ in. & $10 \mathrm{ft}$ \\
\hline 40 & W24x84 & W30x99 \\
\hline 45 & W30x90 & W30x116 \\
\hline 50 & W30x108 & W33×130 \\
\hline 55 & W33x118 & W40x149 \\
\hline 60 & W36x135 & W36x160 \\
\hline 65 & $W 40 \times 149$ & W36x182 \\
\hline 70 & W40x167 & W36x210 \\
\hline 75 & W36x182 & W36x230 \\
\hline 80 & W36x210 & W36x245 \\
\hline 85 & W36x231 & W36x280 \\
\hline 90 & W36x247 & W36x328 \\
\hline 95 & W40x249 & W36x359 \\
\hline 100 & W44x262 & W36x393 \\
\hline 105 & W40×324 & W36x393 \\
\hline
\end{tabular}

WVU $10 \mathrm{ft}$ - 6 in. I AISI $10 \mathrm{ft}$ Comparison

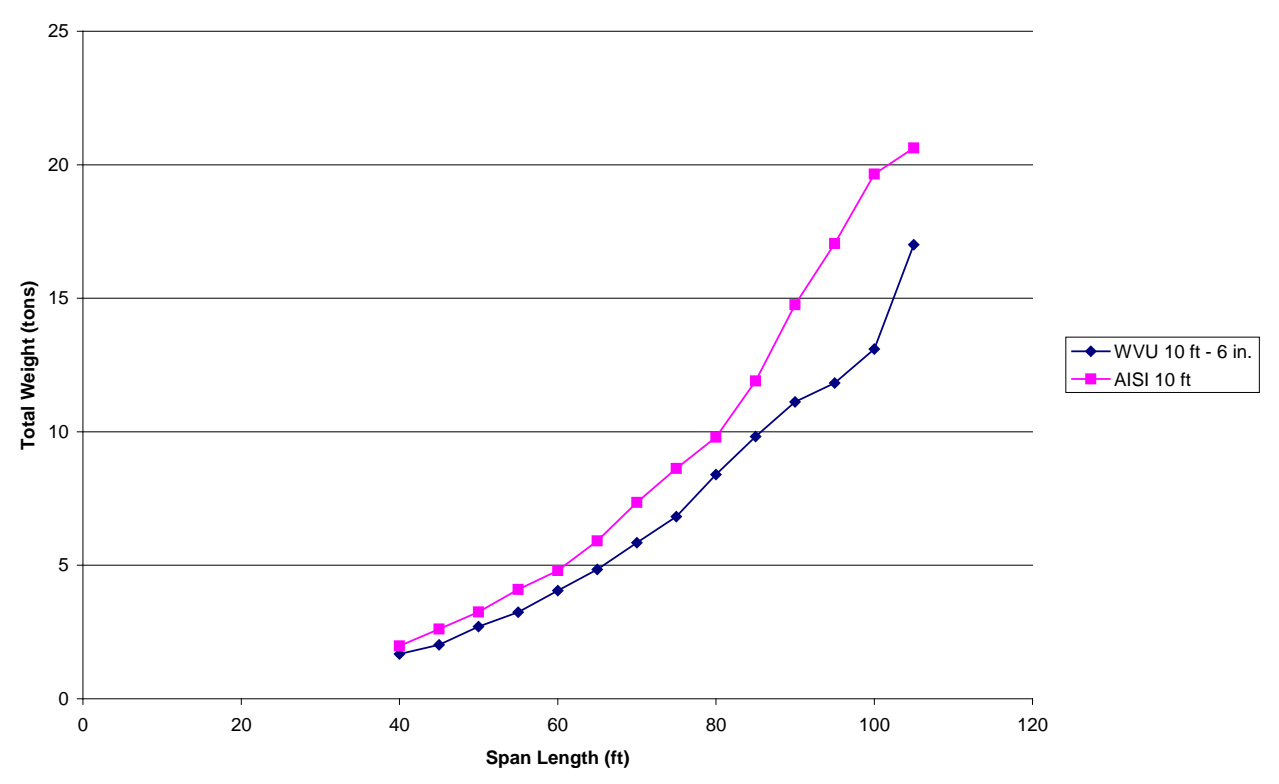

Figure 6-43 WVU $10 \mathrm{ft}$ - 6 in. / AISI $10 \mathrm{ft}$ Weight Comparison 


\subsubsection{Overview of Comparisons}

Overall, the sections developed in this research are similar to the sections found in various bridge standards. Comparing bridges with similar design parameters, the girder weights were found to be similar. The greatest variations were found when comparing the sections of this study to those of the Virginia and AISI standards. This variation may be attributed to the methods used to design the sections. Virginia stated that their sections need to be updated for current design specifications, and the AISI sections were developed using Load Factor Design. 


\section{Chapter 7: Summary and Conclusions}

\subsection{Introduction}

The objective of this research was to investigate economical steel solutions to the large number of short span bridges in the country that are in need of repair or replacement. Chapter 3 presented the survey that was performed to receive data from the state bridge departments on current bridge design practices and preferences, specifically in the area of short span bridges. With this data collected, two courses were pursued to find ways to increase the efficiency of designing and replacing the structurally deficient and functionally obsolete short span bridges in the country. Chapter 4 presented the results developing a collection of modular bridge elements and systems that can be applied to short span steel bridges. Chapter 5 presented the grading system that was developed in order for professionals in the bridge industry to determine which modular bridge system has the most promise for future development of economical and efficient short span bridges. Chapter 6 presented the development of a set of predesigned steel bridge girders for a variety of bridge possibilities. Sections were designed using different girder options, design approaches and bridge parameters to make a suite of pre-designed girders that can meet the standard design practices of several bridge departments in the United States.

\subsection{Standardized Short Span Modular Bridges}

A collection of modular bridge elements and systems were collected, researched and evaluated. This collection consisted of uses of modular bridge technology in bridge substructures, decks, superstructures and in modular bridge systems that are comprised of multiple bridge elements. The benefits and disadvantages of each element and system were presented in the areas of application, constructability and research required for the system. Based on these benefits and disadvantages, a general evaluation of each element and system was presented.

Following the principles of the Federal Highway Association's Highways for LIFE initiative, a system was created to allow professionals in the bridge industry to evaluate each major bridge system. Based on the results of this grading process, an evaluation can be performed to assess which system has the most promise for development of economical and efficient standardized bridge systems. These standardized bridge designs can be used as a method to provide a more efficient bridge design process, and the use of modular bridges have the potential to provide a more efficient bridge construction process. 


\subsection{Standardized Short Span Steel Bridge Designs}

Using conventional steel girder design approaches, optimized designs were developed for a variety of bridges to be used in the development of a design aid for bridge engineers. In these designs, plate girder sections and rolled steel girder sections were developed for bridges that spanned lengths of 40 feet to 140 feet in 5 foot increments. To account for the variety of bridge cross-sections used by different agencies around the country, four different girder spacing arrangements were used in the bridge designs: 6 feet, 7 feet -6 inches, 9 feet and 10 feet -6 inches.

The steel plate girder sections were designed using two material configurations: homogeneous and hybrid. The homogeneous steel sections were made up entirely of $50 \mathrm{ksi}$ steel plates. The hybrid steel sections were made up of $50 \mathrm{ksi}$ steel plates for the top flange and web and a $70 \mathrm{ksi}$ steel plate for the bottom flange. The rolled steel girder sections were designed with $50 \mathrm{ksi}$ steel. The steel plate girder sections employed limited plate sizes to take advantage of stock piling common plate sizes. A limited suite of rolled steel girders were developed to provide a reduced number of girder sections for efficient design and to allow stock piling of commonly used rolled sections.

\subsection{Future Work}

Research indicates that several bridge departments in the United States have either experience or interest in the use of modular bridge systems. In the results of the web survey performed, modular bridge systems were recommended by professionals in the bridge community to be the best option for development into a set of standardized designs. Based on the design framework developed in this thesis, it is suggested that future work is performed to develop a standardized set of plans for short span modular bridge systems that would be applicable to a wide variety of bridge scenarios and to meet the design standards of most state bridge departments. 


\section{References}

[1] "AASHTO - AASHTO Technology Implementation Group - Self Propelled Modular Transporters." AASHTO - AASHTO Technology Implementation Group - TIG Home. AASHTO. Web. 26 May 2010. $<$ http://tig.transportation.org/?siteid=57\&pageid=2478>.

[2] AASHTO. LRFD Bridge Design Specifications, 5th Edition. 2010. American Association of State Highway and Transportation Officials, Washington, D.C.

[3] AASHTO TIG Lead States Team. The Use of Self Propelled Modular Transporters to Remove \& Install Bridges. Rep. 2007. Print.

[4] Acrow Corporation. ACROW 700XS Panel Bridge Technical Handbook. Rep. Third ed. ACROW, 2009. Print.

[5] "About SSSBA." Short Span Steel Bridge Alliance. Web. 13 May 2010. <http://www.shortspansteelbridges.org/about.html>.

[6] A New Orthotropic Deck for Multiple Longitudinal Girder Bridges: A Structal-Bridges Innovation. Web. 10 May 2010. <http://www.canamsteeljoist.ws/www/v4/newslet.nsf/va_redir/ch_especialv5n1>.

[7] Assembly Pretopped Girder Section. Digital image. Big R Bridge Homepage. Big R Bridge. Web. 13 May 2010. <http://www.bigrmfg.com/>.

[8] Azizinamini, Atorod. "A New Era for Short-Span Bridges." Modern Steel Construction Sept. 2009: 5354. Web.

[9] Big R Bridge Homepage. Big R Bridge. Web. 13 May 2010. <http://www.bigrmfg.com/>.

[10] Big R Bridge. Super - Cor. Greely, Colorado: Big R Bridge, 2008. Big R Bridge. Big R Bridge, June 2008. Web. 22 June 2010. <http://www.bigrmfg.com/assets/pdf/BigR_SuperCor_2008.pdf>.

[11] "Chapter 7 Selecting the Right Bridge Type." Steel Bridge Design Handbook. National Steel Bridge Alliance. Web. 13 May 2010. <http://www.aisc.org/WorkArea/showcontent.aspx?id=20232>.

[12] "Chapter 8 Stringer Bridges." Steel Bridge Design Handbook. National Steel Bridge Alliance. Web. 14 June 2010. <http://www.aisc.org/WorkArea/showcontent.aspx?id=20234>.

[13] Clemens, David. "Fwd: Short Span Modular Steel Bridge Concepts." Message to Karl E. Barth. 1 June 2010. E-mail.

[14] Connection Details for Prefabricated Bridge Elements and Systems. Rep. U.S. Department of Transportation Federal Highway Administration, 2007. Print. 
[15] Corrugated Pipe Circular Shape. Digital image. Civil Engineering Products. Nippon Steel \& Sumikin Metal Products Co., Ltd. Web. 25 May 2010. <http://www.nskenzai.co.jp/english/042civil_engineering.html>.

[16] Das, Braja M. "9: Sheet Pile Walls." Principles of Foundation Engineering. Toronto, Ontario, Canada: Thomson, 2007. 409-13. Print.

[17] Federal Highway Administration. "Highways for LIFE - Highways for LIFE - FHWA." Highways for LIFE. United States Department of Transportation. Web. 07 Nov. 2010. $<$ http://www.fhwa.dot.gov/hfl/>.

[18] Geosynthetically Confined Soil Bridge Abutment. Digital image. A New Design and Construction Guidelines for Geosynthetically Confined Soil. Web. 13 May 2010. <http://www.gcswall.com/upload/A\%20new\%20approach\%20to\%20a\%20GCS\%20design\%20gui deline.pdf>.

[19] Geosynthetically Confined Soil Website. Web. 11 May 2010. <http://www.gcswall.com/>.

[20] Greenwald, Jeffrey H. "Comments on Short Span Paper." Message to Karl E. Barth. 2 June 2010. Email.

[21] I-95 Bridgeport, CT. Digital image. Acrow Bridges. Web. 18 May 2010. <http://www.acrowusa.com/index.php?page=photo-gallery>.

[22] "Innovative Bridge Research Construction." City of Bettendorf Public Works Department. Web. 27 May 2010. <http://archive.bettendorf.org/publicworks/ibrc/ibrc.html>.

[23] Inverset Section Being Placed. Digital image. Amcrete Products. Web. 10 May 2010. <http://www.amcrete.com/bridges.htm\#inverset>.

[24] J. Muller International Bridge Engineering Consultants, and American Iron and Steel Institute. High Performance Steel Bridge Concepts. Rep. American Iron and Steel Institute, 1996. Print.

[25] Kozy, Brian, Ronnie Medlock, and Derek Mitch. Orthotropic Deck Girder Bridges for a Rapid and Long Lasting Solution. Rep. Print.

[26] Lampe, Nick, and Atorod Azizinamini. Steel Bridge System, Simple for Dead Load and Continuous for Live Load. Rep. Print.

[27] Maneetes, H., and D. G. Linzell. Cross-frame and Lateral Bracing Influence on Curved Steel Bridge Free Vibration Response. Rep. Vol. 59. ELSEVIER, 2003. Print. Journal of Constructional Steel Research.

[28] McGough, Michael. Proposed Research Project for Flexible Metal Culverts. Rep. Print.

[29] Mechanically Stabilized Earth Wall Abutment. Digital image. Bridge Abutments. Big R Bridge. Web. 12 May 2010. <http://www.bigrmfg.com/products/abutment/>. 
[30] Mertz, Dennis R. Designer's Guide to Cross-Frame Diaphragms. Rep. American Iron and Steel Institute, 2001. Web. 14 June 2010.

<http://www.steel.org/AM/Template.cfm?Section=PDFs1\&CONTENTID=9157\&TEMPLATE=/CM/ ContentDisplay.cfm>.

[31] Modern Steel Construction. "National Award Box Elder Creek Bridge." Modern Steel Construction Nov. 2007. Web. 22 June 2010.

<http://www.steel.org/bridges/AIB_BoxElderCreekCaseStudyReprint.pdf>.

[32] National Corrugated Steel Pipe Association. "Chapter 2: Product Details and Fabrication." Corrugated Steel Pipe Design Manual. National Corrugated Steel Pipe Association, 2008. 23-129. Print.

[33] The Neel Company. T-WALL Retaining Wall System Design Guide \& Technical Information. Neel Company, 2008. Print.

[34] The Neel Company. Southard St Bridge Replacement. Digital image. T-WALL Retaining Wall System. The Neel Company. Web. 22 June 2010. <http://www.neelco.com/gallery.php4?a=Bridges\&i=TW2642_CD81_03.jpg>.

[35] North American Steel Sheet Piling Association. "Roadway Embankments Using Steel Sheet Piling NASSPA." North American Steel Sheet Piling Association - Promoting Hot-rolled Steel Sheet Piling. Web. 22 June 2010. <http://www.nasspa.com/roadway-embankments.php>.

[36] North American Steel Sheet Piling Association. "Steel Sheet Piling Used in Bridge Abutments NASSPA." North American Steel Sheet Piling Association - Promoting Hot-rolled Steel Sheet Piling. Web. 22 June 2010. <http://www.nasspa.com/bridge-abutments-1.php>.

[37] Open Grid Deck. Digital image. Web. 11 May 2010. <http://i733.photobucket.com/albums/ww340/emmons1315/ehbridge026.jpg>.

[38] Peterson, Kris, and Mary Lou Ralls. Accelerated Bridge Construction (ABC) and the Utah Experience. Rep. 2008. Print.

[39] Precast Concrete Pile. Digital image. Web. 11 May 2010. <http://cee.engr.ucdavis.edu/faculty/chai/Research/Extended\%20Pile\%20Shafts/TestPit5.jpg>.

[40] Reeves, Will. Modular Piers. Rep. 2009. Print.

[41] Roy, Sougata, and Yeun Chul Park. "Fatigue Evaluation and Enhancement of a Modular Steel Orthotropic Deck." The 27th Annual International Bridge Conference. David L. Lawrence Convention Center, Pittsburgh. 8 June 2010. Lecture.

[42] SDR Engineering Consultants, Inc. Prefabricated Steel Bridge Systems. Rep. no. DTFH61-03-R-00113. Washington, DC: Federal Highway Administration, 2005. Print.

[43] Sheet Piling Bridge Abutments, Robert J. Carle, Scott S. Whitaker, DFI Proceedings 14th Annual Conference, 1989, Baltimore, MD. 
[44] Simple for Dead Load and Continuous for Live Load Example. Digital image. Cost Effective Detailing of a Dead Load Simple Live Load Continuous Weathering Steel Girder Bridge in New Mexico. New Mexico Department of Transportation. Web. 11 May 2010.

<http://www.aisc.org/assets/0/1209478/1209480/1236512/483d552c-fabe-49a9-8d39-

b32ef3f0d69a.pdf>.

[45] Steel Bridge Construction: Myths \& Realities. Rep. no. D432-07. National Steel Bridge Alliance and American Institute of Steel Construction. Web. 13 May 2010. <http://www.shortspansteelbridges.org/pdf/MythsAndRealitiesOfSteelBridges.pdf>.

[46] Steel Has the Solution. Digital image. Short Span Steel Bridge Alliance. Web. 10 May 2010. <http://www.shortspansteelbridges.org/pdf/SSSBA_MeasurementBrochure_sm.pdf>.

[47] Steel Truss Bridge. Digital image. Vehicular Truss. U.S. Bridge. Web. 13 May 2010. <http://www.usbridge.com/index.php/usb/bridges/C62/>.

[48] SuperSill Abutment. SuperSill Abutment System. Web. 10 May 2010. <http://www.roscoebridge.com/?a=20\&b=supersill-abutment-system>.

[49] "Traffic Barricades: How J-J Hooks Barriers Can Keep You Safe." Precast Concrete Barriers: J-J Hooks Connection System. Web. 15 June 2010. <http://www.jjhooks.com/traffic.shtml>.

[50] Transportation Research Board. "Accelerating Bridge Construction - Seismic Connections." Lecture. Transportation Research Board. Transportation Research Board. Web. 25 June 2010. <http://www.wsdot.wa.gov/eesc/bridge/ABC/TRB_Research_Proposal_Webinar.pdf>.

[51] Transportation Research Board of the National Academies. "Installing a Bridge Superstructure on a Weekend." TR News Mar.-Apr. 2010: 17. Print.

[52] Transverse Deck Stringer Bridge. Digital image. Transverse Deck Timber Vehicle Bridges. Web. 10 May 2010. <http://www.wheeler-con.com/wheeler/highway/transversedeck/index.php>.

[53] Tricon Precast, Ltd. "Con-Struct Prefabricated Bridge System." Tricon Precast, Ltd. Web. 07 Nov. 2010. <http://www.triconprecast.com/con-struct.php>.

[54] Tricon Precast, Ltd. Con-Struct Prefabricated Bridge System Standard Plans. 21 Aug. 2008. Standard Design Plans. Houston, Texas.

[55] Trinity Highway Products. Building Tomorrow's Highway Safety Solutions Today. Dallas, TX: Trinity Highway Products, 2008. Print.

[56] Virginia's Superstructure Replacement of I-95 James River Bridge. Digital image. Highways for Life. U.S. Department of Transportation Federal Highway Administration. Web. 13 May 2010. <http://www.fhwa.dot.gov/hfl/ralls.cfm>.

[57] Wipf, Terry J., F. Wayne Klaiber, Holly A. Boomsma, and Kristine S. Palmer. Field Testing of Railroad Flatcar Bridges Volume I: Single Spans. Rep. no. TR-498. lowa Department of Transportation, 2007. Print. 
[58] Wright, William. Sandwich Panel Modular Steel Bridge Deck System. Rep. Virginia Tech, 2010. Print. 
Appendix A - AISI Short Span Bridge Survey Responses 


\section{Research Statement}

The Federal Highway Administration in conjunction with the American Iron and Steel Institute [AISI] has recently conducted two workshops focused on developing ideas for improved steel bridge construction. One of the target areas of these workshops has been to develop design standards for short span steel bridges. As a result, the AISI Short Span Steel Bridge Alliance has contracted with Dr. Karl Barth at West Virginia University to conduct a survey of State DOT's and County Engineers. The focus of this survey is to study and catalog statistics and methods employed in short-span bridge design and construction. The overall projected outcome of this research is a best practices manual for the design and construction of short-span steel bridges (i.e. bridges up to $140 \mathrm{ft}$.) and a table outlining suggested pre-selected steel beam sizes and shapes for given span lengths.

\section{Part I. General Information}

Date: November 30, 2009

Time:

Agency/DOH: Alabama Department of Transportation

Name: John Black

Position / Title: State Bridge Engineer

Address: 1409 Coliseum Boulevard, Montgomery, AL 36110-3050

Phone: 334-242-6004

E-mail: blackj@dot.state.al.us

Other Information: 


\section{Part II. General Questions}

1. If possible, please provide a list of bridges built in your region in the past year along with their respective span lengths, whether they are simple or continuous span, cross-section widths and any other general information you can offer (ADT, wearing surface, deck and superstructure choices, substructure and pier choices, number of lanes, etc.).

2. If information for question 1 is not readily available, please provide us with the following information: How many bridges were built in your region in the past year in the following length categories? Also, of those, how many bridges consisted of steel superstructures?

\begin{tabular}{|l|l|l|}
\hline Length Categony & Number of buthes & W Sted Smperstructurcs \\
\hline$<40 \mathrm{ft}$ & & \\
\hline $40-60 \mathrm{ft}$ & & \\
\hline $60-80 \mathrm{ft}$ & & \\
\hline $80-100 \mathrm{ft}$ & & \\
\hline $100-120 \mathrm{ft}$ & & \\
\hline $120-140 \mathrm{ft}$ & & \\
\hline
\end{tabular}


3. For the following bridge components, please specify whether you have a preferred/specified type of design and whether or not there are any particular types of bridge component that you do not approve:

\begin{tabular}{|c|c|c|c|}
\hline Brige compurent & Bucturie & 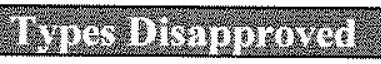 & Brte Drohming \\
\hline Decking Systems & $\begin{array}{l}\text { Circle Choice } \\
\text { Cast-in-place } \\
\text { concrete } \\
\text { Precast concrete } \\
\text { panels } \\
\text { Steel stay-in-place } \\
\text { formwork } \\
\text { Other (list): }\end{array}$ & & \\
\hline $\begin{array}{l}\text { Railing/Guardrail } \\
\text { Systems }\end{array}$ & $\begin{array}{l}\text { Concrete } \\
\text { barrier/New Jersey } \\
\text { shape }\end{array}$ & & \\
\hline $\begin{array}{l}\text { Topping/Wearing } \\
\text { Surfaces }\end{array}$ & None allowed & & \\
\hline $\begin{array}{l}\text { Bridge } \\
\text { Superstructures }\end{array}$ & Prestressed girder & $\begin{array}{l}\text { Fracture critical steel } \\
\text { girder }\end{array}$ & \\
\hline Abutments & $\begin{array}{l}\text { Reinforced } \\
\text { concrete/steel } \\
\text { pile/concrete } \\
\text { pile/drilled shaft }\end{array}$ & & \\
\hline Pier Systems & $\begin{array}{l}\text { Reinforced } \\
\text { concrete/steel } \\
\text { pile/concrete } \\
\text { pile/drilled shafi }\end{array}$ & & \\
\hline
\end{tabular}


4. Do you have typical standards for cross-section widths and girder spacings? If so, please provide.

For 2 lane facility, $40^{\prime}$ gutter to gutter, 7 foot girder spacing For 4 lane facility, 44 gutter to gutter, 8 foot girder spacing

5. Do you have different design specifications for low-volume roads versus high-volume roads? If so, what are they?

On rural road system use precast reinforced concrete channel shape (bolted side to side) with precast concrete cap on piles often times. Standard drawings are available for these type structures.

6. Do you use any bridge analysis or design software? If so, what brand of software is used?

In house programs, GTStrudl, L-PIle, LEAP, PSBeam, etc.

7. Do you use any bridge design/component standards (or templates)? Examples may include beam sizes for different span lengths and roadway widths. If you have any, are they available on the web?

Standard AASHTO prestressed girder shapes

8. Do you use modular bridge systems?

Not at this time but are considering these

9. If a best practices manual for accelerated construction/modular bridge systems was developed, what would you like to see included? For example pre-selected beam sizes, cross-sections, etc.

Not sure at this time.

10. Do you use the AASHTO LRFD specified load factors/combinations or different load factors/combinations? If different, what are they?

ALDOT has not yet fully implemented to LRFD design so 1 am not able to comment on this question

11. Would a table outlining pre-selected steel beam sizes and shapes for given span lengths based on AASHTO LRFD Bridge Design Specifications be useful for assisting in your design development process? 
Probably so as a starting point anyway, however AL DO does very few short span steel designs so I am not sure how much use this office would find in a table like this.

12. What is your preferred material choice for short-span bridges? Why?

Concrete - economy (up front cost during construction) and less maintenance cost

13. Are there any other comments that you have that you feel might be relevant to this study?

none 
14. What are your most important sources for bridge design and construction technical information and industry news? (Circle which are relevant)

- INDUSTRY PUBLICATIONS/WEB SITES:

- ENR

- Roads and Bridges

- GoBridges.com

- Better Roads (BetterRoads.com)

- Journal of Structural Engineering

- Transportation Builder

- Public Works Magazine

- Engineering Journal

- Public Roads

- Design Engineering

- Government Engineering (GovEngr.com)

- Civil Engineering

- CE News

- Others?

- INDUSTRY CONFERENCES (name which ones)

- PROFESSIONAL ORGANIZATION NEWSLETTER?

- NACE?

- Others?

- WEB SITES

- FHWA

- steel.org

- Steelbridges.org

- Others? 


\section{Research Statement}

The Federal Highway Administration in conjunction with the American Iron and Steel Institute [AISI] has recently conducted two workshops focused on developing ideas for improved steel bridge construction. One of the target areas of these workshops has been to develop design standards for short span steel bridges. As a result, the AISI Short Span Steel Bridge Alliance has contracted with Dr. Karl Barth at West Virginia University to conduct a survey of State DOT's and County Engineers. The focus of this survey is to study and catalog statistics and methods employed in short-span bridge design and construction. The overall projected outcome of this research is a best practices manual for the design and construction of short-span steel bridges (i.e. bridges up to $140 \mathrm{ft}$.) and a table outlining suggested pre-selected steel beam sizes and shapes for given span lengths.

\section{Part I. General Information}

Date: $12 / 09 / 2009$

Time: 1: $33 \mathrm{pm}$

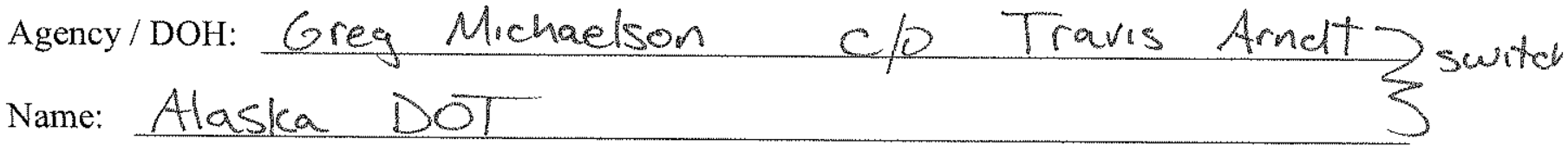

Position/ Title:

Address:

Phone: $907 / 465-8892$

E-mail: travis.arndt@alaska.gor

Other Information: 


\section{Part II. General Questions}

1. If possible, please provide a list of bridges built in your region in the past year along with their respective span lengths, whether they are simple or continuous span, cross-section widths and any other general information you can offer (ADT, wearing surface, deck and superstructure choices, substructure and pier choices, number of lanes, etc.).

2. If information for question 1 is not readily available, please provide us with the following information: How many bridges were built in your region in the past year in the following length categories? Also, of those, how many bridges consisted of steel superstructures?

\begin{tabular}{|l|l|l|}
\hline Lenghi Catcgovy & Number of Bringes & W Sted Superstruetires \\
\hline$<40 \mathrm{ft}$ & & \\
\hline $40-60 \mathrm{ft}$ & & \\
\hline $60-80 \mathrm{ft}$ & & \\
\hline $80-100 \mathrm{ft}$ & & \\
\hline $100-120 \mathrm{ft}$ & & \\
\hline $120-140 \mathrm{ft}$ & & \\
\hline
\end{tabular}


3. For the following bridge components, please specify whether you have a preferred/specified type of design and whether or not there are any particular types of bridge component that you do not approve:

\begin{tabular}{|c|c|c|c|}
\hline Britge Component & Preference: & Types Disapproved & Brief Brylanation \\
\hline Decking Systems & $\begin{array}{l}\text { Circle Choice } \\
\text { Cast-in-place } \\
\text { concrete } \\
\text { (Precast concrete } \\
\text { panels } \\
\text { Steel stay-in-place } \\
\text { formwork } \\
\text { Other (list): }\end{array}$ & $\begin{array}{l}\text { buthw stay-m } \\
\text { place formusork } \\
\text { (reason = inspectron) }\end{array}$ & cheapest \\
\hline $\begin{array}{l}\text { Railing/Guardrail } \\
\text { Systems }\end{array}$ & & & \\
\hline $\begin{array}{l}\text { Topping/Wearing } \\
\text { Surfaces }\end{array}$ & $\begin{array}{c}\text { asphalt } \\
\text { milling } \\
\text { surfece }\end{array}$ & & 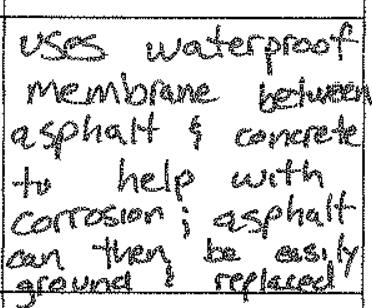 \\
\hline $\begin{array}{l}\text { Bridge } \\
\text { Superstructures }\end{array}$ & $\begin{array}{l}\text { deck } \\
\text { bulb-T }\end{array}$ & & $\begin{array}{c}\text { quick } \\
4 \\
\text { cherp }\end{array}$ \\
\hline Abutments & & & \\
\hline Pier Systems & & & \\
\hline
\end{tabular}


4. Do you have typical standards for cross-section widths and girder spacings? If so, please provide.

Alaska is divided mto 3 districts; highly depends on WHERE I IS

5. Do you have different design specifications for low-volume roads versus high-volume roads? If so, what are they?

$n<$

6. Do you use any bridge analysis or design software? If so, what brand of software is used?

SAP, RISA, Excel, in-house Visual BASIC apps

7. Do you use any bridge design/component standards (or templates)? Examples may include beam sizes for different span lengths and roadway widths. If you have any, are they available on the web?

no

8. Do you use modular bridge systems?

Note: modular systems

in emergency/detour situations

have a MoHEt final cost than

9. If a best practices manual for accelerated construction/modular bridge stoundard. systems was developed, what would you like to see included? For example pre-selected beam sizes, cross-sections, etc. bridges

$N / A-$ 
10. Do you use the AASHTO LRFD specified load factors/combinations or different load factors/combinations? If different, what are they?

USE AASHTO RFD;

in many cases, the design vehicle is much larger due to the application of the bridge

11. Would a table outlining preselected steel beam sizes and shapes for given span lengths based on AASHTO LRFD Bridge Design Specifications be useful for assisting in your design development process?

not really

12. What is your preferred material choice for short-span bridges? Why?

whatever is cheapest

13. Are there any other comments that you have that you feel might be relevant to this study?

If the steel industry were to get the prices lowered, it would become a more competitive material chore 
14. What are your most important sources for bridge design and construction technical information and industry news? (Circle which are relevant)

- INDUSTRY PUBLICATIONS/WEB SITES:

- EN

- Roads and Bridges

- GoBridges.com

- Better Roads (BetterRoads.com)

- Journal of Structural Engineering

- Transportation Builder

- Public Works Magazine

- Engineering Journal

- Public Roads

- Design Engineering

- Government Engineering (GovEngr.com)

- Civil Engineering

- CE News

- Others?

- INDUSTRY CONFERENCES (name which ones)

- PROFESSIONAL ORGANIZATION NEWSLETTER?

- MACE?

- Others?

- WEB SITES

- FHWA

- steel.org

- Steelbridges.org

- Others?

* When it comes to technical information

for example, a problem with a particular equation) We will contact the university who supplied the research that went behind that equation. 


\section{$\underline{\text { Research Statement }}$}

The Federal Highway Administration in conjunction with the American Iron and Steel Institute [AISI] has recently conducted two workshops focused on developing ideas for improved steel bridge construction. One of the target areas of these workshops has been to develop design standards for short span steel bridges. As a result, the AISI Short Span Steel Bridge Alliance has contracted with Dr. Karl Barth at West Virginia University to conduct a survey of State DOT's and County Engineers. The focus of this survey is to study and catalog statistics and methods employed in short-span bridge design and construction. The overall projected outcome of this research is a best practices manual for the design and construction of short-span steel bridges (i.e. bridges up to $140 \mathrm{ft}$.) and a table outlining suggested pre-selected steel beam sizes and shapes for given span lengths.

\section{Part I. General Information}

Date: $11 / 30 / 2009$

Time: 10:00AM

Agency/DOH: ADOT

Name: Pe-Shen Yang

Position / Title: Assistant State Bridge Engineer

Address: 205 S. $17^{\text {th }}$ Ave., Mail Drop 613E, Phoenix, AZ 85007

Phone: 602.712 .8606

E-mail: pyang@azdot.gov

Other Information: 


\section{Part II. General Questions}

1. If possible, please provide a list of bridges built in your region in the past year along with their respective span lengths, whether they are simple or continuous span, cross-section widths and any other general information you can offer (ADT, wearing surface, deck and superstructure choices, substructure and pier choices, number of lanes, etc.).

2. If information for question 1 is not readily available, please provide us with the following information: How many bridges were built in your region in the past year in the following length categories? Also, of those, how many bridges consisted of steel superstructures?

\begin{tabular}{|l|c|l|}
\hline Longh Categony & Nomber of Brthges & W Sted Superentemies \\
\hline$<40 \mathrm{ft}$ & & \\
\hline $40-60 \mathrm{ft}$ & 2 & \\
\hline $60-80 \mathrm{ft}$ & 2 & \\
\hline $80-100 \mathrm{ft}$ & & \\
\hline $100-120 \mathrm{ft}$ & & \\
\hline $120-140 \mathrm{ft}$ & 2 & \\
\hline
\end{tabular}


3. For the following bridge components, please specify whether you have a preferred/specified type of design and whether or not there are any particular types of bridge component that you do not approve:

\begin{tabular}{|c|c|c|c|}
\hline Enigge Component & Preference & These bisuppred & Bref Evplamiton \\
\hline Decking Systems & $\begin{array}{l}\text { Circle Choice } \\
\text { Cast-in-place } \\
\text { concrete } \\
\text { Precast concrete } \\
\text { panels } \\
\text { Steel stay-in-place } \\
\text { formwork } \\
\text { Other (list): }\end{array}$ & & \\
\hline $\begin{array}{l}\text { Railing/Guardrail } \\
\text { Systems }\end{array}$ & $\begin{array}{l}\text { F-Shape Concrete } \\
\text { Barrier } \\
\text { NCHRP } 350\end{array}$ & & \\
\hline $\begin{array}{l}\text { Topping/Wearing } \\
\text { Surfaces }\end{array}$ & $1 / 2 "$ Wearing Surface & & \\
\hline $\begin{array}{l}\text { Bridge } \\
\text { Superstructures }\end{array}$ & $\begin{array}{ll}\text { - Steel } \\
\text { - Concrete } \\
\text { - Prestressed } \\
\text { Concrete }\end{array}$ & & \\
\hline Abutments & $\begin{array}{c}\text { Concrete full weight } \\
\text { Or } \\
\text { Stub Abutment }\end{array}$ & & \\
\hline Pier Systems & $\begin{array}{l}\text { Steel (H-pile) or } \\
\text { Concrete }\end{array}$ & & \\
\hline
\end{tabular}


4. Do you have typical standards for cross-section widths and girder spacings? If so, please provide.

No

5. Do you have different design specifications for low-volume roads versus high-volume roads? If so, what are they?

No

6. Do you use any bridge analysis or design software? If so, what brand of software is used?

Conbox, Conspan, MDX, GT-Strudl, PC Frame, RC Pier and Virtis.

7. Do you use any bridge design/component standards (or templates)? Examples may include beam sizes for different span lengths and roadway widths. If you have any, are they available on the web?

No

8. Do you use modular bridge systems?

No

9. If a best practices manual for accelerated construction/modular bridge systems was developed, what would you like to see included? For example pre-selected beam sizes, cross-sections, etc.

Yes 
10. Do you use the AASHTO LRFD specified load factors/combinations or different load factors/combinations? If different, what are they?

Yes, AASHTO LRFD Design Specifications.

11. Would a table outlining pre-selected steel beam sizes and shapes for given span lengths based on AASHTO LRFD Bridge Design Specifications be useful for assisting in your design development process?

Yes

12. What is your preferred material choice for short-span bridges? Why? Concrete due to its availability locally.

13. Are there any other comments that you have that you feel might be relevant to this study? 
14. What are your most important sources for bridge design and construction technical information and industry news? (Circle which are relevant)

- INDUSTRY PUBLICATIONS/WEB SITES:

- ENR

- Roads and Bridges

- GoBridges.com

- Better Roads (BetterRoads.com)

- Journal of Structural Engineering

- Transportation Builder

- Public Works Magazine

- Engineering Journal

- Public Roads

- Design Engineering

- Government Engineering (GovEngr.com)

- Civil Engineering

- CE News

- Others?

- INDUSTRY CONFERENCES (name which ones)

- PROFESSIONAL ORGANIZATION NEWSLETTER?

- NACE?

- Others?

- WEB SITES

- FHWA

- steel.org

- Steelbridges.org

- Others? 
Goal: "Done Before Christmas"

Research Statement

The Federal Highway Administration in conjunction with the American Iron and Steel Institute [AISI] has recently conducted two workshops focused on developing ideas for improved steel bridge construction. One of the target areas of these workshops has been to develop design standards for short span steel bridges. As a result, the AISI Short Span Steel Bridge Alliance has contracted with Dr. Karl Barth at West Virginia University to conduct a survey of State DOT's and County Engineers. The focus of this survey is to study and catalog statistics and methods employed in short-span bridge design and construction. The overall projected outcome of this research is a best practices manual for the design and construction of short-span steel bridges (ie. bridges up to $140 \mathrm{ft}$.) and a table outlining suggested preselected steel beam sizes and shapes for given span lengths.

Part 1. General Information

Date: $\quad 12-2 /-09$

Time:

Agency/DOH: Arkansas State Highway \& Transp. Dept.

Name: Charles Ellis

Position/Title: StafF Bridge Design Engineer

Address:

Phone: $\quad 501-569-2134$

Email: rick.ellise arkansas highways. com

Other Information: 


\section{Part II. General Questions}

1. If possible, please provide a list of bridges built in your region in the past year along with their respective span lengths, whether they are simple or continuous span, cross-section widths and any other general information you can offer (ADT, wearing surface, deck and superstructure choices, substructure and pier choices, number of lanes, etc.).

$$
\text { See Spreadsheet }
$$

2. If information for question 1 is not readily available, please provide us with the following information: How many bridges were built in your region in the past year in the following length categories? Also, of those, how many bridges consisted of steel superstructures?

\begin{tabular}{|c|c|c|}
\hline 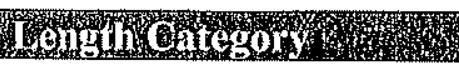 & 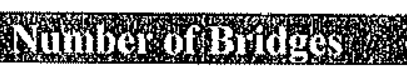 & 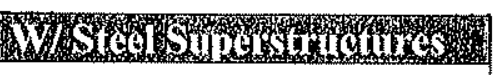 \\
\hline$<40 \mathrm{ft}$ & & \\
\hline $40-60 \mathrm{ft}$ & & \\
\hline $60-80 \mathrm{ft}$ & & \\
\hline $80-100 \mathrm{ft}$ & & \\
\hline $100-120 \mathrm{ft}$ & & \\
\hline $120-140 \mathrm{ft}$ & & \\
\hline
\end{tabular}


3. For the following bridge components, please specify whether you have a preferred/specified type of design and whether or not there are any particular types of bridge component that you do not approve:

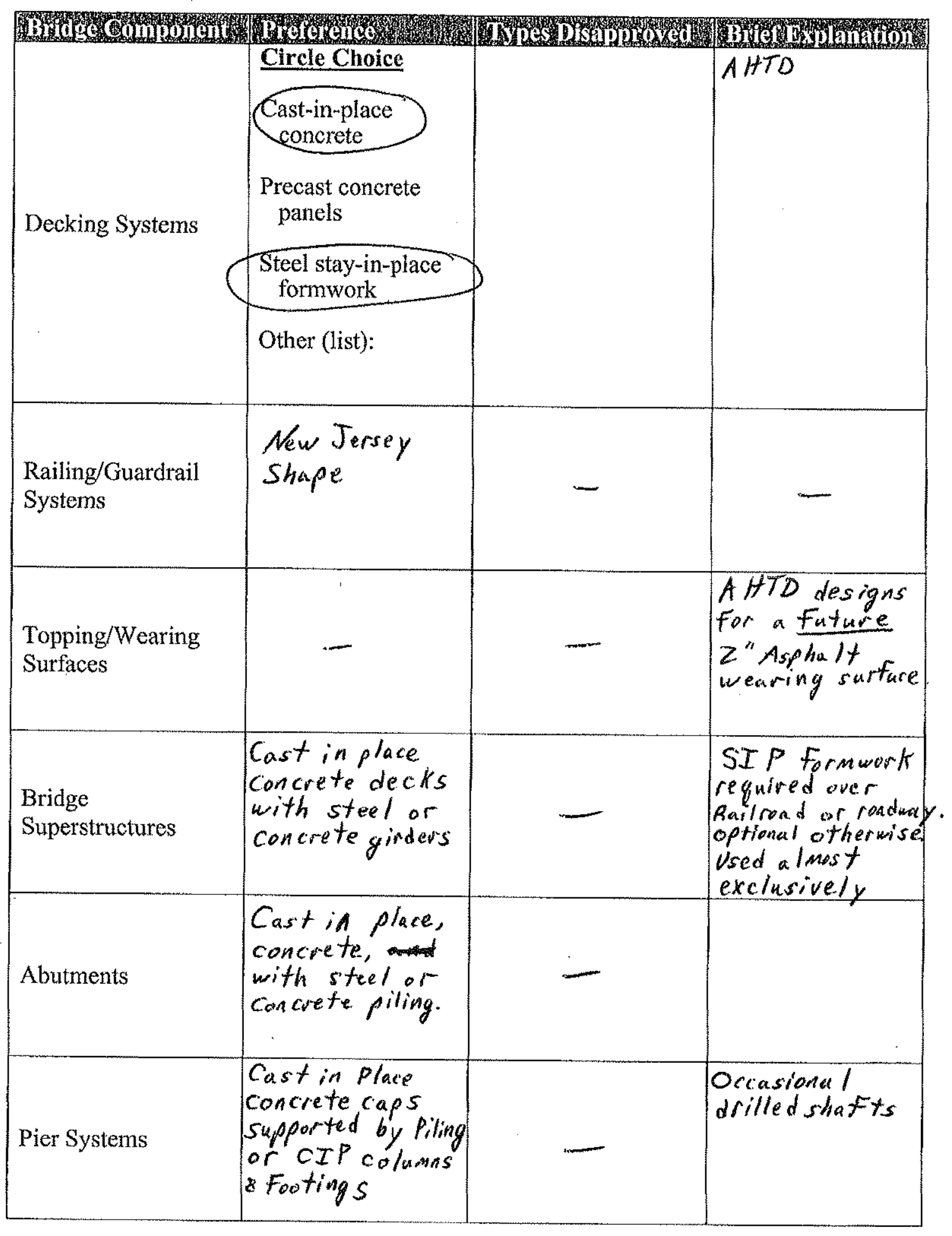


4. Do you have typical standards for cross-section widths and girder spacings? If so, please provide.

Have not developed any for $\angle R F D$ but, some patterns can be seen on spreadsheet.

5. Do you have different design specifications for low-volume roads versus high-volume roads? If so, what are they?

$\angle R F D$ For all new design.

$T L-4$ loading for all railing (almost exclusive)

6. Do you use any bridge analysis or design software? If so, what brand of software is used?

MDX - Steel Beam Design, Bentley/Con-Span for

Conc. Girder Design, Bentley/RC Pier For Substructure Design.

7. Do you use any bridge design/component standards (or templates)? Examples may include beam sizes for different span lengths and roadway widths. If you have any, are they available on the web?

Do not use any.

8. Do you use modular bridge systems?

No

9. If a best practices manual for accelerated construction/modular bridge systems was developed, what would you like to see included? For example pre-selected beam sizes, cross-sections, etc. 
10. Do you use the AASHTO LRFD specified load factors/combinations or different load factors/combinations? If different, what are they?

$\angle R F D$

11. Would a table outlining pre-selected steel beam sizes and shapes for given span lengths based on AASHTO LRFD Bridge Design Specifications be useful for assisting in your design development process?

Maybe

12. What is your preferred material choice for short-span bridges? Why? Steel Beams w Canc. Deck, comfort level \& Cost

13. Are there any other comments that you have that you feel might be relevant to this study? 
14. What are your most important sources for bridge design and construction technical information and industry news? (Circle which are relevant)

- INDUSTRY PUBLICATIONS/WEB SITES:

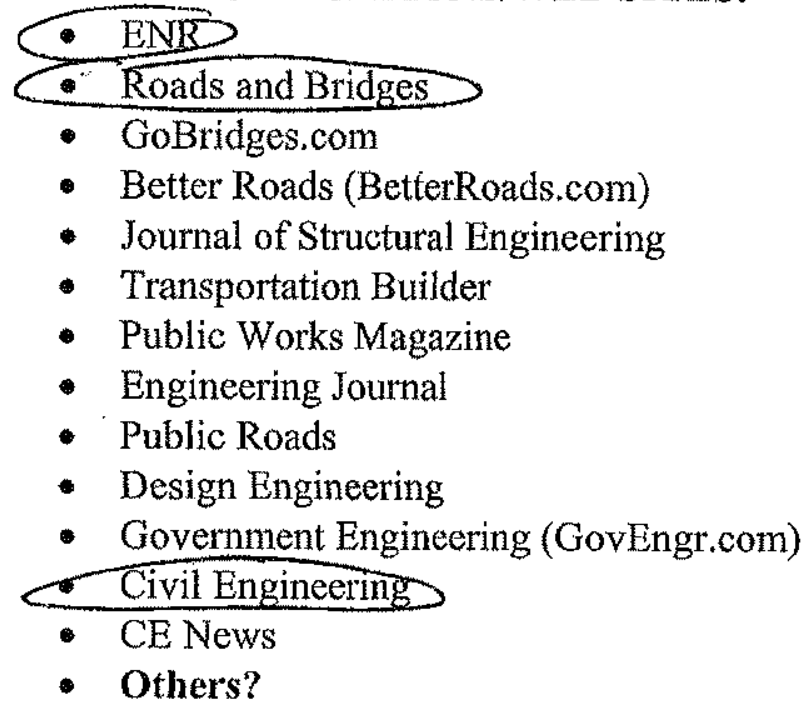

- INDUSTRY CONFERENCES (name which ones)

- PROFESSIONAL ORGANIZATION NEWSLETTER?

- NACE?

- Others?

- WEB SITES

Steel.org

- Steelbridges.org

- Others? 


\section{$\underline{\text { Research Statement }}$}

The Federal Highway Administration in conjunction with the American Iron and Steel Institute [AISI] has recently conducted two workshops focused on developing ideas for improved steel bridge construction. One of the target areas of these workshops has been to develop design standards for short span steel bridges. As a result, the AISI Short Span Steel Bridge Alliance has contracted with Dr. Karl Barth at West Virginia University to conduct a survey of State DOT's and County Engineers. The focus of this survey is to study and catalog statistics and methods employed in short-span bridge design and construction. The overall projected outcome of this research is a best practices manual for the design and construction of short-span steel bridges (i.e. bridges up to $140 \mathrm{ft}$.) and a table outlining suggested pre-selected steel beam sizes and shapes for given span lengths.

\section{Part l. General Information}

Date: $\quad 12 / 29 / 2009$

Time:

Agency / DOH: California Department of Transportation

Name: Lian Duan

Position / Title: Senior Bridge Engineer

Address: $180130^{\text {th }}$ Street, MS9-FMII 1/5C, Sacramento, CA 95816

Phone: $916-227-8220$

E-mail: Lian_Duan@dot.ca.gov

Other Information: 


\section{Part II. General Questions}

1. If possible, please provide a list of bridges built in your region in the past year along with their respective span lengths, whether they are simple or continuous span, cross-section widths and any other general information you can offer (ADT, wearing surface, deck and superstructure choices, substructure and pier choices, number of lanes, etc.).

2. If information for question 1 is not readily available, please provide us with the following information: How many bridges were built in your region in the past year in the following length categories? Also, of those, how many bridges consisted of steel superstructures?

\begin{tabular}{|c|c|c|}
\hline Lengin Categany & Nomber of burges & W Steel Stuperstrichres: \\
\hline$<40 \mathrm{ft}$ & 1118 & 75 \\
\hline $40-60 \mathrm{ft}$ & 543 & 13 \\
\hline $60-80 \mathrm{ft}$ & 620 & 15 \\
\hline $80-100 \mathrm{ft}$ & 733 & 22 \\
\hline $100-120 \mathrm{ft}$ & 778 & 26 \\
\hline $120-140 \mathrm{ft}$ & 996 & 35 \\
\hline
\end{tabular}


3. For the following bridge components, please specify whether you have a preferred/specified type of design and whether or not there are any particular types of bridge component that you do not approve:

\begin{tabular}{|c|c|c|c|}
\hline Whigh oonvintont & Brefrengne? & 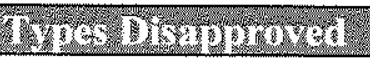 & Bref Exuminton \\
\hline Decking Systems & $\begin{array}{l}\text { Circle Choice } \\
\text { Cast-in-place } \\
\text { concrete } \\
\text { Precast concrete } \\
\text { panels } \\
\text { Steel stay-in-place } \\
\text { formwork } \\
\text { Other (list): }\end{array}$ & & \\
\hline $\begin{array}{l}\text { Railing/Guardrail } \\
\text { Systems }\end{array}$ & Concrete Barrel & & \\
\hline $\begin{array}{l}\text { Topping/Wearing } \\
\text { Surfaces }\end{array}$ & Concrete & & \\
\hline $\begin{array}{l}\text { Bridge } \\
\text { Superstructures }\end{array}$ & I-beam & & \\
\hline Abutments & Seat Type & & \\
\hline Pier Systems & Concrete & & \\
\hline
\end{tabular}


4. Do you have typical standards for cross-section widths and girder spacings? If so, please provide.

No

5. Do you have different design specifications for low-volume roads versus high-volume roads? If so, what are they?

California Bridge Design Specifications, LFC Version, April, 2000. http:/www.dot.ca.gov/ho/esc/techpubs/manual/bridgemanuals/bridge-designspecifications/bds.html

California Amendments (2008) to AASHTO LRFD Bridge Design Specifications, $4^{\text {th }}$ Edition (2007)

http://www.dot.ca.gov/hq/esc/techpubs/manual/bridgemanuals/ca-to-aashto-Irfdbds/caalbds v4.html

6. Do you use any bridge analysis or design software? If so, what brand of software is used?

MDX

7. Do you use any bridge design/component standards (or templates)? Examples may include beam sizes for different span lengths and roadway widths. If you have any, are they available on the web?

No.

8. Do you use modular bridge systems?

Sometime for temporary bridges

9. If a best practices manual for accelerated construction/modular bridge systems was developed, what would you like to see included? For example pre-selected beam sizes, cross-sections, etc. 
Pre-selected beam size, cross sections and all superstructure details.

10. Do you use the AASHTO LRFD specified load factors/combinations or different load factors/combinations? If different, what are they?

Yes - some specified LRFD load factors and combinations are used.

No. - See California Amendments (2008) to AASHTO LRFD Bridge Design Specifications, $4^{\text {th }}$ Edition (2007)

http:/www.dot.ca.gov/ho/esc/techpubs/manual/bridgemanuals/ca-to-aashto-Irfdbds/caalbds v4.html

11. Would a table outlining pre-selected steel beam sizes and shapes for given span lengths based on AASHTO LRFD Bridge Design Specifications be useful for assisting in your design development process?

Yes.

12. What is your preferred material choice for short-span bridges? Why?

Depends on so many factors. Precast prestressed concrete may be more economical and better to maintain.

13. Are there any other comments that you have that you feel might be relevant to this study? 
14. What are your most important sources for bridge design and construction technical information and industry news? (Circle which are relevant)

- INDUSTRY PUBLICATIONS/WEB SITES:

- ENR

- Roads and Bridges

- GoBridges.com

- Better Roads (BetterRoads.com)

- Journal of Structural Engineering

- Public Works Magazine

- Engineering Journal

- Public Roads

- Design Engineering

- Government Engineering (GovEngr.com)

- Civil Engineering

- CE News

- INDUSTRY CONFERENCES (name which ones) Western Bridge Engineers' Seminar

World Steel Bridge Symposium

- PROFESSIONAL ORGANIZATION NEWSLETTER?

- NACE?

- Others?

- WEB SITES

- FHWA

- steel.org

- Steelbridges.org

- Others? 


\section{Research Statement}

The Federal Highway Administration in conjunction with the American Iron and Steel Institute [AISI] has recently conducted two workshops focused on developing ideas for improved steel bridge construction. One of the target areas of these workshops has been to develop design standards for short span steel bridges. As a result, the AISI Short Span Steel Bridge Alliance has contracted with Dr. Karl Barth at West Virginia University to conduct a survey of State DOT's and County Engineers. The focus of this survey is to study and catalog statistics and methods employed in short-span bridge design and construction. The overall projected outcome of this research is a best practices manual for the design and construction of short-span steel bridges (i.e. bridges up to $140 \mathrm{ft}$.) and a table outlining suggested pre-selected steel beam sizes and shapes for given span lengths.

\section{Part I. General Information}

Date: December 3,2009

Time: 9:05 AM

Agency / DOH: Colorado DOT

Name: Teddy Meshesha

Position / Title: Staff Bridge/ PEI

Address: 4201 E. Arkansas Ave. Rm\# 107

Denver, Colorado 80222

Phone: $\quad \underline{303-757-9046}$

E-mail: tawedrose.meshesha@dot.state.co.us

Other Information: 


\section{Part II. General Questions}

1. If possible, please provide a list of bridges built in your region in the past year along with their respective span lengths, whether they are simple or continuous span, cross-section widths and any other general information you can offer (ADT, wearing surface, deck and superstructure choices, substructure and pier choices, number of lanes, etc.).

2. If information for question 1 is not readily available, please provide us with the following information: How many bridges were built in your region in the past year in the following length categories? Also, of those, how many bridges consisted of steel superstructures?

\begin{tabular}{|l|c|c|}
\hline Length Category & Nimber of Bitages & Stea Superstucures \\
\hline$<40 \mathrm{ft}$ & 17 & 2 \\
\hline $40-60 \mathrm{ft}$ & 9 & 0 \\
\hline $60-80 \mathrm{ft}$ & 11 & 1 \\
\hline $80-100 \mathrm{ft}$ & 7 & 0 \\
\hline $100-120 \mathrm{ft}$ & 7 & 1 \\
\hline $120-140 \mathrm{ft}$ & 17 & 0 \\
\hline$>140 \mathrm{ft}$ & 77 & 6 \\
\hline
\end{tabular}

The figures given are for the last 5 vears and total bridge length. The number of bridges and length vary widely from year to year. A given bridge can have spans of different lengths, therefore total bridge length given here. 
3. For the following bridge components, please specify whether you have a preferred/specified type of design and whether or not there are any particular types of bridge component that you do not approve:

\begin{tabular}{|c|c|c|c|}
\hline $\begin{array}{l}\text { Bridge } \\
\text { Componcht }\end{array}$ & Preficrence & $\begin{array}{l}\text { Types } \\
\text { Disapproved }\end{array}$ & $\begin{array}{l}\text { Brite } \\
\text { Explanation }\end{array}$ \\
\hline Decking Systems & $\begin{array}{l}\text { Circle Choice } \\
\text { Cast-in-place } \\
\text { concrete } \\
\text { Precast concrete } \\
\text { panels } \\
\text { Steel stay-in-place } \\
\text { formwork } \\
\text { Other (list): } \\
\text { All of the above }\end{array}$ & & \\
\hline $\begin{array}{l}\text { Railing/Guardrail } \\
\text { Systems }\end{array}$ & $\begin{array}{l}\text { See the link } \\
\text { http://www.dot.state.co.us/Bridge/Worksheets/DGN/Sheet B- } \\
606-10 . \text { dgn }\end{array}$ & & \\
\hline $\begin{array}{l}\text { Topping/Wearing } \\
\text { Surfaces }\end{array}$ & $\begin{array}{l}\text {-membrane \& HBP generally preferred. } \\
\text {-thin bonded overlay. } \\
\text {-bare deck often used when approach roadway is bare } \\
\text { concrete. }\end{array}$ & & \\
\hline $\begin{array}{l}\text { Bridge } \\
\text { Superstructures }\end{array}$ & No preference & & \\
\hline Abutments & No preference & & \\
\hline Pier Systems & No preference & & \\
\hline
\end{tabular}


4. Do you have typical standards for cross-section widths and girder spacings? If so, please provide.

No. Developing for steel. See the link

http://www.dot.state.co.us/Bridge/DesignManual/dm s09.pdf

5. Do you have different design specifications for low-volume roads versus high-volume roads? If so, what are they?

$\underline{\text { No }}$

6. Do you use any bridge analysis or design software? If so, what brand of software is used?

Opis/Virtis, MDX, Larsa, LEAP products

7. Do you use any bridge design/component standards (or templates)? Examples may include beam sizes for different span lengths and roadway widths. If you have any, are they available on the web?

See 4 above

8. Do you use modular bridge systems?

Modular combined deck \& girder systems only occasionally used.

9. If a best practices manual for accelerated construction/modular bridge systems was developed, what would you like to see included? For example pre-selected beam sizes, cross-sections, etc.

Out-to-Out Width, Length, Depth of superstructure, etc

10. Do you use the AASHTO LRFD specified load factors/combinations or different load factors/combinations? If different, what are they?

As specified by AASHTO specs.

11. Would a table outlining pre-selected steel beam sizes and shapes for given span lengths based on AASHTO LRFD Bridge Design Specifications be useful for assisting in your design development process?

$\underline{Y e s}$ 
12. What is your preferred material choice for short-span bridges? Why? No Preference, designers are required to consider steel, CIP and Precast concrete.

13. Are there any other comments that you have that you feel might be relevant to this study? 
14. What are your most important sources for bridge design and construction technical information and industry news? AASHTO, FHWA, NSBA, PCI, and other industrv Organization such as AISI.

(Circle which are relevant)

- INDUSTRY PUBLICATIONS/WEB SITES:

- ENR

- Roads and Bridges

- GoBridges.com

- Better Roads (BetterRoads.com)

- Journal of Structural Engineering

- Transportation Builder

- Public Works Magazine

- Engineering Journal

- Public Roads

- Design Engineering

- Government Engineering (GovEngr.com)

- Civil Engineering

- CE News

- Others?

- INDUSTRY CONFERENCES (name which ones)

- PROFESSIONAL ORGANIZATION NEWSLETTER?

- NACE?

- Others?

- WEB SITES

- FHWA

- steel.org

- Steelbridges.org

- Others? 


\section{Research Statement}

The Federal Highway Administration in conjunction with the American Iron and Steel Institute [AISI] has recently conducted two workshops focused on developing ideas for improved steel bridge construction. One of the target areas of these workshops has been to develop design standards for short span steel bridges. As a result, the AISI Short Span Steel Bridge Alliance has contracted with Dr. Karl Barth at West Virginia University to conduct a survey of State DOT's and County Engineers. The focus of this survey is to study and catalog statistics and methods employed in short-span bridge design and construction. The overall projected outcome of this research is a best practices manual for the design and construction of short-span steel bridges (i.e. bridges up to $140 \mathrm{ft}$.) and a table outlining suggested pre-selected steel beam sizes and shapes for given span lengths.

\section{Part I. General Information}

Date: $11 / 16 / 09$

Time: 11:20AM

Agency / DOH: Delaware Department of Transportation

Name: Jiten K. Soneji

Position / Title: Bridge Design Engineer

Address: DelDOT

P.O.Box 778, Dover, DE 19903

Phone: (302) 760-2299

E-mail: jiten.soneji@state.de.us

Other Information: 


\section{Part II. General Questions}

1. If possible, please provide a list of bridges built in your region in the past year along with their respective span lengths, whether they are simple or continuous span, cross-section widths and any other general information you can offer (ADT, wearing surface, deck and superstructure choices, substructure and pier choices, number of lanes, etc.).

2. If information for question 1 is not readily available, please provide us with the following information: How many bridges were built in your region in the past year in the following length categories? Also, of those, how many bridges consisted of steel superstructures?

\begin{tabular}{|l|c|c|}
\hline Length Category & Mrmber of Widges & W Sred Supertrictures \\
\hline$<40 \mathrm{ft}$ & 1 & \\
\hline $40-60 \mathrm{ft}$ & 1 & 1 \\
\hline $60-80 \mathrm{ft}$ & & \\
\hline $80-100 \mathrm{ft}$ & 1 & \\
\hline $100-120 \mathrm{ft}$ & & \\
\hline $120-140 \mathrm{ft}$ & & \\
\hline
\end{tabular}


3. For the following bridge components, please specify whether you have a preferred/specified type of design and whether or not there are any particular types of bridge component that you do not approve:

\begin{tabular}{|c|c|c|c|}
\hline 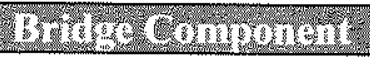 & Brorongs & 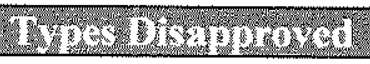 & 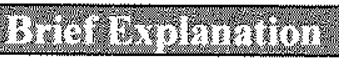 \\
\hline Decking Systems & $\begin{array}{l}\text { Circle Choice } \\
\text { Cast-in-place } \\
\text { concrete } \\
\text { Precast concrete } \\
\text { panels } \\
\text { Steel stay-in-place } \\
\text { formwork } \\
\text { Other (list): }\end{array}$ & & \\
\hline $\begin{array}{l}\text { Railing/Guardrail } \\
\text { Systems }\end{array}$ & $\begin{array}{l}\text { Concrete F-Shape } \\
\text { barrier }\end{array}$ & & \\
\hline $\begin{array}{l}\text { Topping/Wearing } \\
\text { Surfaces }\end{array}$ & Concrete deck & & \\
\hline $\begin{array}{l}\text { Bridge } \\
\text { Superstructures }\end{array}$ & $\begin{array}{l}\text { Steel beam/girder, } \\
\text { prestressed concrete } \\
\text { bulb-t, prestressed } \\
\text { concrete box } \\
\text { beam/voided slab }\end{array}$ & & \\
\hline Abutments & $\begin{array}{l}\text { Full-height and } \\
\text { half-height integral, } \\
\text { full-height and half- } \\
\text { height cast-in-place, } \\
\text { stub abutments } \\
\text { behind MSE walls }\end{array}$ & & \\
\hline Pier Systems & $\begin{array}{l}\text { Pile bents, concrete } \\
\text { columns }\end{array}$ & & $\begin{array}{l}\text { Integral piers are } \\
\text { allowed but not } \\
\text { preferred }\end{array}$ \\
\hline
\end{tabular}


4. Do you have typical standards for cross-section widths and girder spacings? If so, please provide. acceptable.

No standards. Our Bridge Design Manual gives ranges for what is

5. Do you have different design specifications for low-volume roads versus high-volume roads? If so, what are they?

We follow the AASHTO Green Book and use AASHTO's design guide for low volume roads where necessary

6. Do you use any bridge analysis or design software? If so, what brand of software is used?

PSLRFD, STLRFD, PAPIER, DESCUS, MERLIN-DASH, PGSUPER, QCONBRIDGE, BRASS, STAAD

7. Do you use any bridge design/component standards (or templates)? Examples may include beam sizes for different span lengths and roadway widths. If you have any, are they available on the web?

No

8. Do you use modular bridge systems?

We use prefab bridges for pedestrian bridges. We have used ACROW bridges for emergency bridge replacements in the past. 
9. If a best practices manual for accelerated construction/modular bridge systems was developed, what would you like to see included? For example pre-selected beam sizes, cross-sections, etc.

10. Do you use the AASHTO LRFD specified load factors/combinations or different load factors/combinations? If different, what are they?

We strictly adhere to AASHTO

LRFD

11. Would a table outlining pre-selected steel beam sizes and shapes for given span lengths based on AASHTO LRFD Bridge Design Specifications be useful for assisting in your design development process?

Yes

12. What is your preferred material choice for short-span bridges? Why?

Prestressed adjacent box beams due to cost effectiveness, ease of construction, and low profile

13. Are there any other comments that you have that you feel might be relevant to this study? 
14. What are your most important sources for bridge design and construction technical information and industry news? (Circle which are relevant)

- INDUSTRY PUBLICATIONS/WEB SITES:

- ENR

- Roads and Bridges

- GoBridges.com

- Better Roads (BetterRoads.com)

- Journal of Structural Engineering

- Transportation Builder

- Public Works Magazine

- Engineering Journal

- Public Roads

- Design Engineering

- Government Engineering (GovEngr.com)

- Civil Engineering

- CE News

- Others?

- INDUSTRY CONFERENCES (name which ones)

- PROFESSIONAL ORGANIZATION NEWSLETTER?

- NACE?

- Others?

- WEB SITES

- FHWA

- steel.org

- Steelbridges.org

- Others? 


\section{Research Statement}

The Federal Highway Administration in conjunction with the American Iron and Steel Institute [AISI] has recently conducted two workshops focused on developing ideas for improved steel bridge construction. One of the target areas of these workshops has been to develop design standards for short span steel bridges. As a result, the AISI Short Span Steel Bridge Alliance has contracted with Dr. Karl Barth at West Virginia University to conduct a survey of State DOT's and County Engineers. The focus of this survey is to study and catalog statistics and methods employed in short-span bridge design and construction. The overall projected outcome of this research is a best practices manual for the design and construction of short-span steel bridges (i.e. bridges up to $140 \mathrm{ft}$.) and a table outlining suggested pre-selected steel beam sizes and shapes for given span lengths.

\section{Part I. General Information}

Date: November 12, 2009

Time:

Agency / DOH: FDOT

Name: Robert Robertson

Position / Title: State Structures Design Engineer

Address: 605 Suwannee St MS 33

Phone: (850) 414-4267

E-mail:Robert.Robertson2@dot.state.fl.us

Other Information: 


\section{Part II. General Questions}

1. If possible, please provide a list of bridges built in your region in the past year along with their respective span lengths, whether they are simple or continuous span, cross-section widths and any other general information you can offer (ADT, wearing surface, deck and superstructure choices, substructure and pier choices, number of lanes, etc.).

2. If information for question 1 is not readily available, please provide us with the following information: How many bridges were built in your region in the past year in the following length categories? Also, of those, how many bridges consisted of steel superstructures?

\begin{tabular}{|l|l|l|}
\hline Lengh Categon: & Nomber a infiges & W Stec Superstructures \\
\hline$<40 \mathrm{ft}$ & & \\
\hline $40-60 \mathrm{ft}$ & & \\
\hline $60-80 \mathrm{ft}$ & & \\
\hline $80-100 \mathrm{ft}$ & & \\
\hline $100-120 \mathrm{ft}$ & & \\
\hline $120-140 \mathrm{ft}$ & & \\
\hline
\end{tabular}


3. For the following bridge components, please specify whether you have a preferred/specified type of design and whether or not there are any particular types of bridge component that you do not approve:

\begin{tabular}{|c|c|c|c|}
\hline Bribge Combontur & Broromente & 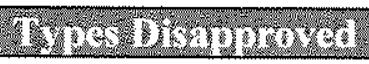 & Brof bothingros \\
\hline Decking Systems & $\begin{array}{l}\text { Cast-in-place } \\
\text { concrete }\end{array}$ & $\begin{array}{l}\text { Precast panels with } \\
\text { toppings }\end{array}$ & \\
\hline $\begin{array}{l}\text { Railing/Guardrail } \\
\text { Systems }\end{array}$ & $\begin{array}{l}\text { Cast-in-place } \\
\text { concrete }\end{array}$ & $\begin{array}{l}\text { Permanent precast } \\
\text { systems }\end{array}$ & \\
\hline $\begin{array}{l}\text { Topping/Wearing } \\
\text { Surfaces }\end{array}$ & None used & & \\
\hline $\begin{array}{l}\text { Bridge } \\
\text { Superstructures }\end{array}$ & $\begin{array}{l}\text { Precast beams with } \\
\text { CIP decks }\end{array}$ & & \\
\hline Abutments & $\begin{array}{l}\text { Cast-in-place } \\
\text { concrete }\end{array}$ & & \\
\hline Pier Systems & $\begin{array}{l}\text { Cast-in-place } \\
\text { concrete }\end{array}$ & & $\begin{array}{l}\text { Precast allowed } \\
\text { but is not usually } \\
\text { economical choice }\end{array}$ \\
\hline
\end{tabular}


4. Do you have typical standards for cross-section widths and girder spacings? If so, please provide.

no,

optimized

each

bridge

5. Do you have different design specifications for low-volume roads versus high-volume roads? If so, what are they?

all bridges built to LRFD

standards

6. Do you use any bridge analysis or design software? If so, what brand of software is used?

7. Do you use any bridge design/component standards (or templates)? Examples may include beam sizes for different span Iengths and roadway widths. If you have any, are they available on the web?

Florida has a family of precast prestressed girders from 36" to 78" height spanning

to

over $170^{\prime}$

8. Do you use modular bridge systems?

\begin{tabular}{lllll} 
used & very & rarely & but & are \\
\hline allowed & & & \\
\hline
\end{tabular}

9. If a best practices manual for accelerated construction/modular bridge systems was developed, what would you like to see included? For example pre-selected beam sizes, cross-sections, etc. 
predetermined sizes rarely take advantage of optimization and thus can lead to cost increases. We would be interested in evaluation the manual for possible

use

10. Do you use the AASHTO LRFD specified load factors/combinations or different load factors/combinations? If different, what are they? Standard

LRFD

11. Would a table outlining pre-selected steel beam sizes and shapes for given span lengths based on AASHTO LRFD Bridge Design Specifications be useful for assisting in your design development process?

FDOT rarely uses steel beams for any short span bridge. Concrete is cheaper

12. What is your preferred material choice for short-span bridges? Why?

Precast prestressed Concrete___ due to initial cost and is essentially maintenance

free

13. Are there any other comments that you have that you feel might be relevant to this study? 
14. What are your most important sources for bridge design and construction technical information and industry news? (Circle which are relevant)

- INDUSTRY PUBLICATIONS/WEB SITES:

- ENR

- Roads and Bridges

- GoBridges.com

- Better Roads (BetterRoads.com)

- Journal of Structural Engineering

- Transportation Builder

- Public Works Magazine

- Engineering Journal

- Public Roads

- Design Engineering

- Government Engineering (GovEngr.com)

- Civil Engineering

- CE News

- Others?

- INDUSTRY CONFERENCES (name which ones)

- PROFESSIONAL ORGANIZATION NEWSLETTER?

- NACE?

- Others?

- WEB SITES

- FHWA

- steel.org

- Steelbridges.org

- Others? 


\section{Research Statement}

The Federal Highway Administration in conjunction with the American Iron and Steel Institute [AISI] has recently conducted two workshops focused on developing ideas for improved steel bridge construction. One of the target areas of these workshops has been to develop design standards for short span steel bridges. As a result, the AISI Short Span Steel Bridge Alliance has contracted with Dr. Karl Barth at West Virginia University to conduct a survey of State DOT's and County Engineers. The focus of this survey is to study and catalog statistics and methods employed in short-span bridge design and construction. The overall projected outcome of this research is a best practices manual for the design and construction of short-span steel bridges (i.e. bridges up to $140 \mathrm{ft}$.) and a table outlining suggested pre-selected steel beam sizes and shapes for given span lengths.

\section{Part I. General Information}

Date: May 4, 2010

Time: 5:30 P.M.

Agency/DOH: Georgia DOT

Name: Paul V. Liles, Jr.

Position / Title: State Bridge Engineer

Address: 600 West Peachtree Street, $24^{\text {th }}$ Floor Atlanta, GA 30308

Phone: (404) 631-1882

E-mail: pliles@dot.ga.gov

Other Information: 


\section{Part II. General Questions}

1. If possible, please provide a list of bridges built in your region in the past year along with their respective span lengths, whether they are simple or continuous span, cross-section widths and any other general information you can offer (ADT, wearing surface, deck and superstructure choices, substructure and pier choices, number of lanes, etc.).

2. If information for question 1 is not readily available, please provide us with the following information: How many bridges were built in your region in the past year in the following length categories? Also, of those, how many bridges consisted of steel superstructures?

\begin{tabular}{|c|c|c|}
\hline Wouth Cargenx & Ninber buthes & Wilstel stupertromes \\
\hline$<40 \mathrm{ft}$ & 0 & 0 \\
\hline $40-60 \mathrm{ft}$ & 1 & 0 \\
\hline $60-80 \mathrm{ft}$ & 0 & 0 \\
\hline $80-100 \mathrm{ft}$ & 0 & 0 \\
\hline $100-120 \mathrm{ft}$ & 3 & 0 \\
\hline $120-140 \mathrm{ft}$ & 0 & 0 \\
\hline
\end{tabular}


3. For the following bridge components, please specify whether you have a preferred/specified type of design and whether or not there are any particular types of bridge component that you do not approve:

\begin{tabular}{|c|c|c|c|}
\hline Bridge Component & Preferenge: & 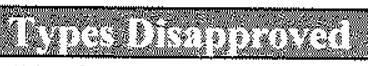 & Bref Bxplantion \\
\hline Decking Systems & $\begin{array}{l}\text { Circle Choice } \\
\text { Cast-in-place } \\
\text { concrete } \\
\text { Steel stay-in-place } \\
\text { formwork }\end{array}$ & Timber & \\
\hline $\begin{array}{l}\text { Railing/Guardrail } \\
\text { Systems }\end{array}$ & Concrete Barrier & & Low maintenance \\
\hline $\begin{array}{l}\text { Topping/Wearing } \\
\text { Surfaces }\end{array}$ & None & & \\
\hline $\begin{array}{l}\text { Bridge } \\
\text { Superstructures }\end{array}$ & $\begin{array}{l}\text { PSC Beams w/ } \\
\text { concrete deck }\end{array}$ & & \\
\hline Abutments & Concrete abutments & & \\
\hline Pier Systems & $\begin{array}{l}\text { Concrete bents } \\
\text { Pile bents }\end{array}$ & & \\
\hline
\end{tabular}


4. Do you have typical standards for cross-section widths and girder spacings? If so, please provide.

None

5. Do you have different design specifications for low-volume roads versus high-volume roads? If so, what are they?

low volume road bridges are slightly narrower than high volume road bridges.

6. Do you use any bridge analysis or design software? If so, what brand of software is used?

Yes,

$\underline{\text { In-house-programs }}$

7. Do you use any bridge design/component standards (or templates)? Examples may include beam sizes for different span lengths and roadway widths. If you have any, are they available on the web? No

8. Do you use modular bridge systems?

No

9. If a best practices manual for accelerated construction/modular bridge systems was developed, what would you like to see included? For example pre-selected beam sizes, cross-sections, etc.

No, no preference 
10. Do you use the AASHTO LRFD specified load factors/combinations or different load factors/combinations? If different, what are they?

AASHTO LRFD

11. Would a table outlining pre-selected steel beam sizes and shapes for given span lengths based on AASHTO LRFD Bridge Design Specifications be useful for assisting in your design development process?

Perhaps it might be useful

12. What is your preferred material choice for short-span bridges? Why? PSC Concrete - because it is low maintenance

13. Are there any other comments that you have that you feel might be relevant to this study?

None 
14. What are your most important sources for bridge design and construction technical information and industry news? (Circle which are relevant)

- INDUSTRY PUBLICATIONS/WEB SITES:

- ENR - XX

- Roads and Bridges

- GoBridges.com

- Better Roads (BetterRoads.com)

- Journal of Structural Engineering

- Transportation Builder

- Public Works Magazine

- Engineering Journal

- Public Roads

- Design Engineering

- Government Engineering (GovEngr.com)

- Civil Engineering

- CE News

- Others?

- INDUSTRY CONFERENCES (name which ones) AASHTO, TRB, ASBI

- PROFESSIONAL ORGANIZATION NEWSLETTER? ASBI

- NACE?

- Others?

- WEB SITES - None

- FHWA

- steel.org

- Steelbridges.org

- Others? 


\section{$\underline{\text { Research Statement }}$}

The Federal Highway Administration in conjunction with the American Iron and Steel Institute [AISI] has recently conducted two workshops focused on developing ideas for improved steel bridge construction. One of the target areas of these workshops has been to develop design standards for short span steel bridges. As a result, the AISI Short Span Steel Bridge Alliance has contracted with Dr. Karl Barth at West Virginia University to conduct a survey of State DOT's and County Engineers. The focus of this survey is to study and catalog statistics and methods employed in short-span bridge design and construction. The overall projected outcome of this research is a best practices manual for the design and construction of short-span steel bridges (i.e. bridges up to $140 \mathrm{ft}$.) and a table outlining suggested pre-selected steel beam sizes and shapes for given span lengths.

\section{Part I. General Information}

Date:

Time:

Agency / DOH: Hawaii DOT

Name: Paul Santo

Position/Title: Bridge Design Engineer

Address: 601 Kamokila Blvd., Rm. 611

Kapolei, Hawaii 96707

Phone: 808-692-7611

E-mail: paul.santo@hawaii.gov

Other Information: 


\section{Part II. General Questions}

1. If possible, please provide a list of bridges built in your region in the past year along with their respective span lengths, whether they are simple or continuous span, cross-section widths and any other general information you can offer (ADT, wearing surface, deck and superstructure choices, substructure and pier choices, number of lanes, etc.).

2. If information for question 1 is not readily available, please provide us with the following information: How many bridges were built in your region in the past year in the following length categories? Also, of those, how many bridges consisted of steel superstructures?

\begin{tabular}{|l|l|l|}
\hline Leingin Category & Number of Brifges & W Sted Superctuctures \\
\hline$<40 \mathrm{ft}$ & & \\
\hline $40-60 \mathrm{ft}$ & 1 & 0 \\
\hline $60-80 \mathrm{ft}$ & 1 & 0 \\
\hline $80-100 \mathrm{ft}$ & & \\
\hline $100-120 \mathrm{ft}$ & & \\
\hline $120-140 \mathrm{ft}$ & & \\
\hline
\end{tabular}


3. For the following bridge components, please specify whether you have a preferred/specified type of design and whether or not there are any particular types of bridge component that you do not approve:

\begin{tabular}{|c|c|c|c|}
\hline Detge Commutent & Dreferents & 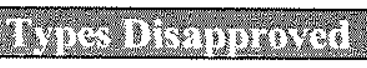 & Brol Bromberton \\
\hline Decking Systems & $\begin{array}{l}\text { Circle Choice } \\
\text { Cast-in-place } \\
\text { concrete }\end{array}$ & & \\
\hline $\begin{array}{l}\text { Railing/Guardrail } \\
\text { Systems }\end{array}$ & CIP Concrete & & \\
\hline $\begin{array}{l}\text { Topping/Wearing } \\
\text { Surfaces }\end{array}$ & CIP Concrete & & \\
\hline $\begin{array}{l}\text { Bridge } \\
\text { Superstructures }\end{array}$ & $\begin{array}{l}\text { Precast prestressed } \\
\text { girders with CIP } \\
\text { concrete deck slabs. }\end{array}$ & & \\
\hline Abutments & CIP Concrete & & \\
\hline Pier Systems & ClP Concrete & & \\
\hline
\end{tabular}


4. Do you have typical standards for cross-section widths and girder spacings? If so, please provide.

No

5. Do you have different design specifications for low-volume roads versus high-volume roads? If so, what are they?

No

6. Do you use any bridge analysis or design software? If so, what brand of software is used?

SAP2000 for analysis \& BRASS for load rating

7. Do you use any bridge design/component standards (or templates)? Examples may include beam sizes for different span lengths and roadway widths. If you have any, are they available on the web?

No

8. Do you use modular bridge systems?

Generally use ACROW for temporary bridges.

9. If a best practices manual for accelerated construction/modular bridge systems was developed, what would you like to see included? For example pre-selected beam sizes, cross-sections, etc.

No preference. 
10. Do you use the AASHTO LRFD specified load factors/combinations or different load factors/combinations? If different, what are they?

AASHTO LRFD

11. Would a table outlining pre-selected steel beam sizes and shapes for given span lengths based on AASHTO LRFD Bridge Design Specifications be useful for assisting in your design development process?

Yes

12. What is your preferred material choice for short-span bridges? Why?

For permanent bridges, we use concrete. The main reason is maintenance.

13. Are there any other comments that you have that you feel might be relevant to this study? 
14. What are your most important sources for bridge design and construction technical information and industry news? (Circle which are relevant)

- INDUSTRY PUBLICATIONS/WEB SITES:

- ENR

- Roads and Bridges

- GoBridges.com

- Better Roads (BetterRoads.com)

- Journal of Structural Engineering

- Transportation Builder

- Public Works Magazine

- Engineering Journal

- Public Roads

- Design Engineering

- Government Engineering (GovEngr.com)

- Civil Engineering

- CE News

- Others?

Roads and Bridges, Better Roads, PCI Journal, Concrete International.

- INDUSTRY CONFERENCES (name which ones) AASHTO Subcommittee on Bridges and Structures Meeting

- PROFESSIONAL ORGANIZATION NEWSLETTER?

- NACE?

- Others?

- WEB SITES

- FHWA

- steel.org

- Steelbridges.org

- Others? 


\section{Research Statement}

The Federal Highway Administration in conjunction with the American Iron and Steel Institute [AISI] has recently conducted two workshops focused on developing ideas for improved steel bridge construction. One of the target areas of these workshops has been to develop design standards for short span steel bridges. As a result, the AISI Short Span Steel Bridge Alliance has contracted with Dr. Karl Barth at West Virginia University to conduct a survey of State DOT's and County Engineers. The focus of this survey is to study and catalog statistics and methods employed in short-span bridge design and construction. The overall projected outcome of this research is a best practices manual for the design and construction of short-span steel bridges (i.e. bridges up to $140 \mathrm{ft}$.) and a table outlining suggested pre-selected steel beam sizes and shapes for given span lengths.

\section{Part I. General Information}

Date: $11-16-09$

Time:

Agency / DOH: Idaho Transportation Department

Name: Matt Farrar

Position / Title: State Bridge Engineer

Address: PO Box 7129

Boise, ID 83707

Phone: 208-334-8538

E-mail: matt.farrar@itd.idaho.gov

Other Information: 


\section{Part II. General Questions}

1. If possible, please provide a list of bridges built in your region in the past year along with their respective span lengths, whether they are simple or continuous span, cross-section widths and any other general information you can offer (ADT, wearing surface, deck and superstructure choices, substructure and pier choices, number of lanes, etc.).

2. If information for question 1 is not readily available, please provide us with the following information: How many bridges were built in your region in the past year in the following length categories? Also, of those, how many bridges consisted of steel superstructures?

\begin{tabular}{|c|c|c|}
\hline 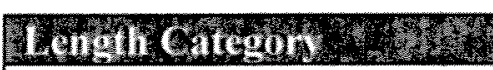 & Sunberborbridses & 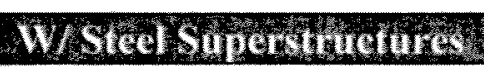 \\
\hline$<40 \mathrm{ft}$ & (9) & \\
\hline $40-60 \mathrm{ft}$ & , & (1) \\
\hline $60-80 \mathrm{ft}$ & 111 & \\
\hline $80-100 \mathrm{ft}$ & 11 & \\
\hline $100-120 \mathrm{ft}$ & & \\
\hline $120-140 \mathrm{ft}$ & 111111111111110 & 11111 \\
\hline
\end{tabular}


3. For the following bridge components, please specify whether you have a preferred/specified type of design and whether or not there are any particular types of bridge component that you do not approve:

\begin{tabular}{|c|c|c|c|}
\hline Bridge Compionefit & Preforence & 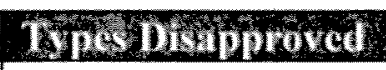 & Brief Dxplanation \\
\hline Decking Systems & $\begin{array}{l}\text { Cast-in-place } \\
\begin{array}{c}\text { Precast concrete } \\
\text { panels }\end{array} \\
\begin{array}{c}\text { Steel stay-in-place } \\
\text { formwork }\end{array} \\
\text { Other (list): }\end{array}$ & $\begin{array}{l}\text { Corcrete } \\
\text { Precastipanels }\end{array}$ & $\begin{array}{l}\text { contractors aren' } \\
\text { - Generd not us } \\
\text { as viewed by } \\
\text { as more expan }\end{array}$ \\
\hline $\begin{array}{l}\text { Railing/Guardrail } \\
\text { Systems }\end{array}$ & $\begin{array}{l}\text { - Conrete } \\
\text { versey-face kail } \\
\text { otwo-tube mitl }\end{array}$ & 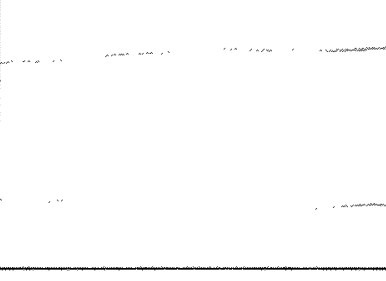 & $\begin{array}{l}\text { anarally profes } \\
\text { viewed as more } \\
\text { pleasing, moree }\end{array}$ \\
\hline $\begin{array}{l}\text { Topping/Wearing } \\
\text { Surfaces }\end{array}$ & $\begin{array}{l}\text {-bare deck } \\
\text { in general }\end{array}$ & & \\
\hline $\begin{array}{l}\text { Bridge } \\
\text { Superstructures }\end{array}$ & $\begin{array}{l}\text { prentressed } \\
\text { concrete } \\
\text { geselro in this } \\
\text { renge } 40^{\prime}-140^{\circ}\end{array}$ & & \\
\hline Abutments & $\begin{array}{l}\text { integrat } \\
\text { costinplaie } \\
\text { an piting }\end{array}$ & & \\
\hline Pier Systems & $\begin{array}{l}\text { Wall piers, } \\
\text { Hawimer haied } \\
\text { piewt on } \\
\text { H-pilus }\end{array}$ & & \\
\hline
\end{tabular}


4. Do you have typical standards for cross-section widths and girder spacings? If so, please provide.

No

5. Do you have different design specifications for low-volume roads versus high-volume roads? If so, what are they?

No, CRFD HL-93

6. Do you use any bridge analysis or design software? If so, what brand of software is used?

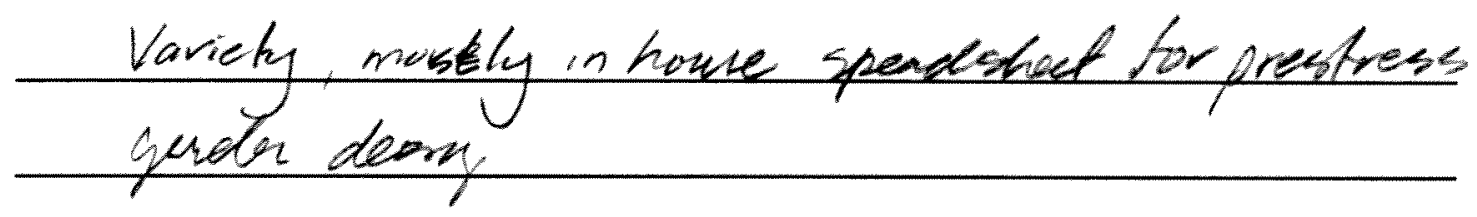

7. Do you use any bridge design/component standards (or templates)? Examples may include beam sizes for different span lengths and roadway widths. If you have any, are they available on the web?

not so much, yes

8. Do you use modular bridge systems?

no

9. If a best practices manual for accelerated construction/modular bridge systems was developed, what would you like to see included? For example pre-selected beam sizes, cross-sections, etc.

substructure dotsils 
10. Do you use the AASHTO LRFD specified load factors/combinations or different load factors/combinations? If different, what are they?

we une CRFD

11. Would a table outlining pre-selected steel beam sizes and shapes for given span lengths based on AASHTO LRFD Bridge Design Specifications be useful for assisting in your design development process?

No

12. What is your preferred material choice for short-span bridges? Why?

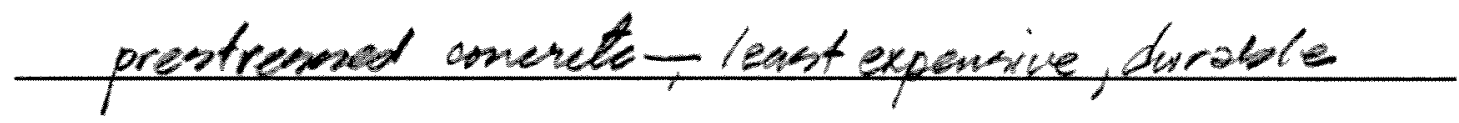

13. Are there any other comments that you have that you feel might be relevant to this study? 
14. What are your most important sources for bridge design and construction technical information and industry news? (Circle which are relevant)

- INDUSTRY RUBLICATIONS/WEB SITES:

- ENR

- Roads and Bridges

- GoBridges.com

- Better Roads (BetterRoads.com)

- Journal of Structural Engineering

- Transportation Builder

- Public Works Magazine

- Engineering Journal

- Public Roads

- Design Engineering

- Government Engineering (GovEngr.com)

- Civil Engineering

- CE News 2

- Others?

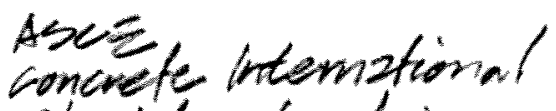

Modecu steel Construction

- INDUSTRY CONFERENCES (name which ones)

- PROFESSIONAL ORGANIZATION NEWSLETTER?

- NACE?

- Others? Phex

- WEB SITES

- FHWA

- steel.org

- Steelbridges.org

- Others? 


\section{$\underline{\text { Research Statement }}$}

The Federal Highway Administration in conjunction with the American Iron and Steel Institute [AISI] has recently conducted two workshops focused on developing ideas for improved steel bridge construction. One of the target areas of these workshops has been to develop design standards for short span steel bridges. As a result, the AISI Short Span Steel Bridge Alliance has contracted with Dr. Karl Barth at West Virginia University to conduct a survey of State DOT's and County Engineers. The focus of this survey is to study and catalog statistics and methods employed in short-span bridge design and construction. The overall projected outcome of this research is a best practices manual for the design and construction of short-span steel bridges (i.e. bridges up to $140 \mathrm{ft}$.) and a table outlining suggested pre-selected steel beam sizes and shapes for given span lengths.

\section{Part I. General Information}

Date: May 12, 2010

Time:

Agency / DOH: _ Structural Services / INDOT

Name: Anne Rearick

Position / Title: Manager

Address: IGCN Room N642, Indiana Department of Transportation,

100 N. Senate Ave., Indianapolis, IN 46204

Phone: $\quad 317-232-5152$

E-mail: _ARearick@indot.in.gov

Other Information: 


\section{Part II. General Questions}

1. If possible, please provide a list of bridges built in your region in the past year along with their respective span lengths, whether they are simple or continuous span, cross-section widths and any other general information you can offer (ADT, wearing surface, deck and superstructure choices, substructure and pier choices, number of lanes, etc.).

2. If information for question 1 is not readily available, please provide us with the following information: How many bridges were built in your region in the past year in the following length categories? Also, of those, how many bridges consisted of steel superstructures?

\begin{tabular}{|c|c|c|}
\hline Length Category & Number of Bridges & W/ Steel Superstructures \\
\hline & 9 INDOT & $0 \quad$ INDOT \\
\hline & & \\
\hline $40-60 \mathrm{ft}$ & $\begin{array}{ll}4 & \text { INDOT } \\
1 & \text { Local Agency }\end{array}$ & $\begin{array}{ll}0 & \text { INDOT } \\
0 & \text { Local Agency }\end{array}$ \\
\hline $60-80 \mathrm{ft}$ & $\begin{array}{l}14 \text { INDOT } \\
9 \text { Local Agency }\end{array}$ & $\begin{array}{ll}0 & \text { INDOT } \\
1 & \text { Local Agency }\end{array}$ \\
\hline $80-100 \mathrm{ft}$ & $\begin{array}{ll}6 & \text { INDOT } \\
5 & \text { Local Agency }\end{array}$ & $\begin{array}{ll}0 & \text { INDOT } \\
0 & \text { Local Agency }\end{array}$ \\
\hline $100-120 \mathrm{ft}$ & $\begin{array}{ll}5 & \text { INDOT } \\
5 & \text { Local Agency }\end{array}$ & $\begin{array}{ll}0 & \text { INDOT } \\
0 & \text { Local Agency }\end{array}$ \\
\hline $120-140 \mathrm{ft}$ & $\begin{array}{ll}3 & \text { INDOT } \\
5 & \text { Local Agency }\end{array}$ & $\begin{array}{ll}1 & \text { INDOT } \\
0 & \text { Local Agency }\end{array}$ \\
\hline$>140 \mathrm{ft}$ & $\begin{array}{l}42 \text { INDOT } \\
7 \text { Local Agency }\end{array}$ & $\begin{array}{ll}6 & \text { INDOT } \\
0 & \text { Local Agency }\end{array}$ \\
\hline Totals & $\begin{array}{ll}83 & \text { INDOT } \\
36 & \text { Local Agency }\end{array}$ & $\begin{array}{ll}7 & \text { INDOT } \\
1 & \text { Local Agency }\end{array}$ \\
\hline
\end{tabular}


3. For the following bridge components, please specify whether you have a preferred/specified type of design and whether or not there are any particular types of bridge component that you do not approve:

\begin{tabular}{|c|c|c|c|}
\hline Bridge Component & Preference & $\begin{array}{l}\text { Types } \\
\text { Disapproved }\end{array}$ & $\begin{array}{l}\text { Brief } \\
\text { Explanation }\end{array}$ \\
\hline Decking Systems & $\begin{array}{l}\text { Circle Choice } \\
\text { Cast-in-place concrete } \\
\text { Precast concrete panels } \\
\text { Steel stay-in-place } \\
\text { formwork } \\
\text { Other (list): }\end{array}$ & $\begin{array}{l}\text { Full depth not } \\
\text { allowed. }\end{array}$ & \\
\hline $\begin{array}{l}\text { Railing/Guardrail } \\
\text { Systems }\end{array}$ & Concrete Barrier & & \\
\hline $\begin{array}{l}\text { Topping/Wearing } \\
\text { Surfaces }\end{array}$ & $\begin{array}{l}\text { No toppings on new } \\
\text { construction }\end{array}$ & $\begin{array}{l}\text { Asphalt } \\
\text { overlays are not } \\
\text { normally } \\
\text { permitted }\end{array}$ & \\
\hline $\begin{array}{l}\text { Bridge } \\
\text { Superstructures }\end{array}$ & $\begin{array}{l}\text { RC Slab } \\
\text { Post-Tensioned Slab } \\
\text { Prestressed Beams } \\
\text { P-T Beams } \\
\text { Segmental Box Girders } \\
\text { Steel Beams } \\
\text { Steel Welded Plate Girders } \\
\text { Structure under fill }\end{array}$ & & \\
\hline Abutments & $\begin{array}{l}\text { Integral End Bents } \\
\text { Semi-Integral End Bents } \\
\text { Cantilever Abutment }\end{array}$ & & \\
\hline Pier Systems & $\begin{array}{l}\text { Wall Piers } \\
\text { Hammerhead Piers } \\
\text { Column and Cap Piers }\end{array}$ & & \\
\hline
\end{tabular}


4. Do you have typical standards for cross-section widths and girder spacings? If so, please provide.

No

5. Do you have different design specifications for low-volume roads versus high-volume roads? If so, what are they?

NHS routes have an importance factor of 1.05 , we also have some dimensional criteria that change based on $3 R$ and $4 R$ roadways, and some routes that allow different design truck axle loads and spacing.

6. Do you use any bridge analysis or design software? If so, what brand of software is used?

Merlin-Dash

7. Do you use any bridge design/component standards (or templates)? Examples may include beam sizes for different span lengths and roadway widths. If you have any, are they available on the web?

No

8. Do you use modular bridge systems?

No

9. If a best practices manual for accelerated construction/modular bridge systems was developed, what would you like to see included? For example pre-selected beam sizes, cross-sections, etc.

Connections / Bridge Seats required for attachment to substructure units.

Loads to be resisted by the substructure unit. Consider the effect that the modular unit might have on seismic loading criteria. 
10. Do you use the AASHTO LRFD specified load factors/combinations or different load factors/combinations? If different, what are they?

Yes

11. Would a table outlining pre-selected steel beam sizes and shapes for given span lengths based on AASHTO LRFD Bridge Design Specifications be useful for assisting in your design development process?

This would be helpful for cost comparisons when determining structure type

to use during project development.

12. What is your preferred material choice for short-span bridges? Why?

We don't have a preferred material for short span bridges. The type of

structure selected is based on historical cost data.

Our data indicates it is cost-effective for our agency to use prestressed

concrete beams for our superstructures at this short span range.

13. Are there any other comments that you have that you feel might be relevant to this study?

In our situation, we might benefit more from effort by the industry to help us minimize bid costs at larger span lengths. Steel in our experience has trouble competing at the larger span lengths where the steel industry normally expects to be successful in bidding competitions. 
14. What are your most important sources for bridge design and construction technical information and industry news? (Circle which are relevant)

- INDUSTRY PUBLICATIONS/WEB SITES:

- ENR

- Roads and Bridges

- GoBridges.com

- Better Roads (BetterRoads.com)

- Journal of Structural Engineering

- Transportation Builder

- Public Works Magazine

- Engineering Journal

- Public Roads

- Design Engineering

- Government Engineering (GovEngr.com)

- Civil Engineering

- CE News

- Others?

$\bullet$

- AASHTO publications

- AISC publications

- Modern Steel Construction

- Structure (SEI)

- other DOT Design Manuals

- misc internet sites

- INDUSTRY CONFERENCES (name which ones) AASHTO Conferences FHWA Courses

- PROFESSIONAL ORGANIZATION NEWSLETTER?

- NACE? No

- Others?

- WEB SITES

- FHWA

- steel.org

- Steelbridges.org

- Others?

-

- $\operatorname{AISC}$ (NSBA) 


\section{$\underline{\text { Research Statement }}$}

The Federal Highway Administration in conjunction with the American Iron and Steel Institute [AISI] has recently conducted two workshops focused on developing ideas for improved steel bridge construction. One of the target areas of these workshops has been to develop design standards for short span steel bridges. As a result, the AISI Short Span Steel Bridge Alliance has contracted with Dr. Karl Barth at West Virginia University to conduct a survey of State DOT's and County Engineers. The focus of this survey is to study and catalog statistics and methods employed in short-span bridge design and construction. The overall projected outcome of this research is a best practices manual for the design and construction of short-span steel bridges (i.e. bridges up to $140 \mathrm{ft}$.) and a table outlining suggested pre-selected steel beam sizes and shapes for given span lengths.

\section{Part I. General Information}

Date: $12-3-09$

Time: High Noon

Agency / DOH: Office of Bridges and Structures, Iowa DOT

Name: Dean Bierwagen

Position / Title: Final Design Section Leader

Address: 800 Lincoln Way, Ames, IA 50010

Phone: $515-239-1174$

E-mail: Dean.Bierwagen@dot.iowa.gov

Other Information: 


\section{Part II. General Questions}

1. If possible, please provide a list of bridges built in your region in the past year along with their respective span lengths, whether they are simple or continuous span, cross-section widths and any other general information you can offer (ADT, wearing surface, deck and superstructure choices, substructure and pier choices, number of lanes, etc.).

2. If information for question 1 is not readily available, please provide us with the following information: How many bridges were built in your region in the past year in the following length categories? Also, of those, how many bridges consisted of steel superstructures?

\begin{tabular}{|c|c|c|}
\hline 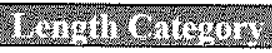 & 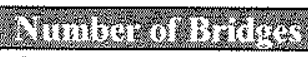 & 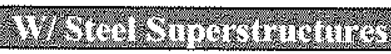 \\
\hline$<40 \mathrm{ft}$ & 0 & 0 \\
\hline $40-60 \mathrm{ft}$ & 0 & 0 \\
\hline $60-80 \mathrm{ft}$ & 0 & 0 \\
\hline $80-100 \mathrm{ft}$ & 1-Cont Conc Slab & 0 \\
\hline$>100-120 \mathrm{ft}$ & 8-Cont Conc Slab & 0 \\
\hline$>120-140 \mathrm{ft}$ & 3-Cont Conc Slab & 0 \\
\hline
\end{tabular}


3. For the following bridge components, please specify whether you have a preferred/specified type of design and whether or not there are any particular types of bridge component that you do not approve:

\begin{tabular}{|c|c|c|c|}
\hline Hotge crovronont & Wharomo & 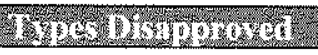 & 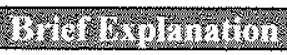 \\
\hline Decking Systems & $\begin{array}{l}\text { Circle Choice } \\
\frac{\text { Cast-in-place }}{\text { concrete }}\end{array}$ & $\begin{array}{l}\text { Steel stay-in-place } \\
\text { Formwork are not } \\
\text { allowed }\end{array}$ & $\begin{array}{l}\text { Precast concrete } \\
\text { Panels stay in } \\
\text { place forms-on low } \\
\text { volume roads only } \\
\text { for prestressed } \\
\text { concrete beams } \\
\text { only. Not allowed } \\
\text { on steel beams. }\end{array}$ \\
\hline $\begin{array}{l}\text { Railing/Guardrail } \\
\text { Systems }\end{array}$ & $\begin{array}{l}\text { F Section barrier } \\
\text { rail }\end{array}$ & & $\begin{array}{l}\text { Some steel rails for } \\
\text { special situations, } \\
\text { urban or aesthetics }\end{array}$ \\
\hline $\begin{array}{l}\text { Topping/Wearing } \\
\text { Surfaces }\end{array}$ & $\begin{array}{l}\text { Assume } 1 / 2 \text { in } \\
\text { wearing surface in } \\
\text { CIP deck }\end{array}$ & $\begin{array}{l}\text { MMA deck overlay is } \\
\text { not allowed }\end{array}$ & $\begin{array}{l}\text { For special } \\
\text { situations such as } \\
\text { long bridges } \\
\text { overlays (two- } \\
\text { course deck) may } \\
\text { beused }\end{array}$ \\
\hline $\begin{array}{l}\text { Bridge } \\
\text { Superstructures }\end{array}$ & $\begin{array}{l}\text { Prestressed beam or } \\
\text { cont. conc. Slab } \\
\text { bridges }\end{array}$ & & $\begin{array}{l}\text { Some steel beams } \\
\text { for special } \\
\text { situations. }\end{array}$ \\
\hline Abutments & Integral Abutments & & $\begin{array}{l}\text { Stub or Semi- } \\
\text { integral Abutments } \\
\text { for special } \\
\text { situations (high } \\
\text { skews or long } \\
\text { hridoes) }\end{array}$ \\
\hline Pier Systems & $\begin{array}{l}\text { Tpier (Hammer } \\
\text { Head), Frame Piers } \\
\text { (multi column), Pile } \\
\text { bents. }\end{array}$ & & $\begin{array}{l}\text { Spread footings on } \\
\text { rock only. }\end{array}$ \\
\hline
\end{tabular}


4. Do you have typical standards for cross-section widths and girder spacings? If so, please provide.

See web site listed below for standard cross sections

ftp://65.206.203.34/dotmain/bridges/standards/english/EnglishIntegralBridges.pdf

5. Do you have different design specifications for low-volume roads versus high-volume roads? If so, what are they?

Use precast panels on low volume roads only.

Formatted: Indent: Left: $0^{n}$, First line: $0.25^{\prime \prime}$

6. Do you use any bridge analysis or design software? If so, what brand of software is used?

Yes, Conspan, RCPier, QCon, Merlin Dash, Steelbridge, PCA Column,

7. Do you use any bridge design/component standards (or templates)? Examples may include beam sizes for different span lengths and roadway widths. If you have any, are they available on the web?

Yes, see web site listed below.

http://www.iowadot.gov/bridge/v8ebrgstd.htm

\section{Do you use modular bridge systems?}

Have only used modular bridge systems in research projects or special cases. Not typically used.

9. If a best practices manual for accelerated construction/modular bridge systems was developed, what would you like to see included? For example pre-selected beam sizes, cross-sections, etc.

Yes, precast deck panels, precast abutment details, and precast pier details (including columns, pier caps, and footings.

10. Do you use the AASHTO LRFD specified load factors/combinations or different load factors/combinations? If different, what are they? 
Use only AASHTO LRFD specified loads for new bridges, Use lowa legal loads for some repairs.

11. Would a table outlining pre-selected steel beam sizes and shapes for given span lengths based on AASHTO LRFD Bridge Design Specifications be useful for assisting in your design development process?

No, typically steel welded plate girders beams are used in unusual situations for span arrangement, clearance, etc. In addition, already have standards available for rolled sections from 160 to $340 \mathrm{ft}$.

\section{What is your preferred material choice for short-span bridges? Why?}

Continuous concrete slab or prestressed concrete beams are the most economical for short spans.

13. Are there any other comments that you have that you feel might be relevant to this study? 
14. What are your most important sources for bridge design and construction technical information and industry news? (Circle which are relevant)

- INDUSTRY PUBLICATIONS/WEB SITES:

SEE LIST BELOW:

- AASHTO LRFD specifications

- AISC manual

- PCI journal

- ASCE Bridge Journal

- ASCE Structural Journal

- NCHRP publications

- ACI Code and publications

- PCI Bridge Design Manual

- NSBA publications and examples

- Iowa Highway Research Board publications

- Examples and research publications from other State DOT's

\section{- INDUSTRY CONFERENCES (name which ones)}

SEE LIST BELIOW:

- ASCE yearly structures conf.

- PCl yearly conference

- NSBA yearly conference

- Transportation Research Board yearly conference

- PROFESSIONAL ORGANIZATION NEWSLETTER?

- Others?

\section{- WEB SITES}

- FHWA

- AASHTO

- NCHRP

- www.steel.org

- www.Steelbridges.org

- www.pciorg

- other DOT web sites

- other states DOT's research sites

- product sites 


\section{Research Statement}

The Federal Highway Administration in conjunction with the American Iron and Steel Institute [AISI] has recently conducted two workshops focused on developing ideas for improved steel bridge construction. One of the target areas of these workshops has been to develop design standards for short span steel bridges. As a result, the AISI Short Span Steel Bridge Alliance has contracted with Dr. Karl Barth at West Virginia University to conduct a survey of State DOT's and County Engineers. The focus of this survey is to study and catalog statistics and methods employed in short-span bridge design and construction. The overall projected outcome of this research is a best practices manual for the design and construction of short-span steel bridges (i.e. bridges up to $140 \mathrm{ft}$.) and a table outlining suggested pre-selected steel beam sizes and shapes for given span lengths.

\section{Part I. General Information}

Date: $\quad$ November 13, 2009

Time:

Agency / DOH: Kansas Department of Transportation

Name: John P. Jones

Position / Title: Manuals, Modeling a\& Policy Engineer, State Bridge Office

Address: $\quad 700$ sw Harrison St, Eisenhower State office Building, Topeka, KS 66603

Phone: $\quad$ (785) $368-7175$

E-mail: $\quad$ jones@ksdot.org

Other Information: 


\section{Part II. General Questions}

1. If possible, please provide a list of bridges built in your region in the past year along with their respective span lengths, whether they are simple or continuous span, cross-section widths and any other general information you can offer (ADT, wearing surface, deck and superstructure choices, substructure and pier choices, number of lanes, etc.).

Use 5myear average (2004-2008). Include only Open Spans $\leq 140^{\prime}$ in total Length.

[State System only]

\begin{tabular}{|c|c|c|c|c|c|c|c|c|c|c|c|}
\hline $\begin{array}{c}\text { Structural } \\
\text { Type }\end{array}$ & $\begin{array}{l}\text { Simple or } \\
\text { Continuous }\end{array}$ & $\begin{array}{l}\text { Width } \\
\text { O to } 0\end{array}$ & $\begin{array}{l}\text { Painted or } \\
\text { Weathering }\end{array}$ & ADT & $\begin{array}{l}\text { Number } \\
\text { of Lanes }\end{array}$ & $\begin{array}{c}\text { Deck } \\
\text { Material }\end{array}$ & $\begin{array}{l}\text { Wearing } \\
\text { Surface }\end{array}$ & $\begin{array}{l}\text { Beam Size } \\
\text { \& Spacing }\end{array}$ & Spans & $\begin{array}{l}\text { Sub } \\
\text { Type }\end{array}$ & $\begin{array}{l}\text { Rail } \\
\text { Type }\end{array}$ \\
\hline PBMS & S-Curve & 32 & $n / a$ & 510 & 2 & CEPO & $n / a$ & $\mathrm{~K} 3$ & 64.5 & Pile & $32^{\prime \prime} \mathrm{C}$ \\
\hline PBMS & $S$ & 94.9 & $n / a$ & 20,970 & 4 & CEPO & SFO & $\mathrm{K} 4+3^{\prime \prime}$ & 100.9 & Pile & $32^{\prime \prime} \mathrm{B}$ \\
\hline PITS & S-Skew & 46 & $n / a$ & 10,485 & 4 & CEPO & $n / a$ & IT & 60 & Pile & $32^{\prime \prime} \mathrm{C}$ \\
\hline & & & & & & & & & & & \\
\hline $\mathrm{RCSH}$ & C & 38.1 & $n / a$ & 1,810 & 2 & CEPO & $n / a$ & $n / a$ & $30-40-30=100.9$ & DS & $32^{\prime \prime} \mathrm{C}$ \\
\hline RCSH & 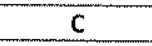 & 34.1 & $n / a$ & 550 & 2 & CEPO & $n / a$ & $n / a$ & $30-40-30=100.9$ & Pile & $32^{\prime \prime} \mathrm{C}$ \\
\hline RCSH & C-Skew & 34.1 & $n / a$ & 355 & 2 & CEPO & $n / a$ & $n / a$ & $30-40-30=101.6$ & Pile & $32^{\prime \prime} \mathrm{C}$ \\
\hline $\mathrm{RCSH}$ & $C$ & 34 & $n / a$ & 405 & 2 & CEPO & $n / a$ & $n / a$ & $30-40-30=102.5$ & Pile & $32^{\prime \prime} \mathrm{C}$ \\
\hline $\mathrm{RCSH}$ & C & 42 & $\mathrm{n} / \mathrm{a}$ & 865 & 2 & CEPO & $n / a$ & $n / a$ & $34-46-34=117.3$ & DS & $32^{\prime \prime C}$ \\
\hline RCSH & C & 40 & $n / a$ & 625 & 2 & CEPO & $n / a$ & $n / a$ & $34-46-34=117.3$ & Pile & $32^{\prime \prime} \mathrm{C}$ \\
\hline $\mathrm{RCSH}$ & $C$ & 42 & $n / a$ & 1,520 & 2 & CEPO & $\mathrm{n} / \mathrm{a}$ & $n / a$ & $34-46-34=117.3$ & DS & $32^{\prime \prime C}$ \\
\hline $\mathrm{RCSH}$ & $C$ & 42 & $n / a$ & 1,570 & 2 & CEPO & $n / a$ & $n / a$ & $34-46-34=117.3$ & Pile & $32^{\prime \prime} \mathrm{C}$ \\
\hline $\mathrm{RCSH}$ & C & 42 & $n / a$ & - & 2 & CEPO & $\mathrm{n} / \mathrm{a}$ & $n / a$ & $36-48-36=122.5$ & Pile & $32^{\prime \prime} \mathrm{C}$ \\
\hline $\mathrm{RCSH}$ & C & 42 & $n / a$ & - & 2 & CEPO & $n / a$ & $n / a$ & $36-48-36=122.5$ & Pile & $32^{\prime \prime} \mathrm{C}$ \\
\hline RCSH & C & 64 & $n / a$ & 4,810 & 2 & CEPO & $\mathrm{n} / \mathrm{a}$ & $n / a$ & $36-48-36=122.5$ & DS & $32^{\prime \prime C}$ \\
\hline $\mathrm{RCSH}$ & $c$ & 45.9 & $n / a$ & 4,705 & 2 & CEPO & $n / a$ & $n / a$ & $39-52-39=133.7$ & DS & $32^{\prime \prime} \mathrm{C}$ \\
\hline $\mathrm{RCSH}$ & $\mathrm{C}$ & 38 & $n / a$ & 645 & 2 & CEPO & $n / a$ & $n / a$ & $39-52-39=133.7$ & Pile & $32^{\prime \prime} \mathrm{C}$ \\
\hline $\mathrm{RCSH}$ & C & 45.9 & $n / a$ & 5,580 & 2 & CEPO & $n / a$ & $\mathrm{n} / \mathrm{a}$ & $39-52-39=133.7$ & Pile & $32^{\prime \prime} \mathrm{C}$ \\
\hline RCSH & $C$ & 38 & $n / a$ & 1,025 & 2 & CEPO & $\mathrm{n} / \mathrm{a}$ & $n / a$ & $39-52-39=133.7$ & Pile & $32^{\prime \prime} \mathrm{C}$ \\
\hline $\mathrm{RCSH}$ & C-Curve & 40 & $n / a$ & 1,120 & 2 & CEPO & $n / a$ & $n / a$ & $39-52-39=133.7$ & Pile & $32^{\prime \prime} \mathrm{C}$ \\
\hline $\mathrm{RCSH}$ & C & 34.1 & $n / a$ & 575 & 2 & CEPO & $n / a$ & $n / a$ & $39-52-39=133.7$ & Pile & $32^{\prime \prime} \mathrm{C}$ \\
\hline $\mathrm{RCSH}$ & C & 45.9 & $n / a$ & 3,250 & 2 & CEPO & $n / a$ & $\mathrm{n} / \mathrm{a}$ & $39-52-39=133.7$ & $\mathrm{Ftg}$ & $32^{\prime \prime} \mathrm{C}$ \\
\hline $\mathrm{RCSH}$ & $c$ & 64.8 & $n / a$ & 2,845 & 2 & CEPO & $n / a$ & $n / a$ & $39-52-39=133.7$ & Pile & $32^{\prime \prime} \mathrm{C}$ \\
\hline $\mathrm{RCSH}$ & C & 40 & $n / a$ & 1,055 & 2 & CEPO & $n / a$ & $n / a$ & $39-52-39=133.7$ & Pile & $32^{\prime \prime} \mathrm{C}$ \\
\hline RCSH & $c$ & 38 & $\mathrm{n} / \mathrm{a}$ & 645 & 2 & CEPO & $n / a$ & $n / a$ & $39-52-39=133.7$ & Pile & $32^{\prime \prime} \mathrm{C}$ \\
\hline WMCC & c & 42.5 & $w$ & - & & & $n / a$ & W $24 \times 73$ & & & (1"10 \\
\hline & & & & & 2 & CEPO & & & $34-46-34=117.8$ & Pile & $42^{\prime \prime} B$ \\
\hline
\end{tabular}

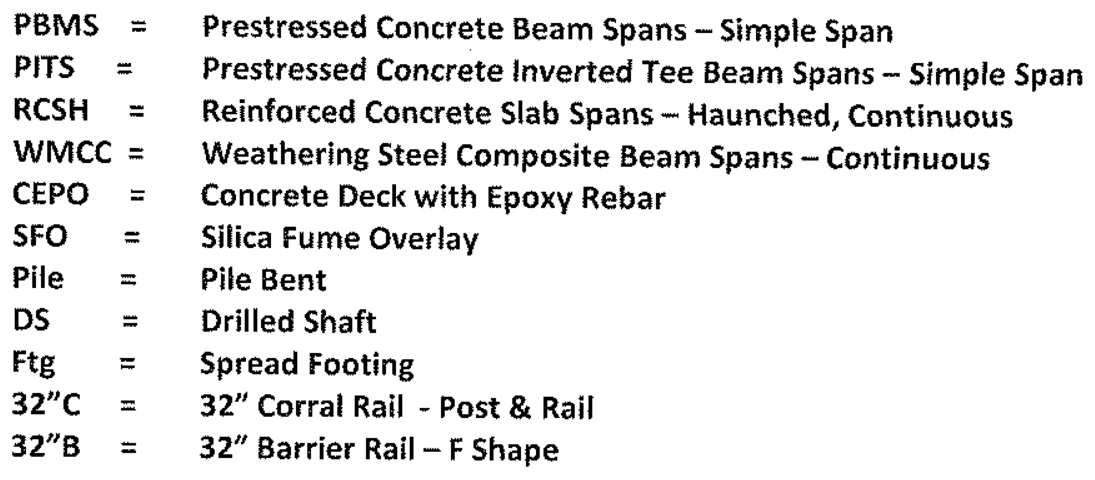


2. If information for question 1 is not readily available, please provide us with the following information: How many bridges were built in your region in the past year in the following length categories? Also, of those, how many bridges consisted of steel superstructures?

Approximate Total for State \& Local Systems for 1 year

\begin{tabular}{|l|c|c|}
\hline beight Categor: & Nimber of Britges & W/ Stect Superstmetures \\
\hline$<40 \mathrm{ft}$ & 3 & 2 \\
\hline $40-60 \mathrm{ft}$ & 2 & 0 \\
\hline $60-80 \mathrm{ft}$ & 1 & 0 \\
\hline $80-100 \mathrm{ft}$ & 4 & 1 \\
\hline $100-120 \mathrm{ft}$ & 12 & 1 \\
\hline $120-140 \mathrm{ft}$ & 10 & 1 \\
\hline
\end{tabular}

Use 5-year average (2004-2008). Include only Open Spans $\leq 140^{\prime} \mathrm{in}$ total Length.

\begin{tabular}{|c|c|c|c|c|c|c|c|c|c|}
\hline \multicolumn{5}{|c|}{ All Open Span - State System *BROMS } & \multicolumn{5}{|c|}{ All Open Span - Local System *Fed Cost Rep } \\
\hline count & Area & $\$$ & Use & & count & Area & $\$$ & Use & \\
\hline $31.7 \%$ & $25.0 \%$ & $28.0 \%$ & 30 & PBM? & $10.9 \%$ & $16.3 \%$ & $17.9 \%$ & 15 & PBM? \\
\hline $1.0 \%$ & $0.4 \%$ & $0.3 \%$ & 0 & PIT? & $79.1 \%$ & $56.0 \%$ & $41.4 \%$ & 45 & RCS? \\
\hline $29.8 \%$ & $12.0 \%$ & $22.2 \%$ & 23 & $\mathrm{RCSH}$ & $0.9 \%$ & $0.4 \%$ & $0.8 \%$ & 0 & RRF \\
\hline $34.6 \%$ & $61.1 \%$ & $47.9 \%$ & 45 & Steel & $6.6 \%$ & $23.8 \%$ & $36.1 \%$ & 35 & Steel \\
\hline $2.9 \%$ & $1.4 \%$ & $1.6 \%$ & 2 & $\mathrm{XCSH}$ & $2.4 \%$ & $3.4 \%$ & $3.8 \%$ & 5 & $\mathrm{XCSH}$ \\
\hline
\end{tabular}

\section{5-Yrs State System from Federal Cost Report}

\begin{tabular}{|c|c|c|c|c|c|c|c|c|c|c|c|c|}
\hline Cost & Area & $\$ / S F$ & Type & $\leq 140$ & $0-40$ & $40-60$ & $60-80$ & $80-100$ & $100-120$ & $120-140$ & $>140$ & All \\
\hline$\$ 60,019,497.16$ & $816,177.57$ & 73.54 & PBM? & 2 & 0 & 0 & 2 & 0 & 0 & 0 & 67 & 69 \\
\hline$\$ 36,755,740.90$ & $779,366.37$ & 47.16 & $\mathrm{RCSH}$ & 25 & 0 & 0 & 0 & 0 & 12 & 13 & 45 & 70 \\
\hline$\$ 376,863.60$ & $2,849.59$ & 132.25 & RRF & 2 & 0 & 2 & 0 & 0 & 0 & 0 & 0 & 2 \\
\hline$\$ 137,338,865.60$ & $1,309,766.75$ & 104.86 & Steel & 2 & 0 & 0 & 0 & 1 & 1 & 0 & 59 & 61 \\
\hline$\$ 2,765,943.40$ & $35,893.75$ & 77.06 & $\mathrm{XCSH}$ & 0 & 0 & 0 & 0 & 0 & 0 & 0 & 4 & 4 \\
\hline$\$ 237,256,910.66$ & $2,944,054.03$ & 80.59 & All & 31 & 0 & 2 & 2 & 1 & 13 & 13 & 175 & 206 \\
\hline
\end{tabular}

5-Yrs Local System from Federal Cost Report

\begin{tabular}{|c|c|c|c|c|c|c|c|c|c|c|c|c|}
\hline Cost & Area & $\$ / S F$ & Type & $\leq 140$ & $0-40$ & $40-60$ & $60-80$ & $80-100$ & $100-120$ & $120-140$ & $>140$ & All \\
\hline$\$ 15,925,020.75$ & $227,402.59$ & 70.03 & PBM? & 4 & 0 & 0 & 1 & 1 & 0 & 2 & 19 & 23 \\
\hline$\$ 36,755,740.90$ & $779,366.37$ & 47.16 & RCS? & 115 & 13 & 6 & 0 & 16 & 48 & 32 & 52 & 167 \\
\hline$\$ 667,835.00$ & $5,605.03$ & 119.15 & RRF & 2 & 1 & 1 & 0 & 0 & 0 & 0 & 0 & 2 \\
\hline$\$ 32,034,022.20$ & $331,499.64$ & 96.63 & Steel & 6 & 0 & 0 & 1 & 2 & 1 & 2 & 8 & 14 \\
\hline$\$ 3,394,948.00$ & $47,605.52$ & 71.31 & $\mathrm{XCSH}$ & 0 & 0 & 0 & 0 & 0 & 0 & 0 & 5 & 5 \\
\hline$\$ 88,777,566.85$ & $1,391,479.15$ & 63.80 & All & 127 & 14 & 7 & 2 & 19 & 49 & 36 & 84 & 211 \\
\hline
\end{tabular}


For the following bridge components, please specify whether you have a preferred/specified type of design and whether or not there are any particular types of bridge component that you do not approve:

\begin{tabular}{|c|c|c|c|}
\hline Brigne componont & Whichoo & Whater & 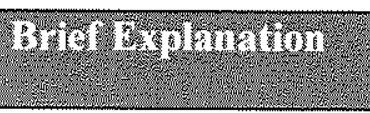 \\
\hline Decking Systems & $\begin{array}{l}\text { Circle Choice } \\
\text { Cast-in-place } \\
\text { Precast concrete } \\
\text { panels } \\
\text { Steel stay-in-place } \\
\text { formwork } \\
\text { Other (list): }\end{array}$ & $\begin{array}{l}\text { Avold where } \\
\text { possible } \\
\text { Avoid where } \\
\text { possible }\end{array}$ & $\begin{array}{l}\text { Reflective cracking } \\
\text { with precast panels. } \\
\text { Bridge Inspectors do } \\
\text { not like steel } \\
\text { formwork. Hides } \\
\text { bottom of deck. }\end{array}$ \\
\hline $\begin{array}{l}\text { Railing/Guardrail } \\
\text { Systems }\end{array}$ & 32" Post \& Rail (no curb) & & \\
\hline $\begin{array}{l}\text { Topping/Wearing } \\
\text { Surfaces }\end{array}$ & $\begin{array}{l}\text { Typical Epoxy } 2.5^{\prime \prime} \text { Clear; } \\
\text { Epoxy with } 3 " \text { Clear (ADT) }\end{array}$ & & \\
\hline $\begin{array}{l}\text { Bridge } \\
\text { Superstructures }\end{array}$ & $\begin{array}{lcc}\text { Open Spans: } & \text { State } & \text { Local } \\
\text { Slabs } & 23 \% & 45 \% \\
\text { Slabs (P-T) } & 2 \% & 5 \% \\
\text { Prestressed Beams } & 30 \% & 15 \% \\
\text { Steel } & 45 \% & 35 \%\end{array}$ & & \\
\hline Abutments & Integral Pile Bent on H-Pile & & \\
\hline Pier Systems & $\begin{array}{l}\text { Pile Bent - H or Plpe } \\
\text { Column Bent - Plie }\end{array}$ & & \\
\hline
\end{tabular}


3. Do you have typical standards for cross-section widths and girder spacings? If so, please provide.

Bridge Design Manual: LFD Manual - http://kart.ksdot.org/

4. Do you have different design specifications for low-volume roads versus high-volume roads? If so, what are they?

By ADT

5. Do you use any bridge analysis or design software? If so, what brand of software is used?

AASHTO Opis, BRASS, Simons, PG Super, in-house

6. Do you use any bridge design/component standards (or templates)? Examples may include beam sizes for different span lengths and roadway widths. If you have any, are they available on the web?

?

7. Do you use modular bridge systems?

Detour Spans - 70' Simple spans

8. If a best practices manual for accelerated construction/modular bridge systems was developed, what would you like to see included? For example pre-selected beam sizes, cross-sections, etc.

Detalls by Span and Roadway with Substructure details. Must be continuous spans. Standard bracing details. 
9. Do you use the AASHTO LRFD specified load factors/combinations or different load factors/combinations? If different, what are they?

Use LRF HL93 plus some additional trucks. See BDM.

10. Would a table outlining pre-selected steel beam sizes and shapes for given span lengths based on AASHTO LRFD Bridge Design Specifications be useful for assisting in your design development process?

Only if continuous spans.

11. What is your preferred material choice for short-span bridges? Why?

RCSH - a continuous reinforced concrete haunched slab span. Initial cost and longuterm durability.

12. Are there any other comments that you have that you feel might be relevant to this study?

The steel industry has a history of ignoring the transportation market when the commercial market is booming. Standard designs are worthless if the mills won't roll the shapes on a dependable schedule. This may not be a problem with shortspan bridges but the industry has been quite innovative when it comes to shooting itself in the foot. 
13. What are your most important sources for bridge design and construction technical information and industry news? (Circle which are relevant)

- INDUSTRY PUBLICATIONS/WEB SITES:

6 ENR

(6) Roads and Bridges

- GoBridges.com

6 Better Roads (BetterRoads.com)

- Journal of Structural Engineering

- Transportation Builder

- Public Works Magazine

- Engineering Journal

- Public Roads

- Design Engineering

- Government Engineering (GovEngr.com)

(6) Civil Engineering

- CE News

6 Others? ASCE, AASHTO,

- INDUSTRY CONFERENCES (name which ones)

- PCI,

- PROFESSIONAL ORGANIZATION NEWSLETTER?

- NACE?

6 Others? ASCE

- WEB SITES
(o) FHWA
(1) steel.org NSPA
- Steelbridges.org
- Others? 


\section{$\underline{\text { Research Statement }}$}

The Federal Highway Administration in conjunction with the American Iron and Steel Institute [AISI] has recently conducted two workshops focused on developing ideas for improved steel bridge construction. One of the target areas of these workshops has been to develop design standards for short span steel bridges. As a result, the AISI Short Span Steel Bridge Alliance has contracted with Dr. Karl Barth at West Virginia University to conduct a survey of State DOT's and County Engineers. The focus of this survey is to study and catalog statistics and methods employed in short-span bridge design and construction. The overall projected outcome of this research is a best practices manual for the design and construction of short-span steel bridges (i.e. bridges up to $140 \mathrm{ft}$.) and a table outlining suggested pre-selected steel beam sizes and shapes for given span lengths.

\section{Part I. General Information}

Date: Nov 17,2009

Time:

Agency/DOH: KYTC Div of STRUCTURAL DESIGN

Name: Marvin WOLFE

Position/Title: T,E, SPECIALIST

Address:

200 MEROST

FrANKFORT, KY 40622

Phone: $\quad 502.564 .4560$

E-mail: MARVIN.WOLFE@KY.gOV

Other Information: 


\section{Part II. General Questions}

1. If possible, please provide a list of bridges built in your region in the past year along with their respective span lengths, whether they are simple or continuous span, cross-section widths and any other general information you can offer (ADT, wearing surface, deck and superstructure choices, substructure and pier choices, number of lanes, etc.).

2. If information for question 1 is not readily available, please provide us with the following information: How many bridges were built in your region in the past year in the following length categories? Also, of those, how many bridges consisted of steel superstructures?

\begin{tabular}{|c|c|c|}
\hline Hength Gatsoris & Number of bititges & W/ Sted Supr wuctures \\
\hline$<40 \mathrm{ft}$ & & \\
\hline $40-60 \mathrm{ft}$ & & \\
\hline $60-80 \mathrm{ft}$ & & \\
\hline $80-100 \mathrm{ft}$ & & \\
\hline $100-120 \mathrm{ft}$ & & \\
\hline $120-140 \mathrm{ft}$ & & \\
\hline
\end{tabular}


3. For the following bridge components, please specify whether you have a preferred/specified type of design and whether or not there are any particular types of bridge component that you do not approve:

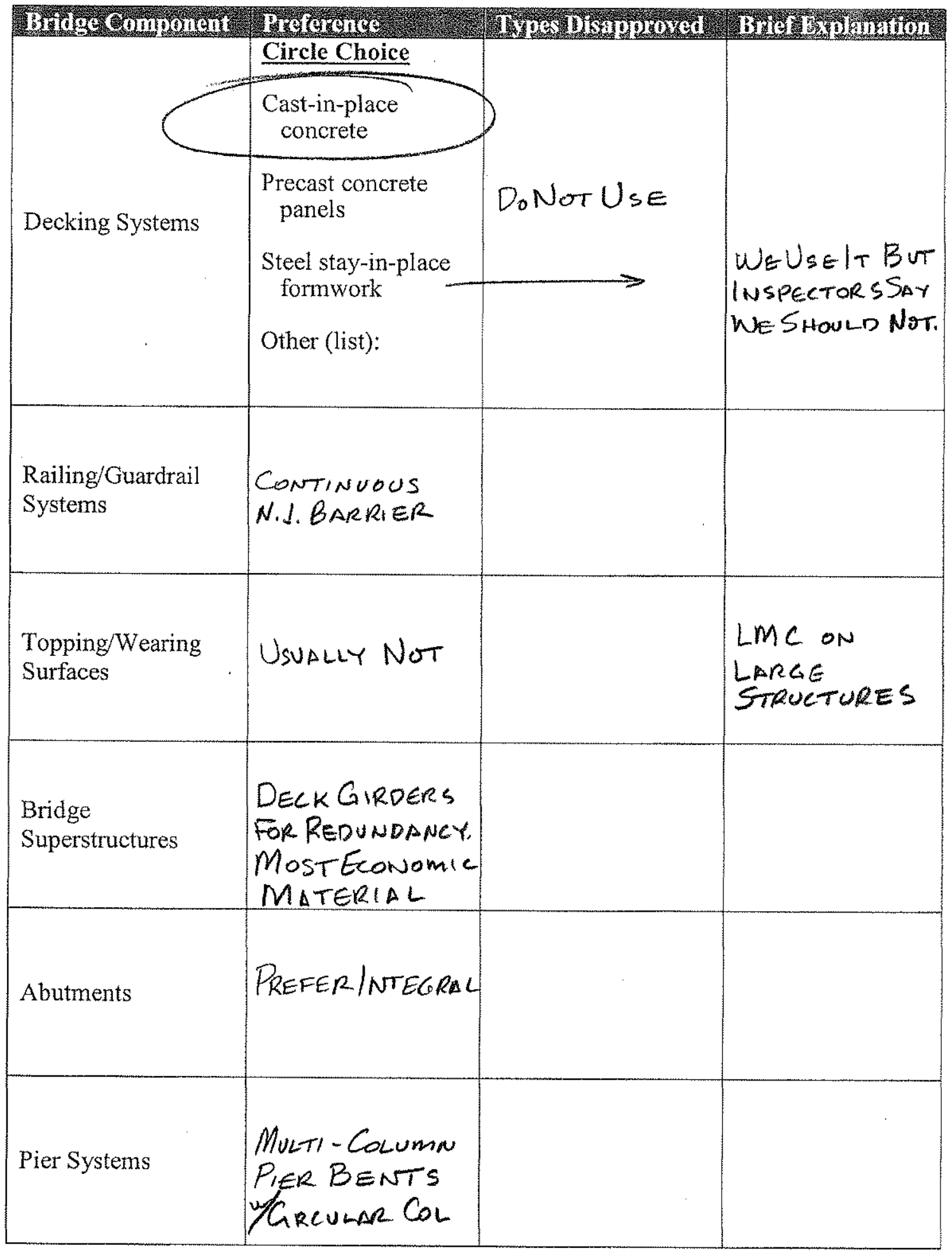


4. Do you have typical standards for cross-section widths and girder spacings? If so, please provide.

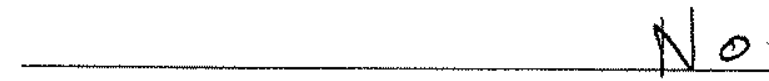

5. Do you have different design specifications for low-volume roads versus high-volume roads? If so, what are they?

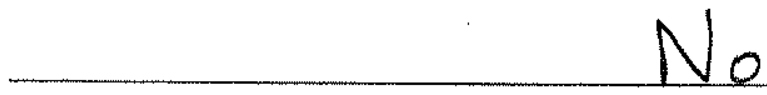

6. Do you use any bridge analysis or design software? If so, what brand of software is used?

Conspan. MDX, GTStrud, Math cad, In -House ProGrams

7. Do you use any bridge design/component standards (or templates)? Examples may include beam sizes for different span lengths and roadway widths. If you have any, are they available on the web?

STD Box Beams in STD D Was. transportation.ky.gor/design/standards/standard_drawings.html

8. Do you use modular bridge systems?

$$
\text { No }
$$

9. If a best practices manual for accelerated construction/modular bridge systems was developed, what would you like to see included? For example preselected beam sizes, cross-sections, etc.

Design Flow Chart, Details for

Simple Made Continuous for liveload. 
10. Do you use the AASHTO LRFD specified load factors/combinations or different load factors/combinations? If different, what are they?

$$
\begin{gathered}
\text { USE AASHTO LRFD LOADFACTORS } \\
\text { M RELUCTANTLY } \\
\text { MODIFY HL-93 by INCREASING } 25 \% \text { (TRUCKE) }
\end{gathered}
$$

11. Would a table outlining pre-selected steel beam sizes and shapes for given span lengths based on AASHTO LRFD Bridge Design Specifications be useful for assisting in your design development process?

ProBABLY

12. What is your preferred material choice for short-span bridges? Why?

CONCRETE

Lower Cost $\%$ Corrosion Resistance

13. Are there any other comments that you have that you feel might be relevant to this study?

Such a Best Practices Manual may Assist

WITH AN INITIAL SECTION. We WOULD STILL

Have to do a Full Desicn for any SteelBridge, 
14. What are your most important sources for bridge design and construction technical information and industry news? (Circle which are relevant)

- INDUSTRY PUBLICATIONS/WEB SITES:

- ENR

- Roads and Bridges

- GoBridges.com

- Better Roads (BetterRoads.com)

- Journal of Structural Engineering

- Transportation Builder

- Public Works Magazine

- Engineering Journal

- Public Roads

- Design Engineering

- Government Engineering (GovEngr.com)

- Civil Engineering

- CE News

- Others?

- INDUSTRY CONFERENCES (name which ones) AASHTO BRIDGEMTE

- PROFESSIONAL ORGANIZATION NEWSLETTER?

- NACE?

- Others?

- WEB SITES
$\checkmark$ - FHWA
- steel.org
- Steelbridges.org
- Others? 
$\underline{\text { Research Statement }}$

The Federal Highway Administration in conjunction with the American Iron and Steel Institute [AISI] has recently conducted two workshops focused on developing ideas for improved steel bridge construction. One of the target areas of these workshops has been to develop design standards for short span steel bridges. As a result, the AISI Short Span Steel Bridge Alliance has contracted with Dr. Karl Barth at West Virginia University to conduct a survey of State DOT's and County Engineers. The focus of this survey is to study and catalog statistics and methods employed in short-span bridge design and construction. The overall projected outcome of this research is a best practices manual for the design and construction of short-span steel bridges (ie. bridges up to $140 \mathrm{ft}$.) and a table outlining suggested preselected steel beam sizes and shapes for given span lengths.

Part I. General Information

Date: May 19,2010

Time:

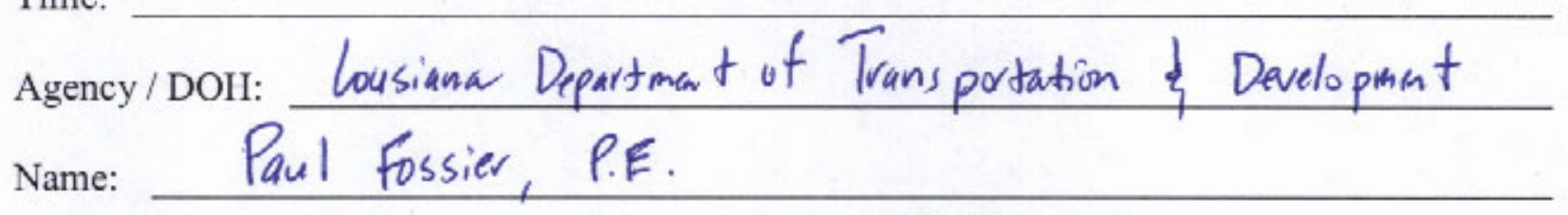

Position/Title: Assistant Bridge Design Administrator

Address: P.O. Box 94245 Baton Rouge, LA 70804

Phone: $\quad 225-379-1323$

E-mail:

paul. fussier e la. gov

Other Information: 


\section{Part II. General Questions}

1. If possible, please provide a list of bridges built in your region in the past year along with their respective span lengths, whether they are simple or continuous span, cross-section widths and any other general information you can offer (ADT, wearing surface, deck and superstructure choices, substructure and pier choices, number of lanes, etc.).

2. If information for question 1 is not readily available, please provide us with the following information: How many bridges were built in your region in the past year in the following length categories? Also, of those, how many bridges consisted of steel superstructures?

\begin{tabular}{|l|c|c|}
\hline Length Catcgory & Number of Bridges & W/ Steel Superstructures \\
\hline$<40 \mathrm{ft}$ & 9 & \\
\hline $40-60 \mathrm{ft}$ & 2 & \\
\hline $60-80 \mathrm{ft}$ & 4 & 1 \\
\hline $80-100 \mathrm{ft}$ & 3 & \\
\hline $100-120 \mathrm{ft}$ & 4 & 2 (Mavable Bridges) \\
\hline $120-140 \mathrm{ft}$ & 2 & \\
\hline
\end{tabular}


3. For the following bridge components, please specify whether you have a preferred/specified type of design and whether or not there are any particular types of bridge component that you do not approve:

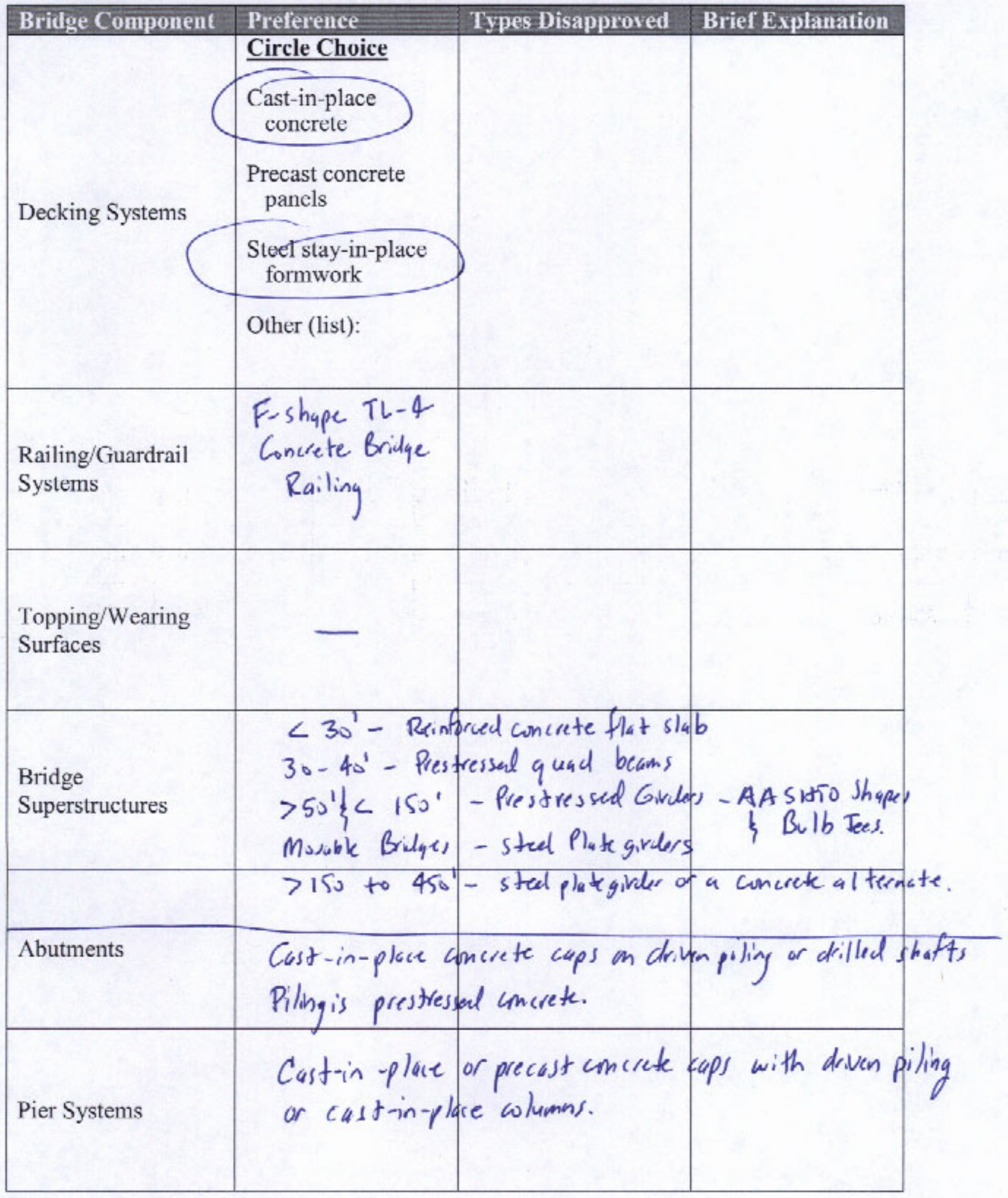


4. Do you have typical standards for cross-section widths and girder spacings? If so, please provide.

No. steel standards Jest concrete standards for shortspan C40'

5. Do you have different design specifications for low-volume roads versus high-volume roads? If so, what are they?

No.

6. Do you use any bridge analysis or design software? If so, what brand of software is used?

Conspan, RCPier, STAAD, Lusas, Flyida Pier, MDX Virtis

7. Do you use any bridge design/component standards (or templates)? Examples may include beam sizes for different span lengths and roadway widths. If you have any, are they available on the web?

No.

8. Do you use modular bridge systems?

No.

9. If a best practices manual for accelerated construction/modular bridge systems was developed, what would you like to see included? For example pre-selected beam sizes, cross-sections, etc.

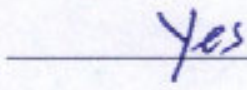


10. Do you use the AASHTO LRFD specified load factors/combinations or different load factors/combinations? If different, what are they?

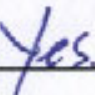

11. Would a table outlining pre-selected steel beam sizes and shapes for given span lengths based on AASHTO LRFD Bridge Design Specifications be useful for assisting in your design development process?

Yes.

12. What is your preferred material choice for short-span bridges? Why?

prestressud loncrete. Low mointanance, longlite and

we get excellent prices and competition from siveral precast fabicators in ous arca.

13. Are there any other comments that you have that you feel might be relevant to this study? 
14. What are your most important sources for bridge design and construction technical information and industry news? (Circle which are relevant)

- INDUSTR FPUBLICATIONS/WEB SITES:

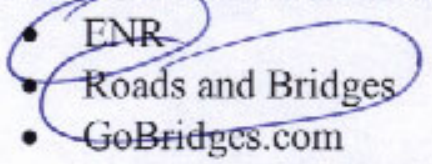

- Better Roads (BetterRoads.com)

- Journal of Structural Engineering

- Transportation Builder

- Public Works Magazine

- Engineering Journal

- Public Roads

- Design Engineering

- Government Engineering (GovEngr.com)

- Civil Engineering

- CE News

- Others? fHwA website,

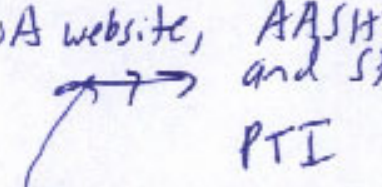

- INDUSTRY CONFERENCES (name which ones)

- PROFESSIONAL ORGANIZATION NEWSLETTER?

- NACE?

- Others?

- WEB SITES

- FHWA

- steel.org

- Steelbridges.org

- Others? 


\section{Research Statement}

The Federal Highway Administration in conjunction with the American Iron and Steel Institute [AISI] has recently conducted two workshops focused on developing ideas for improved steel bridge construction. One of the target areas of these workshops has been to develop design standards for short span steel bridges. As a result, the AISI Short Span Steel Bridge Alliance has contracted with Dr. Karl Barth at West Virginia University to conduct a survey of State DOT's and County Engineers. The focus of this survey is to study and catalog statistics and methods employed in short-span bridge design and construction. The overall projected outcome of this research is a best practices manual for the design and construction of short-span steel bridges (i.e. bridges up to $140 \mathrm{ft}$.) and a table outlining suggested pre-selected steel beam sizes and shapes for given span lengths.

\section{Part 1. General Information}

Date:

$4 \cdot 30 \cdot 2010$

Time:

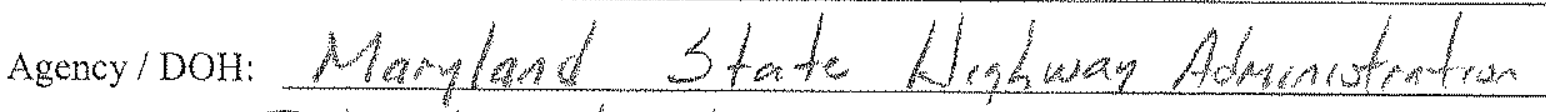

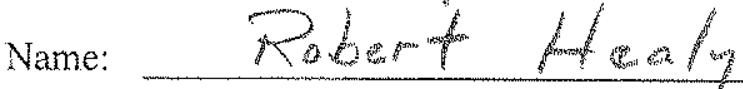

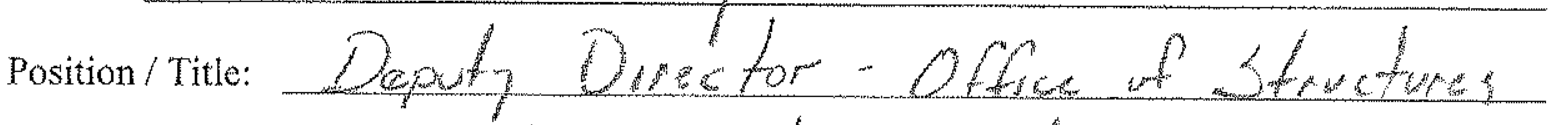

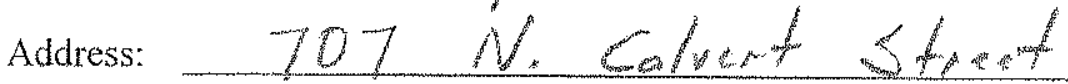

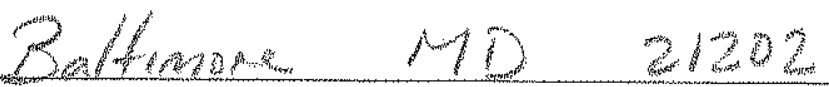

Phone:

$410 \cdot 545 \cdot 8063$

E-mail:

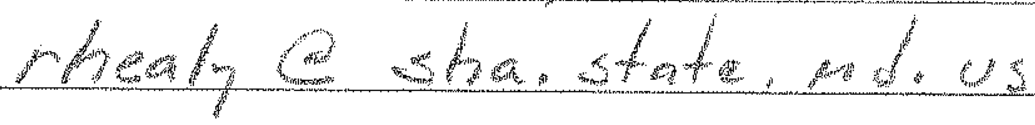

Other Information: 
Part II. General Questions

1. If possible, please provide a list of bridges built in your region in the past year along with their respective span lengths, whether they are simple or continuous span, cross -section widths and any other general information you can offer (ADT, wearing surface, deck and superstructure choices, substructure and pier choices, number of lanes, etc.).

2. If information for question $I$ is not readily available, please provide us with the following information: How many bridges were built in your region in the past year in the following length categories? Also, of those, how many bridges consisted of steel superstructures?

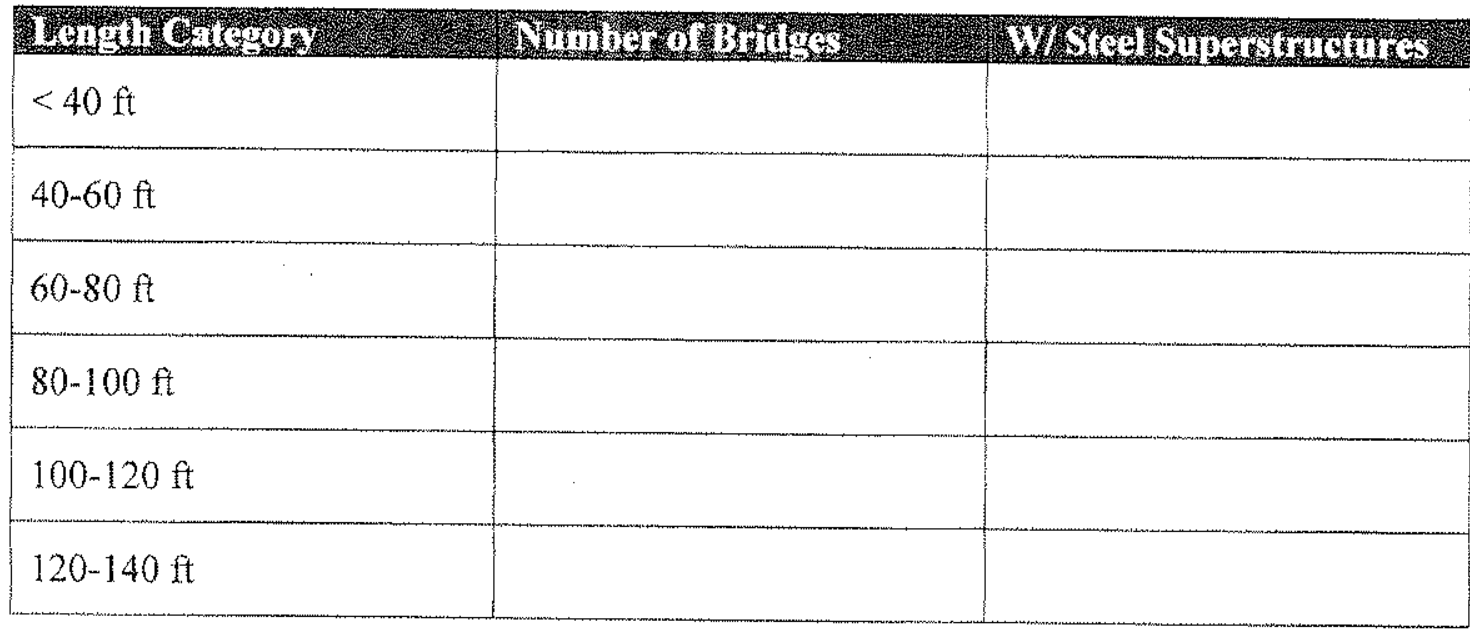

See attached spread sheets with data from last 3 years $(2007-2001)$ 
3. For the following bridge components, please specify whether you have a preferred/specified type of design and whether or not there are any particular types of bridge component that you do not approve:

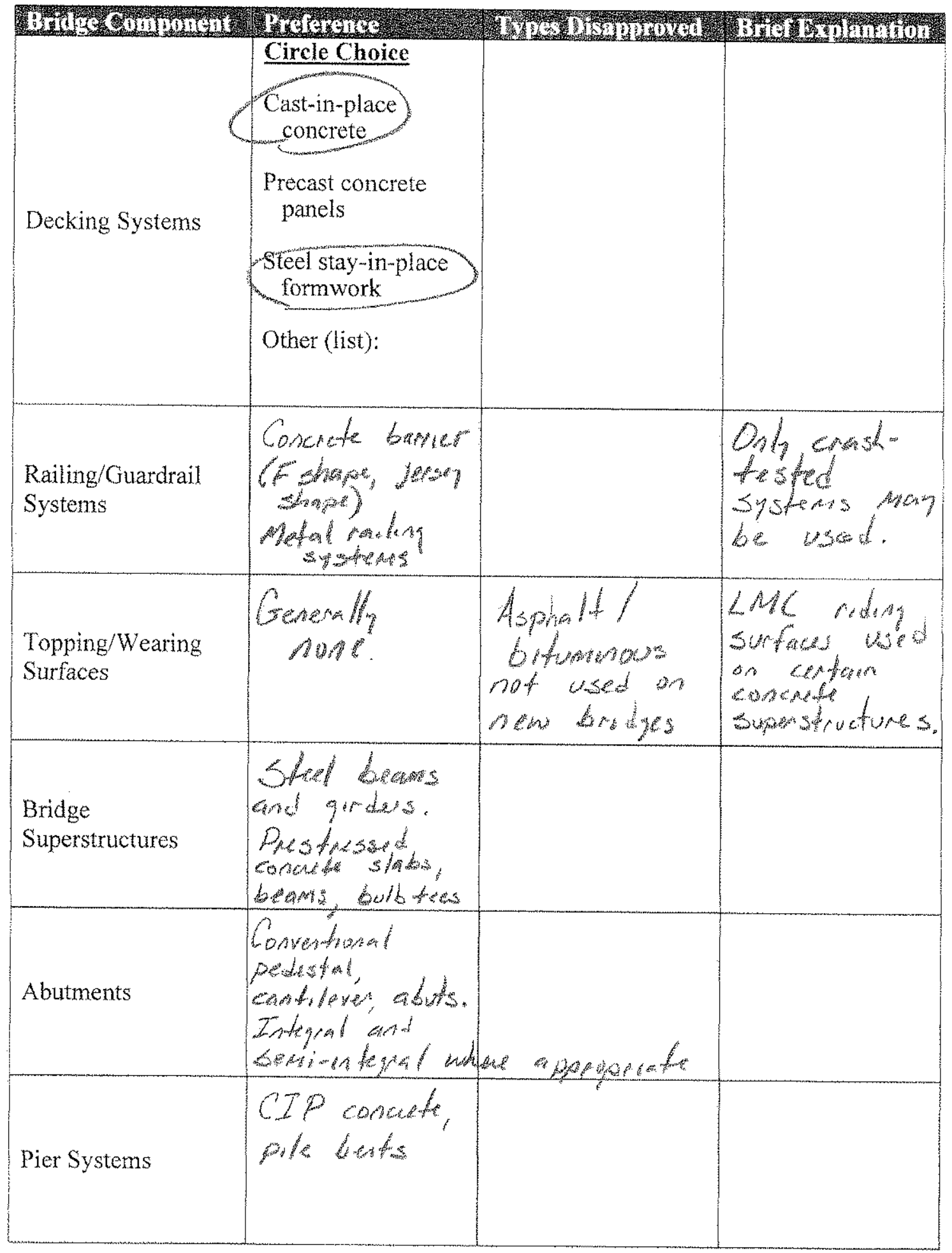


4. Do you have typical standards for cross-section widths and girder spacings? If so, please provide.

No.

5. Do you have different design specifications for low-volume roads versus high-volume roads? If so, what are they?

$N$

6. Do you use any bridge analysis or design software? If so, what brand of software is used?

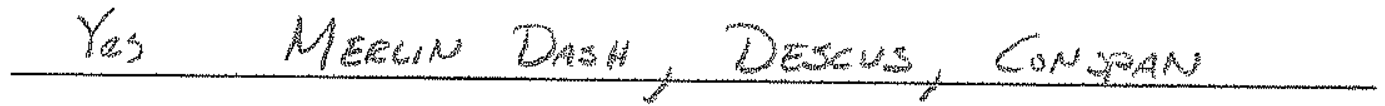

7. Do you use any bridge design/component standards (or templates)? Examples may include beam sizes for different span lengths and roadway widths. If you have any, are they available on the web?

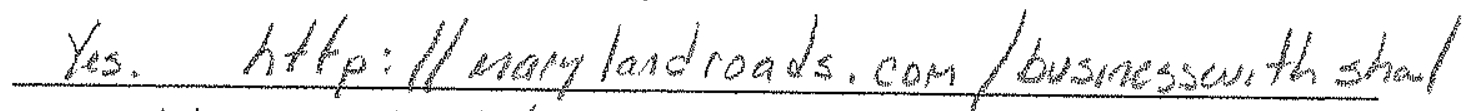

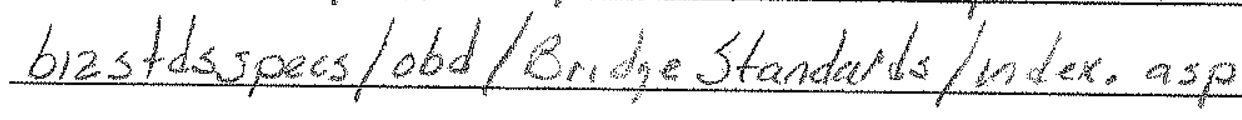

8. Do you use modular bridge systems?

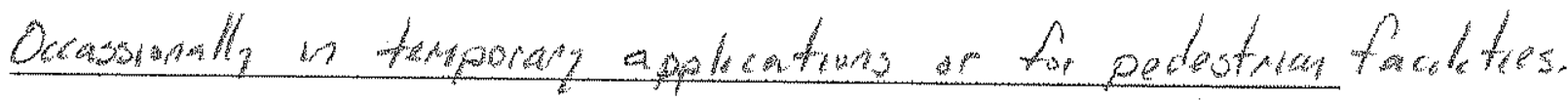

9. If a best practices manual for accelerated construction/modular bridge systems was developed, what would you like to see included? For example pre-selected beam sizes, cross-sections, etc.

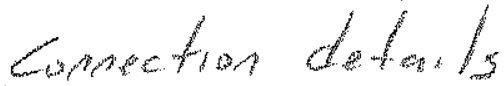


10. Do you use the AASHTO LRFD specified load factors/combinations or different load factors/combinations? If different, what are they?

Yes, we wa the AASHO LEFD factors/

contentions.

11. Would a table outlining preselected steel beam sizes and shapes for given span lengths based on AASHTO LRFD Bridge Design Specifications be useful for assisting in your design development process?

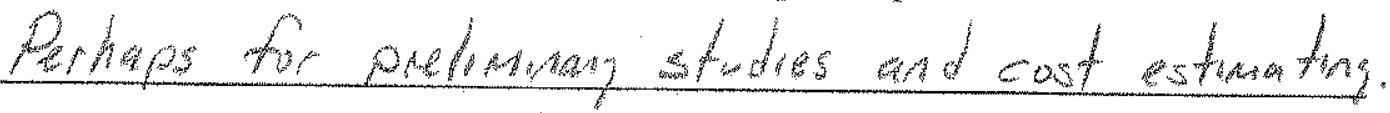

12. What is your preferred material choice for short-span bridges? Why?

Both concrete and steel are viable options in
my state. Commute is frequent favored in minor

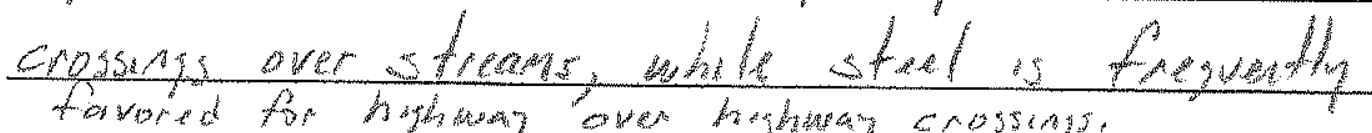

13. Are there any other comments that you have that you feel might be relevant to this study?

No 
14. What are your most important sources for bridge design and construction technical information and industry news? (Circle which are relevant)

- INDUSTRY PUBLICATIONS/WEB SITES:

- ENR

- Roads and Bridges

- GoBridges.com

- Better Roads (BetterRoads.com)

- Journal of Structural Engineering

- Transportation Builder

- Public Works Magazine

- Engineering Journal

- Public Roads

- Design Engineering

- Government Engineering (GovEngr.com)

- Civil Engineering

- CE News

- Others?

- INDUSTRY CONFERENCES (name which ones)

- PROFESSIONAL ORGANIZATION NEWSLETTER?

- NACE?

- Others?

- WEB SITES

- FHWA

- steel.org

- Steelbridges.org

- Others? 


\section{Research Statement}

The Federal Highway Administration in conjunction with the American Iron and Steel Institute [AISI] has recently conducted two workshops focused on developing ideas for improved steel bridge construction. One of the target areas of these workshops has been to develop design standards for short span steel bridges. As a result, the AISI Short Span Steel Bridge Alliance has contracted with Dr. Karl Barth at West Virginia University to conduct a survey of State DOT's and County Engineers. The focus of this survey is to study and catalog statistics and methods employed in short-span bridge design and construction. The overall projected outcome of this research is a best practices manual for the design and construction of short-span steel bridges (i.e. bridges up to $140 \mathrm{ft}$.) and a table outlining suggested pre-selected steel beam sizes and shapes for given span lengths.

\section{Part 1. General Information}

Date: December 15, 2009

Time:

Agency / DOH: Massachusetts Department of Transportation

Name: Alexander Bardow

Position / Title: Director of Bridges and Structures

Address: 10 Park Plaza, Boston, MA 02116

Phone: $617-973-7570$

E-mail: Alexander.bardow@mhd.state.ma.us

Other Information: 


\section{Part II. General Questions}

1. If possible, please provide a list of bridges built in your region in the past year along with their respective span lengths, whether they are simple or continuous span, cross-section widths and any other general information you can offer (ADT, wearing surface, deck and superstructure choices, substructure and pier choices, number of lanes, etc.).

2. If information for question 1 is not readily available, please provide us with the following information: How many bridges were built in your region in the past year in the following length categories? Also, of those, how many bridges consisted of steel superstructures?

\begin{tabular}{|c|c|c|}
\hline Leigh Catcgny & Nownher of Brotoges & 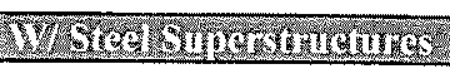 \\
\hline$<40 \mathrm{ft}$ & & \\
\hline $40-60 \mathrm{ft}$ & & \\
\hline $60-80 \mathrm{ft}$ & & \\
\hline $80-100 \mathrm{ft}$ & & \\
\hline $100-120 \hat{\mathrm{ft}}$ & & \\
\hline $120-140 \mathrm{ft}$ & & \\
\hline
\end{tabular}


3. For the following bridge components, please specify whether you have a preferred/specified type of design and whether or not there are any particular types of bridge component that you do not approve:

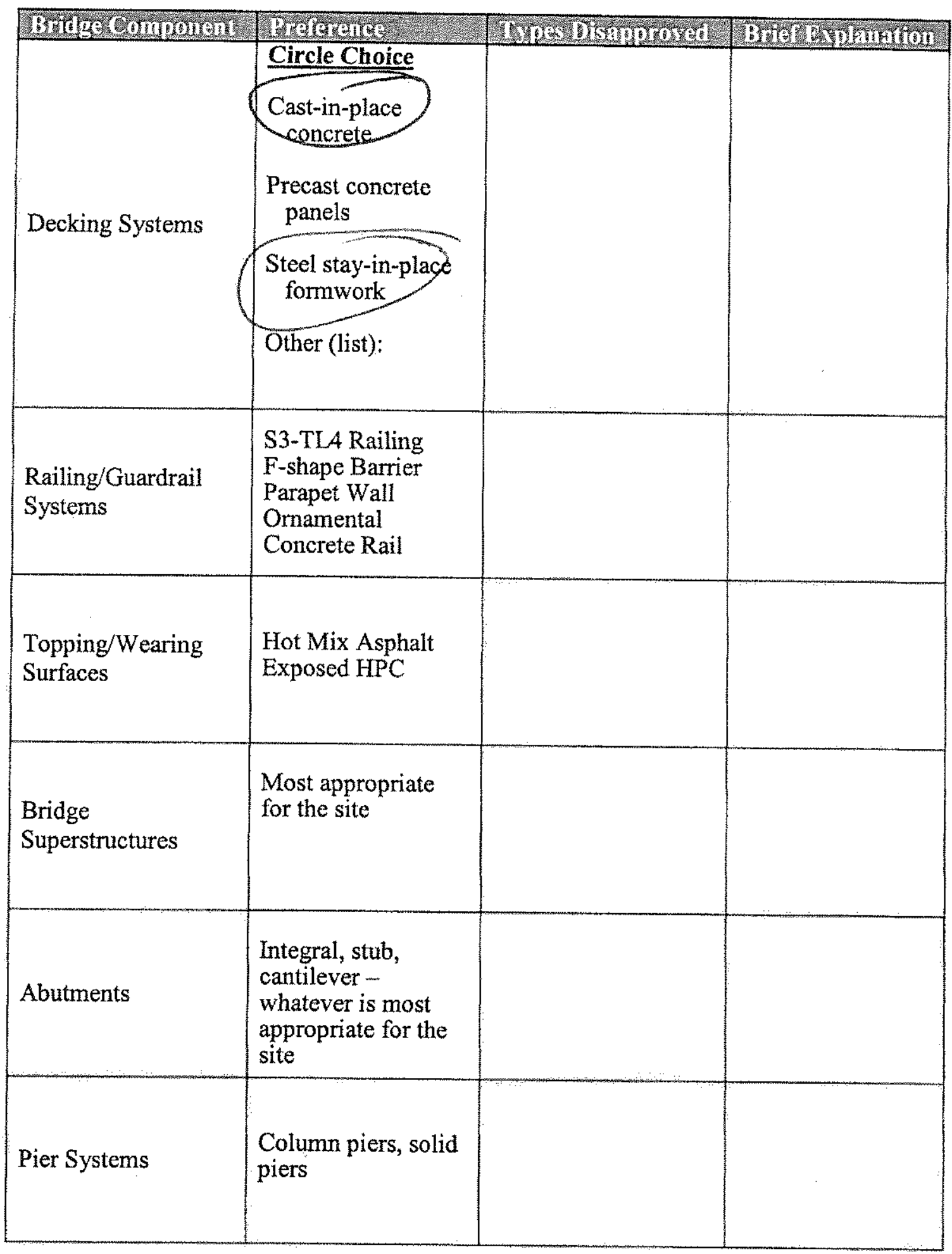


4. Do you have typical standards for cross-section widths and girder spacings? If so, please provide.

No, cross section and beam spacing depends on the road design and, most often, stage construction considerations

5. Do you have different design specifications for low-volume roads versus high-volume roads? If so, what are they?

No.

6. Do you use any bridge analysis or design software? If so, what brand of software is used?

OPIS, other internally developed spreadsheets.

7. Do you use any bridge design/component standards (or templates)? Examples may include beam sizes for different span lengths and roadway widths. If you have any, are they available on the web?

Yes, the entire Bridge Manual, standard details and design guidelines is available on-line at:

http://www.mhd.state.ma.us//default.asp?pgid=content/bridgeman_new_intro\&s id=about

8. Do you use modular bridge systems?

Yes, we use Inverset Units, precast arches and frames

9. If a best practices manual for accelerated construction/modular bridge systems was developed, what would you like to see included? For example pre-selected beam sizes, cross-sections, etc.

Connection details are the most important. 
10. Do you use the AASHTO LRFD specified load factors/combinations or different load factors/combinations? If different, what are they?

AASHTO LRFD

11. Would a table outlining pre-selected steel beam sizes and shapes for given span lengths based on AASHTO LRFD Bridge Design Specifications be useful for assisting in your design development process?

Yes, to be used as a guide.

12. What is your preferred material choice for short-span bridges? Why?

We use whatever material is best suited for the site considering environmental effects, highway geometry, traffic and stage construction.

13. Are there any other comments that you have that you feel might be relevant to this study? 
What are your most important sources for bridge design and construction technical information and industry news? (Circle which are relevant)

- INDUSTRY PXBLICATIONS/WEB SITES:

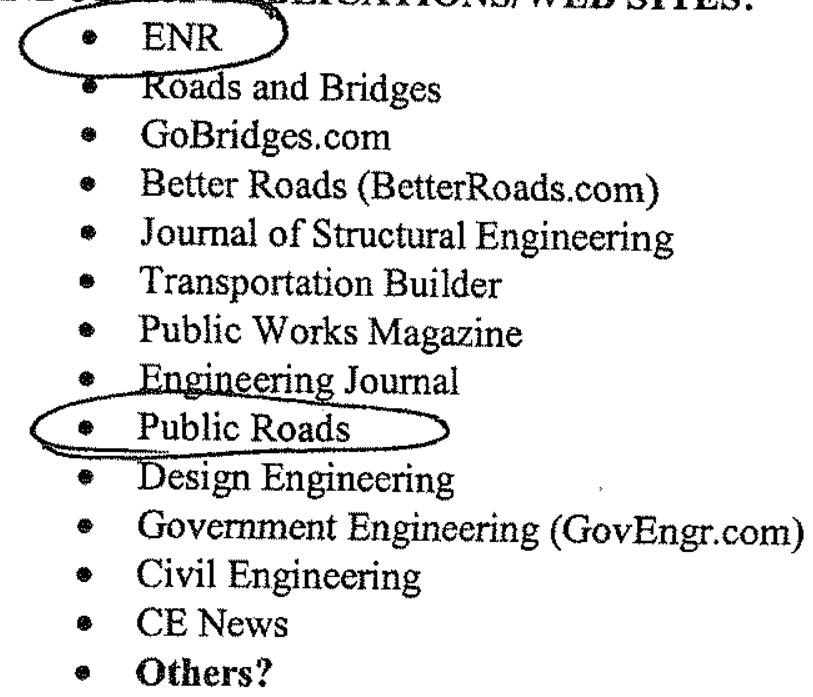

- INDUSTRY CONFERENCES (name which ones)

AASHTO Subcommittee on Bridges and Structures

- PROFESSIONAL ORGANIZATION NEWSLETTER?

- NACE?

- Others?

- WER SITES
- FHWA
- steel.org
- Steelbridges.org
- Others? 


\section{Research Statement}

The Federal Highway Administration in conjunction with the American Iron and Steel Institute [AISI] has recently conducted two workshops focused on developing ideas for improved steel bridge construction. One of the target areas of these workshops has been to develop design standards for short span steel bridges. As a result, the AISI Short Span Steel Bridge Alliance has contracted with Dr. Karl Barth at West Virginia University to conduct a survey of State DOT's and County Engineers. The focus of this survey is to study and catalog statistics and methods employed in short-span bridge design and construction. The overall projected outcome of this research is a best practices manual for the design and construction of short-span steel bridges (i.e. bridges up to $140 \mathrm{ft}$.) and a table outlining suggested pre-selected steel beam sizes and shapes for given span lengths.

\section{Part I. General Information}

Date:

Time:

Agency / DOH:

Name: Steven P. Beck

Position / Title: Bridge Design Supervising Engineer

Address: VanWagoner Building

425 W. Ottawa St

PO Box 30050

Lansding MI 48909

Phone:

E-mail: becks2@michigan.gov 
Other Information:

\section{Part II. General Questions}

1. If possible, please provide a list of bridges built in your region in the past year along with their respective span lengths, whether they are simple or continuous span, cross-section widths and any other general information you can offer (ADT, wearing surface, deck and superstructure choices, substructure and pier choices, number of lanes, etc.).

No available

2. If information for question 1 is not readily available, please provide us with the following information: How many bridges were built in your region in the past year in the following length categories? Also, of those, how many bridges consisted of steel superstructures?

Not available

\begin{tabular}{|l|l|l|}
\hline Length Catggov & Nomber of Brifges & W/Sted Superstructures \\
\hline$<40 \mathrm{ft}$ & & \\
\hline $40-60 \mathrm{ft}$ & & \\
\hline $60-80 \mathrm{ft}$ & & \\
\hline $80-100 \mathrm{ft}$ & & \\
\hline $100-120 \mathrm{ft}$ & & \\
\hline $120-140 \mathrm{ft}$ & & \\
\hline
\end{tabular}


3. For the following bridge components, please specify whether you have a preferred/specified type of design and whether or not there are any particular types of bridge component that you do not approve:

\begin{tabular}{|c|c|c|c|}
\hline Briberomurion & Whorence & 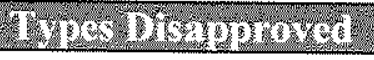 & Brret bxphathen \\
\hline Decking Systems & $\begin{array}{l}\text { Circle Choice } \\
\frac{\text { Cast-in-place }}{\text { concrete }} \\
\text { Precast concrete } \\
\text { panels } \\
\text { Steel stay-in-place } \\
\text { formwork } \\
\text { Other (list): }\end{array}$ & & \\
\hline $\begin{array}{l}\text { Railing/Guardrail } \\
\text { Systems }\end{array}$ & $\begin{array}{l}\text { Crash tested } \\
\text { concrete barrier }\end{array}$ & & \\
\hline $\begin{array}{l}\text { Topping/Wearing } \\
\text { Surfaces }\end{array}$ & $\begin{array}{l}\text { Concrete deck, no } \\
\text { separate wearing } \\
\text { course }\end{array}$ & & \\
\hline $\begin{array}{l}\text { Bridge } \\
\text { Superstructures }\end{array}$ & $\begin{array}{l}\text { Concrete } \\
\text { prestressed I beams } \\
\text { Concrete box beams } \\
\text { Steel beam, in that } \\
\text { order }\end{array}$ & & \\
\hline Abutments & $\begin{array}{l}\text { Cast in place } \\
\text { concrete }\end{array}$ & & \\
\hline Pier Systems & Cast in place & & \\
\hline
\end{tabular}


4. Do you have typical standards for cross-section widths and girder spacings? If so, please provide.

See MDOT website

http://mdotwas1.mdot.state.mi.us/public/design/englishbridgeguides/

5. Do you have different design specifications for low-volume roads versus high-volume roads? If so, what are they?

bridge design is the same, road geometry differs - see MDOT Road std plans ex.htm

http://mdotwas1.mdot.state.mi.us/public/design/englishstandardplans/ind road manual

_http://mdotwas 1.mdot.state.mi.us/public/design/englishroadmanual/

6. Do you use any bridge analysis or design software? If so, what brand of software is used?

in house bridge

program

7. Do you use any bridge design/component standards (or templates)? Examples may include beam sizes for different span lengths and roadway widths. If you have any, are they available on the web?

no

8. Do you use modular bridge systems?

rarely 
9. If a best practices manual for accelerated construction/modular bridge systems was developed, what would you like to see included? For example pre-selected beam sizes, cross-sections, etc.

10. Do you use the AASHTO LRFD specified load factors/combinations or different load factors/combinations? If different, what are they? follow

LRFD

11. Would a table outlining pre-selected steel beam sizes and shapes for given span lengths based on AASHTO LRFD Bridge Design Specifications be useful for assisting in your design development process?

possibly for preliminary

design

12. What is your preferred material choice for short-span bridges? Why?

$\begin{array}{llll}\text { concrete } & - & \text { best } & \text { life }\end{array}$

13. Are there any other comments that you have that you feel might be relevant to this study? 
14. What are your most important sources for bridge design and construction technical information and industry news? (Circle which are relevant)

- INDUSTRY PUBLICATIONS/WEB SITES:

- ENR

- Roads and Bridges

- GoBridges.com

- Better Roads (BetterRoads.com)

- Journal of Structural Engineering

- Transportation Builder

- Public Works Magazine

- Engineering Journal

- Public Roads

- Design Engineering

- Government Engineering (GovEngr.com)

- Civil Engineering

- CE News

- Others?

- INDUSTRY CONFERENCES (name which ones)

- PROFESSIONAL ORGANIZATION NEWSLETTER?

- NACE?

- Others?

- WEB SITES

- FHWA

- steel.org

- Steelbridges.org

- Others? 


\section{$\underline{\text { Research Statement }}$}

The Federal Highway Administration in conjunction with the American Iron and Steel Institute [AISI] has recently conducted two workshops focused on developing ideas for improved steel bridge construction. One of the target areas of these workshops has been to develop design standards for short span steel bridges. As a result, the AISI Short Span Steel Bridge Alliance has contracted with Dr. Karl Barth at West Virginia University to conduct a survey of State DOT's and County Engineers. The focus of this survey is to study and catalog statistics and methods employed in short-span bridge design and construction. The overall projected outcome of this research is a best practices manual for the design and construction of short-span steel bridges (i.e. bridges up to $140 \mathrm{ft}$.) and a table outlining suggested pre-selected steel beam sizes and shapes for given span lengths.

\section{Part I. General Information}

Date: $\underline{11 / 19 / 09}$

Time: 9:00 AM

Agency / DOH: Minnesota Department of Transportation - Bridge Office

Name: Daniel Dorgan

Position / Title: State Bridge Engineer

Address: 3485 Hadley Avenue North, Oakdale MN 55128-3307

Phone: $\underline{651-366-4501}$

E-mail; dan.dorgan@state.mn.us

Other Information: 


\section{Part II. General Questions}

1. If possible, please provide a list of bridges built in your region in the past year along with their respective span lengths, whether they are simple or continuous span, cross-section widths and any other general information you can offer (ADT, wearing surface, deck and superstructure choices, substructure and pier choices, number of lanes, etc.).

2. If information for question 1 is not readily available, please provide us with the following information: How many bridges were built in your region in the past year in the following length categories? Also, of those, how many bridges consisted of steel superstructures?

\begin{tabular}{|c|c|c|}
\hline Eengh Caregory & Number of Britges & W/Sred Supersintetures \\
\hline$<40 \mathrm{ft}$ & 0 & 0 \\
\hline $40-60 \mathrm{ft}$ & 0 & 0 \\
\hline $60-80 \mathrm{ft}$ & 3 & 0 \\
\hline $80-100 \mathrm{ft}$ & 6 & 0 \\
\hline $100-120 \mathrm{ft}$ & 1 & 0 \\
\hline $120-140 \mathrm{ft}$ & 5 & 0 \\
\hline
\end{tabular}


For the following bridge components, please specify whether you have a $\mathrm{preferred} / \mathrm{specified} \mathrm{type} \mathrm{of} \mathrm{design} \mathrm{and} \mathrm{whether} \mathrm{or} \mathrm{not} \mathrm{there} \mathrm{are} \mathrm{any} \mathrm{particular} \mathrm{types}$ of bridge component that you do not approve:

\begin{tabular}{|c|c|c|c|}
\hline Britige Comporten & Prefeneired & Troes Disupproved & Butef Explatiation \\
\hline Decking Systems & $\begin{array}{l}\text { Circle Choice } \\
\text { Preferred system is } \\
\text { Cast-in-place } \\
\text { concrete } \\
\text { Precast concrete } \\
\text { panels } \\
\text { Steel stay-in-place } \\
\text { formwork } \\
\text { Other (list): }\end{array}$ & $\begin{array}{l}\text { We generally avoid } \\
\text { steel stay in place } \\
\text { since we cannot } \\
\text { inspect the underside } \\
\text { of the concrete deck } \\
\text { with SIP formwork. } \\
\text { Therefore only used } \\
\text { in special situations.. }\end{array}$ & $\begin{array}{l}\text { Have used precast } \\
\text { panels with CIP } \\
\text { topping but } \\
\text { experienced } \\
\text { excessive cracking. }\end{array}$ \\
\hline $\begin{array}{l}\text { Railing/Guardrail } \\
\text { Systems }\end{array}$ & $\begin{array}{l}\text { Generally use } \\
\text { concrete J rail. Also } \\
\text { use concrete base } \\
\text { with metal rail } \\
\text { above to provide } \\
\text { more "see thru" rail }\end{array}$ & & \\
\hline $\begin{array}{l}\text { Topping/Wearing } \\
\text { Surfaces }\end{array}$ & $\begin{array}{l}\text { Either none or } \\
\text { concrete overlay }\end{array}$ & $\begin{array}{l}\text { Bituminous with } \\
\text { membrane systems } \\
\text { were unsuccessful in } \\
\text { past. }\end{array}$ & \\
\hline $\begin{array}{l}\text { Bridge } \\
\text { Superstructures }\end{array}$ & Use a variety & & \\
\hline Abutments & $\begin{array}{l}\text { Integral where } \\
\text { possible to } \\
\text { eliminate joints }\end{array}$ & & \\
\hline
\end{tabular}




\begin{tabular}{|l|l|l|l|}
\hline Pier Systems & $\begin{array}{l}\text { Cast in place } \\
\text { concrete or pile } \\
\text { bents with a cap }\end{array}$ & & \\
\hline
\end{tabular}

3. Do you have typical standards for cross-section widths and girder spacings? If so, please provide.

Yes. Based on ADT the width and shoulder width varies. Information is in our LRFD Bridge Design Manual on our webstie.

4. Do you have different design specifications for low-volume roads versus high-volume roads? If so, what are they?

Roadway widths are slightly less for low volume. The actual liveload requirements are

the same.

5. Do you use any bridge analysis or design software? If so, what brand of software is used?

MDX, Descus, Merlin-Dash, PS Beam, Conspan, and mathcad systems developed house.

6. Do you use any bridge design/component standards (or templates)? Examples may include beam sizes for different span lengths and roadway widths. If you have any, are they available on the web?

Have standard details for our prestressed concrete beams and slabs that are on our website. 
7. Do you use modular bridge systems?

Modular systems are used for retaining walls and at times wingwalls and abutment faces. Have only had one bridge with precast substructures..

8. If a best practices manual for accelerated construction/modular bridge systems was developed, what would you like to see included? For example pre-selected beam sizes, cross-sections, etc.

FHWA already has a website for precast systems for accelerated construction with details and projects. Mainly looking for the specific details that another owner used when we see a system that appears to have potential for our use..

9. Do you use the AASHTO LRFD specified load factors/combinations or different load factors/combinations? If different, what are they?

Yes we use LRFD but also have some additional load cases described in our Design Manual on line.

10. Would a table outlining pre-selected steel beam sizes and shapes for given span lengths based on AASHTO LRFD Bridge Design Specifications be useful for assisting in your design development process?

$\begin{array}{llll}\text { No, we can those } & \text { wesign thes }\end{array}$ quickly.

11. What is your preferred material choice for short-span bridges? Why?

Prestressed beam with cast in place decks, or precast boxes for very short spans. Those types are preferred due to least costly and meet performance needs. 
12. Are there any other comments that you have that you feel might be relevant to this study?

Unfortunately, our experience has been that steel superstructures are no longer competitive in price with prestressed concrete for spans under 150 feet. When we have designed steel in those span lengths in the last decade the contractors value engineer the design to prestressed. 
13. What are your most important sources for bridge design and construction technical information and industry news? (Circle which are relevant)

- INDUSTRY PUBLICATIONS/WEB SITES:

- ENR - yes

- Roads and Bridges

- GoBridges.com

- Better Roads (BetterRoads.com)

- Journal of Structural Engineering

- Transportation Builder

- Public Works Magazine

- Engineering Journal

- Public Roads

- Design Engineering

- Government Engineering (GovEngr.com)

- Civil Engineering - yes

- CE News

- Others? Modern STeel

- INDUSTRY CONFERENCES (name which ones) NSBA, ASBI and PCI

- PROFESSIONAL ORGANIZATION NEWSLETTER?

- NACE?

- Others?

- WEB SITES

- FHWA - yes

- steel.org -yes

- Steelbridges.org

- Others? 


\section{$\underline{\text { Research Statement }}$}

The Federal Highway Administration in conjunction with the American Iron and Steel Institute [AISI] has recently conducted two workshops focused on developing ideas for improved steel bridge construction. One of the target areas of these workshops has been to develop design standards for short span steel bridges. As a result, the AISI Short Span Steel Bridge Alliance has contracted with Dr. Karl Barth at West Virginia University to conduct a survey of State DOT's and County Engineers. The focus of this survey is to study and catalog statistics and methods employed in short-span bridge design and construction. The overall projected outcome of this research is a best practices manual for the design and construction of short-span steel bridges (i.e. bridges up to $140 \mathrm{ft}$.) and a table outlining suggested pre-selected steel beam sizes and shapes for given span lengths.

\section{Part I. General Information}

Date:

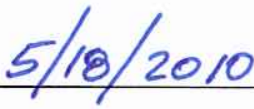

Time:

Agency / DOH: Mississippi Department of Transponlation Name: Mitch Carr

Position/Title: Bridge Engineer

Address: P.0. Box 1850

jackson, ms 39215-1850

Phone: $601-359-7200$

E-mail:_mcarr@mdot.state.ms.us

Other Information: 


\section{Part II. General Questions}

1. If possible, please provide a list of bridges built in your region in the past year along with their respective span lengths, whether they are simple or continuous span, cross-section widths and any other general information you can offer (ADT, wearing surface, deck and superstructure choices, substructure and pier choices, number of lanes, etc.).

2. If information for question 1 is not readily available, please provide us with the following information: How many bridges were built in your region in the past year in the following length categories? Also, of those, how many bridges consisted of steel superstructures?

\begin{tabular}{|c|c|c|}
\hline Leorgth Chtegory & Niminber of bridiges & W// Streol Superstmuctumes \\
\hline$<40 \mathrm{ft}$ & & \\
\hline $40-60 \mathrm{ft}$ & & \\
\hline $60-80 \mathrm{ft}$ & & \\
\hline $80-100 \mathrm{ft}$ & & \\
\hline $100-120 \mathrm{ft}$ & & \\
\hline $120-140 \mathrm{ft}$ & & \\
\hline
\end{tabular}


3. For the following bridge components, please specify whether you have a preferred/specified type of design and whether or not there are any particular types of bridge component that you do not approve:

\begin{tabular}{|c|c|c|c|}
\hline Bridge Component & Pheference & Types Disaguroved & Bricef Dinglamation \\
\hline Decking Systems & $\begin{array}{l}\text { Circle Choice } \\
\begin{array}{c}\text { Cast-in-place } \\
\text { concrete }\end{array} \\
\begin{array}{l}\text { Precast concrete } \\
\text { panels }\end{array} \\
\begin{array}{l}\text { Steel stay-in-place } \\
\text { formwork }\end{array} \\
\text { Other (list): }\end{array}$ & $\begin{array}{l}\text { Precast concrete } \\
\text { panels } \\
\text { steel stay-in- } \\
\text { place formwork }\end{array}$ & $\begin{array}{l}\text { reflective cracking } \\
\text { Notins poctable } \\
\text { from bottom; } \\
\text { holds woter/solts } \\
\text { in the slab. }\end{array}$ \\
\hline $\begin{array}{l}\text { Railing/Guardrail } \\
\text { Systems }\end{array}$ & $\begin{array}{l}\text { Castin place or } \\
\text { slipform concrete } \\
\text { bridgerail }\end{array}$ & & \\
\hline $\begin{array}{l}\text { Topping/Wearing } \\
\text { Surfaces }\end{array}$ & $\begin{array}{l}\text { Generslly not } \\
\text { used. Concrete } \\
\text { deck is the } \\
\text { riding Surface }\end{array}$ & & \\
\hline $\begin{array}{l}\text { Bridge } \\
\text { Superstructures }\end{array}$ & $\begin{array}{l}\text { prestressad } \\
\text { concrete Girders, } \\
\text { steel girders, } \\
\text { steel tubgirders }\end{array}$ & & \\
\hline Abutments & $\begin{array}{l}\text { Cast-in-place } \\
\text { concrete on } \\
\text { driven piles or } \\
\text { drilled shafts. }\end{array}$ & & \\
\hline Pier Systems & $\begin{array}{l}\text { Cast-y -place } \\
\text { concrete on } \\
\text { supported by ping } \\
\text { or drilled shafts }\end{array}$ & & \\
\hline
\end{tabular}


4. Do you have typical standards for cross-section widths and girder spacings? If so, please provide.

No.

5. Do you have different design specifications for low-volume roads versus high-volume roads? If so, what are they?

No.

6. Do you use any bridge analysis or design software? If so, what brand of software is used?

Conspan; RC Pier, Merlin Dash; SAP 2000; Seisab

7. Do you use any bridge design/component standards (or templates)? Examples may include beam sizes for different span lengths and roadway widths. If you have any, are they available on the web?

No.

8. Do you use modular bridge systems?

No.

9. If a best practices manual for accelerated construction/modular bridge systems was developed, what would you like to see included? For example pre-selected beam sizes, cross-sections, etc.

No Comments at this time. 
10. Do you use the AASHTO LRFD specified load factors/combinations or different load factors/combinations? If different, what are they?

AASHTO LRFD specified load Factors

11. Would a table outlining pre-selected steel beam sizes and shapes for given span lengths based on AASHTO LRFD Bridge Design Specifications be useful for assisting in your design development process?

Yes

12. What is your preferred material choice for short-span bridges? Why?

Prestressed Concrete Girders - Durability, Low Mointenance,

Low Cost, more tolorance to over-londs, Availibility of Fabricators, Contractors like them.

13. Are there any other comments that you have that you feel might be relevant to this study?

$N / A$ 
14. What are your most important sources for bridge design and construction technical information and industry news? (Circle which are relevant)

- INDUSTRYPUBLICATIONS/WEB SITES:

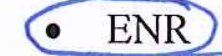

- Roads and Bridges

- GoBridges.com

- Better Roads (BetterRoads.com)

- Journal of Structural Engineering

- Transportation Builder

- Public Works Magazine

- Engineering Journal

- Public Roads

- Design Engineering

- Government Engineering (GovEngr.com)

- Civil Engineering

- CE News

- Others?

- INDUSTRY CONFERENCES (name which ones) AASHTO SCOBS

- PROFESSIONAL ORGANIZATION NEWSLETTER?

- NACE?

- Others?

- WEB SITES

- FHWA

- steel.org

- Steelbridges.org

- Others? 


\section{$\underline{\text { Research Statement }}$}

The Federal Highway Administration in conjunction with the American Iron and Steel Institute [AISI] has recently conducted two workshops focused on developing ideas for improved steel bridge construction. One of the target areas of these workshops has been to develop design standards for short span steel bridges. As a result, the AISI Short Span Steel Bridge Alliance has contracted with Dr. Karl Barth at West Virginia University to conduct a survey of State DOT's and County Engineers. The focus of this survey is to study and catalog statistics and methods employed in short-span bridge design and construction. The overall projected outcome of this research is a best practices manual for the design and construction of short-span steel bridges (i.e. bridges up to $140 \mathrm{ft}$.) and a table outlining suggested pre-selected steel beam sizes and shapes for given span lengths.

\section{Part I. General Information}

Date: 18 November 2009

Time: $\underline{\text { :00 AM }}$

Agency / DOH: Missouri Department of Transportation

Name: Kent Nelson, P.E.

Position / Title: Fabrication Operations Engineer

Address: P.O. Box 270

Jefferson City, MO 65102

Phone: (573) 751-3693

E-mail: kent.nelson@modot.mo.gov

Other Information: 


\section{Part II. General Questions}

1. If possible, please provide a list of bridges built in your region in the past year along with their respective span lengths, whether they are simple or continuous span, cross-section widths and any other general information you can offer (ADT, wearing surface, deck and superstructure choices, substructure and pier choices, number of lanes, etc.).

2. If information for question 1 is not readily available, please provide us with the following information: How many bridges were built in your region in the past year in the following length categories? Also, of those, how many bridges consisted of steel superstructures? See Attached Spreadsheet

\begin{tabular}{|c|c|c|}
\hline Length Caresony & Number of Britiges & Wi Sted Sypentructires \\
\hline$<40 \mathrm{ft}$. & & \\
\hline $40-60 \mathrm{ft}$ & & \\
\hline $60-80 \mathrm{ft}$ & & \\
\hline $80-100 \mathrm{ft}$ & & \\
\hline $100-120 \mathrm{ft}$ & & \\
\hline $120-140 \mathrm{ft}$ & & \\
\hline
\end{tabular}


3. For the following bridge components, please specify whether you have a preferred/specified type of design and whether or not there are any particular types of bridge component that you do not approve:

\begin{tabular}{|c|c|c|c|}
\hline Bringe Component & Prefcreine & Typer Disapporyed & Bref Exyelanation \\
\hline Decking Systems & $\begin{array}{l}\text { Circle Choice } \\
\text { Cast-in-place } \\
\text { concrete } \\
\text { Precast concrete } \\
\text { panels } \\
\text { Steel stay-in-place } \\
\text { formwork } \\
\text { Other (list): }\end{array}$ & & \\
\hline $\begin{array}{l}\text { Railing/Guardrail } \\
\text { Systems }\end{array}$ & $\begin{array}{l}\text { NJ Shape Type B } \\
\text { and Type D }\end{array}$ & & \\
\hline $\begin{array}{l}\text { Topping/Wearing } \\
\text { Surfaces }\end{array}$ & $\begin{array}{l}\text { Modified Latex } \\
\text { Concrete } \\
\text { Low Slump Concrete } \\
\text { Silica Fume Concrete } \\
\text { Asphalt for worn decks }\end{array}$ & $\begin{array}{l}\text { Integral design } \\
\text { Initial wearing } \\
\text { surface added at time } \\
\text { of new deck } \\
\text { construction }\end{array}$ & \\
\hline $\begin{array}{l}\text { Bridge } \\
\text { Superstructures }\end{array}$ & $\begin{array}{l}\text { P/C P/S Conc Box Bms } \\
\text { P/C P/S Conc I-Girders } \\
\text { P/C P/S Conc Bulb T } \\
\text { Cont. Comp Wide } \\
\text { Flange } \\
\text { Cont. Comp. Plate Gdr }\end{array}$ & & \\
\hline Abutments & $\begin{array}{l}\text { Integral Conc End Bent } \\
\text { on Pile } \\
\text { Non-Integral Conc Enf } \\
\text { Bent on Pile } \\
\text { Integral and Non Itegral } \\
\text { Conc on spread ftg } \\
\text { Conc Semi-Deep Abut } \\
\text { on pile }\end{array}$ & & \\
\hline Pier Systems & $\begin{array}{l}\text { Multi-column bents on } \\
\text { pile, spread footing or } \\
\text { drilled shaft } \\
\text { Pile cap bents }\end{array}$ & & \\
\hline
\end{tabular}


4. Do you have typical standards for cross-section widths and girder spacings? If so, please provide.

Yes

5. Do you have different design specifications for low-volume roads versus high-volume roads? If so, what are they?

We have different requrements for major and minor rooutes as indicated by our Engineering Policy Guide. Final designs are based on site specific conditions.

6. Do you use any bridge analysis or design software? If so, what brand of software is used?

Conspan for concrete superstructures, MDX for steel superstrucutre, RCPier for substructure design. SAP 2000

7. Do you use any bridge design/component standards (or templates)? Examples may include beam sizes for different span lengths and roadway widths. If you have any, are they available on the web?

We have general guides for superstructure selection but no component tables or standards

\section{Do you use modular bridge systems?}

Primarily for temporary bridges only.

9. If a best practices manual for accelerated construction/modular bridge systems was developed, what would you like to see included? For example pre-selected beam sizes, cross-sections, etc.

Loadings used; loadings to substructure for quick design; flange widths for including shear connectors and precast panels for decking; splice locations (if needed); high performance materials including both steel and concrete; slab designs; modular construction methods such as twin lifts; modular transportation for construction off site. 
10. Do you use the AASHTO LRFD specified load factors/combinations or different load factors/combinations? If different, what are they?

Currently use AASHTO. We are researching using different live load factors for strength limit state only - they are unknown but expected to be less for some strucutres based on ADTT.

11. Would a table outlining pre-selected steel beam sizes and shapes for given span lengths based on AASHTO LRFD Bridge Design Specifications be useful for assisting in your design development process?

Maybe: Design is site specific dependent so standard tables are difficult to use.

12. What is your preferred material choice for short-span bridges? Why?

Precast prestressed concrete: Construction costs are significantly less for these structures compared to steel structures in the span ranges up to 120 feet.

13. Are there any other comments that you have that you feel might be relevant to this study?

None 
14. What are your most important sources for bridge design and construction technical information and industry news? (Circle which are relevant)

- INDUSTRY PUBLICATIONS/WEB SITES:

- ENR - Yes

- Roads and Bridges - Yes

- GoBridges.com

- Better Roads (BetterRoads.com) - Yes

- Journal of Structural Engineering

- Transportation Builder

- Public Works Magazine

- Engineering Journal

- Public Roads - Yes

- Design Engineering

- Government Engineering (GovEngr.com)

- Civil Engineering - Yes

- CE News

- Others?

- INDUSTRY CONFERENCES (name which ones)

Wonld Steel Bridge Symposium

- PROFESSIONAL ORGANIZATION NEWSLETTER?

- NACE? - Yes

- Others?

- JPCL from SSPC

- WEB SITES

- FHWA -yes

- steel.org

- Steelbridges.org - yes

- Others? - yes 


\section{$\underline{\text { Research Statement }}$}

The Federal Highway Administration in conjunction with the American Iron and Steel Institute [AISI] has recently conducted two workshops focused on developing ideas for improved steel bridge construction. One of the target areas of these workshops has been to develop design standards for short span steel bridges. As a result, the AISI Short Span Steel Bridge Alliance has contracted with Dr. Karl Barth at West Virginia University to conduct a survey of State DOT's and County Engineers. The focus of this survey is to study and catalog statistics and methods employed in short-span bridge design and construction. The overall projected outcome of this research is a best practices manual for the design and construction of short-span steel bridges (i.e. bridges up to $140 \mathrm{ft}$.) and a table outlining suggested pre-selected steel beam sizes and shapes for given span lengths.

\section{Part I. General Information}

Date: December 18, 2009

Time:

Agency / DOH: Montana

Name: Kent Barnes

Position / Title: Bridge Engineer

Address: 2701 prospect, Helena MT 59620

Phone: 406-444-6260

E-mail: kbarnes@mt.gov

Other Information: 


\section{Part II. General Questions}

1. If possible, please provide a list of bridges built in your region in the past year along with their respective span lengths, whether they are simple or continuous span, cross-section widths and any other general information you can offer (ADT, wearing surface, deck and superstructure choices, substructure and pier choices, number of lanes, etc.).

2. If information for question 1 is not readily available, please provide us with the following information: How many bridges were built in your region in the past year in the following length categories? Also, of those, how many bridges consisted of steel superstructures?

\begin{tabular}{|l|l|l|}
\hline Tengh Catciory & Nimber of Brighes & Wi Sted Suberstruturcs \\
\hline$<40 \mathrm{ft}$ & & \\
\hline $40-60 \mathrm{ft}$ & & \\
\hline $60-80 \mathrm{ft}$ & & \\
\hline $80-100 \mathrm{ft}$ & & \\
\hline $100-120 \mathrm{ft}$ & & \\
\hline $120-140 \mathrm{ft}$ & & \\
\hline
\end{tabular}


3. For the following bridge components, please specify whether you have a preferred/specified type of design and whether or not there are any particular types of bridge component that you do not approve:

\begin{tabular}{|c|c|c|c|}
\hline Brrigc Comuroment & Berereirs & 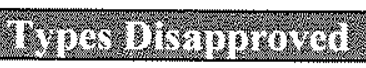 & 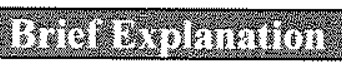 \\
\hline Decking Systems & $\begin{array}{l}\text { Circle Choice } \\
\begin{array}{l}\text { Cast-in-place } \\
\text { concrete }\end{array} \\
\begin{array}{c}\text { Precastconcrete } \\
\text { panels }\end{array} \\
\text { Steel-sty-in-place } \\
\text { formwork } \\
\text { Other(list): }\end{array}$ & & \\
\hline $\begin{array}{l}\text { Railing/Guardrail } \\
\text { Systems }\end{array}$ & $\begin{array}{l}\text { We have several } \\
\text { approved rails we } \\
\text { use. Must meet } \\
\text { crash testing or } \\
\text { equivalent approval. }\end{array}$ & & \\
\hline $\begin{array}{l}\text { Topping/Wearing } \\
\text { Surfaces }\end{array}$ & & & \\
\hline $\begin{array}{l}\text { Bridge } \\
\text { Superstructures }\end{array}$ & & & \\
\hline Abutments & Semi-integral & & \\
\hline Pier Systems & Any & & \\
\hline
\end{tabular}


4. Do you have typical standards for cross-section widths and girder spacings? If so, please provide.

Standard

roadway

widths

only

5. Do you have different design specifications for low-volume roads versus high-volume roads? If so, what are they?

No

6. Do you use any bridge analysis or design software? If so, what brand of software is used?

Both commercial and in-house software. Bentley, MDX, Leap, Merlin-Dash, Virtis/Opis, Siesab $\quad$ PSBeam

7. Do you use any bridge design/component standards (or templates)? Examples may include beam sizes for different span lengths and roadway widths. If you have any, are they available on the web?

No

8. Do you use modular bridge systems?

No

standards.

current

9. If a best practices manual for accelerated construction/modular bridge systems was developed, what would you like to see included? For example pre-selected beam sizes, cross-sections, etc. 
details.

10. Do you use the AASHTO LRFD specified load factors/combinations or different load factors/combinations? If different, what are they?

LRFD

11. Would a table outlining pre-selected steel beam sizes and shapes for given span lengths based on AASHTO LRFD Bridge Design Specifications be useful for assisting in your design development process?

Yes

12. What is your preferred material choice for short-span bridges? Why?

Prestress

Concrete.

Cost.

13. Are there any other comments that you have that you feel might be relevant to this study? 
14. What are your most important sources for bridge design and construction technical information and industry news? (Circle which are relevant)

- INDUSTRY PUBLICATIONS/WEB SITES:

- ENR

- Roads and Bridges

- GoBridges.com

- Better Roads (BetterRoads.com)

- Journal of Structural Engineering

- Transportation Builder

- Public Works Magazine

- Engineering Journal

- Public Roads

- Design Engineering

- Government Engineering (GovEngr.com)

- Civil Engineering

- CE News

- Others? AASHTO, FHWA

- INDUSTRY CONFERENCES (name which ones)

- PROFESSIONAL ORGANIZATION NEWSLETTER?

- NACE?

- Others?

- WEB SITES

- FHWA

- steel.org

- Steelbridges.org

- Others? 


\section{$\underline{\text { Research Statement }}$}

The Federal Highway Administration in conjunction with the American Iron and Steel Institute [AISI] has recently conducted two workshops focused on developing ideas for improved steel bridge construction. One of the target areas of these workshops has been to develop design standards for short span steel bridges. As a result, the AISI Short Span Steel Bridge Alliance has contracted with Dr. Karl Barth at West Virginia University to conduct a survey of State DOT's and County Engineers. The focus of this survey is to study and catalog statistics and methods employed in short-span bridge design and construction. The overall projected outcome of this research is a best practices manual for the design and construction of short-span steel bridges (i.e. bridges up to $140 \mathrm{ft}$.) and a table outlining suggested pre-selected steel beam sizes and shapes for given span lengths.

\section{Part l. General Information}

Date: November $23^{\text {rd }}, 2009$

Time: $11: 45$ am

Agency / DOH: Nebraska Department Of Road

Name: Fouad Jaber

Position / Title: Assistant State Bridge engineer

Address: 1500 Highway 2 PO Box 94759

Lincoln, Nebraska $68509-4759$

Phone: 402-479-3967

E-mail: fouad.jaber@nebraska.gov

Other Information: 


\section{Part II. General Questions}

1. If possible, please provide a list of bridges built in your region in the past year along with their respective span lengths, whether they are simple or continuous span, cross-section widths and any other general information you can offer (ADT, wearing surface, deck and superstructure choices, substructure and pier choices, number of lanes, etc.).

2. If information for question 1 is not readily available, please provide us with the following information: How many bridges were built in your region in the past year in the following length categories? Also, of those, how many bridges consisted of steel superstructures?

\begin{tabular}{|c|c|c|}
\hline Eengih Catcrony & Nimber of Bridges & W/ Stecl Suporstrietires \\
\hline$<40 \mathrm{ft}$ & 86 & 11-steel simple span \\
\hline $40-60 \mathrm{ft}$ & 22 & 12-steelsimple span \\
\hline $60-80 \mathrm{ft}$ & 6 & 2-simple span \\
\hline $80-100 \mathrm{ft}$ & 10 & 4-steel simple span \\
\hline $100-120 \mathrm{ft}$ & 4 & 1-steel simple span \\
\hline $120-140 \mathrm{ft}$ & 5 & 0 \\
\hline
\end{tabular}


3. For the following bridge components, please specify whether you have a preferred/specified type of design and whether or not there are any particular types of bridge component that you do not approve:

\begin{tabular}{|c|c|c|c|}
\hline Bridge Comironent & Breferense & Wpes olitupproved & Brief Drophation \\
\hline Decking Systems & $\begin{array}{l}\text { Circle Choice } \\
\text { Cast-in-place } \\
\text { concrete } \\
\text { Precast concrete } \\
\text { panels } \\
\text { Steel stay-in-place } \\
\text { formwork } \\
\text { Other (list): }\end{array}$ & $\begin{array}{l}\text { We don't use } \\
\text { concrete stay-in- } \\
\text { place formwork. }\end{array}$ & $\begin{array}{l}\text { For off system } \\
\text { bridges. Timber, } \\
\text { CMP were also } \\
\text { used. }\end{array}$ \\
\hline $\begin{array}{l}\text { Railing/Guardrail } \\
\text { Systems }\end{array}$ & $\begin{array}{l}\text { Concrete Rail } \\
\text { Tubular thrie beam } \\
\text { (Approaches) }\end{array}$ & No new $\mathrm{W}$ beam & \\
\hline $\begin{array}{l}\text { Topping/Wearing } \\
\text { Surfaces }\end{array}$ & $\begin{array}{l}\text { Nothing on new } \\
\text { bridges } \\
\text { Silica fume on } \\
\text { rehabbed bridges }\end{array}$ & $\begin{array}{l}\text { No asphalt overlay } \\
\text { without a membrane }\end{array}$ & \\
\hline $\begin{array}{l}\text { Bridge } \\
\text { Superstructures }\end{array}$ & $\begin{array}{l}\text { I-girder type for } \\
\text { steel and concrete }\end{array}$ & & \\
\hline Abutments & $\begin{array}{l}\text { Sheet pile stub } \\
\text { abutments with u- } \\
\text { wing on water } \\
\text { crossing. } \\
\text { Full integral u-wing } \\
\text { abutments on non } \\
\text { water crossing }\end{array}$ & $\begin{array}{l}\text { No back wall } \\
\text { abutments on state } \\
\text { system. } \\
\text { No deep abutment }\end{array}$ & $\begin{array}{l}\text { On off system } \\
\text {,flared wings } \\
\text { allowd }\end{array}$ \\
\hline
\end{tabular}




\begin{tabular}{|l|l|l|l|}
\hline Pier Systems & $\begin{array}{l}\text { Concrete encased } \\
\text { piles, open piles } \\
\text { bents and hammer } \\
\text { heads type piers }\end{array}$ & No timber piles. & \\
\hline
\end{tabular}

4. Do you have typical standards for cross-section widths and girder spacings? If so, please provide.

NO

5. Do you have different design specifications for low-volume roads versus high-volume roads? If so, what are they?

NO $\quad$ t B Federal mandate Allbridge has to be designed according to LRFD by October 2007. All rehab can be Either LRFD or LFD

6. Do you use any bridge analysis or design software? If so, what brand of software is used?

Steel Bridge

YES. Merlin Dash-

7. Do you use any bridge design/component standards (or templates)? Examples may include beam sizes for different span lengths and roadway widths. If you have any, are they available on the web?

$\begin{array}{llllll}\text { plans. We use standard } & \text { details } & \text { but } & \text { no } & \text { standard }\end{array}$

8. Do you use modular bridge systems? 
system

Not on state

9. If a best practices manual for accelerated construction/modular bridge systems was developed, what would you like to see included? For example pre-selected beam sizes, cross-sections, etc.

We could use this manual on off system project but not on state project

10. Do you use the AASHTO LRFD specified load factors/combinations or different load factors/combinations? If different, what are they?

— We have increased live load factor to 2.0 from 1.75 on state bridges

-Deflection of L/800 in enforced.

- We

use

our

own

geotech

factors

11. Would a table outlining pre-selected steel beam sizes and shapes for given span lengths based on AASHTO LRFD Bridge Design Specifications be useful for assisting in your design development process?

system.

Not on state system. Could be useful on off

12. What is your preferred material choice for short-span bridges? Why?

design

No preference

It's all on market prices and bridge

demands. 
13. Are there any other comments that you have that you feel might be relevant to this study? No

14.

Nebraska has a policy of providing two alternate plans : one concrete super structure and one steel superstructure

The market will decide which way to

go. 
15. What are your most important sources for bridge design and construction technical information and industry news? (Circle which are relevant)

- INDUSTRY PUBLICATIONS/WEB SITES:

- ENR

- Roads and Bridges

- GoBridges.com

- Better Roads (BetterRoads.com)

- Joumal of Structural Engineering

- Transportation Builder

- Public Works Magazine

- Engineering Journal

- Public Roads

- Design Engineering

- Government Engineering (GovEngr.com)

- Civil Engineering

- CE News

- Others?

- INDUSTRY CONFERENCES (name which ones)

- PROFESSIONAL ORGANIZATION NEWSLETTER?

- NACE?

- Others?

- WEB SITES

- FHWA

- steel.org

- Steelbridges.org

- Others? 


\section{Research Statement}

The Federal Highway Administration in conjunction with the American Iron and Steel Institute [AISI] has recently conducted two workshops focused on developing ideas for improved steel bridge construction. One of the target areas of these workshops has been to develop design standards for short span steel bridges. As a result, the AISI Short Span Steel Bridge Alliance has contracted with Dr. Karl Barth at West Virginia University to conduct a survey of State DOT's and County Engineers. The focus of this survey is to study and catalog statistics and methods employed in short-span bridge design and construction. The overall projected outcome of this research is a best practices manual for the design and construction of short-span steel bridges (i.e. bridges up to $140 \mathrm{ft}$.) and a table outlining suggested pre-selected steel beam sizes and shapes for given span lengths.

\section{Part I. General Information}

Date: $5 / 14 / 10$

Time:

Agency / DOH: NV DOT

Name: TODD STEFONOWILZ

Position / Title: STRUCTURES Division

Address:

1263 S. STEWAART ST.

CAnSOU Cit4, NV 89712

Phone: (775) $888-7550$

E-mail: tstefonowicz e dot. statenv.us

Other Information: 
Part II. General Questions

1. If possible, please provide a list of bridges built in your region in the past year along with their respective span lengths, whether they are simple or continuous span, cross-section widths and any other general information you can offer (ADT, wearing surface, deck and superstructure choices, substructure and pier choices, number of lanes, etc.).

2. If information for question 1 is not readily available, please provide us with the following information: How many bridges were built in your region in the past year in the following length categories? Also, of those, how many bridges consisted of steel superstructures?

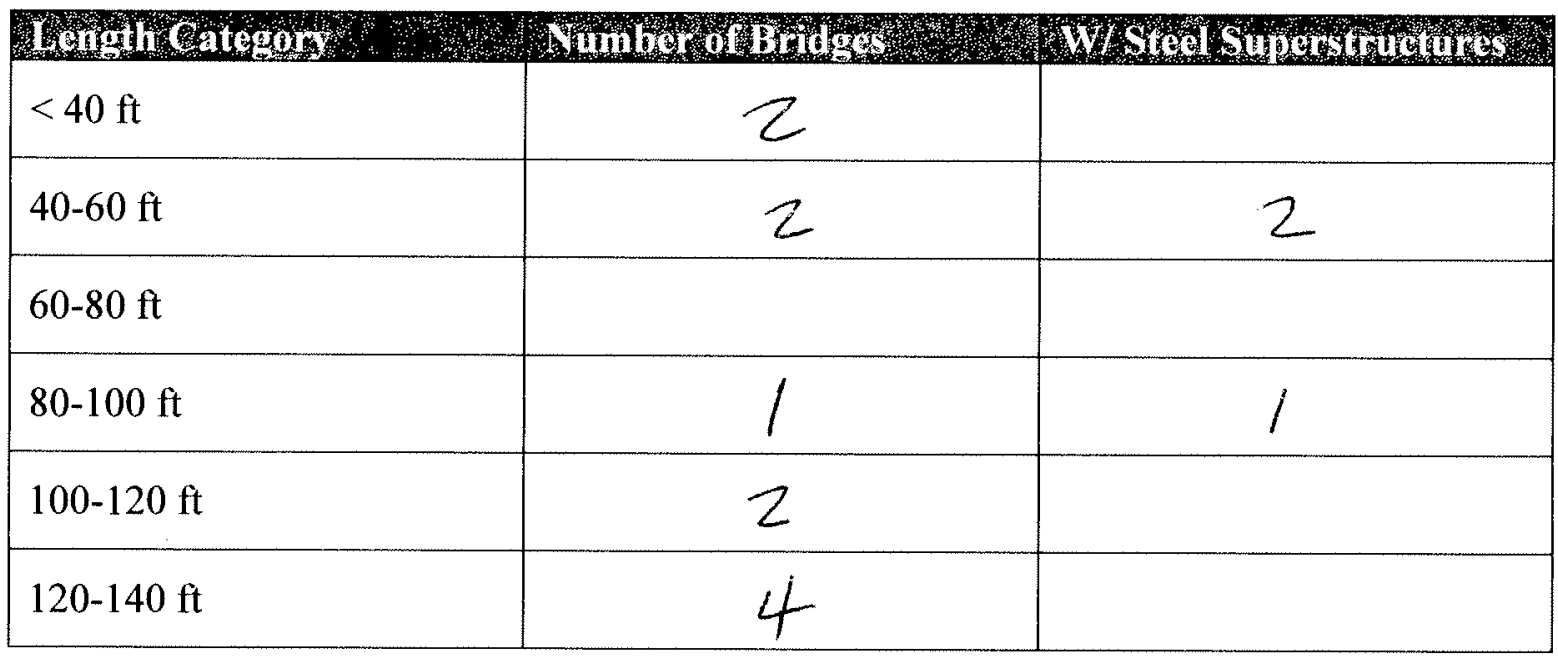


3. For the following bridge components, please specify whether you have a preferred/specified type of design and whether or not there are any particular types of bridge component that you do not approve:

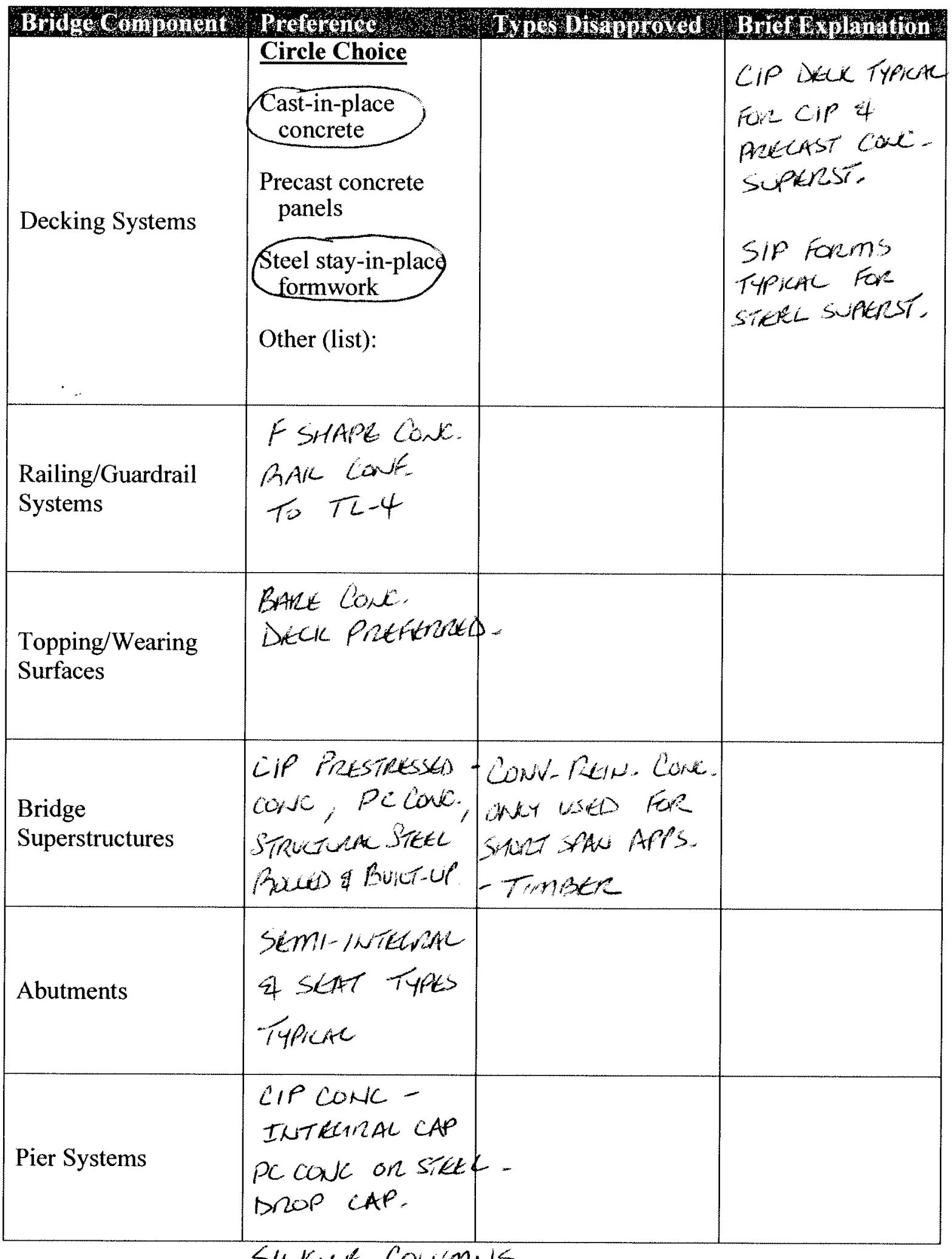

Sinciput Columns, multiple columns

OR PIER KALE. 
4. Do you have typical standards for cross-section widths and girder spacings? If so, please provide.
Girder Spacina - Per Stavetures Manda (set attached)

NO STANARD K-SECTION WIOTHS.

5. Do you have different design specifications for low-volume roads versus high-volume roads? If so, what are they?

SAME DESILN STANDARDS FOR BRIDIE DESMN-

BOADWAY WIDTH MAY BE NARROWIER CI-E

SINGLE CANE, REDUED SRUUUSERS)

6. Do you use any bridge analysis or design software? If so, what brand of software is used?

SEE ATTALAED,

7. Do you use any bridge design/component standards (or templates)? Examples may include beam sizes for different span lengths and roadway widths. If you have any, are they available on the web?

No

8. Do you use modular bridge systems?

havent constrivteis a completecy modvare bridire.

9. If a best practices manual for accelerated construction/modular bridge systems was developed, what would you like to see included? For example pre-selected beam sizes, cross-sections, etc. 
10. Do you use the AASHTO LRFD specified load factors/combinations or different load factors/combinations? If different, what are they?

VSE AASHTO LRKD

11. Would a table outlining pre-selected steel beam sizes and shapes for given span lengths based on AASHTO LRFD Bridge Design Specifications be useful for assisting in your design development process?

12. What is your preferred material choice for short-span bridges? Why?

PRESTRESSED CIP CEVRETE-LOWEST COST

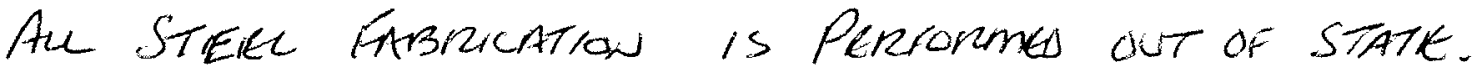

13. Are there any other comments that you have that you feel might be relevant to this study? 
14. What are your most important sources for bridge design and construction technical information and industry news? (Circle which are relevant)

- INDUSTRY PUBLICATIONS/WEB SITES:

- ENR

- Roads and Bridges

- GoBridges.com

- Better Roads (BetterRoads.com)

- Journal of Structural Engineering

- Transportation Builder

- Public Works Magazine

- Engineering Journal

- Public Roads

- Design Engineering

- Government Engineering (GovEngr.com)

- Civil Engineering

- CE News

- Others?

- INDUSTRY CONFERENCES (name which ones)

- PROFESSIONAL ORGANIZATION NEWSLETTER?

- NACE?

- Others?

Confentures

AASHTO BRIDGE SUBCOMMITTEK

- WEB SITES

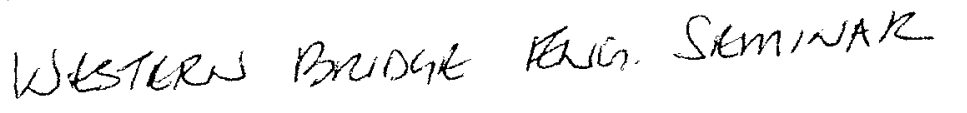

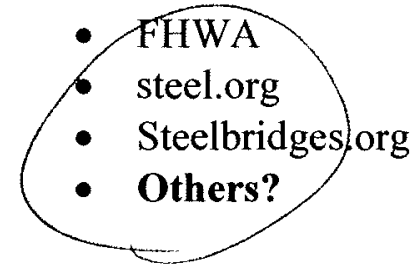
NSBA STEKL BRIDGE CONF.

VARIOUS DOT WEBSITES 


\section{$\underline{\text { Research Statement }}$}

The Federal Highway Administration in conjunction with the American Iron and Steel Institute [AISI] has recently conducted two workshops focused on developing ideas for improved steel bridge construction. One of the target areas of these workshops has been to develop design standards for short span steel bridges. As a result, the AISI Short Span Steel Bridge Alliance has contracted with Dr. Karl Barth at West Virginia University to conduct a survey of State DOT's and County Engineers. The focus of this survey is to study and catalog statistics and methods employed in short-span bridge design and construction. The overall projected outcome of this research is a best practices manual for the design and construction of short-span steel bridges (i.e. bridges up to $140 \mathrm{ft}$.) and a table outlining suggested pre-selected steel beam sizes and shapes for given span lengths.

\section{Part I. General Information}

Date: December 31, 2009

Time: $1: 00 \mathrm{pm}$ EST \pm

Agency / DOH: New Hampshire Department of Transportation - Bridge Design Bureau

Name: Mark W. Richardson, PE

Position / Title: Administrator, Bridge Design Bureau

Address: NHDOT, 7 Hazen Drive, PO Box 483, Concord, NH 03302-0483

Phone: $603-271-2731$

E-mail: mrichardson@dot.state.nh.us

Other Information: You may also contact David L. Scott, PE, NHDOT Bridge Design In-House Design Chief (dscott@dot.state.nh.us)-he compiled some of the information contained in this response. The address and telephone information is the same as that listed above. 


\section{Part II. General Questions}

1. If possible, please provide a list of bridges built in your region in the past year along with their respective span lengths, whether they are simple or continuous span, cross-section widths and any other general information you can offer (ADT, wearing surface, deck and superstructure choices, substructure and pier choices, number of lanes, etc.). Please see atrached -polf nle that hists NH bridges as requested.

2. If information for question 1 is not readily available, please provide us with the following information: How many bridges were built in your region in the past year in the following length categories? Also, of those, how many bridges consisted of steel superstructures?

\begin{tabular}{|c|c|c|}
\hline 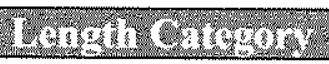 & 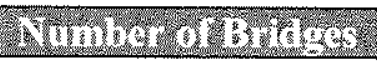 & What Sworthlemes \\
\hline$<40 \mathrm{ft}$ & 3 & (1) \\
\hline $40-60 \mathrm{ft}$ & 2 & 1 \\
\hline $60-80 \mathrm{ft}$ & 1 & 1 \\
\hline $80-100 \mathrm{ft}$ & 0 & 0 \\
\hline $100-120 \mathrm{ft}$ & 1 & 1 \\
\hline $120-140 \mathrm{ft}$ & 2 & 1 \\
\hline$>140 \mathrm{f}$ & 3 & 3 \\
\hline
\end{tabular}




\section{For the following bridge components, please specify whether you have a preferred/specified type of design and whether or not there are any particular types of bridge component that you do not approve:}

\begin{tabular}{|c|c|c|c|}
\hline $\begin{array}{l}\text { Whes } \\
\text { monnons }\end{array}$ & 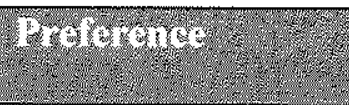 & Hots Dhrumpor & 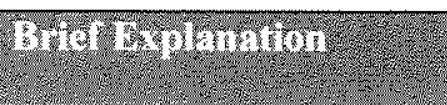 \\
\hline Decking Systems & $\begin{array}{l}\text { Circle Choice } \\
\text { Cast-in-place } \\
\text { concrete } \\
\text { Precast concrete } \\
\text { panels } \\
\text { Steel stay-in-place } \\
\text { formwork } \\
\text { Other (list): }\end{array}$ & $\begin{array}{l}\text { Disapprove steel stay-in- } \\
\text { place forms due to our } \\
\text { concern with trapping } \\
\text { chloride laden water on } \\
\text { the steel forms and in the } \\
\text { concrete deck. This } \\
\text { accelerates comrosion of } \\
\text { the rebar and prevents } \\
\text { visual inspection of the } \\
\text { deck underside. }\end{array}$ & $\begin{array}{l}\text { For most projects we design } \\
\text { and provide specifications } \\
\text { for cast-in-place concrete } \\
\text { bridge decks, however, we } \\
\text { also include stay-in-place } \\
\text { partial depth concrete deck } \\
\text { panels as an accepted } \\
\text { contractor's option. Full } \\
\text { depth concrete deck panels } \\
\text { have also been used on } \\
\text { several deck replacenent } \\
\text { projects. }\end{array}$ \\
\hline $\begin{array}{l}\text { Railing/Guardrail } \\
\text { Systems }\end{array}$ & Steel tubular T2 & & \\
\hline $\begin{array}{l}\text { Topping/Wearing } \\
\text { Surfaces }\end{array}$ & $\begin{array}{l}\text { Torch applied } \\
\text { bamier membrane } \\
\text { with } 2 \text { " to } 2 / 2 \text { of } \\
\text { asphalt wearing } \\
\text { surface }\end{array}$ & & \\
\hline $\begin{array}{l}\text { Bridge } \\
\text { Superstructures }\end{array}$ & $\begin{array}{l}\text { Steel (rolled beams } \\
\text { or plate girders) } \\
\text { or } \\
\text { Concrete givders } \\
\text { (prestressed NEBT) }\end{array}$ & & \\
\hline Abutments & $\begin{array}{l}\text { Cantilevered cast-in- } \\
\text { place reinforced } \\
\text { conerete; Detalls for } \\
\text { optional precast } \\
\text { sections that are post- } \\
\text { tensioned are } \\
\text { offered/allowed; } \\
\text { Stub abuments (w) } \\
\text { or who piles) and } \\
\text { MSE retaining walls } \\
\text { wingwalls are also } \\
\text { used regularly }\end{array}$ & & \\
\hline
\end{tabular}




\begin{tabular}{|l|l|l|l|}
\hline Pier Systems & $\begin{array}{l}\text { Generally a wall } \\
\text { type pier of } \\
\text { reinforced concrete } \\
\text { if in a waterway; } \\
\text { Other applications } \\
\text { Over roadways } \\
\text { include multi- } \\
\text { column piers or } \\
\text { drilled shafts; }\end{array}$ & & \\
\hline
\end{tabular}

4. Do you have typical standards for cross-section widths and girder spacings? If so, please provide.

No.

5. Do you have different design specifications for low-volume roads versus high-volume roads? If so, what are they?

No.

6. Do you use any bridge analysis or design software? If so, what brand of software is used?

Please see attached file and listing.

7. Do you use any bridge design/component standards (or templates)? Examples may include beam sizes for different span lengths and roadway widths. If you have any, are they available on the web?

We have standard details for partial depth precast prestressed concrete deck panels these should be available on our web site. We have not developed any standard beam/girder sizes or details.

8. Do you use modular bridge systems?

No.

9. If a best practices manual for accelerated construction/modular bridge systems was developed, what would you like to see included? For example pre-selected beam sizes, cross-sections, etc.

Expansion joint details might be helpful; perhaps others. Most bridges are designed for specific bridge sites and constraints. 
10. Do you use the AASHTO LRFD specified load factors/combinations or different load factors/combinations? If different, what are they?

\section{AASHTO LRFD}

11. Would a table outlining pre-selected steel beam sizes and shapes for given span lengths based on AASHTO LRFD Bridge Design Specifications be useful for assisting in your design development process?

Probably not -- again, most bridges are designed for specific sites and constraints that necessitate specific dimensions and details for that specific application. Also, different states have different design requirements (such as deflection) that can make it difficult to standardize beam/girder sizes.

12. What is your preferred material choice for short-span bridges? Why?

For single span bridges $<40 \pm \mathrm{ft}$, we often use precast concrete frames due to their durability / low maintenance requirements. These stuctures also do not require construction of a separate abutment element.

13. Are there any other comments that you have that you feel might be relevant to this study?

Na. 
14. What are your most important sources for bridge design and construction technical information and industry news? (Circle which are relevant)

- INDUSTRY PUBLICATIONS/WEB SITES:

- ENR

- Roads and Bridges

- GoBridges.com

- Better Roads (BetterRoads.com)

- Journal of Structural Engineering

- Transportation Builder

- Public Works Magazine

- Engineering Journal

- Public Roads

- Design Engineering

- Government Engineering (GovEngr.com)

- Civil Engineering

- CE News

- Ohers? PCY Wowmal.

- INDUSTRY CONFERENCES (name which ones)

AASHO Sub Commitre on Bridges \& Structures

ICI Amunal Convention

- PROFESSIONAL ORGANIZATION NEWSLETTER?

- NACE?

- Others? PCl, AISC, NSBA

- WEB SITES

- WHWA

- steel.org

- Steelbridges.org

- Others? 


\section{Research Statement}

The Federal Highway Administration in conjunction with the American Iron and Steel Institute [AISI] has recently conducted two workshops focused on developing ideas for improved steel bridge construction. One of the target areas of these workshops has been to develop design standards for short span steel bridges. As a result, the AISI Short Span Steel Bridge Alliance has contracted with Dr. Karl Barth at West Virginia University to conduct a survey of State DOT's and County Engineers. The focus of this survey is to study and catalog statistics and methods employed in short-span bridge design and construction. The overall projected outcome of this research is a best practices manual for the design and construction of short-span steel bridges (i.e. bridges up to $140 \mathrm{ft}$.) and a table outlining suggested pre-selected steel beam sizes and shapes for given span lengths.

\section{Part I. General Information}

Date: August 6,2010

Time:

Agency / DOH: NJDOT

Name: Richard Dunne

Position/ Title: Deputy Bridge Engineer

Address: NJDOT - Engineering \& Operations BIdg $-5^{\text {th }}$ Floor

1035 Parkway Ave, Trenton NJ 08625

Phone: $609-5302663$

E-mail: Richard.Dunne@dot.state.nj.us

Information: 


\section{Part II. General Questions}

1. If possible, please provide a list of bridges built in your region in the past year along with their respective span lengths, whether they are simple or continuous span, cross-section widths and any other general information you can offer (ADT, wearing surface, deck and superstructure choices, substructure and pier choices, number of lanes, etc.).

2. If information for question 1 is not readily available, please provide us with the following information: How many bridges were built in your region in the past year in the following length categories? Also, of those, how many bridges consisted of steel superstructures?

\begin{tabular}{|c|c|c|}
\hline 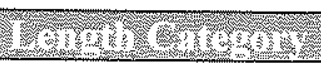 & 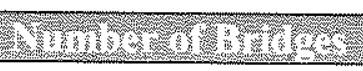 & 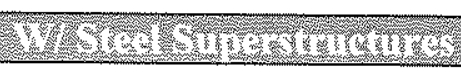 \\
\hline$<40 \mathrm{ft}$ & 0 & 0 \\
\hline $40-60 \mathrm{ft}$ & 4 & 1 \\
\hline $60-80 \mathrm{ft}$ & 2 & 1 \\
\hline $80-100 \mathrm{ft}$ & 1 & 1 \\
\hline $100-120 \mathrm{ft}$ & 0 & 0 \\
\hline $120-140 \mathrm{ft}$ & 2 & 2 \\
\hline
\end{tabular}


3. For the following bridge components, please specify whether you have a preferred/specified type of design and whether or not there are any particular types of bridge component that you do not approve:

\begin{tabular}{|c|c|c|c|}
\hline Frenter brumbint & mortorone & $\begin{array}{l}\text { Tyres } \\
\text { Drepromere }\end{array}$ & 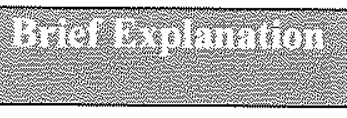 \\
\hline Decking Systems & $\begin{array}{l}\text { Circle Choice } \\
\text { Cast-in-place Preferred } \\
\text { Concrete (2139) } \\
\text { Precast concrete preferred } \\
\text { Panels (8) } \\
\text { Steel stay-in-place } \\
\text { Formwork } \\
\text { Other (list): }\end{array}$ & & \\
\hline $\begin{array}{l}\text { Railing/Guardrail } \\
\text { Systems }\end{array}$ & $\mathrm{N} / \mathrm{A}$ & & \\
\hline $\begin{array}{l}\text { Topping/Wearing } \\
\text { Surfaces }\end{array}$ & $\begin{array}{l}\text { Bituminous: Epoxy } \\
\text { Overlay: } \\
\text { Latex: } \\
\text { Monolithic: Preferred } \\
\text { Other: }\end{array}$ & & . \\
\hline $\begin{array}{l}\text { Bridge } \\
\text { Superstructures }\end{array}$ & Stringer/Girder Types & & \\
\hline Abutments & $\begin{array}{l}\text { Full height } \\
\text { Stub }\end{array}$ & & \\
\hline
\end{tabular}




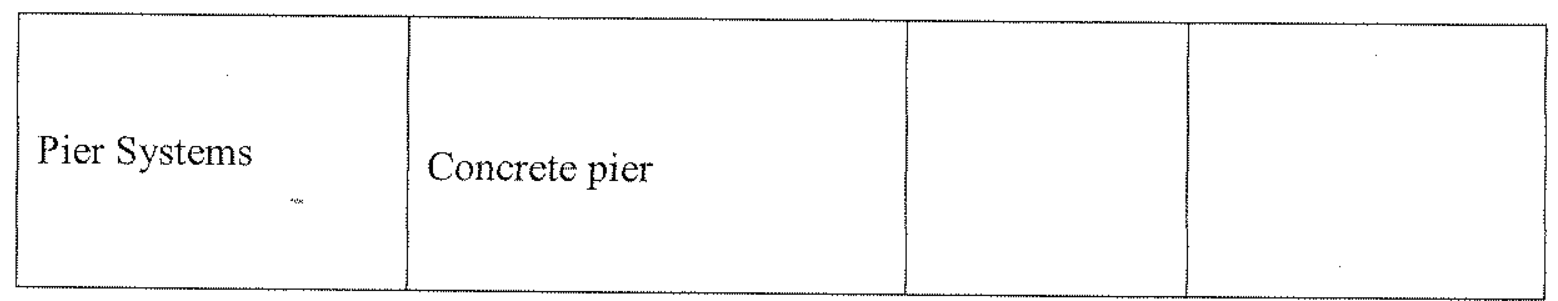

4. Do you have typical standards for cross-section widths and girder spacings? If so, please provide.

NO. WE RECOMMEND TO KEEP GIRDER SPACINGS AROUND 10 TO 11 FEET.

5. Do you have different design specifications for low-volume roads versus high-volume roads? If so, what are they?

NO. HOWEVER, LOW AND HIGH ADT WILL DETERMINE WARRANT FOR APPROACH SLABS.

6. Do you use any bridge analysis or design software? If so, what brand of software is used?

SEE ATTACHMENT A

7. Do you use any bridge design/component standards (or templates)? Examples may include beam sizes for different span lengths and roadway widths. If you have any, are they available on the web?

NO.

8. Do you use modular bridge systems?

PRIMARILY FOR TEMPORARY STRUCTURES.

9. If a best practices manual for accelerated construction/modular bridge systems was developed, what would you like to see included? For example pre-selected beam sizes, cross-sections, etc.

PRE SELECTED BEAM SIZES VS. SPAN LENGTH, CROSS SECTION, SKEW LIMITATION, HORIZONTAL AND VERTICAL CURVATURE.

10. Do you use the AASHTO LRFD specified load factors/combinations or different load factors/combinations? If different, what are they? 
YES.

11. Would a table outlining pre-selected steel beam sizes and shapes for given span lengths based on AASHTO LRFD Bridge Design Specifications be useful for assisting in your design development process?

YES.

12. What is your preferred material choice for short-span bridges? Why?

PRE-STRESSED CONCRETE SLAB OR BOX BEAMS. NO PAINTING OVER THE LIFE OF THE BRIDGE.

13. Are there any other comments that you have that you feel might be relevant to this study? 
14. What are your most important sources for bridge design and construction technical information and industry news? (Circle which are relevant)

- INDUSTRY PUBLICATIONS/WEB SITES:

- ENR

- Roads and Bridges

- GoBridges.com

- Better Roads (BetterRoads.com)

- Journal of Structural Engineering

- Transportation Builder

- Public Works Magazine

- Engineering Journal

- Public Roads

- Design Engineering

- Government Engineering (GovEngr.com)

- Civil Engineering

- CE News

- Others?

- INDUSTRY CONFERENCES (name which ones)

- PROFESSIONAL ORGANIZATION NEWSLETTER?

- NACE?

- Others?

- WEB SITES

- FHWA

- steel.org

- Steelbridges.org

- Others? 


\section{$\underline{\text { Research Statement }}$}

The Federal Highway Administration in conjunction with the American Iron and Steel Institute [AISI] has recently conducted two workshops focused on developing ideas for improved steel bridge construction. One of the target areas of these workshops has been to develop design standards for short span steel bridges. As a result, the AISI Short Span Steel Bridge Alliance has contracted with Dr. Karl Barth at West Virginia University to conduct a survey of State DOT's and County Engineers. The focus of this survey is to study and catalog statistics and methods employed in short-span bridge design and construction. The overall projected outcome of this research is a best practices manual for the design and construction of short-span steel bridges (i.e. bridges up to $140 \mathrm{ft}$.) and a table outlining suggested pre-selected steel beam sizes and shapes for given span lengths.

\section{Part !. General Information}

Date: December 9, 2009

Time:

Agency / DOH: New Mexico Department of Transportation

Name: Sherman Peterson

Position / Title: Civil Engineer - Advanced

Address: 1120 Cerrillos Road, Room 214, Santa Fe, NM 87507

Phone: 505-827-3293

E-mail: sherman.peterson@state.nm.us

Other Information: 


\section{Part II. General Questions}

1. If possible, please provide a list of bridges built in your region in the past year along with their respective span lengths, whether they are simple or continuous span, cross-section widths and any other general information you can offer (ADT, wearing surface, deck and superstructure choices, substructure and pier choices, number of lanes, etc.).

2. If information for question 1 is not readily available, please provide us with the following information: How many bridges were built in your region in the past year in the following length categories? Also, of those, how many bridges consisted of steel superstructures?

\begin{tabular}{|c|c|c|}
\hline Longth Categon & Ninnber of thuges & W/ Sred Supertmicturas \\
\hline$<40 \mathrm{ft}$ & 3 & 0 \\
\hline \multicolumn{3}{|l|}{$40-60 \mathrm{ft}$} \\
\hline $60-80 \mathrm{ft}$ & 2 & 0 \\
\hline $80-100 \mathrm{ft}$ & 1 & 0 \\
\hline $100-120 \mathrm{ft}$ & 1 & 0 \\
\hline $120-140 \mathrm{ft}$ & & \\
\hline
\end{tabular}

Data is for 2008 . One project was let in 2009 for a three-span steel superstructure replacement. 
3. For the following bridge components, please specify whether you have a preferred/specified type of design and whether or not there are any particular types of bridge component that you do not approve:

\begin{tabular}{|c|c|c|c|}
\hline Whige componery & Prebrotive & 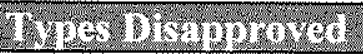 & brted sevpriviton \\
\hline \multirow{5}{*}{ Decking Systems } & Circle Choice & \multirow[t]{5}{*}{ None. } & \multirow{5}{*}{$\begin{array}{l}\text { Cast-in-place } \\
\text { bridge decks with } \\
\text { ventilated stay-in- } \\
\text { place forms are } \\
\text { customary, Other } \\
\text { systems, such as } \\
\text { precast concrete } \\
\text { deck panels, are } \\
\text { entertained on a } \\
\text { case-by-case basis } \\
\text { and are selected } \\
\text { for reasons other } \\
\text { than cost. }\end{array}$} \\
\hline & $\begin{array}{l}\text { Cast-in-place } \\
\text { concrete }\end{array}$ & & \\
\hline & $\begin{array}{l}\text { Precast concrete } \\
\text { panels }\end{array}$ & & \\
\hline & $\begin{array}{l}\text { Steel stay-in-place } \\
\text { formwork }\end{array}$ & & \\
\hline & Other (list): & & \\
\hline $\begin{array}{l}\text { Railing/Guardrail } \\
\text { Systems }\end{array}$ & $\begin{array}{l}\text { Concrete bridge } \\
\text { barrier railing, metal } \\
\text { barrier railing. }\end{array}$ & & $\begin{array}{l}\text { Concrete railings } \\
\text { are used for } \\
\text { bridges with speed } \\
>55 \text { mph and/or } \\
\text { large truck } \\
\text { volumes. Metal } \\
\text { railings are } \\
\text { entertained and } \\
\text { often selected for } \\
\text { other bridges. }\end{array}$ \\
\hline $\begin{array}{l}\text { Topping/Wearing } \\
\text { Surfaces }\end{array}$ & $\begin{array}{l}1 / 4 \text { sacrificial } \\
\text { concrete. }\end{array}$ & & $\begin{array}{l}\text { Provision is made } \\
\text { for future } 30 \text { psf } \\
\text { overlay, such as } \\
\text { asphalt. }\end{array}$ \\
\hline $\begin{array}{l}\text { Bridge } \\
\text { Superstructures }\end{array}$ & $\begin{array}{l}\text { Prestressed } \\
\text { concrete, structural } \\
\text { steel, cast-in-place } \\
\text { deck slabs. }\end{array}$ & & $\begin{array}{l}\text { Selection of } \\
\text { structural type } \\
\text { influenced most by } \\
\text { geometric } \\
\text { requirements. }\end{array}$ \\
\hline Abutments & $\begin{array}{l}\text { Cast-in place } \\
\text { concrete. }\end{array}$ & & $\begin{array}{l}\text { Precast systems } \\
\text { may be used in } \\
\text { rapid construction } \\
\text { projects. }\end{array}$ \\
\hline
\end{tabular}




\begin{tabular}{|l|l|l|l|}
\hline Pier Systems & $\begin{array}{l}\text { Cast-in place } \\
\text { concrete. }\end{array}$ & $\begin{array}{l}\text { Precast systems } \\
\text { may be used in } \\
\text { rapid construction } \\
\text { projects. }\end{array}$ \\
\hline
\end{tabular}

4. Do you have typical standards for cross-section widths and girder spacings? If so, please provide.

The policy in New Mexico is to provide the typical roadway width, including shoulders, on the bridge. The minimum shoulder width is four feet.

5. Do you have different design specifications for low-volume roads versus high-volume roads? If so, what are they?

Yes. High-volume roads will typically require higher bridge barrier railings and are more likely to be designed for permit vehicles.

6. Do you use any bridge analysis or design software? If so, what brand of software is used?

LEAP Bridge, PCA Column, Virtis/Opis, QConBridge, STAAD, have used Merlin-DASH in the past.

7. Do you use any bridge design/component standards (or templates)? Examples may include beam sizes for different span lengths and roadway widths. If you have any, are they available on the web?

No.

8. Do you use modular bridge systems?

Occasionally, but most would be precast concrete units. Pedestrian bridges would be one area where we would use modular steel systems.

9. If a best practices manual for accelerated construction/modular bridge systems was developed, what would you like to see included? For example pre-selected beam sizes, cross-sections, etc.

Relatively standardized details for expansion restrainers and bearings in addition to the things you would expect to see for superstructures.

10. Do you use the AASHTO LRFD specified Ioad factors/combinations or different load factors/combinations? If different, what are they?

We use the specified LRFD load factors and combinations. 
11. Would a table outlining pre-selected steel beam sizes and shapes for given span lengths based on AASHTO LRFD Bridge Design Specifications be useful for assisting in your design development process?

Yes.

12. What is your preferred material choice for short-span bridges? Why?

Precast prestressed concrete bridges. This is primarily because there are no major steel fabricators in New Mexico.

13. Are there any other comments that you have that you feel might be relevant to this study? 
14. What are your most important sources for bridge design and construction technical information and industry news? (Circle which are relevant)

- INDUSTRY PUBLICATIONS/WEB SITES:

- ENR

- Roads and Bridges

- GoBridges.com

- Better Roads (BetterRoads.com)

- Journal of Structural Engineering

- Transportation Builder

- Public Works Magazine

- Engineering Journal

- Public Roads

- Design Engineering

- Government Engineering (GovEngr.com)

- Civil Engineering

- CE News

- Others?

- INDUSTRY CONFERENCES (name which ones)

- PROFESSIONAL ORGANIZATION NEWSLETTER?

- NACE?

- Others?

- WEB SITES

- FHWA

- steel.org

- Steelbridges org

- Others? 


\section{$\underline{\text { Research Statement }}$}

The Federal Highway Administration in conjunction with the American Iron and Steel Institute [AISI] has recently conducted two workshops focused on developing ideas for improved steel bridge construction. One of the target areas of these workshops has been to develop design standards for short span steel bridges. As a result, the AISI Short Span Steel Bridge Alliance has contracted with Dr. Karl Barth at West Virginia University to conduct a survey of State DOT's and County Engineers. The focus of this survey is to study and catalog statistics and methods employed in short-span bridge design and construction. The overall projected outcome of this research is a best practices manual for the design and construction of short-span steel bridges (i.e. bridges up to $140 \mathrm{ft}$.) and a table outlining suggested pre-selected steel beam sizes and shapes for given span lengths.

\section{Part I. General Information}

Date: November 25, 2009

Time:

Agency / DOH: New York State Department of Transportation

Name: Arthur P. Yannotti, P.E.

Position/Title: Director, Structures Design Bureau

Address: 50 Wolf Road

Albany, New York 12232

Phone: $518457-4453$

E-mail: ayannotti@dot.state.ny.us

Other Information: 


\section{Part II. General Questions}

1. If possible, please provide a list of bridges built in your region in the past year along with their respective span lengths, whether they are simple or continuous span, cross-section widths and any other general information you can offer (ADT, wearing surface, deck and superstructure choices, substructure and pier choices, number of lanes, etc.).

2. If information for question 1 is not readily available, please provide us with the following information: How many bridges were built in your region in the past year in the following length categories? Also, of those, how many bridges consisted of steel superstructures?

\begin{tabular}{|c|c|c|}
\hline Lengith Categon & Number of britiges & W/Sted Supertwuctires \\
\hline$<40 \mathrm{ft}$ & 8 & 0 \\
\hline $40-60 \mathrm{ft}$ & 3 & 0 \\
\hline $60-80 \mathrm{ft}$ & 9 & 2 \\
\hline $80-100 \mathrm{ft}$ & 5 & 2 \\
\hline $100-120 \mathrm{ft}$ & 8 & 3 \\
\hline $120-140 \mathrm{ft}$ & 8 & 8 \\
\hline
\end{tabular}


3. For the following bridge components, please specify whether you have a preferred/specified type of design and whether or not there are any particular types of bridge component that you do not approve:

\begin{tabular}{|c|c|c|c|}
\hline 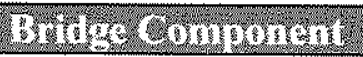 & Broronome & 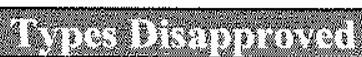 & 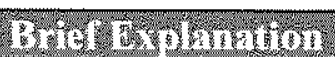 \\
\hline Decking Systems & $\begin{array}{l}\text { Circle Choice } \\
\text { Cast-in-place } \\
\text { Concrete- } \\
\text { Preferred } \\
\text { Precast concrete } \\
\text { panels } \\
\text { Steel stay-in-place } \\
\text { formwork } \\
\text { Other (list): }\end{array}$ & & \\
\hline $\begin{array}{l}\text { Railing/Guardrail } \\
\text { Systems }\end{array}$ & $\begin{array}{l}\text { Concrete single } \\
\text { slope barrier }\end{array}$ & & \\
\hline $\begin{array}{l}\text { Topping/Wearing } \\
\text { Surfaces }\end{array}$ & $\begin{array}{l}\text { Monolithic } \\
\text { Concrete Deck }\end{array}$ & & \\
\hline $\begin{array}{l}\text { Bridge } \\
\text { Superstructures }\end{array}$ & & & \\
\hline Abutments & Integral & & \\
\hline
\end{tabular}




\begin{tabular}{|l|l|l|l|}
\hline Pier Systems & Cast in Place & & \\
\hline
\end{tabular}

4. Do you have typical standards for cross-section widths and girder spacings? If so, please provide.

No

5. Do you have different design specifications for low-volume roads versus high-volume roads? If so, what are they?

No

6. Do you use any bridge analysis or design software? If so, what brand of software is used?

Virtis/Opis, Merlin Dash

STAAD, LEAP Bridge, MDX

7. Do you use any bridge design/component standards (or templates)? Examples may include beam sizes for different span lengths and roadway widths. If you have any, are they available on the web?

No

8. Do you use modular bridge systems?

Only for temporary bridges 
9. If a best practices manual for accelerated construction/modular bridge systems was developed, what would you like to see included? For example pre-selected beam sizes, cross-sections, etc.

Suggested Details, Methods of Construction, Typical Sections

10. Do you use the AASHTO LRFD specified load factors/combinations or different load factors/combinations? If different, what are they? Yes

11. Would a table outlining pre-selected steel beam sizes and shapes for given span lengths based on AASHTO LRFD Bridge Design Specifications be useful for assisting in your design development process?

No, there is too much variation in specific bridge conditions to make preselected beam tables useful.

12. What is your preferred material choice for short-span bridges? Why?

Concrete, especially precast boxes and three sided frames in the short span ranges. Cost, Durability and speed of construction are the reasons.

13. Are there any other comments that you have that you feel might be relevant to this study? 
14. What are your most important sources for bridge design and construction technical information and industry news? (Circle which are relevant)

- INDUSTRY PUBLICATIONS/WEB SITES:

- ENR -X

- Roads and Bridges - X

- GoBridges.com

- Better Roads (BetterRoads.com) -X

- Journal of Structural Engineering

- Transportation Builder

- Public Works Magazine

- Engineering Journal

- Public Roads

- Design Engineering

- Government Engineering (GovEngr.com)

- Civil Engineering

- CE News

- Others?

- INDUSTRY CONFERENCES (name which ones)

- PROFESSIONAL ORGANIZATION NEWSLETTER?

- NACE?

- Others?

- WEB SITES

- FHWA - X

- steel.org -X

- Steelbridges.org $-X$

- Others? 


\section{Research Statement}

The Federal Highway Administration in conjunction with the American Iron and Steel Institute [AISI] has recently conducted two workshops focused on developing ideas for improved steel bridge construction. One of the target areas of these workshops has been to develop design standards for short span steel bridges. As a result, the AISI Short Span Steel Bridge Alliance has contracted with Dr. Karl Barth at West Virginia University to conduct a survey of State DOT's and County Engineers. The focus of this survey is to study and catalog statistics and methods employed in short-span bridge design and construction. The overall projected outcome of this research is a best practices manual for the design and construction of short-span steel bridges (i.e. bridges up to $140 \mathrm{ft}$.) and a table outlining suggested pre-selected steel beam sizes and shapes for given span lengths.

\section{Part I. General Information}

Date: $11.17 \cdot 09$

Time:

Agency / DOH:

Name: Grég perfett

Position / Title: smó banpere Deslun ÉNZR

Address: 1581 MAL SEPUICE GR RAutat NC $27699-1581$

Phone: $919-250-4037$

E-mail: GPERETT O NCDOT.GTON

Other Information: 


\section{Part II. General Questions}

1. If possible, please provide a list of bridges built in your region in the past year along with their respective span lengths, whether they are simple or continuous span, cross-section widths and any other general information you can offer (ADT, wearing surface, deck and superstructure choices, substructure and pier choices, number of lanes, etc.).

2. If information for question 1 is not readily available, please provide us with the following information: How many bridges were built in your region in the past year in the following length categories? Also, of those, how many bridges consisted of steel superstructures?

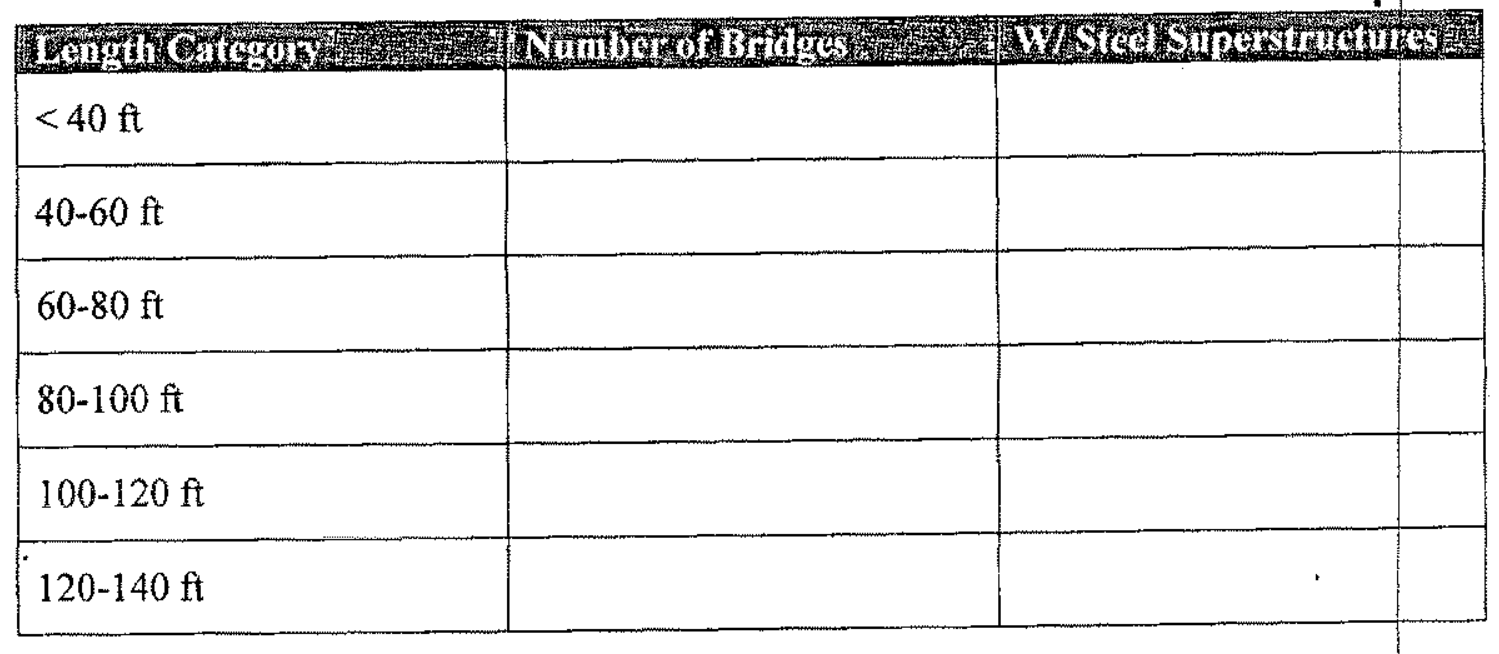

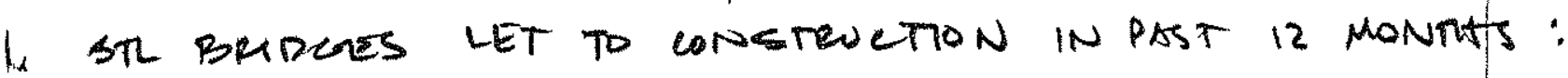
B. $4622150^{\prime}, 63^{\circ}$ RCOR (INTELRAR CONSTR)

$$
\begin{aligned}
& R-2417 C \text { 153'-137', 72" Re GD-CDRVD (CONTINUOUS) } \\
& \text { U-4444AA } 124^{\prime}-131^{\prime}, 60^{\circ} \text { R CDR - TANGENT (CONTNUOUS) } \\
& \text { B- } 4137 \text { 143',60" } \\
& B-4410 \quad 14^{\prime}-120^{\prime}-58^{\prime} \text {, 电 CDR - TANLENT (SIMPLE) }
\end{aligned}
$$

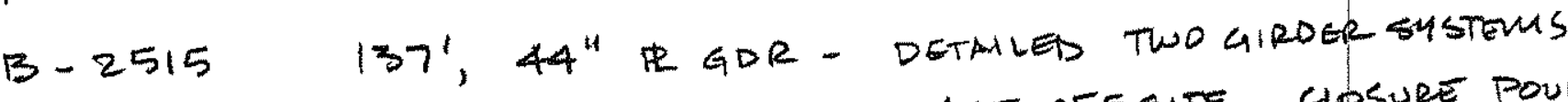

$$
\begin{aligned}
& \text { WITH CIP DELK, LAST OFFSITE, CLOSURE POURS } \\
& \text { ON-SITE (ACCELERATED CONGTRUCTION) } \\
& \text { B.4307 135', 54" RE GDR (IN RERAR CONSTR) } \\
& B-4523120^{\prime}, 50^{\circ} \text { R CDR TANZENT (SIMPLE) }
\end{aligned}
$$

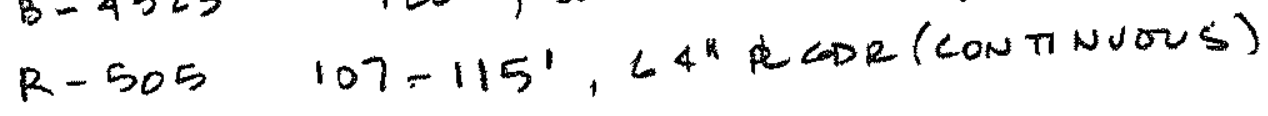

$$
\begin{aligned}
& \text { (CONT'D Q END OF SURER) }
\end{aligned}
$$


3. For the following bridge components, please specify whether you have a preferred/specified type of design and whether or not there are any particular types of bridge component that you do not approve:

\begin{tabular}{|c|c|c|c|}
\hline Brofor Couroteit & Drforing ss & 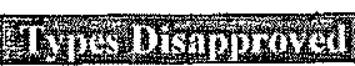 & 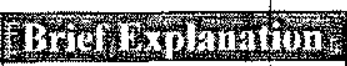 \\
\hline Decking Systems & $\begin{array}{l}\text { Circle Choice } \\
\text { concrete }\end{array}$ & -1 & \\
\hline $\begin{array}{l}\text { Railing/Guardrail } \\
\text { Systems }\end{array}$ & NJ Stape & & • \\
\hline $\begin{array}{l}\text { Topping/Wearing } \\
\text { Surfaces }\end{array}$ & $\begin{array}{l}8^{\prime \prime} \min \\
\text { cip deck }\end{array}$ & . & $\begin{array}{l}\text { Do aot use } \\
\text { dense overlay } \\
\text { on asphalt } \\
\text { w/mentiane }\end{array}$ \\
\hline $\begin{array}{l}\text { Bridge } \\
\text { Superstructures }\end{array}$ & $\begin{array}{l}\text { As reyid by } \\
\text { onte conditions }\end{array}$ & & $\begin{array}{l}\text { PC conc } \\
\text { typieally bids } \\
\text { lower }\end{array}$ \\
\hline Abutments & $\begin{array}{l}\text { End bents } \\
\text { w/ spill thru } \\
\text { slopes }\end{array}$ & & \\
\hline Pier Systems & $\begin{array}{l}\text { Pik Bents } \\
\text { or Post + Boan } \\
\text { on Pile Ftys }\end{array}$ & & $\begin{array}{l}\text { Try to avid } \\
\text { drilled shaft } \\
\text { foundatims } \\
\text { if piles work. }\end{array}$ \\
\hline
\end{tabular}


4. Do you have typical standards for cross-section widths and girder spacings? If so, please provide.

Not for steel superstructures

5. Do you have different design specifications for low-volume roads versus high-volume roads? If so, what are they?

Ne has Subregional Tier Design Curtelines that basically allow some flexibility on bridge widths.

6. Do you use any bridge analysis or design software? If so, what brand of software is used?

Deseus, Marlin-Dash, RC Pier for bridges with steely. superstructures.

7. Do you use any bridge design/component standards (or templates)? Examples may include beam sizes for different span lengths and roadway widths. If you have any, are they available on the web?

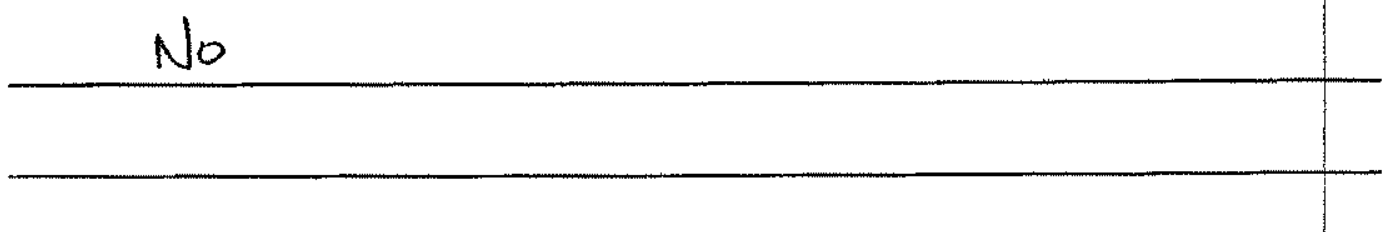

8. Do you use modular bridge systems?

Yes, type ally precast concrete, See B.2515 description Though - an INVERSE T approach cast Tight side up.

9. If a best practices manual for accelerated construction/modular bridge systems was developed, what would you like to see included? For example preselected beam sizes, cross-sections, etc. 
10. Do you use the AASHTO LRFD specified load factors/combinations or different load factors/combinations? If different, what are they?

LRFD

11. Would a table outlining pre-selected steel beam sizes and shapes for given span lengths based on AASHTO LRFD Bridge Design Specifications be useful for assisting in your design development process?

Somewhat

12. What is your preferred material choice for short-span bridges? Why?

PC concreta - cost (imtial + Lfeaych) Note This is for span ungthe up to $120^{\circ}$.

13. Are there any other comments that you have that you feel might be relevant to this study? 
14. What are your most important sources for bridge design and construction technical information and industry news? (Circle which are relevant)

- INDUSTRY PUBLICATIONS/WEB SITES:

- ENR

- Roads and Bridges

- GoBridges.com

- Better Roads (BetterRoads.com)

- Journal of Structural Engineering

- Transportation Builder

- Public Works Magazine

- Engineering Journal

- Public Roads

- Design Engineering

- Government Engineering (GovEngr.com)

- Civil Engineering

- CE News

- Others?

- INDUSTRY CONFERENCES (name which ones)

- PROFESSIONAL ORGANIZATION NEWSLETTER?

- NACE?

- Others?

- WEB SITES

- FHWA

- steel.org

- Steelbridges.org

- Others?

B-2965 150-200-150', 54't teDR (coNTINUOUS)

$R-4430$ 100',40"RGDR (STMPLE)

$132^{\prime}-11^{\prime}, 65^{\prime \prime}$ teor (CoNTNovons)

$B-4239 \quad 110^{\prime}, 54^{n} R 60 R$ (SIMPLE)

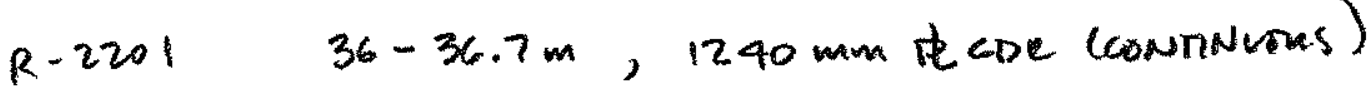




\section{$\underline{\text { Research Statement }}$}

The Federal Highway Administration in conjunction with the American Iron and Steel Institute [AISI] has recently conducted two workshops focused on developing ideas for improved steel bridge construction. One of the target areas of these workshops has been to develop design standards for short span steel bridges. As a result, the AISI Short Span Steel Bridge Alliance has contracted with Dr. Karl Barth at West Virginia University to conduct a survey of State DOT's and County Engineers. The focus of this survey is to study and catalog statistics and methods employed in short-span bridge design and construction. The overall projected outcome of this research is a best practices manual for the design and construction of short-span steel bridges (i.e. bridges up to $140 \mathrm{ft}$.) and a table outlining suggested pre-selected steel beam sizes and shapes for given span lengths.

\section{Part I. General Information}

Date: June 17, 2010

Time: $1: 48 \mathrm{pm}$

Agency / DOH: North Dakota Department of Transportation

Name: Terrence R. Udland

Position / Title: State Bridge Engineer

Address: 608 East Boulevard

Bismarck ND 58505-0700

Phone: 701-328-1969

E-mail: tudland@nd.gov

Other Information: 


\section{Part II. General Questions}

1. If possible, please provide a list of bridges built in your region in the past year along with their respective span lengths, whether they are simple or continuous span, cross-section widths and any other general information you can offer (ADT, wearing surface, deck and superstructure choices, substructure and pier choices, number of lanes, etc.).

2. If information for question 1 is not readily available, please provide us with the following information: How many bridges were built in your region in the past year in the following length categories? Also, of those, how many bridges consisted of steel superstructures?

\begin{tabular}{|l|l|l|}
\hline Length Category & Number of Bridges & W/ Steel Superstructures \\
\hline$<40 \mathrm{ft}$ & 7 Concrete Box Culverts & \\
\hline $40-60 \mathrm{ft}$ & $\begin{array}{l}\text { 5 Concrete Box Culverts } \\
\text { 1 Pre-stressed Beam Br. }\end{array}$ & \\
\hline $60-80 \mathrm{ft}$ & & \\
\hline $80-100 \mathrm{ft}$ & & \\
\hline $100-120 \mathrm{ft}$ & 1 Pre-stressed Beam Br. & \\
\hline $120-140 \mathrm{ft}$ & 2 Pre-stressed Beam Br. & \\
\hline
\end{tabular}


3. For the following bridge components, please specify whether you have a preferred/specified type of design and whether or not there are any particular types of bridge component that you do not approve:

\begin{tabular}{|c|c|c|c|}
\hline Bridge Component & Preference & Types Disapproved & Brief Explanation \\
\hline Decking Systems & $\begin{array}{l}\text { Circle Choice } \\
\text { Cast-in-place } \\
\text { Concrete X } \\
\text { Precast concrete } \\
\text { panels } \\
\text { Steel stay-in-place } \\
\text { formwork } \\
\text { Other (list): }\end{array}$ & & \\
\hline $\begin{array}{l}\text { Railing/Guardrail } \\
\text { Systems }\end{array}$ & Jersey Barrier & & \\
\hline $\begin{array}{l}\text { Topping/Wearing } \\
\text { Surfaces }\end{array}$ & $\begin{array}{l}\text { Low Slump } \\
\text { Concrete }\end{array}$ & & \\
\hline $\begin{array}{l}\text { Bridge } \\
\text { Superstructures }\end{array}$ & $\begin{array}{l}\text { Pre-stressed } \\
\text { Concrete Beams }\end{array}$ & & \\
\hline Abutments & $\begin{array}{l}\text { Integral Concrete } \\
\text { on Piling }\end{array}$ & & \\
\hline Pier Systems & Concrete on Piling & & \\
\hline
\end{tabular}


4. Do you have typical standards for cross-section widths and girder spacings? If so, please provide.

Widths depend on the ADT and the Roadway Classification

Do not have standards for girder spacings.

5. Do you have different design specifications for low-volume roads versus highvolume roads? If so, what are they?

Geometry is based on ADT and the Roadway Classsification

Do not have different design specifications

6. Do you use any bridge analysis or design software? If so, what brand of software is used?

Virtis - Rating Analysis

Simon - Design

7. Do you use any bridge design/component standards (or templates)? Examples may include beam sizes for different span lengths and roadway widths. If you have any, are they available on the web?

No

8. Do you use modular bridge systems?

No

9. If a best practices manual for accelerated construction/modular bridge systems was developed, what would you like to see included? For example pre-selected beam sizes, cross-sections, etc.

\section{Beam Sizes}

10. Do you use the AASHTO LRFD specified load factors/combinations or different load factors/combinations? If different, what are they?

Yes 
11. Would a table outlining pre-selected steel beam sizes and shapes for given span lengths based on AASHTO LRFD Bridge Design Specifications be useful for assisting in your design development process?

Yes

12. What is your preferred material choice for short-span bridges? Why?

Pre-stressed Concrete - Locally available and economical

13. Are there any other comments that you have that you feel might be relevant to this study? 
14. What are your most important sources for bridge design and construction technical information and industry news? (Circle which are relevant)

- INDUSTRY PUBLICATIONS/WEB SITES:

- ENR - X

- Roads and Bridges - X

- GoBridges.com

- Better Roads (BetterRoads.com) - X

- Journal of Structural Engineering

- Transportation Builder

- Public Works Magazine

- Engineering Journal

- Public Roads

- Design Engineering

- Government Engineering (GovEngr.com)

- Civil Engineering - X

- CE News

- Others?

- INDUSTRY CONFERENCES (name which ones)

- PROFESSIONAL ORGANIZATION NEWSLETTER?

- NACE?

- Others?

- WEB SITES

- FHWA - X

- steel.org

- Steelbridges.org

- Others? 


\section{Research Statement}

The Federal Highway Administration in conjunction with the American Iron and Steel Institute [AISI] has recently conducted two workshops focused on developing ideas for improved steel bridge construction. One of the target areas of these workshops has been to develop design standards for short span steel bridges. As a result, the AISI Short Span Steel Bridge Alliance has contracted with Dr. Karl Barth at West Virginia University to conduct a survey of State DOT's and County Engineers. The focus of this survey is to study and catalog statistics and methods employed in short-span bridge design and construction. The overall projected outcome of this research is a best practices manual for the design and construction of short-span steel bridges (i.e. bridges up to $140 \mathrm{ft}$.) and a table outlining suggested pre-selected steel beam sizes and shapes for given span lengths.

\section{Part I. General Information}

Date: $11 / 20 / 09$

Time: 11:01

Agency / DOH: Okla. DOT

Name: Jack Schmiedel

Position/Title: Acting Assistant Division Engineer

Address: $200 \mathrm{NE} 21^{\text {st }}$ St, Oklahoma City

Phone: 405-521-6488

E-mail: jschmiedel@odot.org

Other Information: 


\section{Part II. General Questions}

1. If possible, please provide a list of bridges built in your region in the past year along with their respective span lengths, whether they are simple or continuous span, cross-section widths and any other general information you can offer (ADT, wearing surface, deck and superstructure choices, substructure and pier choices, number of lanes, etc.).

2. If information for question 1 is not readily available, please provide us with the following information: How many bridges were built in your region in the past year in the following length categories? Also, of those, how many bridges consisted of steel superstructures?

\begin{tabular}{|c|c|c|}
\hline Longul Caregry & Number of biriges & WSTted Sindesituciures \\
\hline$<40 \mathrm{ft}$ & & \\
\hline $40-60 \mathrm{ft}$ & & \\
\hline $60-80 \mathrm{ft}$ & & \\
\hline $80-100 \mathrm{ft}$ & & \\
\hline $100-120 \mathrm{ft}$ & & \\
\hline $120-140 \mathrm{ft}$ & & \\
\hline
\end{tabular}

$$
\begin{aligned}
& \text { We DO NOT HAVE ANY } \\
& \text { WAY TO FIND THIS }
\end{aligned}
$$


3. For the following bridge components, please specify whether you have a preferred/specified type of design and whether or not there are any particular types of bridge component that you do not approve:

\begin{tabular}{|c|c|c|c|}
\hline Buigo Connonon & Afolow of & 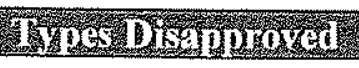 & 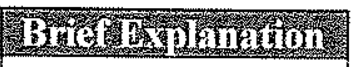 \\
\hline Decking Systems & $\begin{array}{l}\text { Circle Choice } \\
\text { Cast-in-place } \\
\text { concrete } \\
\text { Precast concrete } \\
\text { panels } \\
\text { Steel stay-in place } \\
\text { formwork } \\
\text { Other (list): }\end{array}$ & & $\begin{array}{l}\text { WE ALOW } \\
\text { AU } 3 \text { OF } \\
\text { THESE. OOR } \\
\text { CONTRACTOS } \\
\text { SSOACY BOLD } \\
\text { STEE S I-P } \\
\text { OR CIP } \\
\text { CONCRETE }\end{array}$ \\
\hline $\begin{array}{l}\text { Railing/Guardrail } \\
\text { Systems }\end{array}$ & $\begin{array}{l}\text { TR-4 OR } \\
42^{\prime \prime} F-\text { SAAPE }\end{array}$ & & 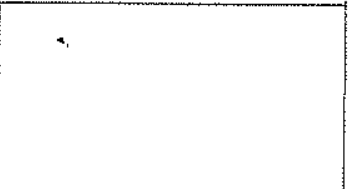 \\
\hline $\begin{array}{l}\text { Topping/Wearing } \\
\text { Surfaces }\end{array}$ & $\begin{array}{l}\text { CONLRETE } \\
\text { DECKS ONIY }\end{array}$ & & \\
\hline $\begin{array}{l}\text { Bridge } \\
\text { Superstructures }\end{array}$ & $\begin{array}{l}\text { AASHTO PCB } \\
\text { ROLED SETTIONS } \\
\text { PLATE CORDORS }\end{array}$ & & 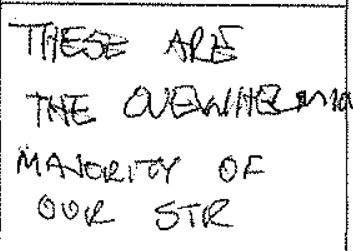 \\
\hline Abutments & SKELETH ABOTMEN & & 1 \\
\hline Pier Systems & 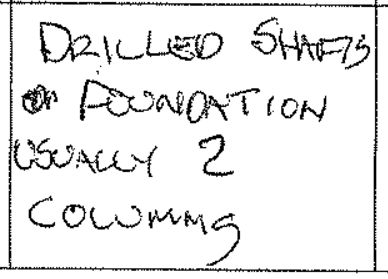 & & \\
\hline
\end{tabular}


4. Do you have typical standards for cross-section widths and girder spacings? If so, please provide.

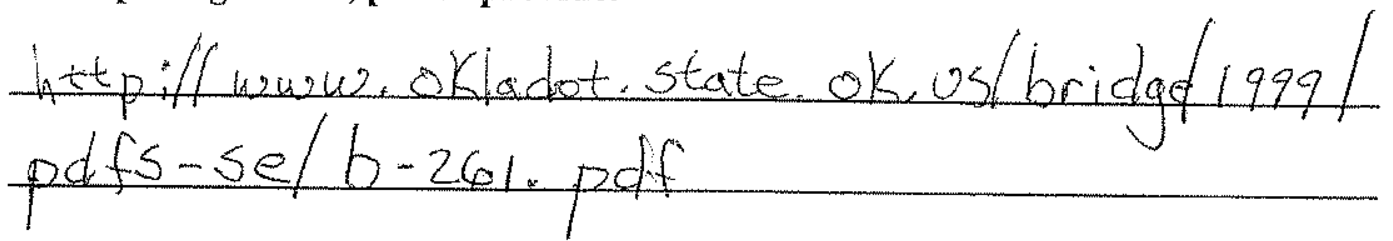

5. Do you have different design specifications for low-volume roads versus high-volume roads? If so, what are they?

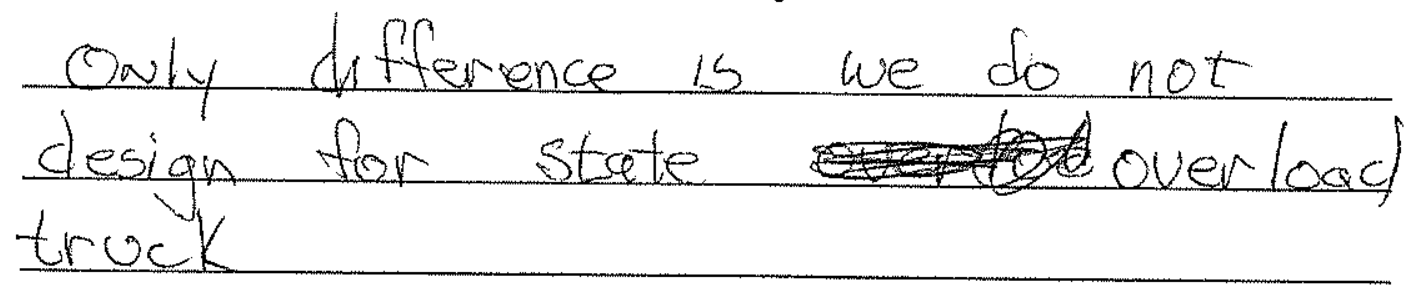

6. Do you use any bridge analysis or design software? If so, what brand of software is used?

STRUDL

7. Do you use any bridge design/component standards (or templates)? Examples may include beam sizes for different span lengths and roadway widths. If you have any, are they available on the web?

YES, YES

8. Do you use modular bridge systems?

nO

9. If a best practices manual for accelerated construction/modular bridge systems was developed, what would you like to see included? For example pre-selected beam sizes, cross-sections, etc.

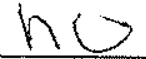


10. Do you use the AASHTO LRFD specified load factors/combinations or different load factors/combinations? If different, what are they?

Yes

11. Would a table outlining pre-selected steel beam sizes and shapes for given span lengths based on AASHTO LRFD Bridge Design Specifications be useful for assisting in your design development process?

Do

12. What is your preferred material choice for short-span bridges? Why?

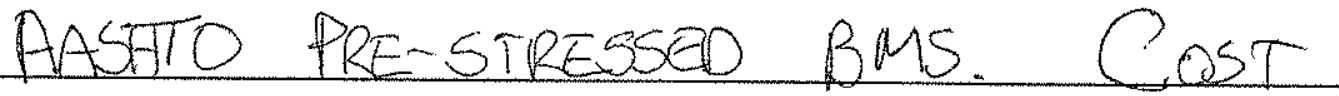

13. Are there any other comments that you have that you feel might be relevant to this study? 
14. What are your most important sources for bridge design and construction technical information and industry news? (Circle which are relevant)

- INDUSTRY PUBLICATIONS/WEB SITES:

$$
\text { - Roads and Bridges }
$$

- GoBridges.com

- Better Roads (BetterRoads.com)

- Journal of Structural Engineering

- Transportation Builder

- Public Works Magazine

- Engineering Journal

- Public Roads

- Design Engineering

- Government Engineering (GovEngr.com)

- Civil Engineering

- CENews

- Others?

- INDUSTRY CONFERENCES (name which ones)

- PROFESSIONAL ORGANIZATION NEWSLETTER?

- NACE?

- others? AASHTO SCOBS

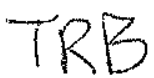

- WEB SITES

- FHWA

- steel.org

- Steelbridges.org

- Others? 


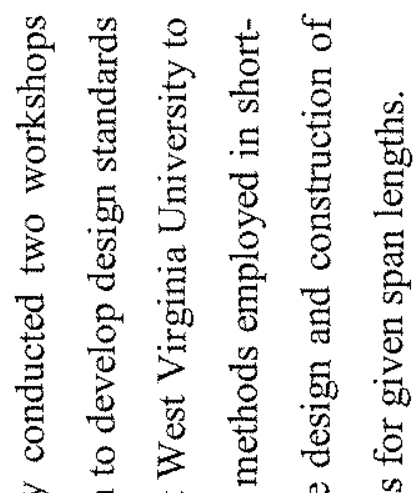

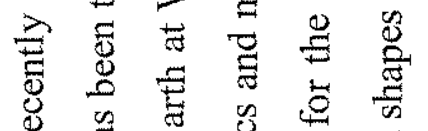

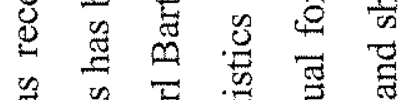

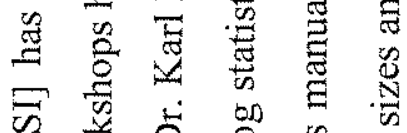

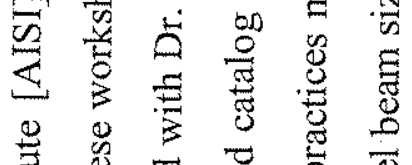

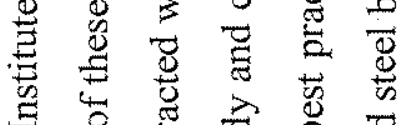

可要

is

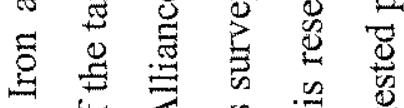

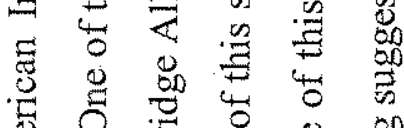

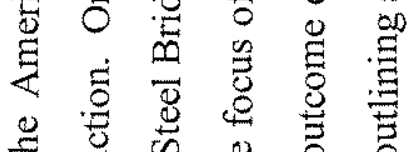

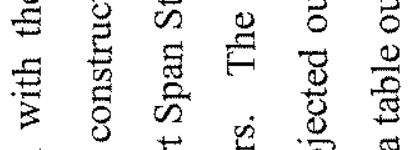

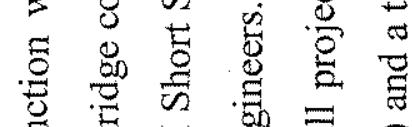

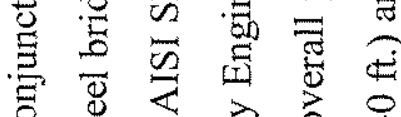

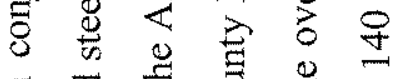

$\exists$ 要击

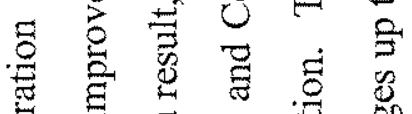

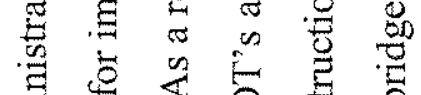

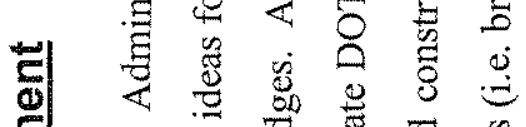

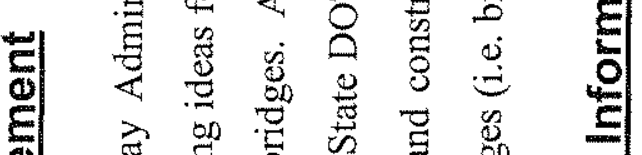

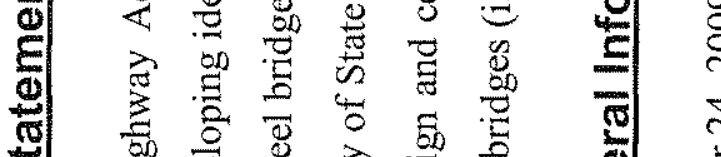

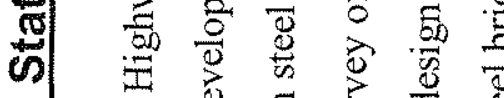

근
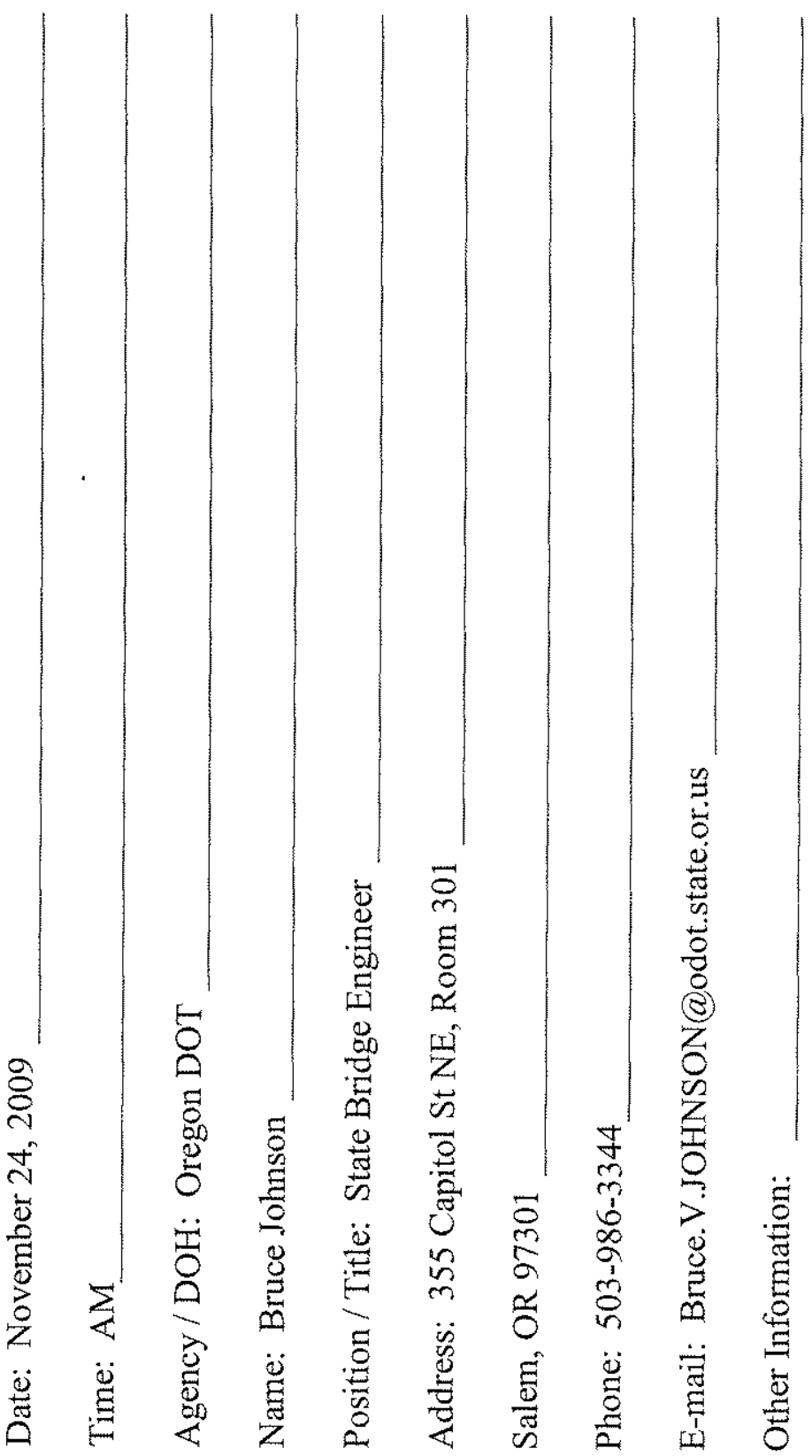

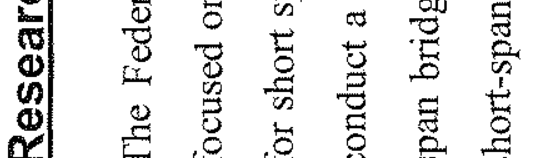

言望 


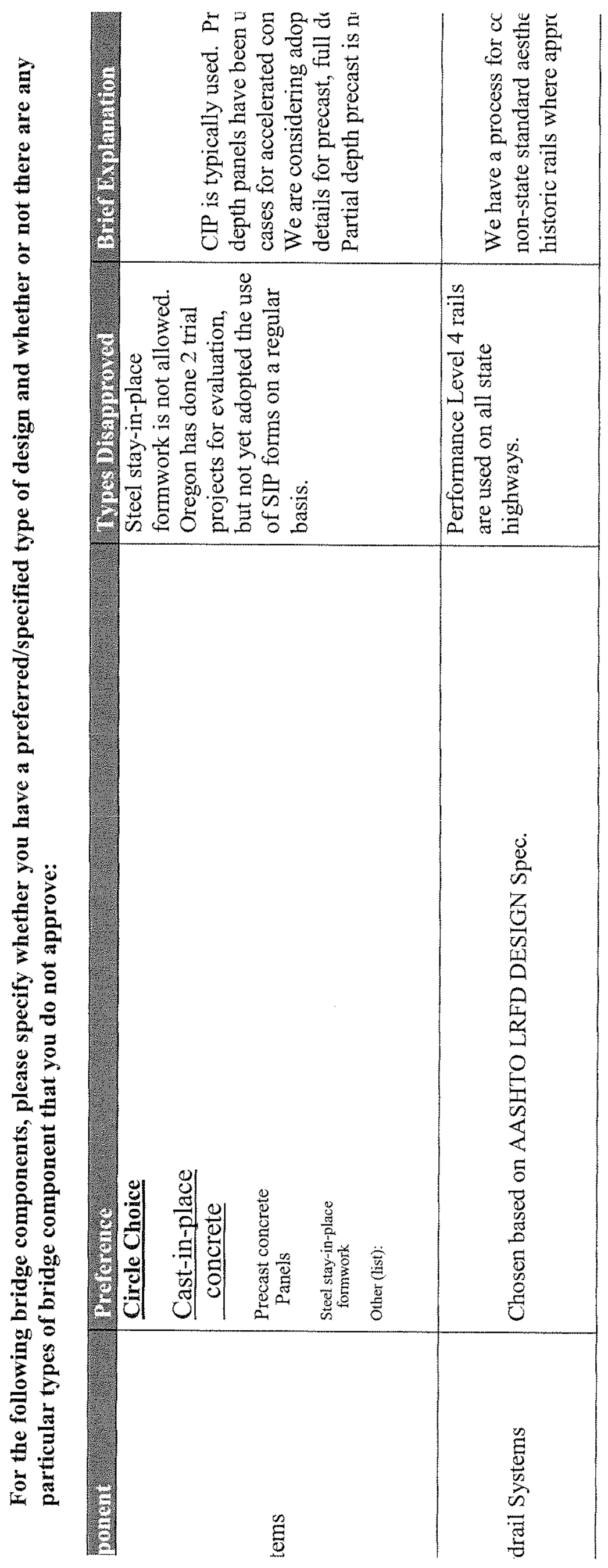




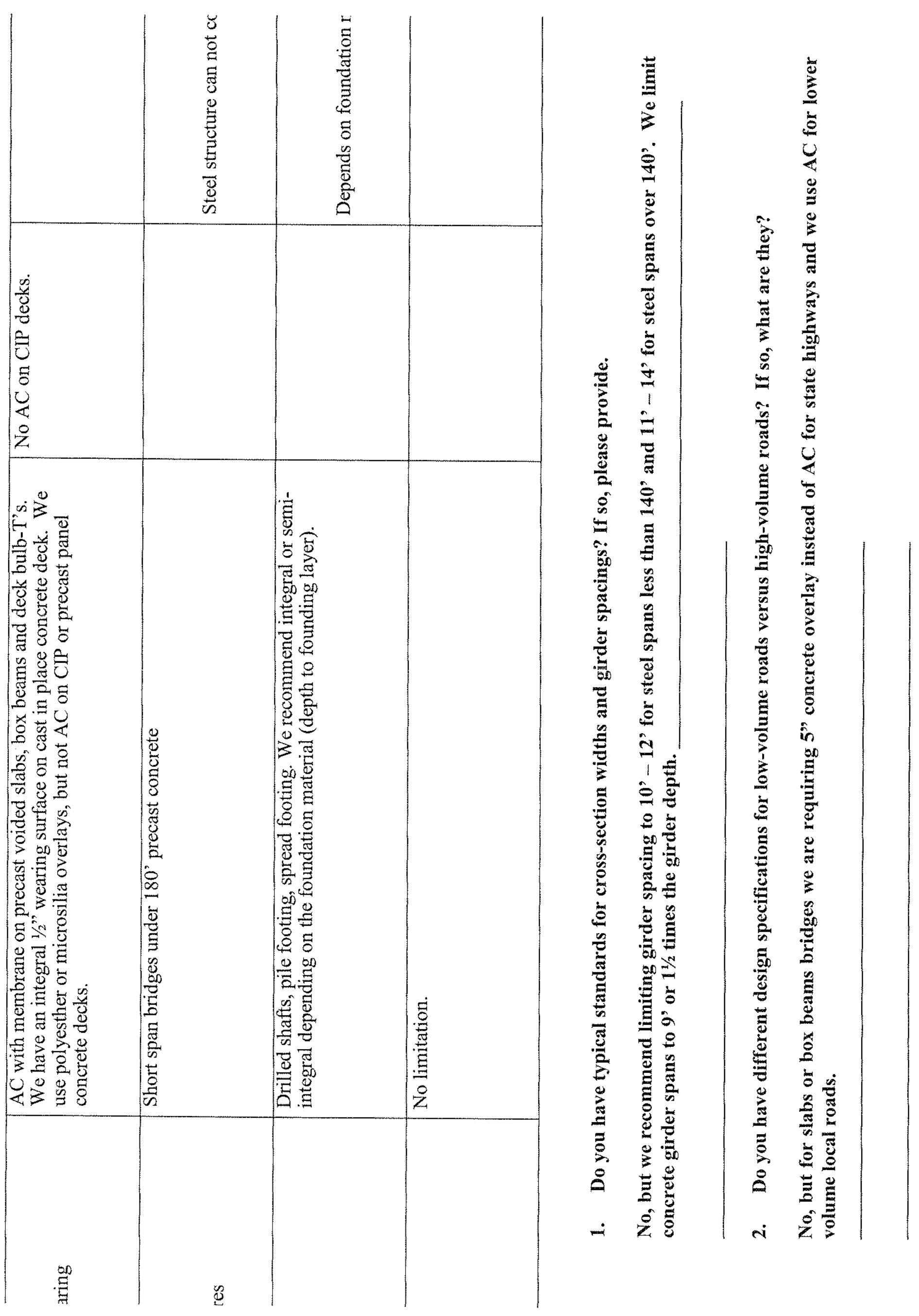




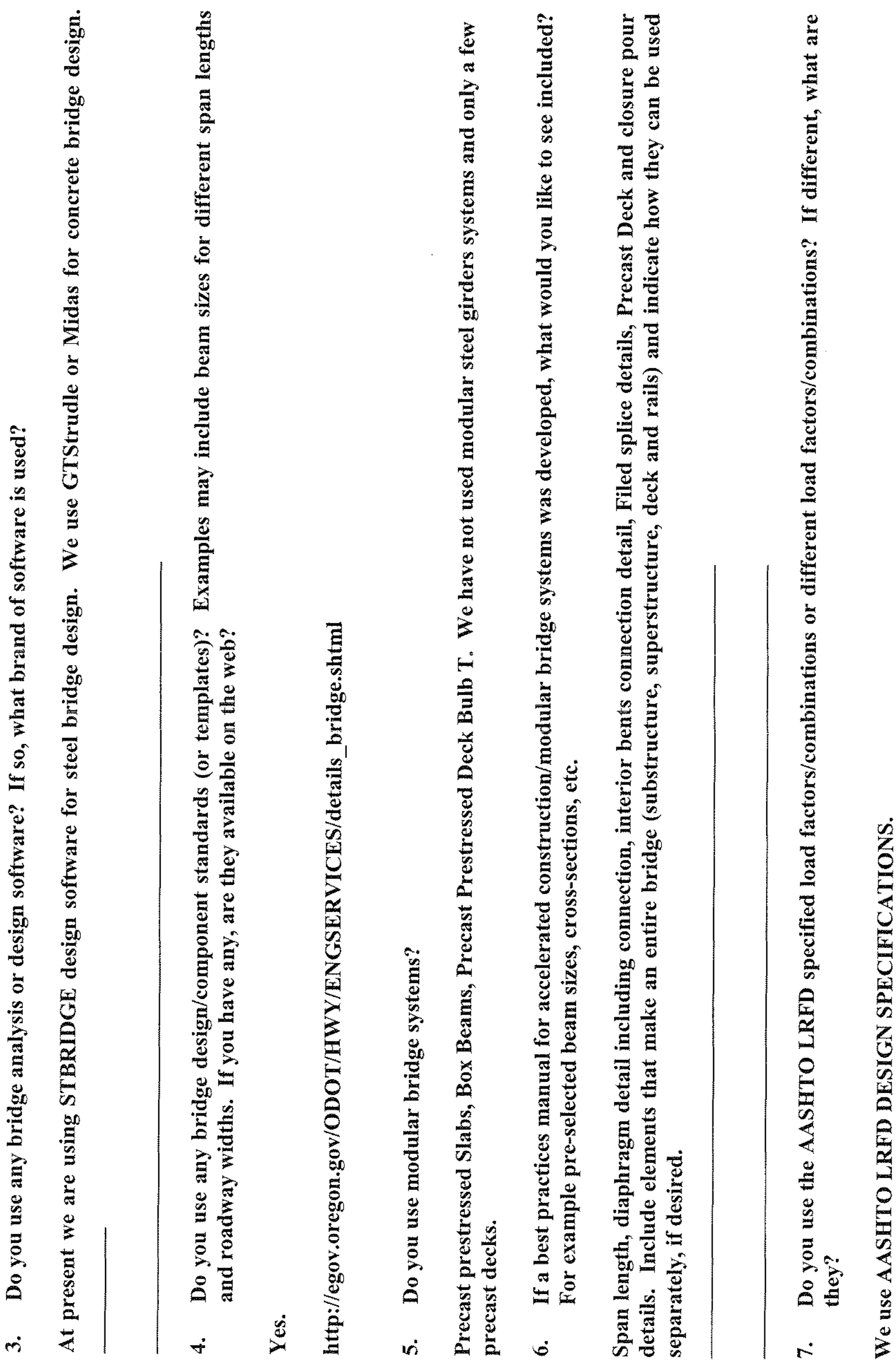




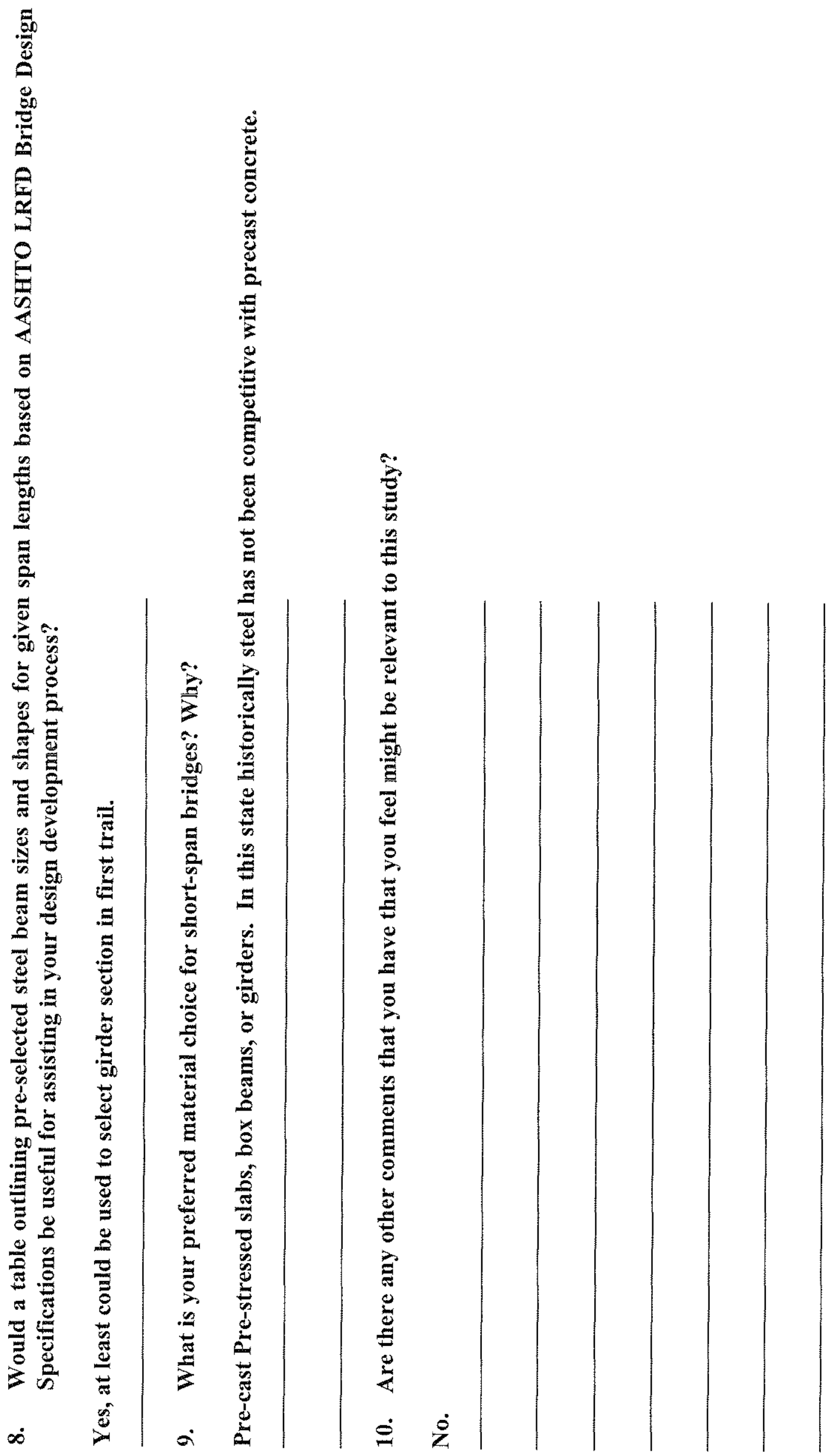




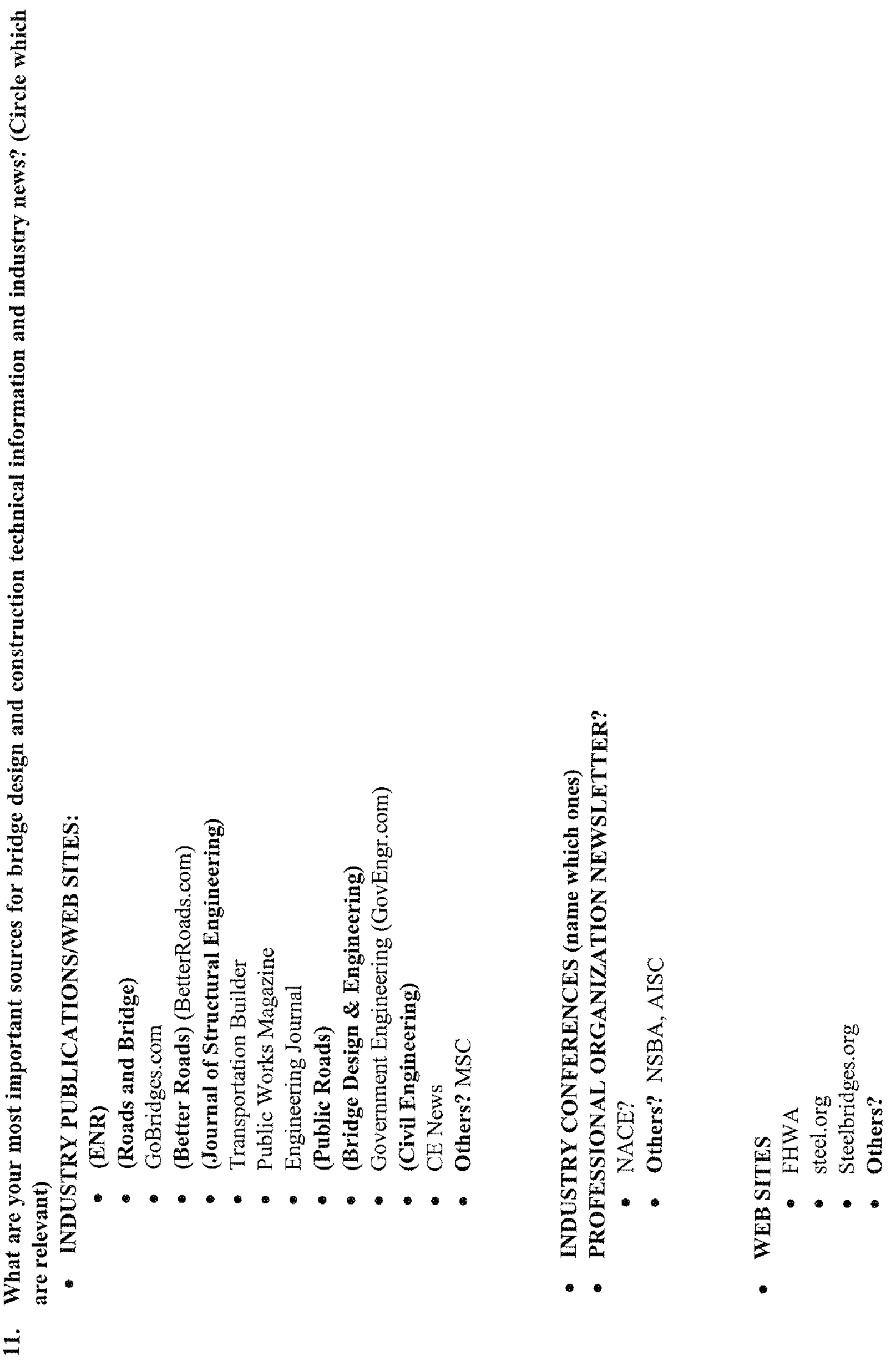




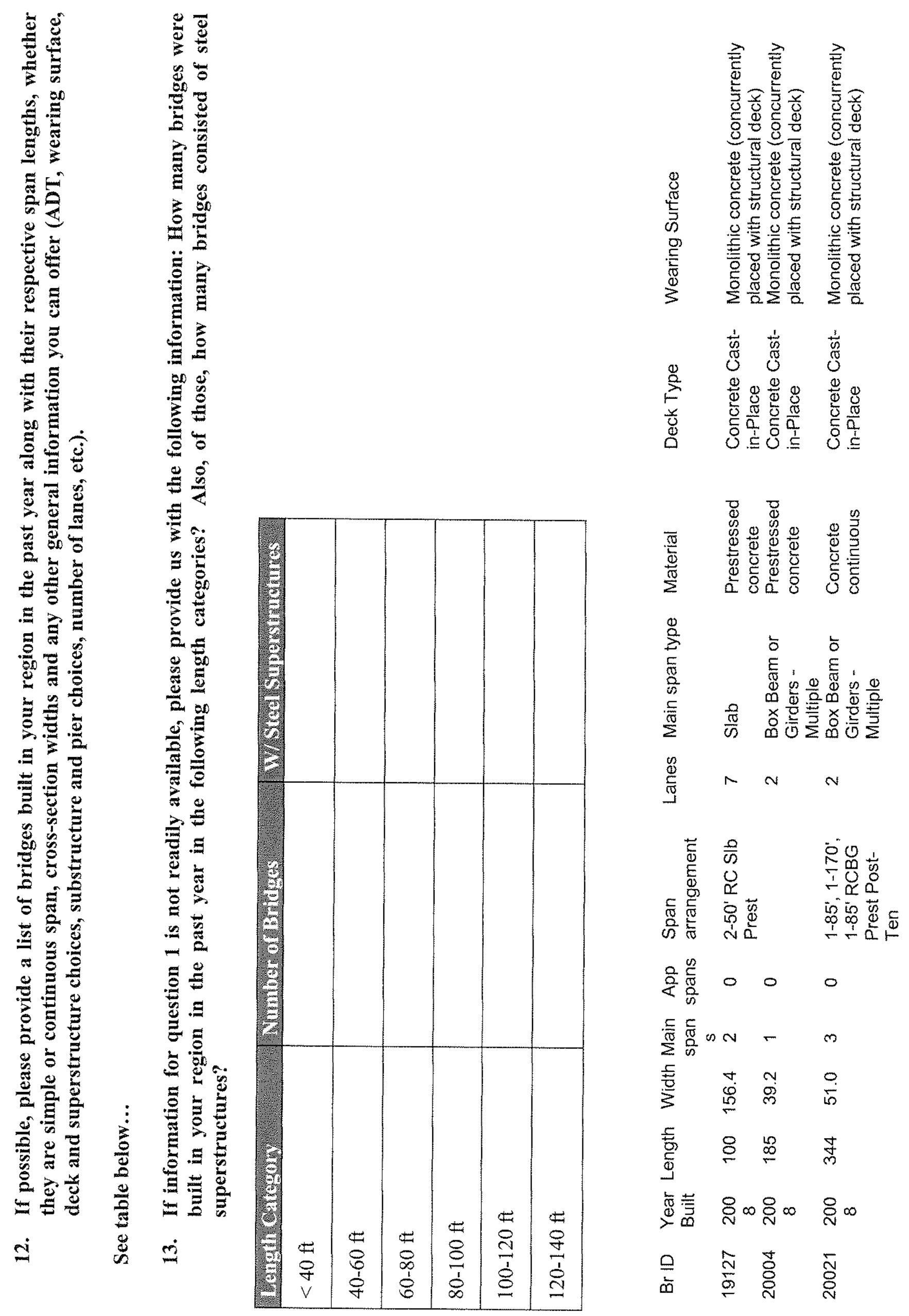




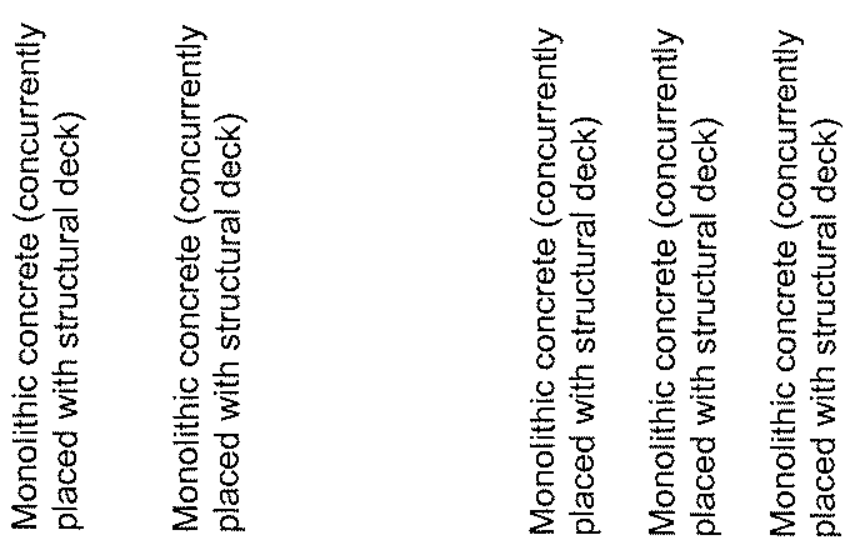

$\dot{1}$
$心$

$\stackrel{0}{0} \stackrel{0}{\square} 8$

ड़ $\begin{array}{lll}\frac{1}{n} & \frac{1}{n} & \frac{3}{n} \\ 0 & 0 & 0\end{array}$

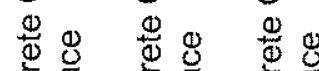

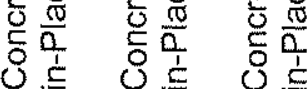
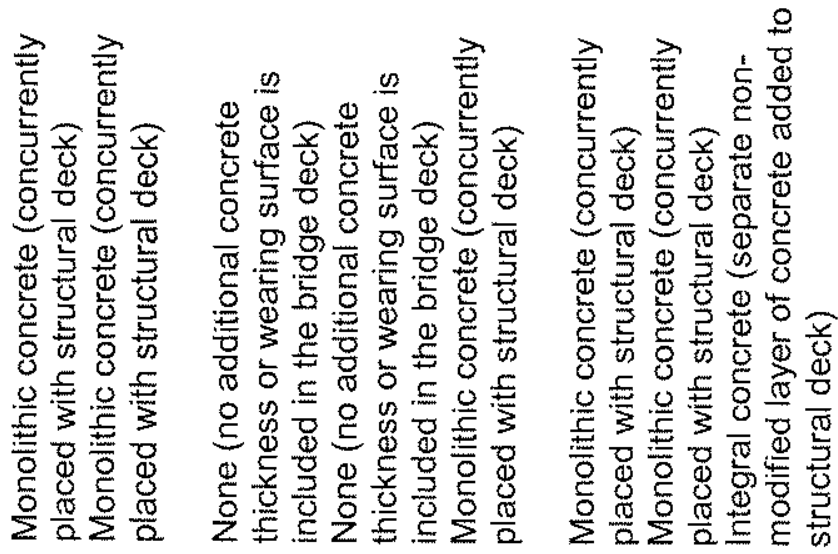

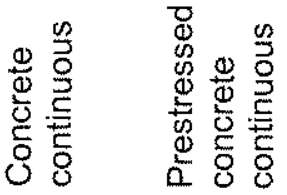

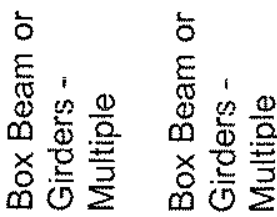

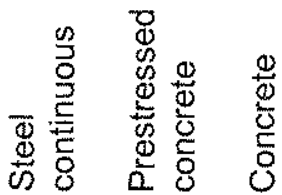

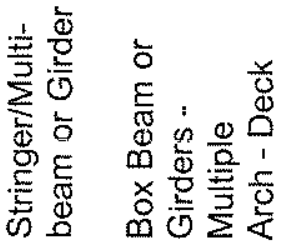

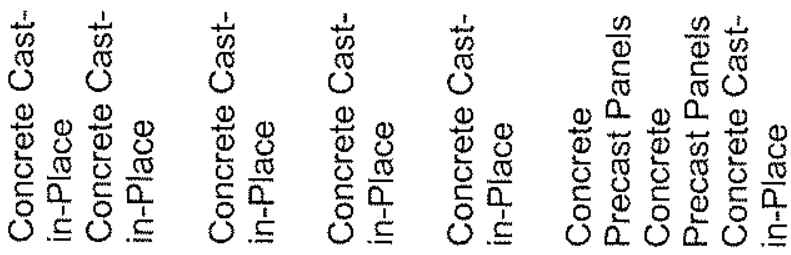

N $\quad N$

$N$

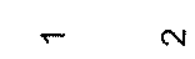

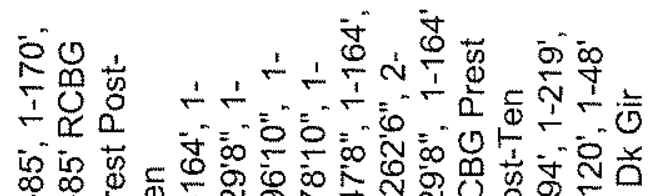

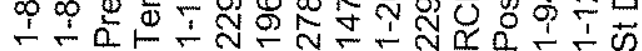

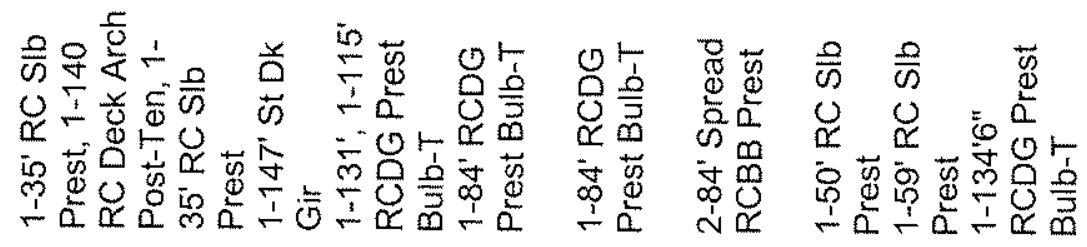

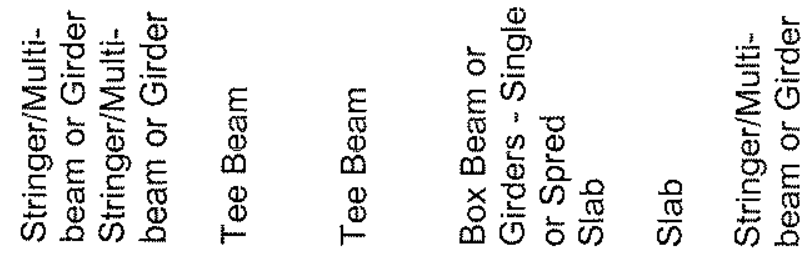

$N \quad N \quad N \quad N \quad N \quad N$

\begin{tabular}{|c|c|c|c|c|c|c|c|c|c|c|c|}
\hline 0 & 0 & 0 & 0 & $N$ & 0 & 0 & 0 & 0 & 0 & 0 & 0 \\
\hline$m$ & $\stackrel{ }{\circ}$ & $\checkmark$ & $r$ & $r$ & $r$ & $N$ & $r$ & $\sigma$ & $N$ & - & - \\
\hline$\frac{0}{i n}$ & 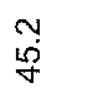 & $\hat{y}$ & $\stackrel{\text { O }}{\text { O্ }}$ & $\frac{N}{\sin }$ & $\stackrel{\sim}{\infty}$ & $\stackrel{5}{\forall}$ & $\hat{\sim}$ & $\stackrel{\mathcal{N}}{\mathcal{Y}}$ & $\stackrel{\widetilde{v}}{\widetilde{\gamma}}$ & $\begin{array}{l}\circ \\
\mathbb{J}\end{array}$ & $\begin{array}{l}0 \\
\infty \\
0\end{array}$ \\
\hline ষ & $\stackrel{\mathscr{N}}{ }^{N}$ & $\stackrel{\infty}{q}$ & 5 & $\stackrel{\circ}{N}$ & $\underset{\sim}{\stackrel{f}{5}}$ & $\stackrel{0}{\stackrel{0}{\sim}}$ & ఫ & $\underset{\infty}{\forall}$ & $\mathscr{0}$ & 요 & 8 \\
\hline
\end{tabular}

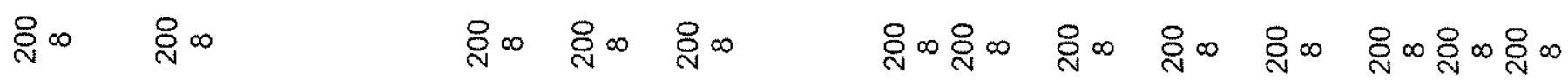

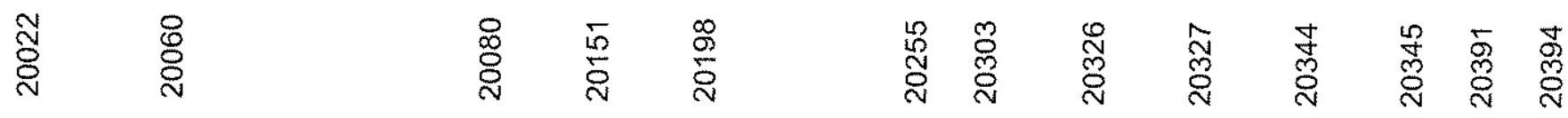




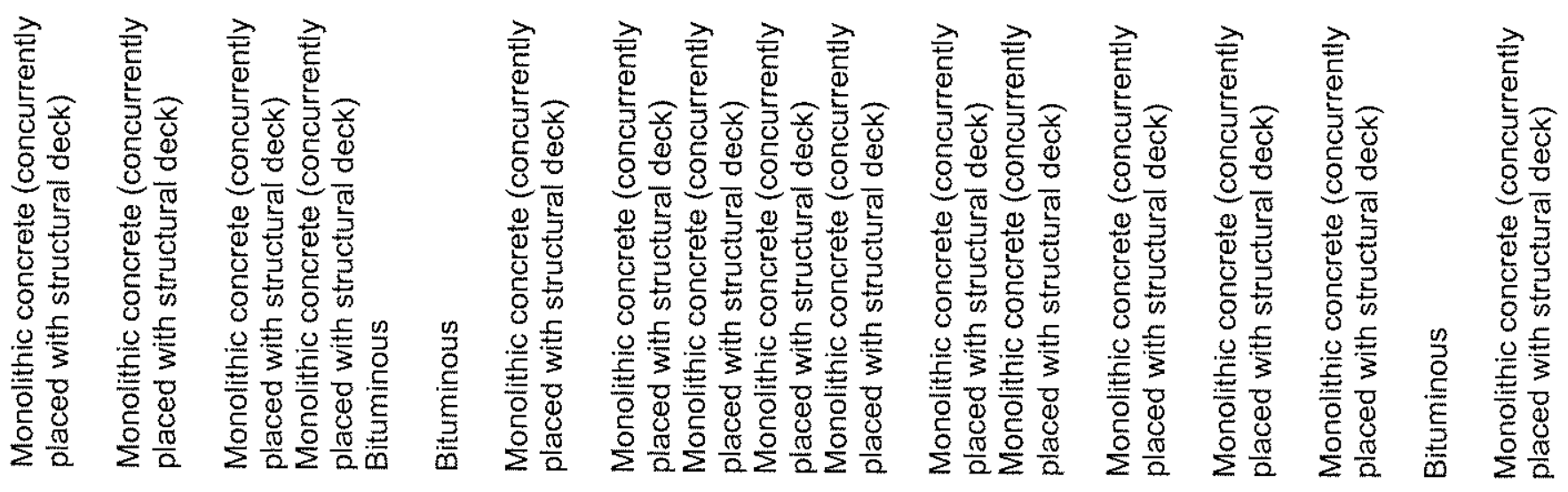

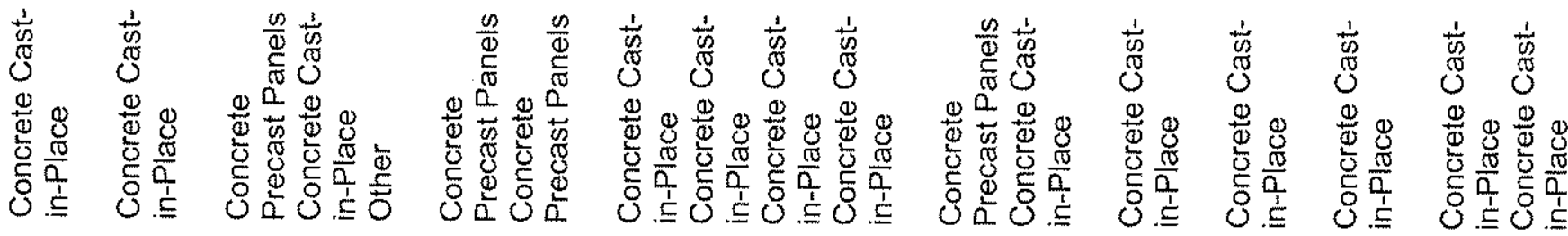

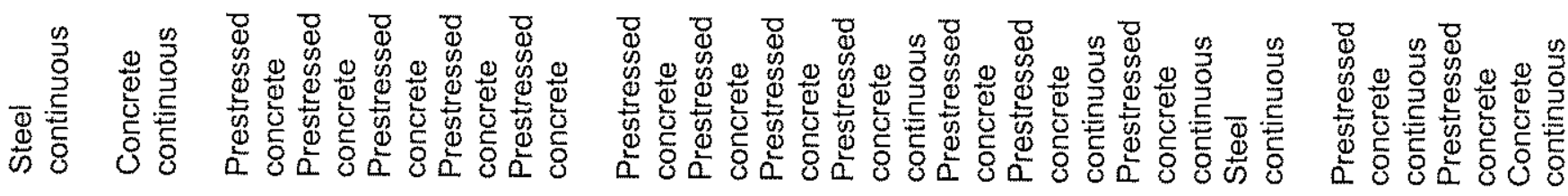

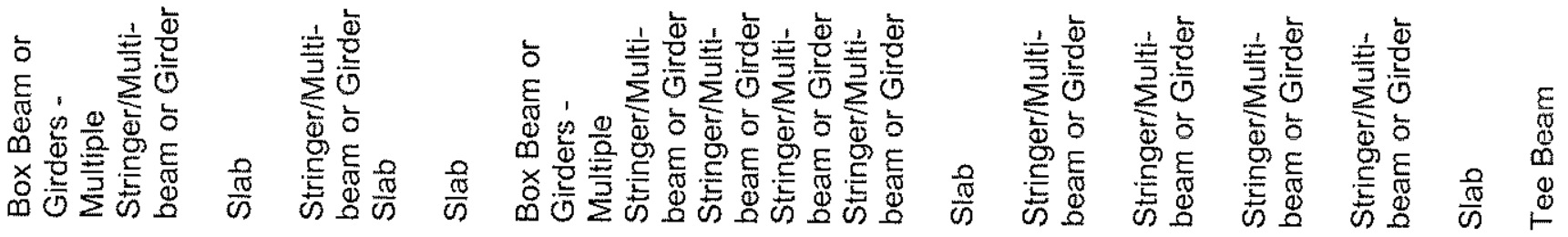

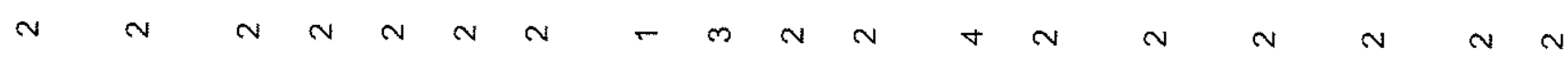

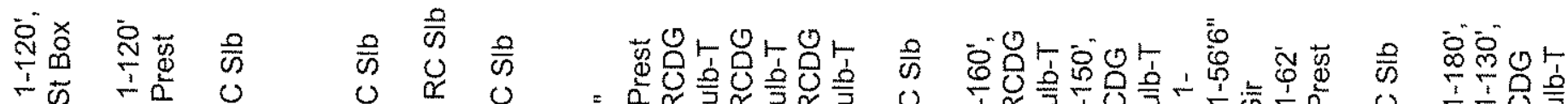

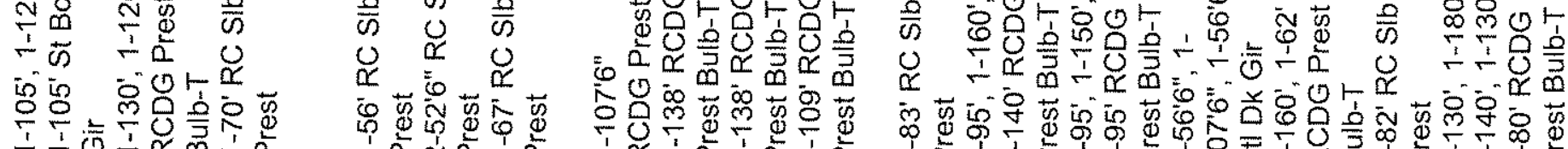

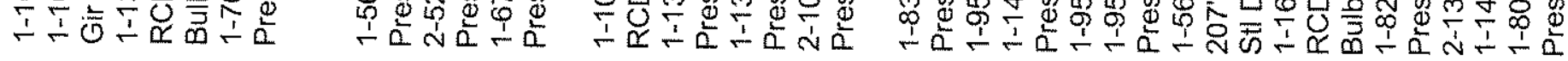

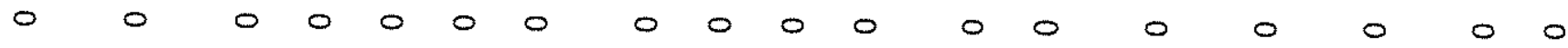

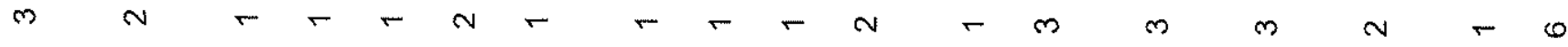

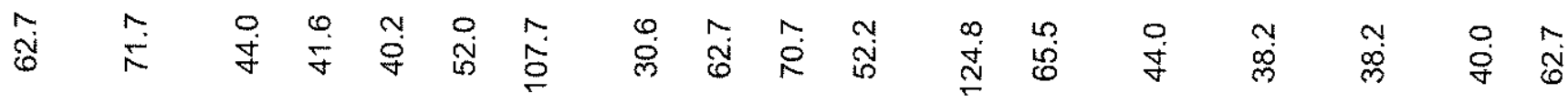

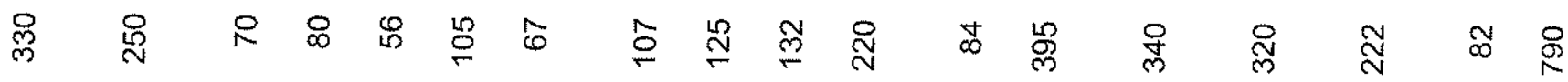

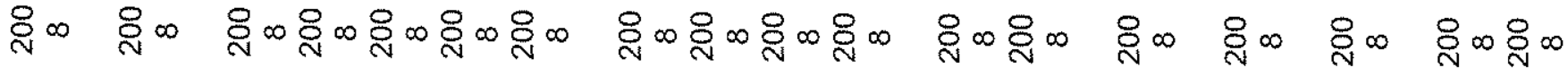

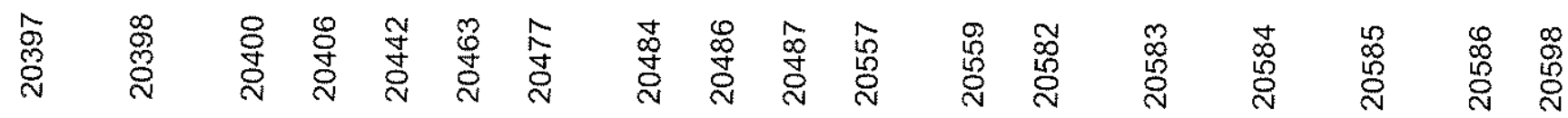



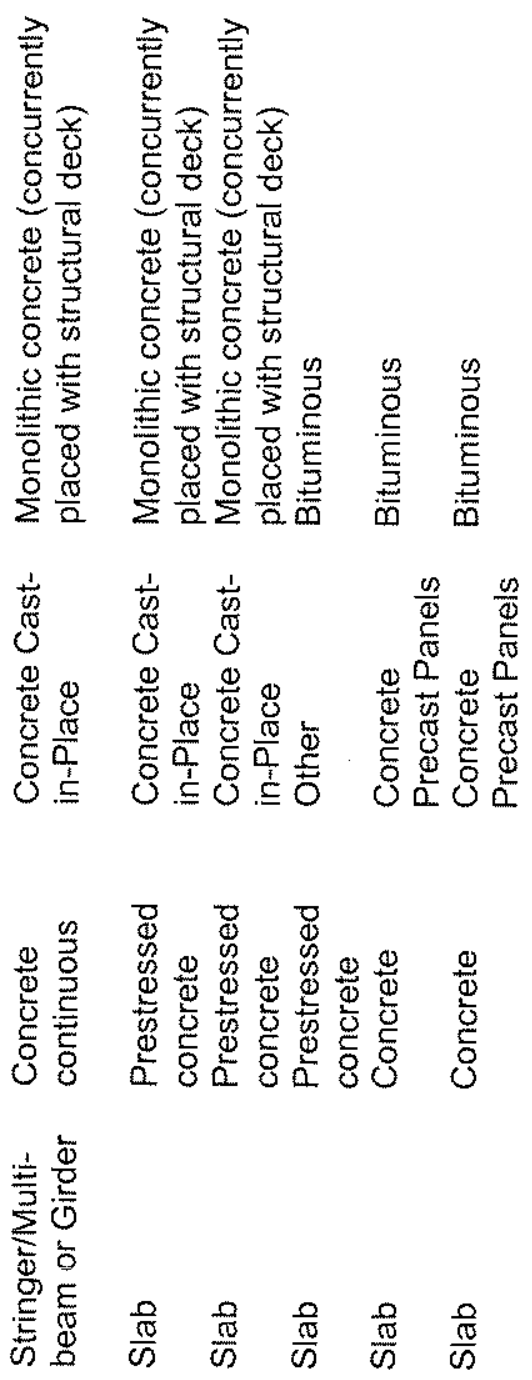

$N \quad m+N N$

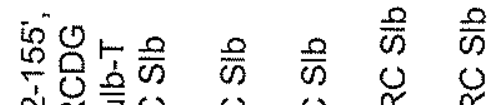

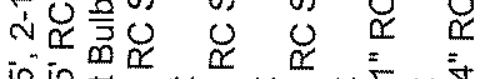

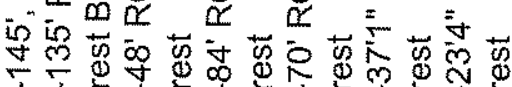

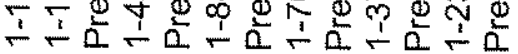

$\begin{array}{lllll}0 & 0 & 0 & 0 & 0\end{array}$

$\nabla+\leftarrow \leftarrow$

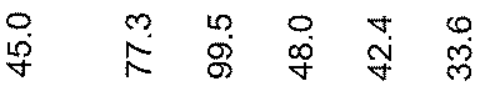

品 学索

:

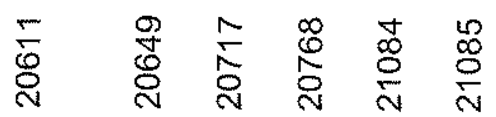




\section{$\underline{\text { Research Statement }}$}

The Federal Highway Administration in conjunction with the American Iron and Steel Institute [AISI] has recently conducted two workshops focused on developing ideas for improved steel bridge construction. One of the target areas of these workshops has been to develop design standards for short span steel bridges. As a result, the AISI Short Span Steel Bridge Alliance has contracted with Dr. Karl Barth at West Virginia University to conduct a survey of State DOT's and County Engineers. The focus of this survey is to study and catalog statistics and methods employed in short-span bridge design and construction. The overall projected outcome of this research is a best practices manual for the design and construction of short-span steel bridges (i.e. bridges up to $140 \mathrm{ft}$.) and a table outlining suggested pre-selected steel beam sizes and shapes for given span lengths.

\section{Part I. General Information}

Date: $11 / 16 / 09$

Time:

Agency / DOH: PennDOT

Name: Tom Macioce

Position / Title: Chief Bridge Engineer

Address: Bureau of Design/BQAD PO Box 3560, Harrisburg, PA 17120-3560

Phone: (717) 787-2881

E-mail: tmacioce@state.pa.us

Other Information: 


\section{Part II. General Questions}

1. If possible, please provide a list of bridges built in your region in the past year along with their respective span lengths, whether they are simple or continuous span, cross-section widths and any other general information you can offer (ADT, wearing surface, deck and superstructure choices, substructure and pier choices, number of lanes, etc.).

2. If information for question 1 is not readily available, please provide us with the following information: How many bridges were built in your region in the past year in the following length categories? Also, of those, how many bridges consisted of steel superstructures?

\begin{tabular}{|c|c|c|}
\hline Length Carggory & Number of Brolges & W/ STeel SHpens intictures \\
\hline$<40 \mathrm{ft}$ & 7 & \\
\hline $40-60 \mathrm{ft}$ & 17 & \\
\hline $60-80 \mathrm{ft}$ & 22 & 2 \\
\hline $80-100 \mathrm{ft}$ & 10 & 2 \\
\hline $100-120 \mathrm{ft}$ & 5 & 0 \\
\hline $120-140 \mathrm{ft}$ & 5 & 0 \\
\hline
\end{tabular}


3. For the following bridge components, please specify whether you have a preferred/specified type of design and whether or not there are any particular types of bridge component that you do not approve:

\begin{tabular}{|c|c|c|c|}
\hline Britge Component & Preference & 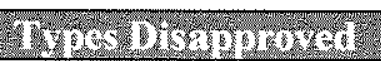 & Brich Explanation \\
\hline Decking Systems & $\begin{array}{l}\text { Circle Choice } \\
\text { Cast-in-place } \\
\text { concrete }\end{array}$ & $\begin{array}{l}\text { PennDOT does not } \\
\text { use } 1 / 2 \text { depth } \\
\text { concrete form panels. }\end{array}$ & $\begin{array}{l}\text { Experience with } \\
\text { this concrete deck } \\
\text { panels as forms } \\
\text { leads to reflective } \\
\text { cracking in the } \\
\text { cast-in place deck. }\end{array}$ \\
\hline $\begin{array}{l}\text { Railing/Guardrail } \\
\text { Systems }\end{array}$ & $\begin{array}{l}\text { Cast in place, } \\
\text { barrier, TL-5 }\end{array}$ & $\begin{array}{l}\text { We do not use } \\
\text { precast barriers in } \\
\text { permanent } \\
\text { applications }\end{array}$ & $\begin{array}{l}\text { Precast barriers } \\
\text { were used in the } \\
\text { past. The barriers } \\
\text { were anchored } \\
\text { with epoxy } \\
\text { anchors that do not } \\
\text { have a long term } \\
\text { performance }\end{array}$ \\
\hline $\begin{array}{l}\text { Topping/Wearing } \\
\text { Surfaces }\end{array}$ & & & \\
\hline $\begin{array}{l}\text { Bridge } \\
\text { Superstructures }\end{array}$ & $\begin{array}{l}\text { Steel or prestressed } \\
\text { beams are not used } \\
\text { systems }\end{array}$ & & \\
\hline Abutments & $\begin{array}{l}\text { Integral abutments } \\
\text { are preference }\end{array}$ & $\begin{array}{l}\text { MSE wall abutment } \\
\text { without supporting } \\
\text { the pile cap on piles. }\end{array}$ & \\
\hline
\end{tabular}




\begin{tabular}{|l|l|l|l|}
\hline Pier Systems & $\begin{array}{l}\text { Conventional } \\
\text { reinforced concrete. }\end{array}$ & & \\
\hline
\end{tabular}

4. Do you have typical standards for cross-section widths and girder spacings? If so, please provide.

Based on design. But typically space girders between 10-14

5. Do you have different design specifications for low-volume roads versus high-volume roads? If so, what are they?

6. Do you use any bridge analysis or design software? If so, what brand of software is used?

PennDOT has entire suite of LRFD design software. The programs are on the Department's web site, and also listed in Design Manual Part 4

7. Do you use any bridge design/component standards (or templates)? Examples may include beam sizes for different span lengths and roadway widths. If you have any, are they available on the web?

8. Do you use modular bridge systems?

9. If a best practices manual for accelerated construction/modular bridge systems was developed, what would you like to see included? For example pre-selected beam sizes, cross-sections, etc. 
10. Do you use the AASHTO LRFD specified load factors/combinations or different load factors/combinations? If different, what are they?

PennDOT has complete design manual with load factors. The Design Manual Part 4 can be accessed on the Department web site.

11. Would a table outlining pre-selected steel beam sizes and shapes for given span lengths based on AASHTO LRFD Bridge Design Specifications be useful for assisting in your design development process?

12. What is your preferred material choice for short-span bridges? Why?

13. Are there any other comments that you have that you feel might be relevant to this study? 
14. What are your most important sources for bridge design and construction technical information and industry news? (Circle which are relevant)

- INDUSTRY PUBLICATIONS/WEB SITES:

- ENR

- Roads and Bridges

- GoBridges.com

- Better Roads (BetterRoads.com)

- Journal of Structural Engineering

- Transportation Builder

- Public Works Magazine

- Engineering Journal

- Public Roads

- Design Engineering

- Government Engineering (GovEngr.com)

- Civil Engineering

- CE News

- Others?

- INDUSTRY CONFERENCES (name which ones)

- PROFESSIONAL ORGANIZATION NEWSLETTER?

- NACE?

- Others?

- WEB SITES

- FHWA

- steel.org

Steelbridges.org

- Others? 


\section{Research Statement}

The Federal Highway Administration in conjunction with the American Iron and Steel Institute [AISI] has recently conducted two workshops focused on developing ideas for improved steel bridge construction. One of the target areas of these workshops has been to develop design standards for short span steel bridges. As a result, the AIST Short Span Steel Bridge Allance has contracted with Dr. Karl Barth at West Virginia University to conduct a survey of State DOT's and County Engineers. The focus of this survey is to study and catalog statistics and methods employed in short-span bridge design and construction. The overall projected outcome of this research is a best practices manual for the design and construction of short-span steel bridges (i.e. bridges up to $140 \mathrm{ft}$ ) and a table outlining suggested pre-selected steel beam sizes and shapes for given span lengths:

\section{Part l. General Information}

Date: December 10,2009

Time: $\quad 800 \mathrm{AM}$

Agency/DOH: South Carolina Department of Transportation Name: Barry Bowers

Position/Title: Structural Design Support Engineer Address: 955 Park Strect Columbia, SC 29201

Phone: $\quad 803-737-4814$

E-mail: bowersbw@scolot.org

Other Information: 


\section{Part II. General Questions}

1. If possible, please provide a list of bridges built in your region in the past year along with their respective span lengths, whether they are simple or continuous span, cross-section widths and any other general information you can offer (ADT, wearing surface, deck and superstructure choices, substructure and pier choices, number of lanes, ete.).

2. If information for question 1 is not readily available, please provide us with the following information: How many bridges were built in your region in the past year in the following length categories? Also, of those, how many bridges consisted of steel superstructures?

\begin{tabular}{|c|c|c|}
\hline 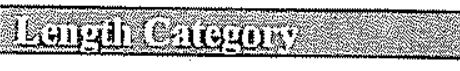 & Sinine ob Buidgch & 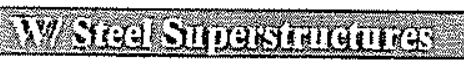 \\
\hline$<40 \mathrm{ft}$ & & \\
\hline $40-60 \mathrm{ft}$ & & \\
\hline $60-80 \mathrm{ft}$ & & \\
\hline $80-100 \mathrm{ft}$ & & \\
\hline $100-120 \mathrm{ft}$ & & \\
\hline $120-140 \mathrm{ft}$ & & \\
\hline
\end{tabular}

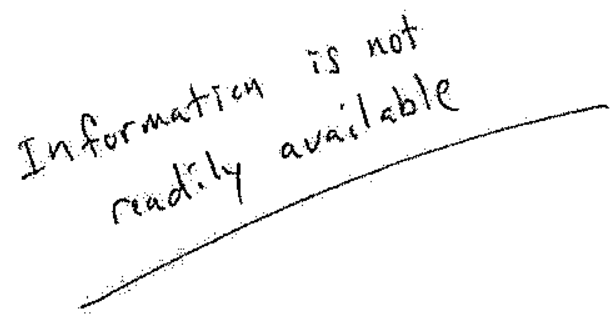


3. For the following bridge components, please specify whether you have a preferred/specified type of design and whether or not there are any particular types of bridge component that you do not approve:

\begin{tabular}{|c|c|c|c|}
\hline 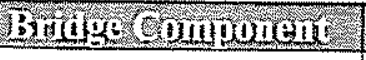 & Drecteroito & 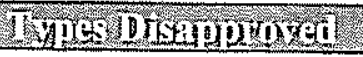 & 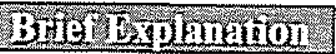 \\
\hline Decking Systems & $\begin{array}{l}\text { Circle Choice } \\
\begin{array}{c}\text { Cast-in-place } \\
\text { concrete }\end{array} \\
\begin{array}{c}\text { Precast concrete } \\
\text { panels }\end{array} \\
\text { Steel stay-in-place } \\
\text { formwork } \\
\text { Other (list): }\end{array}$ & & \\
\hline $\begin{array}{l}\text { Ralling/Guardrail } \\
\text { Systems }\end{array}$ & Conerete & & \\
\hline $\begin{array}{l}\text { Topping/Wearing } \\
\text { Surfaces }\end{array}$ & Concrete & & \\
\hline $\begin{array}{l}\text { Bridge } \\
\text { Superstructures }\end{array}$ & $\begin{array}{l}\text { Bepends on } \\
\text { ste cudterons }\end{array}$ & & \\
\hline Abutments & $\begin{array}{l}\text { Pile Sopported } \\
\text { Spill. Through }\end{array}$ & & \\
\hline Pier Systems & $\begin{array}{l}\text { Depouds on } \\
\text { sik conditions }\end{array}$ & & \\
\hline
\end{tabular}


4. Do you have typical standards for cross-section widths and girder spacings? If so, please provide.

See Section 12.2.5 of the SCDOT Bridge Design Manual (available on the wob)

5. Do you have different design specifications for low-volume roads versus high-volume roads? If so, what are they?

No, only detailing differences (roadway width, wearing surface, etc)

6. Do you use any bridge analysis or design software? If so, what brand of software is used?

Yes CONSPAN, RC-PIER, MERLIN-DASH, SAPZOOO

7. Do you use any bridge design/component standards (or templates)? Examples may include beam sizes for different span lengths and roadway widths. If you have any, are they available on the web?

Not fur structural steel

8. Do you ase modular bridge systems?

Precast cored slab spans on low velume roads

9. If a best practices manual for accelerated construction/modular bridge systems was developed, what would you like to see included? For example pre-selected beam sizes, cross-sections, etc. 
10. Do you use the AASHTO LRTD specified load factors/combinations or different load factors/combinations? If different, what are they?

AASHTO LRFD

11. Would a table outlining pre-selected steel beam sizes and shapes for given span lengths based on AASHTO LRFD Bridge Design Specifications be useful for assisting in your design development process?

$$
\text { Only for a prelmmary desqu }
$$

12. What is your preferred material choice for short-span bridges? Why?

$$
\text { Corrently it is typically concrete - Cost }
$$

13. Are there any other comments that you have that you feel might be relevant to this study? 
14. What are your most important sources for bridge design and construction technical information and industry news? (Circle which are relevant)

- INDUSTRY PUBLICATIONS/WEB SITES:

- ENR

- Roads and Bridges

- GoBridges.com

- Better Roads (BetterRoads;com)

- Journal of Structural Engineering

- Transportation Builder

- Public Works Magazine

- Engineering Joumal

- Public Roads

- Design Engineering

- Government Engineering (GovEngr.com)

- Civil Engineenng

- CENews

- Others?

- INDUSTR CONFERENCES (name which ones) AASHTO Conference

- PROFESSIONAT ORGANIZATION NEWSLETTER? (Sub committee on
NACE?

- Others? Bridges \& Structuret)

- WEB SITES
(. FHWA
- Steelbridges.org
- Others? 


\section{Research Statement}

The Federal Highway Administration in conjunction with the American Iron and Steel Institute [AISI] has recently conducted two workshops focused on developing ideas for improved steel bridge construction. One of the target areas of these workshops has been to develop design standards for short span steel bridges. As a result, the AISI Short Span Steel Bridge Alliance has contracted with Dr. Karl Barth at West Virginia University to conduct a survey of State DOT's and County Engineers. The focus of this survey is to study and catalog statistics and methods employed in short-span bridge design and construction. The overall projected outcome of this research is a best practices manual for the design and construction of short-span steel bridges (i.e. bridges up to $140 \mathrm{ft}$.) and a table outlining suggested pre-selected steel beam sizes and shapes for given span lengths.

\section{Part I. General Information}

Date: $\underline{11 / 17 / 2009}$

Time:

Agency / DOH: South Dakota Department of Transportation

Name: Kevin Goeden

Position / Title: Chief Bridge Engineer

Address: 700 East Broadway Avenue, Pierre, SD 57501

Phone: $\underline{605.773 .3285}$

E-mail: Kevin.goeden@state.sd.us

Other Information: 


\section{$\underline{\text { Part II. General Questions }}$}

1. If possible, please provide a list of bridges built in your region in the past year along with their respective span lengths, whether they are simple or continuous span, cross-section widths and any other general information you can offer (ADT, wearing surface, deck and superstructure choices, substructure and pier choices, number of lanes, etc.).

2. If information for question 1 is not readily available, please provide us with the following information: How many bridges were built in your region in the past year in the following length categories? Also, of those, how many bridges consisted of steel superstructures?

\begin{tabular}{|c|c|c|}
\hline Lengh Cregron & Nomber of Britges & Wi Sted Smperstrubtures \\
\hline$<40 \mathrm{ft}$ & $\begin{array}{l}1 \text { Pre-stressed concrete } \\
\text { double tee deck bridge with } \\
28^{\prime} \text { Roadway Width }\end{array}$ & $x_{1}$ \\
\hline $40-60 \mathrm{ft}$ & $\begin{array}{l}1 \text { Pre-stressed concrete } \\
\text { double tee deck bridge with } \\
27 \text { ' Roadway Width }\end{array}$ & 0 \\
\hline $60-80 \mathrm{ft}$ & $\begin{array}{l}6 \text { Pre-stressed concrete } \\
\text { double tee deck bridges } \\
\text { with } 27^{\prime}-30^{\prime} \text { Roadway } \\
\text { Widths }\end{array}$ & 0 \\
\hline $80-100 \mathrm{ft}$ & $\begin{array}{l}1 \text { Pre-stressed concrete } \\
\text { double tee deck bridge with } \\
34.5^{\prime} \text { roadway width and } 1 \\
\text { pre-stressed concrete bulb } \\
\text { tee deck bridge with } 32.5 \text { ' } \\
\text { Roadway Width } \\
\end{array}$ & 0 \\
\hline $100-120 \mathrm{ft}$ & $\begin{array}{l}1 \text { Pre-stressed concrete I- } \\
\text { girder bridge with CIP } \\
\text { reinforced concrete deck } \\
\text { and } 42 \text { ' roadway width }\end{array}$ & 0 \\
\hline $120-140 \mathrm{ft}$ & $\begin{array}{l}1 \text { reinforced concrete slab } \\
\text { bridge with } 32 \text { ' roadway } \\
\text { width }\end{array}$ & 0 \\
\hline
\end{tabular}


3. For the following bridge components, please specify whether you have a preferred/specified type of design and whether or not there are any particular types of bridge component that you do not approve:

\begin{tabular}{|c|c|c|c|}
\hline Britge Component & Dreference & Types Disapuroved & Brief Explamition \\
\hline Decking Systems & 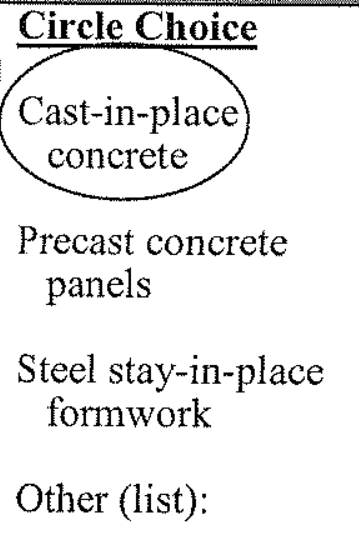 & $\begin{array}{l}\text { Stay-in-place } \\
\text { formwork }\end{array}$ & $\begin{array}{l}\text { Past experience } \\
\text { with stay-in-place } \\
\text { formwork has } \\
\text { shown issues with } \\
\text { interface moisture } \\
\text { entrapment \& } \\
\text { corrosion. Also, } \\
\text { the formwork } \\
\text { hinders underside } \\
\text { deck inspection. }\end{array}$ \\
\hline $\begin{array}{l}\text { Railing/Guardrail } \\
\text { Systems }\end{array}$ & $\begin{array}{l}\text { New Jersey Barrier } \\
\text { F-Shape Barrier } \\
\text { Kansas Corral Rail } \\
\text { (concrete) } \\
\text { Wyoming 2-tube } \\
\text { steel rail }\end{array}$ & & \\
\hline $\begin{array}{l}\text { Topping/Wearing } \\
\text { Surfaces }\end{array}$ & $\begin{array}{l}\text { Low Slump Dense } \\
\text { Concrete Overlay } \\
\text { Epoxy Deck Chip } \\
\text { Seal } \\
\text { Membrane \& } \\
\text { Asphalt Overlay }\end{array}$ & & $\begin{array}{l}\text { These treatments } \\
\text { are generally } \\
\text { applied to older } \\
\text { concrete bridge } \\
\text { decks. New decks } \\
\text { are full denth }\end{array}$ \\
\hline $\begin{array}{l}\text { Bridge } \\
\text { Superstructures }\end{array}$ & $\begin{array}{l}\text { Reinforced } \\
\text { Concrete Slab } \\
\text { Steel I-Girder } \\
\text { Pre-stressed } \\
\text { Concrete I-Girder }\end{array}$ & & \\
\hline Abutments & $\begin{array}{l}\text { Integral concrete } \\
\text { spill through } \\
\text { Concrete sill with } \\
\text { cantilever backwall } \\
\text { Vertical cantilever }\end{array}$ & & $\begin{array}{l}\text { These abutment } \\
\text { types may be } \\
\text { founded on steel, } \\
\text { timber or } \mathrm{p} / \mathrm{s} \\
\text { concrete piles. }\end{array}$ \\
\hline Pier Systems & $\begin{array}{l}\text { R/C Single Column } \\
\text { R/C Multi-Column } \\
\text { Bent } \\
\text { R/C Pier Wall }\end{array}$ & & $\begin{array}{l}\text { These pier types } \\
\text { may be founded on } \\
\text { steel, timber or } p / s \\
\text { concrete piles; or } \\
\text { drilled shafts. }\end{array}$ \\
\hline
\end{tabular}


4. Do you have typical standards for cross-section widths and girder spacings? If so, please provide.

No

5. Do you have different design specifications for low-volume roads versus high-volume roads? If so, what are they?

No

6. Do you use any bridge analysis or design software? If so, what brand of software is used?

AASHTOWare (OPIS \& VIRTIS), STAAD, PCAColumn, PCASlabbridge, Georgia Beam, AISI Beam Design Program

7. Do you use any bridge design/component standards (or templates)? Examples may include beam sizes for different span lengths and roadway widths. If you have any, are they available on the web?

No

8. Do you use modular bridge systems?

No

9. If a best practices manual for accelerated construction/modular bridge systems was developed, what would you like to see included? For example pre-selected beam sizes, cross-sections, etc.

Pre-selected beam sizes with std spacing and deck design for various std widths. 
10. Do you use the AASHTO LRFD specified load factors/combinations or different load factors/combinations? If different, what are they?

No.

11. Would a table outlining pre-selected steel beam sizes and shapes for given span lengths based on AASHTO LRFD Bridge Design Specifications be useful for assisting in your design development process?

Yes.

12. What is your preferred material choice for short-span bridges? Why?

Pre-cast pre-stressed concrete I-Beams based on economics.

13. Are there any other comments that you have that you feel might be relevant to this study?

Note that the information in the table on Part II question 2 reflects bridges let by SDDOT in calendar year 2009. The majority of them are owned by local government entities (county, city and townships). Bridges on the state system and owned by SDDOT typically do not incorporate deck beam type superstructures. 
14. What are your most important sources for bridge design and construction technical information and industry news? (Circle which are relevant)

- INDUSTRKPUBLICATIONS/WEB SITES:

- ENR

- Roads and Bridges

- GoBridges.com

- Better Roads (BetterRoads.com D

- Journat of Structurat Engineering

- Transportation Builder

- Public Works Magazine

- Engineering Journal

- Public Roads

- Design Engineering

- Goverment Engineering (GovEngr.com)

- Civil Engineering

- CENews

- Others?

- PCI Journal

- TRB/NCHRP Reports

- Structural Engineer

- Welding Joumal

- INDUSTRY CONFERENCES (name which ones)

- AASHTO Subcommittee on Bridges and Structures

- North Central States Consortium

- AISC World Steel Bridge Symposium

- International Bridge Conference

- PROFESSIONAL ORGANIZATION NEWSLETTER?

- NACE?

- Others?

- WEB SITES

- FHWA

- Steelorgs

- Steelbridges.org

- Others?

- AASHTO Bridge

- NHI

- TRB

- USACE 


\section{Research Statement}

The Federal Highway Administration in conjunction with the American Iron and Steel Institute [AISI] has recently conducted two workshops focused on developing ideas for improved steel bridge construction. One of the target areas of these workshops has been to develop design standards for short span steel bridges. As a result, the AISI Short Span Steel Bridge Alliance has contracted with Dr. Karl Barth at West Virginia University to conduct a survey of State DOT's and County Engineers. The focus of this survey is to study and catalog statistics and methods employed in short-span bridge design and construction. The overall projected outcome of this research is a best practices manual for the design and construction of short-span steel bridges (i.e. bridges up to $140 \mathrm{ft}$.) and a table outlining suggested pre-selected steel beam sizes and shapes for given span lengths.

\section{Part I. General Information}

Date: $10 \quad \operatorname{Dec} 09$

Time: 8:00 Am

Agency/DOH: Tennesser DoT

Name: Ed Wasserman

Position/Title: Direetar

Address: Suit 1100 Jas.k. Polk Bloly Nashuile, TN $37243-0339$

Phone: $615-741-3351$

E-mail: ed.wassermanestate itnus

Other Information: 


\section{Part II. General Questions}

1. If possible, please provide a list of bridges built in your region in the past year along with their respective span lengths, whether they are simple or continuous span, cross-section widths and any other general information you can offer (ADT, wearing surface, deck and superstructure choices, substructure and pier choices, number of lanes, etc.). See atfached.

2. If information for question $\mathbf{1}$ is not readily available, please provide us with the following information: How many bridges were built in your region in the past year in the following length categories? Also, of those, how many bridges consisted of steel superstructures?

\begin{tabular}{|c|c|c|}
\hline Lengith Category & Number of Britges & W/ Sterl Suphermichres \\
\hline$<40 \mathrm{ft}$ & & \\
\hline $40-60 \mathrm{ft}$ & & \\
\hline $60-80 \mathrm{ft}$ & & \\
\hline $80-100 \mathrm{ft}$ & & \\
\hline $100-120 \mathrm{ft}$ & & \\
\hline $120-140 \mathrm{ft}$ & & \\
\hline
\end{tabular}


3. For the following bridge components, please specify whether you have a preferred/specified type of design and whether or not there are any particular types of bridge component that you do not approve:

\begin{tabular}{|c|c|c|c|}
\hline Britge Component & Preforence & Thues Dikapuroved & Brief Explanation \\
\hline Decking Systems & 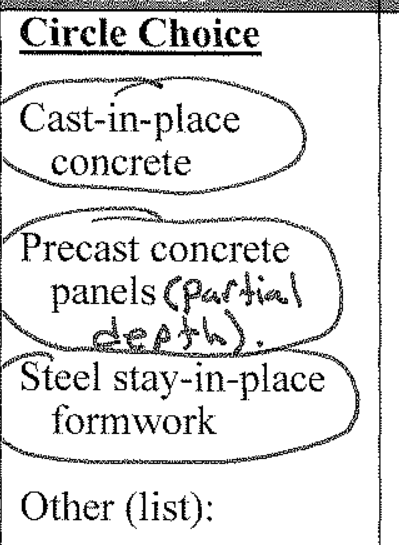 & $\begin{array}{l}\text { No usoken } \\
\text { decks, grid } \\
\text { decks (openor } \\
\text { filled) or } \\
\text { metal plank } \\
\text { with asphalt. }\end{array}$ & $\begin{array}{l}\text { me cuant a } \\
\text { minimum } \\
40 \text { year deck, } \\
\text { but hope to } \\
\text { get } 50 \text { or } \\
\text { more years. }\end{array}$ \\
\hline $\begin{array}{l}\text { Railing/Guardrail } \\
\text { Systems }\end{array}$ & 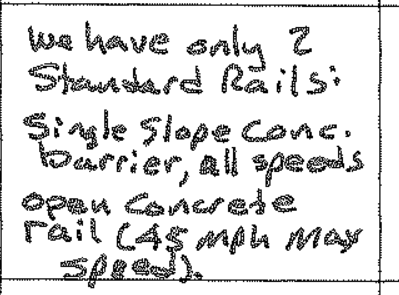 & $\begin{array}{l}\text { Metal or wosd } \\
\text { guardrails }\end{array}$ & $\begin{array}{l}\text { We wae saly } \\
\text { the the rails } \\
\text { as they are } \\
\text { practically } \\
\text { naintemance } \\
\text { free. }\end{array}$ \\
\hline $\begin{array}{l}\text { Topping/Wearing } \\
\text { Surfaces }\end{array}$ & 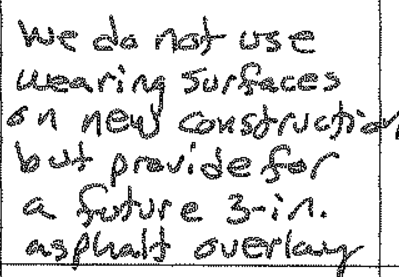 & & \\
\hline $\begin{array}{l}\text { Bridge } \\
\text { Superstructures }\end{array}$ & $\begin{array}{l}\text { Continuas, comps } \\
\text { prestressed } \\
\text { concrete or } \\
\text { Sheel girder } \\
\text { systems }\end{array}$ & $\begin{array}{l}\text { Timber bridges } \\
\text { Simple span bridye }\end{array}$ & $\begin{array}{l}\text { we want the } \\
\text { best service } \\
\text { life materials } \\
\text { only. }\end{array}$ \\
\hline Abutments & 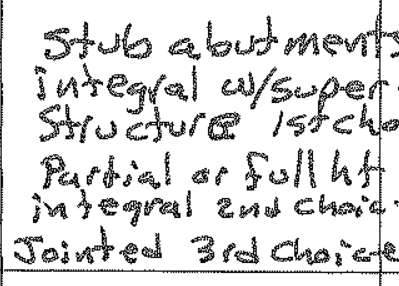 & 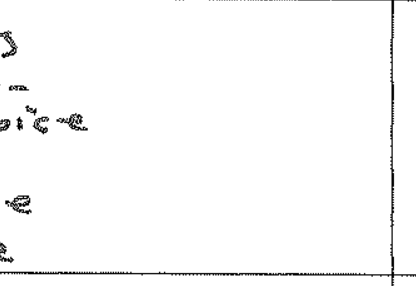 & \\
\hline Pier Systems & $\begin{array}{l}\text { Cast-in-place } \\
\text { concrete } \\
\text { Steel ar concrete } \\
\text { pile-type }\end{array}$ & & \\
\hline
\end{tabular}


4. Do you have typical standards for cross-section widths and girder spacings? If so, please provide.

No

5. Do you have different design specifications for low-volume roads versus high-volume roads? If so, what are they?

No, as far as design loadings or fatigue life.

6. Do you use any bridge analysis or design software? If so, what brand of software is used?

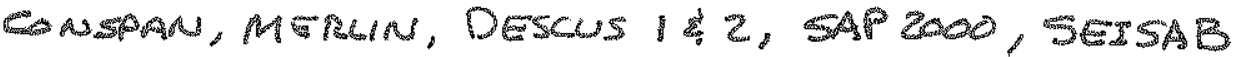

FLA PIER

7. Do you use any bridge design/component standards (or templates)? Examples may include beam sizes for different span lengths and roadway widths. If you have any, are they available on the web?

No

8. Do you use modular bridge systems?

No

9. If a best practices manual for accelerated construction/modular bridge systems was developed, what would you like to see included? For example pre-selected beam sizes, cross-sections, etc.

Nane 
10. Do you use the AASHTO LRFD specified load factors/combinations or different load factors/combinations? If different, what are they?

USE AASHTO LRFD widhat exepptians

11. Would a table outlining pre-selected steel beam sizes and shapes for given span lengths based on AASHTO LRFD Bridge Design Specifications be useful for assisting in your design development process?

Not appreciably, as we use ong continuous bridges sueh that variance in spun ratio's affect beam sizes.

12. What is your preferred material choice for short-span bridges? Why?

precast, prestressed conerate beans. The reasan is speed

of delivery and low cost. We've tried to make rolled bean Loriges competive but theyve nt proven to be.

13. Are there any other comments that you have that you feel might be relevant to this study? 
14. What are your most important sources for bridge design and construction technical information and industry news? (Circle which are relevant)

- INDUSTRY PUBLICATIONS/WEB SITES:

- ENR

(2) Roads and Bridges

- GoBridges.com

6 Better Roads (BetterRoads.com)

Nona of those

- Journal of Structural Engineering

- Transportation Builder

- Public Works Magazine

- Engineering Journal

- Public Roads

- Design Engineering

- Government Engineering (GovEngr.com)

(-) Civil Engineering

- CE News

- Others?

warked are particulatly helphel.

\author{
-
}

NSBA Bridge Conferences

- INDUSTRY CONFERENCES (name which ones) $\int$ RA/OcL Bridye Conferences

- PROFESSIONAL ORGANIZATION NEWSLETTER?

- NACE? Naga

- Others? PCJ ansa neuslellers

- WEB SITES

- FHWA

- steel.org

- Steelbridges.org

- Others?

(3) peiorg 


\section{Research Statement}

The Federal Highway Administration in conjunction with the American Iron and Steel Institute [AISI] has recently conducted two workshops focused on developing ideas for improved steel bridge construction. One of the target areas of these workshops has been to develop design standards for short span steel bridges. As a result, the AISI Short Span Steel Bridge Alliance has contracted with Dr. Karl Barth at West Virginia University to conduct a survey of State DOT's and County Engineers. The focus of this survey is to study and catalog statistics and methods employed in short-span bridge design and construction. The overall projected outcome of this research is a best practices manual for the design and construction of short-span steel bridges (i.e. bridges up to $140 \mathrm{ft}$.) and a table outlining suggested pre-selected steel beam sizes and shapes for given span lengths.

\section{Part I. General Information}

Date: $12 / 3 / 09$

Time: Daytime

Agency / DOH: Texas DOT

Name: David Hohmann

Position / Title: Director, Bridge Division

Address: $125 \mathrm{E} 11^{\text {th }}$ St. Austin, TX 78701

Phone: 5124162183

E-mail: dhohmann@dot.state.tx.us

Other Information: 


\section{Part Il. General Questions}

1. If possible, please provide a list of bridges built in your region in the past year along with their respective span lengths, whether they are simple or continuous span, cross-section widths and any other general information you can offer (ADT, wearing surface, deck and superstructure choices, substructure and pier choices, number of lanes, etc.).

See response to 2 .

2. If information for question 1 is not readily available, please provide us with the following information: How many bridges were built in your region in the past year in the following length categories? Also, of those, how many bridges consisted of steel superstructures?

\begin{tabular}{|l|l|l|}
\hline Legth Catcgory & Nimber of Bfiges & W/ Stea Superstmetures \\
\hline$<40 \mathrm{ft}$ & 45 & 0 \\
\hline $40-60 \mathrm{ft}$ & 55 & 2 \\
\hline $60-80 \mathrm{ft}$ & 44 & 1 \\
\hline $80-100 \mathrm{ft}$ & 25 & 0 \\
\hline $100-120 \mathrm{ft}$ & 31 & 0 \\
\hline $120-140 \mathrm{ft}$ & 26 & 1 \\
\hline$>140 \mathrm{ft}$ & 191 & 7 \\
\hline
\end{tabular}

Notes:

(1) Above numbers are for bridge replacement or new construction projects let during TxDOT FY2009 (9/1/08 to 8/31/09).

(2) "Number of Bridges" column values include bridge-class culverts.

(3) Numbers include on-system and off-system structures. 
For the following bridge components, please specify whether you have a preferred/specified type of design and whether or not there are any particular types of bridge component that you do not approve:

\begin{tabular}{|c|c|c|c|}
\hline Brtage Component & Preferense & Whs Thaneroust & Brier Explanation \\
\hline Decking Systems & $\begin{array}{l}\text { Circle Choice } \\
\text { Cast-in-place } \\
\text { concrete } \\
\text { Precast concrete } \\
\text { panels } \\
\text { Steel stay-in-place } \\
\text { formwork } \\
\text { Other (list): }\end{array}$ & $\begin{array}{l}\text { Note: TXDOT does } \\
\text { not informally or } \\
\text { officially } \\
\text { "disapprove" any } \\
\text { structure types. }\end{array}$ & $\begin{array}{l}\text { All three types are } \\
\text { approved an used } \\
\text { in Texas. } \\
\text { Contractors prefer } \\
\text { precast concrete } \\
\text { sub-deck panels } \\
\text { with a } 4 \text { inch cast- } \\
\text { in-place topping. }\end{array}$ \\
\hline $\begin{array}{l}\text { Railing/Guardrail } \\
\text { Systems }\end{array}$ & Concrete. & & $\begin{array}{l}\text { Concrete is } \\
\text { preferred due to } \\
\text { cost. Railings with } \\
\text { steel components } \\
\text { are often provided. }\end{array}$ \\
\hline $\begin{array}{l}\text { Topping/Wearing } \\
\text { Surfaces }\end{array}$ & None & & $\begin{array}{l}\text { Prefer to not } \\
\text { provide a topping } \\
\text { or wearing surface. } \\
\text { If one is provided } \\
\text { it typically is ACP. }\end{array}$ \\
\hline $\begin{array}{l}\text { Bridge } \\
\text { Superstructures }\end{array}$ & $\begin{array}{l}\text { Simple span } \\
\text { prestressed concrete } \\
\text { beams. }\end{array}$ & & $\begin{array}{l}\text { Steel beams are } \\
\text { seldom used due to } \\
\text { cost. }\end{array}$ \\
\hline Abutments & $\begin{array}{l}\text { Cast-in-place } \\
\text { concrete on piling } \\
\text { (steel or concrete) } \\
\text { or drilled shafts. }\end{array}$ & & $\begin{array}{l}\text { Some precast } \\
\text { abutment caps } \\
\text { have been used. }\end{array}$ \\
\hline Pier Systems & $\begin{array}{l}\text { Cast-in-place } \\
\text { concrete on piling } \\
\text { (steel or concrete) } \\
\text { or drilled shafts. }\end{array}$ & & $\begin{array}{l}\text { Some precast pier } \\
\text { caps have been } \\
\text { used }\end{array}$ \\
\hline
\end{tabular}


3. Do you have typical standards for cross-section widths and girder spacings? If so, please provide.

Yes, they are available on the web at:

http:/www.txdot.gov/insdtdot/orgchart/cmd/cserve/standard/bridge-

e.htm

4. Do you have different design specifications for Iow-volume roads versus high-volume roads? If so, what are they?

No

5. Do you use any bridge analysis or design software? If so, what brand of software is used?

PGSuper for prestressed concrete girder design.

STLBRIDGE LRFD for plate girders and rolled beams.

DESCUS for curved plate girder and trap girders.

6. Do you use any bridge design/component standards (or templates)? Examples may include beam sizes for different span lengths and roadway widths. If you have any, are they available on the web?

Tables with recommended span lengths for each superstructure type can be found here:

http:/www.txdot.gov/business/contractors consultants/bridge/super design.htm

7. Do you use modular bridge systems?

No 
8. If a best practices manual for accelerated construction/modular bridge systems was developed, what would you like to see included? For example pre-selected beam sizes, cross-sections, etc.

Details that address accelerated bridge deck construction.

9. Do you use the AASHTO LRFD specified load factors/combinations or different load factors/combinations? If different, what are they?

We use AASHTO LRFD as-is.

10. Would a table outlining pre-selected steel beam sizes and shapes for given span lengths based on AASHTO LRFD Bridge Design Specifications be useful for assisting in your design development process?

It would be useful to some extent. TxDOT already maintains a set of standard drawings for short span rolled beam bridges. These can be found here:

http:/www.txdot.gov/insdtdot/orgchart/cmd/cserve/standard/bridge-

e.htm \#SteelBeams

11. What is your preferred material choice for short-span bridges? Why?

Prestressed concrete. Cost, maintenance and durability.

12. Are there any other comments that you have that you feel might be relevant to this study? No. 
13. What are your most important sources for bridge design and construction technical information and industry news? (Circle which are relevant)

- INDUSTRY PUBLICATIONS/WEB SITES:

- ENR

- Roads and Bridges

- GoBridges.com

- Better Roads (BetterRoads.com)

- Journal of Structural Engineering

- Transportation Builder

- Public Works Magazine

- Engineering Journal

- Public Roads

- Design Engineering

- Government Engineering (GovEngr.com)

- Civil Engineering

- CE News

- Others? Various.

- INDUSTRY CONFERENCES (name which ones) PCI, NSBA, PCA, ACI, AISI, ASBI

- PROFESSIONAL ORGANIZATION NEWSLETTER?

- NACE?

- Others? PCI, NSBA, PCA, ACI, AISI, ASBI

- WEB SITES

- FHWA

- steel.org

- Steelbridges.org

- Others? Various. 


\section{Research Statement}

The Federal Highway Administration in conjunction with the American Iron and Steel Institute [AISI] has recently conducted two workshops focused on developing ideas for improved steel bridge construction. One of the target areas of these workshops has been to develop design standards for short span steel bridges. As a result, the AISI Short Span Steel Bridge Alliance has contracted with Dr. Karl Barth at West Virginia University to conduct a survey of State DOT's and County Engineers. The focus of this survey is to study and catalog statistics and methods employed in short-span bridge design and construction. The overall projected outcome of this research is a best practices manual for the design and construction of short-span steel bridges (i.e. bridges up to $140 \mathrm{ft}$.) and a table outlining suggested pre-selected steel beam sizes and shapes for given span lengths.

\section{Part I. General Information}

Date: $12 / 21 / 09$

Time: $\underline{12: 30}$

Agency / DOH: Utah Department of Transportation / Structures Division

Name: Jason Richins for Carmen Swanwick

Position / Title: Senior Design Engineer

Address: 4501 South 2700 West, Salt Lake City, UT 84114-8470

Phone: $\underline{801964-4470}$

E-mail: jtrichins@utah.gov

Other Information: 


\section{Part II. General Questions}

1. If possible, please provide a list of bridges built in your region in the past year along with their respective span lengths, whether they are simple or continuous span, cross-section widths and any other general information you can offer (ADT, wearing surface, deck and superstructure choices, substructure and pier choices, number of lanes, etc.).

2. If information for question 1 is not readily available, please provide us with the following information: How many bridges were built in your region in the past year in the following length categories? Also, of those, how many bridges consisted of steel superstructures?

\begin{tabular}{|l|l|l|}
\hline Gength Catezon & Nimber of Briges & V Stod Superatnofures \\
\hline$<40 \mathrm{ft}$ & & \\
\hline $40-60 \mathrm{ft}$ & & \\
\hline $60-80 \mathrm{ft}$ & & \\
\hline $80-100 \mathrm{ft}$ & & \\
\hline $100-120 \mathrm{ft}$ & & \\
\hline $120-140 \mathrm{ft}$ & & \\
\hline
\end{tabular}


3. For the following bridge components, please specify whether you have a preferred/specified type of design and whether or not there are any particular types of bridge component that you do not approve:

\begin{tabular}{|c|c|c|c|}
\hline Whobe compunert & Bhorementes & 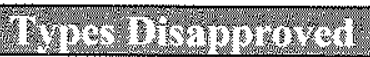 & 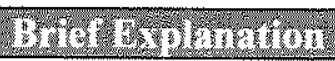 \\
\hline Decking Systems & $\begin{array}{l}\text { Circle Choice } \\
\text { Cast-in-place } \\
\text { concrete } \\
\text { Precast concrete } \\
\text { panels } \\
\text { Steel stay-in-place } \\
\text { formwork } \\
\text { Other (list): }\end{array}$ & $\begin{array}{l}\text { Used to be standard } \\
\text { New standards on } \\
\text { our website. } \\
\text { Not allowed }\end{array}$ & $\begin{array}{l} \\
\text { http://www.dot. } \\
\text { state.ut.us/main } \\
/ f ? \mathrm{p}=100: p g: 0:: \\
1: T, V: 1991, \\
\text { Traps water \& you } \\
\text { can't see the } \\
\text { bottom of the deck. }\end{array}$ \\
\hline $\begin{array}{l}\text { Railing/Guardrail } \\
\text { Systems }\end{array}$ & $\begin{array}{l}\text { Parapet Constant } \\
\text { slope shape }\end{array}$ & & \\
\hline $\begin{array}{l}\text { Topping/Wearing } \\
\text { Surfaces }\end{array}$ & $\begin{array}{l}\text { Thin Bonded } \\
\text { Polymer or } \\
\text { Waterproofing } \\
\text { membranes and } \\
\text { HMA }\end{array}$ & & \\
\hline $\begin{array}{l}\text { Bridge } \\
\text { Superstructures }\end{array}$ & $\begin{array}{l}\text { New Utah Bulb Tee } \\
\text { Standard is on web } \\
\text { or steel girder. }\end{array}$ & & \\
\hline Abutments & $\begin{array}{l}\text { Full or Semi } \\
\text { integral abutments } \\
\text { for spans under } 360^{\prime}\end{array}$ & & \\
\hline Pier Systems & Variable & & \\
\hline
\end{tabular}


4. Do you have typical standards for cross-section widths and girder spacings? If so, please provide.

Standard drawings DD8 and DD9 discuss the cross-section widths (attached), we have design guidance rules on girder spacings and overhang distances.

5. Do you have different design specifications for low-volume roads versus high-volume roads? If so, what are they?

Different Seismic Criteria and Barrier can be TL-3 instead of TL-4

6. Do you use any bridge analysis or design software? If so, what brand of software is used?

PENNDOT Steel LRFD and LARSA - Consultants use MDX, Descus

7. Do you use any bridge design/component standards (or templates)? Examples may include beam sizes for different span lengths and roadway widths. If you have any, are they available on the web?

Not for Steel

8. Do you use modular bridge systems?

YES

9. If a best practices manual for accelerated construction/modular bridge systems was developed, what would you like to see included? For example pre-selected beam sizes, cross-sections, etc.

Address the interaction between the superstructure and substructure design. We still have to do a contract for a consultant design the substructure. It would be nice if they did everything. 
10. Do you use the AASHTO LRFD specified load factors/combinations or different load factors/combinations? If different, what are they?

\section{AASHTO LRFD}

11. Would a table outlining pre-selected steel beam sizes and shapes for given span lengths based on AASHTO LRFD Bridge Design Specifications be useful for assisting in your design development process?

Yes, but we don't use a lot of rolled shapes.

12. What is your preferred material choice for short-span bridges? Why?

Prestressed Concrete Girders. They are cheaper than steel.

13. Are there any other comments that you have that you feel might be relevant to this study? 
14. What are your most important sources for bridge design and construction technical information and industry news? (Circle which are relevant)

- INDUSTRY PUBLICATIONS/WEB SITES:

- ENR

- Roads and Bridges

- GoBridges.com

- Better Roads (BetterRoads.com)

- Journal of Structural Engineering

- Transportation Builder

- Public Works Magazine

- Engineering Journal

- Public Roads

- Design Engineering

- Government Engineering (GovEngr.com)

- Civil Engineering

- CE News

- Others?

- INDUSTRY CONFERENCES (name which ones)

- PROFESSIONAL ORGANIZATION NEWSLETTER?

- NACE?

- Others?

NSBA

- WEB SITES

- FHWA

- steel.org

- Steelbridges.org

- Others? 


\section{$\underline{\text { Research Statement }}$}

The Federal Highway Administration in conjunction with the American Iron and Steel Institute [AISI] has recently conducted two workshops focused on developing ideas for improved steel bridge construction. One of the target areas of these workshops has been to develop design standards for short span steel bridges. As a result, the AISI Short Span Steel Bridge Alliance has contracted with Dr. Karl Barth at West Virginia University to conduct a survey of State DOT's and County Engineers. The focus of this survey is to study and catalog statistics and methods employed in short-span bridge design and construction. The overall projected outcome of this research is a best practices manual for the design and construction of short-span steel bridges (i.e. bridges up to $140 \mathrm{ft}$.) and a table outlining suggested pre-selected steel beam sizes and shapes for given span lengths.

\section{Part I. General Information}

Date: November 16, 2009

Time:

Agency / DOH: Virginia Department of Transportation, Structure and Bridge Division

Name: Julius F. J. Volgyi, Jr., P.E.

Position / Title: Assistant State Structure and Bridge Engineer

Address: 1401 East Broad Street

Richmond, VA 23219

Phone: (804) 786-7537

E-mail: Julius.volgyi@vdot.virginia.gov

Other Information: The website for the Structure and Bridge Division's manuals may be found at: http:/lwww. virginiadot.ong/business/bridge-manuals. asp 


\section{Part II. General Questions}

1. If possible, please provide a list of bridges built in your region in the past year along with their respective span lengths, whether they are simple or continuous span, cross-section widths and any other general information you can offer (ADT, wearing surface, deck and superstructure choices, substructure and pier choices, number of lanes, etc.).

2. If information for question 1 is not readily available, please provide us with the following information: How many bridges were built in your region in the past year in the following length categories? Also, of those, how many bridges consisted of steel superstructures?

\begin{tabular}{|l|c|c|}
\hline Lemgth Category & Number of Bridges & W/ Steel Superstructures \\
\hline$<40 \mathrm{ft}$ & 18 & 10 \\
\hline $40-60 \mathrm{ft}$ & 4 & 6 \\
\hline $60-80 \mathrm{ft}$ & 5 & 2 \\
\hline $80-100 \mathrm{ft}$ & 5 & 3 \\
\hline $100-120 \mathrm{ft}$ & 5 & 3 \\
\hline $120-140 \mathrm{ft}$ & 3 & 3 \\
\hline
\end{tabular}


3. For the following bridge components, please specify whether you have a preferred/specified type of design and whether or not there are any particular types of bridge component that you do not approve:

\begin{tabular}{|c|c|c|c|}
\hline Bridge Component & Preference & Types Disapproved & Brief Explamation \\
\hline Decking Systems & $\begin{array}{l}\text { Circle Choice } \\
\begin{array}{l}\text { Cast-in-place } \\
\text { concrete }\end{array} \\
\text { Precast concrete } \\
\text { panels } \\
\text { Steel stay-in-place } \\
\text { formwork } \\
\text { Other (list): } \\
\text { * Cenarally w/s }\end{array}$ & $\begin{array}{c}x^{(1)} \\
x^{(2)} \\
\text { xy-in-place metal }\end{array}$ & $\begin{array}{l}\text { (1) } \\
\text { notallowed for } \\
\text { shed structures } \\
\text { (2) Wotallowed in } \\
\text { six citics in } \\
\text { coostal area) (Tnde } \\
\text { water area) } \\
\text { froms }\end{array}$ \\
\hline $\begin{array}{l}\text { Railing/Guardrail } \\
\text { Systems }\end{array}$ & $\begin{array}{l}\text { Cash-tested rail } \\
\text { requined unkss } \\
\text { design execption } \\
\text { is approved. (3) }\end{array}$ & & $\begin{array}{l}\text { (3) Requires } \\
\text { * Regres } \\
\text { Lerp yiald line } \\
\text { amalysis if not } \\
\text { crosh tested }\end{array}$ \\
\hline $\begin{array}{l}\text { Topping/Wearing } \\
\text { Surfaces }\end{array}$ & & & \\
\hline $\begin{array}{l}\text { Bridge } \\
\text { Superstructures }\end{array}$ & $\begin{array}{l}\text { Prefer continuous. } \\
\text { structures to } \\
\text { climinate joints. }\end{array}$ & & \\
\hline Abutments & $\begin{array}{l}\text { Prefor jointless } \\
\text { bridges, in onder } \\
\text { of preference: } \\
\text { 1. full integral } \\
\text { 2. semi-integral } \\
\text { 3. deck slab extea }\end{array}$ & sion & \\
\hline Pier Systems & & & \\
\hline
\end{tabular}


4. Do you have typical standards for cross-section widths and girder spacings? If so, please provide.

No - Do have paveenent + shoulder widths based on roadway classifications on aur website.

5. Do you have different design specifications for low-volume roads versus high-volume roads? If so, what are they?

Included in \# 4 above.

6. Do you use any bridge analysis or design software? If so, what brand of software is used?

for $\angle R F D$

7. Do you use any bridge design/component standards (or templates)? Examples may include beam sizes for different span lengths and roadway widths. If you have any, are they available on the web?

We had them (design dater w/standard shects filled in) for spans 40-80 - rolled bean composite - but are not curneit and do not meat $\angle R F D$ reguirements. Do have rolled beam stós with

8. Do you use modular bridge systems?

No.

9. If a best practices manual for accelerated construction/modular bridge systems was developed, what would you like to see included? For example pre-selected beam sizes, cross-sections, etc. 
10. Do you use the AASHTO LRFD specified load factors/combinations or different load factors/combinations? If different, what are they?

As specified w/ no madifications.

11. Would a table outlining pre-selected steel beam sizes and shapes for given span lengths based on AASHTO LRFD Bridge Design Specifications be useful for assisting in your design development process?

No

12. What is your preferred material choice for short-span bridges? Why?

None prefered

13. Are there any other comments that you have that you feel might be relevant to this study?

No. Might study life cycle cost of sted beam design us concrete alternative-initial cost incheling maintenance (painting, et.) 
14. What are your most important sources for bridge design and construction technical information and industry news? (Circle which are relevant)

- INDUSTRY PUBLICATIONS/WEB SITES:

- ENR

- Roads and Bridges

- GoBridges.com

- Better Roads (BetterRoadscom)

- Journal of Structural Engineering

- Transportation Builder

- Public Works Magazine

- Engineering Journal

- Public Roads

- Design Engineering

- Government Engineering (GovEngr.com)

- Civil Engineering

- CE News

- Others? Modern Steed Construction

- INDUSTRY CONFERENCES (name which ones)

- PROFESSIONAL ORGANIZATION NEWSLETTER?

- NACE?

- Others?

None

- WEB SITES

- FHWA

- steel.org

- Steelbridges.org

- Others?

None 
Subject: RE: AISI Short-Span Steel Bridge Survey

From: "Brown, Nathan".

Date: Fri, 20 Nov 2009 15:02:23 -0 0800

To:

CC: "Kapur, Jugesh"<

I'm sorry to say this survey will take a considerable amount of time and department resources to research and complete adequately, and I don't think we are in a position to benefit greatly, nor will it provide much benefit to the industry as a whole. A survey of all WSDOT bridges built within the last year will result in no steel spans under 140 feet. It will show a number of precast girder and slab spans. We even experienced short span steel detour structures being CRIP'd by a general contractor to precast. The shortest span steel girder project under design or construction is 175 feet. Almost all WSDOT steel girders fall within main spans of 170 to 350 feet. Recent steel designs are $200,235,240,300,310$ feet.

Some questions that can be answered in regard to steel design practices at WSDOT:

\#4 no standards on widths and girder spacing \#5 no different specifications for different traffic volumes \#6 MDX, Merlin-Dash, GtStrudl, Sap2000, spreadsheets \#7 no standards for beam designs based on span length \#8 no modular systems with steel for permanent bridges \#9 a modular system for emergency replacement would be of benefit

\#10 WSDOT uses standard LRFD load factors and combinations \#11 standards for short span bridges might be handy for emergency replacement projects \#12 preferred materials for short spans are precast girders and precast slabs...they have good durability and low service costs regionally

Please call if there are questions that need more explanation."

\author{
Nathan Brown \\ brownn@wsdot.wa.gov \\ 360-705-7219 \\ Bridge and Structures Office \\ 7345 Linderson Way SW \\ Tumwater, WA 98501-6504
}




\section{$\underline{\text { Research Statement }}$}

The Federal Highway Administration in conjunction with the American Iron and Steel Institute [AISI] has recently conducted two workshops focused on developing ideas for improved steel bridge construction. One of the target areas of these workshops has been to develop design standards for short span steel bridges. As a result, the AISI Short Span Steel Bridge Alliance has contracted with Dr. Karl Barth at West Virginia University to conduct a survey of State DOT's and County Engineers. The focus of this survey is to study and catalog statistics and methods employed in short-span bridge design and construction. The overall projected outcome of this research is a best practices manual for the design and construction of short-span steel bridges (i.e. bridges up to $140 \mathrm{ft}$.) and a table outlining suggested pre-selected steel beam sizes and shapes for given span lengths.

\section{Part I. General Information}

Date: $12 / 22 / 09$

Time:

Agency / DOH: Wisconsin DOT

Name: Scot Becker

Position / Title: Wisconsin State Bridge Engineer

Address: 4802 Sheboygan ave

Phone: 608-266-5161

E-mail: Scot.becker@dot.wi.gov

Other Information: 


\section{Part II. General Questions}

1. If possible, please provide a list of bridges built in your region in the past year along with their respective span lengths, whether they are simple or continuous span, cross-section widths and any other general information you can offer (ADT, wearing surface, deck and superstructure choices, substructure and pier choices, number of lanes, etc.).

\section{SEE ATTACHED SPREADSHEET}

2. If information for question 1 is not readily available, please provide us with the following information: How many bridges were built in your region in the past year in the following length categories? Also, of those, how many bridges consisted of steel superstructures?

\begin{tabular}{|l|l|l|}
\hline Lengh Carggon & Nimber of Brigges & W Sted Sunerstructures \\
\hline$<40 \mathrm{ft}$ & & \\
\hline $40-60 \mathrm{ft}$ & & \\
\hline $60-80 \mathrm{ft}$ & & \\
\hline $80-100 \mathrm{ft}$ & & \\
\hline $100-120 \mathrm{ft}$ & & \\
\hline $120-140 \mathrm{ft}$ & & \\
\hline
\end{tabular}


3. For the following bridge components, please specify whether you have a preferred/specified type of design and whether or not there are any particular types of bridge component that you do not approve:

\begin{tabular}{|c|c|c|c|}
\hline Whatgo Convpontert & Hoforence & 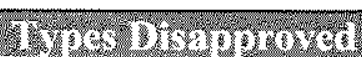 & Drof Explwath \\
\hline Decking Systems & $\begin{array}{l}\text { Circle Choice } \\
\text { Cast-in-place } \\
\text { concrete } \\
\text { Precast concrete } \\
\text { panels } \\
\text { Steel stay-in-place } \\
\text { formwork } \\
\text { Other (list): }\end{array}$ & $\begin{array}{l}\text { Steel stay in place } \\
\text { forms }\end{array}$ & \\
\hline $\begin{array}{l}\text { Railing/Guardrail } \\
\text { Systems }\end{array}$ & $\mathrm{Hf} / \mathrm{Lf}$ parapet & & \\
\hline $\begin{array}{l}\text { Topping/Wearing } \\
\text { Surfaces }\end{array}$ & & & \\
\hline $\begin{array}{l}\text { Bridge } \\
\text { Superstructures }\end{array}$ & Prestress & . & \\
\hline Abutments & Sill & & \\
\hline Pier Systems & $\begin{array}{l}\text { Multi/column } \\
\text { hammer head }\end{array}$ & & \\
\hline
\end{tabular}


4. Do you have typical standards for cross-section widths and girder spacings? If so, please provide. NO

5. Do you have different design specifications for low-volume roads versus high-volume roads? If so, what are they? No

6. Do you use any bridge analysis or design software? If so, what brand of software is used?

All software in house use commercial software to check. In house Simon. Comercial MDX

7. Do you use any bridge design/component standards (or templates)? Examples may include beam sizes for different span lengths and roadway widths. If you have any, are they available on the web?

Many Design Standards. See our Bridge Manual at : http:/on.dot.wi.gov/dtid_bos/extranet/structures/LRFD/LRFDManualIndex.ht m

8. Do you use modular bridge systems?

Research only

9. If a best practices manual for accelerated construction/modular bridge systems was developed, what would you like to see included? For example pre-selected beam sizes, cross-sections, etc. 
10. Do you use the AASHTO LRFD specified load factors/combinations or different load factors/combinations? If different, what are they?

Prestress

LRFD - See Strength 1 and service for

11. Would a table outlining pre-selected steel beam sizes and shapes for given span lengths based on AASHTO LRFD Bridge Design Specifications be Maybe useful for assisting in your design development process?

12. What is your preferred material choice for short-span bridges? Why? Slabs, box beams. Small prestress I. Durability and longevity with minor maintenance costs.

Also

13. Are there any other comments that you have that you feel might be relevant to this study? 
14. What are your most important sources for bridge design and construction technical information and industry news? (Circle which are relevant)

- INDUSTRY PUBLICATIONS/WEB SITES:

- ENR

- Roads and Bridges

- GoBridges.com

- Better Roads (BetterRoads.com)

- Journal of Structural Engineering

- Transportation Builder

- Public Works Magazine

- Engineering Journal

- Public Roads

- Design Engineering

- Government Engineering (GovEngr.com)

- Civil Engineering

- CE News

- Others?

- INDUSTRY CONFERENCES (name which ones)

- PROFESSIONAL ORGANIZATION NEWSLETTER?

- NACE?

- Others?

- WEB SITES

- FHWA

- steel.org

- Steelbridges.org

- Others? 


\section{$\underline{\text { Research Statement }}$}

The Federal Highway Administration in conjunction with the American Iron and Steel Institute [AISI] has recently conducted two workshops focused on developing ideas for improved steel bridge construction. One of the target areas of these workshops has been to develop design standards for short span steel bridges. As a result, the AISI Short Span Steel Bridge Alliance has contracted with Dr. Karl Barth at West Virginia University to conduct a survey of State DOT's and County Engineers. The focus of this survey is to study and catalog statistics and methods employed in short-span bridge design and construction. The overall projected outcome of this research is a best practices manual for the design and construction of short-span steel bridges (i.e. bridges up to $140 \mathrm{ft}$.) and a table outlining suggested pre-selected steel beam sizes and shapes for given span lengths.

\section{Part I. General Information}

Date: December 28, 2009

Time:

Agency / DOH: Wyoming Department of Transportation

Name: Gregg C. Fredrick

Position / Title: State Bridge Engineer

Address: 5300 Bishop Blvd

Cheyenne, WY 82009

Phone: 3077774427

E-mail: Gregg.fredrick@dot.state.wy.us

Other Information: 


\section{Part II. General Questions}

1. If possible, please provide a list of bridges built in your region in the past year along with their respective span lengths, whether they are simple or continuous span, cross-section widths and any other general information you can offer (ADT, wearing surface, deck and superstructure choices, substructure and pier choices, number of lanes, etc.).

2. If information for question 1 is not readily available, please provide us with the following information: How many bridges were built in your region in the past year in the following length categories? Also, of those, how many bridges consisted of steel superstructures?

\begin{tabular}{|l|c|c|}
\hline Cength Crigson & Wuinter of bitches & \\
\hline$<40 \mathrm{ft}$ & 0 & \\
\hline $40-60 \mathrm{ft}$ & 1 & 1 \\
\hline $60-80 \mathrm{ft}$ & 3 & 1 \\
\hline $80-100 \mathrm{ft}$ & 2 & 1 \\
\hline $100-120 \mathrm{ft}$ & 2 & \\
\hline $120-140 \mathrm{ft}$ & 0 & \\
\hline
\end{tabular}


3. For the following bridge components, please specify whether you have a preferred/specified type of design and whether or not there are any particular types of bridge component that you do not approve:

\begin{tabular}{|c|c|c|c|}
\hline 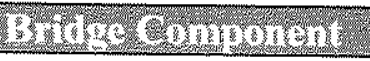 & brorenes & 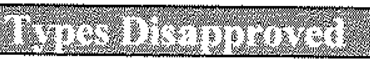 & Nhalownom \\
\hline Decking Systems & $\begin{array}{l}\text { Circle Choice } \\
\text { Cast-in-place } \\
\text { concrete } \\
\text { Precast-conerete } \\
\text { panels } \\
\text { Steel stay-in-place } \\
\text { formwork } \\
\text { Other (list): }\end{array}$ & & \\
\hline $\begin{array}{l}\text { Railing/Guardrail } \\
\text { Systems }\end{array}$ & $\begin{array}{l}\text { Wyoming TL3 and } \\
\text { TL4 steel tube } \\
\text { bridge railing }\end{array}$ & & \\
\hline $\begin{array}{l}\text { Topping/Wearing } \\
\text { Surfaces }\end{array}$ & $\begin{array}{l}\text { None included in } \\
\text { the contract. } \\
\text { However, a DL of } \\
18 \text { psf for a future } \\
\text { wearing surface is } \\
\text { provided in the } \\
\text { design }\end{array}$ & & \\
\hline $\begin{array}{l}\text { Bridge } \\
\text { Superstructures }\end{array}$ & $\begin{array}{l}\text { Prefer steel girders. } \\
\text { Ocassionally, a } \\
\text { prestressed bulb, } \\
\text { twin T or trideck is } \\
\text { used. }\end{array}$ & & \\
\hline Abutments & $\begin{array}{l}\text { Concrete cap type } \\
\text { abutment on piles } \\
\text { with an integral } \\
\text { superstructure. }\end{array}$ & & \\
\hline
\end{tabular}




\begin{tabular}{|l|l|l|l|}
\hline Pier Systems & $\begin{array}{l}\text { Multi Column or } \\
\text { Solid Shaft both on } \\
\text { footings, and/or } \\
\text { piling } \\
\text { Pile bents }\end{array}$ & & $\begin{array}{l}\text { Selection depends } \\
\text { on geology, scour } \\
\text { stream flow, ice } \\
\text { force and drift and } \\
\text { debris. }\end{array}$ \\
\hline
\end{tabular}

4. Do you have typical standards for cross-section widths and girder spacings? If so, please provide.

Yes, see attached

5. Do you have different design specifications for low-volume roads versus high-volume roads? If so, what are they?

Streets.

Follow the policy on the Geometric Design of Highways and

6. Do you use any bridge analysis or design software? If so, what brand of software is used?

Yes, BRASS Girder and BRASS Girder (LRFD) and BRASS PIER. These programs are owned and maintained by the Wyoming DOT.

7. Do you use any bridge design/component standards (or templates)? Examples may include beam sizes for different span lengths and roadway widths. If you have any, are they available on the web?

No.

8. Do you use modular bridge systems?

Do not have a prohibition against them, and would allow the contractor to utilize these systems. 
9. If a best practices manual for accelerated construction/modular bridge systems was developed, what would you like to see included? For example pre-selected beam sizes, cross-sections, etc.

Readily available wide flange sections and a railing system attached to the girder that meets the crash test requirements. There are modular systems that assume composite slabs by intermittently welding the stay in place for to the top flange or assume this connection to adequately brace the top flange from buckling. These should be investigated and proven.

10. Do you use the AASHTO LRFD specified load factors/combinations or different load factors/combinations? If different, what are they?

AASHTO LRFD

11. Would a table outlining pre-selected steel beam sizes and shapes for given span lengths based on AASHTO LRFD Bridge Design Specifications be useful for assisting in your design development process?

Possibly

12. What is your preferred material choice for short-span bridges? Why?

Steel wide flange due to contractor familiarity, shipping costs, ease of erection and design flexibility.

13. Are there any other comments that you have that you feel might be relevant to this study?

Superstructure design is only a portion of the issue. Bridges need to include the requisite preliminary engineering. A hydraulic analysis to determine the appropriate bridge length and channel bottom width.. A subsurface 
investigation is required to determine the appropriate foundation and scour potential. "Catalogs" of bridges are helpful to cities and counties, but these other aspects are equally important. Engineering is still required. 
14. What are your most important sources for bridge design and construction technical information and industry news? (Circle which are relevant)

- INDUSTRY PUBLICATIONS/WEB SITES:

- ENR

- Roads and Bridges

- GoBridges.com

- Better Roads (BetterRoads.com)

- Journal of Structural Engineering

- Transportation Builder

- Public Works Magazine

- Engineering Journal

- Public Roads

- Design Engineering

- Government Engineering (GovEngr.com)

- Civil Engineering

- CE News

- Others?

- INDUSTRY CONFERENCES (name which ones)

- PROFESSIONAL ORGANIZATION NEWSLETTER?

- NACE?

- Others?

1. Subcommittee on Bridges and Structures

2. World Steel Bridge Symposiums

- WEB SITES

- FHWA

- steel.org

- Steelbridges.org

- Others?

1. Subcommittee on Bridges and Structures.

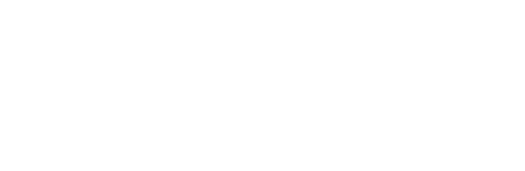

